UNIVERSIDADE DE SÃO PAULO

INSTITUTO DE QUÍMICA DE SÃO CARLOS

QUÍMICA ORGÂNICA E BIOLÓGICA

DANIEL GEDDER SILVA

Planejamento, síntese e avaliação de inibidores da enzima cruzaína e de agentes tripanossomicidas derivados de imidazopiridina

TESE DE DOUTORADO

SÃO CARLOS

2017 


\section{Planejamento, síntese e avaliação de inibidores da enzima cruzaína e de agentes tripanossomicidas derivados de imidazopiridina}

Tese apresentada ao Instituto de Química de São Carlos da Universidade de São Paulo como parte dos requisitos para a obtenção do título de doutor em ciências.

Área de concentração: Química Orgânica e Biológica

Orientador: Prof. Dr. Carlos Alberto Montanari

\section{Exemplar revisado}

$O$ exemplar original encontra-se em acervo reservado na Biblioteca do IQSC-USP

\section{SÃO CARLOS}


A minha familia,

Alos meus pais

OMinha irmã

Dedica 


\section{AGRADECIMENTOS}

A cada vitória o reconhecimento devido ao meu Deus, pois só Ele é digno de toda honra, glória e louvor. Meu Senhor e Nossa Senhora Aparecida, obrigado por permitir que eu continuasse nessa caminhada para o fim de mais uma etapa e o início de muitas outras.

Agradeço ao meu orientador Carlos Alberto Montanari e sua esposa Maria Luiza Cruzera Montanari que gentilmente ofertou a oportunidade de trabalhar no grupo de pesquisa Nequimed e não mediram esforços para que eu viesse cursar o doutorado no Instituto de Química de São Carlos - USP. Agradeço, especialmente, ao meu orientador pela contribuição e empenho no meu processo de formação enquanto aluno e pesquisador. Fico feliz com a minha trajetória no grupo Nequimed. Acredito que ciência se constrói muitas vezes com boas discussões e com visões diferentes. Nesse período do doutorado, tive a oportunidade de trabalhar com vários pesquisadores por intermédio do professor Montanari. Em um projeto desafiador, proposto pelo professor Montanari, consegui desenvolver a pesquisa com a colaboração e participação de vários pesquisadores, alunos e técnicos, os quais, eu destaco a seguir.

Agradeço aos colegas que contribuíram para os estudos computacionais: Geraldo Rodrigues e Josmar Rocha. Agradeço aos colegas que fizeram os ensaios biológicos: Jean Ribeiro e Lorenzo Cianni. Agradeço também ao Josmar Rocha que me ensinou a executar alguns ensaios biológicos e auxiliou no planejamento de alguns inibidores de cruzaína. Agradeço aos colegas que me auxiliaram nas sínteses: Leandro Avelar, Erika Orozco, Cristian Camilo e Daniela de Vita. Agradeço os demais membros e ex-membros do grupo Nequimed: Professor Andrei, Fabiana, Nádia, Igor, William, Karen e Fernanda.

Agradeço ao pesquisador Peter Kenny pela imensa contribuição no processo de planejamento dos inibidores de cruzaína.

Agradeço ao professor Antônio Carlos Bender Burtoloso, por ter me aceitado como seu estagiário no programa de aperfeiçoamento de ensino (PAE) e também por ceder uma bancada de síntese em seu laboratório e pela co-orientação. Nesse período de um ano, enriqueci muito meu conhecimento em espectroscopia e aprendi muitas técnicas de sínteses no laboratório de Síntese Orgânica Warner Bruce Kover.

Agradeço aos orientandos e técnicos do professor Antônio pela contribuição e discussões de síntese orgânica. Muito obrigado Bárbara, Rafael, Edson, Nicolas, João, Meire, Alexander, Gabriela e aos técnicos João Pedro e Marília. Agradeço também a Edvania.

Agradeço também a pós-doutoranda Juliana Gomes pela orientação.

Agradeço ao professor Michael H. Gelb da Universidade de Washington pela oportunidade de realizar o intercâmbio de um ano no seu laboratório, pela grande contribuição no presente trabalho e no meu processo de formação. Agradeço também ao professor Fred Buckner, do departamento de Medicina da Universidade de Washington pelos estudos biológicos desenvolvidos.

O maior desafio profissional e pessoal da minha vida foi viver nos Estados Unidos. Um ano que com certeza não sairá da minha memória. Agradeço aos colegas do grupo do Professor Gelb pela acolhida, pelos bons momentos e pela ajuda na excussão do trabalho. Muito obrigado Sophia, Heather, Xinying, Fan, Arun, Naveen, Nagendar. Agradeço também 
aos pesquisadores do laboratório do professor Fred Buckner, que realizaram os estudos biológicos: J. Robert Gillespie, Ranae M. Ranade, Zackary M. Herbst e Uyen T.T. Nguyen.

Agradeço aos funcionários da Universidade de Washington que ministraram os cursos de manuseio dos equipamentos de RMN e massas.

Agradeço os pos-doutorandos Hamid, Andryi e Donald pelos ensinamentos e orientação.

Um agradecimento especial a Farideh. Uma grande profissional e amiga. Como eu sou grato a tudo que você fez por mim em Seattle.

Agradeço aos professores Salete Linhares Queiroz, Fernanda Canduri e Albérico Borges Ferreira da Silva por contribuírem na minha formação acadêmica, pela orientação e pelos trabalhos desenvolvidos nos três estágios PAE, que consequentemente resultaram nos dois prêmios de melhor trabalho desenvolvido no estágio PAE e uma menção honrosa.

Agradeço também todos os professores do IQSC e da UFSCar que ministraram as disciplinas que eu cursei.

Agradeço aos técnicos Sylvana e André da central de análises Químicas e instrumentais (CAQUI) pelas análises de RMN. Agradeço também o técnico Guilherme e o aluno de pós-doutorado Jonatan pelas análises de massas.

Agradeço a Universidade de São Paulo, em especial ao instituto de Química de São Carlos, muito bem representado pelos funcionários. Agradeço a todo o pessoal da secretária do IQSC, pela cordialidade no atendimento e disposição em ajudar. Estendo meus agradecimentos ao pessoal do Convênios e do Núcleo de Patentes do Instituto.

Agradeço especialmente à Fundação de Amparo à Pesquisa do Estado de São Paulo (FAPESP) pela bolsa de doutorado (2013/01128-0) e pela bolsa de intercambio BEPE (2016/10362-5). Agradeço também o auxílio financeiro para execução dos projetos e para as participações nos congressos.

Agradecer é pouco a minha irmã Marielle Aparecida Silva. Tanto amor, dedicação e disposição em estar ao meu lado sempre. Nessa caminhada, todas as vezes que procurei por alguém, ela esteve lá presente. Muitos problemas, superamos juntos (te amo).

Aos meus maiores e melhores mestres. Aos que me ensinaram a ser gente, a respeitar o próximo, a batalhar por um futuro melhor. Aos que me ensinaram a abraçar o mundo, a voar longe, mas voltar para casa com os pés no chão. Depois de quase 11 anos estudando longe de casa, para conseguir o tão sonhado título de doutor, não aprendi nada mais valioso do que o que meus pais me ensinaram. Muito obrigado Geraldo Antônio da Silva e Zulmira Maria Aparecida Silva por fornecer educação, amor e dedicação.

Agradeço ao meu melhor orientador, aquele que já me orienta há 29 anos. Ao meu velho e amado avô José Galdino da Silva agradeço.

E o que seria de mim sem o amor e apoio de minha família, sempre presente, a qual é responsável por grande parte desta vitória. Obrigado Marly, Neca, Igor, Breno, Lurdinha, Tonho e Silvia.

Enfim, agradeço a todos as pessoas que conheci durante o meu doutorado e que de certa forma contribuíram para a minha pesquisa ou para minha vida pessoal. Nesse longo caminho encontrei pessoas que me estenderam a mão quando eu mais precisava. Especialmente, a toda a população da minha amada terrinha, Itutinga.

Esse era meu grande sonho e vocês fizeram parte dele. Muito obrigado! 
É se não fosse pela fe.

É nem teria comesado,

Quem diria terminar.

Q)aniel Sedder 


\section{RESUMO}

Silva, Daniel Gedder. Planejamento, síntese e avaliação de inibidores da enzima cruzaína e de agentes tripanossomicidas derivados de imidazopiridina. 203 páginas. Tese (Doutorado em ciências com ênfase em Química Orgânica e Biológica) - Universidade de São Paulo - São Paulo. São Carlos, 2017.

No capítulo 1, a modelagem HQSAR, a docagem e os estudos de ROCS foram construídos utilizando uma série de 57 inibidores de cruzaína. O melhor modelo $\operatorname{HQSAR}\left(q^{2}=0,70, r^{2}=\right.$ $0,95, r_{\text {test }}^{2}=0,62, q_{\text {rand. }}^{2}=0,09$ and $\left.r_{\text {rand. }}^{2}=0,26\right)$ foi utilizado para predizer a potência de 121 compostos extraídos da literatura (conjunto de dados V1), resultando em um valor de $r^{2}$ satisfatório de 0,65 para essa validação externa. Uma validação externa adicional foi empregada utilizando uma série de 1223 compostos extraído dos bancos de dados ChEMBL e CDD (conjunto de dados V3); nessa validação externa o valor de AUC (área sob a curva) para a curva ROC foi de 0,70 . Os mapas de contribuição, obtidos para o melhor modelo HQSAR 3.4, estão de acordo com as predições do modo de interação e com as bioatividades dos compostos estudados. Nos estudos de ROCS, a forma molecular utilizada como filtro, foi útil na rápida identificação de modificações moleculares promissoras para inibidores de cruzaína. $\mathrm{O}$ valor de AUC obtido com a curva ROC foi de 0,72 , isso indica que o método foi muito eficiente na distinção entre inibidores ativos e inativos da enzima cruzaína. Em seguida, o melhor modelo HQSAR foi utilizado para predizer os valores de $\mathrm{pIC}_{50}$ para novos compostos. Alguns dos compostos identificados, utilizando esse método, demonstraram valores de potência calculada maior do que a série de treinamento em estudo. No capítulo 2, os efeitos sobre a potência na inibição da enzima cruzaína pela substituição de um grupo nitrila como warhead por outros grupos foi avaliada. Com a síntese de 20 compostos do tipo dipeptidil, avaliou-se a relação estrutura-atividade (SAR), baseado na troca do grupo warhead na porção P1'. O grupo oxima foi mais potente que o grupo correspondente nitrila em 0,7 unidades logarítmicas. Os compostos do tipo dipeptidil aldeídos e azanitrila obtiveram potências mais elevadas do que o correspondente dipeptidil nitrila em duas ordens de magnitude. Os compostos dipeptidil alfa-beta insaturados foram menos potentes do que o correspondente dipeptidil nitrila. No capítulo 3, estratégias de química medicinal foram empregadas nas sínteses de 23 novos análogos, contendo o esqueleto básico de imidazopiridina. Do total de compostos sintetizados, sete e doze compostos exibiram $\mathrm{EC}_{50} \leq 1 \mu \mathrm{M}$ in vitro contra os parasitos Tripanosoma cruzi (T. cruzi) e brucei (T. brucei), respectivamente. Com os resultados promissores de atividade biológica in vitro, citotoxicidade, estabilidade metabólica, ligação proteica e propriedades farmacocinéticas, o composto $\mathbf{4 1}$ foi selecionado como candidato para os estudos de eficácia in vivo. Esse composto foi submetido em um modelo agudo da infecção com T. cruzi em ratos (cepa Tulahuen). Depois de estabelecida a infecção, os ratos foram dosados duas vezes ao dia, durante 5 dias; e monitorados por 6 semanas usando um sistema de imagem in vivo IVIS (do inglês, "In Vivo Imaging System"). O composto 41 demonstrou inibição parasitária comparável com o grupo de treinamento dosado com benzonidazol. O composto 41 é um potencial líder para o desenvolvimento de novos fármacos para o tratamento de tripanossomíases.

Palavras-chave: HQSAR, Docking, ROCS, Cruzaína, warhead, Anti-infecciosos, Imidazopiridina, Tripanosoma brucei, Tripanosoma cruzi e Tripanossomíases. 


\begin{abstract}
Silva, Daniel Gedder. Molecular design, synthesis and evaluation of cruzain inhibitors and antitrypanosomal agents based on imidazopyridines. 203 pages. Thesis (Doutorado em ciências com ênfase em Química Orgânica e Biológica) - University of São Paulo - São Paulo. São Carlos, 2017.

In chapter 1, the HQSAR, molecular docking and ROCS were applied to a dataset of 57 cruzain inhibitors. The best HQSAR model $\left(q^{2}=0.70, r^{2}=0.95, r_{\text {test }}^{2}=0.62, q_{\text {rand. }}^{2}=0.09\right.$ and $r^{2}$ rand. $=0.26$ ) was then used to predict the potencies of 121 unknown compounds (the V1 database), giving rise to a satisfactory predictive $r^{2}$ value of 0.65 (external validation). By employing an extra external dataset comprising 1223 compounds (the V3 database) either retrieved from the ChEMBL or CDD databases, an overall ROC AUC (area under the curve) score well over 0.70 was obtained. The contribution maps obtained with the best HQSAR model (model 3.4) are in agreement with the predicted binding mode and with the biological potencies of the studied compounds. We also screened these compounds using the ROCS method, a Gaussian-shape volume filter able to identify quickly the shapes that match a query molecule. The AUC obtained with the ROC curves (ROC AUC) was 0.72, indicating that the method was very efficient in distinguishing between active and inactive cruzain inhibitors. These set of information guided us to propose novel cruzain inhibitors to be synthesized. Then, the best HQSAR model obtained was used to predict the $\mathrm{pIC}_{50}$ values of these new compounds. Some compounds identified using this method has shown calculated potencies higher than those which have originated them. In chapter 2, the effects on potency of cruzain inhibition of replacing a nitrile group with alternative warheads were explored; with the syntheses of 20 dipeptidyl compounds, we explored the structure activity relationships (SAR) based on exchanging of the warhead portion (P1'). The oxime was 0.7 units more potent than the corresponding nitrile. Dipeptide aldehydes and azadipeptide nitriles were found to be two orders of magnitude more potent than the corresponding dipeptide nitriles. The vinyl esters and amides were less potent than the corresponding nitrile by between one and two orders of magnitude. In chapter 3 , we synthesized 23 new imidazopyridine analogues arising from medicinal chemistry optimization at different sites on the molecule. Seven and twelve compounds exhibited an in vitro $\mathrm{EC}_{50} \leq 1 \mu \mathrm{M}$ against Trypanosoma cruzi $(T$. cruzi) and Trypanosoma brucei (T. brucei) parasites, respectively. Based on promising results of in vitro activity $\left(\mathrm{EC}_{50}<100 \mathrm{nM}\right)$, cytotoxicity, metabolic stability, protein binding and pharmacokinetics (PK) properties, compound 41 was selected as a candidate for in vivo efficacy studies. This compound was screened in an acute mouse model against T.cruzi (Tulahuen strain). After established infection, mice were dosed twice a day for 5 days, and then monitored for 6 weeks using an in vivo imaging system (IVIS). Compound 41 demonstrated parasite inhibition comparable to the benznidazole treatment group. Compound 41 represents a potential lead for the development of drugs to treat trypanosomiasis.
\end{abstract}

Keywords: HQSAR, Molecular Docking, ROCS, Cruzain, warhead, Anti-infectives, Imidazopyridine, Trypanosoma brucei, Trypanosoma cruzi and Trypanosomiasis 


\section{LISTA DE ESQUEMAS}

Esquema 1. Relação estrutura atividade dos grupos warheads $\left(\mathrm{P} 1{ }^{\prime}\right)$................................... 73

Esquema 2. Relação estrutura atividade dos grupos warheads (P1') e na porção P1 dos compostos dipeptidil............................................................................ 75

Esquema 3. Relação estrutura-atividade dos compostos dipeptidil-nitrilas e dipeptidilazanitrilas. Marcados com um asterisco os compostos extraídos do estudo de Avelar e colaboradores ${ }^{37 \mathrm{~d}}$ 77

Esquema 6. Rotas sintéticas para obtenção dos compostos 12-16 99

Esquema 7. Rotas sintéticas para obtenção dos compostos 17-20 99

Esquema 8. Rotas sintéticas para obtenção dos compostos derivados de imidazopiridina 2143 100

Reagentes e condições: a) diaminopiridina/pirimidina e bromoacetofenona apropriados, $\mathrm{NaHCO}_{3}, \mathrm{MeOH}$, refluxo, 12h; b) trifosgênio, $\mathrm{Et}_{3} \mathrm{~N}, \mathrm{DCM}, 0{ }^{\circ} \mathrm{C}$ e depois a amina $2^{\mathrm{a}}$ apropriada adicionada, $0^{\circ} \mathrm{C}$ para $25^{\circ} \mathrm{C}, 15 \mathrm{~h}$ ou c) cloreto de carbonila apropriado, $\mathrm{Et}_{3} \mathrm{~N}, \mathrm{DCM}, 0{ }^{\circ} \mathrm{C}$ para $25^{\circ} \mathrm{C}, 16 \mathrm{~h} .{ }^{*} \mathrm{O}$ grupo ureia foi conectado na posição 7 , nomeada X............................................................... 100 


\section{LISTA DE FIGURAS}

Figura 1. Sub-sítios da enzima cruzaína e as regiões de modificações do ligante .20

Figura 2. Cronologia da construção e distinção entre os formalismos da metodologia QSAR ...22

Figura 3. Fluxograma das etapas envolvidas na realização do presente capítulo 27

Figura 4. Esqueleto básico da série de dipeptil nitrilas estudadas no trabalho ${ }^{40-41}$ .27

Figura 5. Conjunto de dados utilizado na construção e validação dos modelos HQSAR (destacado em azul). O filtro utilizado para selecionar os compostos de referência (query) e os compostos para construção do modelo 3D ROCS (destacado em vermelho). Os filtros utilizados para gerar as curvas ROC (destacado em verde).......32

Figura 6. Distribuição dos valores experimentais de $\mathrm{pIC}_{50}$ dos 40 compostos do conjunto de treinamento (a), dos 17 compostos do conjunto de teste (b) e dos 57 compostos do conjunto total (c). O teste de normalidade Shapiro-Wilk para os valores de $\mathrm{pIC}_{50}$ são $\mathrm{W}=0,97$, valor de $\mathrm{p}=0,17$ e os pontos em vermelho indica o intervalo de confiança de $95 \%$ (d) .36

Figura 7. $\mathrm{pIC}_{50}$ experimentais vs. ajustados/preditos utilizando o melhor modelo HQSAR (modelo 3.4), tamanho do fragmento 6-9 e validação cruzada LOO. Os conjuntos de teste das validações cruzadas LTO e LGO também foram acrescentados. Mais informações no material suplementar.

Figura 8. Alguns exemplos de compostos extraídos do banco de dados CDD e ChEMBL, bem como os valores experimentais de $\mathrm{pIC}_{50}$ e preditos pelo modelo HQSAR 3.4

Figura 9. Valores experimentais versus preditos de $\mathrm{pIC}_{50}$, obtidos na predição do modelo HQSAR 3.4 para o conjunto de dados V1. Parâmetros estatísticos do modelo: $r^{2}=$ $0,95, q^{2}=0,70, r_{\text {teste }}^{2}=0,62, \mathrm{SEP}=0,80$, e SEE $=0,33$. Parâmetros estatísticos da predição: $r^{2}=0,65$ e SEP $=0,43$

Figura 10. Gráfico ROC construído com as predições realizadas pelo modelo HQSAR utilizando o conjunto de validação V3

Figura 11. Pose de interação do peptídeo mimético NOW no sítio ativo da cruzaína (a); predição da pose de interação pela docagem e sobreposição da série de 57 dipeptidil nitrilas no sítio ativo da cruzaína (b); sobreposição das enzimas catepsina L com o inibidor NOW e cruzaína com o inibidor mais potente da série de dipeptidil nitrilas (composto 37, pIC $_{50}=10.0$ ), simulação de docagem covalente e não covalente do composto 37 (c) 42

Figura 12. Mapas de contribuição de fragmentos moleculares fornecido pelo HQSAR (a) e representação 2D das interações do composto Neq0400 no sítio ativo da cruzaína predita na docagem .44 
Figura 13. Mapas de contribuição de fragmentos moleculares fornecido pelo HQSAR (a) e representação $2 \mathrm{D}$ das interações do composto 37 no sítio ativo da cruzaína predita na

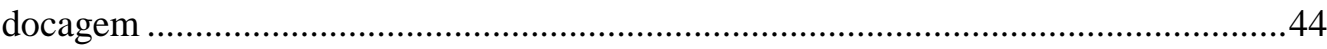

Figura 14. Compostos análogos ao Odanacatib (destacado em verde as modificações no P1).....45

Figura 15. Resultado das análises de ROCS para o composto 37 (destacado em verde) sobreposto no composto 23 (colorido por tipo de átomo) ranqueado na posição $26^{\circ}$ (a). Composto 37 sobreposto no composto CDD-111089 (colorido por tipo de átomo) ranqueado na posição $385^{\circ}$ (b). Ranque estabelecido usando o índice fornecido pela métrica Fit Tversky

Figura 16. Gráfico ROC fornecido pelo método ROCS. Na esquerda, os 24 compostos query utilizado nas análises, os valores experimentais de $\mathrm{pIC}_{50}$, melhor métrica encontrada para cada composto query e os valores de AUC correspondente. Na direita, destacado em verde a curva ROC para o composto 5 como query, que apresentou a melhor AUC com a métrica Color Tanimoto.

Figura 17. Alguns compostos presentes no banco de dados $\mathrm{V} 3$ e suas respectivas posições no ranque estabelecido com a métrica Color Tanimoto e o composto 5 como query. As porções destacadas em verdes representam contribuições positivas e em vermelho negativas, de acordo com as análises efetuadas pelo ROCS. Os valores experimentais de atividade biológica também são mostrados .

Figura 18. Estruturas propostas (A-F) usando a estratégia de combinar subestruturas dos compostos mais ativos experimentalmente da série. Os valores de $\mathrm{pIC}_{50}$ preditos obtidos a partir do modelo HQSAR 3.4 são apresentados abaixo de cada composto ..51

Figura 19. Poses preditas na docagem para os novos compostos propostos .................................52

Figura 20. Inibidores conhecidos de cisteíno proteases e as regiões de modificações P1' (azul), P1 (verde), P2 (vermelho) e P3 (cinza).

Figura 21. Representação esquemática do mecanismo geral de catálise de enzimas cisteínoproteases ${ }^{59}$

Figura 22. Mecanismo de inibição proposto para dipeptidil-azanitrilas.........................................59

Figura 23. Fluxograma do ciclo planeja-sintetiza-testa. As setas em azul indicam o fluxo progressivo, as setas em vermelho o fluxo retroativo ${ }^{86}$

Figura 24. Modificações realizadas no P1 (verde), P2 (vermelho) e P3 (cinza) do protótipo dipeptidil-nitrilas inibidor da enzima cruzaína. Em destaque (preto) as modificações escolhidas para os estudos de SAR do presente trabalho

Figura 25. Formalismo no MMPs: a) organização do banco de dados; b) quebra da ligação no sítio de interesse por meio do programa MUDO e b) obtenção dos MMPs

Figura 26. Hipótese para proteção do warhead nitrila (destacado em azul). A clivagem in vivo (CYP450) da ligação N-O resultaria no metabólito ativo. 
Figura 27. MMP 1: os diferentes esqueleto básicos utilizados para gerar os pares moleculares (destacado em cinza). A troca do grupo "a" para o grupo "b" gerou um incremento de $\Delta \mathrm{p} K_{I}=2.88$ unidades logarítmicas

Figura 28. Análise MMP adicional realizada no P1 (ensaio ChEMBL: 606254) ${ }^{39,41,107}$............69

Figura 29. Compostos em estudo para o tratamento de HAT ........................................................ 81

Figura 30. Conjunto de modificações propostas para o esqueleto básico de imidazopiridina .......83

Figura 31. Atividade tripanossomicidas para os derivados de imidazopiridina 21-32, organizados por grupos de análogos: a) piperidil, b) pirrolidil e c) 3-fluoropirrolidil. Destacado em azul e em preto os valores de $\mathrm{EC}_{50}$ em $\mu \mathrm{M}$ para T. cruzi e T. brucei, respectivamente 85

Figura 32. Atividades tripanossomicidas para os derivados de imidazopiridina, organizados por grupos de modificações na porção a) $R_{2}$ e b) $R_{1}$. Destacado em azul e em preto os valores de $\mathrm{EC}_{50}$ em $\mu \mathrm{M}$ para T. cruzi e T. brucei, respectivamente..............................86

Figura 33. Relação estrutura-atividade estabelecida para os análogos 32, 40-43........................87

Figura 34. a) Imagens dos camundongos na posição ventral infectados com bioluminescência "PpyRE9h-expressing T.cruzi" antes e depois do tratamento com o composto 41, o controle benzonidazol (BNZ) e os veículos. A quantidade de $120 \mathrm{mg} / \mathrm{kg}$ de D-luciferin foi injetada nos ratos, em seguida anestesiados e fotografados usando o sistema IVIS. Os grupos de veículos tiveram que ser removidos do experimento no dia 13 devido à infecção avançada e um rato do grupo do veículo (BNZ) teve que ser removido no dia 9; b) Sinal de radiação dos grupos de tratamento (dorsal + ventral) ao longo do experimento. Janela de dosagem destacada em cinza. O sinal diminuído entre os dias 24 e 42 pode ser devido a um provável avanço da infecção na fase aguda para a fase crônica

Figura 35. Os sinais resultantes dos acoplamentos mais importantes do espectro de RMN de ${ }^{1} \mathrm{H}$ para o ácido A. 101

Figura 36. Região do RMN de ${ }^{1} \mathrm{He} \mathrm{e}^{13} \mathrm{C}$ características para os compostos $1 \mathrm{e} 2$........................102

Figura 37. Região do $\mathrm{RMN}$ de ${ }^{1} \mathrm{H}$ e ${ }^{13} \mathrm{C}$ características para os compostos 3 e 4 .......................102

Figura 38. Região do $\mathrm{RMN}$ de ${ }^{1} \mathrm{He}$ e ${ }^{13} \mathrm{C}$ características para o composto 5 ................................103

Figura 39. Região do $\mathrm{RMN}$ de ${ }^{1} \mathrm{He}$ e ${ }^{13} \mathrm{C}$ características para o composto 6 ................................104

Figura 40. Região do $\mathrm{RMN}$ de ${ }^{1} \mathrm{H}$ e ${ }^{13} \mathrm{C}$ características para os compostos $7-11$........................104

Figura 41. Região do RMN de ${ }^{1} \mathrm{He} \mathrm{e}^{13} \mathrm{C}$ características para o composto 14 ..............................105

Figura 42. Região do $\mathrm{RMN}$ de ${ }^{1} \mathrm{He}$ e ${ }^{13} \mathrm{C}$ características para o composto 18 .............................106

Figura 43. Região do $\mathrm{RMN}$ de ${ }^{1} \mathrm{H}$ característica de sinais de hidrogênios aromáticos para os compostos selecionados 32, 40 e 41, contendo os anéis fundidos imidazo[1,2a]piridina, imidazo[1,2-a]pirimidina e imidazo[1,2-c]pirimidina. Destacado em vermelho os principais sinais que diferenciam os anéis fundidos. Observação: os RMNs de hidrogênio para os compostos 32 e 40 foram feitos em metanol deuterado e 
para o composto 41 em ácido acético deuterado. Isso explica o sinal do hidrogênio da amida na região dos hidrogênios aromáticos 


\section{LISTA DE TABELAS}

Tabela 1. Níveis de complexidade na execução da docagem........................................ 24

Tabela 2. Parâmetros usados na construção dos modelos HQSAR ................................ 29

Tabela 3. Resultado da análise de HQSAR usando várias distinções de fragmentos e os principais parâmetros estatísticos, bem como validação cruzada "leave-oneout" que indica a qualidade do modelo. O tamanho padrão do fragmento (4-7) foi utilizado

Tabela 4. Influência do tamanho do fragmento, nos parâmetros estatísticos usando a distinção dos fragmentos do modelo $3(\mathrm{~A} / \mathrm{B} / \mathrm{H})$

Tabela 5. Resultado da análise de HQSAR com a aleatorização do bloco Y (Yrandomização), com a avaliação da influência do tamanho do fragmento nos parâmetros estatísticos usando a distinção dos fragmentos do modelo 3 $(\mathrm{A} / \mathrm{B} / \mathrm{H})$ 38

Tabela 6. Resultado das validações cruzadas para o melhor modelo obtido (modelo 3.4, distinção do fragmento: $\mathrm{A} / \mathrm{B} / \mathrm{H})$ 38

Tabela 7. Análises de MMPs de inibidores de cisteíno proteases usando o warhead nitrila como referência.....

Tabela 8. Análises de MMPs de inibidores de cisteíno proteases usando o warhead aldeído como referência 71

Tabela 9. Série de dipeptidil sintetizados e seus respectivos valores de constante de inibição 71

Tabela 10. Atividades contra a forma amastigota da cepa $Y$ de $T$. cruzi ........................... 78

Tabela 11. Atividades tripanossomicidas dos derivados de imidazopiridina......................84

Tabela 12. Avaliação da toxicidade e seletividade para a série de compostos derivados de imidazopiridina.

Tabela 13. Estabilidade metabólica, solubilidade e ligação proteica para os compostos selecionados 90 


\section{SUMÁRIO}

Introdução geral

Capítulo I.

3.2.2.6 Curva ROC e os conjuntos de validação externa - V2 e V3 ........................... 31

3.3.1.2 Curva ROC para avaliar a capacidade preditiva do modelo HQSAR 3.4 ......40

3.3.2 Docagem e interpretação do melhor modelo HQSAR 41 
3.3.4 Planejamento de novos potenciais inibidores para a cruzaína........................49

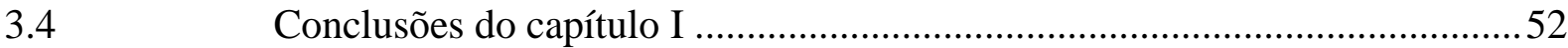

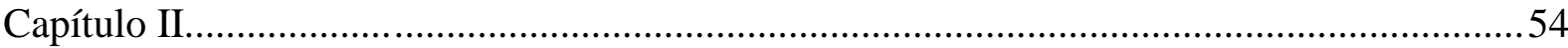

Planejamento e estudo da relação estrutura-atividade de grupos warheads em

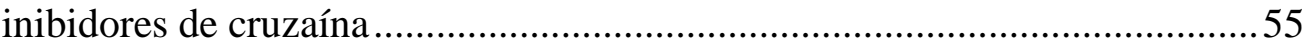

Introdução

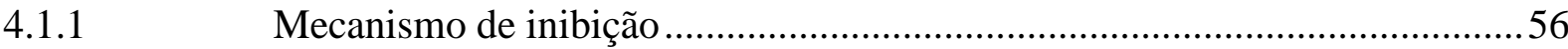

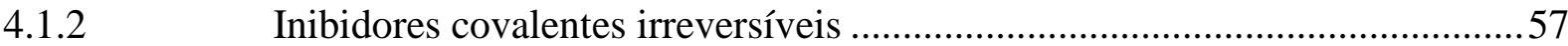

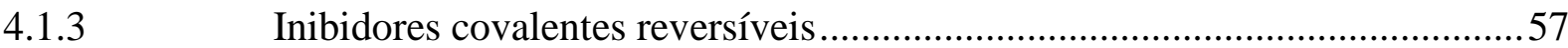

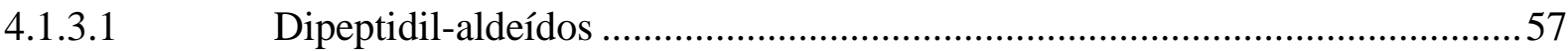

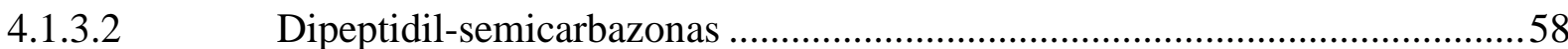

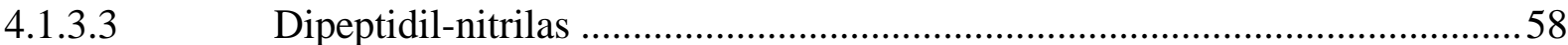

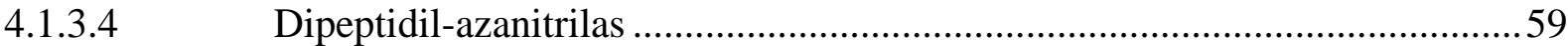

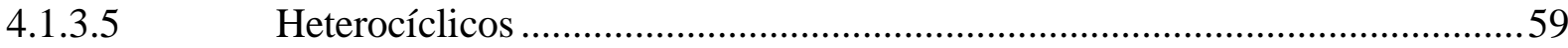

4.1.4 Análise sistemática de pares moleculares (MMPs) …...................................60

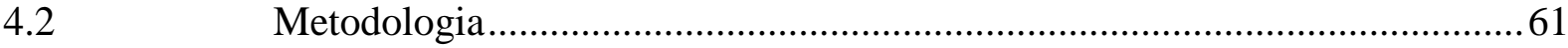

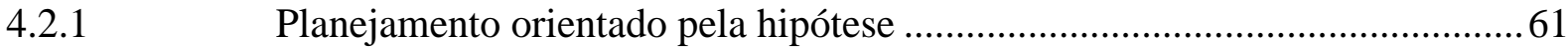

4.2.2 Planejamento: estabelecimento das hipóteses e seleção de grupos warheads 64

4.2.2.1 Justificativas para as hipóteses estabelecidas ............................................. 64

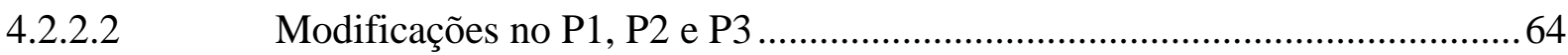

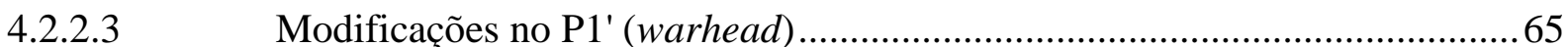

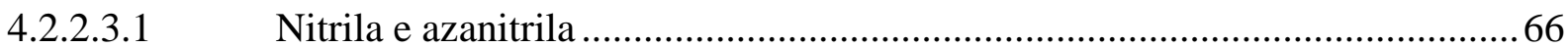

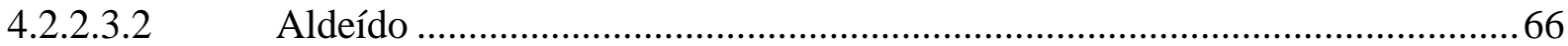

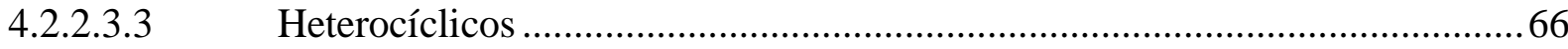

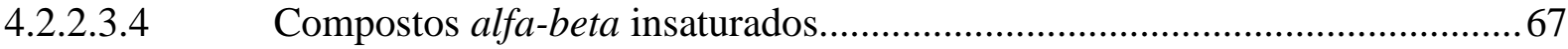

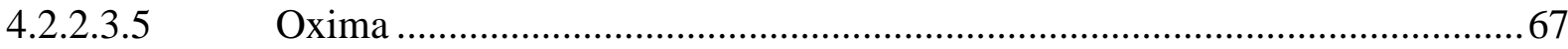


4.3.1 Análises de MMPs de inibidores de cisteíno proteases extraídos do

Análise da SAR de grupos warheads em inibidores de cruzaína sintetizados71

4.3.2.3 Analises de SAR entre nitrilas e azanitrilas com variações nas porções P2 e P3 .76

Ensaios celulares contra a forma amastigota da cepa $\mathrm{Y}$ de $T$. cruzi... .78

Estudo de relação estrutura-atividade da nova classe de agentes tripanossomicidas derivados de imidazopiridina.

Análises da relação estrutura-atividade baseado nos ensaios contra o $T$. cruzi. Avaliação da toxicidade e da seletividade dos novos derivados de imidazopiridina.

Avaliação da estabilidade metabólica, solubilidade e ligação proteica para os compostos selecionados.

Avaliação da capacidade dos compostos 32 e 41 em atravessar a barreira hematocenfálica (BHE) 
Capítulo IV .95

6

Sínteses de grupos warheads em compostos do tipo dipeptidil e de derivados de imidazopiridina .96

6.1

Introdução 96

6.2

Metodologia 96

Rotas sintéticas para síntese dos compostos 1-20 97

6.2 .2

Rotas sintéticas para síntese dos compostos 21-43 100

6.2.3 Caracterização espectroscópica dos compostos 1-20 …............................. 101

6.2.4 Caracterização espectroscópica dos compostos 21-43 ............................... 106

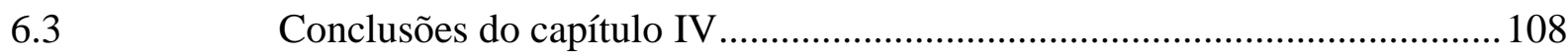

Capítulo V.

7.2 Procedimentos experimentais para síntese dos compostos do tipo dipeptidil.

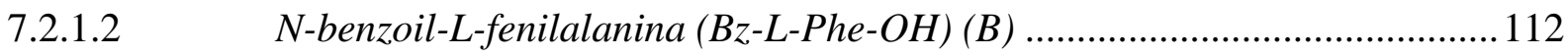

7.2.2 Procedimento Geral 1 - reação de acoplamento ..........................................113

7.2.3 Procedimento Geral 2 - reação de proteção com BOC.................................. 113

7.2.4 Procedimento Geral 3 - reação de desproteção com TFA ............................ 114

7.2.5 Benzil (S)-(1-((cianometil)amino)-1-oxo-3-fenilpropan-2-il)carbamato (1)114

7.2.6 Benzil (S)-(1-((1-cianociclopropil)amino)-1-oxo-3-fenilpropan-2-

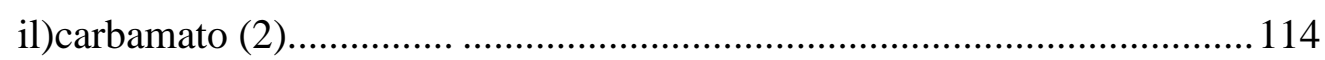

7.2.7 Benzil (S)-(1-oxo-1-((2-oxoetil)amino)-3-fenilpropan-2-il)carbamato (3).. 115 7.2.8 Benzil (S)-(1-((1-formilciclopropil)amino)-1-oxo-3-phenilpropan-2il)carbamato(4).. 
e Etil

(S,Z)-4-(2-(((Benziloxi)carbonil)amino)-3fenilpropanamida)but-2-enoato (12)

Etil

(S,E)-3-(1-(2-(((Benziloxi)carbonil)amino)-3-fenilpropanamida) ciclopropil)acrilato (14)

Benzil (S,E)-(1-((1-(3-(dietilamino)-3-oxoprop-1-en-1-il)ciclopropil) amino)1-oxo-3-fenilpropan-2-il)carbamato (15)

Benzil (S,E)-(1-((1-(3-(metilamino)-3-oxoprop-1-en-1-il)ciclopropil) amino)1-oxo-3-fenilpropan-2-il)carbamato (16)

Benzil (S)-(1-(2-ciano-1,2-dimetilhidrazinil)-1-oxo-3-fenilpropan-2il)carbamato (17).

3-tert-butil-N-[(1S)-1-(N'-ciano-N,N'-dimetilhidrazinacarbonil)-2-feniletil]-1metil-1H-pirazol-5-carboxamida (19)

3-tert-butil-N-[(1S)-1-(N'-ciano-N,N'-dimetilhidrazinacarbonil)-3-metilbutil]1-metil-1H-pirazol-5-carboxamida (20)

Procedimentos experimentais para síntese dos compostos do tipo imidazopiridina. 
7.3.3 Procedimento geral 6 - sínteses dos compostos derivados de amida

7.3.4 N-\{2-fenilimidazo[1,2-a]piridin-7-il $\}$ piperidina-1-carboxamida (21) ........ 129

7.3.5 N-\{2-fenilimidazo[1,2-a]piridin-7-il $\}$ pirrolidina-1-carboxamida (22) ....... 130

7.3.6 (3S)-3-fluoro-N- $\{2$-fenilimidazo[1,2-a]piridin-7-il $\}$ pirrolidina-1-carboxamida

7.3.7 N-[2-(3-fluorofenil)imidazo[1,2-a]piridin-7-il]piperidina-1-

carboxamida(24)

7.3.8 N-[2-(3-fluorofenil)imidazo[1,2-a]piridin-7-il]pirrolidina-1-

carboxamida(25)

7.3.9 (3S)-3-fluoro-N-[2-(3-fluorofenil)imidazo[1,2-a]piridin-7-il]pirrolidina-1carboxamida (26)

7.3.10 N-[2-(2,3-difluorofenil)imidazo[1,2-a]piridin-7-il]piperidina-1-carboxamida

7.3.11 N-[2-(2,3-difluorofenil)imidazo[1,2-a]piridin-7-il]pirrolidina-1-carboxamida

(3S)-N-[2-(2,3-difluorofenil)imidazo[1,2-a]piridin-7-il]-3-fluoropirrolidina-1carboxamida (29)

$\mathrm{N}$-[2-(3,4-difluorofenil)imidazo[1,2-a]piridin-7-il]piperidina-1-carboxamida

$\mathrm{N}$-[2-(3,4-difluorofenil)imidazo[1,2-a]piridin-7-il]pirrolidina-1-carboxamida

(3S)-N-[2-(3,4-difluorofenil)imidazo[1,2-a]piridin-7-il]-3-fluoropirrolidina-1carboxamida (32)

(3S)-3-fluoro-N-[2-(1,3-tiazol-2-il)imidazo[1,2-a]piridin-7-il]pirrolidina-1carboxamida (33)

(3S)-3-fluoro-N-[2-(tiofen-2-il)imidazo[1,2-a]piridin-7-il]pirrolidina-1carboxamida (34)

2.3.18 2-cloro-N-[2-(3,4-difluorofenil)imidazo[1,2-a]piridin-7-il]piridina-3carboxamida (35) 
7.3.20 N-[2-(3,4-difluorofenil)imidazo[1,2-a]piridin-7-il]piridina-3-carboxamida

7.3.21 N-[2-(3,4-difluorofenil)imidazo[1,2-a]piridin-7-il]-1,3-tiazol-2-carboxamida

3-tert-butil-N-[2-(3,4-difluorofenil)imidazo[1,2-a]piridin-7-il]-1-metil-1Hpirazol-5-carboxamida (39)

(3S)-N-[2-(3,4-difluorofenil)imidazo[1,2-a]pirimidin-7-il]-3-

fluoropirrolidina-1-carboxamida (40).

(3S)-N-[2-(3,4-difluorofenil)imidazo[1,2-c]pirimidin-7-il]-3-

fluoropirrolidina-1-carboxamida (41).

3-tert-butil-N-[2-(3,4-difluorofenil)imidazo[1,2-c]pirimidin-7-il]-1-metil-1H-

pirazol-5-carboxamida (42)

(3S)-N-[2-(3,4-difluorofenil)imidazo[1,2-a]piridin-6-il]-3-fluoropirrolidina-1carboxamida (43)

Conclusão geral

Referências

Apêndice

APÊNDICE A - Tabela com a série de compostos usada para construir os modelos HQSAR, ROCS e os estudos de docagem. Os valores experimentais, preditos e ajustados de $\mathrm{pIC}_{50}$ obtidos pelo modelo HQSAR 3.4

APÊNDICE B - Tabela com os resultados das análises HQSAR com o bloco Y usando diferentes distinções de fragmento e tamanho do fragmento fixado de 4-7 átomos 161

APÊNDICE C - Influência do tamanho do fragmento nos parâmetros estatísticos do modelo 11 usando A/B/Ch/D como distinção do fragmento 162

APÊNDICE D - Resultados das análises HQSAR com diferentes tamanhos de fragmentos e aleatorização do bloco Y (Y-rand) para o modelo $11(\mathrm{~A} / \mathrm{B} / \mathrm{Ch} / \mathrm{D})$ 162 
APÊNDICE E - Números ChEMBL de referência para os compostos extraídos da base de dados e utilizados nas análises de MMPs e os números dos respectivos ensaios biológicos........................................................................ 163

APÊNDICE F - Série de compostos do tipo dipeptidil sintetizada .................................... 164

APÊNDICE G - Série de análogos derivados de imidazopiridina sintetizada...................... 165

APÊNDICE H - Espectros de RMN de ${ }^{1} \mathrm{H}$ e ${ }^{13} \mathrm{C}$ para os compostos sintetizados mais

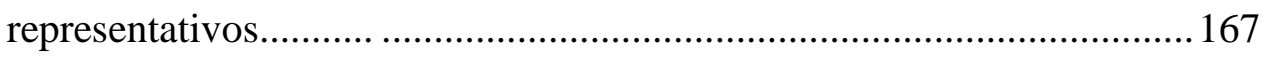




\section{Introdução geral}

A tripanossomíase, causada pelos parasitas protozoários unicelulares tripanosoma brucei e cruzi, são obstáculos economicamente significativos para o bem-estar humano. A doença do sono (HAT, do inglês Human African Trypanosomiasis ou sleeping sickness), causada por T. brucei, ocorre na África subsaariana, enquanto a doença de Chagas, causada por T. cruzi, é uma doença humana devastadora nas Américas (OMS). ${ }^{1}$ Os medicamentos existentes para o tratamento dessas doenças são insuficientes, tóxicos, propensos à resistência parasitária e requerem administração parenteral. ${ }^{2}$

A descoberta e o desenvolvimento de novos fármacos caracterizam-se como um processo multidisciplinar; antes que qualquer composto torne-se candidato a ensaios préclínicos, diferentes propriedades devem ser otimizadas, tais como: potência, biodisponibilidade, toxicidade, seletividade e etc. ${ }^{3}$ A sequência fundamental usada na atribuição de propriedades para um composto-líder, não sofreram alterações consideráveis nos últimos anos (Gênese planejada de fármacos); ${ }^{4}$ envolve a formulação de uma hipótese, seguida da síntese e ensaios biológicos de compostos, para explicar a presença da possível propriedade desejada.

Na Química Medicinal a busca por candidatos a fármaco concentra-se, principalmente, na exploração da relação estrutura-atividade $(\mathrm{SARs}){ }^{5}$ Explicar a forma pela qual modificações estruturais altera a atividade biológica de pequenas moléculas, constitui o objetivo central nos estudos de SAR. A realização desta tarefa compreende na utilização da base do conhecimento em química medicinal, na experiência ou intuição. Entretanto, métodos computacionais emergiram nos últimos anos como uma alternativa racional, barata e rápida na proposta de modificações moleculares, que podem revelar tendências quimicamente interpretáveis. ${ }^{6}$

No estudo desenvolvido no presente trabalho, buscou-se integrar todas as áreas do conhecimento de Química Medicinal, com o objetivo principal de encontrar novas estruturas químicas promissoras, como agentes tripanossomicidas. Para tanto, o presente trabalho encontra-se organizado em 3 capítulos.

No capítulo 1, empregaram-se estudos de modelagem molecular para a construção de modelos computacionais capazes de predizer a atividade biologica, forma molecular e modo de interação de inibidores de cruzaína do tipo dipeptidil nitrilas. O artigo intitulado "Highly predictive hologram QSAR models of nitrile-containing cruzain inhibitors" 7 publicado na 
revista "Journal of Biomolecular Structure and Dynamics" foi escrito com os resultados obtidos no capítulo 1.

No capítulo 2, realizaram-se estudos de relação estrutura-atividade frente a enzima cruzaína com uma serie de compostos sintetizados do tipo dipeptidil, com modificações variadas na porção warhead. Compostos foram selecionados para ensaios contra a forma amastigota da cepa Y de T. cruzi. O artigo intitulado "A comparative study of warheads for design of cysteine protease inhibitors" ${ }^{8}$ foi publicado na revista "Bioorganic \& Medicinal Chemistry Letters" com os resultados obtidos no capítulo 2.

No capítulo 3, uma nova série de agentes tripanossomicidas derivados de imidazopiridina foi sintetizada para compor os estudos de relação estrutura-atividade contra o T. cruzi, T. brucei e em células de mamíferos. O capítulo também apresenta os estudos de estabilidade metabólica, solubilidade, ligação protéica, penetração na barreira hematocenfálica, biodisponibilidade oral e eficácia in vivo para o modelo agudo de T. cruzi. O artigo intitulado "New class of antitrypanosomal agents based on imidazopyridines" ${ }^{9}$ foi publicado na revista "ACS Medicinal Chemistry Letters" com os resultados obtidos no capítulo 3. Ainda, parte dos resultados encontra-se patenteados (patente intitulada "Compounds for treatment of trypanosomes and neurological pathogens and uses thereof") 10 pela Universidade de Washington, em parceria com a Universidade de São Paulo. 


\section{Objetivos}

O objetivo geral do presente trabalho é planejar, sintetizar e identificar novos compostos inibidores covalentes reversíveis da enzima cruzaína e compostos com atividade tripanossomicida.

Especificamente,

Capítulo 1: Mineração de dados para a obtenção de informações relevantes em bancos de dados para compor a série de treinamento, teste, validações internas e externas. Construir modelos HQSAR altamente preditivos e robustos para uma série de inibidores da enzima cruzaína. Construir um modelo ROCS e utilizar o parâmetro forma molecular para identificar fragmentos moleculares de interesse, bem como extrair informações físicas, químicas e/ou biológicas úteis para propor estruturas químicas potencialmente ativas. Realizar estudos de docagem, para avaliação das interações enzima-ligante que respondem pela atividade biológica das moléculas propostas. Elaborar novas estruturas químicas potencialmente ativas como inibidores de cruzaína, por meio das técnicas computacionais HQSAR, ROCS e docagem.

Capítulo 2: Mapear e selecionar informações relevantes de SARs, mais especificamente, modificações realizadas na porção P1' (warhead), em banco de dados de inibidores de cisteíno proteases disponível no ChEMBL, por meio de analises de pares moleculares (MMPs). Empregar estratégias de química medicinal, bem como o ciclo planeja-sintetiza-testa para obter novos compostos com esqueleto molecular dipeptidil e avaliar a influência do grupo warhead no processo de inibição da enzima cruzaína. Por fim, avaliar a relação estrutura-atividade com os novos compostos sintetizados e selecionar compostos para ensaios contra a forma amastigota da cepa Y de T. cruzi.

Capítulo 3: Planejar e sintetizar novos agentes tripanossomicidas derivados de imidazopiridina. Construir um estudo de relação estrutura-atividade baseado em ensaios contra o T. cruzi, T. brucei e em células de mamíferos. Selecionar e submeter os melhores compostos para estudos de estabilidade metabólica, 
ligação proteica e solubilidade. Selecionar e submeter um composto para estudos de eficácia in vivo no modelo agudo de T. cruzi. 
Sapíuta 1
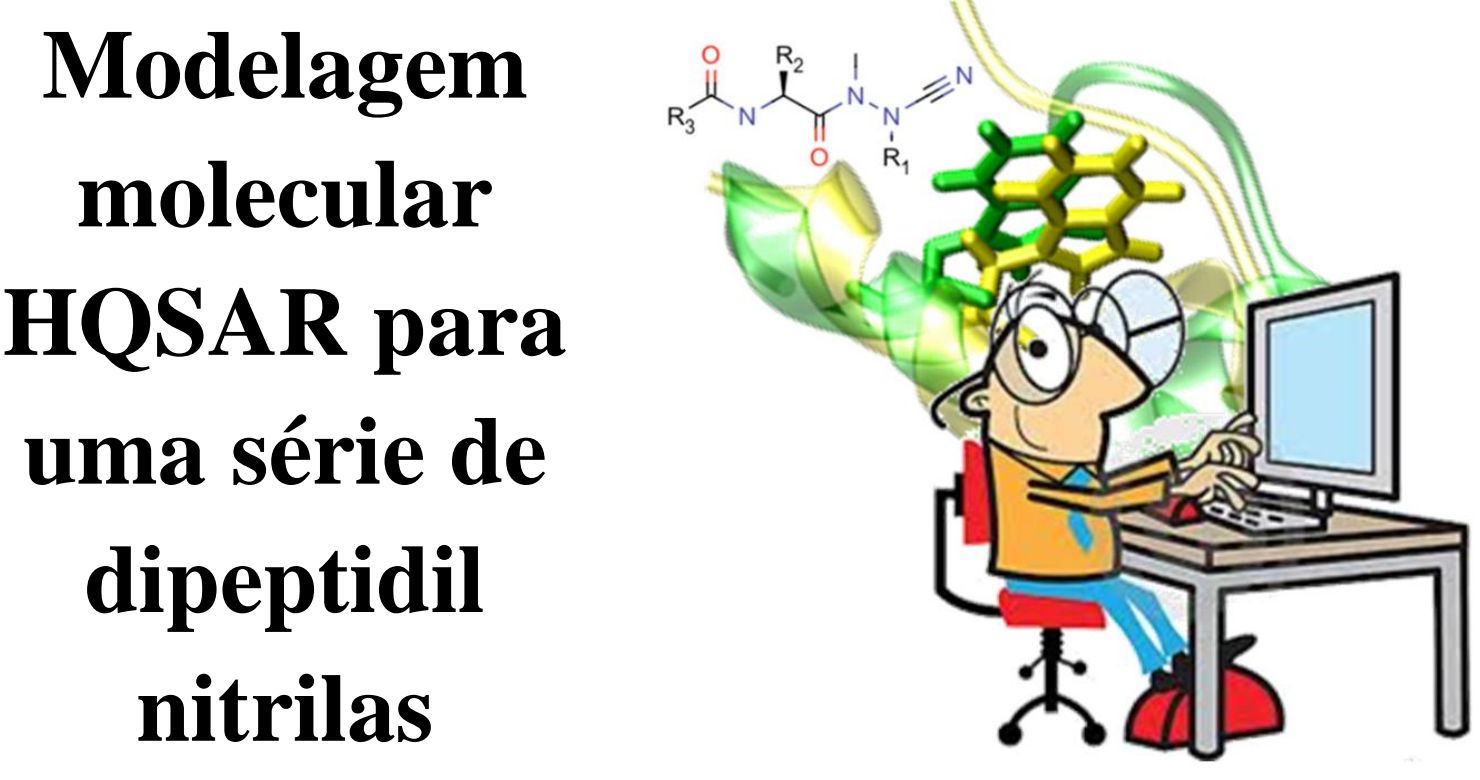


\section{Capítulo I}

\section{Modelagem molecular HQSAR para uma série de dipeptidil nitrilas}

\subsection{Introdução}

A cruzaína, forma recombinante da enzima cruzipaína (EC 3.4.22.51) ${ }^{11}$ é a cisteínoprotease mais abundante presente no parasito Trypanosoma cruzi, o agente causador da Doença de Chagas. A enzima é modulada por diferentes tipos de inibidores, ${ }^{12}$ que se diferenciam de acordo com o modo de ação: interação que ocorre entre o inibidor e enzima. 12e, $12 \mathrm{f}, 13$

O planejamento de ligantes, que inibem a cruzaína, baseia-se em quatro regiões especificas do sítio ativo: o sub-sítio de direção (S3), o sub-sítio de reconhecimento (S2), o sub-sítio de potencialização (S1) e o sub-sítio do "warhead" (S1'). ${ }^{14}$ A Figura 1 apresenta os sub-sítios (S1', S1, S2 e S3) ${ }^{15}$ e os principais aminoácidos presentes na enzima cruzaína, bem como as possíveis modificações no ligante (P1', P1, P2 e P3).

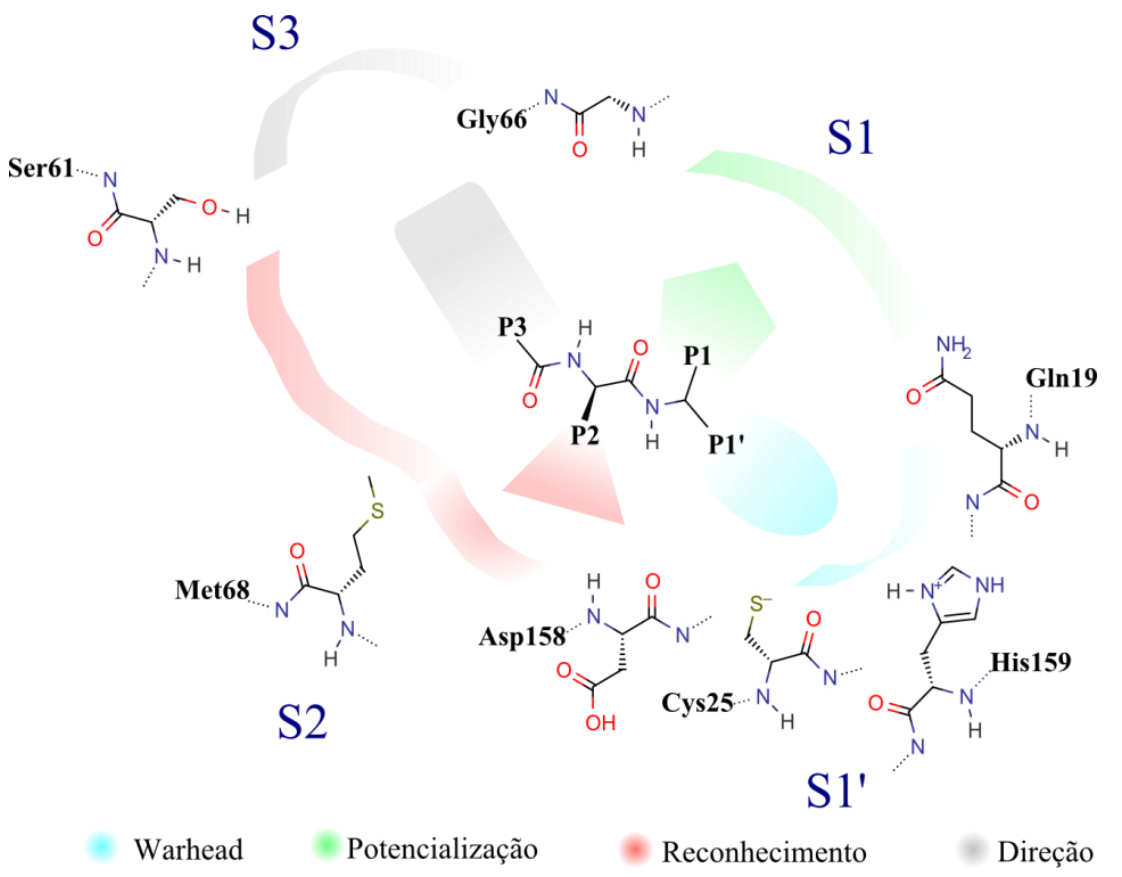

Figura 1. Sub-sítios da enzima cruzaína e as regiões de modificações do ligante

Geralmente o P2 é composto por um di- ou tripeptídeos selecionado para adaptar-se ao S2. Contudo, apenas esta modificação não é suficiente para conferir especificidade adequada frente à enzima. Assim, o reconhecimento, de modo adicional acontece com a inserção de grupos hidrofóbicos na região do P3, devido às características do sub-sítio S3 da enzima. 
Outras modificações podem ocorrer de forma a explorar outro sub-sítio (S1: potencialização). Localizado próximo da tríade catalítica (cisteína 25, histidina 159 e glutamina 19), as modificações no P1 podem potencializar ou diminuir a interação do "warhead” com cisteína catalítica.

\subsubsection{Métodos computacionais}

Assim como em outras áreas do conhecimento humano, o uso do termo "Química Computacional" se popularizou devido a uma confluência de fatores: científicos, históricos, tecnológicos e culturais. O desenvolvimento dessa área apenas se tornou possível devido ao poder de processamento dos computadores modernos, de softwares sofisticados e de uma melhor compreensão de alguns princípios básicos da ciência. O potencial oferecido pela tecnologia recente teve como consequência o desenvolvimento de uma grande variedade de técnicas para cálculos numéricos e simbólicos, dentre os quais, destacam-se: as relações quantitativas estrutura-atividade (QSAR, do inglês "quantitative structure-activity relationship"), a docagem (do inglês "docking") e o ROCS (do inglês "Rapid Overlay of Chemical Structures"). ${ }^{16}$ Esses métodos se estendem a muitas áreas de aplicação e aumentam o potencial das simulações, o que torna a Química Computacional um dos domínios interdisciplinares mais promissores do século XXI. Avanços que podem auxiliar, em um percurso mais seguro para propostas de novas entidades químicas (NCE, do inglês "New Chemistry Entity”), com baixo custo e em menor tempo, acelerando o processo.

A junção do conhecimento biológico e químico de sistemas macromoleculares aos avanços tecnológicos geraram enormes quantidades de informações úteis para delineamento de novas substâncias químicas; porém, esses números são exacerbados o suficiente, para tornar essa tarefa quase impossível sem o uso de métodos computacionais.

\subsubsection{QSAR}

Estratégias diversificadas empregadas na identificação e predição de transformações químicas favoráveis, no processo de desenvolvimento de fármacos encontram-se estritamente relacionadas às análises quantitativas ou qualitativas de SARs, de uma determinada série de compostos. As relações quantitativas estrutura-atividade (QSAR) baseia-se na possibilidade de a atividade e/ou propriedade ser uma função da estrutura molecular, ou seja, correlaciona a 
estrutura com determinada resposta biológica, com o objetivo de fundamentar o planejamento de novas substâncias que possuam perfil terapêutico mais adequado às necessidades. ${ }^{17}$

Os modelos QSAR(s) mais populares podem ser divididos em duas classes: análises clássicas do tipo Hansch - 2Ds (bidimensionais) e análises com parâmetros 3Ds (tridimensionais). Ambas englobam dois procedimentos gerais, $i$ ) cálculo de descritores moleculares e ii) geração estatística do modelo QSAR. Outras classes, menos populares (4D, 5D e 6D), derivaram-se dos mesmos fundamentos dos métodos 2D e 3D.

As metodologias QSAR(s) 2D, desde seu surgimento com as observações de Cros, em 1863 (Figura 2), e sistematização, por volta de 1964, com o trabalho de Hansch e Fujita, ${ }^{18}$ até os dias atuais, passaram por diversas transformações. ${ }^{6 \mathrm{~m}}$ Com a inserção de parâmetros moleculares tridimensionais, as técnicas sofreram profunda reestruturação. ${ }^{19}$ Nos anos seguintes, mais variáveis foram incorporadas, constituindo a quarta (QSAR 4D), ${ }^{18}$ quinta $\left(\right.$ QSAR 5D) ${ }^{20}$ e sexta (QSAR 6D) ${ }^{21}$ dimensão.

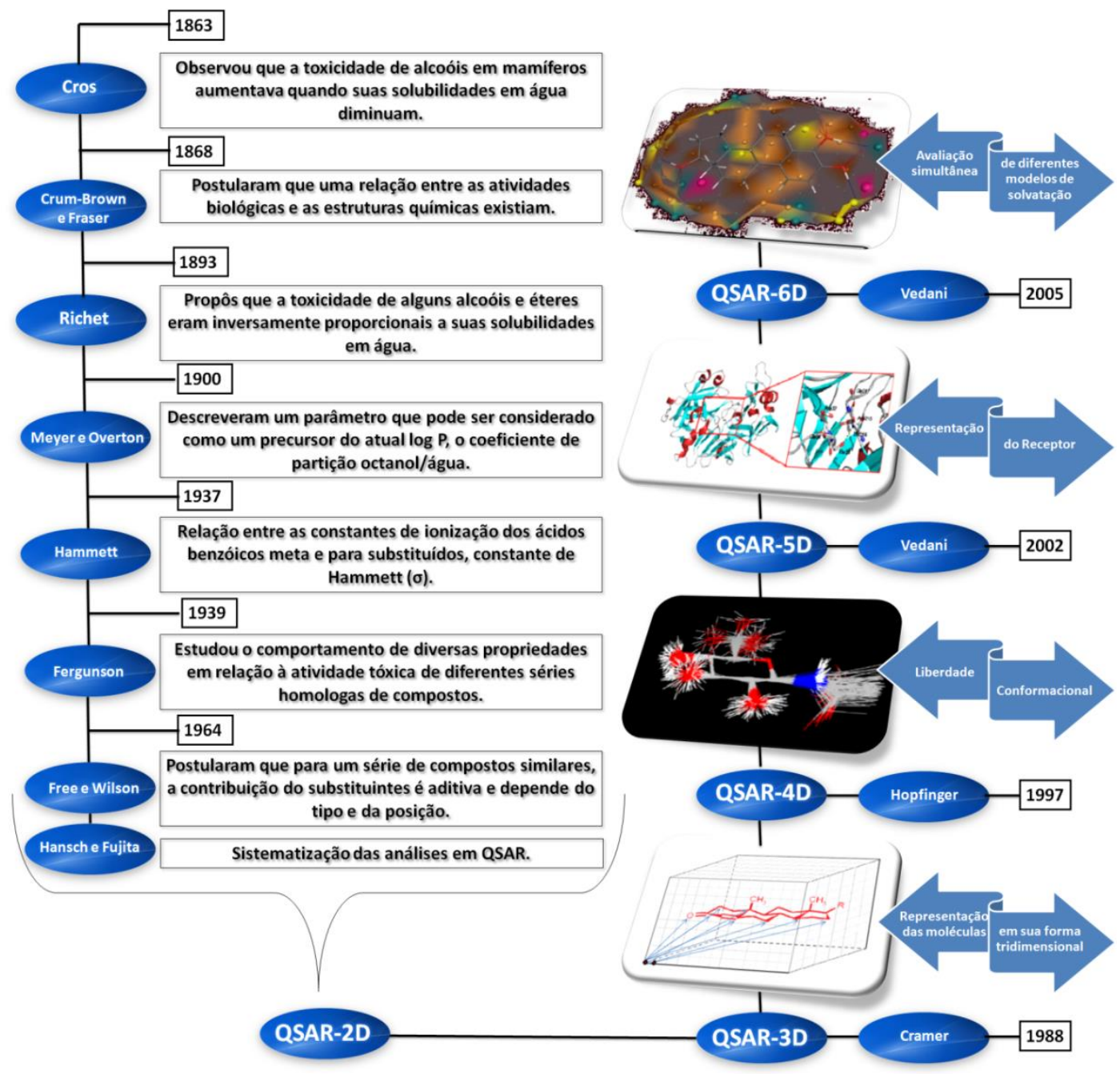

Figura 2. Cronologia da construção e distinção entre os formalismos da metodologia QSAR Fonte: adaptado de Silva (2013) 
Todas as metodologias QSAR(s) exibem diferenças, vantagens e desvantagens, mas buscam descrever um sistema de dados da maneira mais semelhante ao real possível. $\mathrm{Na}$ Figura 2 estão sintetizadas as diferenças básicas entre as técnicas QSAR(s) 2D, 3D, 4D, 5D e $6 \mathrm{D}$.

\subsubsection{HQSAR}

Diversos métodos já foram propostos para obtenção de modelos QSAR(s)-2D, tais como: MIA-QSAR, ${ }^{22}$ FB-QSAR, ${ }^{23}$ e FS-QSAR; ${ }^{24}$ dentre outros, que utilizam descritores 2D para alcançar a correlação quantitativa estrutura-atividade. ${ }^{25}$

Em 1997, surgiu uma nova forma de construir um modelo QSAR. ${ }^{61} \mathrm{O}$ método, denominado Holograma-QSAR (HQSAR, do inglês "hologram quantitavive structureactivity relationships”), baseia-se em fragmentos moleculares da estrutura 2D (impressões digitais), utilizados para correlacionar às informações experimentais (resposta biológica).

Os descritores (bloco $\mathbf{X}$ ) são gerados por meio da fragmentação molecular, um algoritmo (CRC, do inglês "cyclic redundancy check") converte as impressões digitais em hologramas de comprimentos fixos (variáveis independentes), a composição de cada holograma é diferenciada pela distinção do fragmento. Opções do tipo: átomo (A), ligação (B), conectividade $(\mathrm{C})$, hidrogênio $(\mathrm{H})$ e quiralidade $(\mathrm{Ch})$, podem ser escolhidas. Finalmente, a correlação é obtida com a regressão linear dos mínimos quadrados parciais (PLS, do inglês "Partial least squares").

HQSAR não requer nenhum tipo de alinhamento do conjunto de dados na construção dos modelos. Assim, consegue-se aplicar a metodologia em grandes bibliotecas de dados de forma rápida e prática, sem perder a qualidade dos resultados, consequência da alta capacidade preditiva e robustez. O método fornece também, resultados comparável com a metodologia 3D (CoMFA, do inglês "Comparative Molecular Field Analysis") ${ }^{61,26}$ e, além disso, fornece resultados superiores se comparado com outras metodologias QSARs (maior valor de $\left.q^{2}\right) .{ }^{61,24,27}$

\subsubsection{Docagem}

Para entender o mecanismo de interação de um fármaco, é essencial saber o posicionamento tridimensional para a sua interação molecular com a proteína alvo. ${ }^{28} \mathrm{O}$ 
processo de docagem envolve a predição da conformação do ligante e sua orientação dentro do sítio de interação da proteína. Essa simulação computacional (docagem) é uma das mais importantes técnicas de investigação das interações moleculares entre a proteína e o ligante, nos casos em que a estrutura 3D da proteína já foi elucidada. ${ }^{29}$ Esse tipo de simulação encontra a estrutura mais estável do complexo "proteína-ligante" e calcula essa estabilidade relativa.

Para inferir qual é a estrutura de menor energia, sem qualquer suposição prévia, necessita-se de uma análise de todos os modos de interação, considerando a flexibilidade conformacional do ligante a ser introduzido no sítio ativo da proteína e sua potencialidade, com isso, grande número de estruturas são geradas. Como esses problemas estão interligados, podem ser resolvidos ao mesmo tempo. Contudo, o número de combinações envolvidas é demasiado o suficiente para tornar essa tarefa complicada. Assim, classificar os candidatos de acordo com algum critério, que normalmente é a aplicação de uma função de pontuação, pode facilitar a escolha do ligante..$^{30}$

Dentre os procedimentos que podem ser realizados por meio dessa metodologia (Tabela 1), estão o cálculo da energia potencial de interação (encaixe rígido), minimização de energia potencial do sistema (encaixe parcialmente flexível) ou a simulação de dinâmica molecular (encaixe flexível); ${ }^{31}$ dependendo do objetivo e da disponibilidade de demanda computacional, são simulações indispensáveis na busca por novos compostos que modulem determinado alvo.

Tabela 1. Níveis de complexidade na execução da docagem

\begin{tabular}{lll}
\hline Ligante & Receptor & Graus de liberdade \\
\hline Rígido & Rígido & 3 translacionais +3 rotacionais \\
Flexível & Rígido & 3 translacionais +3 rotacionais $+\mathrm{n}$ diedral \\
Flexível & Flexível & 3 translacionais +3 rotacionais $+\mathrm{n}$ diedral $+\mathrm{m}$ diedral \\
\hline
\end{tabular}

O modo de realização da docagem, geralmente, encontra-se implementado nas funções dos programas de docagem disponíveis (pagos ou gratuitos). ${ }^{32}$ Comumente, os programas de docagem avaliam a energia potencial ou a energia livre de interação como uma soma de contribuições específica, quais sejam: interações hidrofóbicas, de van der Waals, ligações de hidrogênio e outras interações eletrostáticas. Esses elementos integram os chamados campos 
de força, que são descritos em função de parâmetros geométricos: distâncias e ângulos interatômicos. $^{31}$

Os programas de docagem, para executar sua função devem superar dois problemas inerentes: $i$ ) predizer a orientação e a conformação do ligante no sítio de ligação do alvo e $i i$ ) produzir uma classificação hierárquica dos compostos de base de dados, por meio da afinidade do ligante com o receptor. Neste último caso, geralmente empregam-se funções de pontuação, como o docking score. ${ }^{31}$

\subsubsection{ROCS}

Informações moleculares 3Ds são importantes no reconhecimento da provável conformação bioativa do ligante. Apesar de ser esta, uma complexa tarefa, eliminam-se chances de erros, quando disponível a estrutura cristalográfica do ligante co-cristalizado no alvo de interesse. Contudo, as dificuldades são maiores, quando essas informações não existem, o que torna subjetiva a busca pela conformação bioativa ao utilizar intervenções manuais e superimposições; como consequência, muitos modelos QSAR(s) 3D não são reprodutíveis. ${ }^{24}$ Alguns trabalhos, ainda, reportam que o poder de predição nesta metodologia é inferior aos QSAR(s) 2D. ${ }^{61,27 b, 29 b, 33}$

Em conjunto com a metodologia QSAR, outras técnicas 3Ds podem ser aplicadas, a fim de melhorar o entendimento e o conhecimento de um determinado grupo de moléculas, bem como as interações e as afinidades desses ligantes com seus respectivos receptores, de forma a validar e interpretar os dados bioquímicos.

O ROCS, ${ }^{16}$ um programa da OpenEye, consegue avaliar a forma molecular como propriedade no reconhecimento de ligantes em um alvo macromolecular. ${ }^{27 a} \mathrm{O}$ rápido desempenho do programa torna-o atrativo para a busca de novas substâncias bioativas para a enzima cruzaína. ${ }^{34}$ Qualquer enzima apresenta forma molecular única no sítio ativo e este parâmetro, se explorado, auxilia no planejamento e síntese de novos inibidores.

\subsubsection{A combinação de métodos computacionais}

O HQSAR, comumente utilizado para pesquisar fragmentos moleculares passiveis de modificações estruturais; ${ }^{61,26}$ também pode ser aplicado prospectivamente para a predição de atividade biológica de compostos ainda não sintetizados. ${ }^{61,35}$ 
A propriedade fundamental no processo de reconhecimento molecular entre alvos macromoleculares e ligantes é a forma molecular, ${ }^{27 a}$ caracterizando-se como um parâmetro essencial a ser avaliado na proposta de novos inibidores. O emprego das metodologias ROCS com a docagem mostra-se uma estratégia útil para identificar inibidores de cruzaína em grandes bibliotecas de compostos, contendo inibidores ativos e inativos contra esta enzima, e ainda, consegue distinguir características únicas para essa classe de inibidores, baseando-se na forma molecular 3D. ${ }^{29 b, 29 c}$

A combinação de métodos computacionais pode guiar no planejamento de novas estruturas químicas potencialmente ativas como inibidores da cruzaína. 6m, 32e, 36 Nesta perspectiva, aglomerar os métodos pode ser uma solução com a justaposição de informações: a docagem fornece interações específicas entre ligante e receptor, o ROCS pode fornecer a forma molecular adequada para aprimorar os inibidores da cruzaína e o HQSAR pode ser mais útil na predição da propriedade biológica. Essa junção, inclusive, é útil para validar as estimativas de bioatividades de novas moléculas concebidas por meio de análises QSAR(s).

\subsection{Metodologia}

O desenvolvimento desse capítulo do trabalho ocorreu no Laboratório do Grupo de Estudos em Química Medicinal (Nequimed), no Instituto de Química (IQSC) da Universidade de São Paulo (USP), por meio de uma estação de trabalho Intel ${ }^{\circledR}$ Core ${ }^{\mathrm{TM}} 2$ (processador Intel Quad-Core Q6600 2,4 GHz, 3 GB DDR3 de memória e HD de 500 GB, sistema operacional Linux). O aluno de doutorado Geraldo Rodrigues e o pos-doutorando Josmar Rocha contribuíram com os estudos computacionais.

Na Figura 3 é mostrado um fluxograma com as sequências das etapas que foram realizadas, além da metodologia aplicada; sua construção foi baseada em artigos de revisão, ${ }^{6 c \text {, }}$ 6d, 6f, 24 que apresenta os procedimentos essenciais para obtenção de modelos QSAR(s) preditivos, robustos e de alta qualidade.

\subsubsection{Conjunto de dados}

Para a construção de um modelo HQSAR robusto e preditivo (Figura 3, $1^{\circ}$ Etapa), realizaram-se buscas na literatura com pesquisas sistemáticas, em bancos de dados, disponíveis na rede mundial de computadores (internet). 


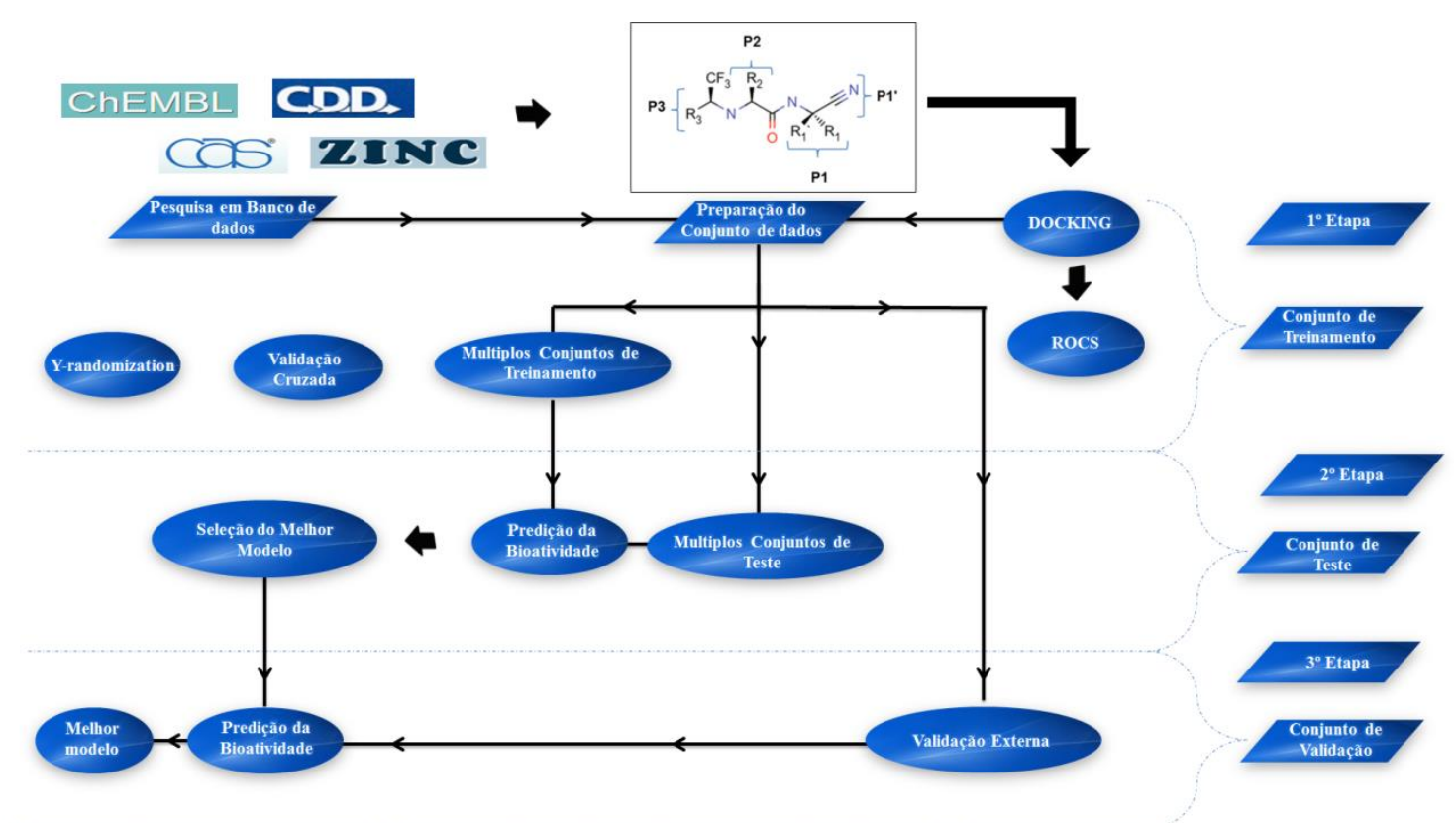

Figura 3. Fluxograma das etapas envolvidas na realização do presente capítulo

O esqueleto básico do inibidor de cruzaína mais avançado na gênese planejada de fármacos (K777), ${ }^{12 f}$, 37 bem como, o ensaio biológico de interesse $\left(\mathrm{IC}_{50}=50 \%\right.$ de concentração inibitória para a cruzaína, em $\mathrm{mol} \mathrm{L}^{-1}$ ), foram empregados como filtros para garimpar o alto número de informações disponíveis.

As buscas de subestruturas químicas realizadas no ChEMBL ${ }^{38}$ e CDD (do inglês "Collaborative Drug Discovery"), ${ }^{39}$ resultaram na seleção de 44 compostos dipeptidil nitrilas, ${ }^{40}$ com valores de $\mathrm{pIC}_{50}$ entre 6,30 e 10,00. Mais 13 dipeptidil nitrilas, ${ }^{41}$ previamente, sintetizadas e testadas contra a cruzaína em nosso grupo, usando o mesmo protocolo de ensaio, ${ }^{29 \mathrm{c}}$ foi incluído no conjunto de compostos para cobrir uma distribuição de faixa maior de $\mathrm{pIC}_{50}$ (entre 5,0 a 10,0). A Figura 4 mostra o esqueleto básico do conjunto de dados com 57 compostos (na seção apêndice encontra-se uma tabela com todos os compostos usados nas análises).
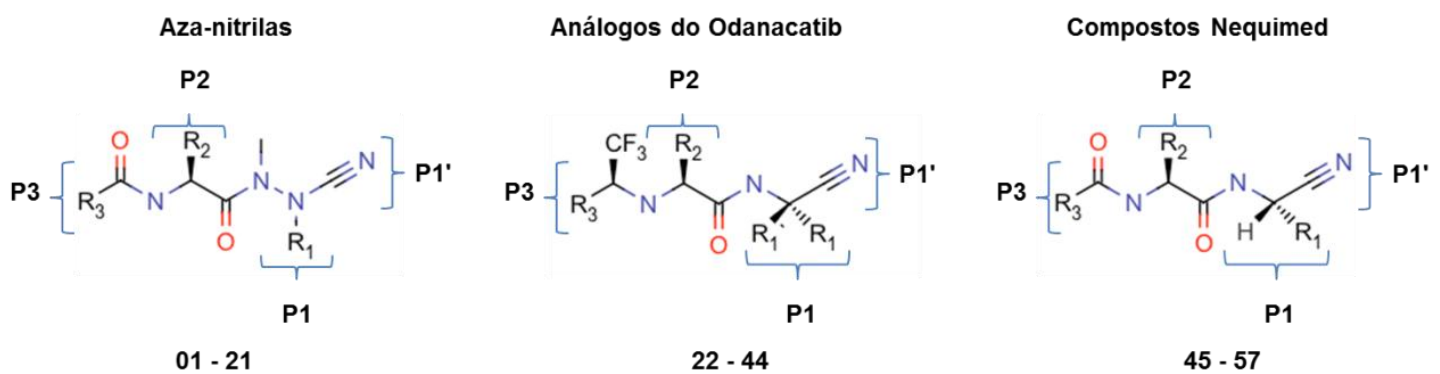

Figura 4. Esqueleto básico da série de dipeptil nitrilas estudadas no trabalho ${ }^{40-41}$ 


\subsubsection{HQSAR}

O método para construção de modelos preditivos HQSAR, implementado no programa SybylX, ${ }^{42}$ busca identificar padrões no conjunto de compostos usado, que são fragmentos subestruturais (holograma molecular) relevantes para a atividade biológica. Os hologramas moleculares são compostos por arranjos fragmentares, fundamentados em impressões digitais binárias 2Ds tradicionais, empregadas na pesquisa em bancos de dados e técnicas de diversidade molecular.

\subsubsection{Escolha do conjunto de treinamento e teste}

Com o objetivo de construir os modelos HQSAR(s), as 57 amostras com valores experimentais de $\mathrm{pIC}_{50}$ disponíveis, foram divididas em múltiplos grupos de treinamento (40 compostos, aproximadamente $70 \%$ do conjunto de dados) e teste (cerca de 30\%, 17 compostos) de forma que cada molécula participou pelo menos uma vez do conjunto de treinamento e pelo menos uma vez do conjunto de teste (Figura 3).

As amostras do grupo teste foram escolhidas cuidadosamente para compor a validação interna, de forma que os compostos com valores extremos de $\mathrm{pIC}_{50}$ fossem evitados, mas que uma distribuição regular fosse mantida ao longo de todo o conjunto. Assim como, uma análise detalhada das similaridades estruturais, para que aquelas moléculas com características únicas fossem mantidas no conjunto de treinamento.

\subsubsection{Construção do modelo HQSAR}

A qualidade do modelo HQSAR altera-se com a escolha de três parâmetros: i) comprimento do holograma, ii) tamanho do fragmento e iii) distinção do fragmento. Essas opções encontram-se na Tabela 2.

O primeiro parâmetro (Tabela 2) controla o número de "bins" em cada holograma molecular, portanto, alterações no comprimento do holograma podem alterar a posição e a quantidade de "bins" presentes em cada holograma molecular. As alterações na disposição do holograma molecular provocam contribuições, negativas ou positivas, na correlação com a variação da atividade biológica. Entretanto, não se sabe, quais das doze opções de comprimento do holograma disponível, alcançara a melhor correlação. Por isso, inicialmente, fixa-se todas as opções. 
Tabela 2. Parâmetros usados na construção dos modelos HQSAR

\begin{tabular}{|c|c|c|c|c|c|c|c|c|c|}
\hline \multicolumn{3}{|c|}{$\begin{array}{l}\text { 1) Comprimento } \\
\text { do Holograma }\end{array}$} & \multicolumn{2}{|c|}{$\begin{array}{l}\text { 2) Tamanho } \\
\text { do } \\
\text { Fragmento }\end{array}$} & \multicolumn{2}{|c|}{$\begin{array}{l}\text { 3) Distinção } \\
\text { do Fragmento }\end{array}$} & \multicolumn{3}{|c|}{$\begin{array}{l}\text { 3.1) Combinações da Distinção do } \\
\text { Fragmento }\end{array}$} \\
\hline 53 & 59 & 61 & $2-5$ & $3-6$ & $\bar{A}$ & B & $\overline{A / B}$ & $A / B / C$ & $A / B / H$ \\
\hline 71 & 83 & 97 & 47 & & C & $\pi$ & $A / B / C h$ & $A / B / D$ & $A / B / C / H$ \\
\hline 151 & 199 & 257 & $4-1$ & $J-0$ & 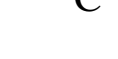 & 11 & $A / B / C / C h$ & $A / B / C / D$ & $A / B / H / C h$ \\
\hline 307 & 353 & 401 & $6-9$ & $7-10$ & \multicolumn{2}{|c|}{$\mathrm{Ch}$} & $A / B / H / D$ & $A / B / C h / D$ & $A / B / C / H / C h / D$ \\
\hline
\end{tabular}

Ao contrário do procedimento anterior, não se pode fixar todos os tamanhos do fragmento (Tabela 2, parte 2) de uma só vez. Então, para escolher esse parâmetro, o primeiro procedimento é fixar um único tamanho do fragmento, que geralmente é de 4 a 7 , escolha baseada em testes feitos por Lowis, ${ }^{61,35}$ que demonstrou ser esse um padrão. Nesta etapa, controla-se o número mínimo $(\mathrm{M}=4)$ e máximo $(\mathrm{N}=7)$ de fragmentos em cada holograma.

Uma vez fixado os dois parâmetros iniciais, resta avaliar qual distinção de fragmento melhor se correlaciona com a resposta biológica. Diversas combinações são possíveis, por isso, adotou-se a estratégia de selecionar todos os comprimentos do holograma, seguida da fixação do tamanho do holograma de 4-7, e por último, variou-se a distinção do fragmento (Tabela 2, parte 3.1).

Após a averiguação de qual distinção de fragmento melhor se correlaciona com a variação de $\mathrm{pIC}_{50}$ da série de compostos, por meio da observação dos valores ótimos do coeficiente de correlação $\left(r^{2}>0,8\right)$, do coeficiente de correlação das validações cruzadas $\left(q^{2}>\right.$ $0,5)$, do teste de validação interna $\left(r_{\text {teste }}^{2}>0,5\right),{ }^{6 \mathrm{~d}, 24}$ da randomização do bloco $\mathbf{Y}$ e erros de predição, inicia-se a variação do tamanho do fragmento, de acordo com as opções presentes na Tabela 2, parte 2 .

Realizado todos esses procedimentos, consegue-se estabelecer os três melhores parâmetros para a obtenção do modelo HQSAR, que surge da correlação, por meio da regressão dos mínimos quadrados parciais (PLS) ${ }^{43}$ entre características subestruturais da série de compostos (comprimento do holograma, tamanho e distinção do fragmento) e atividade biológica.

\subsubsection{Métodos de validação dos modelos QSAR}

A utilização de validações estatísticas (Figura 3, $1^{\circ}$ Etapa) se faz necessária, para que o modelo QSAR construído seja considerado robusto e preditivo. Três validações cruzadas 
$\left(q^{2}\right)$ foram empregadas no modelo de calibração: a validação cruzada leave-one-out (LOOCV, deixe uma amostra fora), leave-two-out (LTOCV, deixe duas amostras fora), leave-group-out (LGOCV, deixe um grupo de amostras fora, que neste caso, foram cinco compostos por vez).

$\mathrm{Na}$ validação cruzada retira-se uma, duas ou cinco moléculas do conjunto de treinamento (dependendo da validação cruzada utilizada); em seguida, realiza-se a regressão e, após esse procedimento, a atividade biológica é predita para a molécula que permaneceu de fora do modelo de calibração. Repete-se o processo até que todas as moléculas tenham ficado de fora do conjunto de calibração pelo menos uma vez. Utiliza-se essa validação interna para calcular um número ótimo de variáveis latentes (ou componentes PLS) e construir o modelo QSAR. Outra validação importante baseia-se em desorganizar o bloco Y (Y-randomization). Então, com os valores de $\mathrm{pIC}_{50 \text { exp }}$. não correspondentes às suas verdadeiras amostras, esperase que o $r_{\text {rand. }}^{2}$ (randomizado) resulte em valores menores que o $r_{c a l}^{2}$, isso demonstra que o modelo QSAR construído não é obra do acaso.

Dessa forma, obtém-se uma ideia inicial do poder de previsibilidade e robustez, compreendendo estes os passos essências para conclusão da $1^{\circ}$ Etapa (Figura 3).

A avaliação inicial do poder preditivo do modelo com conjunto de teste está entre os procedimentos obrigatórios em metodologias QSAR (Figura 3, $2^{\circ}$ Etapa). ${ }^{6 \mathrm{~d}}$ Esse método de validação consiste em utilizar o modelo construído para predizer o $\mathrm{pIC}_{50 \text { pred }}$ (predito) do conjunto de teste, composto por moléculas que em nenhum momento fizeram parte da calibração do modelo. Como o pIC $_{50 \exp }$ (experimental) dessas moléculas é conhecido, pode-se comparar o pIC $\mathrm{I0pred}_{\text {. }}$ com o $\mathrm{pIC}_{50 \exp }$. Com isso, consegue-se selecionar o melhor modelo QSAR, baseando-se no poder de predição.

\subsubsection{Validações externas}

Mesmo após a realização de todas as análises estatísticas, a comprovação e validação definitiva, de que um bom modelo QSAR foi construído, é alcançada com a validação externa (Figura 3, $3^{\circ}$ Etapa). ${ }^{6 c-f}$ A partir da escolha na literatura de outro conjunto de moléculas pertencentes à mesma classe e com dados experimentais disponíveis (valores de $\mathrm{pIC}_{50}$ ), valida-se o modelo QSAR ao predizer os valores de $\mathrm{pIC}_{50}$ para esse novo conjunto de amostras. 


\subsubsection{Conjunto de validação externa - V1}

Uma nova busca nos bancos de dados, utilizando os mesmos critérios mencionados no tópico 3.2.1, resultou num conjunto de 121 compostos com $\mathrm{pIC}_{50}$ experimental contra a cruzaína, denominado como conjunto de validação - V1 (composição: 4 compostos extraídos da base de dados CDD, ${ }^{39} 108$ compostos selecionados na base de dados ChEMBL ${ }^{38}$ e 9 novos compostos sintetizados pelo grupo Nequimed). ${ }^{41} \mathrm{Em}$ seguida, o melhor modelo HQSAR 3.4 foi usado para predizer as bioatividades desse conjunto de compostos e o coeficiente de correlação foi calculado $\left(r^{2}\right)$.

\subsubsection{Curva ROC e os conjuntos de validação externa - V2 e V3}

Outra série de compostos contendo 1085 dipeptidil nitrilas, com valores experimentais de percentual de inibição (PI\%) em concentração de $0,1 \mu M$ foi extraído do CDD e denominado como conjunto de validação - V2.

Com o propósito de utilizar conjuntos de dados com respostas biológicas diferentes ( $\mathrm{pIC}_{50}$ e PI\%), estabeleceu-se uma classificação para distinguir compostos ativos dos compostos inativos. Compostos que apresentam PI\% $<50 \%$ em $0,1 \mu M$, pertencem a classe 0 (inativos), enquanto que os compostos que apresentam $\mathrm{PI} \% \geq 50 \%$ nesta mesma concentração, pertencem a classe 1 (ativos). O mesmo critério foi adotado para o conjunto de validação V1. Classificou-se os compostos com $\mathrm{pIC}_{50}<7$ como inativos e aqueles com $\mathrm{pIC}_{50}$ $\geq 7$ como ativos.

Essa estratégia permite que sejam utilizados compostos com ensaios biológicos diferentes na mesma validação externa.

A predição do modelo HQSAR das atividades biológicas dos conjuntos de validação externa (V1 e V2) podem ser avaliados por meio da construção da curva ROC (do inglês "Receiver operating characteristic"). ${ }^{44} \mathrm{O}$ método consiste na representação gráfica da taxa de verdadeiros positivos (eixo $\mathrm{y}$, sensibilidade) versus a taxa de falsos positivos (eixo $\mathrm{x}$, especificidade). Assim, uma distribuição ideal ocorre quando os compostos ativos (classe 1) são completamente separados dos compostos inativos (classe 0), então a curva sobe verticalmente para o canto superior esquerdo e se encontra horizontalmente com o canto superior direito. Desta forma, a avaliação do gráfico ROC baseia-se na área acima da curva (AUC, do inglês "area under the curve"). 
No exemplo em que a uma curva ideal foi obtida, o valor de AUC corresponde a 1,0. 44

Portanto, empregou-se a metodologia para confirmar se o modelo HQSAR consegue discriminar compostos ativos de inativos com acurácia.

O mesmo critério de classificação de compostos foi aplicado ao conjunto de teste (17 compostos) usado na construção do modelo HQSAR. Com o filtro utilizado o último conjunto de validação foi gerado (V3), com 38 compostos ativos (verdadeiros positivos) e 1185 compostos inativos (falsos positivos). Neste conjunto, todos os compostos das validações foram incluídos (conjunto de teste, V1 e V2), totalizando 1223 compostos. O conjunto de validação V3, também foi empregado nas análises de ROCS. A Figura 5 sumaria o apresentado no texto.
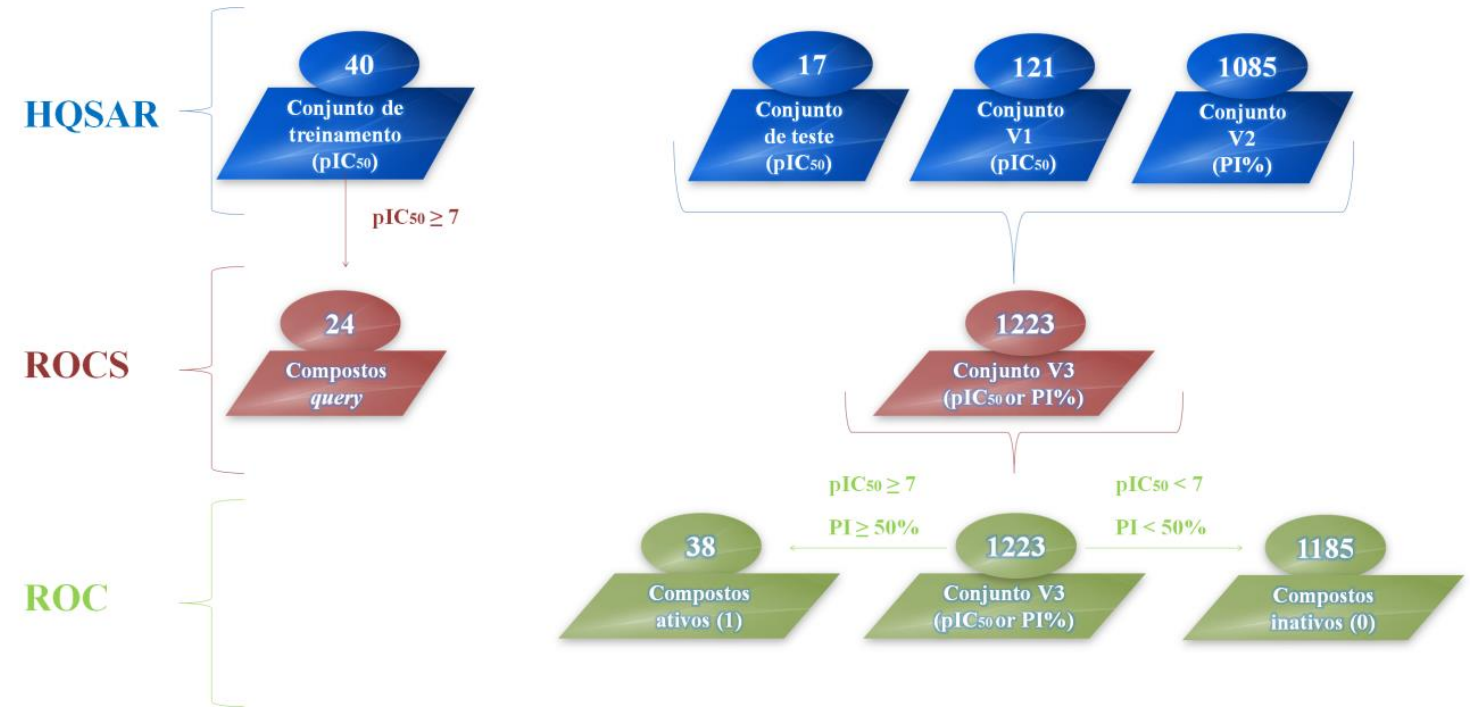

Figura 5. Conjunto de dados utilizado na construção e validação dos modelos HQSAR (destacado em azul). O filtro utilizado para selecionar os compostos de referência (query) e os compostos para construção do modelo 3D ROCS (destacado em vermelho). Os filtros utilizados para gerar as curvas ROC (destacado em verde)

\subsubsection{ROCS}

A busca por reconhecimento da forma molecular, que distinguem compostos ativos contra a cruzaína dos inativos, pode ser alcançada com a metodologia ROCS. ${ }^{16} \mathrm{Na}$ construção do modelo 3D, avalia-se a forma molecular baseado na sobreposição dos confôrmeros de todos os compostos, em uma ou mais conformações, sobre uma entrada de referência (query), que geralmente são inibidores enzimáticos potentes e conhecidos. Então, gera-se um banco multiconformacional dos compostos de interesse, usando o programa OMEGA, ${ }^{45}$ capaz de reproduzir conformações bioativas. ${ }^{46}$ 
Os compostos classificados como ativos do conjunto de treino do HQSAR foram usados como compostos query (24 compostos com $\mathrm{pIC}_{50} \geq 7$, Figura 5, destacado em vermelho) e o conjunto de dados $\mathbf{V 3}$ foi usado para avaliar se é possível discriminar entre compostos ativos e inativos baseado na forma molecular 3D.

Cerca de 200 conformações foram geradas para cada composto query e para todos os compostos do conjunto de dados $\mathbf{V 3}$.

A descrição da forma molecular ocorre com a utilização de funções Gaussianas contínuas, centralizadas nos átomos. A sobreposição da coleção multiconformacional, pelo programa ROCS, simula as moléculas como esferas rígidas para maximizar o recobrimento do volume molecular. ${ }^{16 a, 16 b} \mathrm{O}$ ROCS usa somente átomos pesados do ligante; os hidrogênios são ignorados. Uma vez que forma e volume molecular são relacionados, a maximização do recobrimento do volume é um excelente método para obter a similaridade da forma. ${ }^{29 \mathrm{~d}}$

Com a sobreposição realizada entre os 24 compostos query e o conjunto de validação V3, avaliou-se a similaridade da forma molecular por meio das seguintes métricas: Shape Tanimoto, Color Tanimoto, Combo Tanimoto, Fit Color Tversky, Fit Tversky, Fit Tversky Combo, Ref Color Tversky, Ref Tversky, Ref Tversky Combo, Color Score, Scaled Color, Combo Score e Overlap.

A análise dos dados objetivou reconhecer qual métrica e qual query apresenta melhor taxa de recuperação dos compostos ativos entre os inativos. Logo, todas as métricas foram avaliadas por meio da curva ROC.

\subsubsection{Docagem}

\subsubsection{Preparação da proteína e dos ligantes}

As estruturas 2Ds dos 57 derivados de nitrila com a devida estereoquímica foram desenhados no programa MarvinSketch. ${ }^{47}$ Em seguida, gerou-se a estrutura 3D e os estados de protonação em $\mathrm{pH}$ de 5,5 (o mesmo usado nos ensaios bioquímicos) para todas as estruturas, usando um modulo denominado LigPrep do pacote de programa Maestro, da Schrödinger. ${ }^{48}$

A porção correspondente ao warhead nitrila foi representado como aldimina primaria, forma mais apropriada para realizar docagem não covalente e simular um pseudo-estado de transição do warhead com a proteína, ligados covalentemente.

Inicialmente, foi feita uma busca pela estrutura cristalográfica da enzima cruzaína (EC 3.4.22.51) para o organismo T. cruzi no banco de dados de proteínas (PDB, do inglês 
"Protein Data Bank"). ${ }^{49}$ A escolha da estrutura da proteína para os estudos de docagem foi baseada em parâmetros cristalográficos de resolução, expressos em $\AA$, R e $\mathrm{R}_{\text {free, bem como }}$ nos estudos realizados por Wiggers e colaboradores no nosso grupo. ${ }^{50}$ A estrutura cristalográfica PDB 1ME4 foi selecionada por apresentar o ligante co-cristalizado (P10) ocupando as cavidades S1', S1, S2 e S3, e ainda; valores de resolução desejáveis $(1,20 \AA$. $\mathrm{R}=$ 0,091 e $\left.R_{\text {free }}=0,124 ; R_{\text {free }}-R=0,033\right)$. A diferença entre os parâmetros $R_{\text {free }}$ e $R_{\text {factor }}$ é uma medida parcial da extensão na qual o modelo superestima os dados. Esta diferença $\left(R_{\text {free }}-\right.$ $\mathrm{R}_{\text {factor }}$ ) deve ser baixa para o modelo final, idealmente $<0,05$. Valores acima de 0,05 tornam a modelagem mais subjetiva, do que baseada em informações experimentais. ${ }^{51}$

Até o momento da realização deste estudo, não foram encontradas estruturas cristalográficas contendo dipeptidil nitrilas co-cristalizadas com a cruzaína. Então, o ligante da estrutura de código PDB 3HHA, de catepsina L de Homo sapiens, co-cristalizada com a dipeptidil nitrila (NOW) foi utilizado como modelo inicial para a posição da nitrila em cisteíno-proteases, visto que cruzaína e catepsina L compartilham $81 \%$ de similaridade.

O modelo híbrido contendo cruzaína e o ligante NOW foi construído usando o programa Maestro. ${ }^{48}$ As estruturas tridimensionais de 3HHA e 1ME4 foram sobrepostas aproveitando a alta conservação do enovelamento de ambas às proteínas (catepsina L de Homo sapiens e cruzaína de T. cruzi). Feito isso, foram removidos o ligante P10 da estrutura $1 \mathrm{ME} 4$, a proteína da estrutura 3HHA e todos os agentes de cristalização. Restou o complexo com a enzima cruzaína, as moléculas águas do modelo 1ME4 e o ligante derivado de nitrila (NOW), que foi ligado covalentemente com o resíduo de cisteína 25 (Cys25) da enzima cruzaína e exportados como um único modelo no formato PDB.

O modelo exportado foi preparado utilizando o ambiente de modelagem molecular Maestro, por meio do módulo ProteinPreparationWizard, realizou-se o ajuste nas ordens de ligação de toda a proteína, corrigidas cadeias laterais incompletas, adicionados os átomos de hidrogênio e retiradas as águas estruturais de cristalização. Ainda com o script ProteinPreparationWizard, efetuou-se a predição do estado de protonação e tautomerização mais provável dos aminoácidos em $\mathrm{pH}$ 5,5 (com base no $\mathrm{pK}_{\mathrm{a}}$ das cadeias laterais), com exceção da Histidina 159 (His159), que foi carregada positivamente para simular um estado de transição protonado.

Os átomos de hidrogênio adicionados foram minimizados de forma a aumentar a capacidade de doação de ligações de hidrogênio entre os próprios aminoácidos da proteína e o ligante co-cristalizado. Então, procedeu-se com uma leve minimização utilizando o campo de 
força OPLS, de modo a relaxar a estrutura cristalográfica, até que o RMSD atingisse um valor menor que $0,3 \AA$.

A ligação covalente entre o inibidor NOW e a cruzaína foi removida, e o resíduo de Cys25 foi alterado para um resíduo de Glicina. Depois, as coordenadas finais foram salvadas em formato PDB, para os estudos de docagem.

\subsubsection{Geração do grid e da pose de interação}

Uma caixa cúbica de $20 \AA$ centrado no centroide do ligante NOW foi gerada no programa Glide e uma restrição posicional esférica foi definida para o carbono da aldimina em um raio de $1,8 \AA$, a partir do centro da porção $\mathrm{C}=\mathrm{N}$.

Para avaliar os parâmetros estabelecidos na docagem e a consistência do modelo gerado, a molécula NOW foi re-docada no sítio ativo da cruzaína usando o modo GlideSP do programa Glide. ${ }^{52}$ Todos os demais parâmetros foram mantidos como padrão. Em seguida, os 57 compostos derivados de nitrila foram docados usando as mesmas configurações.

\subsection{Resultados e discussões}

\subsubsection{Modelagem HQSAR para os derivados de nitrila}

O conjunto de dados com 57 compostos ${ }^{40-41}$ foram divididos em múltiplos conjuntos de treinamento (40 compostos) e teste (17 compostos). Cerca de 400 modelos foram construídos. No entanto, apenas o melhor conjunto de treinamento, de acordo com Myint e Xie ${ }^{24}$ Tropsha e Golbraikh ${ }^{6 c-f}$ deve ser escolhido para predizer as bioatividades de novas amostras, baseando-se em todas as validações internas e externas.

Ao final desta etapa (divisão do conjunto em treinamento e teste), buscou-se alcançar uma distribuição proporcional de valores de $\mathrm{pIC}_{50}$, além de características moleculares semelhantes entre as moléculas pertencentes ao conjunto de treinamento e teste. A Figura 6 apresenta a distribuição normal de valores experimentais de $\mathrm{pIC}_{50}$ entre o conjunto de treinamento e teste, comparado com o conjunto total.

Para obter o modelo HQSAR, uma avaliação inicial foi feita, com todos os comprimentos do holograma escolhidos e tamanho do fragmento fixado (4-7). Feito isso, variou-se a combinação da distinção do fragmento. Os modelos que apresentaram os menores erros padrão na predição (SEP) e na estimativa (SEE), assim como, valores de $q^{2}$ e $r^{2}$ acima do estabelecido na literatura ${ }^{6 \mathrm{~d}}$ estão apresentados na Tabela 3. 
(a)

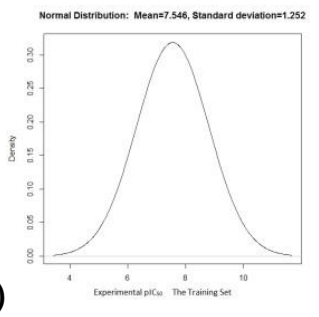

(b)

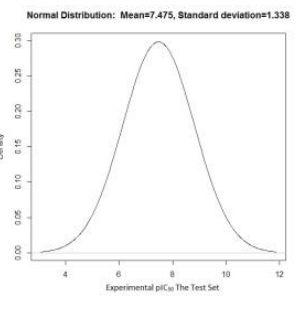

(c)

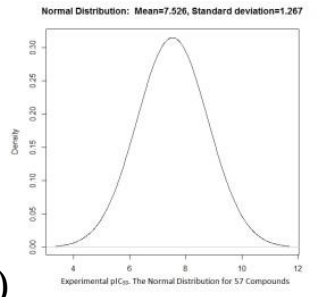

(d)

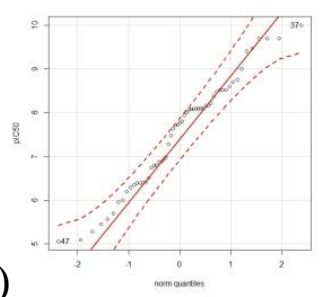

Figura 6. Distribuição dos valores experimentais de $\mathrm{pIC}_{50}$ dos 40 compostos do conjunto de treinamento (a), dos 17 compostos do conjunto de teste (b) e dos 57 compostos do conjunto total (c). O teste de normalidade Shapiro-Wilk para os valores de $\mathrm{pIC}_{50}$ são $\mathrm{W}=0,97$, valor de $\mathrm{p}=0,17$ e os pontos em vermelho indica o intervalo de confiança de $95 \%$ (d).

Ao variar a distinção do fragmento, 12 modelos HQSAR apresentaram valores de $r^{2}$, que variaram de 0,876 (Modelo 1) a 0,966 (Modelo 8), e $q^{2}$ (LOOCV) de 0,583 (Modelo 1) a 0,727 (Modelo 10), ou seja, todos os modelos alcançaram parâmetros estatísticos satisfatórios.

Tabela 3. Resultado da análise de HQSAR usando várias distinções de fragmentos e os principais parâmetros estatísticos, bem como validação cruzada "leave-oneout" que indica a qualidade do modelo. O tamanho padrão do fragmento (4-7) foi utilizado

\begin{tabular}{|c|c|c|c|c|c|c|c|c|}
\hline Modelo (4-7) & $\begin{array}{c}\text { Distinção do } \\
\text { fragmento }\end{array}$ & $q^{2}(\mathrm{LOOCV})$ & $r^{2}$ & SEP & SEE & $\mathbf{N}$ & HL & $r^{2}$ teste \\
\hline 1 & $\mathrm{~A} / \mathrm{B}$ & 0,583 & 0,876 & 0,879 & 0,479 & 6 & 71 & 0,375 \\
\hline 2 & $\mathrm{~A} / \mathrm{B} / \mathrm{C}$ & 0,674 & 0,943 & 0,801 & 0,336 & 8 & 151 & 0,418 \\
\hline 3 & $\mathbf{A} / \mathbf{B} / \mathbf{H}$ & 0,676 & 0,925 & 0,799 & 0,384 & 8 & 199 & $\mathbf{0 , 5 0 0}$ \\
\hline 4 & $\mathrm{~A} / \mathrm{B} / \mathrm{Ch}$ & 0,646 & 0,955 & 0,849 & 0,304 & 9 & 353 & 0,472 \\
\hline 5 & $\mathrm{~A} / \mathrm{B} / \mathrm{D}$ & 0,685 & 0,959 & 0,789 & 0,284 & 8 & 257 & 0,418 \\
\hline 6 & $\mathrm{~A} / \mathrm{B} / \mathrm{C} / \mathrm{H}$ & 0,660 & 0,936 & 0,819 & 0,355 & 8 & 307 & 0,437 \\
\hline 7 & $\mathrm{~A} / \mathrm{B} / \mathrm{C} / \mathrm{Ch}$ & 0,676 & 0,939 & 0,787 & 0,342 & 7 & 307 & 0,334 \\
\hline 8 & $\mathrm{~A} / \mathrm{B} / \mathrm{C} / \mathrm{D}$ & 0,708 & 0,966 & 0,758 & 0,258 & 8 & 257 & 0,380 \\
\hline 9 & $\mathrm{~A} / \mathrm{B} / \mathrm{H} / \mathrm{Ch}$ & 0,720 & 0,940 & 0,743 & 0,343 & 8 & 199 & 0,432 \\
\hline 10 & $\mathrm{~A} / \mathrm{B} / \mathrm{H} / \mathrm{D}$ & 0,727 & 0,950 & 0,734 & 0,315 & 8 & 353 & 0,468 \\
\hline 11 & $\mathrm{~A} / \mathrm{B} / \mathrm{Ch} / \mathrm{D}$ & 0,703 & 0,959 & 0,765 & 0,284 & 8 & 199 & 0,552 \\
\hline 12 & $\mathrm{~A} / \mathrm{B} / \mathrm{C} / \mathrm{H} / \mathrm{Ch} / \mathrm{D}$ & 0,725 & 0,943 & 0,725 & 0,330 & 7 & 53 & 0,334 \\
\hline \multicolumn{9}{|c|}{$\begin{array}{l}\text { Legenda: 4-7 = número mínimo e máximo de átomos em cada fragmento. Distinção do fragmento = átomos }(\mathrm{A}) \text {, ligações }(\mathrm{B}) \text {, conectividade } \\
\text { (C), hidrogênio }(\mathrm{H}) \text {, quiralidade }(\mathrm{Ch}) \text { e doador/aceitador }(\mathrm{D}) . \mathrm{SEP}=\text { erro padrão da predição. } \mathrm{SEE}=\text { erro padrão da estimativa. } \mathrm{N}=\text { número } \\
\text { ótimo de variáveis latentes. } \mathrm{HL}=\text { comprimento do holograma }\end{array}$} \\
\hline
\end{tabular}

Para atestar a qualidade inicial da capacidade preditiva dos 12 modelos, os 17 compostos que não fizeram parte, em nenhum momento, do conjunto de treinamento tiveram seus valores de $\mathrm{pIC}_{50}$ preditos (validação interna). Como os valores de $\mathrm{pIC}_{50}$ experimentais dessas amostras (conjunto de teste) são conhecidas, obtém-se uma ideia inicial de qual modelo conseguirá avançar para as próximas etapas, bons modelos devem apresentar valores 
de $r^{2}$ teste maiores que 0.5. ${ }^{\text {6e }}$ Assim sendo, apenas os modelos 3 e 11 satisfizeram essas exigências. Resta, portanto, avaliar a influência do tamanho do fragmento na qualidade desses modelos.

A Tabela 4, mostra os resultados para o modelo 3, com a variação do tamanho do fragmento, usando a distinção do fragmento A/B/H e o melhor comprimento do holograma em cada modelo

Tabela 4. Influência do tamanho do fragmento, nos parâmetros estatísticos usando a distinção dos fragmentos do modelo $3(\mathrm{~A} / \mathrm{B} / \mathrm{H})$

\begin{tabular}{ccccccccc}
\hline Modelo (3) & Tamanho do fragmento & $\boldsymbol{q}^{2}(\mathbf{L O O C V})$ & $\boldsymbol{r}^{2}$ & SEP & SEE & $\mathbf{N}$ & HL & $\boldsymbol{r}_{\text {teste }}$ \\
\hline 3.1 & $(2-5)$ & 0,688 & 0,943 & 0,810 & 0,347 & 10 & 97 & 0,253 \\
3.2 & $(3-6)$ & 0,669 & 0,936 & 0,835 & 0,368 & 10 & 61 & 0,578 \\
3.0 & $(4-7)$ & 0,676 & 0,925 & 0,799 & 0,384 & 8 & 199 & 0,500 \\
3.3 & $(5-8)$ & 0,679 & 0,955 & 0,823 & 0,308 & 10 & 401 & 0,568 \\
$\mathbf{3 . 4}$ & $(\mathbf{6 - 9 )}$ & $\mathbf{0 , 6 9 8}$ & $\mathbf{0 , 9 5 0}$ & $\mathbf{0 , 7 9 8}$ & $\mathbf{0 , 3 2 5}$ & $\mathbf{1 0}$ & $\mathbf{9 7}$ & $\mathbf{0 , 6 1 8}$ \\
3.5 & $(7-10)$ & 0,694 & 0,934 & 0,777 & 0,36 & 8 & 83 & 0,401 \\
\hline
\end{tabular}

. O conjunto de teste foi utilizado para avaliar a capacidade preditiva e o modelo 3.4 apresentou o melhor poder de predição $\left(r_{\text {teste }}^{2}=0.618\right)$.

Antes de eleger o melhor modelo HQSAR, outros cuidados devem ser tomados. A correlação entre estrutura e atividade biológica pode surgir, simplesmente, por obra do acaso. A desordem do bloco $\mathbf{Y}$ ( $\mathrm{pIC}_{50}$ experimentais), seguida da regressão com o bloco $\mathbf{X}$ intacto (compostos), garantem que os modelos não são fictícios. Com valores experimentais de $\mathrm{pIC}_{50}$ não correspondentes aos compostos, construiu-se, de novo, os mesmos modelos apresentados na Tabela 4, e os resultados são exibidos na Tabela 5.

Com a aleatorização do bloco $\mathbf{Y}$ (cinco vezes), seguida da regressão com o bloco $\mathbf{X}$, praticamente, não existe correlação. Os valores de $r^{2}$ e $q^{2}$ (média de cinco repetições) diminuíram bruscamente, enquanto que os erros padrão da predição (SEP) e estimativa (SEE) subiram (Tabela 5), demonstrando que os modelos HQSAR não foram obtidos por mera coincidência.

As mesmas variações dos tamanhos do fragmento aplicadas ao modelo 3, e também, a validação interna com o conjunto teste, foram usadas no modelo 11. Todos os modelos, apesar de, apresentarem valores ótimos de $r^{2}$ e $q^{2}$, possuem capacidade preditiva inferior ao modelo $3.4\left(r^{2}\right.$ teste $<0.618$, esses resultados encontram-se em apêndice). 
Tabela 5. Resultado da análise de HQSAR com a aleatorização do bloco Y (Yrandomização), com a avaliação da influência do tamanho do fragmento nos parâmetros estatísticos usando a distinção dos fragmentos do modelo 3 $(\mathrm{A} / \mathrm{B} / \mathrm{H})$

\begin{tabular}{cccccc}
\hline $\begin{array}{c}\text { Modelo } \\
(3)\end{array}$ & $\begin{array}{c}\text { Tamanho do } \\
\text { fragmento }\end{array}$ & $\begin{array}{c}\boldsymbol{q}^{2}-\boldsymbol{Y}- \\
\text { rand }^{*}\end{array}$ & $\begin{array}{c}\boldsymbol{r}^{2} \boldsymbol{- Y}- \\
\text { rand }^{*}\end{array}$ & $\begin{array}{c}\text { SEP-Y- } \\
\text { rand* }\end{array}$ & $\begin{array}{c}\text { SEE-Y- } \\
\text { rand* }\end{array}$ \\
\hline 3.1 & $(2-5)$ & 0,096 & 0,277 & 1,211 & 1,078 \\
3.2 & $(3-6)$ & 0,138 & 0,366 & 1,196 & 1,016 \\
3.0 & $(4-7)$ & 0,115 & 0,280 & 1,201 & 1,069 \\
3.3 & $(5-8)$ & 0,077 & 0,300 & 1,234 & 1,056 \\
3.4 & $(6-9)$ & 0,092 & 0,257 & 1,215 & 1,097 \\
3.5 & $(7-10)$ & 0,085 & 0,255 & 1,220 & 1,108 \\
$*$ OS valores apresentados correspondem a média de 5 repetiçôes. & & & \\
\hline
\end{tabular}

Logo, conclui-se que, o modelo 3.4, com tamanho do fragmento 6-9, e comprimento do holograma 97, dentre todos os modelos, deve ser o mais capacitado de predizer com acurácia novos compostos.

Para comprovar a robustez do modelo mais preditivo (3.4), além da validação cruzada "leave-one-out", duas outras validações foram empregadas: "leave-two-out" e "leave-groupout”. Os resultados estão na Tabela 6.

Tabela 6. Resultado das validações cruzadas para o melhor modelo obtido (modelo 3.4, distinção do fragmento: $\mathrm{A} / \mathrm{B} / \mathrm{H})$

\begin{tabular}{cccccccccc}
\hline Modelo (3) & Tamanho do fragmento & $\begin{array}{c}\text { Validação } \\
\text { cruzada }\end{array}$ & $\boldsymbol{q}^{2}$ & $\boldsymbol{r}^{2}$ & SEP & SEE & $\mathbf{N}$ & HL & $\boldsymbol{r}^{2}$ teste \\
\hline $\mathbf{3 . 4}$ & $\mathbf{( 6 - 9 )}$ & LOOCV & $\mathbf{0 . 6 9 8}$ & $\mathbf{0 . 9 5 0}$ & $\mathbf{0 . 7 9 8}$ & $\mathbf{0 . 3 2 5}$ & $\mathbf{1 0}$ & $\mathbf{9 7}$ & $\mathbf{0 . 6 1 8}$ \\
3.4 .1 & $(6-9)$ & LTOCV & 0.672 & 0.902 & 0.792 & 0.433 & 7 & 97 & 0.380 \\
3.4 .2 & $(6-9)$ & LGOCV* & 0.661 & 0.950 & 0.845 & 0.325 & 10 & 97 & 0.617 \\
"Grupo de cinco compostos & & & & & & & & & \\
\hline
\end{tabular}

Depois da aplicação de todas as validações cruzadas, conforme apresentado na Tabela 6, os resultados foram satisfatórios, com exceção do $r_{\text {teste }}^{2}$ para a validação cruzada "leavetwo-out", por isso, os dois modelos mais indicados para predizer as bioatividades de novas amostras são 3.4 e 3.4.2.

O modelo 3.4, por apresentar valores de validações internas um pouco acima do modelo 3.4.2, foi o escolhido. A representação gráfica dos resultados e os valores de $\mathrm{pIC}_{50}$ experimentais, ajustados e preditos por esse modelo, encontram-se no Figura 7. 


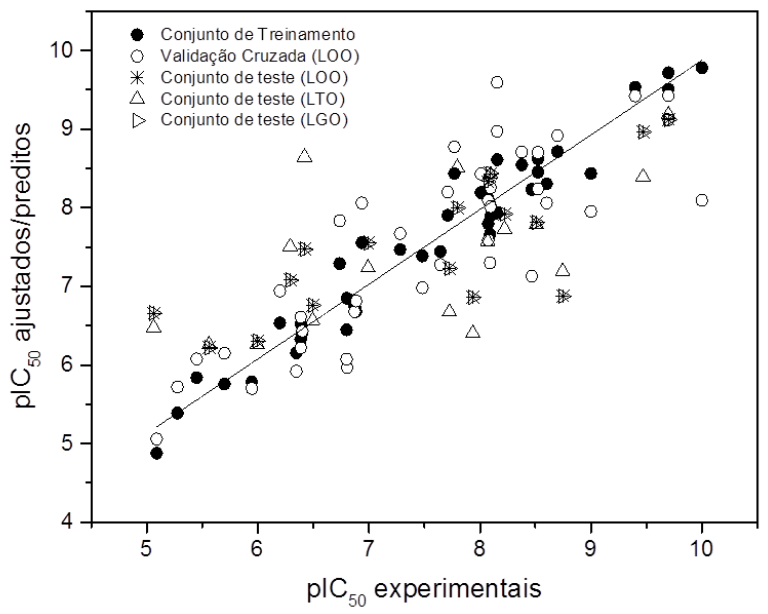

Figura 7. $\mathrm{pIC}_{50}$ experimentais vs. ajustados/preditos utilizando o melhor modelo HQSAR (modelo 3.4), tamanho do fragmento 6-9 e validação cruzada LOO. Os conjuntos de teste das validações cruzadas LTO e LGO também foram acrescentados. Mais informações no material suplementar.

\subsubsection{Validação externa - V1}

Recomenda-se que os modelos QSAR(s) antes de serem usados para predizer atividade biológica para compostos ainda não sintetizados, seja submetido a validações externas. ${ }^{6 \mathrm{~d}-\mathrm{f}} \mathrm{O}$ melhor modelo HQSAR 3.4 foi validado com moléculas que não fizeram parte do conjunto de treinamento e teste. Para tanto, o conjunto de validação externa V1 (121 compostos) foi submetido à predição usando o modelo HQSAR 3.4 construído. A Figura 8 mostra alguns exemplos preditos pelo melhor modelo para os compostos extraídos do banco de dados CDD e ChEMBL.

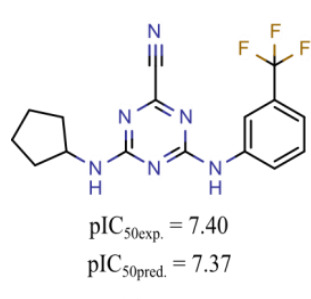

ChEMBL579273

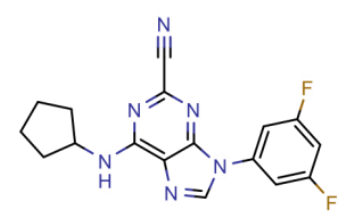

$\mathrm{pIC}_{50 \text { exp. }}=6.50$

$\mathrm{pIC}_{50 \text { pred. }}=6.39$

ChEMBL585873

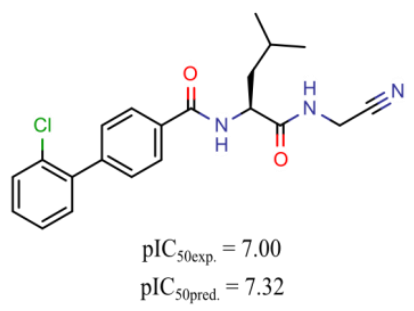

CRA-017404<smiles>CCNc1nc(C#N)nc(Nc2ccccc2)n1</smiles>

$\mathrm{pIC}_{50 \text { exp. }}=6.15$

$\mathrm{pIC}_{50 \text { pred. }}=6.10$

ChEMBL567161

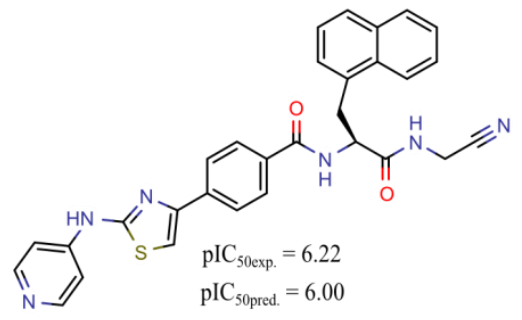

CRA-011612<smiles>N#Cc1nc(Nc2ccccc2)nc(Nc2ccccc2)n1</smiles>

$\mathrm{pIC}_{50 \text { exp. }}=5.85$

$\mathrm{pIC}_{50 \text { pred. }}=6.18$

ChEMBL578161

Figura 8. Alguns exemplos de compostos extraídos do banco de dados CDD e ChEMBL, bem como os valores experimentais de $\mathrm{pIC}_{50}$ e preditos pelo modelo HQSAR 3.4 
Com a predição do conjunto de validação V1 o modelo HQSAR 3.4 foi validado. Um cálculo do desvio padrão para a taxa residual demostra que o erro padrão de predição (SEP) varia de mais ou menos 0,43 (Figura 9).

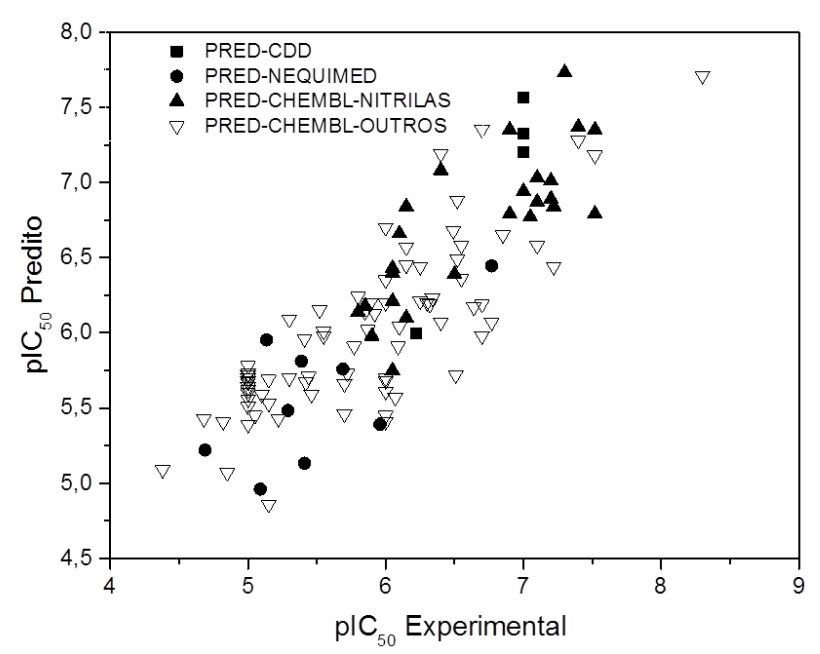

Figura 9. Valores experimentais versus preditos de $\mathrm{pIC}_{50}$, obtidos na predição do modelo HQSAR 3.4 para o conjunto de dados V1. Parâmetros estatísticos do modelo: $r^{2}=$ $0,95, q^{2}=0,70, r_{\text {teste }}^{2}=0,62, \mathrm{SEP}=0,80$, e SEE $=0,33$. Parâmetros estatísticos da predição: $r^{2}=0,65$ e SEP $=0,43$

O desvio padrão para predição das moléculas sintetizadas no grupo Nequimed foi similar à predição das moléculas extraídas dos bancos de dados, evidenciando, mais uma vez, a qualidade do modelo construído.

A excelente correlação entre valores de $\mathrm{pIC}_{50}$ preditos e experimentais é confirmada pelo $r^{2}$ obtido, que segundo Golbraikh e Tropsha, ${ }^{6 \mathrm{~d}}$ é a única maneira de alcançar um modelo QSAR confiável: o $r^{2}$ deve ser superior a 0,5. ${ }^{6 c-f, 24,27 a, 43 b}$ O $r^{2}$ encontrado para essa validação foi de 0,65 .

\subsubsection{Curva ROC para avaliar a capacidade preditiva do modelo HQSAR 3.4}

Outra avaliação, por meio da curva ROC, foi empregada para avaliar a capacidade preditiva do modelo HQSAR, usando o conjunto de dados V3 (1223 compostos).

Nesta validação, buscou-se observar a habilidade do modelo HQSAR em separar compostos ativos dos inativos.

Após a predição das bioatividades do conjunto de dados V3 a curva ROC foi construída e apresenta um AUC de 0.71 (Figura 10). O resultado confirma que o método HQSAR, além de predizer bioatividades de compostos com acurácia, consegue discriminar quais compostos são potencialmente ativos ou inativos contra a cruzaína. 


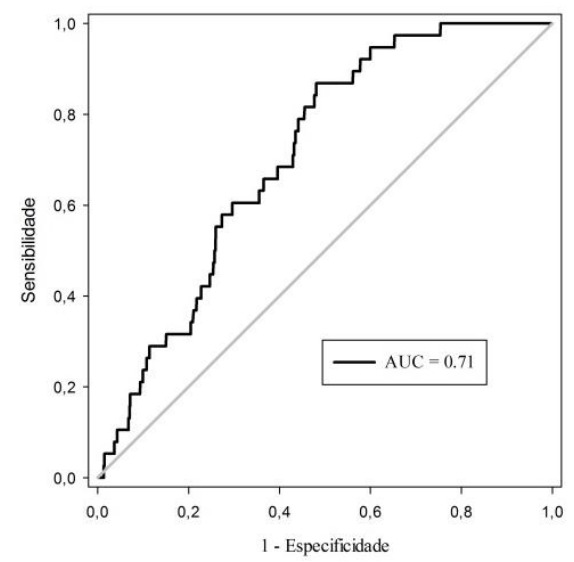

Figura 10. Gráfico ROC construído com as predições realizadas pelo modelo HQSAR utilizando o conjunto de validação $\mathbf{V 3}$

Finalmente, validou-se o modelo para ser usado nas propostas de novos inibidores de cruzaína.

\subsubsection{Docagem e interpretação do melhor modelo HQSAR}

O método HQSAR não requer conformações 3Ds, alinhamento e modo de interação do ligante para correlacionar a estrutura química com a atividade biológica. No entanto, informações ortogonais complementam e ajudam na elucidação de interações especificas que influenciam no reconhecimento molecular, entre a proteína e o ligante. Neste sentido, a docagem flexível foi empregado para predizer a pose de interação dos compostos em estudo.

A série de 57 dipeptil nitrilas é estruturalmente relacionada com o composto de referência (NOW), logo se consegue estabelecer uma predição altamente confiável, pois além da similaridade estrutural dos ligantes, tem-se a alta similaridade das enzimas: catepsina L e cruzaína (Figura 11).

A pose de interação dos ligantes estudados compreende na formação de ligações de hidrogênio da porção amida localizada no P1-P2 com os aminoácidos Glicina 66 (Gly66) e Aspartato (Asp158). Ainda, na posição P2-P3 a porção NH do grupo amida interage somente com a Gly66, visto que o oxigênio do carbono cabonílico está exposto ao solvente, conforme ilustra a Figura 11a, que apresenta os resultados da re-docagem do inibidor NOW de catepsina L. Este é um arranjo muito comum para os inibidores peptídicos de cisteíno proteases. $^{53}$ 

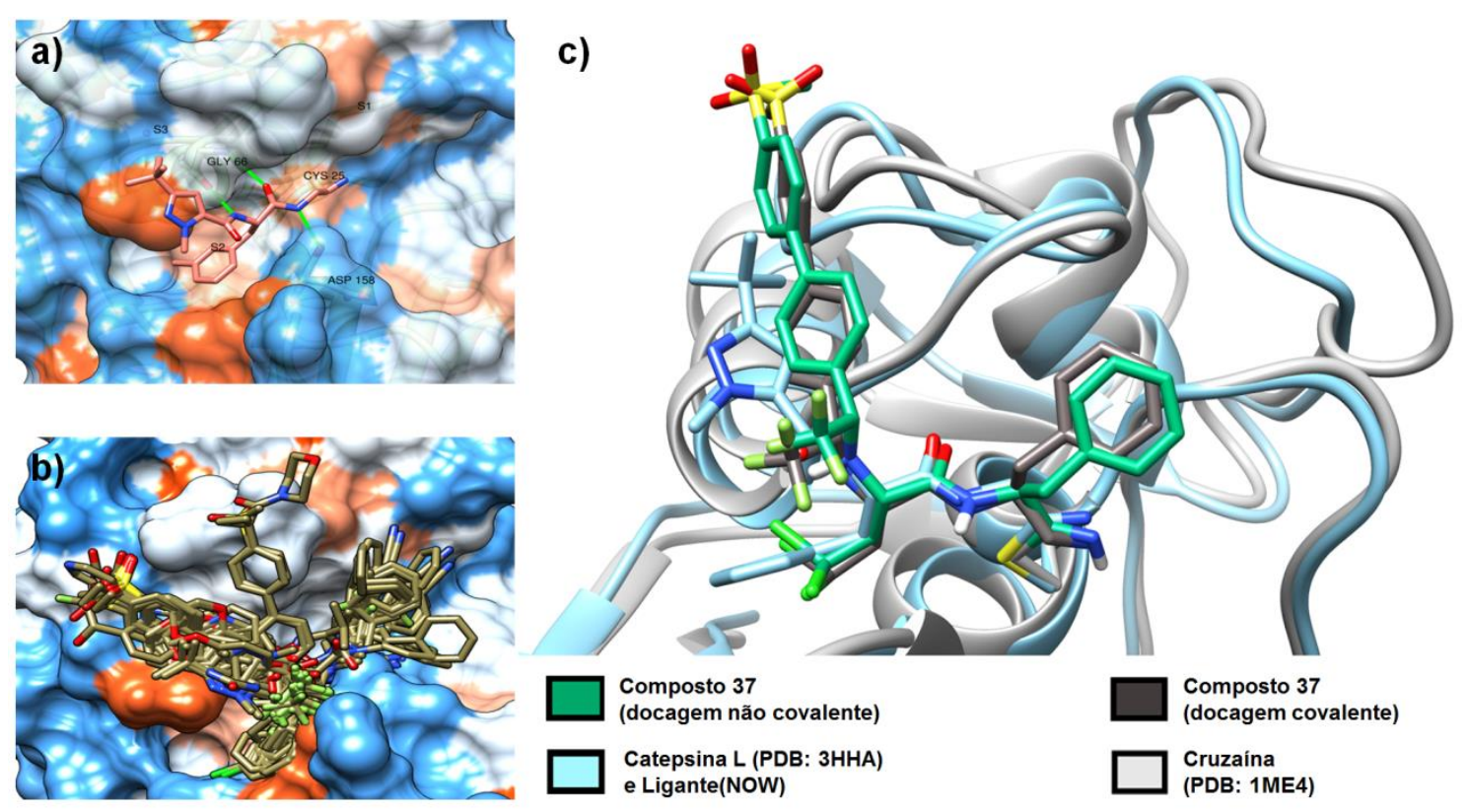

Figura 11. Pose de interação do peptídeo mimético NOW no sítio ativo da cruzaína (a); predição da pose de interação pela docagem e sobreposição da série de 57 dipeptidil nitrilas no sítio ativo da cruzaína (b); sobreposição das enzimas catepsina L com o inibidor NOW e cruzaína com o inibidor mais potente da série de dipeptidil nitrilas (composto $37, \mathrm{pIC}_{50}=10.0$ ), simulação de docagem covalente e não covalente do composto 37 (c)

A Figura 11b mostra a sobreposição da pose de ligação predita pela docagem para série de inibidores estudados. Observa-se que todos os ligantes ocupam os sub-sítios da cruzaína de forma muito similar, devido às interações já mencionadas que ocorrem no P1-P2 e P2-P3.

Conforme discutido na literatura, ${ }^{53-54}$ o sub-sítio S2 da cruzaína acomoda grupos hidrofóbicos e volumosos por meio de interações com os resíduos de aminoácidos Leucina (Leu67 e 157) e Metionina 68 (Met68), destacados em superfície laranja na Figura 11b. Além disso, os resultados de docagem mostram a ausência de interações especificas entre a porção P1 do ligante e o sub-sítio S1 da cruzaína, resultando em poses aparentemente aleatórias.

O sub-sítio S3 é plano e apresenta uma porção exposta ao solvente (superfície azul na Figura 11b), os resíduos de aminoácidos Serina 61 (Ser61) e Asp60 compõem a região polar. Alguns ligantes que apresentam a porção metil-sulfona no P3 foram capazes de formar ligação de hidrogênio com a Ser61, presente no sub-sítio S3 da enzima cruzaína. 
O grupo $-\mathrm{CF}_{3}$, localizado na interface da região $\mathrm{P} 2-\mathrm{P} 3$ na série de compostos análogos ao Odanacatib, está sempre exposto ao solvente nas poses de docagem, sugerindo que tal grupo desempenha um papel biológico importante, ao obrigar a porção P3 a permanecer próxima da superfície $\mathrm{S} 3$, potencializando as interações entre ligante-receptor.

Na Figura 11c, a sobreposição da cruzaína e catepsina L demonstra o alto grau de similaridade compartilhado por estas enzimas. Observa-se também, que a conformação e as principais interações do composto NOW (destacado em azul), extraído da estrutura cristalográfica 3HHA, é altamente similar à conformação e as interações preditas na docagem para o composto 37 , o mais ativo da série $\left(\mathrm{pIC}_{50}=10,0\right)$.

Um teste suplementar também foi executado com o composto 37, realizou-se docagem covalente e a docagem flexível com a mutação da Cys25 para Gly, bem como a restrição no grupo aldimina (conforme descrito no tópico 3.2.4.2). Os resultados de ambas as docagens foram idênticos, o que valida a pose de interação predita.

Todo esse conjunto de informações é útil para validar e interpretar os mapas de contribuição fornecido nas análises HQSAR, e ainda auxilia na busca da forma molecular de compostos bioativos contra cruzaína, nos estudos de ROCS.

\subsubsection{Avaliação dos mapas de contribuições utilizando a docagem}

A interpretação do modelo HQSAR baseia-se em mapas de contribuições, construídos para série de compostos do conjunto de treinamento, onde as interações positivas, neutras e negativas são representadas por cores diferentes. Gradativamente, a cor vermelha e laranja simbolizam as interações mais negativas, cinza as neutras, amarela e verde as positivas. A cor azul mostra o esqueleto comum a todas as estruturas. Dessa forma, identificam-se as porções na estrutura química essenciais para aumentar as bioatividades, ou até mesmo aquelas que prejudicam, portanto, passiveis de modificações moleculares.

Na Figura 12a, o mapa de contribuições fornecido pelo modelo HQSAR 3.4, para o composto Neq0400, ${ }^{41 d}$ auxilia na elucidação de interações importantes no processo de inibição da cruzaína. O composto possui um valor de pIC $_{50}$ de 5,09 (menos ativo da série). O grupo terc-butil éter, em vermelho, não contribui para uma interação significativa entre ligante-receptor, de acordo com o mapa de contribuições. Note que a docagem também não identificou nenhuma interação favorável entre o grupo mencionado e o receptor (Figura 12b). 


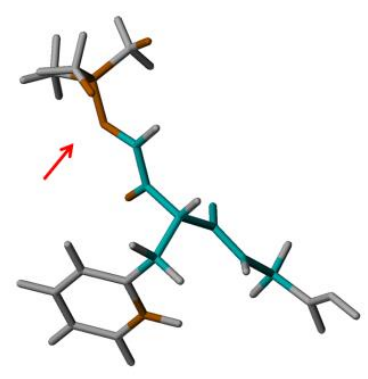

a)

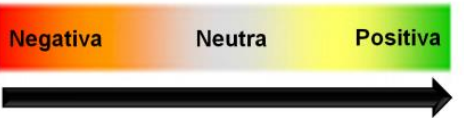

S3

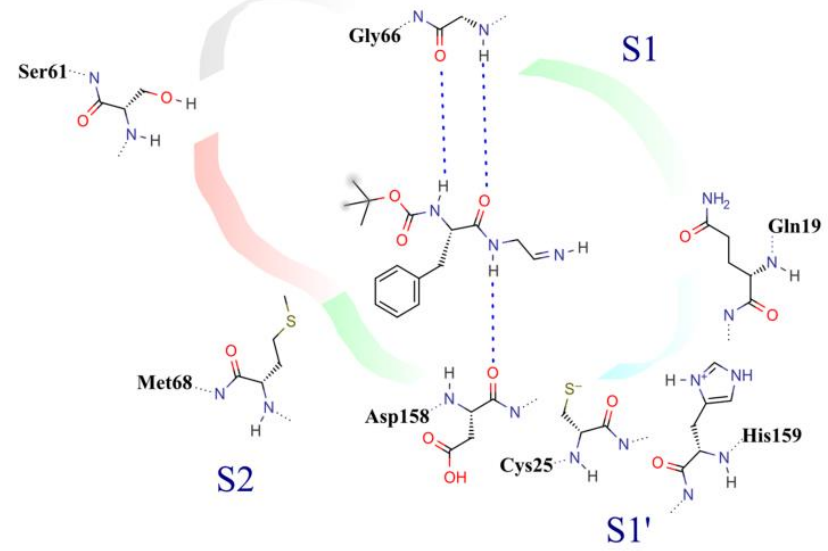

b) * Carga (negativa)

... Ligação de $\mathrm{H}$

Carga (positiva)

Exposto ao solvente

Ligação Covalente

Figura 12. Mapas de contribuição de fragmentos moleculares fornecido pelo HQSAR (a) e representação 2D das interações do composto Neq0400 no sítio ativo da cruzaína predita na docagem

De fato, a porção correspondente ao grupo terc-butil éter encontra-se, inevitavelmente, exposta ao solvente, porque o sub-sítio S3 apresenta superfície plana e poucos pontos de ancoramento.

$\mathrm{O}$ composto 37 encontra-se no outro extremo de valor de $\mathrm{pIC}_{50}$ (mais ativo). $\mathrm{A}$ interpretação do mapa de contribuições para esse inibidor demonstra a credibilidade das informações fornecidas nessa análise (Figura 13a).

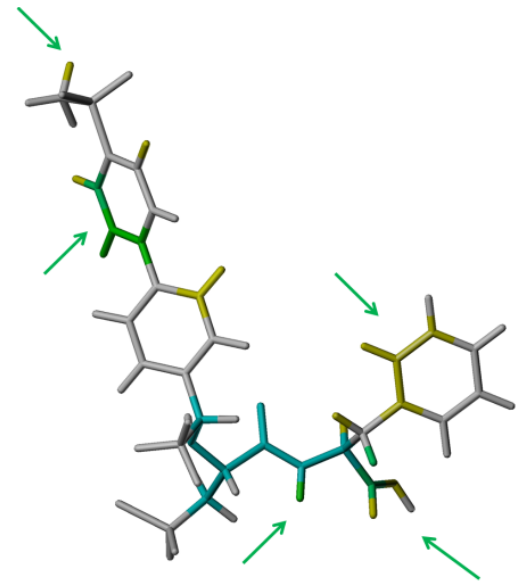

a)

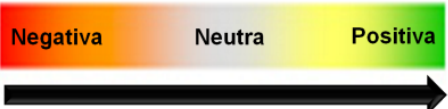

S3

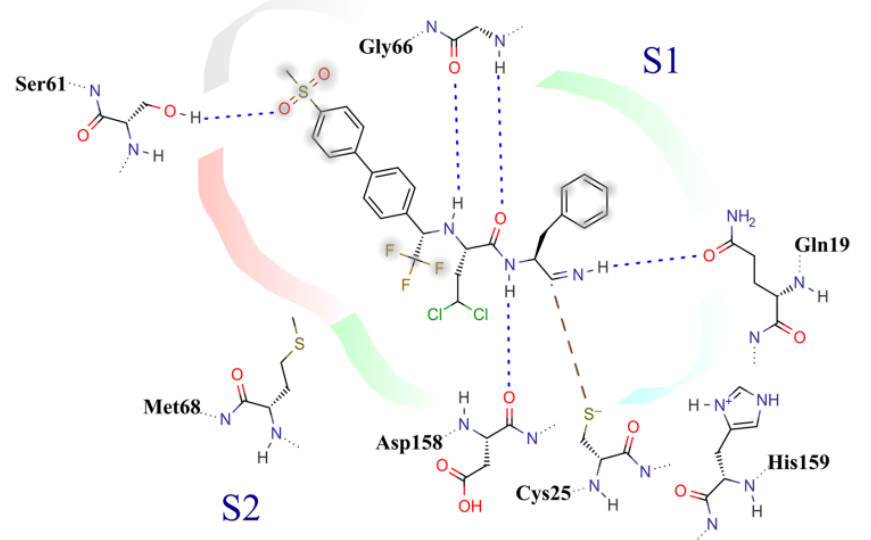

S1'

b) $*$ Carga (negativa)

Hidrofóbico

... Ligação de $\mathrm{H}$

Exposto ao solvente

Ligação Covalente

Figura 13. Mapas de contribuição de fragmentos moleculares fornecido pelo HQSAR (a) e representação $2 \mathrm{D}$ das interações do composto 37 no sítio ativo da cruzaína predita na docagem 
O método empregado na construção do modelo HQSAR, foi capaz de detectar a interação do warhead com os resíduos de aminoácidos presentes no sub-sítio S1' (cor verde no grupo aldimina no mapa de contribuições da Figura 13a) e a docagem mostra as interações com a Cys25 e Gln19 (Figura 13b). Outras porções na molécula, também contribuem, interagindo corretamente com os sub-sítios da enzima (S1, S2 e S3), tornando o inibidor eficiente na sua tarefa. ${ }^{37}$

O modelo HQSAR foi capaz de reconhecer interações e fragmentos moleculares imprescindíveis, não somente para inibição, mas também para o reconhecimento do inibidor nos sub-sítios da cruzaína. Na Figura 13a, as setas verdes destacam as contribuições positivas detectadas no mapa de contribuições. De maneira igual, os resultados da docagem realizado para o composto 37, (Figura 13b) apresentam interações chaves no processo de reconhecimento entre o inibidor e a enzima cruzaína (ligações de hidrogênio entre o composto 37 e os resíduos de aminoácidos Gly66 e Asp158). E ainda, uma interação adicional que ocorre com Ser61 no sub-sítio S3 foi corretamente pontuada pelo mapa de contribuições, o que pode ser a razão para a elevada potência desse composto (Figura 13).

Informações importantes, não diferentes das obtidas em métodos experimentais, como a cristalografia de raio-X. ${ }^{29 d, 37}$ A interação com o resíduo de aminoácido Ser61 também foi encontrada na estrutura cristalográfica do inibidor de cruzaína Neq0176 (PDB ID 1ME3). ${ }^{50}$

Adicionalmente, a porção correspondente ao grupo benzil (P1) mostrou contribuição positiva para o incremento de potência (destacado com uma seta verde na Figura 13a). No entanto, ao analisar a estrutura do complexo formada pelo composto 37 e a enzima cruzaína, nenhuma evidência de interações foi notada entre o grupo benzil e o sub-sítio S1. Todavia, ao investigar toda a série de dipeptidil nitrilas, constatou-se que o grupo benzil exerce influência positiva no incremento da bioatividade.

Os compostos 23 e 24 são idênticos, exceto pela modificação na porção P1 do grupo benzil para o átomo de hidrogênio. Essa modificação resultou na diminuição de 1.35 unidades logarítmicas de $\mathrm{pIC}_{50}$, conforme ilustra a Figura 14.
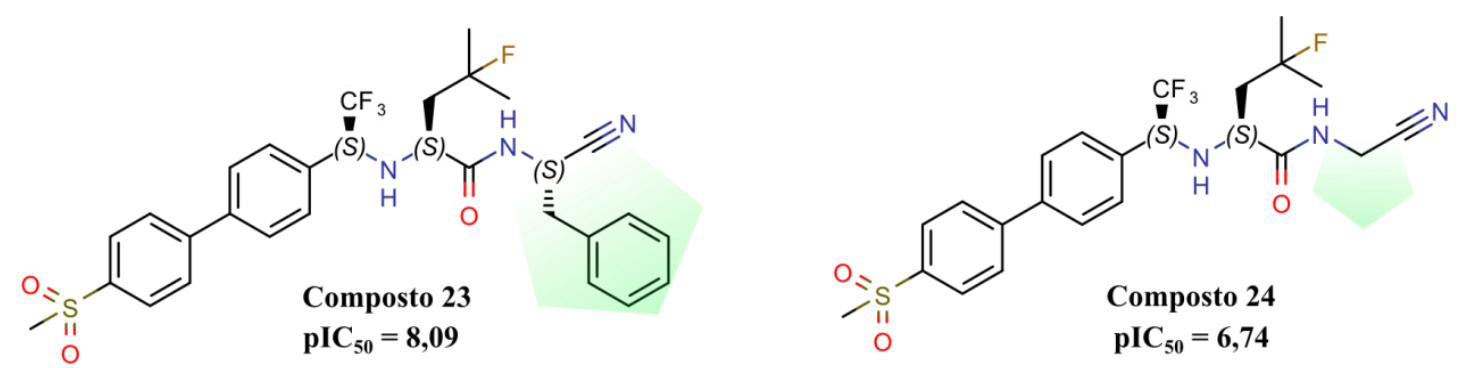

Figura 14. Compostos análogos ao Odanacatib (destacado em verde as modificações no P1) 
Não obstante, a ausência de qualquer interação explícita entre o grupo hidrofóbico e o sub-sítio S1 da enzima cruzaína, sugere que a contribuição positiva para a potência está relacionada com a forma molecular do ligante, o que pode favorecer a conformação adequada do carbono eletrofílico do warhead na direção do ataque da Cys $S \gamma$ catalítica.

O modelo HQSAR 3.4 mostrou-se altamente preditivo e os resultados do modo de interações fornecidos pelo mapa de contribuições, correlacionam-se com os estudos de docagem. Esse conjunto de informações podem guiar a síntese de compostos mais potentes e seletivos contra a enzima cruzaína.

\subsubsection{ROCS}

ROCS é uma poderosa ferramenta de varredura virtual (do inglês “virtual screening”) capaz de identificar potenciais compostos ativos utilizando comparações da forma molecular de um composto de referência (query). Ao empregar as métricas de similaridade estrutural, consegue-se identificar importantes características que tornam os compostos potentes e seletivos contra a enzima cruzaína.

Após a execução do ROCS, todos os 1223 compostos do conjunto de dados V3 encontram-se sobrepostos aos 24 compostos query. O composto 37, utilizado como query destaca-se como um excelente exemplo para discutir os resultados da análise ROCS. A Figura 15a, mostra o composto 37 (destacado em verde) sobreposto ao composto 23 (colorido por tipo de átomo) ranqueado na posição 26, utilizando a métrica Fit Tversky (índice de 0,96). Apesar do composto 23 encontrar-se completamente sobreposto ao query (composto 37), sua classificação distancia-se do composto de referência. Estruturalmente os compostos 37 e 23 são idênticos, com exceção do substituinte na porção P2.

No composto 37 a porção P2 corresponde ao resíduo de aminoácido dicloroleucina, enquanto que no composto $\mathbf{2 3}$ corresponde ao resíduo de aminoácido fluoroleucina. Portanto, de acordo com a análise ROCS esta simples modificação faria com que o composto 23 perdesse forma molecular ideal nas interações com a enzima cruzaína, tornando-o menos ativo. Em consonância com os resultados do ROCS, encontra-se os valores experimentais de pIC $\mathrm{I0}_{50}$, o composto 23 tem pIC $\mathrm{IC}_{50}$ de 8,09 e o composto $37 \mathrm{pIC}_{50}$ de 10,00 . 

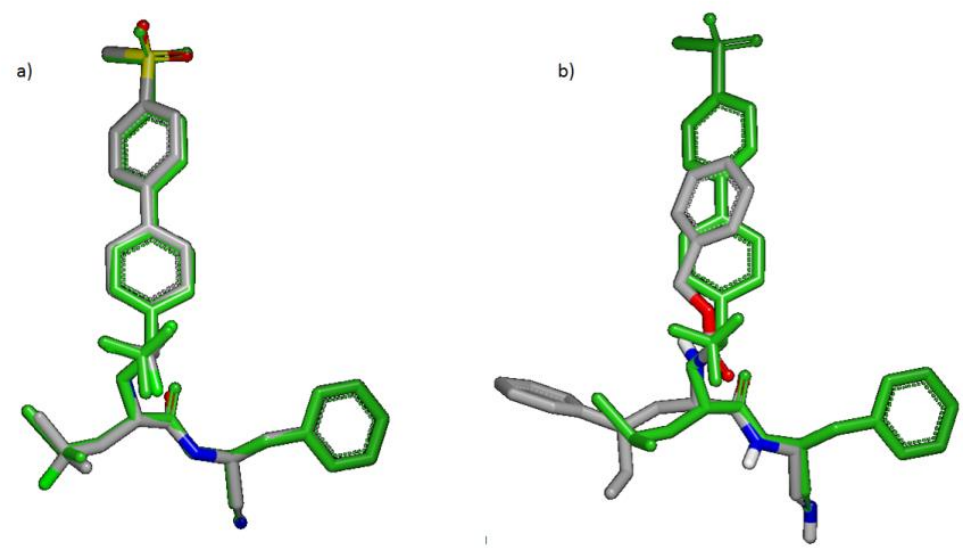

Figura 15. Resultado das análises de ROCS para o composto 37 (destacado em verde) sobreposto no composto 23 (colorido por tipo de átomo) ranqueado na posição $26^{\circ}$ (a). Composto 37 sobreposto no composto CDD-111089 (colorido por tipo de átomo) ranqueado na posição $385^{\circ}$ (b). Ranque estabelecido usando o índice fornecido pela métrica Fit Tversky

Na Figura 15b, o composto 37 está sobreposto ao composto extraído do CDD (colorido por tipo de átomo). As modificações estruturais no composto CDD-111089 fizeram com que o ROCS atribuísse a posição no ranque de número 385 e um índice de 0,86, utilizando a métrica Fit Tversky. Essa métrica mede a representação da similaridade parcial da forma molecular. Quando mais próximo o índice se encontra do valor 1,0, significa que uma dada unidade estrutural é uma subestrutura da molécula, com a qual está sendo comparada, ou seja, mais semelhante é a forma molecular. ${ }^{55}$ Sendo assim, mesmo que os compostos ativos utilizados como query, sejam sobrepostos integralmente aos inativos, a metodologia ROCS consegue identificar sutis modificações estruturais, importantes no reconhecimento entre inibidor e alvo macromolecular.

Para avaliar o desempenho de todas as métricas presentes no método ROCS e para selecionar qual métrica é capaz de recuperar compostos ativos dos inativos, em cada query utilizado, a curva ROC foi aplicada, ${ }^{44}$. Na Figura 16 a melhor métrica para cada composto query é mostrada.

Para essa série de compostos query, a métrica Fit Tversky apresentou a melhor taxa de recuperação usando o composto 37 como query $(\mathrm{AUC}=0,60)$. Enquanto que todos os outros compostos query obtiveram outras métricas diferentes do composto 37. Isto sugere a presença de uma forma única nesta molécula, o que pode provocar o aumento da potência. Outros sete compostos query apresentaram taxas de recuperação AUC entre 0,57 e 0,67, utilizando a métrica Fit Color Tversky. 


\begin{tabular}{|c|c|c|c|}
\hline $\begin{array}{c}\text { Compostos } \\
\text { Query }\end{array}$ & $\mathrm{pIC}_{50}$ & $\begin{array}{l}\text { Melhor } \\
\text { Métrica }\end{array}$ & AUC \\
\hline-37 & 10,00 & FitTversky & 0,60 \\
\hline ….. 35 & 9,70 & FitColorTversky & 0,57 \\
\hline ..... 28 & 9,00 & FitColorTversky & 0,58 \\
\hline 39 & 8,70 & TanimotoCombo & 0,55 \\
\hline-14 & 8,60 & FitColorTversky & 0,58 \\
\hline-30 & 8,52 & TanimotoCombo & 0,58 \\
\hline-31 & 8,52 & TanimotoCombo & 0,59 \\
\hline-17 & 8,47 & TanimotoCombo & 0,62 \\
\hline 12 & 8,38 & FitColorTversky & 0,67 \\
\hline 38 & 8,16 & TanimotoCombo & 0,55 \\
\hline 40 & 8,16 & TanimotoCombo & 0,58 \\
\hline 23 & 8,10 & FitColorTversky & 0,60 \\
\hline 33 & 8,10 & TanimotoCombo & 0,57 \\
\hline 4 & 8,09 & TanimotoCombo & 0,67 \\
\hline 15 & 8,08 & FitColorTversky & 0,63 \\
\hline 18 & 8,08 & TanimotoCombo & 0,62 \\
\hline-13 & 8,01 & FitColorTversky & 0,58 \\
\hline 29 & 7,77 & TanimotoCombo & 0,59 \\
\hline 2 & 7,71 & ColorTanimoto & 0,68 \\
\hline 19 & 7,64 & TanimotoCombo & 0,67 \\
\hline-34 & 7,48 & TanimotoCombo & 0,57 \\
\hline$=5$ & 7,28 & ColorTanimoto & 0,72 \\
\hline
\end{tabular}

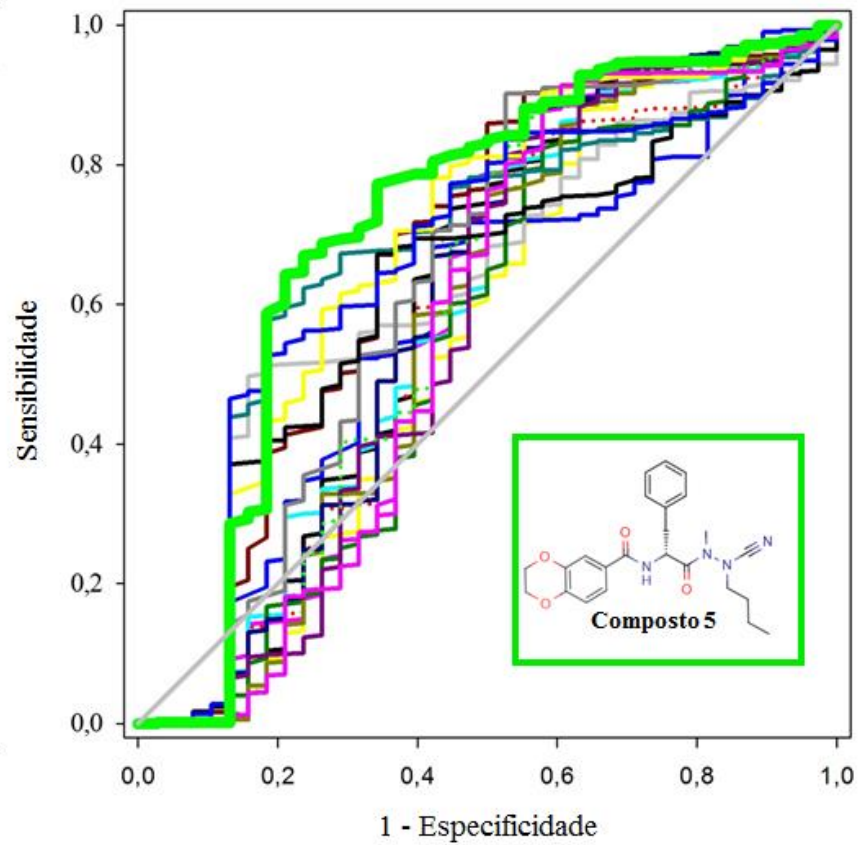

Figura 16. Gráfico ROC fornecido pelo método ROCS. Na esquerda, os 24 compostos query utilizado nas análises, os valores experimentais de $\mathrm{pIC}_{50}$, melhor métrica encontrada para cada composto query e os valores de AUC correspondente. $\mathrm{Na}$ direita, destacado em verde a curva ROC para o composto 5 como query, que apresentou a melhor AUC com a métrica Color Tanimoto.

A métrica Tanimoto combo representa uma combinação entre as métricas Tanimoto e Color, resultando em melhores discriminações entre classes de compostos. ${ }^{45 a, 45 c}$ A média de valores AUCs de 12 compostos query foi de 0,60 (Figura 16).

$\mathrm{O}$ composto $2(\mathrm{AUC}=0,68)$ e o $\mathbf{5}(\mathrm{AUC}=0,72)$ produziu as melhores taxas de recuperação utilizando a métrica Color Tanimoto, que é útil para a comparação do alinhamento de grupos funcionais entre os confôrmeros. ${ }^{45 a, 45 c}$

Quando todo o conjunto de dados V3 foi submetido à análise ROCS, utilizando o composto 5 como query e a métrica Tanimoto Color, uma parte considerável dos compostos classificados como ativos ocuparam as primeiras posições no ranque (Figura 17). No entanto, os compostos 6 ( $3^{\circ}$ posição) e CRA-017404 (341 ${ }^{\circ}$ posição) apresentam pIC ${ }_{50}$ experimental similar e foram ranqueados em posições muito distintas.

No conjunto de dados V3, 96,9 \% dos compostos apresentam $\mathrm{pIC}_{50}<7$ ou $\mathrm{PI} \%<50$ $\%$ em $0,1 \mu \mathrm{M}$, portanto classificados como inativos. Os 3,10\% restante são os compostos ativos. Os compostos classificados como inativos se sobrepõem tão bem quanto os compostos classificados como ativos. Mesmo assim, pequenas alterações estruturais resultam em posições completamente distintas no ranque. 

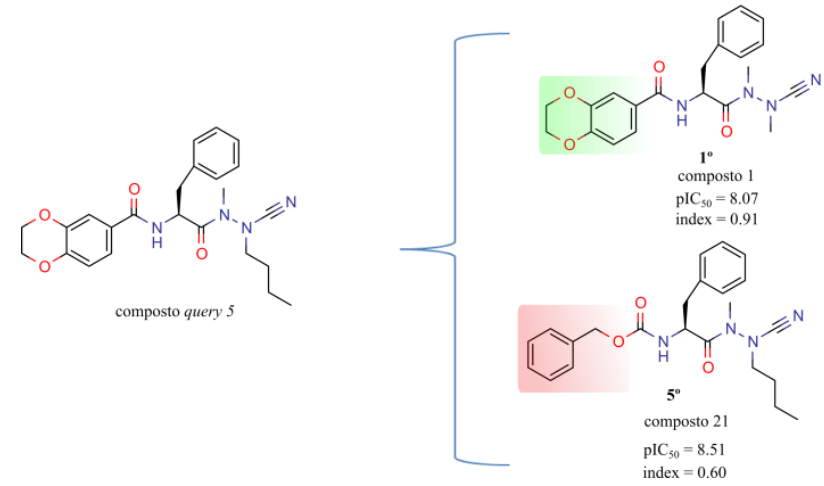
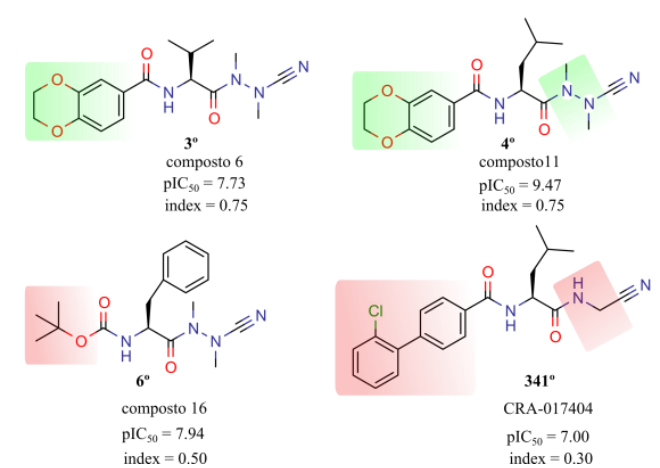

Figura 17. Alguns compostos presentes no banco de dados $\mathbf{V} 3$ e suas respectivas posições no ranque estabelecido com a métrica Color Tanimoto e o composto $\mathbf{5}$ como query. As porções destacadas em verdes representam contribuições positivas e em vermelho negativas, de acordo com as análises efetuadas pelo ROCS. Os valores experimentais de atividade biológica também são mostrados

A Figura 17 destaca em verde e vermelho as modificações estruturais percebidas pelo ROCS. Os compostos que ocupam as primeiras posições apresenta o mesmo grupo na porção P3 (destacado em verde na Figura 17). A substituição na porção P3 para o grupo terc-butil éter alterou o índice Color Tanimoto de 0,91 (composto 1) para 0,50 no composto 16 (destacado em vermelho na Figura 17).

Os resultados de ROCS estão em concordância com os resultados já apresentados na docagem e os mapas de contribuição do HQSAR. Em última análise, no estudo de SAR realizado por Yang e colaboradores ${ }^{40 \mathrm{~b}}$ o grupo terc-butil éter mostrou baixa afinidade pela enzima cruzaína.

\subsubsection{Planejamento de novos potenciais inibidores para a cruzaína}

O modelo HQSAR 3.4 mostrou-se altamente preditivo após as validações externas, os resultados dos estudos de ROCS são consistentes quando comparados com o modo de interação predito na docagem para a série de compostos em estudo. Sendo assim, os estudos computacionais obtidos em torno das porções P1, P2 e P3 podem guiar o planejamento de novos compostos.

Nessa perspectiva, por meio dos estudos de ROCS observou-se que o grupo 2,3dihidro-1,4-benzodioxin-6-il (destacado em verde na Figura 17) apresenta forma molecular adequada para aumentar a atividade biológica.

Alguns dos análogos do Odanacatib ${ }^{40 a}$ contém o grupo 4-metanosulfonil bifenil na porção P3, como por exemplo, o composto 37 (o mais ativo dessa série de compostos). Esse 
grupo contribui significativamente para um ganho de potência e seletividade (cruzaína versus catepsinas), quando comparado com outros grupos bifenil para substituídos. No modo de interação predito pela docagem para esse grupo, identificou-se que o ancoramento acontece por meio de interações "pi-stacking" entre os anéis aromáticos do grupo 4-metanosulfonil bifenil e os aminoácidos Gly66, Asp60 e Ser61. Adicionalmente, a porção 4-metanosulfonil funciona como um ponto a mais de ancoramento, por meio da ligação de hidrogênio do átomo de oxigênio do grupo sulfonil e Ser61 no sub-sítio S3.

Observou-se também nas poses de docagem, que a ausência desse ponto adicional de ancoramento (átomo de oxigênio do grupo sulfona) em outros compostos com grupos bifenil, muda a conformação da molécula deixando a porção P3 sempre exposta ao solvente.

Os inibidores derivados do composto Odanacatib, ${ }^{40 a}$ desenvolvidos para inibir a catepsina K, tiveram o grupo ciclopropil adicionado na porção P1 no curso da otimização de suas propriedades farmacocinéticas. O grupo ocupa a cavidade S1 e apresenta propriedades que evita o metabolismo. ${ }^{56}$ De fato, a presença de grupos hidrofóbicos nesta região é comumente encontrado em complexos cristalográficos depositados no PDB (exemplos: PDB ID 1ME4, 1ME3, 2OZ2, 3LXS, 3HD3, 3BWK, 1F29, 1F2A, 1F2B, 1F2C e 1EWO). Além disso, os dados da atividade biológica, para a série de 57 dipeptidil nitrilas estudadas, mostram também as vantagens de um grupo hidrofóbico no sub-sítio S1, quando a seletividade sobre catepsinas é levado em consideração na formulação de agentes tripanossomicidas. ${ }^{40 a}$

Sabe-se que para alcançar altas potências de inibição, é essencial a presença e correto posicionamento do "warhead" no sítio ativo da cruzaína (S1'), para que ocorra a ligação covalente com a Cys25. Neste caso, a nitrila deve posicionar-se de forma a inibir a tríade catalítica (Cys25, Gln19 e His159).

Com essas observações e todo o conjunto de resultados obtidos, a proposta de novos inibidores foi feita a partir da combinação de subestruturas dos compostos mais ativos biologicamente, presentes em cada série congênere utilizada para a construção dos modelos computacionais. Os valores de $\mathrm{pIC}_{50}$ desses análogos de dipeptídeos miméticos foram preditos utilizando-se o modelo HQSAR 3.4 (Figura 18), que foi considerado mais confiável para essa finalidade. 

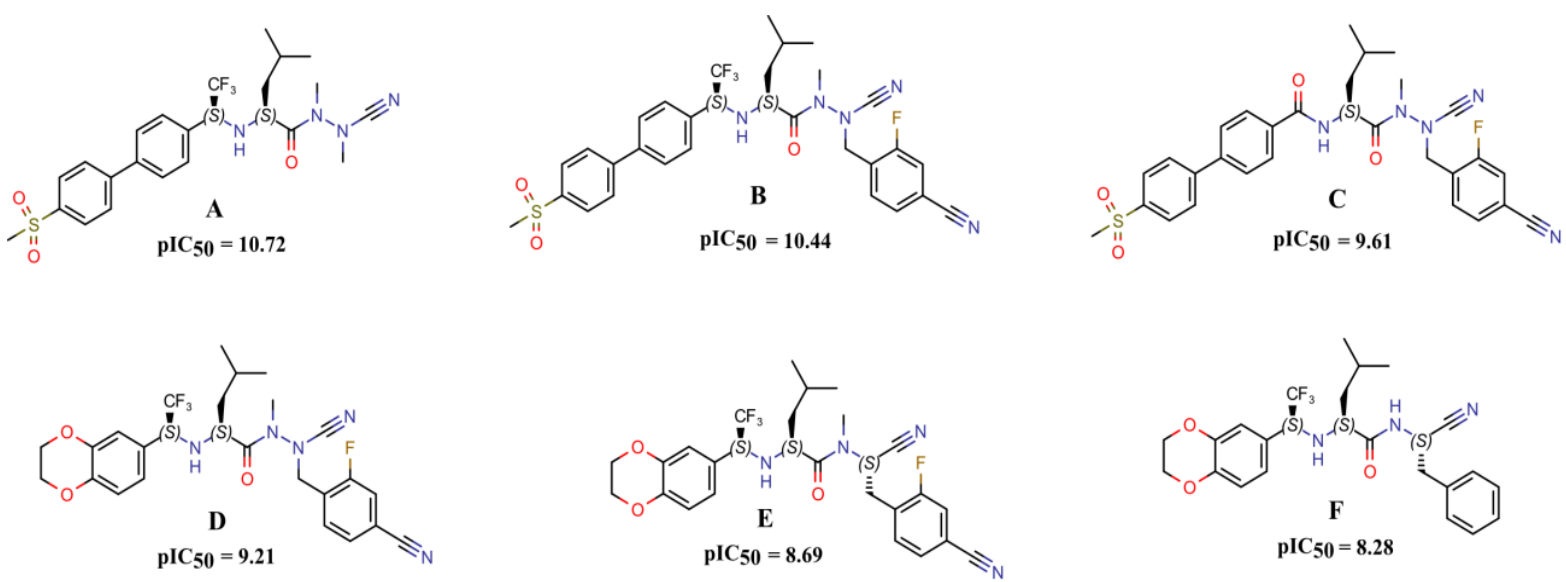

Figura 18. Estruturas propostas (A-F) usando a estratégia de combinar subestruturas dos compostos mais ativos experimentalmente da série. Os valores de $\mathrm{pIC}_{50}$ preditos obtidos a partir do modelo HQSAR 3.4 são apresentados abaixo de cada composto

De fato, novos análogos de dipeptídeos miméticos com bioatividades potencialmente altas podem ser concebidos pela combinação de subestruturas de dois ou mais compostos altamente ativos de diferentes séries, mantendo o esqueleto comum inalterado. Surpreendentemente, esta combinação tem mostrado sinergismo, ou seja, alguns compostos obtidos a partir dessa metodologia têm mostrado bioatividades calculadas maiores do que aqueles que os originaram, ${ }^{36 b, 57}$ já que a melhor porção de cada composto foi utilizada.

Os compostos A e $\mathbf{B}$ exibiram valores de $\mathrm{pIC}_{50 \text { pred }}($ Figura 18) mais elevados do que o maior valor encontrado dentro dos dados experimentais (composto 37, $\mathrm{pIC}_{50}=10,0$ ), indicando o efeito sinérgico mencionado acima.

Conforme discutido anteriormente e confirmado pelas predições do HQSAR, as presenças dos grupos $-\mathrm{CF}_{3}$ e 4-metanosulfonil bifenil, nas melhores estruturas propostas $(\mathbf{A}$ e B), tais como nos análogos do Odanacatib, desempenham um papel biológico importante na contribuição para a elevada atividade inibidora da cruzaína.

Para validar as previsões obtidas pelas análises de HQSAR, estudos de docagem foram realizados para A-F. As poses obtidas na docagem para os novos compostos propostos encontram-se na Figura 19.

Todos os compostos propostos estabelecem ligações de hidrogênio com os resíduos de aminoácido Gly66, Asp158, Leu67 e 157 e Met68, mas apenas os melhores (A e B) estabeleceram interação adicional entre o átomo de oxigênio do grupo sulfona e o resíduo de aminoácido Ser61. 

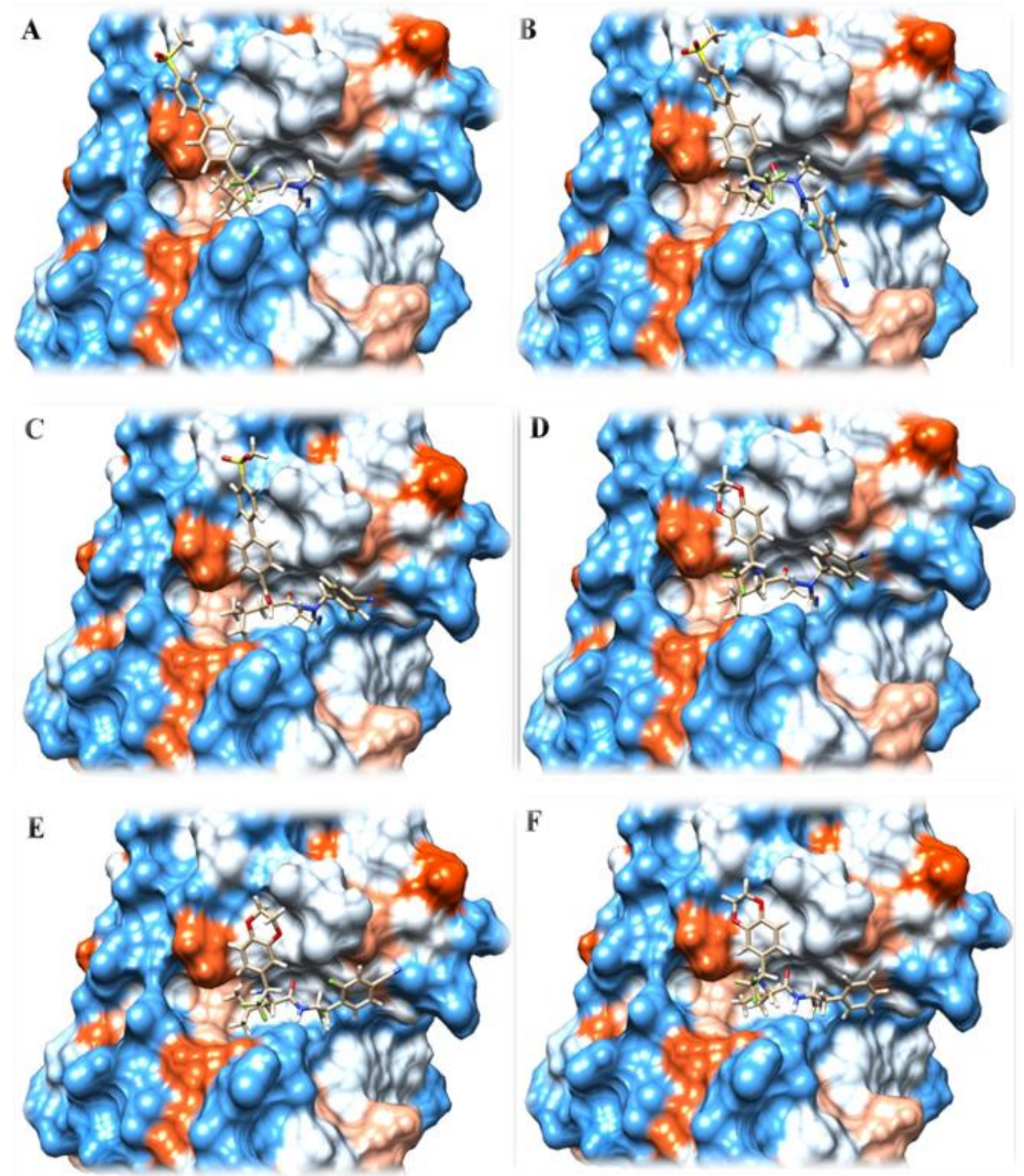

Figura 19. Poses preditas na docagem para os novos compostos propostos

\subsection{Conclusões do capítulo I}

O melhor modelo HQSAR 3.4, além de obter, bons resultados nas validações internas, conseguiu predizer com acurácia moléculas de dois bancos de dados (ChEMBL e CDD). A validação externa utilizando a curva ROC também obteve resultados satisfatórios. As interpretações dos mapas de contribuições fornecidos pelo HQSAR, estão de acordo com o 
docagem e dados experimentais de ligantes co-cristalizado na cruzaína, disponíveis na literatura.

Os estudos de ROCS validam as interpretações obtidas nos mapas de contribuições fornecidos pelo HQSAR, e ainda corroboram na identificação de grupos substituintes promissores no processo de inibição da enzima cruzaína ao distinguir entre compostos ativos e inativos nos bancos de dados utilizados no estudo. Além disso, essas metodologias empregadas, em conjunto com a docagem, identificaram interações importantes para o planejamento de novas estruturas químicas.

Ao utilizar o melhor modelo HQSAR para predizer inibidores da cruzaína elaborados com todas as informações disponíveis (teóricas e experimentais), obteve-se valores de pIC $\mathrm{p}_{50}$ preditos mais elevados do que os compostos da série de treinamento. Este suporte teórico, em conjunto com a capacidade de modelagem e informações químicas fornecidas pelos modelos computacionais, pode conduzir à síntese de novos (e mais potentes) inibidores da cruzaína. 


\section{Bapítula 2}

\section{Planejamento e} estudo da relação estrutura-atividade de grupos warheads em inibidores de cruzaína

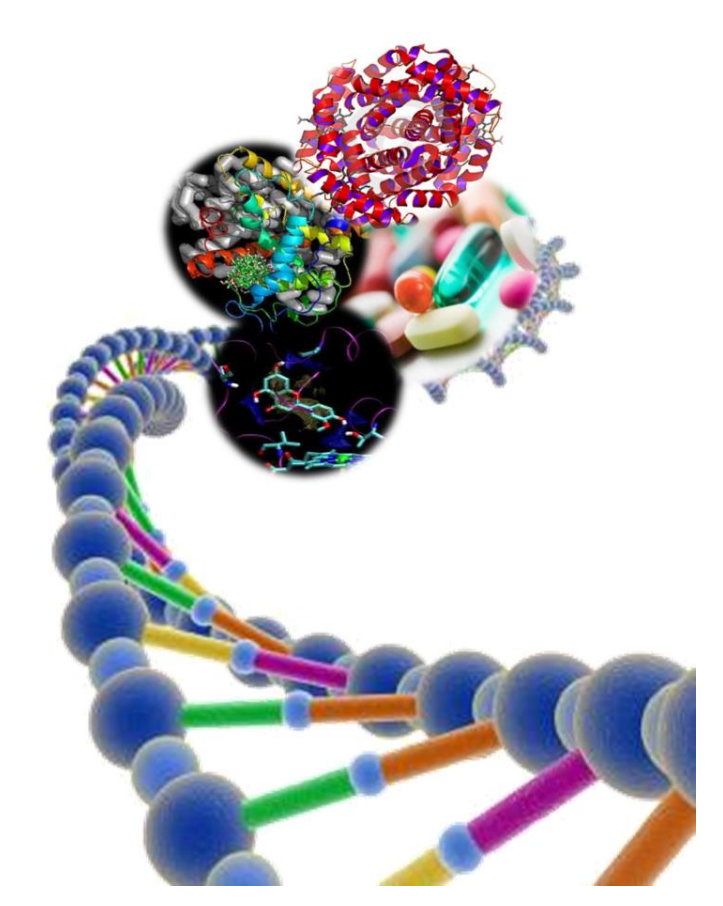




\section{Capítulo II}

\section{Planejamento e estudo da relação estrutura-atividade de grupos warheads em inibidores de cruzaína}

\subsection{Introdução}

A estrutura de raios-X do inibidor de catepsina B (dipeptidil-nitrila apresentado na Figura 20, composto 2) ${ }^{58}$ auxiliou na elucidação do mecanismo de inibição de cisteíno proteases. Similarmente para cruzaína, o processo de inibição ocorre com a formação de um hemi-tioacetal, cetal ou um intermediário tetraédrico, ${ }^{12 \mathrm{~b}}$ dependendo da natureza do warhead.

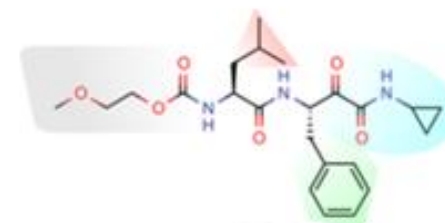

$18 B d$

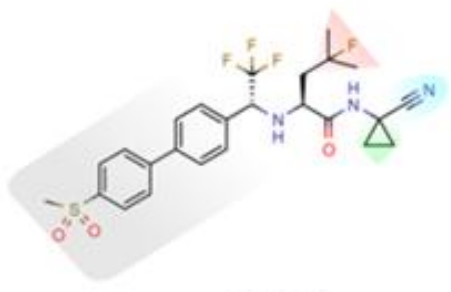

MK-0822

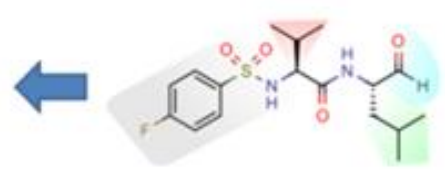

SJA6017

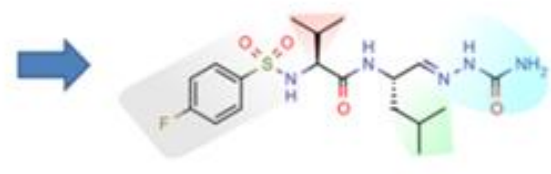

2*

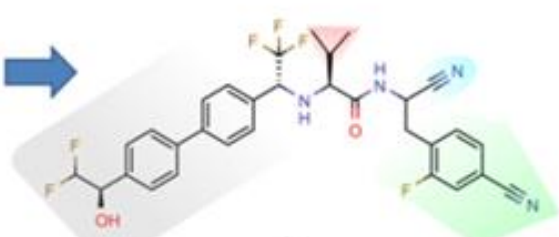

26

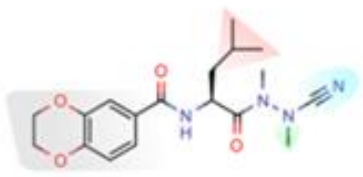

$1 \mathrm{~K}$
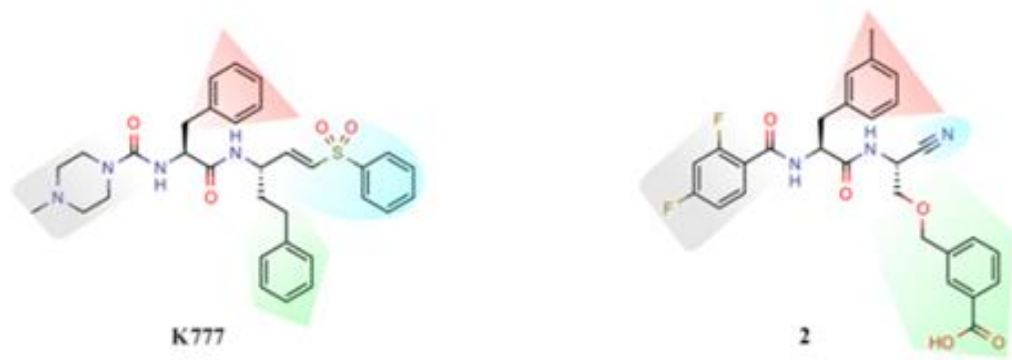

Figura 20. Inibidores conhecidos de cisteíno proteases e as regiões de modificações P1' (azul), P1 (verde), P2 (vermelho) e P3 (cinza).

A principal subunidade farmacofórica dessa classe de inibidores corresponde ao warhead (P1'): presença de grupos eletrofílicos que possam reagir com o tiol ativo da cisteína catalítica ( $\left.\mathrm{S} 1^{\prime}\right) .{ }^{12 \mathrm{a}, 12 \mathrm{~b}}$ As interações acontecem tanto de forma não covalente, por meio de ligações de hidrogênio, interações eletrostáticas, interações hidrofóbicas e forças de van der 
Waals, ${ }^{12 b}$ quanto de forma covalente, formação de uma ligação sigma. Os inibidores covalentes são classificados como irreversíveis ou reversíveis, ${ }^{12 b, 12 c}$ dependendo da natureza do warhead. A Figura 20 apresenta alguns exemplos de warheads destacados em azul.

\subsubsection{Mecanismo de inibição}

O mecanismo de hidrólise de peptídeos desempenhado pela cruzaína e demais cisteíno-proteases envolve quatro etapas (Figura 21). A primeira é a desprotonação do grupo tiol da cisteína catalítica pela histidina adjacente. No próximo passo, o enxofre aniônico nucleofílico liga-se ao carbono cabonílico do substrato, formando um intermediário tetraédrico que é estabilizado pela cavidade do oxiânion. Em seguida o fragmento amino terminal do substrato é liberado e a histidina é restituída na sua forma desprotonada. $\mathrm{Na}$ sequência, o intermediário acil-enzima é hidrolisado e um segundo intermediário tetraédrico é formado; novamente, há a estabilização pela cavidade do oxiânion. Por fim, o substituinte Nterminal é liberado restituindo a enzima no estado inicial. ${ }^{59}$

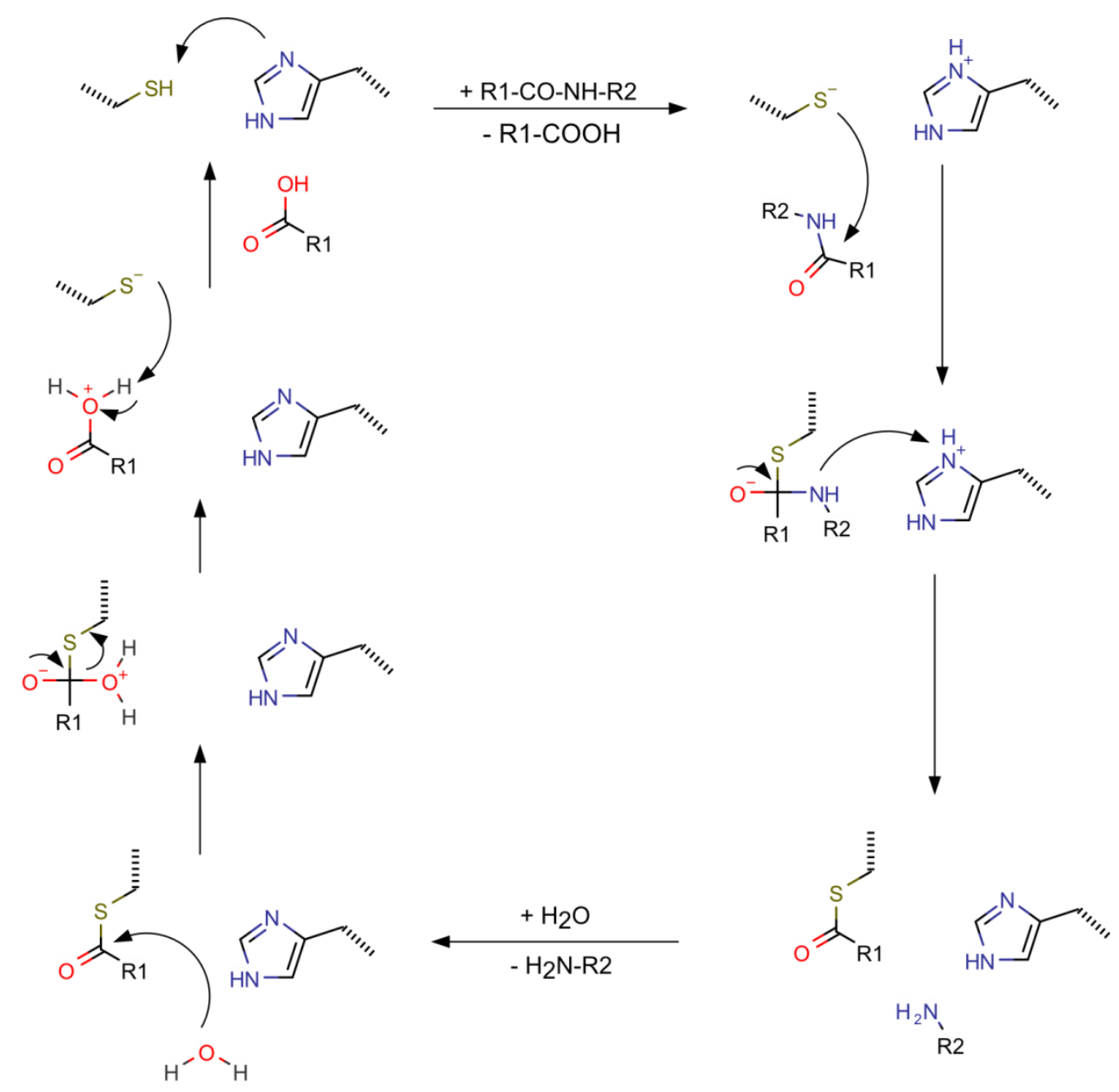

Figura 21. Representação esquemática do mecanismo geral de catálise de enzimas cisteínoproteases $59^{3}$ 


\subsubsection{Inibidores covalentes irreversíveis}

Compostos como peptidil diazometil-cetonas, fluorometil-cetonas, epóxidos e vinilsulfonas, são capazes de se ligar irreversivelmente à cisteína catalítica da cruzaína, atuando como inibidores "suicidas". 12d A interação covalente irreversível potencializa interações "off-target", consequentemente, agravam-se os efeitos adversos.

O composto peptídeo-mimético K777 ${ }^{12 e, ~ 12 f ~(F i g u r a ~ 20) ~ i n i b e ~ a ~ c r u z a i ́ n a ~ e m ~}$ concentração nanomolar e atua por um mecanismo de inibição irreversível (vinilsulfona como warhead). Estudos demostraram a capacidade deste composto em induzir o acumulo de cruzaína no complexo de Golgi, com consequente erradicação da forma epimastigostas de $T$. cruzi. ${ }^{60}$ Entretanto, os estudos pré-clínicos ao constatar tolerância em baixas doses nos primatas e cães, suspendeu os testes por recomendação do comitê Iniciativa Medicamentos para Doenças Negligenciadas (DNDi, do inglês "Drugs for Neglected Diseases initiative”). ${ }^{61}$

\subsubsection{Inibidores covalentes reversíveis}

Exemplos de inibidores covalentes reversíveis, tais como: peptídeos aldeídos, $\alpha$ cetoamidas, $\alpha$-dicetonas, $\alpha$-cetoésteres, $\alpha$-cetoácidos, semicarbazonas e nitrilas, ${ }^{13}$ constituem uma classe de grupos eletrofílicos que podem diminuir os efeitos off-target, resultando em melhores perfis farmacodinâmicos.

\subsubsection{Dipeptidil-aldeídos}

Vários tipos de inibidores reversíveis de cisteíno proteases foram isolados de microorganismos, ${ }^{62}$ a classe mais comum são os dipeptidil-aldeídos. ${ }^{63} \mathrm{O}$ mecanismo de interação resulta em um intermediário hemi-tioacetal. ${ }^{62}$

O composto SJA6017 (Figura 20) demonstrou potencial terapêutico contra a calpaína em estudos in vivo (atividade anticatarata), ${ }^{63 \mathrm{~g},}{ }^{64}$ porém, baixa solubilidade em água $(0,1$ $\mathrm{mg} / \mathrm{mL})$ e alta instabilidade metabólica $(97,5 \%$ das amostras metabolizadas após 1 hora de incubação em microssomas humanos). Tais propriedades permitem com que os aldeídos sofram rápido metabolismo em álcool ou ácido, ${ }^{13 b}$ assim, as possíveis reações com outras enzimas in vivo limita sua permeabilidade na membrana e biodisponibilidade oral.

As substituições: $i$ ) do grupo aldeído para o grupo $\alpha$-cetoamida ligada a um grupo ciclopropil na porção $\mathrm{P} 1$ '; ii) do resíduo de leucina para o resíduo de fenilalanina na porção 
$\mathrm{P} 1$; iii) do resíduo de valina para o resíduo de leucina na porção $\mathrm{P} 2$; iv) do grupo 4-fluorofenil sulfona para o grupo dietilenoglicol metil éter na porção P3; foram modificações combinadas na estrutura do composto aldeídico (SJA6017), ${ }^{13 b}$ que aumentou a estabilidade metabólica e a solubilidade em água, sem perder a permeabilidade na membrana. Além disso, melhorou a biodisponibilidade oral (composto 18Bd, Figura 20).

\subsubsection{Dipeptidil-semicarbazonas}

Semicarbazonas também possuem utilidade como "warhead", ${ }^{65}$ obedecem ao conceito de pró-fármaco: uma provável biotransformação in vivo, pode produzir o aldeído (metabólito ativo). ${ }^{65 a}$ Apesar de ser um inibidor menos potente que seu bioisóstero aldeído, a perda é recompensada com o aumento da solubilidade em água e melhor perfil farmacocinético. O aldeído SJA6017 apresentou $\mathrm{IC}_{50}$ contra a calpaína de $0,035 \mathrm{nM},{ }^{63 \mathrm{~g}, 64}$ enquanto a semicarbazona $(2 *$, Figura 20$)$ apresentou $\mathrm{IC}_{50}$ de 0,68 nM. ${ }^{65 b}$

As dipeptidil-semicarbazonas inibe cisteíno proteases reversivelmente, pelo ataque do tiolato no carbono cabonílico protegido, formando. O intermediário tetraédrico formado é estabilizado pela porção semicarbazonas, que possui tanto grupo doador quanto aceptor de ligação de hidrogênio. ${ }^{12 b, 65 c}$

\subsubsection{Dipeptidil-nitrilas}

As dipeptidil-nitrilas, reconhecidas como inibidoras de papaína há mais de três décadas, ${ }^{12 b}$ apresentam atividade inibitória e seletividade contra cisteíno proteases. ${ }^{66} \mathrm{Na}$ nitrila, o tiolato da Cys ataca o carbono $s p$ formando um tioimidato. Esta é uma reação reversível, conhecida como Reação de Pinner. ${ }^{12 b, 67}$

O inibidor da catepsina B (composto 2, Figura 20), ${ }^{58 \mathrm{~b}}$ além de elevada potência ( $\mathrm{IC}_{50}$ $=0,012 \mu \mathrm{M})$ e seletividade (100 vezes em relação a catepsina L e S), apresenta excelente biodisponibilidade $(5,27 \mu \mathrm{M})$. Estudos mais recentes realizados pela Merck, ${ }^{56,68}$ na busca de fármacos para o tratamento da osteoporose, resultaram em um candidato conhecido como Odanacatib (MK-0822, Figura 20), inibidor da catepsina K, que se encontra na fase III, dos estudos clínicos. A otimização deste possível fármaco, por meio de estudos de relação estrutura-atividade (SAR, do inglês "structure-activity relationship"), originou o composto 26 $\left(\mathrm{IC}_{50}=0,4 \mathrm{nM}\right.$, Figura 20), ${ }^{40 \mathrm{a}}$ que possui alta seletividade contra a cruzaína, quando comparada a atividade inibitória contra as catepsinas $\left(\mathrm{IC}_{50}=1060,0 \mathrm{nM}\right.$ para catL; $\mathrm{IC}_{50}=$ 
$87,0 \mathrm{nM}$ para catB; $\mathrm{IC}_{50}=56,0 \mathrm{nM}$ para catF $; \mathrm{IC}_{50}=322,0 \mathrm{nM}$ para catS; $\mathrm{IC}_{50}=2,0 \mathrm{nM}$ para catK e $\mathrm{IC}_{50}=69,0 \mathrm{nM}$ para catV).

\subsubsection{Dipeptidil-azanitrilas}

A substituição isoeletrônica do grupo $\mathrm{C}_{\alpha} \mathrm{H}$ por um átomo de nitrogênio ocorre comumente na química de peptídeos e peptídeos miméticos, ${ }^{69}$ transformando nitrilas em azanitrilas (1k, Figura 20). A metilação dos nitrogênios "aza" aumenta à estabilidade destes compostos e evita a clivagem proteolítica. ${ }^{70}$

As dipeptidil-azanitrilas reagem por um mecanismo dependente do tempo (em inglês "slow-binding"). A inibição é um fenômeno em que o equilíbrio entre enzima, inibidor e complexo enzima-inibidor (EI) é estabelecido lentamente em uma escala de tempo de segundos a minutos. ${ }^{71}$ Sendo assim, a formação da ligação covalente ocorre por um processo lento e reversível por meio de um intermediário isotiosemicarbazida com o sítio ativo da cisteína. ${ }^{70 a}$ A Figura 22 ilustra esse processo.

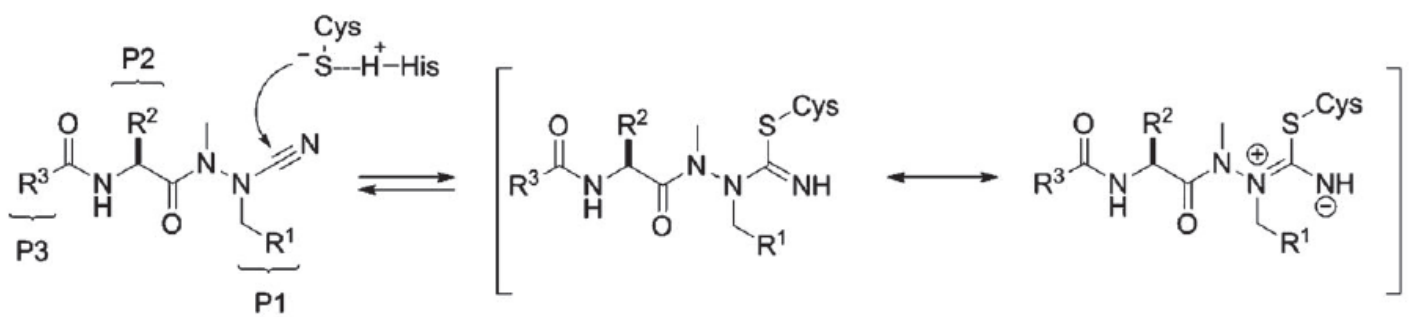

Figura 22. Mecanismo de inibição proposto para dipeptidil-azanitrilas Adaptado de Golicnik, 2004 e Loser 2008.

Azadipeptidil-nitrilas pertencem a uma nova classe de inibidores potentes contra cisteíno proteases. ${ }^{70,72}$ Uma série de 21 compostos contendo a função orgânica azanitrila foi testada contra a cruzaína. Modificações no P1, P2 e P3 foram feitas sistematicamente. No SAR estabelecido, a metilação do nitrogênio no P1, o aminoácido Leucina no P2 e o grupo 2,3-dihidro-1,4-benzodioxano no $\mathrm{P} 3$ resultaram no composto mais potente da série $\left(\mathbf{1} \mathbf{k}, \mathrm{IC}_{50}=\right.$ $0,34 \mathrm{nM}),{ }^{40 \mathrm{~b}}$ como é mostrado na Figura 20.

\subsubsection{Heterocíclicos}

Oxazol, oxazolina, oxatriazol, tiazol, tiazolina, imidazol e outros heterocíclicos são utilizados consubstancialmente como "warhead". 73 Alguns destes grupos são considerados aldeídos ou $\alpha$-cetoamidas mascaradas, isto aumenta a atividade metabólica e pode auxiliar na 
farmacocinética entre o inibidor e o alvo enzimático de interesse. A $\alpha$-cetoamida forma um intermediário tetraédrico estável, devido à ligação de hidrogênio entre a carbonila eletrofílica da $\alpha$-cetoamidas com o resíduo de aminoácido da protease. ${ }^{13 b, 13 c, 62}$ Além disso, $\alpha$-cetoheterocíclicos estabelecem relação isostérica com $\alpha$-ceto-ácidos, 13d, 13e logo, fornecem substituição adequada para garantir restrição conformacional; como resultado, o inibidor é mais bem incorporado pelo organismo. ${ }^{74} \mathrm{O}$ mecanismo de interação com a proteína alvo de heterocíclicos é análogo ao de aldeídos e cetonas, resulta em um intermediário hemi-tioacetal ou cetal, respectivamente. ${ }^{62}$

A relação entre aumento da atividade inibitória e potencial eletro-retirador de grupos usados como warheads é conhecida. ${ }^{75}$ Heterocíclicos que possuem alto poder indutivo, por meio da retirada de elétrons, ativa a cetona adjacente e potencializa o ataque do tiol da cisteína catalítica. Para tanto, encontrar as propriedades físico-químicas adequadas de grupos substituintes (warheads) que possam interagir frente à cruzaína de modo covalente-reversível constitui-se uma tarefa primordial na busca por novos inibidores.

\subsubsection{Análise sistemática de pares moleculares (MMPs)}

Buscas consistentes e de aplicação geral para analisar SAR é fornecido pelo conceito de pares moleculares combinados (MMP, do inglês "Matched Molecular Pair"), que se tornou popular em química medicinal nos últimos anos. ${ }^{6 a, 6 b, 76}$ As moléculas que formam o par são estruturalmente relacionadas, mas distinguem-se por uma determinada modificação em um ponto único, denominado MMP. A metodologia é comumente empregada em estudos de bioisosterismo, ${ }^{77}$ solubilidade aquosa, ${ }^{76 \mathrm{~d}, 78}$ ligação às proteínas plamáticas, ${ }^{76 \mathrm{~d}, 78 \mathrm{a}}$ exposição oral, ${ }^{76 \mathrm{~d}} \mathrm{SAR}$ local, ${ }^{79}$ metabolismo ${ }^{78 \mathrm{~b}, 80} \mathrm{e}$, sobretudo, na relação entre modificação molecular e potência. ${ }^{77 b, 81}$

O processo empregado na obtenção de MMPs consiste em estabelecer relações estruturais entre os compostos sem utilizar critérios subjetivos, identificar alterações químicas que transformam compostos estruturalmente relacionados e facilitar uma análise em larga escala de relações estrutura-atividade. ${ }^{6 a, 6 b, 76 b}$

A análise sistemática de MMPs avançou de forma significativa no campo da química medicinal computacional, proporcionando uma base para muitas aplicações práticas. Algoritmos apropriados foram desenvolvidos e programas de visualização gráfica das relações estrutura-atividade encontram-se disponíveis. ${ }^{6 a, 6 b, 82}$ Nesta perspectiva, o programa MUDO (MolecUle eDitOr), ${ }^{36 \mathrm{~d}}$ criado com um pacote de ferramentas da OEChem ${ }^{41 \mathrm{~d}}$ edita 
automaticamente estruturas químicas definidas como SMIRKS, ${ }^{83}$ uma ferramenta útil na análise de bancos de dados.

O programa MUDO pode processar estruturas com ou sem coordenadas 3D, desde que, sejam fornecidas as estruturas químicas em formato canônico SMILES. ${ }^{84}$ A análise MMPs permite o acesso rápido e com acurácia da predição de propriedades de compostos pertencentes a uma série congenérica, ${ }^{36 \mathrm{~d}, 81 \mathrm{~b}, 84 \mathrm{~b}}$ em outras palavras, um tipo especial de metodologia de relações estrutura atividade ou propriedade (QSAR/QSPR). ${ }^{76 a, 76 c, 81 b, 85}$

A título de exemplificação, o programa MUDO foi utilizado para explorar a SAR do sub-sítio S3, do inibidor covalente irreversível de cruzaína K777 (Figura 20). ${ }^{36 d}$ A diversidade química explorada neste estudo forneceu uma lista de análogos que podem ser utilizados para ampliar o espaço químico no P3, guiando a síntese de novos inibidores mais potentes.

Um alto grau de similaridade e identidade compartilhado por enzimas da mesma classe, quando explorado pode fornecer informações características, úteis para o planejamento de inibidores mais potentes e seletivos. A cruzaína, pertence à família das cisteíno proteases, logo, o SAR de inibidores desta classe contém informações relevantes, que se exploradas, auxiliam na busca por propostas de inibidores mais promissores. Baseando-se em informações previamente estabelecidas na literatura para cisteíno proteases, as modificações moleculares para inibidores de cruzaína podem acontecer de forma guiada.

\subsection{Metodologia}

O desenvolvimento desse capítulo do trabalho ocorreu nos Laboratórios do Grupo de Estudos em Química Medicinal (Nequimed) e de Síntese Orgânica Warner Bruce Kover (Laboratório do Professor Antônio Carlos Bender Burtoloso), no Instituto de Química (IQSC) da Universidade de São Paulo (USP). As sínteses encontram-se descritas e discutidas no capítulo 4. Os ensaios biológicos foram realizados pelos alunos de doutorado Jean Ribeiro, Daniel Gedder e Lorenzo Cianni do grupo Nequimed. Os detalhes dos ensaios biológicos podem ser obtidos no artigo de Avelar e colaboradores. ${ }^{8,41 \mathrm{~d}}$

\subsubsection{Planejamento orientado pela hipótese}

$\mathrm{Na}$ descoberta de fármacos, o processo central de construir e testar hipóteses, conduzido por experimentos e análise dos dados, associados a novas informações é conhecido 
como o ciclo planeja-sintetiza-testa. ${ }^{86}$ Cada passo depende muito das informações de entradas e saídas destes três componentes.

O processo de desenvolvimento de moléculas bioativas baseado nesta estratégia é retroativo, e segue um ciclo que compreende a construção da hipótese, avaliação experimental e análise de resultados. A partir desses resultados são determinadas as alterações que devem ser realizadas (geração de novos conhecimentos) ou chega-se no resultado almejado (compostos mais potentes). ${ }^{87}$ A Figura 23 ilustra o ciclo por meio de um fluxograma.

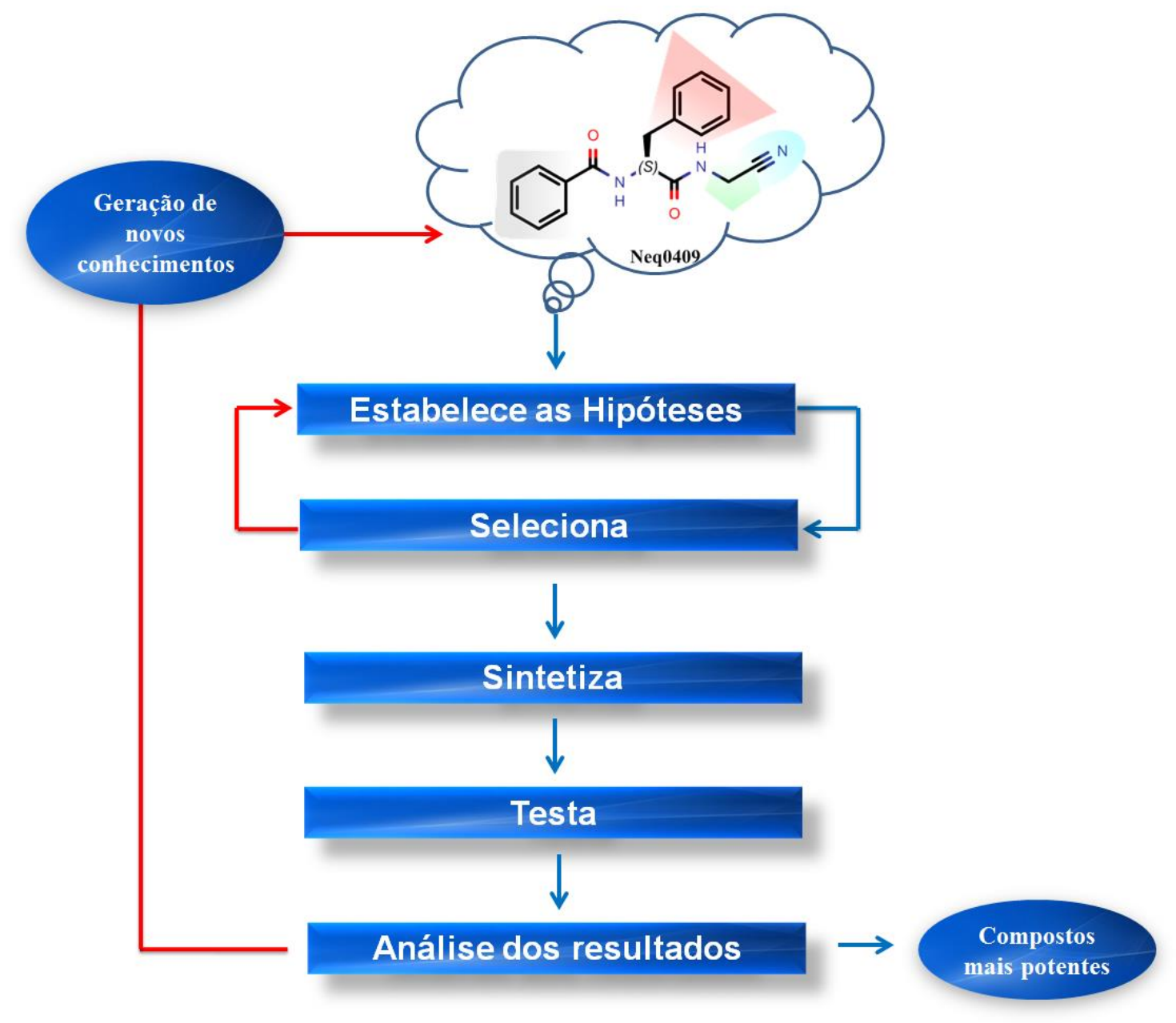

Figura 23. Fluxograma do ciclo planeja-sintetiza-testa. As setas em azul indicam o fluxo progressivo, as setas em vermelho o fluxo retroativo ${ }^{86}$

Fonte: Adaptado de Plowright, et al., 2012

A estratégia inicial do processo inicia-se com a escolha de um protótipo, hipóteses para alterar a estrutura molecular são criadas, com o objetivo de alcançar melhores propriedades farmacodinâmicas e farmacocinéticas.

O inibidor conhecido de catepsina $\mathrm{L}^{88}$ foi escolhido pelo grupo Nequimed como composto protótipo (Figura 23). Um dipeptidil contendo nitrila como warhead (na porção 
P1'), dois hidrogênio na porção $\mathrm{P} 1$, o resíduo de fenilalanina na porção P2 e um anel benzênico na porção P3, denominado Neq0409; ${ }^{41 b, ~}{ }^{41 d}$ possui $\mathrm{K}_{\mathrm{I}}=0,45 \mu \mathrm{M}\left(\mathrm{pK}_{\mathrm{I}}=6,34\right)$ contra a cruzaína. ${ }^{41 \mathrm{~d}}$

Várias modificações estruturais no esqueleto básico foram realizadas e um estudo de SAR foi estabelecido por meio de três, onze e doze variações nas porções P1, P2 e P3, respectivamente. A Figura $\mathbf{2 4}$ mostra as modificações realizadas a partir do composto protótipo.<smiles>N#[P+]NC(=O)[PH2+][NH2+]C(=O)[18OH]</smiles>
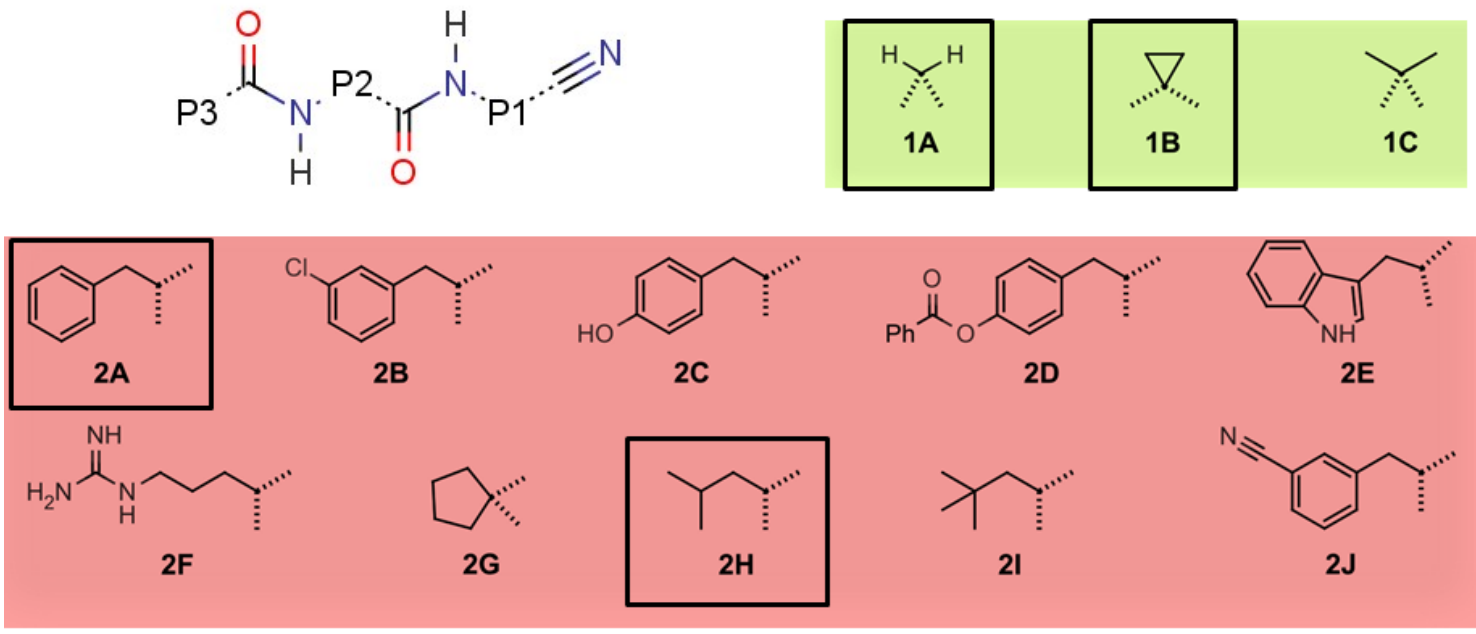
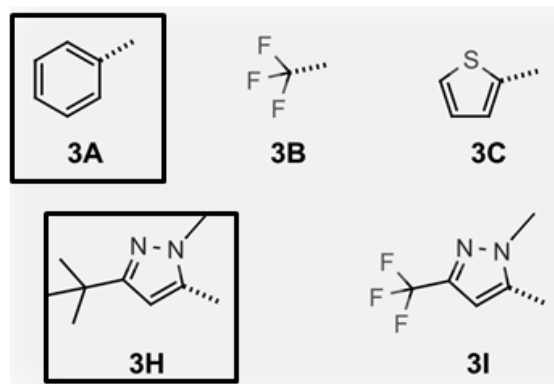

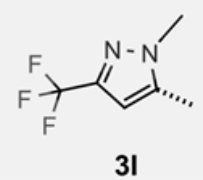

31
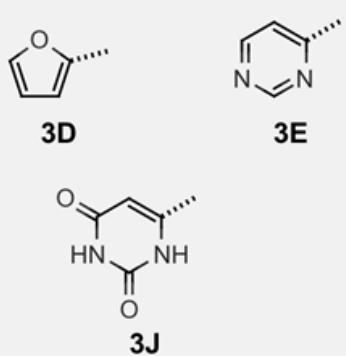

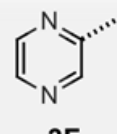

$3 \mathrm{~F}$

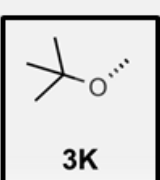

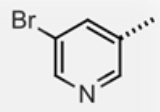

$3 G$

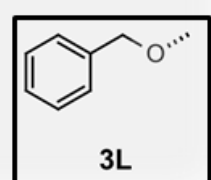

Figura 24. Modificações realizadas no P1 (verde), P2 (vermelho) e P3 (cinza) do protótipo dipeptidil-nitrilas inibidor da enzima cruzaína. Em destaque (preto) as modificações escolhidas para os estudos de SAR do presente trabalho Fonte: adaptado de Avelar (2015)

Os resultados demonstram moderada capacidade de inibir a cruzaína e erradicar formas celulares do parasita T. cruzi. ${ }^{41} \mathrm{O}$ composto mais potente dessa série de dipeptidilnitrilas possui um $\mathrm{K}_{\mathrm{i}}$ de valor de $16 \mathrm{nM}$ contra a enzima cruzaína (Figura 24: P1 = 1A, P2 = $2 \mathrm{~B}$ e $\mathrm{P} 3=3 \mathrm{H}$ ). $\mathrm{O}$ inibidor mais ativo possui um $\mathrm{EC}_{50}$ de valor de $28 \mu \mathrm{M}$ (Figura 24: $\mathrm{P} 1=1 \mathrm{~A}$, $\mathrm{P} 2=2 \mathrm{E}$ e $\mathrm{P} 3=3 \mathrm{~A})$.

Contudo, as modificações realizadas concentraram-se no P1, P2 e P3 e a nitrila foi mantida como "warhead". Esses resultados revelam a necessidade de modificações no P1' (warhead), visto que, os valores de $\mathrm{EC}_{50}$ e de $\mathrm{K}_{\mathrm{i}}$ mantiveram-se no patamar de concentração 
semelhante, mesmo após todas as modificações propostas. ${ }^{41}$ Com isso obteve-se o primeiro ciclo planeja-sintetiza-testa.

Nesse novo ciclo objetivou-se potencializar a interação entre a enzima e o inibidor por meio da inserção de novos warheads covalentes reversíveis, diferentes do grupo nitrila. Para tanto, algumas modificações foram selecionadas para compor as porções P1, P2 e P3 (Figura 24), e novos grupos warheads propostos por meio de análises de MMP e conhecimentos de química medicinal (conforme apresentado nos próximos tópicos).

\subsubsection{Planejamento: estabelecimento das hipóteses e seleção de grupos warheads}

Na proposta de síntese de novos warheads para a construção do estudo de SAR, o esqueleto básico do Neq0409 e modificações nas porções P1, P2 e P3 foram selecionados (Figura 24), quais sejam:

a) o grupo ciclopropil (grupo 1B) ou hidrogênios (grupo 1A) na porção P1. Além disso, metilação do nitrogênio da amida adjacente à porção P1;

b) os aminoácidos fenilalanina (Phe, grupo 2A) ou leucina (Leu, grupo 2H) na porção P2;

c) os grupos benzoil (grupo 3A), benzil éter (Cbz, grupo 3L), terc-butil éter (Boc, grupo 3K) e 1-metil, 3-terc-butilpirazol-5-il (PyrA, grupo 3H) na porção P3;

\subsubsection{Justificativas para as hipóteses estabelecidas}

\subsubsection{Modificações no P1, P2 e P3}

Na enzima cruzaína, o sub-sitío de reconhecimento (S2) acomoda grupos hidrofóbicos e volumosos e o sub-sítio de direção (S3) apresenta superfície plana e uma porção exposta ao solvente. ${ }^{53-54}$

No composto protótipo dipeptidil, variações na porção P2 com os aminoácidos Phe ou Leu, em conjunto com as variações no $\mathrm{P} 3$, com os grupos protetores (Cbz e Boc), amplamente utilizados em inibidores de cisteíno proteases, ${ }^{40 \mathrm{~b},} 88-89$ buscam promover interações moderadas entre inibidor e enzima. Tendo em vista que, o objetivo nesta etapa consiste em avaliar apenas a contribuição da interação entre os grupos warheads selecionados e sub-sítio S1' da enzima cruzaína. Na etapa subsequente, para aumentar a atividade biológica do inibidor protótipo, o grupo PyrA foi selecionado. 
Modificações no P1 podem potencializar ou diminuir a interação do warhead por meio do favorecimento da sua adequada conformação na direção do ataque da Cys S $\gamma$ catalítica, e ainda, pode evitar clivagens proteolíticas. Para tanto, o grupo ciclopropil foi selecionado para compor a porção P1. Ainda, a metilação do nitrogênio da amida adjacente à porção P1 busca evitar esse metabolismo. ${ }^{56}$

\subsubsection{Modificações no P1' (warhead)}

Para explorar e mapear a contribuição do warhead (P1') no processo de inibição de cisteíno proteases, um estudo amplo de MMPs foi realizado, ${ }^{6 a}, 6 \mathrm{~b}$ a fim de coletar informações para propostas e síntese de novos inibidores.

A Figura 25 ilustra o processo de obtenção dos pares moleculares.
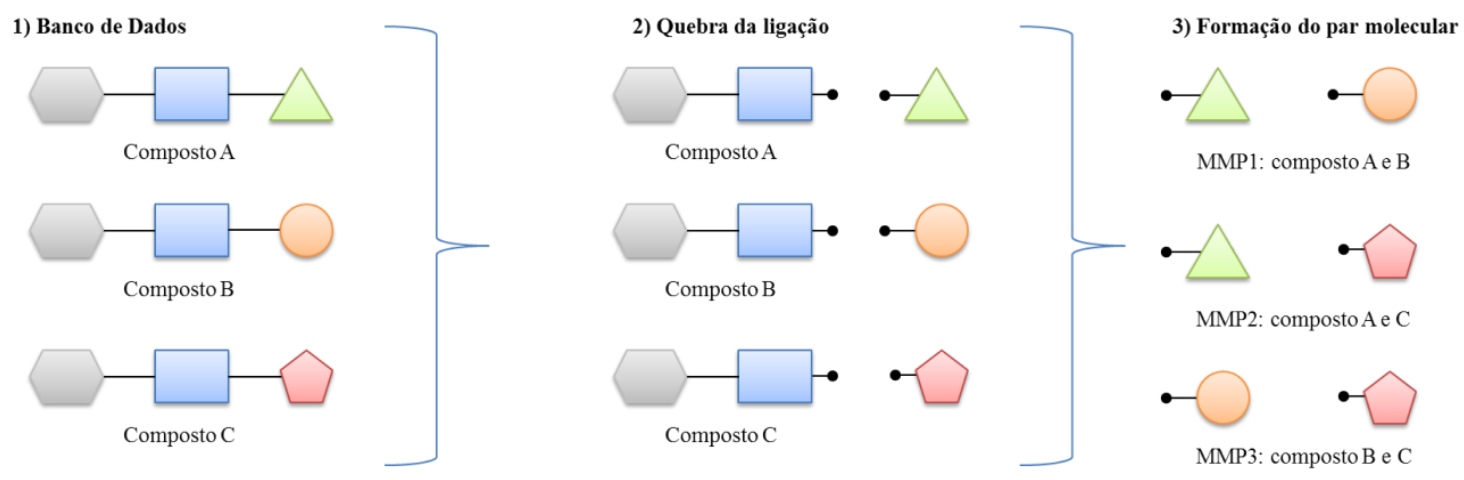

Figura 25. Formalismo no MMPs: a) organização do banco de dados; b) quebra da ligação no sítio de interesse por meio do programa MUDO e b) obtenção dos MMPs

A primeira etapa (Figura 25a) para obtenção dos MMPs, consistiu na organização do Banco de Dados de cisteíno proteases extraído do ChEMBL, ${ }^{38,90}$ que possui cerca de 60 mil compostos sintetizados e testados. Todo o banco foi tratado e organizado, de forma que apenas as informações consistentes fossem preservadas. $\mathrm{O}$ tratamento incluiu a verificação das estruturas químicas, deleção de sais e organometais e a seleção de ensaios biológicos coerentes ao estudo, tais como: $\mathrm{K}_{\mathrm{I}}$ e $\mathrm{IC}_{50}$. A organização permitiu agrupar conjuntos de compostos com esqueleto básico comum e eliminar informações irrelevantes. Um filtro também foi utilizado para selecionar apenas compostos que fossem dipeptidil.

Na segunda etapa, a ligação foi quebrada no sítio de interesse (Figura 25b) com a utilização do programa MUDO, ${ }^{36 \mathrm{~d}}$ como o banco de dados encontra-se disposto de acordo com a estrutura química, criaram-se os blocos referentes aos MMPs (Figura 25c). 
$\mathrm{Na}$ terceira etapa todos os blocos formados foram analisados. Geralmente os grupos warheads possuem um centro eletrofílico contendo um átomo de carbono insaturado. Neste sentido, buscou selecionar funções orgânicas com tripla ligação (nitrila e azanitrila) ou dupla ligação (oxima, heterocíclicos e éster/amidas alfa-beta insaturados), e também, grupos com a função orgânica carbonila (aldeído e amida).

\subsection{Nitrila e azanitrila}

O grupo nitrila representa uma importante classe de warhead com propriedades biológicas consideradas favoráveis, quais sejam: grupo cilíndrico de baixo peso molecular, metabolicamente estável e polar. 17, 41d, 56, 66b Similarmente, o grupo azanitrila tem demonstrado ser um warhead potente e proteoliticamente estável. ${ }^{18}$ Portanto, para estabelecer o estudo de SAR de interesse, ambos os grupos foram selecionados.

\subsection{Aldeído}

A reatividade da porção aldeído proporciona um excelente ponto de partida para a modificação química do warhead em compostos dipeptidil, para produzir inibidores menos reativos e mais seletivos. No estudo realizado por Choe e colaboradores, ${ }^{91}$ os compostos com a função aldeídica obtiveram altas potências contra a cruzaína. Contudo, a instabilidade de compostos contendo esse grupo, caracteriza-se como um problema. Por isso, na tentativa de minimizar esse efeito, selecionou-se o grupo aldeído como warhead e adicionou-se na porção P1 o grupo ciclopropil.

\subsection{Heterocíclicos}

Diversos estudos reportam o uso de heterocíclicos como "warhead". ${ }^{65 b, 73}$ Mais de 300 patentes publicadas apresentam o uso dessa função orgânica como inibidores de proteases.

O grupo aminoisoxazol possui a função orgânica nitrila mascarada, isto pode aumentar a atividade metabólica e auxiliar na farmacocinética entre o inibidor e o alvo enzimático de interesse. Nesta hipótese (in vivo), esse grupo seria hidrolisado pelas enzimas do citocromo (CYP450) e atingiria o alvo na sua forma intacta (hipótese de clivagem da ligação oxigênionitrogênio, Figura 26). O composto bioativo teria menor instabilidade metabólica e maior 
potência, seguindo o conceito de pró-fármaco, ${ }^{65}$ como no exemplo do fármaco anti-reumática Leflunomida. ${ }^{92}$ A biotransformação, que gera o metabólito ciano, resulta na atividade farmacológica de interesse. ${ }^{93}$
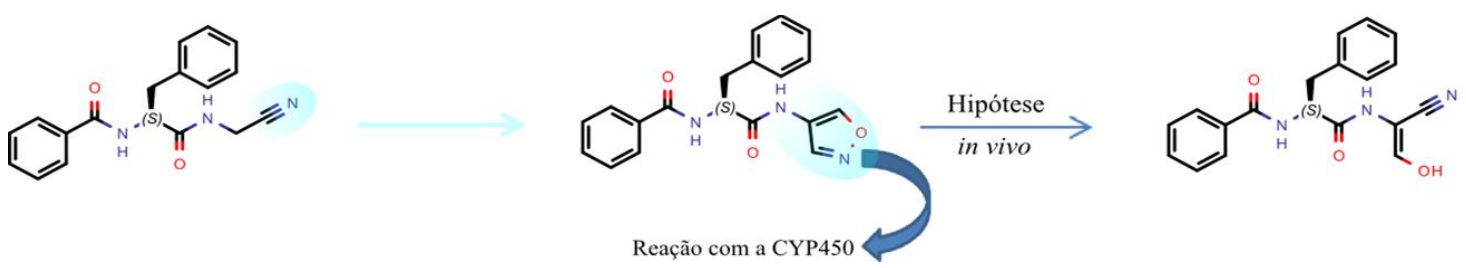

Figura 26. Hipótese para proteção do warhead nitrila (destacado em azul). A clivagem in vivo (CYP450) da ligação N-O resultaria no metabólito ativo.

Mesmo não sendo o foco neste estágio do estudo confirmar essas hipóteses dois heterocíclicos foram selecionados como warheads.

\subsection{Compostos alfa-beta insaturados}

Estudos na literatura revelam que alquenos possuem baixa potência contra cisteíno proteases quando comparado com o warhead nitrila. ${ }^{94}$ Contudo, grupos denominados como aceitadores de Michael, ${ }^{95}$ comumente empregados no processo de inibição de cisteíno proteases, é uma alternativa para aumentar a potência de alquenos. Nesta perspectiva, compostos contendo éster e amidas alfa-beta insaturados foram selecionados.

\subsection{Oxima}

Grupos eletrofílicos que contém uma ligação dupla carbono-nitrogênio têm o potencial de proporcionar um melhor acesso a Cys $\mathrm{S} \gamma$ catalítica do que nitrilas ou aldeídos. Acredita-se que as Iminas e bases de Schiff sejam insuficientemente instáveis em condições fisiológicas para serem úteis warheads. Todavia, dipeptidil hidrazonas foram relatadas como inibidoras de cisteíno proteases. ${ }^{94}$ Por exemplo, uma hidrazona de benzoílo demonstrou ser equipotente ao aldeído correspondente, contra ambas as catepsinas B e S.

Os warheads baseados em hidrazona são tipicamente substituídos por grupos retiradores de elétrons, isso aumenta tanto o impedimento estérico quanto a complexidade molecular dos inibidores. ${ }^{18}$ Em contraste, os warheads não substituídos, como a oxima podem ser usados e, se necessário, podem ser mais elaborados sinteticamente, ligando o 
oxigênio ao carbono saturado. Essa função orgânica, nunca antes foi empregada como warhead.

\subsection{Resultados e discussão}

\subsubsection{Análises de MMPs de inibidores de cisteíno proteases extraídos do ChEMBL}

As análises de MMPs concentraram-se em dipeptidil ensaiados utilizando o protocolo $\mathrm{K}_{\mathrm{I}}$ (mesmo protocolo de ensaio usado nesse capítulo), ${ }^{41 \mathrm{a}-\mathrm{c}}$ que expressa o grau de interação entre um respectivo inibidor enzimático e a enzima inibida $\left(\mathrm{K}_{\mathrm{i}}\right.$, expressos em $\left.\mathrm{pK} \mathrm{K}_{\mathrm{I}}=-\log \mathrm{K}_{\mathrm{i}}\right)$.

A Tabela 7 mostra os MMPs obtidos usando o warhead nitrila como referência (grupo a) seguido do par molecular (grupo b); número de vezes que o par se repete no banco de dados $(\mathrm{N}){ }^{1}$ os valores médios do logaritmo de $\mathrm{K}_{\mathrm{I}}\left(\Delta \mathrm{pK}_{\mathrm{I}}\right)$ obtidos no estudo, bem como o desvio e o erro padrão.

Tabela 7. Análises de MMPs de inibidores de cisteíno proteases usando o warhead nitrila como referência

\begin{tabular}{|c|c|c|c|c|c|c|c|}
\hline MMP & Grupo a & Grupo b & $\mathbf{N}$ & $\Delta p K_{I}$ & $\begin{array}{c}\boldsymbol{\alpha}_{\text {média }} \\
\left(\mathbf{p} \mathbf{K}_{\mathrm{I}}\right)\end{array}$ & $\begin{array}{r}\boldsymbol{\alpha}_{\text {erro }} \\
\left(\mathbf{p} \mathbf{K}_{\mathbf{I}}\right)\end{array}$ & Ref. \\
\hline 1 & & & 7 & 2,88 & 0,52 & 0,20 & 96 \\
\hline 2 & & & 4 & $-0,94$ & 1,35 & 0,67 & $66 \mathrm{~b}$ \\
\hline 3 & & & 1 & $-3,28$ & - & - & $66 \mathrm{~b}$ \\
\hline 4 & & & 1 & $-3,28$ & - & - & $66 \mathrm{~b}$ \\
\hline 5 & & & 4 & 1,44 & 0,22 & 0,11 & $66 \mathrm{~b}$ \\
\hline
\end{tabular}

Legenda: $\mathrm{N}=$ número de vezes que o par se repete; $\Delta \mathrm{pK} \mathrm{K}_{\mathrm{I}}=$ média do logaritmo de $\mathrm{K}_{\mathrm{I}} ; \alpha_{\text {média }}=$ desvio padrão de $\Delta \mathrm{pK}$; $\alpha_{\text {erro }}=$ erro padrão de $\Delta \mathrm{pK}$; Ref. = artigo de referência.

\footnotetext{
${ }^{1}$ Isto ocorre quando o par molecular foi ensaiado utilizando protocolos diferentes ou há mais de um esqueleto básico e uma única modificação no P1'. Em apêndice encontra-se uma tabela com essas informações detalhadas
} 
No caso do primeiro MMP, existem três pares de compostos que apresentam esqueleto básico diferente (nitrila versus azanitrila), com a mesma modificação no P1'(grupo "a" foi modificado para o grupo "b" nesses três esqueletos); logo: o incremento desta modificação é representado pela média de todos os ensaios biológicos nesses três pares moleculares $\left(\Delta \mathbf{p} \mathbf{K}_{\mathbf{I}}=\right.$ $\mathbf{2 , 8 8})$. O desvio padrão $\left(\boldsymbol{\alpha}_{\text {média }}=\mathbf{0 , 5 2}\right)$ e o erro padrão da média $\left(\boldsymbol{\alpha}_{\mathbf{e r r o}}=\mathbf{0 , 2 0}\right)$ são mostrados na sequência. A Figura 27 ilustra as informações presentes no MMP1.

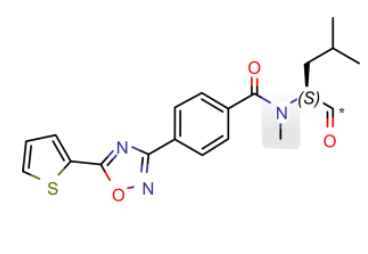

Esqueleto Básico 1

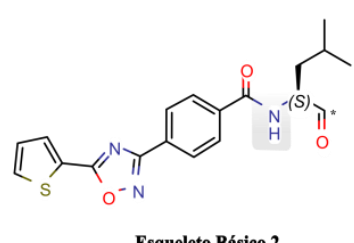

Esqueleto Básico 2

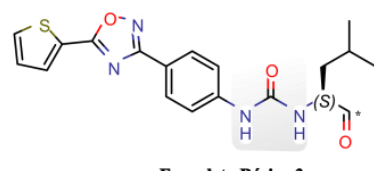

Esqueleto Básico 3

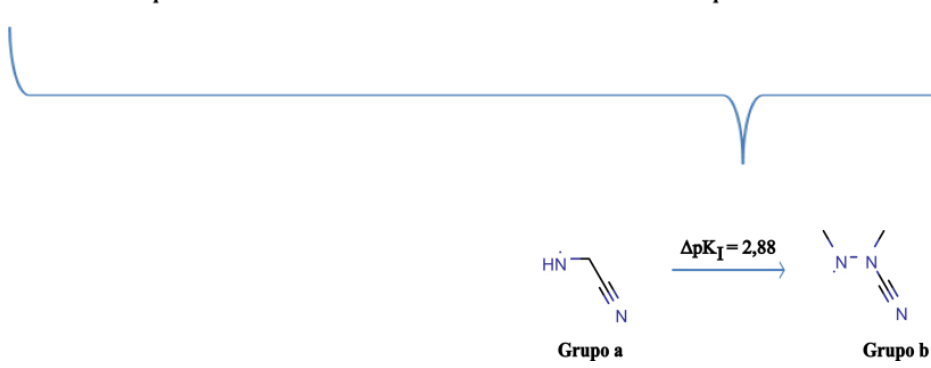

Figura 27. MMP 1: os diferentes esqueleto básicos utilizados para gerar os pares moleculares (destacado em cinza). A troca do grupo "a" para o grupo "b" gerou um incremento de $\Delta \mathrm{p} K_{I}=2.88$ unidades logarítmicas

A substituição do grupo nitrila "a" para o grupo azanitrila "b" demonstrou ser sinergicamente favorável no processo de inibição, em três pares moleculares com esqueleto diferentes (Figura 27). ${ }^{72 a}$ Em outros estudos, essa substituição isoeletrônica ${ }^{69}$ em conjunto com a metilação dos nitrogênios " $a z a$ " 70 resultou em compostos altamente potentes contra a cruzaína. No processo de inibição, a potência do warhead (P1') é influenciada por grupos substituintes adjacentes (P1), como demonstrado na Figura 28.

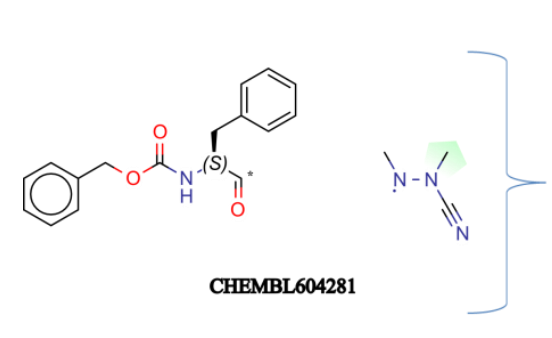

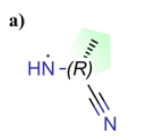

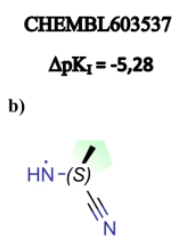

CHEMBL595637 $\Delta \mathrm{pK}_{\mathrm{I}}=-\mathbf{2 , 7 5}$
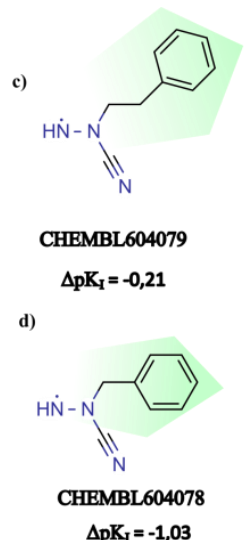

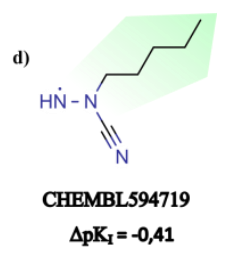

$\Delta \mathrm{pK}_{\mathrm{I}}=-0,41$

Figura 28. Análise MMP adicional realizada no P1 (ensaio ChEMBL: 606254) 39,41, 107 
A análise MMP adicional realizada no P1 (Figura 28) confirma que a metilação do nitrogênio " $a z a$ " estabelece a melhor relação substituição/potência $(\Delta \mathrm{pK} \mathrm{I}=-0,21,-1,03$, e 0,41 para os MMPs c-d, respectivamente), assim como, a troca do carbono pelo nitrogênio $\left(\Delta \mathrm{pK}_{\mathrm{I}}=-5,28\right.$ e -2,75 para os MMPs "a" e "b", respectivamente); esses dois últimos pares também demostram que o isômero $\mathrm{S}$ é mais potente que o isômero R. ${ }^{39,41,107}$

Substituições não favoráveis ocorrem com a troca do grupo nitrila pelos grupos alquino $\left(\mathrm{MMP} 3, \Delta \mathrm{pK}_{\mathrm{I}}=-3,28\right)$ e alqueno $\left(\mathrm{MMP} 4, \Delta \mathrm{pK}_{\mathrm{I}}=-3,28\right){ }^{66 \mathrm{~b}}$

Com a substituição da nitrila "a" para função orgânica cetona "b" ocorreu um pequeno decréscimo em unidades logarítmicas (MMP2, $\left.\Delta \mathrm{pK}_{\mathrm{I}}=-0,94\right)$. ${ }^{66 \mathrm{~b}}$ Contudo, informações presentes na literatura ${ }^{97}$ demonstram que o grupo metil de cetonas quando substituídos por heterocíclicos são mais potentes.

Alguns substituintes heterocíclico ligados à cetona aumenta o poder indutivo por meio da retirada de elétrons, ${ }^{97}$ o que está de acordo com os dados teóricos da constante de Hammett. ${ }^{75,98}$ No estudo realizado por Palmer e colaboradores, ${ }^{97 \mathrm{~b}}$ uma serie de Ceto-1,3,4oxadiazol testados contra catepsinas $\mathrm{B}, \mathrm{L}, \mathrm{S}$ e $\mathrm{K}$ alcançaram potência de sub-nanomolar. $\mathrm{O}$ composto 13i (ChEMBL379622) ${ }^{102,103}$ é pouco seletivo contra catepsina $\mathrm{K}\left(\mathrm{pK}_{\mathrm{I}}=10,48\right)$, quando comparado às outras catepsinas (pK $=10,03$ “CatB.”; 9,79 “CatL.”; 9,49 “CatS.”).

A seletividade frente à catepsina $\mathrm{K}$, foi atingida por meio de modificações estruturais nos sub-sítios P2 e P3. A transposição de informações da catepsina K para cruzaína propiciou excelentes resultados no estudo realizado pela indústria farmacêutica Merck. ${ }^{40 a}$ Portanto, as informações adquiridas nos MMPs para inibidores de catepsina $\mathrm{K}$, podem guiar a síntese de inibidores potentes e seletivos contra a cruzaína. Inclusive, o aldeído desponta como alternativa viável para aumentar a potência de inibidores de cruzaína.

No MMP5 (Tabela 7) a substituição da nitrila "a" para o aldeído "b" também é favorável. O grupo aldeído (b) é mais ativo em 1,44 unidades logarítmicas que a nitrila ( $\alpha_{\text {média }}$ $=0,22$ e $\left.\alpha_{\text {erro }}=0,11\right)$.

A função orgânica aldeídica (Tabela 8) ainda se mostrou promissora em outros pares analisados, onde o aldeído foi mantido como referência $\left(\Delta \mathrm{pK}_{\mathrm{I}}\right.$ de $-4,52$ para os MMPs 6 e 7; e $-2,37$ para o MMP8). ${ }^{66 \mathrm{~b}}$

Buscas por pares moleculares contendo a substituição nitrila por éster/amidas alfa-beta insaturados ou nitrila por oxima, no banco de dados de inibidores de cisteíno proteases extraídos do ChEMBL, não resultaram em combinações de interesse para este estudo. 
Tabela 8. Análises de MMPs de inibidores de cisteíno proteases usando o warhead aldeído como referência

\begin{tabular}{|c|c|c|c|c|c|c|c|}
\hline MMP & Grupo a & Grupo b & $\mathbf{N}$ & $\Delta p K_{I}$ & $\begin{array}{c}\boldsymbol{\alpha}_{\text {média }} \\
\left(\mathbf{p K} \mathbf{K}_{\mathrm{I}}\right)\end{array}$ & 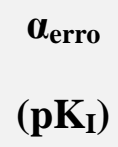 & Ref. \\
\hline 6 & & & 1 & $-4,52$ & - & - & $66 \mathrm{~b}$ \\
\hline 7 & & & 1 & $-4,52$ & - & - & $66 \mathrm{~b}$ \\
\hline 8 & & & 4 & $-2,37$ & 1,18 & 0,59 & $66 \mathrm{~b}$ \\
\hline $\begin{array}{l}\text { Legenda: } \\
\Delta \mathrm{pK} \text {; } ; \text { Ref. }\end{array}$ & $\begin{array}{l}\text { vezes que o } \\
\text { rência. }\end{array}$ & & & dita $=\mathrm{de}$ & adrão de & & Idrão de \\
\hline
\end{tabular}

\subsubsection{Análise da SAR de grupos warheads em inibidores de cruzaína sintetizados}

Uma vez mapeado as informações de interesse, realizou-se a síntese dos novos dipeptidil contendo os warheads selecionados. Esse conjunto de alterações no composto protótipo resultou na síntese de vinte compostos ensaiados contra a cruzaína. As rotas sintéticas e detalhes experimentais estão apresentados nos capítulos 4 e 5, respectivamente. Neste estudo foram determinadas as constantes de inibição $\left(K_{i}\right.$, expressos em $\left.p K_{I}=-\log K_{i}\right)$ contra a enzima cruzaína, apresentados na Tabela 9.

Tabela 9. Série de dipeptidil sintetizados e seus respectivos valores de constante de inibição<smiles>[R7]CC(N[R])C(=O)N([R3])N=[Pt]</smiles>

\begin{tabular}{cccccc}
\hline Comp. & $\mathbf{R}_{\mathbf{1}}$ & $\mathbf{R}_{\mathbf{2}}$ & $\mathbf{R}_{\mathbf{3}}$ & Warhead & $\mathbf{p K}_{\mathbf{i}}{ }^{\mathbf{a}}$ \\
\hline $\mathbf{1}$ & $\mathrm{Cbz}$ & $\mathrm{Phe}$ & $\mathrm{H}$ & $\mathrm{N}^{\mathrm{N}}$ & 6,3 \\
\hline $\mathbf{2}$ & $\mathrm{Cbz}$ & $\mathrm{Phe}$ & $\mathrm{H}$ & $\underbrace{\mathrm{N}}$ & 5,2 \\
\hline $\mathbf{3}$ & $\mathrm{Cbz}$ & $\mathrm{Phe}$ & $\mathrm{H}$ & $\mathrm{N}_{\mathrm{H}}$ & 8,1
\end{tabular}




\begin{tabular}{|c|c|c|c|c|c|}
\hline Comp. & $\overline{R_{1}}$ & $\overline{\mathbf{R}_{2}}$ & $\mathbf{R}_{\mathbf{3}}$ & Warhead & $p K_{i}^{a}$ \\
\hline 4 & $\mathrm{Cbz}$ & Phe & $\mathrm{H}$ & & 5,4 \\
\hline 5 & $\mathrm{Cbz}$ & $\mathrm{Cbz}$ & $\mathrm{H}$ & & 7,0 \\
\hline 6 & $\mathrm{Cbz}$ & $\mathrm{Cbz}$ & $\mathrm{H}$ & & 4,4 \\
\hline 7 & $\mathrm{Cbz}$ & Phe & $\mathrm{H}$ & & 5,0 \\
\hline 8 & $\mathrm{Bz}$ & Phe $(r, s)$ & $\mathrm{H}$ & & 4,7 \\
\hline 9 & $\mathrm{Bz}$ & Phe $(s)$ & $\mathrm{H}$ & & 5,0 \\
\hline 10 & $\mathrm{Bz}$ & Phe $(r)$ & $\mathrm{H}$ & & 4,0 \\
\hline 11 & $\mathrm{Cbz}$ & Phe & $\mathrm{H}$ & & 4,6 \\
\hline 12 & $\mathrm{Cbz}$ & Phe & $\mathrm{H}$ & & 5,8 \\
\hline 13 & $\mathrm{Cbz}$ & Phe & $\mathrm{H}$ & & 5,2 \\
\hline 14 & $\mathrm{Cbz}$ & Phe & $\mathrm{H}$ & & 3,9 \\
\hline 15 & $\mathrm{Cbz}$ & Phe & $\mathrm{H}$ & & 3,7 \\
\hline 16 & $\mathrm{Cbz}$ & Phe & $\mathrm{H}$ & & 3,4 \\
\hline 17 & $\mathrm{Cbz}$ & Phe & $\mathrm{CH}_{3}$ & & 8,7 \\
\hline 18 & Boc & $\mathrm{CH}\left(\mathrm{CH}_{3}\right)_{2}$ & $\mathrm{CH}_{3}$ & & 8,0 \\
\hline 19 & PyrA & Phe & $\mathrm{CH}_{3}$ & & 8,8 \\
\hline 20 & PyrA & $\mathrm{CH}\left(\mathrm{CH}_{3}\right)_{2}$ & $\mathrm{CH}_{3}$ & & 8,8 \\
\hline
\end{tabular}

Legenda: comp. $=$ composto ${ }^{\mathrm{a}}-\log _{10}\left(\mathrm{~K}_{\mathrm{i}} / \mathrm{M}\right) ; \mathrm{Cbz}=$ benzil fomato; $\mathrm{Boc}$ $=$ tert-butil formato; $\mathrm{Bz}=$ benzoil $; \mathrm{PyrA}=3$-tert-butil-1-metil-1Hpirazol-5-carbonil; Phe $=$ fenil 


\subsubsection{Analises de SAR nas porções P1 e P1' (warhead)}

No Esquema 1 o composto $1\left(\mathrm{pK}_{\mathrm{i}}=6,3\right.$, nitrila como warhead) é o ponto de partida para se estabelecer o SAR deste trabalho. Todos os compostos presentes no Esquema 1 possuem o grupo Cbz na porção P3 e o aminoácido fenilalanina na porção P2 (conforme mostrado na parte superior do Esquema 1). As modificações realizadas na porção P1' revelam somente a contribuição do warhead no processo de inibição da enzima cruzaína.

Destacado em setas na cor azul, encontram-se os grupos eletrofílicos substituídos pela nitrila que aumentaram a constante de inibição, quais sejam: aldeído e oxima. Destacado em setas na cor vermelha, encontram-se os grupos eletrofílicos substituídos pela nitrila que diminuíram a constante de inibição, quais sejam: amida e heterocíclicos.

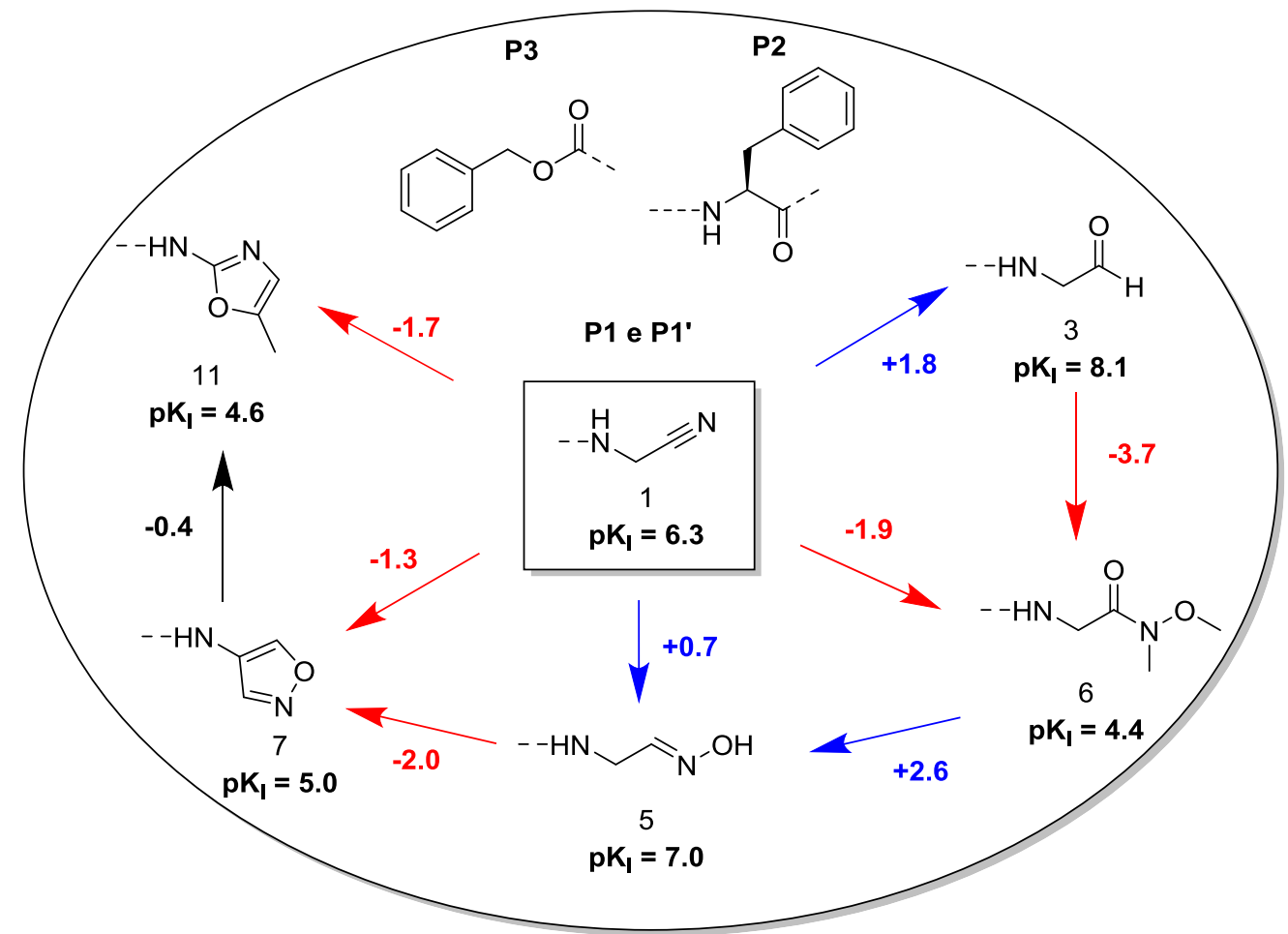

Esquema 1. Relação estrutura atividade dos grupos warheads (P1')

O ensaio biológico para o composto 3 resultou em um $\mathrm{pK}_{\mathrm{I}}$ de 8,12. Desta forma, a alteração da função orgânica nitrila pelo aldeído resultou em um warhead mais potente (acréscimo de 1,8 unidades logarítmicas). Esse resultado está de acordo com os estudos de MMPs.

A modificação do grupo eletrofílico nitrila para oxima (composto $\mathbf{6}, \mathrm{pK}_{\mathrm{i}}=7,0$ ) também resultou em um ganho de afinidade de 0,7 unidades logarítmicas. Isso demonstra que 
tanto carbonos saturados quanto carbonilas são classes orgânicas biologicamente ativas contra a enzima cruzaína. Contudo, ao substituir o warhead nitrila pelo grupo amida de Weinreb (composto 6, $\mathrm{pK}_{\mathrm{i}}=4,4$ ) ocorreu um decréscimo de 1,9 unidades logarítmicas da constante de inibição. Ainda, o warhead aldeído é quase 4 vezes mais potente que o warhead amida.

As substituições do warhead nitrila para os heterocíclicos isoxazol (composto $7, \mathrm{pK}_{\mathrm{i}}=$ 5,0) e oxazol (composto 11, $\mathrm{pK}_{\mathrm{i}}=4.6$ ), resultaram em um decréscimo de 1,3 e 1,7 unidades logarítmicas da constante de inibição, respectivamente. Contudo, a afinidade da enzima pelo heterocíclico isoxazol é ligeiramente maior que para o heterocíclico oxazol $(0,4$ unidades logarítmicas).

Esse resultado corrobora com a hipótese levantada, visto que o heterocíclico isoxazol não possui o warhead nitrila na sua forma ativa, a consequência esperada é a redução da afinidade enzima-inibidor.

O warhead oxima mais potente que o grupo isoxazol em 2,0 unidades logarítmicas, possui uma sequência molecular semelhante a este heterocíclico ( $\mathrm{CH}-\mathrm{N}-\mathrm{O})$. Em outras palavras, o grupo isoxazol contém uma função oxima incorporada no anel.

$\mathrm{O}$ ataque da Cys $\mathrm{S} \gamma$ catalítica ocorre em um mesmo carbono $\left(s p^{2}\right)$ adjacente ao nitrogênio em ambos os warheads. O fato do decréscimo da constante de inibição pode ser explicado pela ressonância presente no grupo isoxazol e restrições geométricas introduzidas pelo anel, diminuindo a interação entre a Cys S $\gamma$ catalítica e o carbono insaturado. O que não ocorre na oxima.

\subsubsection{Analises de SAR na porção P1}

Por apresenta propriedades que evita o metabolismo, ${ }^{56}$ o grupo ciclopropil foi adicionado na porção P1 dos dipeptidil compostos contendo nitrila, aldeído e éster/amida alfa-beta insaturado como warhead. Essas modificações são apresentadas no Esquema 2.

A substituição na porção P1 do grupo metileno pelo ciclopropil em dipeptidil-nitrilas tipicamente conduz a incrementos entre 0,3 a 0,4 na potência de inibição da cruzaína. ${ }^{41 d}$ No entanto, no esqueleto básico utilizado neste trabalho essa substituição diminuiu a potência em 1,1 unidades logarítmicas (1 versus $\mathbf{2}$ ).

Para promover melhorias na estabilidade da função orgânica aldeídica na série de dipeptidil, ${ }^{13 b, 41 d}$ bem como evitar oxidação e ou enolização da função orgânica em condições fisiológicas; mais uma vez o grupo ciclopropil foi introduzido na porção P1. Entretanto, uma 
redução significativa da potência foi observada (1 versus $\mathbf{2}$, redução de 2,7 unidades logarítmicas).

A função orgânica éster alfa-beta insaturado como warhead (composto 12) obteve um $\mathrm{pK}_{\mathrm{I}}$ de 5,8 (0,5 unidades logarítmicas menos potente que a nitrila). Os ensaios biológicos demonstraram que a enzima apresenta ligeira afinidade pelo isômero E (12 versus $\mathbf{1 3}$, 0,57 unidades logarítmicas).

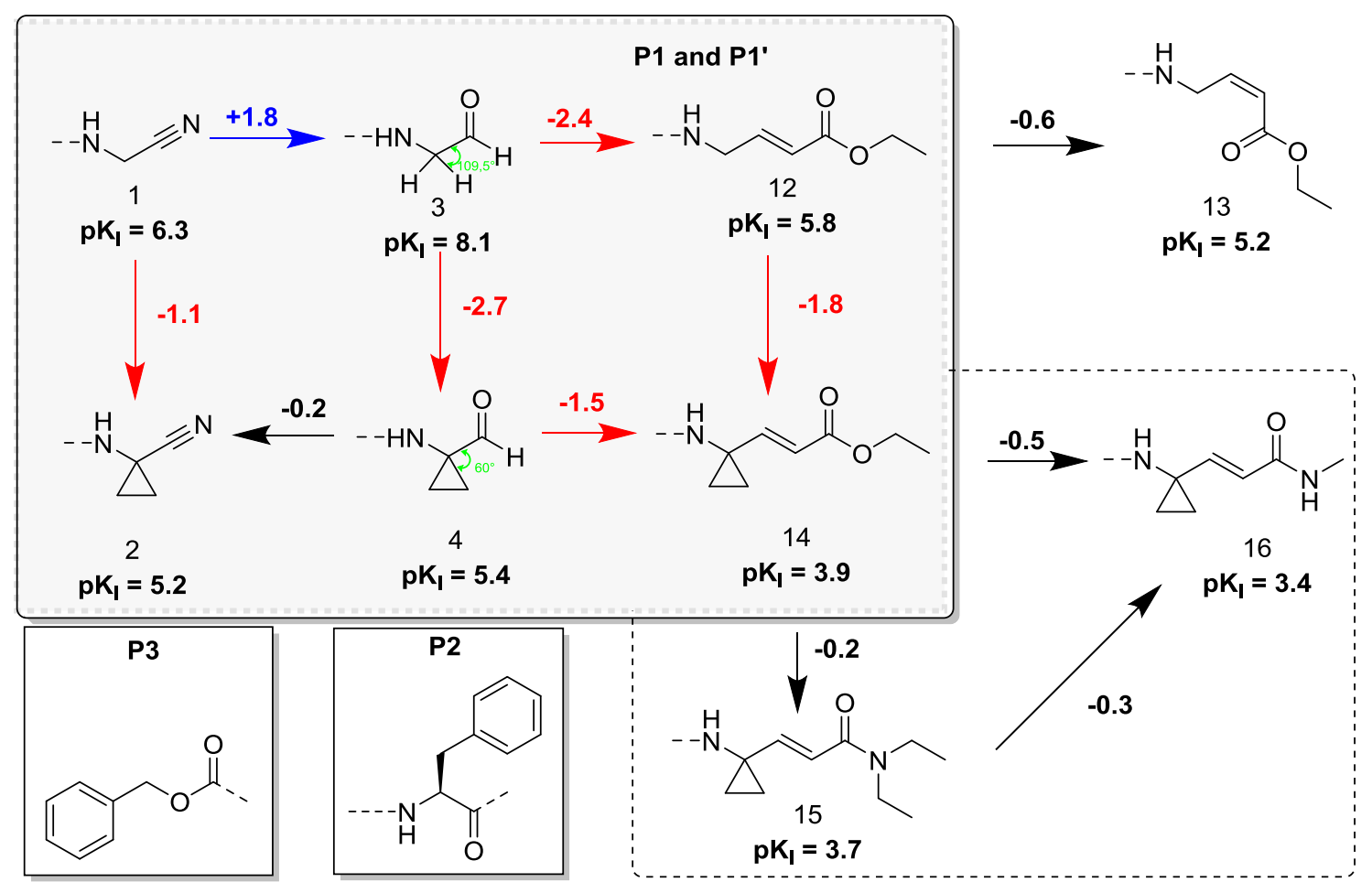

Esquema 2. Relação estrutura atividade dos grupos warheads (P1') e na porção P1 dos compostos dipeptidil

A substituição do grupo metileno pelo grupo ciclopropil na porção P1 também resultou em decréscimo da potência de 1,8 unidades logarítmicas no éster alfa-beta insaturado como warhead (12 versus 14). Esse decréscimo da potência foi ainda maior para as amidas alfabeta insaturadas, com o ciclopropil na porção P1 (compostos 15 e 16).

Os resultados demonstram que, apesar do grupo ciclopropil aumentar a estabilidade metabólica da função orgânica como demonstrado em outros estudos, ${ }^{13 b}$, 41d diminuiu a afinidade da enzima pelo inibidor. A adição do grupo ciclopropil na porção P1 muda o ângulo da ligação do carbono tetraédrico $\mathrm{sp}^{3}$ de $109,2^{\circ}$ graus (compostos $\mathbf{1}, \mathbf{3}$ e 12) para o ângulo de $60^{\circ}$ graus (compostos 2,4 e 14). O desvio de $49,5^{\circ}$ graus, no ângulo de ligação ideal, reflete em diferenças torcionais do carbono trigonal e tetraédrico, o que influencia negativamente no correto posicionamento do warhead no sítio ativo da cruzaína (S1'), para que ocorra a ligação covalente com a Cys25. 


\subsubsection{Analises de SAR entre nitrilas e azanitrilas com variações nas porções P2 e P3}

A substituição do warhead nitrila para azanitrila, mostrou-se sinergicamente favorável nas análises de MMPs do banco de dados de cisteíno proteases, extraído do ChEMBL. Baseado nesses estudos sintetizaram-se quatro dipeptidil-azanitrilas (17-20) com modificações nas porções P2 e P3 (Esquema 3).

As modificações selecionadas do primeiro ciclo planeja-sintetiza-testa ${ }^{41 d}$ é apresentadas no topo da Esquema 3 (compostos marcados com um asterisco) e na parte inferior (destacado em cinza) os novos dipeptidil sintetizados e testados contra a enzima cruzaína, que compõem o segundo ciclo do estudo.

As substituições do warhead nitrila para a azanitrila resultaram em acréscimos de 2,4 e 2,1 de potência nos pares 1 versus 17 e $27 *$ versus 18 , respectivamente. O valor de $\Delta \mathrm{pK}_{\mathrm{I}}$ resultante é de 2,25, comparável com o valor de $\Delta \mathrm{pK}_{\mathrm{I}}$ de 2,88 dos estudos de MMPs do banco de dados de cisteíno proteases.

Na porção P2, as substituições do aminoácido Phe para Leu não alterou a potência em dipeptidil-nitrilas (21* versus 29*, parte superior da Erro! Fonte de referência não encontrada.) ou em dipeptidil-azanitrilas (19 versus 20, parte inferior da Esquema 3).

Em dipeptidil-azanitrilas a substituição do grupo Cbz para PyrA na porção P3 não alterou a potência do inibidor (17 versus 19). Contudo, essa mesma substituição em dipeptidil-nitrilas aumentou a potência em 0,9 unidades logarítmicas (1 versus $\mathbf{2 1}$ *).

A substituição do grupo Boc para PyrA mostrou-se favorável tanto em dipeptidilazanitrilas quanto em dipeptidil-nitrilas (18 versus 20 e 27 versus 29, respectivamente). Ainda na porção P3, o Esquema 3 mostra as substituições do grupo Bz no composto Neq0409* para o grupo PyrA no composto $21^{*}$, bem como para o grupo Cbz no composto $\mathbf{1}$. No primeiro par ocorreu um incremento de 0,9 unidades logarítmicas, enquanto que no segundo par não ocorreu alteração da potência. Essa troca (Bz versus Cbz) também foi efetuada nos pares de compostos dipeptidil-isoxazol 7 e 9, o que não levou a alteração da potência (Esquema 4).

Outro ponto interessante notado no SAR apresentado no Esquema 4 é a afinidade da enzima cruzaína pelo isômero S. Composto 9 é mais ativo em 1 unidade logarítmica que o isômero R (composto 10); já notado também em outros estudos. 12e, 12f, 40a, 41d, 56, 67c 

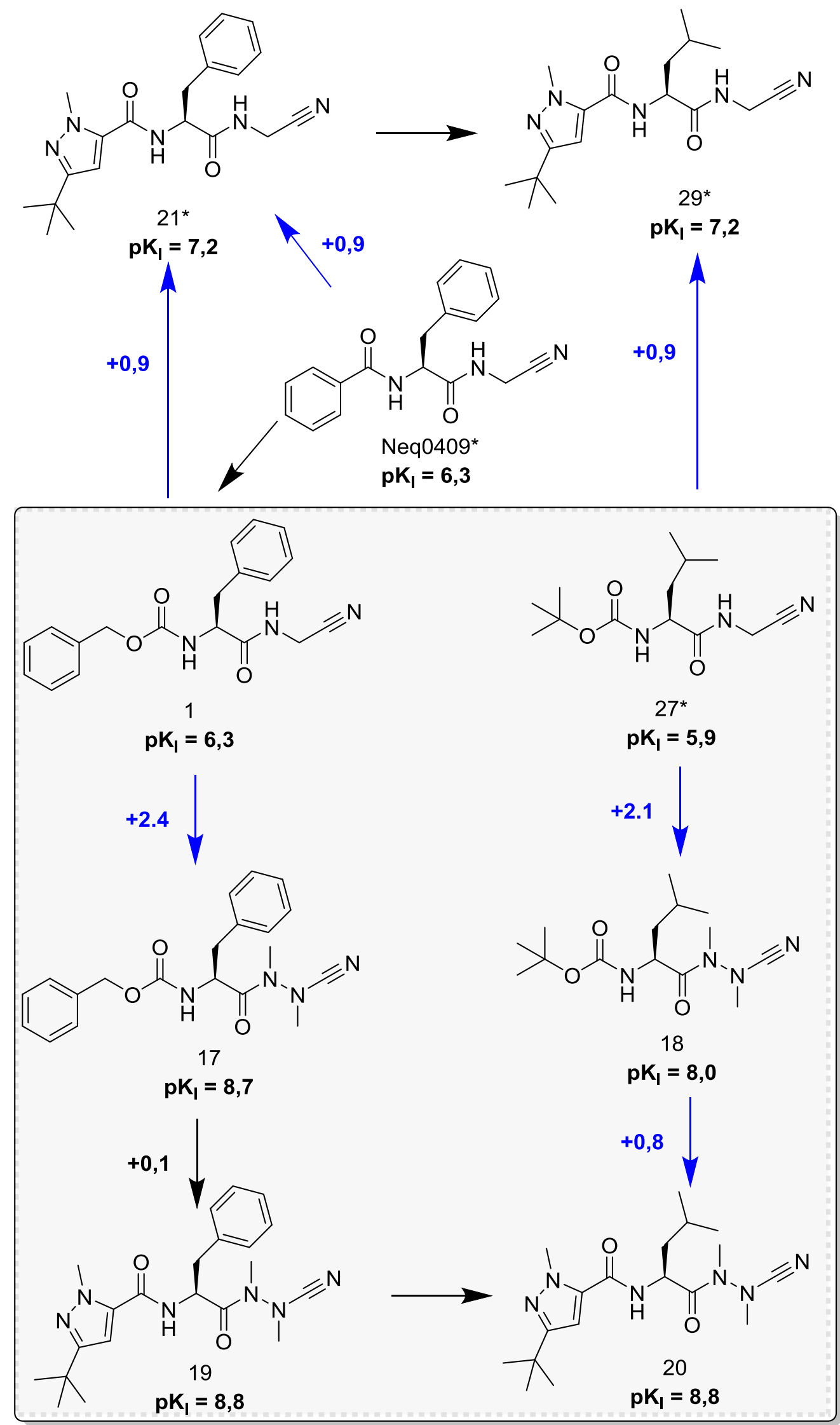

Esquema 3. Relação estrutura-atividade dos compostos dipeptidil-nitrilas e dipeptidilazanitrilas. Marcados com um asterisco os compostos extraídos do estudo de Avelar e colaboradores ${ }^{41 \mathrm{~d}}$ 


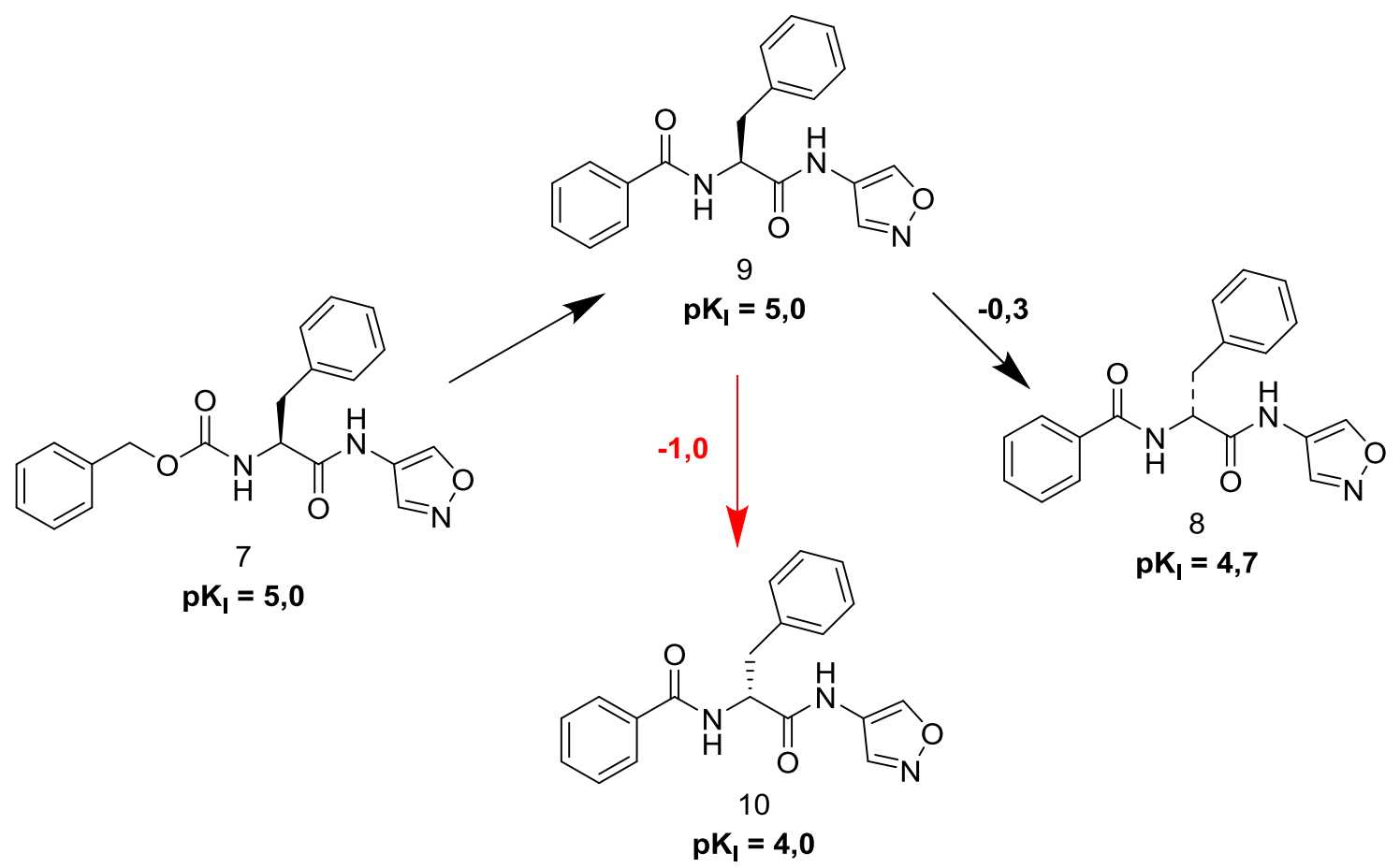

Esquema 4. Relação estrutura-atividade de compostos dipeptidil-isoxazol

\subsection{Ensaios celulares contra a forma amastigota da cepa Y de $T$. cruzi}

Os compostos $1, \mathbf{2}, \mathbf{7}, \mathbf{1 1}, \mathbf{1 7}, \mathbf{1 8}$ e $\mathbf{2 0}$ foram selecionados para os ensaios contra a forma amastigota da cepa Y de T. cruzi, infectada com células hospedeiras U2OS. ${ }^{99}$ A Tabela 10 apresenta os resultados de $\mathrm{EC}_{50}$ obtidos (expressos em $\mathrm{pEC}_{50}$ ), a concentração citotóxica que matou $50 \%$ das células (expressos em $\mathrm{pCC}_{50}$ ) e o erro padrão de cada ensaio ( $\mathrm{SE}$, do inglês "standard error").

Tabela 10. Atividades contra a forma amastigota da cepa Y de T. cruzi

\begin{tabular}{|c|c|c|c|c|}
\hline Comp. & $\mathrm{pEC}_{50}{ }^{\mathrm{a}}$ & $\begin{array}{c}\mathrm{SE} \\
\left(\mathrm{pEC}_{50}\right)^{\mathrm{b}}\end{array}$ & $\mathrm{pCC}_{50}{ }^{\mathrm{c}}$ & $\begin{array}{c}\mathrm{SE} \\
\left(\mathrm{pCC}_{50}\right)^{d}\end{array}$ \\
\hline 1 & $\overline{<4}$ & & $<4$ & \\
\hline 2 & $<4$ & & $<4$ & \\
\hline 7 & $<4$ & & $<4$ & \\
\hline 11 & 4,4 & 0,09 & $<4$ & \\
\hline 17 & 5,3 & 0,22 & 5,0 & 0,06 \\
\hline 18 & 4,4 & 0,14 & 4,3 & 0,02 \\
\hline 20 & 4,9 & 0,6 & 4,8 & 0,6 \\
\hline
\end{tabular}


Os compostos 1, 2 e 7 apresentaram valores de $\mathrm{pEC}_{50}$ e $\mathrm{pCC}_{50}$ inferiores a 4,0. Os compostos 1 e 2 possuem o grupo nitrila como warhead, e a única diferença estrutural entre esses compostos foi a inserção do grupo ciclopropil na porção P1. O composto 7 possui o grupo isoxazol como warhead. O composto 11 (oxazol como warhead) obteve um valor de $\mathrm{pEC}_{50}$ de 4,4 e um valor de $\mathrm{pCC}_{50}$ inferior a 4,0.

Os compostos derivados de dipeptidil azanitrila 17, 18 e 20 obtiveram valores de $\mathrm{pEC}_{50}$ e $\mathrm{pCC}_{50}$ similares. Isso sugere que esses compostos podem estar inibindo diferentes cisteíno proteases na célula hospedeira. Geralmente, a substituição de grupos warheads não é uma tática de planejamento molecular útil para aumentar a seletividade.

\subsection{Conclusões do capítulo II}

Os estudos de MMPs auxiliaram a mapear informações sobre grupos warheads empregados em inibidores de cisteíno proteases do tipo dipeptidil. As principais modificações concentraram-se na porção $\mathrm{P} 1$ ', correspondente ao warhead. O principal objetivo destas modificações foi potencializar a interação entre a enzima e o inibidor, e isto, foi notado com os warheads azanitrila, aldeído e oxima. As substituições com grupos warheads demostraram se promissora no processo de inibição da enzima cruzaína e a oxima foi introduzida como uma nova potente classe de warhead. Contudo, ao realizar a substituição dos hidrogênios no P1 por um grupo ciclopropil, na tentativa de melhorar a estabilidade dos compostos, verificou-se que a constante de afinidade diminuiu. No entanto, todos os inibidores sintetizados possuem valores de $\mathrm{pK}_{\mathrm{I}}$ que podem ser melhorados, se realizado modificações pontuais nos sub-sítios P2 e P3, mais especificamente no P1. 


\section{Capíula 3}

\section{Estudo de relação estrutura-atividade da nova classe de agentes tripanossomicidas derivados de imidazopiridina}
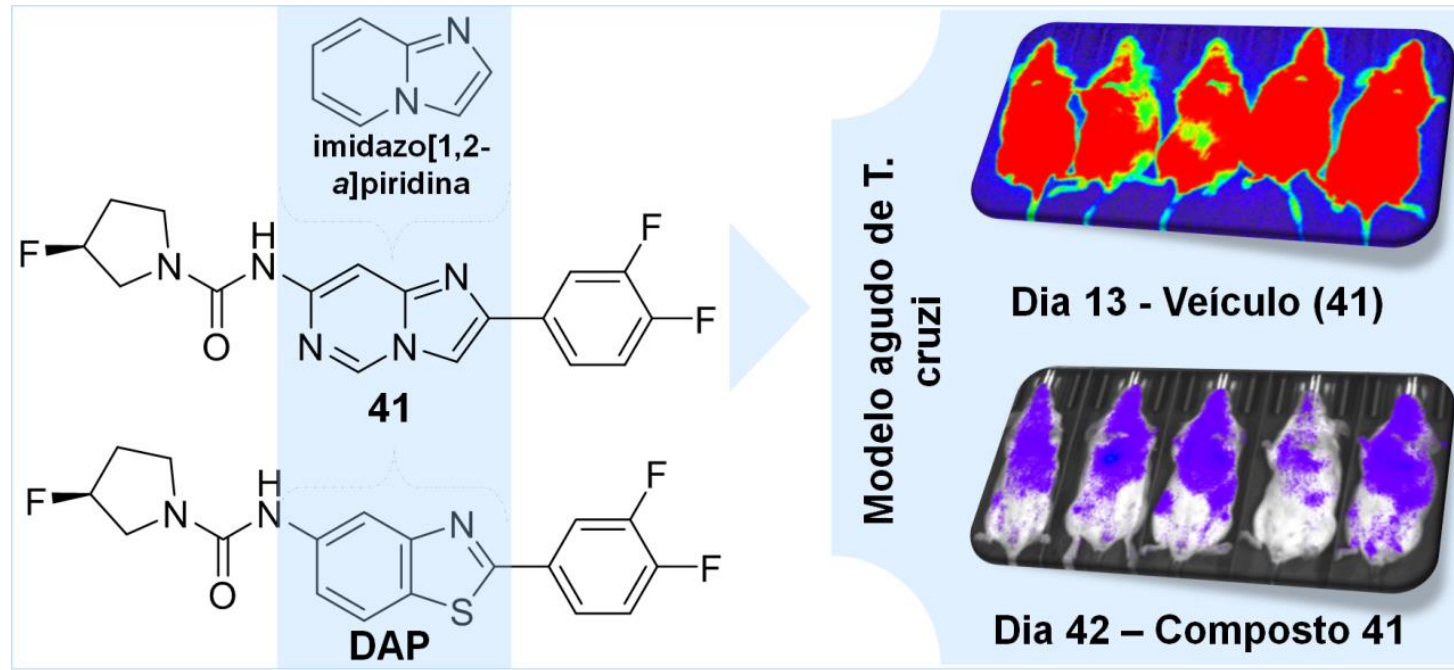


\section{Capítulo III}

\section{Estudo de relação estrutura-atividade da nova classe de agentes tripanossomicidas derivados de imidazopiridina}

\subsection{Introdução}

No desenvolvimento de fármacos, muitos compostos protótipos são eliminados nas etapas de avaliações clínicas por não apresentarem as propriedades farmacocinéticas requeridas. ${ }^{29 a}, 100 \mathrm{O}$ pró-fármaco administrado por via oral Pafuramidina (Figura 29), ${ }^{101}$ inicialmente concebido para o tratamento de pneumonia, ${ }^{102}$ tinha avançado para a fase III dos estudos clínicos do primeiro estágio da infecção com $T$. brucei. No entanto, os estudos constataram nefrotoxicidade nesse fármaco, o que impediu o seu avanço no tratamento de HAT. ${ }^{103}$ Recentemente, o derivado de imidazol nitrado fexinidazol ${ }^{104}$ e o benzoxaborole SCYX-7158 ${ }^{105}$ também entraram nos estudos clínicos como candidatos para o tratamento de tripanossomíases (Figura 29). Todavia, ainda prevalece à alta taxa de insucessos de candidatos nas triagens na fase clínica (cerca de 90\%) ${ }^{106}$ e doenças parasitárias ainda continuam sem um adequado aparato de combate e cura.<smiles>CON=C(N)c1ccc(-c2ccc(-c3ccc(C(N)=NOC)cc3)o2)cc1</smiles>

Pafuramidina<smiles>CC1(C)OB(O)c2cc(NC(=O)c3ccc(F)cc3C(F)(F)F)ccc21</smiles>

benzoxaborole SCYX-7158<smiles>CSc1ccc(OCc2ncc([N+](=O)[O-])n2C)cc1</smiles>

Fexinidazol

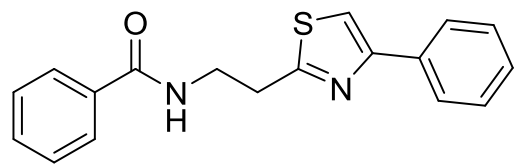

2-(2-benzamido) etil-4-feniltiazol

Figura 29. Compostos em estudo para o tratamento de HAT

$\mathrm{Na}$ tentativa de minimizar a taxa de insucessos, um estudo fenotípico de triagem de alta produtividade (HTS, do inglês high-throughput screen) foi conduzido pelo Instituto de Genômica da Fundação de Pesquisa Novartis (GNF, do inglês Genomics Institute of the Novartis Research Foundation), com uma coleção contendo 700.000 compostos. Neste estudo, identificaram-se mais de 1000 compostos, agrupados por esqueletos básicos distintos que inibiram o crescimento de infecções com $T$. brucei in vitro, em concentrações abaixo de 
3,6 $\mu \mathrm{M}$ e não apresentaram citotoxicidade. Esses grupos de compostos foram organizados, levando em consideração, a relativa facilidade de síntese, falta de átomos de carbono quiral e características semelhantes a fármacos, incluindo baixo peso molecular e adesão às regras de Lipinski. ${ }^{107}$

$\mathrm{Na}$ otimização dos compostos mais promissores, uma colaboração entre o GNF e pesquisadores de universidades americanas de Washington (UW) e Norte da Carolina (UNC), 19, 108 identificaram um composto líder, o 2-(2-benzamido) etil-4-feniltiazol (Figura 29). A série de compostos derivadas de tiazol-2-etilamina, sintetizada e testada contra T. brucei, obteve alta potência contra o parasita, porém baixa estabilidade metabólica. ${ }^{109}$

Para solucionar o problema da estabilidade metabólica, Patrick e colaboradores ${ }^{110}$ transformaram o esqueleto básico derivado de tiazol-2-etilamina em um anel fundido do tipo benzotiazol. O mais potente dos análogos desta série de compostos, o (S)-2-(3,4difluorofenil)-5-(3-fluoro-N-pirrolidilamido)benzotiazol (denominado DAP, apresentado na próxima seção), apresentou bioatividade contra o T. brucei de $35 \mathrm{nM}$. Esse composto representa uma nova oportunidade para o desenvolvimento de fármacos para o combate de doenças negligenciadas.

\subsection{Metodologia}

O desenvolvimento desse capítulo do trabalho ocorreu no laboratório Gelb, do departamento de química na Universidade de Washington em Seattle-USA. Os compostos foram planejados e sintetizados sob a supervisão do Professor Michael H. Gelb, e ensaiados no Laboratório do Professor Fred Buckner, do departamento de Medicina da Universidade de Washington. Todos os ensaios biológicos foram realizados pelos pesquisadores J. Robert Gillespie, Ranae M. Ranade, Zackary M. Herbst e Uyen T.T. Nguyen. Todos os resultados desse capítulo, bem como os detalhes dos ensaios biológicos encontram se publicados no artigo "New Class of Antitrypanosomal Agents Based on Imidazopyridines" na revista American Chemical Society Medicinal Chemistry Letters. ${ }^{28}$ Parte dos resultados foram patenteados ${ }^{10}$ pela Universidade de Washington, em parceria com a Universidade de São Paulo. 


\subsubsection{Planejamento}

Os estudos de Patrick e colaboradores ${ }^{110-111}$ com os derivados de benzotiazol demonstraram que essa classe de compostos exibe atividades tripanossomicidas, mais especificamente contra T. brucei. Nesses estudos, o alvo biológico não foi identificado e, os compostos não foram testados contra o T. cruzi.

Com o objetivo de planejar e sintetizar uma nova classe de agentes tripanossomicidas, baseado nesses resultados prévios, modificou-se o anel fundido benzotiazol para o anel de imidazo[1,2-a]piridina. Esse anel fundido é comumente encontrado em fármacos antipsicóticos, ansiolíticos, analgésicos e para tratamento de enxaqueca; portanto características desejáveis no processo de formulação de fármacos já foram atribuídas a este núcleo aromático. ${ }^{112}$

Como o alvo biológico dessa classe de compostos ainda não foi identificado, empregou-se estratégias de química medicinal para planejar as modificações nas porções $R_{1} \mathrm{e}$ $\mathrm{R}_{2}$ do anel fundido de imidazopiridina (descritas no tópico 4.2.1). As modificações também foram baseadas nos trabalhos de Patrick e colaboradores, ${ }^{110-111}$ bem como, no trabalho desenvolvido pelo grupo Nequimed em compostos do tipo dipeptidil. Os compostos sintetizados são derivados de ureia ou amida com grupos substituintes na posição 2 do imidazol. Ainda, a estrutura interna do anel fundido foi modificada com a inserção de um átomo de nitrogênio nas posições 6 e 8 . O conjunto de modificações selecionadas encontramse ilustrado na Figura 30.

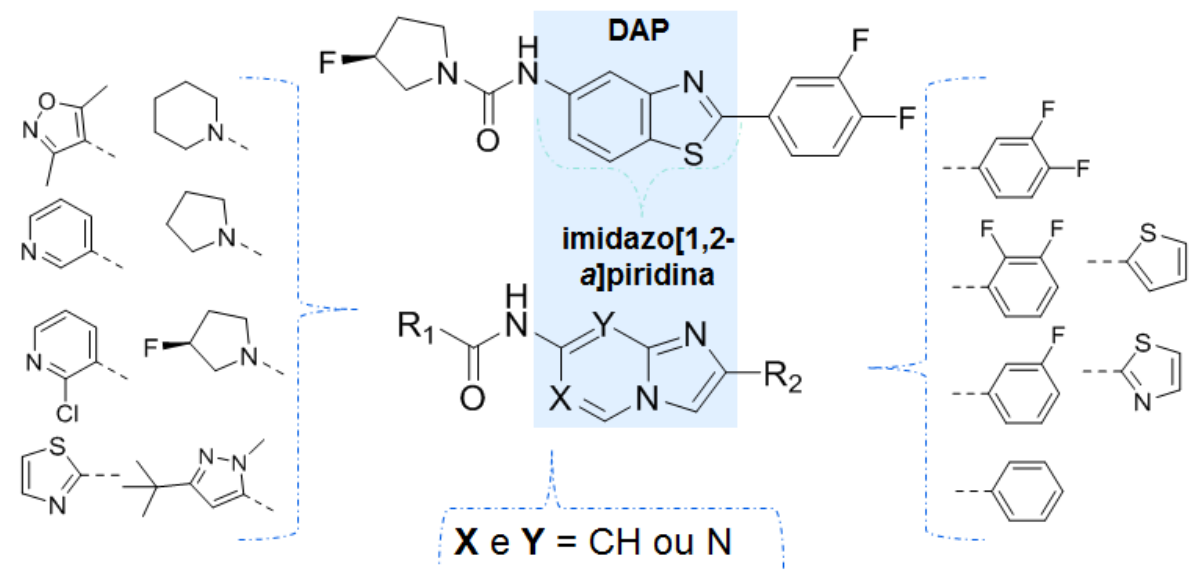

Figura 30. Conjunto de modificações propostas para o esqueleto básico de imidazopiridina 


\subsection{Resultados e discussões}

Com as sínteses de 23 novos compostos, o presente capítulo explora as relações estrutura-atividade (SAR) com base em ensaios biológicos contra T. cruzi, T. brucei e em células de mamíferos. A Tabela 11 apresenta os resultados obtidos.

Tabela 11. Atividades tripanossomicidas dos derivados de imidazopiridina/imidazopirimidina<smiles>[R]C(=O)Nc1ccn2cc(NC([R])=O)nc2c1</smiles>

21-39

40

41,42

43

\begin{tabular}{|c|c|c|c|c|c|c|}
\hline \multirow[b]{2}{*}{ ठ் } & \multirow[b]{2}{*}{$\mathbf{R}_{1}$} & \multirow[b]{2}{*}{$\mathbf{R}_{\mathbf{2}}$} & \multicolumn{2}{|c|}{ T. cruzi } & \multicolumn{2}{|c|}{ T. brucei } \\
\hline & & & $\begin{array}{l}\mathbf{E C}_{50} \\
(\mu \mathrm{M})^{*}\end{array}$ & $\begin{array}{c}\mathbf{E C}_{90} \\
(\mu \mathrm{M})^{*} \\
\end{array}$ & $\begin{array}{c}\mathbf{E C}_{50} \\
(\mu \mathbf{M})^{* * *}\end{array}$ & $\begin{array}{c}\mathbf{E C}_{90} \\
(\mu \mathbf{M})^{* * *}\end{array}$ \\
\hline 21 & piperidin-1-yl & phenyl & 2,75 & 12,28 & 2,51 & 4,20 \\
\hline 22 & pyrrolidin-1-yl & phenyl & 4,46 & 6,44 & 2,23 & 3,27 \\
\hline 23 & (S)-3-fluoropyrrolidin-1-yl & phenyl & 1,08 & 1,73 & 0,62 & 0,77 \\
\hline 24 & piperidin-1-yl & 3-fluorophenyl & 3,10 & 4,53 & 0,97 & 1,48 \\
\hline 25 & pyrrolidin-1-yl & 3-fluorophenyl & 2,95 & 6,01 & 0,73 & 0,88 \\
\hline 26 & (S)-3-fluoropyrrolidin-1-yl & 3-fluorophenyl & 0,71 & 0,88 & 0,16 & 0,82 \\
\hline 27 & piperidin-1-yl & 2,3-difluorophenyl & 1,00 & 1,58 & 0,72 & 0,87 \\
\hline 28 & pyrrolidin-1-yl & 2,3-difluorophenyl & 1,02 & 1,61 & 0,58 & 2,76 \\
\hline 29 & (S)-3-fluoropyrrolidin-1-yl & 2,3-difluorophenyl & 0,94 & 1,36 & 0,18 & 0,92 \\
\hline 30 & piperidin-1-yl & 3,4-difluorophenyl & 2,84 & 4,40 & 1,20 & 1,75 \\
\hline 31 & pyrrolidin-1-yl & 3,4-difluorophenyl & 2,24 & 2,57 & 0,32 & 0,73 \\
\hline 32 & (S)-3-fluoropyrrolidin-1-yl & 3,4-difluorophenyl & 0,39 & 0,60 & 0,16 & 0,31 \\
\hline 33 & (S)-3-fluoropyrrolidin-1-yl & 1,3-thiazol-2-yl & $>20,0$ & $>20,0$ & $>20,0$ & $>20,0$ \\
\hline 34 & (S)-3-fluoropyrrolidin-1-yl & thiophen-2-yl & 2,68 & 3,92 & 1,00 & 2,67 \\
\hline 35 & 2-chloropyridin-3-yl & 3,4-difluorophenyl & 7,34 & $>20,0$ & $>20,0$ & $>20,0$ \\
\hline 36 & 3,5-dimethyloxazol-1,2-yl & 3,4-difluorophenyl & 9,06 & $>20,0$ & $>20,0$ & $>20,0$ \\
\hline 37 & pyridin-3-yl & 3,4-difluorophenyl & 6,27 & $>20,0$ & 6,30 & $>20,0$ \\
\hline 38 & 1,3-thiazol-2-yl & 3,4-difluorophenyl & 7,85 & $>20,0$ & $>1,00$ & $>1,00$ \\
\hline 39 & 1-methyl, 3-t-butylpyrazol-5-yl & 3,4-difluorophenyl & 0,57 & 1,52 & 0,71 & $>20,0$ \\
\hline 40 & (S)-3-fluoropyrrolidin-1-yl & 3,4-difluorophenyl & 2,53 & $>20,0$ & $>20,0$ & $>20,0$ \\
\hline 41 & (S)-3-fluoropyrrolidin-1-yl & 3,4-difluorophenyl & $0,09^{a}$ & $0,15^{a}$ & 0,02 & 0,05 \\
\hline 42 & 1-methyl, 3-t-butylpyrazol-5-yl & 3,4-difluorophenyl & $0,17^{a}$ & $0,64^{a}$ & $6,99^{a}$ & $>20,0$ \\
\hline 43 & (S)-3-fluoropyrrolidin-1-yl & 3,4-difluorophenyl & 9,94 & $>20,0$ & $>20,0$ & $>20,0$ \\
\hline \multicolumn{7}{|c|}{$\begin{array}{l}\text { Legenda: Comp. }=\text { Compostos. }{ }^{*} \text { Os valores são as médias de triplicatas. Benznidazol foi usado como composto de referência: } \mathrm{EC}_{50} \text { para o } T \text {. } \\
\text { cruzi de } 0.69 \pm 0.09 \mu \mathrm{M}(\mathrm{n}=5) \text {. }{ }^{* *} \text { Os valores são as medias de triplicatas. Pentamidina foi usada como composto de referência: } \mathrm{EC}_{50} \text { para } T \text {. } \\
\text { brucei de } 0.00216 \pm 0.0003 \mu \mathrm{M}(\mathrm{n}=6) .{ }^{\mathrm{a}} \mathrm{M} \text { Média de dois ensaios. }{ }^{b} \text { Linfoblastos Humano }(\mathrm{CRL}-8155) .{ }^{c} \text { Quinacrina foi usada como composto } \\
\text { de referência: } \mathrm{EC}_{50} \text { para CRL-8155 de } 4.23 \pm 0.97 \mu \mathrm{M}(\mathrm{n}=7) .{ }^{d} \text { Hepatócitos humano }(\mathrm{HepG} 2) .{ }^{e} \text { Quinacrina foi usada como composto de } \\
\text { referência: } \mathrm{EC}_{50} \text { para HepG2 de } 10.44 \pm 1.39 \mu \mathrm{M}(\mathrm{n}=7) \text {. }\end{array}$} \\
\hline
\end{tabular}

\subsubsection{Análises da relação estrutura-atividade baseado nos ensaios contra o $T$. cruzi}

A primeira análise do SAR concentrou-se em investigar o efeito da presença do átomo de flúor no anel aromático $\left(\mathrm{R}_{2}\right)$, conectado na porção 2 nos derivados de imidazopiridina 2132, para atividade tripanossomicidas contra o T.cruzi, destacados em azul e destacado em preto a atividade tripanossomicidas contra o T. brucei, para comparação (Figura 31). 
a)<smiles>[R]c1cn2ccc(NC(=O)N3CCCCC3)cc2n1</smiles>

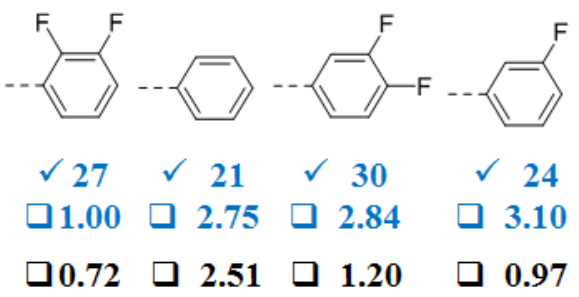

b)<smiles>[R]c1cn2ccc(NC(=O)N3CCCC3)cc2n1</smiles>

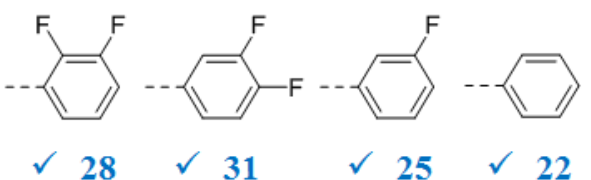

$\square 1.02 \square 2.24 \quad \square 2.95 \square 4.46$

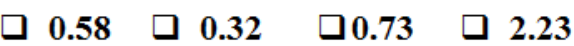

c)<smiles>[R]c1cn2ccc(NC(=O)N3CCC(F)C3)cc2n1</smiles>

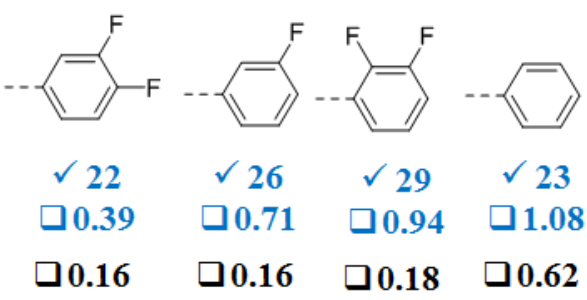

Figura 31. Atividade tripanossomicidas para os derivados de imidazopiridina 21-32, organizados por grupos de análogos: a) piperidil, b) pirrolidil e c) 3fluoropirrolidil. Destacado em azul e em preto os valores de $\mathrm{EC}_{50} \mathrm{em} \mu \mathrm{M}$ para $T$. cruzi e $T$. brucei, respectivamente

As variações presentes no anel aromático concentraram-se nas posições $3 \mathrm{com}$ um átomo de flúor ou nas posições 2,3 e 3,4 com dois átomos de flúor, em derivados de piperidil (a), pirrolidil (b) ou 3-fluoropirrolidil ureia (c), organizados na ordem decrescente (da esquerda para direita) de acordo com as atividades tripanossomicidas contra o T.cruzi (Figura 31).

A introdução do substituinte 2,3-difluorofenil (composto 7) aumentou a potência em menos de 3 vezes quando comparado com o substituinte fenil (composto 21) nos compostos derivados de piperidil ureia (parte a, Figura 31). No entanto, nenhuma alteração na potência foi notada com a introdução do átomo de flúor nas posições 3 e 3,4 (compostos 24 e $\mathbf{3 0}$, respectivamente).

Um padrão semelhante foi observado para os análogos derivados de pirrolidil ureia (parte b, Figura 31). O substituinte 2,3-difluorofenil melhorou a potência dos compostos estruturalmente relacionados a essa série de compostos (composto $\mathbf{1 8}$ versus compostos $\mathbf{2 2}$, 25 e 31$)$. 
Entretanto, a potência foi melhorada para os análogos de 3-fluoropirrolidil ureia (compostos 23, 26, 29 e 32) sequencialmente pela introdução do átomo de flúor no grupo fenil (composto 13) nas posições: 2,3 (composto 19), 3 (composto 16) e 3,4 (composto 32). O composto 32 derivado de 3-fluoropirrolidil ureia com o substituinte 3,4-difluorofenil exibiu um valor de $\mathrm{EC}_{50}$ contra o T. cruzi de $0,39 \mu \mathrm{M}$, o mais potente dessa série de compostos (2132). De fato, os compostos derivados de 3-fluoropirrolidil ureia foram mais potentes que os análogos correspondentes pirrolidil e piperidil em todos os casos.

Outras modificações foram feitas na porção $R_{2}$ e manteve-se a porção 3fluoropirrolidil ureia na molécula (parte c, Figura 32). As substituições do grupo 3,4difluorofenil (composto 32) pelos grupos tiazol (composto 33) e tiofenil (composto 34) resultaram em perda de atividade biológica de 51 vezes e 7 vezes, respectivamente.

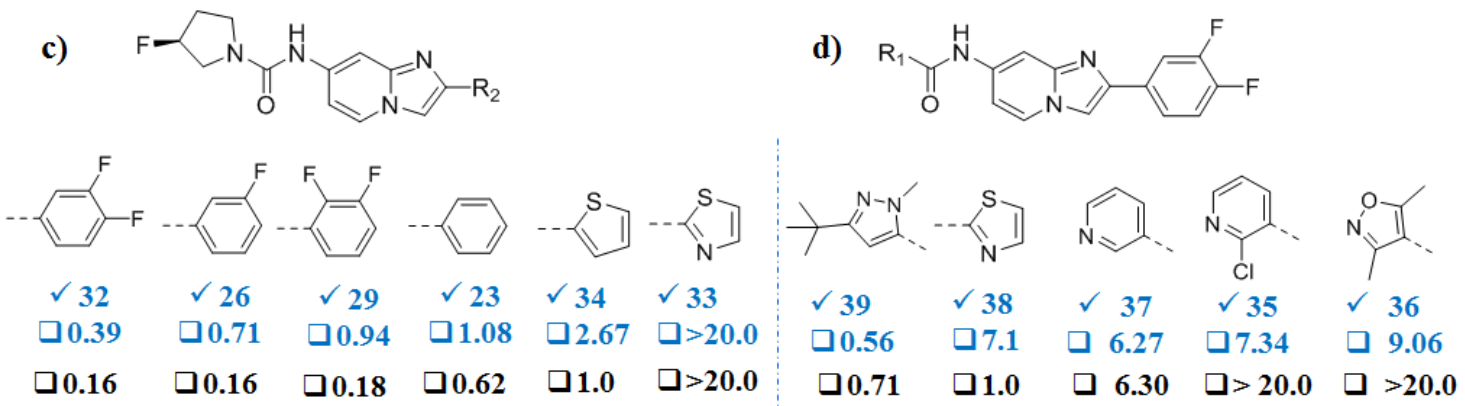

Figura 32. Atividades tripanossomicidas para os derivados de imidazopiridina, organizados por grupos de modificações na porção a) $R_{2}$ e b) $R_{1}$. Destacado em azul e em preto os valores de $\mathrm{EC}_{50}$ em $\mu \mathrm{M}$ para $T$. cruzi e $T$. brucei, respectivamente

A presença do substituinte 3,4-difluorofenil no anel fundido imazopiridina em conjunto com a porção 3-fluoropirrolidil ureia conduziu a melhorias na atividade biológica (composto 32). As modificações realizadas na porção $R_{1}$ (parte d, Figura 32) com os substituintes derivados de amida cloropiridinil (composto 35), dimetiloxazolil (composto 36), piridinil (composto 37) e tiazol (composto 38), consideravelmente diminuiu a potência em 19 vezes, 23 vezes, 16 vezes e 18 vezes, respectivamente. Somente o derivado de amida PyrA (composto 39) obteve potência semelhante ao composto 32. Notou-se também que o grupo tiazol potencializou a atividade biológica na porção $\mathrm{R}_{1}$ (composto 33 versus composto $\mathbf{3 8}$ ).

Mesmo após todas as variações propostas nas porções $R_{1}$ e $R_{2}$ no anel de imidazopiridina, os grupos 3-fluoropirrolidinil, PyrA e 3,4-difluorofenil foram as melhores modificações. Então, esses grupos foram selecionados para compor os novos esqueletos. A Figura 33 mostra a relação estrutura-atividade estabelecida para esse par de compostos e para outros análogos. 


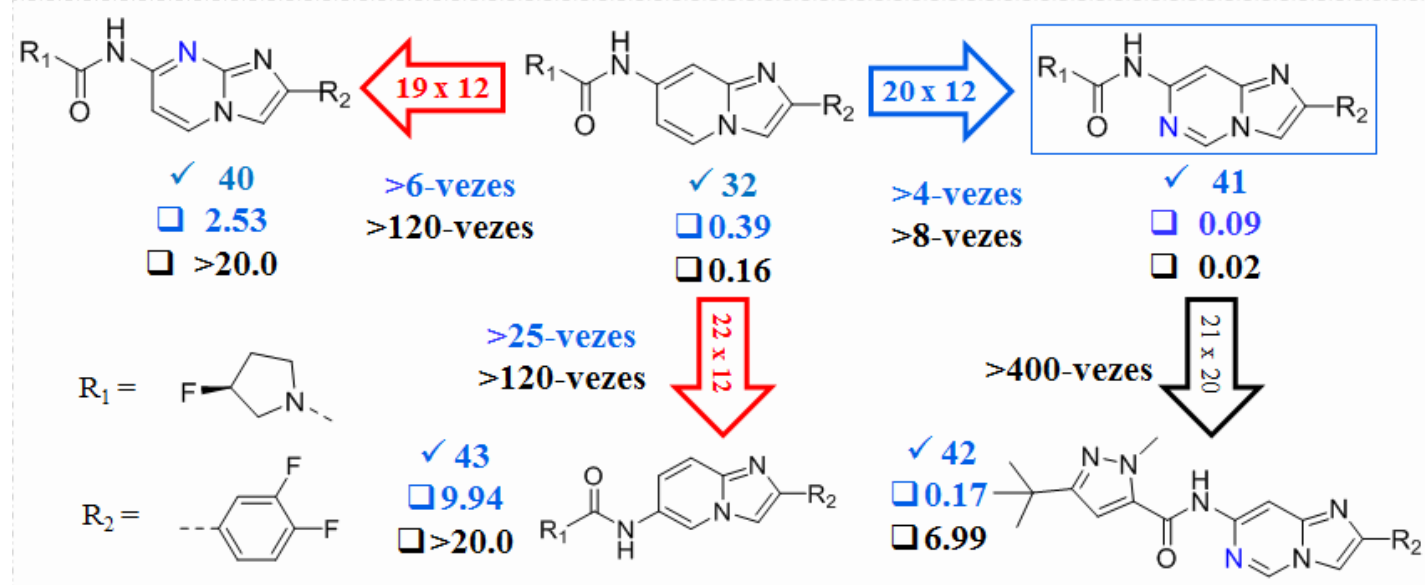

Figura 33. Relação estrutura-atividade estabelecida para os análogos 32, 40-43

Um átomo de nitrogênio básico inserido na posição 8 no anel de imidazopiridina (composto 40) diminuiu em 6 vezes a potência comparado com o composto 32. Em contrapartida, a potência do composto 41 aumentou mais que 4 vezes, com um átomo de nitrogênio inserido na posição 6 no anel de imidazopiridina. Um padrão similar de relação estrutura-atividade foi observado para os derivados de amida contendo a porção PyrA. A inserção do nitrogênio na posição 6 no anel imidazopiridina resultou em acréscimo de 5 vezes da atividade biológica (composto 39 versus composto $\mathbf{4 2}$ ).

A substituição da porção 3-fluoropirrolidil ureia (composto 41) pela porção PyrA amida (composto 42) obteve potência similar, o que está de acordo com o a relação estruturaatividade estabelecida para o par de análogos 32 e 39.

A influência da inserção e da posição do átomo de nitrogênio no sistema imidazopiridina foi notória. O composto $\mathbf{4 1}$ foi mais ativo que o composto $\mathbf{4 0}$ (28 vezes) e também foi o análogo mais potente dessa série de compostos.

Em última análise, a porção 3-fluoropirrolidil ureia conectada na posição 7 mostrou-se essencial para a atividade biológica. O composto 43 é um regioisômero do composto 32, no qual a porção ureia foi conectada na posição 6 ao invés da posição 7. A realocação da função ureia resultou em perda de atividade biológica. Composto 43 foi 25 vezes menos ativo.

\subsubsection{Comparação da relação estrutura-atividade entre T. cruzi e T. brucei}

$\mathrm{Na}$ série de análogos de imidazopiridina existem similaridades e diferenças observadas na comparação entre a atividade biológica para os parasitas $T$. cruzi e $T$. brucei. Na relação estrutura-atividade para o T. brucei, o efeito da fluoração no anel aromático conectado na 
porção $\mathrm{R}_{2}$ no sistema imidazopiridina (compostos 21-32), resultou em incrementos positivos de potência muito maiores que para o T. cruzi. Por exemplo, o composto 31 contendo a porção 3-fluoropirrolidil ureia e o grupo 3,4-difluorofenil exibiu um valor de $\mathrm{EC}_{50}$ de 0,32 $\mu \mathrm{M}$ contra o T. brucei, sete vezes mais potente que para o T. cruzi.

De fato, o efeito da fluoração ocasionou em relações estrutura-atividades ligeiramente diferentes entre os parasitas para os análogos de piperidil ureia (composto 21 versus compostos 24, 27 e 30). Enquanto a potência contra T. brucei sequencialmente diminui com a introdução do átomo de flúor para os análogos de piperidil ureia nessa ordem de posições: 2,3-, > 3-, > 3,4, > fenil; a potência contra o T. cruzi para os mesmos análogos sequencialmente diminui nessa ordem de posições: $2,3->$, fenil >, 3,4 >, 3-.

Para os análogos de pirrolidil ureia (composto 22 versus compostos 25, 28 e 31 ) o efeito da fluoração foi mais efetivo em ambos os parasitas. Melhorias incrementais na potência foram alcançadas com a introdução de um átomo de flúor (composto 25) ou dupla fluoração (compostos 28 e 31). O composto 22, contendo o grupo fenil como substituinte, foi o análogo menos potente da série de pirrolidil ureias.

Surpreendentemente, a potência para os análogos de 3-fluoropirrolidil ureia não se modificou após a introdução do átomo de flúor na posição 3- (composto $26, \mathrm{EC}_{50}=0,16 \mu \mathrm{M}$ ) ou dupla fluoração nas posições 2,3- (composto 29, $\mathrm{EC}_{50}=0,18 \mu \mathrm{M}$ ) e 3,4- (composto 32, $\left.\mathrm{EC}_{50}=0,16 \mu \mathrm{M}\right)$ no grupo fenil conectado na porção $\mathrm{R}_{2}$ no sistema imidazopiridina.

A modificação da função ureia para a função amida substancialmente diminuiu a potência ou resultou em inatividade contra o T. brucei (composto 32 versus compostos 35-38 e composto 41 versus composto 42), exceto para os pares de compostos 32 versus 39 (diminuição da potência em apenas 5 vezes).

A porção 3-fluoropirrolidil ureia demonstrou-se a mais promissora substituição para alcançar incrementos da potência contra o T. brucei. Contudo, o mesmo padrão não se aplicou para as análises de SAR em $T$. cruzi. $\mathrm{O}$ composto $42\left(\mathrm{R}_{1}=\operatorname{PyrA}\right.$ e $\mathrm{R}_{2}=3,4$-difluorofenil $)$ exibiu um valor de $\mathrm{EC}_{50}$ contra o $T$. cruzi de $0,17 \mu \mathrm{M}$; 40 vezes mais potente que o valor de $\mathrm{EC}_{50}$ contra o $T$. brucei de $6,99 \mu \mathrm{M}$.

A inserção do átomo de nitrogênio nas posições 8- e 6-, no anel de imidazopiridina derivados de ureia, resultaram no composto inativo $\mathbf{4 0}$ e o composto mais ativo $\mathbf{4 1}$, respectivamente. $\mathrm{O}$ nitrogênio na posição 6 aumentou a potência 1000 vezes. Portanto, o composto $41\left(\mathrm{EC}_{50}=93 \mathrm{nM}\right.$ contra o $T$. cruzi e $\mathrm{EC}_{50}=18 \mathrm{nM}$ contra o $T$. brucei $)$ é o mais ativo contra ambos os parasitas. 


\subsection{Avaliação da toxicidade e da seletividade dos novos derivados de imidazopiridina}

A avaliação da toxicidade foi realizada para a série de compostos derivados de imidazopiridina contra Linfoblastos humano (CRL-8155) e Hepatócitos humano (HepG2) e comparada com a potência dos compostos contra os parasitas. A Tabela 12 apresenta os resultados obtidos.

Tabela 12. Avaliação da toxicidade e seletividade para a série de compostos derivados de imidazopiridina

\begin{tabular}{|c|c|c|c|c|c|c|c|c|}
\hline \multirow[b]{2}{*}{ Comp. } & \multirow{2}{*}{$\begin{array}{c}\text { T. cruzi } \\
\mathrm{EC}_{50} \\
(\mu \mathrm{M})^{*}\end{array}$} & \multirow{2}{*}{$\begin{array}{c}\text { T. brucei } \\
\text { EC }_{50} \\
(\mu \mathrm{M})^{* *}\end{array}$} & \multicolumn{3}{|c|}{ CLR-8155 ${ }^{b, c}$} & \multicolumn{3}{|c|}{ Hep G2 $2^{d, e}$} \\
\hline & & & $\begin{array}{l}\mathbf{E C}_{50} \\
(\mu \mathbf{M})\end{array}$ & $\begin{array}{c}\mathrm{SI}^{f} \\
\text { T.cruzi }\end{array}$ & $\begin{array}{c}\mathrm{SF}^{f} \\
\text { T.brucei }\end{array}$ & $\begin{array}{l}\mathbf{E C}_{50} \\
(\boldsymbol{\mu M})\end{array}$ & $\begin{array}{c}\text { SI }^{f} \\
\text { T.cruzi }\end{array}$ & $\begin{array}{c}\mathrm{SI}^{f} \\
\text { T.brucei }\end{array}$ \\
\hline 21 & 2,75 & 2,51 & $>50,0$ & $>18$ & $>20$ & $>50,0$ & $>18$ & $>20$ \\
\hline 22 & 4,46 & 2,23 & 35,96 & 8 & 16 & $>50,0$ & $>11$ & $>22$ \\
\hline 33 & 1,08 & 0,62 & 44,59 & 41 & 72 & $>50,0$ & $>46$ & $>81$ \\
\hline 24 & 3,10 & 0,97 & $>50,0$ & $>16$ & $>52$ & $>50,0$ & $>16$ & $>52$ \\
\hline 25 & 2,95 & 0,73 & $>50,0$ & $>17$ & $>69$ & $>50,0$ & $>17$ & $>69$ \\
\hline 26 & 0,71 & 0,16 & 29,74 & 42 & 186 & $>50,0$ & $>70$ & $>313$ \\
\hline 27 & 1,00 & 0,72 & $>50,0$ & $>50$ & $>69$ & $>50,0$ & $>50$ & $>69$ \\
\hline 28 & 1,02 & 0,58 & $>50,0$ & $>49$ & $>86$ & $>50,0$ & $>49$ & $>86$ \\
\hline 29 & 0,94 & 0,18 & $>50,0$ & $>53$ & $>278$ & $>50,0$ & $>53$ & $>278$ \\
\hline 30 & 2,84 & 1,20 & 47,42 & 17 & 40 & $>50,0$ & $>18$ & $>42$ \\
\hline 31 & 2,24 & 0,32 & $>50,0$ & $>22$ & $>156$ & $>50,0$ & $>22$ & $>156$ \\
\hline 32 & 0,39 & 0,16 & 35,33 & 91 & 221 & $>50,0$ & $>128$ & $>313$ \\
\hline 33 & $>20,0$ & $>20,0$ & $>50,0$ & $>3$ & $>3$ & $>50,0$ & $>3$ & $>3$ \\
\hline 34 & 2,68 & 1,00 & $>50,0$ & $>19$ & $>50$ & $>50,0$ & $>19$ & $>50$ \\
\hline 35 & 7,34 & $>20,0$ & $>50,0$ & $>7$ & $>3$ & $>50,0$ & $>7$ & $>3$ \\
\hline 36 & 9,06 & $>20,0$ & $>50,0$ & $>6$ & $>3$ & $>50,0$ & $>6$ & $>3$ \\
\hline 37 & 6,27 & 6,30 & $>50,0$ & $>8$ & $>8$ & $>50,0$ & $>8$ & $>8$ \\
\hline 39 & 0,57 & 0,71 & $>50,0$ & $>88$ & $>70$ & $>50,0$ & $>88$ & $>70$ \\
\hline 40 & 2,53 & $>20,0$ & $>50,0$ & $>20$ & $>3$ & $>50,0$ & $>20$ & $>3$ \\
\hline 41 & $0,09^{a}$ & 0,02 & $>50,0$ & $>556$ & $>2500$ & $>50,0$ & $>556$ & $>2500$ \\
\hline 42 & $0,17^{a}$ & $6,99^{a}$ & 14,50 & $>85$ & $>2$ & $>50,0$ & $>290$ & $>7$ \\
\hline 43 & 9,94 & $>20,0$ & $>50,0$ & $>5$ & $>3$ & $>50,0$ & $>5$ & $>3$ \\
\hline \multicolumn{9}{|c|}{ 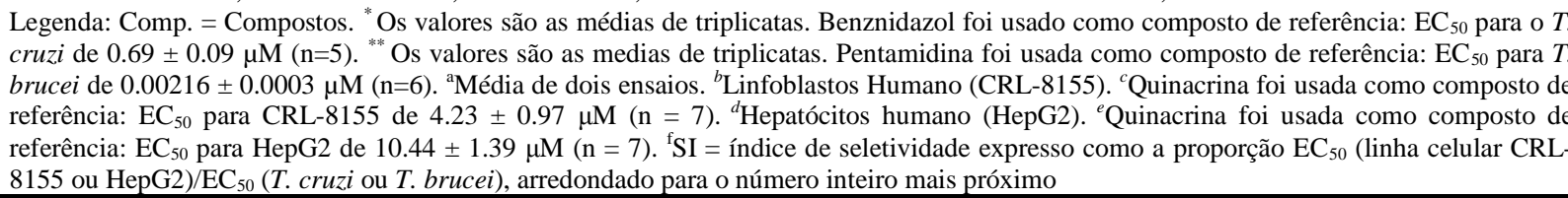 } \\
\hline
\end{tabular}

Os compostos 22, 23, 26, 32 e 42 exibiram toxicidade para linha celular CRL-8155 abaixo da concentração testada de $50 \mu \mathrm{M}$ (um intervalo de $\mathrm{EC}_{50}$ de 14,50 até 47,42 $\mu \mathrm{M}$ ). Um dos compostos mais ativos contra o $T$. cruzi apresentou a concentração mais elevada de toxicidade para essa série congenérica de imidazopiridina (composto 42, $\mathrm{EC}_{50}$ de 14,50). Nenhum composto exibiu toxicidade para linha celular HepG2.

O índice de seletividade (SI, do inglês "selectivity index") de cada composto frente aos parasitas T. cruzi e T. brucei em relação às duas linhas celulares (CRL-8155 e HepG2) foram calculados (Tabela 12). 
Os compostos 33, 35, 36, 37 e 43 exibiram baixos valores de SI para ambos os parasitas nas duas linhas celulares em estudo, variando de $>3$ até $>8$.

O composto 41 (mais ativo) exibiu um valor de $\mathrm{SI}>500$ para o T. cruzi e $>2500$ para o T. brucei contra ambas as linhas celulares; enquanto que o composto $\mathbf{4 2}$ exibiu um valor de SI $>80$ e 290 para T. cruzi, quando comparado com CRL-8155 e HepG2, respectivamente; e baixa seletividade para $T$. brucei contra ambas as linhas celulares.

Os compostos restantes obtiveram moderada seletividade contra as linhas celulares. Esses valorem podem ser conferidos na Tabela 12.

\subsection{Avaliação da estabilidade metabólica, solubilidade e ligação proteica para os compostos selecionados}

Os compostos selecionados 26, 29, 32, 40, 41 e 42 foram submetidos a avaliações da estabilidade metabólica, solubilidade e taxas de ligação proteica. A Tabela 13 apresenta os resultados obtidos.

Tabela 13. Estabilidade metabólica, solubilidade e ligação proteica para os compostos selecionados<smiles>O=C(Nc1ccn2cc(-c3cccc(F)c3)nc2c1)N1CCC(F)C1</smiles><smiles>O=C(Nc1ccn2cc(-c3ccc(F)c(F)c3)nc2n1)N1CCC(F)C1</smiles>

29

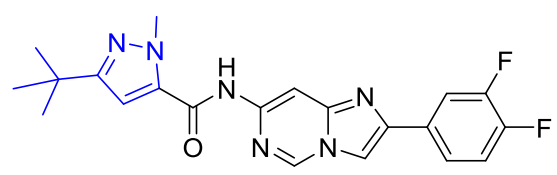

40

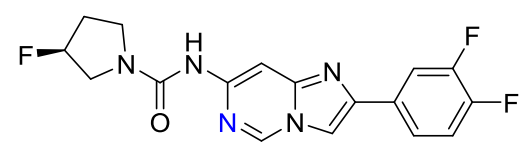

42

41

\begin{tabular}{|c|c|c|c|c|c|c|c|c|}
\hline \multirow[b]{2}{*}{ Comp. } & \multirow{2}{*}{$\begin{array}{c}T . \text { cruzi } \\
\mathrm{EC}_{50}(\mu \mathrm{M})\end{array}$} & \multirow{2}{*}{$\begin{array}{c}\text { T. brucei } \\
\mathrm{EC}_{50}(\mu \mathrm{M})\end{array}$} & \multirow{2}{*}{$\frac{\text { Estabilidade }^{*}}{t_{1 / 2}(\min )}$} & \multicolumn{3}{|c|}{ Solubilidade $(\boldsymbol{\mu M})$} & \multicolumn{2}{|c|}{ Ligação proteica** } \\
\hline & & & & pH 7,4 & pH 6,5 & pH 2,0 & Rec. $(\%)$ & FU (\%) \\
\hline 26 & 0,71 & 0,16 & $>60(84,5 \%)$ & 49,7 & 43,8 & 52,0 & $68,5 \pm 9,4$ & $3,0 \pm 0,3$ \\
\hline 29 & 0,94 & 0,18 & $>60(86,3 \%)$ & 6,4 & 6,8 & 53,1 & $68,4 \pm 8,5$ & $2,6 \pm 0,2$ \\
\hline 32 & 0,39 & 0,16 & $>60(100 \%)$ & 32,8 & 49,9 & 45,9 & $64,5 \pm 8,1$ & $4,0 \pm 0,7$ \\
\hline 40 & 2,53 & $>20,0$ & - & 41,5 & 42,0 & 47,5 & $49,0 \pm 1,7$ & $8,1 \pm 0,4$ \\
\hline 41 & 0,09 & 0,02 & $>60(96,0 \%)$ & $2,1^{a}$ & $2,4^{a}$ & $1,6^{a}$ & $56,1 \pm 4,8$ & $9,9 \pm 0,9$ \\
\hline 42 & 0,17 & 6,99 & $60(47,1 \%)$ & 2,7 & 7,6 & 1,3 & $73,3 \pm 11,2$ & $0,7 \pm 0,1$ \\
\hline
\end{tabular}

Legenda: Comp. $=$ Compostos; $\min =$ minutos; Rec. $=$ recuperados; $\mathrm{FU}=$ fração não ligada. $*$ Os valores são medias de duplicatas. Controles para microssomas de ratos estão incluídos em cada ensaio mostrado como média $\pm \mathrm{SEM}$ : Testosterona $\mathrm{t}_{1 / 2}: 5,68 \pm 0,81$ minutos $(\mathrm{n}=4)$ e Dextrometorfano $\mathrm{t}_{1 / 2}: 11,11 \pm 0,67$ minutos $(\mathrm{n}=4)$.**Propranolol como controle foi incluído em todos os experimentos de ligação proteica com\% de recuperação e \% de média de FU \pm SEM: 75,74 $\pm 3,76 \%$ (n=12) e \%FU 11,43 $\pm 1,88 \%(n=12){ }^{\text {a }}$ : duplicata 
Os tempos de meia-vida para os compostos 26, 29, 32 e $\mathbf{4 1}$ foram maiores que 60 minutos, com uma variação de $84-100 \%$ dos compostos testados que permaneceu estável no tempo de 60 minutos. Para o composto 42 foi encontrado uma fração de $47 \%$ restante, no tempo de 60 minutos.

A introdução de um átomo de flúor aromático adicional (composto 26 versus compostos 29 ou 32) ou a inserção de um átomo de nitrogênio na posição 6 no anel fundido (composto 26 versus composto 41) não ofereceram alterações na estabilidade metabólica (Tabela 13, modificações destacas em azul). No geral, todos os compostos avaliados demostraram excelente estabilidade metabólica, quando incubados com microssomas do fígado de rato. Ainda, o composto $\mathbf{4 1}$ foi adicionalmente incubado em microssomas de bovino e humano; os mesmos resultados foram obtidos: $\mathrm{t}_{1 / 2}>60$ minutos.

A solubilidade é uma propriedade importante para a formulação de dosagem de fármacos in vivo, e também para avaliar a biodisponibilidade. ${ }^{113}$ Para tanto, testaram-se a solubilidade dos compostos selecionados em três diferentes valores de $\mathrm{pH}(7,4,6,5$ e 2,0), correspondentes ao $\mathrm{pH}$ do sangue, intestino e estômago, respectivamente. Os compostos 26, 29 e 32 exibiram maior solubilidade que os análogos 41 e 42 (Tabela 13).

O composto 41 teve um átomo de nitrogênio embutido na posição 6 do anel de imidazopiridina, essa modificação resultou na diminuição da solubilidade nas condições de pH testadas (composto 26 versus composto 41, modificação destaca em azul Tabela 13). Todavia, a adição do átomo de nitrogênio na posição 8 (composto 40) aumentou a solubilidade; porém causou significativa redução da potência comparada com o composto 41.

Com o objetivo de coletar mais informações para auxiliar na identificação de propriedades de ADME (absorção, distribuição, metabolismo e excreção) e direcionar a seleção de compostos para ensaios in vivo, avaliou-se a capacidade dos compostos selecionados de executar ligação a proteínas plasmáticas.

Os compostos 26, 29 e 32 apresentaram porcentagem de fração não ligada em 100\% de plasma de rato de $3,0 \%, 2,6 \%$ e 4,0\%, respectivamente. O composto 21 exibiu a mais baixa fração não ligada $(\mathrm{FU}=0,7 \%)$.

A melhor fração não ligada foi obtida para o composto 41 (FU =9,9\%), o mais ativo dessa série. Esse resultado provavelmente conduz a aumento de eficácia do composto $\mathbf{4 1}$ em estudos in vivo e o elege, como o composto mais promissor, para o tratamento de infecções com os parasitos T. cruzi e T. brucei. 


\subsection{Avaliação da capacidade dos compostos 32 e 41 em atravessar a barreira hematocenfálica (BHE)}

Estudos foram realizados para avaliação da capacidade dos compostos 32 e 41 em atravessar a BHE; com o objetivo de verificar se esses compostos poderiam ser empregados no tratamento da infecção com $T$. brucei, mais especificamente o segundo estágio da doença do sono (HAT, do inglês Human African Trypanosomiasis ou sleeping sickness). ${ }^{20}$

Para tanto, empregou-se dose única de $5 \mathrm{mg} / \mathrm{kg}$ ip de cada composto testado em grupos contendo três ratos cada. Após uma hora os ratos foram sacrificados e foram coletados os cérebros e plasmas para as análises.

O composto 32 exibiu uma concentração média no cérebro de $0,55 \mu \mathrm{M}$ e uma concentração média no plasma de 4,84 $\mu \mathrm{M}$. O composto 41 exibiu uma concentração média no cérebro de $1,12 \mu \mathrm{M}$ e uma concentração média no plasma de 1,31 $\mu \mathrm{M}$. Obteve-se então, uma taxa de concentração cérebro/plasma de $0,114 \mu \mathrm{M}$ para o composto 32 e $0,856 \mu \mathrm{M}$ para o composto 41, um incremento de 7,5 vezes. Isso ocorreu devido à única diferença na estrutura química dos compostos estudados: a troca do átomo de carbono pelo átomo de nitrogênio no anel de imidazopiridina na posição 6 .

\subsection{Estudos de Farmacocinética}

Com todos os resultados obtidos, submeteu-se o composto 41 aos estudos de farmacocinética para qualificar o composto para experimentos de eficácia in vivo. O composto 41 foi oralmente administrado $(50 \mathrm{mg} / \mathrm{kg})$ em três ratos. No período de 24 horas amostras de sangue foram coletadas e analisadas. O composto 41 apresentou $\mathrm{C}_{\mathrm{MAX}}$ de $5,7 \pm 0,9 \mu \mathrm{M}$ (média $\pm \mathrm{SEM}$ ), e um valor de AUC de $3585 \pm 670 \min \mu \mathrm{M}$.

\subsection{Estudos de eficácia in vivo}

Baseado nos resultados promissores de bioatividade in vitro, toxicidade, estabilidade metabólica, ligação proteica e propriedades farmacocinéticas, selecionou-se o composto 41 para os estudos de eficácia in vivo. O modelo agudo da infecção com T. cruzi (cepa Tulahuen, DTU VI) foi empregado para investigar a capacidade do composto em suprimir a infecção com esse parasito.

O composto 41 foi oralmente administrado duas vezes ao dia $(50 \mathrm{mg} / \mathrm{kg})$ durante 5 dias (dias 7 ao 11 após a infecção). Nesta etapa, não se espera provar a cura da parasitemia da 
fase aguda, pelo relativo curto tempo de tratamento, (conforme observado com o grupo controle benzonidazol), ${ }^{114}$ mas avaliar a supressão da infecção.

Os ratos foram infectados subcutaneamente (SC) no dia "0" com $2 \times 10^{4}$ de tripomastigotas que expressam um gene de luciferase, deslocado para a cor vermelha. ${ }^{115}$ Os parasitos foram fotografados usando um espectro IVIS (do inglês, "In Vivo Imaging System") em diferentes períodos durante 6 semanas (totalizando 42 dias).

O substrato D-luciferina sal de potássio foi injetado SC nos ratos, em seguida foram obtidas as imagens entre 10 a 15 minutos após a injeção. As imagens foram tiradas nas posições ventral e dorsal para cada conjunto de ratos. As configurações de exposição automática foram usadas com um tempo máximo de exposição definido para 5 minutos. $\mathrm{O}$ sinal dessas imagens foi combinado e padronizado, convertendo as leituras para radiação (photons $/ \mathrm{sec} / \mathrm{cm}^{2} / \mathrm{sr}$ ). A Figura 34 mostra os resultados de cada dia analisado para o composto 41 e o fármaco de referência benzonidazol

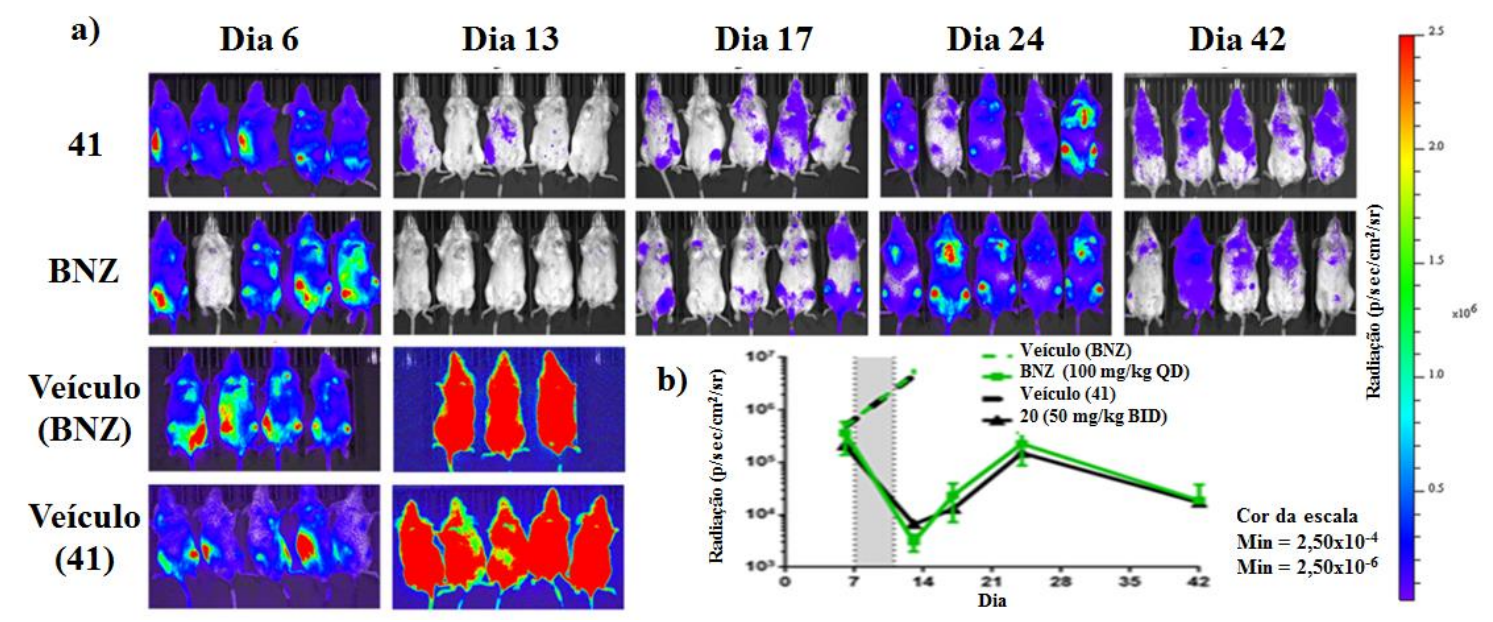

Figura 34. a) Imagens dos camundongos na posição ventral infectados com bioluminescência "PpyRE9h-expressing T.cruzi" antes e depois do tratamento com o composto 41, o controle benzonidazol (BNZ) e os veículos. A quantidade de $120 \mathrm{mg} / \mathrm{kg}$ de Dluciferin foi injetada nos ratos, em seguida anestesiados e fotografados usando o sistema IVIS. Os grupos de veículos tiveram que ser removidos do experimento no dia 13 devido à infecção avançada e um rato do grupo do veículo (BNZ) teve que ser removido no dia 9; b) Sinal de radiação dos grupos de tratamento (dorsal + ventral) ao longo do experimento. Janela de dosagem destacada em cinza. $\mathrm{O}$ sinal diminuído entre os dias 24 e 42 pode ser devido a um provável avanço da infecção na fase aguda para a fase crônica

O composto 41 conduziu a níveis de supressão da parasitemia assim como o fármaco benzonidazol, o que garante futuros estudos com uma duração de tratamento maior e contra um modelo crônico de infecção por T. cruzi. Nesse período de testes não foram observadas toxicidades para os ratos. 
Os níveis do composto 41 no plasma foram medidos no momento da $7^{a}$ dose. Especificamente, o sangue da cauda foi coletado imediatamente antes, 1h e 6h após a administração do composto. Nesse período de $1 \mathrm{~h}$ e $6 \mathrm{~h}$ após a dose, as concentrações encontradas foram de $9,0 \pm 1,4(\mathrm{n}=3) \mu \mathrm{M}$ e $5,8 \pm 1,9(\mathrm{n}=3) \mu \mathrm{M}$, respectivamente. A concentração de $4,8 \mu \mathrm{M}$ da pré-dose do composto 41 foi detectável em apenas 1 dos 3 ratos em estudo.

Os dados demonstram que, através de doses repetidas, o composto 41 atinge concentrações no sangue semelhantes às observadas no estudo de farmacocinética, realizado em dose única. Os valores de $\mathrm{C}_{\mathrm{MAX}}$ ligeiramente superiores após a administração repetida em ratos podem ser devidos, em parte, a mecanismos de depuração saturados.

\subsection{Conclusões do capítulo III}

Uma série contendo 23 novos derivados imidazopiridina possui atividade potente em culturas de parasitas (T. cruzi e T. brucei), baixa citotoxicidade e alta estabilidade metabólica. Dois dos anéis fundidos testados (imidazo[1,2-a]piridina e imidazo[1,2-c]pirimidina), despontam como promissores para o desenvolvimento de fármacos para o tratamento de infecções com tripomastigotas. O composto 41 exibiu excelente exposição ao plasma após administração oral em ratos. A atividade do composto $\mathbf{4 1}$ que leva à supressão substancial da infecção parasitária em camundongos requer desenvolvimento adicional como agentes tripanossomicidas. 
Capícula 4

\section{Sínteses de grupos} warheads em

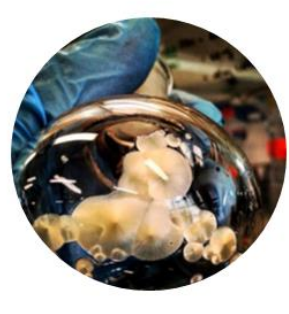

compostos do tipo

dipeptidil e de derivados de imidazopiridina 


\section{Capítulo IV}

\section{Sínteses de grupos warheads em compostos do tipo dipeptidil e de derivados de imidazopiridina}

\subsection{Introdução}

Em Química Medicinal busca-se, na maioria dos trabalhos desenvolvidos, utilizar rotas sintéticas previamente descritas na literatura, com modificações sutis para obter compostos bioativos de interesse. O foco nesta área do conhecimento, não se encontra em produzir novas metodologias sintéticas, mas aplicar de forma rápida e prática todo o conhecimento já disponível na literatura no problema de interesse.

Nesta estratégia, evitam-se altos investimentos, como reagentes caros, dispêndio de tempo e sínteses exploratórias desnecessárias; o que pode garantir um futuro sucesso comercial de um possível fármaco. Além disso, para atingir esse sucesso as propostas de síntese de compostos bioativos devem conter simplicidade estrutural - com possibilidade de modificações, visando à otimização de seu perfil farmacoterapêutico -, e ser membro de uma

série congênere para construção de um estudo de relação estrutura/atividade. ${ }^{116}$

Com o intuito de sintetizar as duas séries distintas de compostos (dipeptidil e imidazopiridina), buscas na literatura por rotas sintéticas foram executadas. Em seguida, modificaram-se as rotas obtidas, de acordo com a necessidade. Os compostos foram então sintetizados, purificados e caracterizados. A seguir, discutem-se as rotas sintéticas e a caracterização dos compostos.

\subsection{Metodologia}

O desenvolvimento desse capítulo do trabalho ocorreu no Laboratório do Grupo de Estudos em Química Medicinal (Nequimed), em parceria com o Laboratório de Síntese Orgânica Warner Bruce Kover (Laboratório do Professor Antônio Carlos Bender Burtoloso), no Instituto de Química (IQSC) da Universidade de São Paulo (USP). Os compostos do tipo dipeptidil foram sintetizados sob a supervisão dos Professores Carlos Alberto Montanari e Antônio Carlos Bender Burtoloso. Parte da orientação também foi realizada pelas pósdoutorandas Juliana Gomes e Daniela de Vita. Daniela também sintetizou os compostos 19 e 20. 
No intercâmbio realizado no laboratório Gelb na Universidade de Washington em Seattle-USA foi sintetizado os compostos do tipo imidazopiridina, sob a supervisão do Professor Michael H. Gelb.

\subsubsection{Rotas sintéticas para síntese dos compostos 1-20}

Para obter a série de compostos do tipo dipeptidil com diferentes grupos warheads, rotas sintéticas variadas foram extraídas da literatura e modificadas de acordo com o apresentado nos esquemas 5-7.

Na síntese dos compostos 1-7 e 11 utilizou-se o ácido A (Cbz-L-Phe-OH), resultado da reação de proteção do aminoácido L-Fenilalanina com o grupo benzil cloroformato $(\mathrm{Cbz})$. ${ }^{89}$ O Cbz-L-Phe-OH foi usado nas reações sem nenhuma purificação.

Na síntese dos compostos 8-10 utilizou-se o ácido B (Bz-L-Phe-OH), resultado da reação entre o cloreto de benzoíla e o aminoácido L-Fenilalanina. O Bz-L-Phe-OH foi usado nas reações sem nenhuma purificação.

A reação mais comum empregada nas sínteses dos compostos foi a de acoplamento mostrada no Esquema 5 (reação 1). Nestas reações, utilizaram-se o reagente de acoplamento EDC (N'-(3-dimetilaminopropil)-N-etilcarbodimida), HOBt (1-hidroxibenzotriazol), DIPEA (N,N-diisopropiletilamina) em DCM (Diclorometano), ${ }^{117}$ juntamente com o grupo warhead de interesse comercialmente disponível ou previamente sintetizado.

Os compostos dipeptidil-nitrilas $\mathbf{1}$ e $\mathbf{2}$, bem como o composto dipeptidil-oxazol 11, foram sintetizados por meio da reação de acoplamento descrita anteriormente e os respectivos reagentes comerciais 2-aminoacetonitrila, 1-aminociclopropano-1-carbonitrila e 2-Amino-4metiloxazol.

Os outros compostos tiveram o grupo warhead de interesse sintetizado previamente e depois acoplado ao ácido A ou B. Por exemplo, para a obtenção do composto 6, partiu-se da proteção do aminoácido glicina com Boc, ${ }^{118}$ seguido do acoplamento do grupo $\mathrm{N}, \mathrm{O}$ dimetilhidroxilamina, ${ }^{119}$ desproteção do aminoácido usando ácido trifluoroacético, para acoplar o 2-Amino- $N$-metoxi- $N$-metil-acetamida no ácido $\mathbf{A} .^{42,82}$

Para obtenção dos compostos dipeptidil-izoxazol 7-10, a porção 4-aminoisoxazol foi sintetizada a partir da nitração do isoxazol, ${ }^{120}$ seguida da redução do grupo nitro para o grupo amino, ${ }^{121}$ e então, acoplado ao ácido A para obtenção do composto $\mathbf{7}$ ou acoplado ao ácido $\mathbf{B}$ para obtenção dos compostos 8-10. 


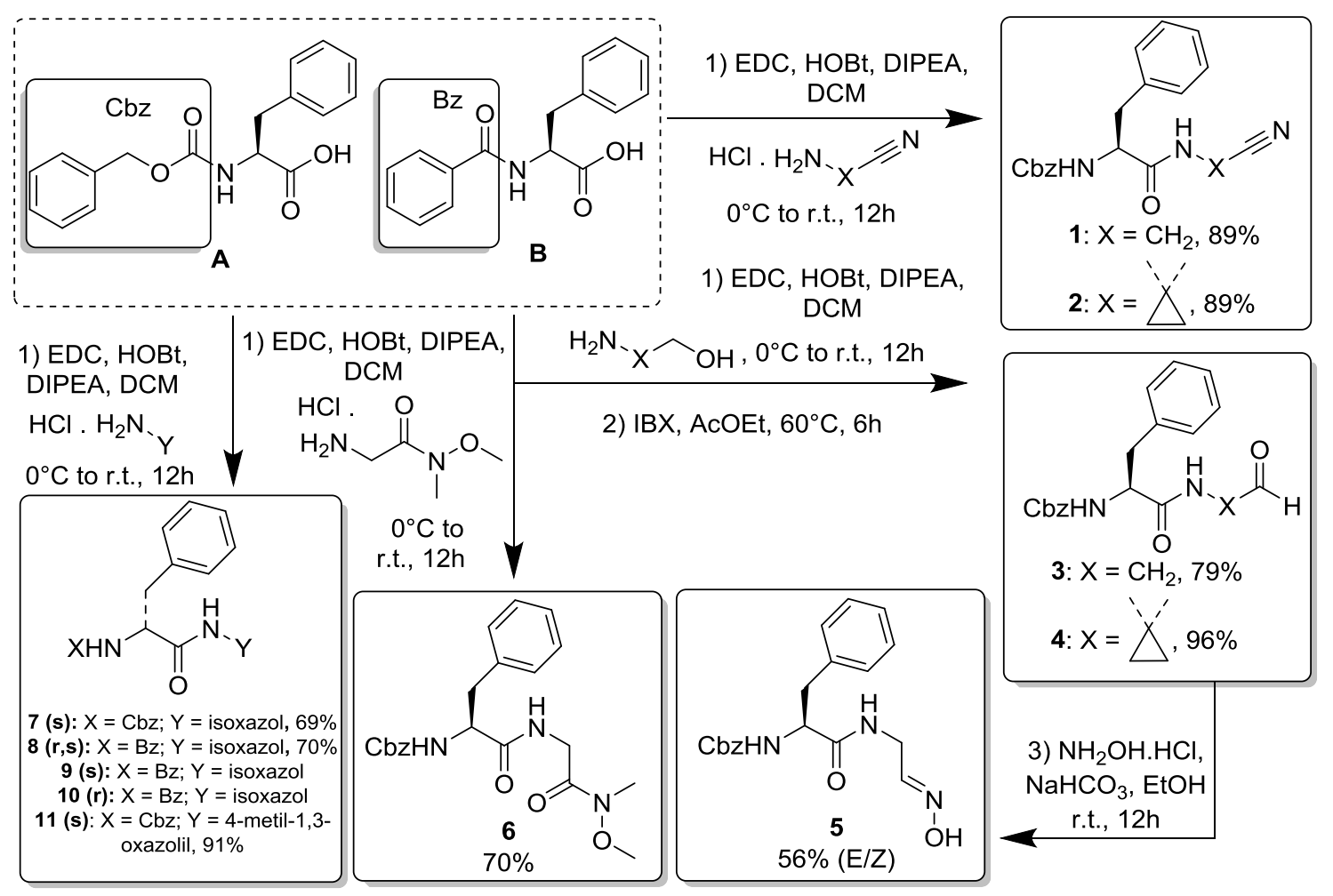

Esquema 5. Rotas sintéticas para obtenção dos compostos 1-11

Para obtenção dos compostos dipeptidil-aldeídos $\mathbf{3}$ e $\mathbf{4}$, três rotas foram testadas: redução da amida de Weinreb (composto 6) com $\mathrm{LiAlH}_{4}$ (Hidreto de Lítio e Alumínio); ${ }^{40 b, 119}$ oxidação do dipeptidil-álcool utilizando $\mathrm{SO}_{3}$.pyr (complexo de Enxofre Trióxido-Piridina) ${ }^{122}$ ou IBX (Ácido 2-Iodobenzoíco), ${ }^{123}$

A reação de redução com $\mathrm{LiAlH}_{4}$ resultou em um aldeído impuro e baixo rendimento. Tentativas de purificação do aldeído não foram bem sucedidas, pelo fato da função orgânica de interesse degradar facilmente na sílica gel.

$\mathrm{Na}$ busca por rotas que fornecessem produtos mais puros e melhores rendimentos, as reações de oxidação foram empregadas, usando $\mathrm{SO}_{3}$.pyr ou IBX. ${ }^{91,122-123}$ Ambas forneceram o produto desejado e melhores rendimentos. Contudo, a reação utilizando o IBX (reação 2 , Esquema 5), como agente oxidante, foi empregada neste trabalho com mais frequência, pois as condições reacionais são mais simples.

Uma vez obtido o dipeptidil-aldeído de interesse, mediante condensação, com catálise ácida utilizando hidroxilamina, obteve-se o dipeptidil-oxima de interesse (reação 3, Esquema 5) ou empregou-se reação de Horner-Wadsworth-Emmons (reação 4), ${ }^{124}$ utilizando os fosfonatos comercialmente disponíveis $(\mathbf{C})$ ou previamente sintetizados (D e E), ${ }^{125}$ para obter os compostos dipeptidil alfa-beta insaturados (Esquema 6). ${ }^{126}$ 


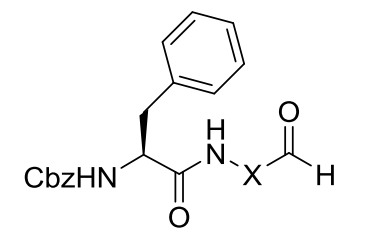

3: $\mathrm{X}=\mathrm{CH}_{2}$

4: $X=$<smiles>[R]C(=O)CP(=O)(OCC)OCC</smiles>

C: $\mathrm{R}=\mathrm{OCH}_{2} \mathrm{CH}_{3}$

D: $\mathrm{R}=\mathrm{N}\left(\mathrm{CH}_{2} \mathrm{CH}_{3}\right)_{2}$

E: $\mathrm{R}=\mathrm{NHCH}_{3}$

4) $\mathrm{NaH}$, THF, r.t., 4 h or $\mathrm{LiBr}, \mathrm{DBU}, \mathrm{THF}$, r.t., $4 \mathrm{~h}$

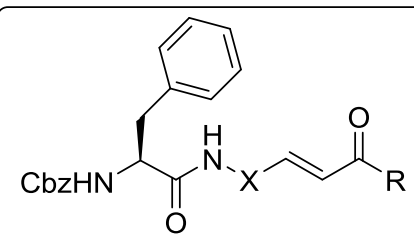

12: $\mathrm{X}=\mathrm{CH}_{2}, \mathrm{R}=\mathrm{OCH}_{2} \mathrm{CH}_{3}, 85 \%$ (E)

13: $X=\mathrm{CH}_{2}, \mathrm{R}=\mathrm{OCH}_{2} \mathrm{CH}_{3}, 6 \%(\mathrm{Z})$

14: $X={ }^{\prime} X^{\prime}, \mathrm{R}=\mathrm{OCH}_{2} \mathrm{CH}_{3}, 86 \%$ (E)

15: $X={ }^{\prime} X^{\prime}, \mathrm{R}=\mathrm{N}\left(\mathrm{CH}_{2} \mathrm{CH}_{3}\right)_{2}, 70 \%(\mathrm{E})$

16: $X={ }^{\prime}{ }^{\prime}, \mathrm{R}=\mathrm{NHCH}_{3}, 80 \%(\mathrm{E})$

Esquema 6. Rotas sintéticas para obtenção dos compostos 12-16

Para sintetizar os compostos dipeptidil-azanitrilas (17-20) utilizaram-se as rotas sintéticas apresentadas no Esquema 7.

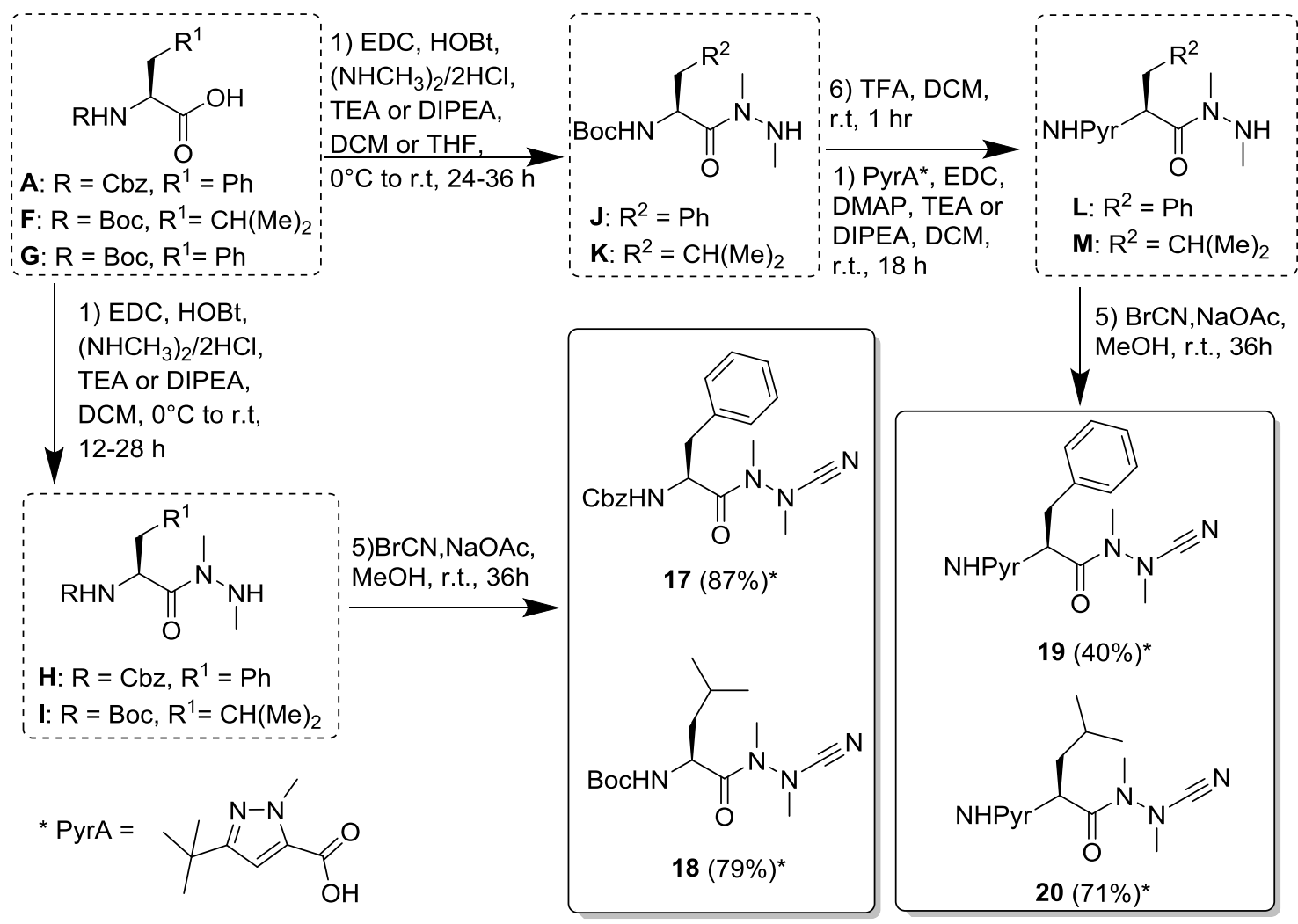

Esquema 7. Rotas sintéticas para obtenção dos compostos 17-20.

*Rendimentos da última etapa.

Para essa série de dipeptidil-azanitrilas introduziu-se variações nas porções P2 e P3 apresentadas no Esquema 7. Para tanto, protegeu-se o aminoácido de interesse com Boc ou Cbz (A, F e G), ${ }^{118}$ em seguida empregou-se a reação de acoplamento (reação 1), ${ }^{119}$ para 
introduzir a porção 1,2-Dimetilhidrazina (H-K). Então, por meio da reação com o brometo de cianogênio (reação 5), ${ }^{72 b}$ obteve-se a função orgânica cianoamina (compostos 17 e 18).

Etapas sintéticas adicionais foram empregadas para obtenção dos compostos 19 e 20. Partiu-se dos aminoácidos leucina (F) ou fenilalanina (G) protegido com Boc, ${ }^{118}$ seguido do acoplamento do grupo 1,2-Dimetilhidrazina (J e K), ${ }^{119}$ desproteção do aminoácido usando ácido trifluoroacético (reações 6 e 1), para acoplar o grupo PyrA no aminoácido protegido de interesse (L e M). ${ }^{42,82}$ Na última etapa (reação 5), obteve-se a função orgânica cianoamina por meio da reação com o brometo de cianogênio (compostos 19 e 20). ${ }^{72 b}$

\subsubsection{Rotas sintéticas para síntese dos compostos 21-43}

Os análogos de imidazopiridina 21-43 foram sintetizados utilizando 3 rotas sinteticas, sendo que o produto final foi obtido em duas etapas. Para os derivados de ureia utilizaram se as rotas 7 e 8 do Esquema 8 e para os derivados de amida 7 e 9 do Esquema 8.

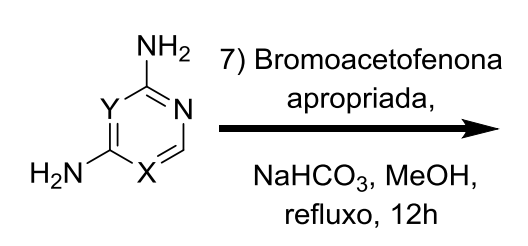

$\mathrm{Y}$ e $\mathrm{X}=\mathrm{CH}$

$\mathrm{Y}=\mathrm{N}, \mathrm{X}=\mathrm{CH}$

$\mathrm{Y}=\mathrm{CH}, \mathrm{X}=\mathrm{N}$

$$
\begin{aligned}
& \text { a; } R_{2}=P h, X, Y=C H \\
& \text { b; } R_{2}=3 \text {-fluorofenil, } X, Y=C H \\
& \text { c; } R_{2}=2,3 \text {-difluorofenill, } X, Y=C H \\
& \text { d; } R_{2}=3,4 \text {-difluorofenill, } X, Y=C H \\
& \text { e; } R_{2}=1,3 \text {-tiazol-2-il, } X, Y=C H \\
& \text { f; } R_{2}=\text { tiofen-2-il, } X, Y=C H \\
& \text { g; } R_{2}=3,4 \text {-difluorofenil, } X=C H, Y=N \\
& \text { h; } R_{2}=3,4 \text {-difluorofenil, } X=N, Y=C H
\end{aligned}
$$

8) Trifosgênio, $\mathrm{Et}_{3} \mathrm{~N}, \mathrm{DCM}, 0$<smiles>[R]C(=O)NC1=[Y]=C2N=C([R2])C=[Y]2=CN1</smiles>

9) Cloreto de acila apropriado, $\mathrm{Et}_{3} \mathrm{~N}, \mathrm{DCM}, 0{ }^{\circ} \mathrm{C}$ para $25^{\circ} \mathrm{C}, 16 \mathrm{~h}$

21-42 and $43^{*}$ $\mathrm{R}_{1}, \mathrm{R}_{2}=$ Veja na Tabela 10

Esquema 8. Rotas sintéticas para obtenção dos compostos derivados de imidazopiridina *O grupo ureia foi conectado na posição 7 , nomeada $\mathrm{X}$.

Na primeira etapa da síntese dos derivados de imidazopiridina (rota 7) empregaram-se diaminopiridina/pirimidina e bromoacetofenona apropriados em uma reação de condensação ${ }^{21}$ para obter o anel fundido de interesse (intermediários a-h, Esquema 8).

Os derivados de ureia foram preparados usando a rota $\mathbf{8}$, ao reagir o intermediário de imidazopiridina obtido com o trifosgênio, ${ }^{127}$ produzindo um intermediário isocianato. A adição da amina $2^{\mathrm{a}}$ apropriada levou ao produto de interesse.

Os derivados de amida foram preparados usando a rota 9, ao reagir o cloreto de carbonila apropriado com o intermediário de imidazopiridina obtido previamente. Então, o produto de interesse foi formado. 


\subsubsection{Caracterização espectroscópica dos compostos 1-20}

Todos os compostos foram caracterizados por Ressonância Magnética Nuclear (RMN) de ${ }^{1} \mathrm{H}$ e ${ }^{13} \mathrm{C}$ e massas de baixa ou alta resolução. Os deslocamentos químicos $(\delta)$ foram representados em ppm. Aqui se discute os sinais característicos dos espectros de ${ }^{1} \mathrm{H},{ }^{13} \mathrm{C}$ e massas (Espectros disponíveis em apêndice).

O ácido A possui o esqueleto básico comum à maioria dos compostos sintetizados. Desta forma, os sinais visualizados na análise de $\mathrm{RMN}$ de ${ }^{1} \mathrm{H}$, para este intermediário, permanecem padrão para os demais compostos, conforme ilustrado na Figura 35.

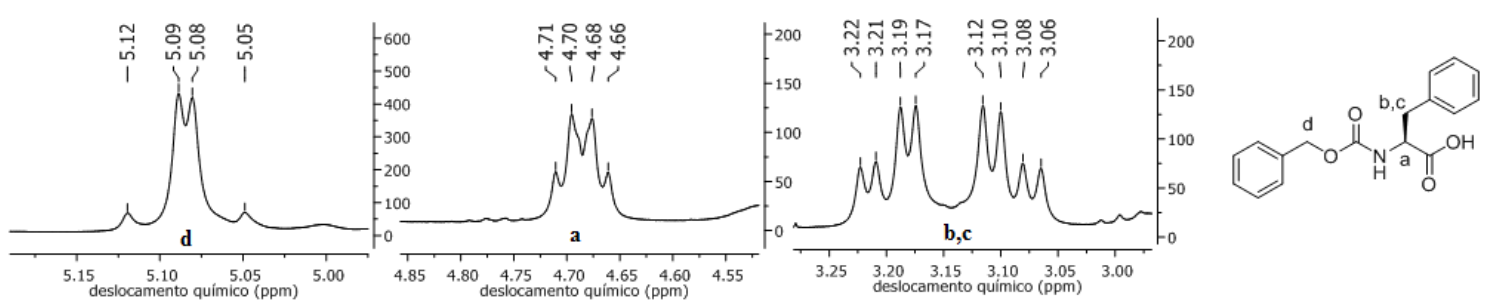

Figura 35. Os sinais resultantes dos acoplamentos mais importantes do espectro de RMN de ${ }^{1} \mathrm{H}$ para o ácido $\mathbf{A}$.

De acordo com o Figura 35, o hidrogênio a do centro estereogênico acopla com os dois hidrogênios diastereotópicos b e c adjacentes (duplo dubletos em 3,20 e 3,09 ppm), e também, com o hidrogênio da amida, resultando em multipleto, com deslocamento químico entre 4,71 e 4,66 ppm (próton a, na Figura 35). Outro sinal importante corresponde aos hidrogênios diastereotópicos da porção benzil carbamato (dois dubletos entre 5,12 e 5,05 ppm, próton d na Figura 35).

Para o composto 1, observou-se no espectro de RMN de ${ }^{1} \mathrm{H}$ um dubleto em 4,14 ppm, referente aos hidrogênios do metileno adjacente a nitrila, que acopla com o hidrogênio da amida (tripleto em 8,77 ppm), por meio de uma constante de acoplamento $\left({ }^{3} J\right)$ de 5,6 $\mathrm{Hz}$ (Hertz). Para o composto 2, que possui um grupo ciclopropil na porção P1, observam-se no espectro de RMN de ${ }^{1} \mathrm{H}$, os sinais correspondentes a essa porção em 0,96 e 1,39 ppm, bem como, o singleto da amida em 6,90 ppm. A Figura 36 apresenta os sinais característicos de hidrogênio e carbono.

A presença do warhead nitrila nos compostos 1 e 2 pode ser notada no espectro de RMN de ${ }^{13} \mathrm{C}$, o sinal do carbono $s p$ dessa função orgânica revela a formação do produto (115,72 ppm para o composto 1 e 119,57 ppm para o composto 2, Figura 36). 
No espectro de massas de alta resolução foram encontrados os sinais em 338,14 e 364,16 referentes aos compostos 1 e 2 , respectivamente.

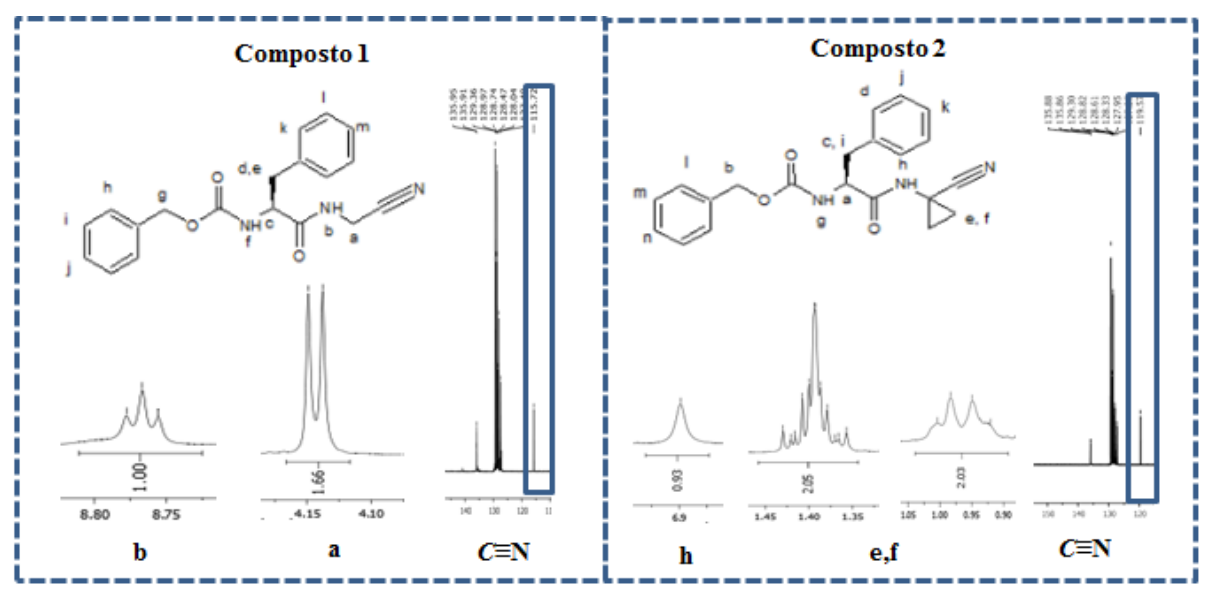

Figura 36. Região do $\mathrm{RMN}$ de ${ }^{1} \mathrm{H}$ e ${ }^{13} \mathrm{C}$ características para os compostos $\mathbf{1}$ e 2

O grupo aldeído presente nos compostos $\mathbf{3}$ e $\mathbf{4}$ possuem sinais característicos em espectros de hidrogênio e carbono. O singleto em 9,52 ppm, correspondente ao hidrogênio do aldeído no espectro de $\mathrm{RMN}$ de ${ }^{1} \mathrm{H}$, bem como, o sinal em 195,48 ppm, do carbono cabonílico do aldeído no espectro de $\mathrm{RMN}$ de ${ }^{13} \mathrm{C}$, indicam a formação do composto 3 (Figura 37). Deslocamentos químicos semelhantes nos espectros de $\mathrm{RMN}$ de ${ }^{1} \mathrm{H} \mathrm{e}{ }^{13} \mathrm{C}$ foram encontrados para o composto 4: 9,02 ppm e 198,51 ppm respectivamente (Figura 37). No espectro de massas de alta resolução foram encontrados os sinais em 341,14 e 367,16 referentes aos compostos $\mathbf{3}$ e $\mathbf{4}$, respectivamente.

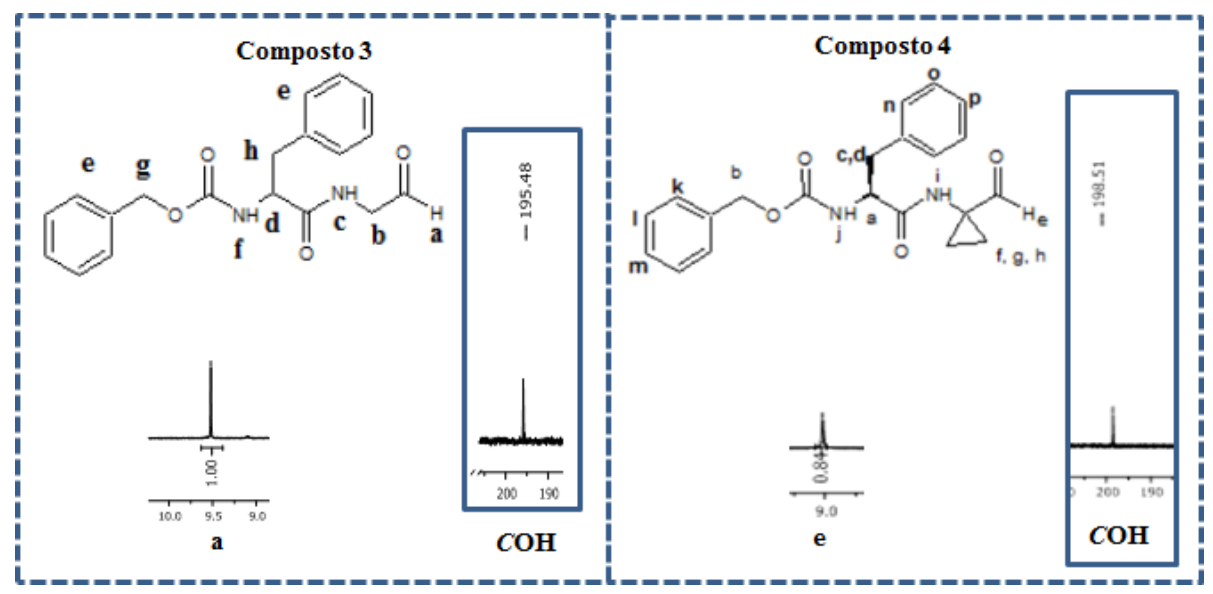

Figura 37. Região do $\mathrm{RMN}$ de ${ }^{1} \mathrm{H}$ e ${ }^{13} \mathrm{C}$ características para os compostos 3 e 4

O composto dipeptidil-oxima 5 obtido em uma mistura E/Z (54/46), apresenta sinais característicos no espectro de RMN de $\mathrm{H}^{1}$, tais como: 11,08 ppm (N-OH anti), 10,76 ppm (N- 
$O H$ syn) $, 7,18 \mathrm{ppm}(\mathrm{t}, J=5.5 \mathrm{~Hz}$, hidrogênio vinílico da oxima assinalado como isômero 'syn', aparece junto com os prótons aromáticos) e 6,42 ppm (t, $J=4.0 \mathrm{~Hz}, 0.5 \mathrm{H}$, hidrogênio vinílico da oxima assinalado como isômero 'anti', aparece junto com os prótons aromáticos). Os hidrogênios vinílicos da oxima assinalados e o cálculo da relação E/Z baseados na integração dos hidrogênios da hidroxila $(\mathrm{N}-\mathrm{OH})$ estão de acordo com a literatura (destacado em azul na Figura 38). ${ }^{128}$ Os sinais dos isômeros E e Z também podem ser observados no espectro de RMN de ${ }^{13} \mathrm{C}$ (Figura 38). No espectro de massas de alta resolução foi encontrado o sinal em 356,23 referente ao composto 5 .

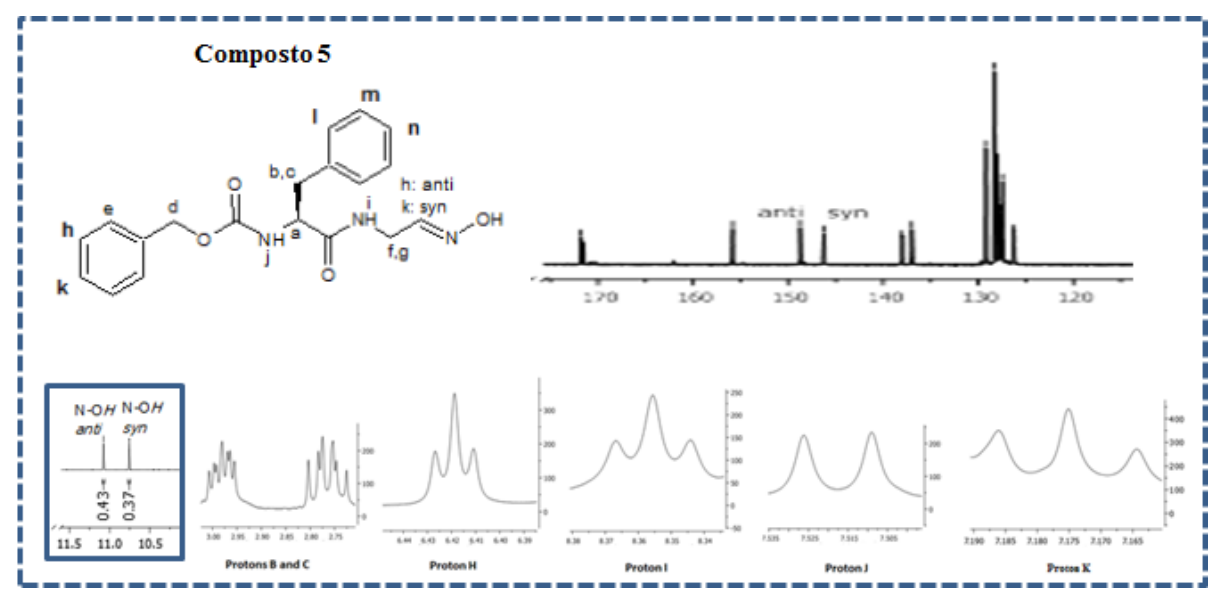

Figura 38. Região do $\mathrm{RMN}$ de ${ }^{1} \mathrm{H}$ e ${ }^{13} \mathrm{C}$ características para o composto 5

Os sinais característicos da porção referente a amida de Weinreb são as metilas: singletos em 3,71 e 3,11 ppm no espectro de RMN de ${ }^{1} \mathrm{H}$ e 65,23 e 37,59 ppm no espectro de RMN de ${ }^{13} \mathrm{C}$. O sinal em 4,05 ppm (duplo dubleto) do metileno acoplado ao hidrogênio da amida (tripleto em 8,18 ppm), complementam a caracterização do composto 6.

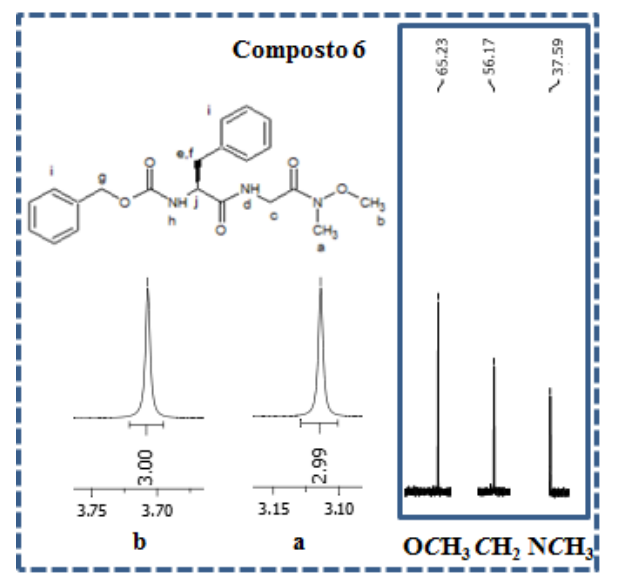

Figura 39. Região do $\mathrm{RMN}$ de ${ }^{1} \mathrm{H}$ e ${ }^{13} \mathrm{C}$ características para o composto 6 
Para os compostos dipeptidil-isoxazol 7-10 observaram-se os dois singletos, característicos da porção isoxazol, entre 8,0 e 9,13 ppm nos espectros de $\mathrm{RMN}$ de ${ }^{1} \mathrm{H}$. Pode ser observado também o hidrogênio da amida em torno de 8,90 ppm (Figura 40).

$\mathrm{Na}$ região do $\mathrm{RMN}$ de ${ }^{13} \mathrm{C}$ característica de sinais de carbonos aromáticos para os compostos 7-10 pode ser observado os 13 sinais correspondentes a porção isoxazol e os dois grupos bezenicos presente nos compostos.

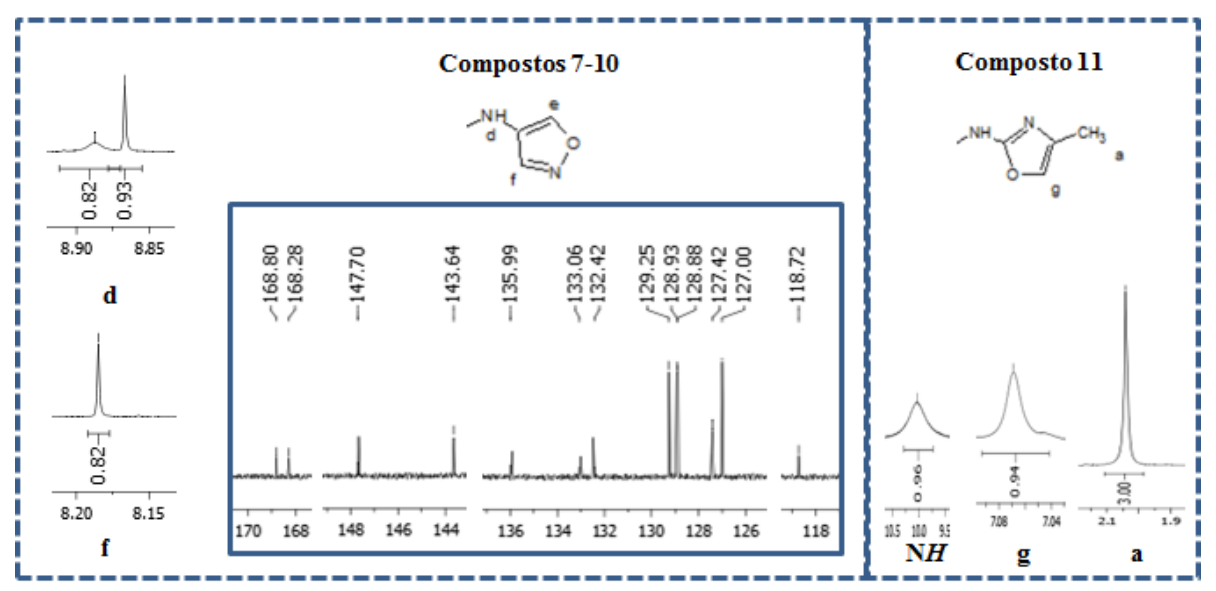

Figura 40. Região do $\mathrm{RMN}$ de ${ }^{1} \mathrm{H}$ e ${ }^{13} \mathrm{C}$ características para os compostos 7-11

Para o composto 11, no espectro de RMN de ${ }^{1} \mathrm{H}$, os singletos correspondentes a metila em 2,04 ppm e ao metino em 7,07 ppm da função orgânica oxazol, assim como o sinal alargado integrando para um hidrogênio em 10,03 ppm (sinal do hidrogênio da amida), evidenciam a formação do produto.

A espectrometria de massas para os compostos 7-11 ratificam as estruturas químicas apresentadas.

A rota sintética usada para os compostos 8-10 resultou na racemização do produto final. Isso ocorre na reação entre o aminoácido fenilalanina e o cloreto de benzoíla. ${ }^{88}$ Os isômeros (9 e 10) foram separados por cromatografia de alta eficiência (HPLC, do inglês "High Performance Liquide Chromatography”), usando uma coluna quiral de celulose (2phase da Phenomenex, tamanho da partícula de $5 \mu \mathrm{M}$, tamanho do poro $1000 \AA$ e fase móvel de $60 \%$ de acetonitrila em água). Os espectros de HPLC encontram-se no Apêndice H.

Para os compostos 12 (isômero E) e $\mathbf{1 3}$ (isômero Z) os espectros de RMN de ${ }^{1} \mathrm{H}$ apresentaram o acoplamento dos hidrogênios da dupla ligação do isômero E de 15,7 Hz e para o isômero $\mathrm{Z}$ de 10,20 Hz. Essas constantes de acoplamento entre os hidrogênios olefínicos confirmam as geometrias da dupla ligação. A mesma constante de acoplamento (em torno de $15,0 \mathrm{~Hz}$ ) foi observada para os compostos $\mathbf{1 4 - 1 6}$, própria de compostos com instauração de 
geometria E. Outra evidência, da formação da dupla ligação, são os sinais dos carbonos em torno de 118 e 148 ppm no espectro de $\mathrm{RMN}$ de ${ }^{13} \mathrm{C}$. A espectrometria de massas para os compostos 12-16 ratificam as estruturas químicas apresentadas. A Figura 41 exemplifica a forma de elucidação adotada na identificação dos compostos dipeptidil alfa-beta insaturados.

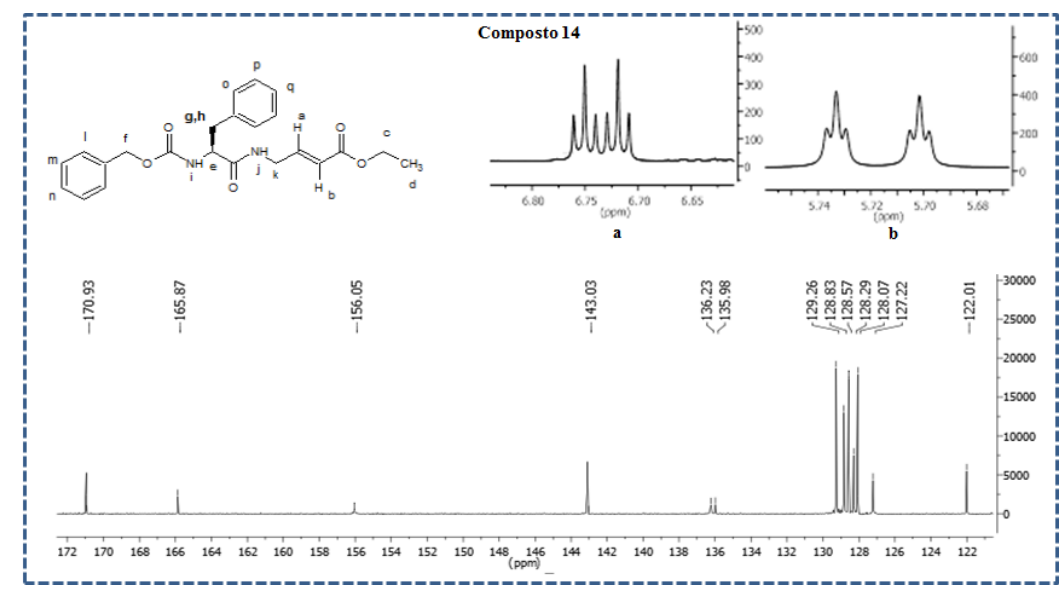

Figura 41. Região do $\mathrm{RMN}$ de ${ }^{1} \mathrm{H}$ e ${ }^{13} \mathrm{C}$ características para o composto 14

As dipeptidil-azanitrilas 17-20 possuem os grupos metílicos nos nitrogênios da porção amida e da porção cianoamina. Os sinais característicos no espectro de $\mathrm{RMN}$ de ${ }^{1} \mathrm{H}$ para esses grupos estão na região entre 3,0 a 3,25 ppm. O sinal do carbono $s p$ da função orgânica cianoamina no espectro de $\mathrm{RMN}$ de ${ }^{13} \mathrm{C}$ encontra-se na região de $114,0 \mathrm{ppm}$. A espectrometria de massas para os compostos 17-20 ratificam as estruturas químicas apresentadas. A Figura 42 exemplifica a forma de elucidação adotada na identificação dos compostos dipeptidil azanitrila

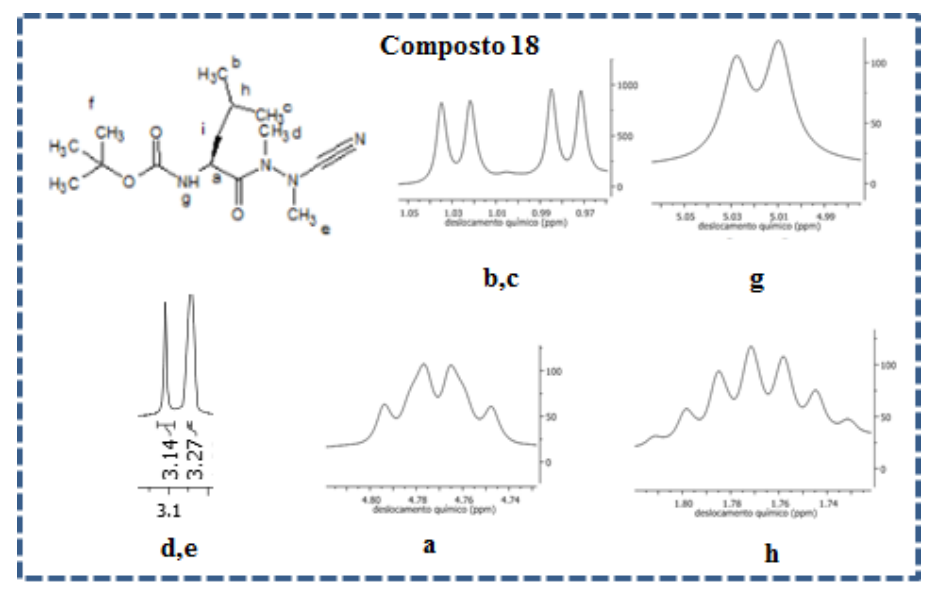

Figura 42. Região do $\mathrm{RMN}$ de ${ }^{1} \mathrm{H}$ e ${ }^{13} \mathrm{C}$ características para o composto $\mathbf{1 8}$ 


\subsubsection{Caracterização espectroscópica dos compostos 21-43}

A porção do anel fundido imidazo[1,2-a]piridina está presente no esqueleto básico comum a maioria dos compostos, com exceção dos compostos 40 e 41; que possuem anéis fundidos do tipo imidazo[1,2-a]pirimidina e imidazo[1,2-c]pirimidina, respectivamente. Neste caso, por se tratar de uma série de compostos congenérica apresentam sinais característicos de RMN de ${ }^{1} \mathrm{H}$ que se assemelham, portanto, apenas as singularidades presentes nos compostos estão discutidas a seguir. A Figura 43 apresenta a região do RMN característica de sinais de hidrogênios aromáticos, os três compostos selecionados $(\mathbf{3 2}, \mathbf{4 0}$ e $\mathbf{4 1})$ contendo as mesmas modificações no $\mathrm{R}_{1}$ e $\mathrm{R}_{2}$ da série de compostos sintetizados e, destacados em vermelho os hidrogênios característicos de cada anel fundido.

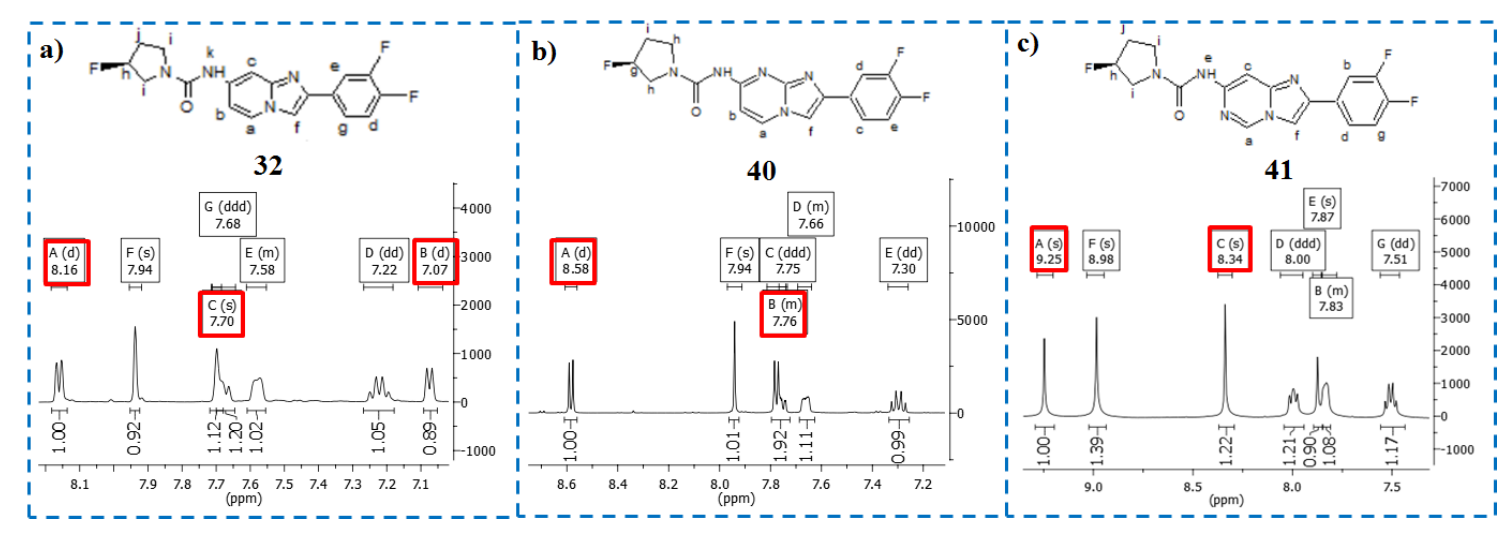

Figura 43. Região do RMN de ${ }^{1} \mathrm{H}$ característica de sinais de hidrogênios aromáticos para os compostos selecionados 32, 40 e 41, contendo os anéis fundidos imidazo[1,2a]piridina, imidazo[1,2-a]pirimidina e imidazo[1,2-c]pirimidina. Destacado em vermelho os principais sinais que diferenciam os anéis fundidos. Observação: os RMNs de hidrogênio para os compostos 32 e 40 foram feitos em metanol deuterado e para o composto 41 em ácido acético deuterado. Isso explica o sinal do hidrogênio da amida na região dos hidrogênios aromáticos

Os compostos 32, 40 e 41 apresenta um hidrogênio comum aos três anéis fundidos (hidrogênio A), contudo com multiplicidades diferentes. Por exemplo, no caso dos compostos 32 e 42, o hidrogênio A acopla com B, como resultado tem-se um dubleto com constante de acoplamento em torno de $7.0 \mathrm{~Hz}$. Porém, para o composto 41 o sinal do hidrogênio A aparece como um singleto. Outra diferença é a presença do sinal do hidrogênio $\mathbf{C}$ (destacado em vermelho) do composto 32 e a ausência desse sinal no composto 40, pois na posição 6 houve a substituição do grupo $\mathrm{CH}$ por um átomo de nitrogênio. $\mathrm{O}$ hidrogênio $\mathbf{C}$, também aparece no RMN de ${ }^{1} \mathrm{H}$ no composto 41 em 8,34 ppm (Figura 43). 
Nas outras porções do anel fundido, dos compostos em discussão, estão presentes os substituintes 3,4-difluorofenil $\left(\mathrm{R}_{2}\right)$ e 3-fluoropirrolidil ureia $\left(\mathrm{R}_{1}\right)$. Para porção $\mathrm{R}_{2}$ os sinais dos hidrogênios aromáticos característicos podem ser identificados na Figura 43, quais sejam um duplo dubleto de dubletos, um multipleto e um duplo dubleto. Essas multiplicidades derivamse dos acoplamentos entre os hidrogênios aromáticos e os átomos de flúor. Ainda, as presenças dos átomos de flúor fazem com que os carbonos, no espectro de RMN de ${ }^{13} \mathrm{C}$, apresentem multiplicidades distintas: dois dubletos e quatro quartetos (veja em apêndice). A presença do átomo de flúor na pirrolidina também modifica o padrão de multiplicidade. No espectro de RMN de ${ }^{1} \mathrm{H}$ observa-se um duplo multipleto referente ao hidrogênio do centro estereogênico e no espectro de $\mathrm{RMN}$ de ${ }^{13} \mathrm{C}$ observam-se três dubletos referentes aos sinais dos carbonos (veja em apêndice).

As fluorações em posições diferentes do anel aromático também resultaram em multiplicidades distintas que auxiliaram na elucidação das estruturas químicas. Com a fluoração na posição 3, do anel aromático conectado na porção $\mathrm{R}_{2}$ no sistema imidazopiridina, visualizaram no espectro de $\mathrm{RMN}$ de ${ }^{1} \mathrm{H}$ dois dubletos, um triplo dubleto e um duplo dubleto. Com a fluoração nas posições 2,3 esse padrão de acoplamento alterou-se para um multipleto (integrado para dois hidrogênios) e um tripleto.

Outros grupos introduzidos na porção $\mathrm{R}_{2}$ no sistema imidazopiridina também possuem sinais característicos no RMN de ${ }^{1} \mathrm{H}$. O grupo tiazol (composto 33) apresentaram dois dubletos em 7,85 e 7,91 ppm, referentes aos hidrogênios da função orgânica. O grupo tiofeno (composto 34) apresentaram três duplos dubletos entre 7,10 e 7,50 ppm, referentes aos hidrogênios da função orgânica.

$\mathrm{O}$ RMN de ${ }^{1} \mathrm{H}$ ainda foi empregado para caracterizar outros grupos introduzidos na porção $\mathrm{R}_{1}$ no sistema imidazopiridina. Os compostos 35-39 são derivados de amidas com os grupos cloropiridinil (composto 35), dimetiloxazolil (composto 36), piridinil (composto 37), tiazol (composto 38) e PyrA (composto 39). Esses grupos possuem sinais característicos de RMN de ${ }^{1} \mathrm{H}$ assinalados nos espectros em apêndice; adicionalmente para alguns compostos o $\mathrm{RMN}$ de ${ }^{13} \mathrm{C}$ também foi utilizado na elucidação.

\subsection{Conclusões do capítulo IV}

Rotas sintéticas foram obtidas da literatura e modificadas de acordo com as necessidades para obter os produtos de interesse. Os compostos sintetizados foram devidamente purificados (conforme descrito na seção experimental) e os RMNs de ${ }^{1} \mathrm{He}{ }^{13} \mathrm{C}$, 
bem como espectroscopia de massas foram empregados na caracterização dos compostos. $\mathrm{Na}$ seção experimental encontram-se mais detalhes da purificação e caracterização dos compostos e em apêndice as cópias dos RMNs. 
Sapitula 5

\section{Experimental}

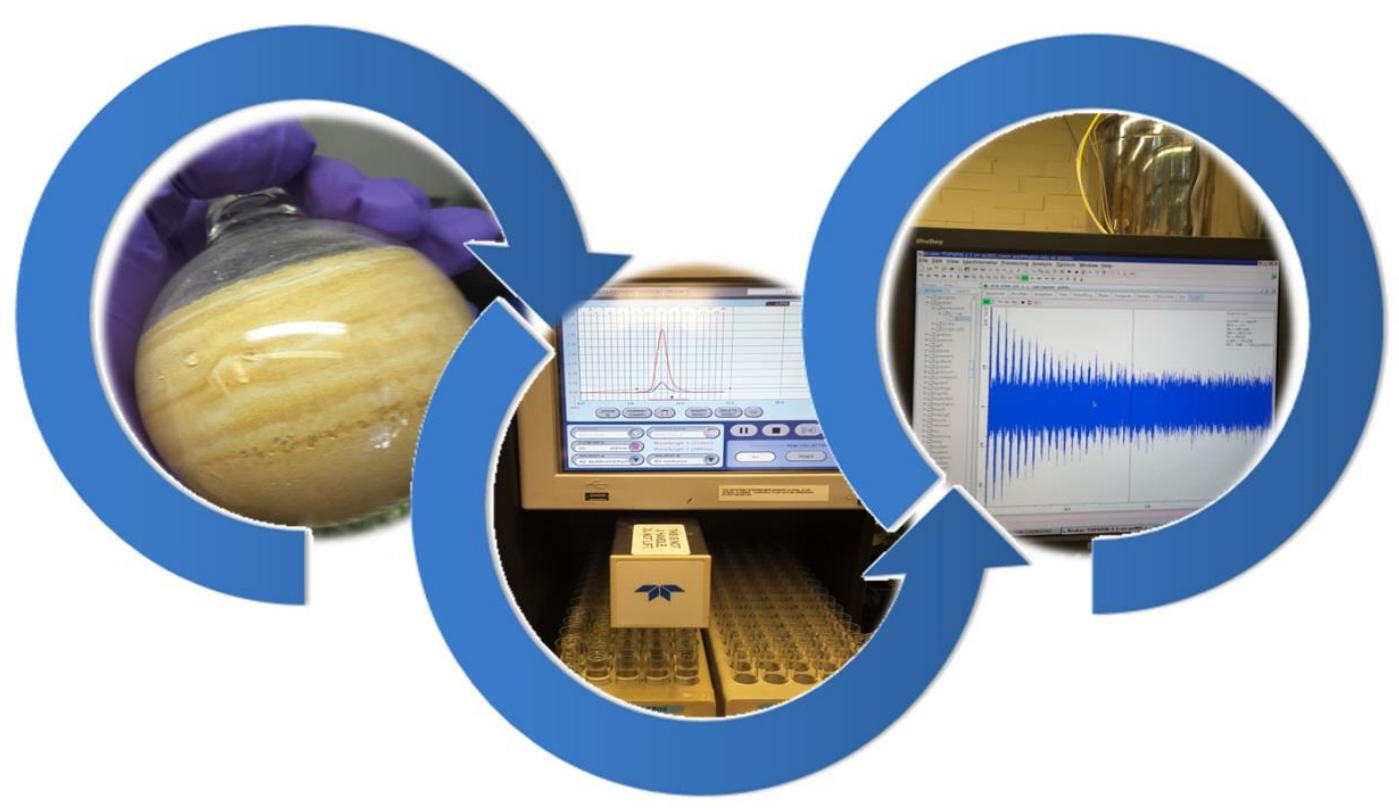




\section{Capítulo V}

\section{Experimental}

\subsection{Considerações Gerais}

Todos os reagentes foram comprados na mais alta qualidade comercial e utilizados sem purificação adicional; a menos que indicado de outra forma. Todos os solventes foram secados e destilados antes da sua utilização por meio de procedimentos padrões indicados a seguir. Tetrahidrofurano (THF) foi destilado em sódio metálico na presença do indicador benzofenona e usado imediatamente. Diclorometano $\left(\mathrm{CH}_{2} \mathrm{Cl}_{2}\right)$ foi destilado em hidreto de cálcio $\left(\mathrm{CaH}_{2}\right)$. As bases foram destiladas em $\mathrm{CaH}_{2}$ e estocadas em peneira molecular de $4 \AA$.

Todas as reações não aquosas foram realizadas sob uma atmosfera de argônio utilizando vidrarias secas em estufa $\left(150^{\circ} \mathrm{C}\right)$, exceto quando indicado. Uma vez removida da estufa, todo o aparato foi resfriado a vácuo e posteriormente a atmosfera trocada por argônio ou nitrogênio.

As temperaturas de reação são indicativas do ponto de referência do termostato ou termômetro, a menos que aquecida a refluxo, que neste caso refere-se à temperatura de refluxo do solvente utilizado. As reações realizadas a $0{ }^{\circ} \mathrm{C}$ referem-se a um banho de resfriamento externo de gelo/água, periodicamente substituído. As reações realizadas a - 20 ${ }^{\circ} \mathrm{C}$ referem-se a um banho de resfriamento externo de gelo/cloreto de sódio/água, periodicamente substituído.

A cromatografia em coluna flash ou CombiFlash foi realizada utilizando sílica gel 60 $\AA(0,040-0,063 \mu \mathrm{m})$ da empresa Fluka Analytical Sigma-Aldrich. As reações foram monitoradas por Cromatografia em Camada Fina (placa CCD, Fluka, matriz sílica gel, suporte de alumínio, com indicador fluorescente $254 \mathrm{~nm}$ e espessura de $200 \mu \mathrm{m}$ ). A visualização pode ser tanto por radiação ultravioleta $(254 \mathrm{~nm})$ ou coloração com uma solução reveladora preparada por procedimentos conhecidos. Todos os rendimentos referem-se a produtos isolados após purificação.

Para as análises de RMN, foram utilizados equipamentos de 400 ou $500 \mathrm{MHz}-$ Agilent RMN Spectrometer (IQSC-USP) ou Bruker AV (University of Washington). Os deslocamentos químicos $(\delta$, discutidos como ppm) são referenciados em relação ao padrão interno TMS, tetrametilsilano $(0.00 \mathrm{ppm})$. Os espectros foram registrados nos solventes indicados (DMSO-D $6, \mathrm{CDCl}_{3}, \mathrm{MeOD}$ e $\mathrm{CD}_{3} \mathrm{CO}_{2} \mathrm{D}$ ). As constantes de acoplamento $(J)$ são reportadas em Hz. As multiplicidades são apresentadas como: s, singleto, d, dubleto; t, 
tripleto; q, quarteto; quintet, quinteto; m, multipleto; dd, duplo dubleto; ddd, duplo dubletos de dubletos e br, sinal alargado de amidas. Os espectros de $\mathrm{RMN}$ de ${ }^{13} \mathrm{C}$ foram registrados usando equipamentos de 100 ou $126 \mathrm{MHz}$. Os dados foram tratados utilizando o programa MestreNova, versão 10.0.

Os espectros de massa foram registrados em espectrômetros Orbitrap QqTDE Bruker Daltonics (IQSC-USP) ou Bruker Esquire Ion Trap Mass Spectrometer (University de Washington) sob condições de ionização de electropulverização (ES, do inglês electrospray), usando ionização positiva.

A elucidação dos espectros de RMN foi realizada no programa Mestre Nova, versão $6.0 .2-5475$.

O método desenvolvido para caracterização, separação ou purificação dos compostos do tipo dipeptidil foi executado em um HPLC da Shimadzu CBM-20A. O detector foi ajustado para 200-800 nm. O controle do sistema e as análises dos dados foram executados usando o programa LC solutions. No protocolo de HPLC estabelecido, a análise quiral e a separação foram realizadas a $35^{\circ} \mathrm{C}$, utilizando coluna analítica e semi-preparativa Phenomenex de celulose-2 (analítica: $5 \mu \mathrm{m}, 250 \mathrm{~mm}$ x 4,6 mm ID, semi-preparativa: $5 \mu \mathrm{m}$, $250 \mathrm{~mm}$ x $10 \mathrm{~mm}$ I.D), por eluição isocrática com fluxo de 0,5 (analítica) e 2,36 mL min ${ }^{-1}$ (semi-preparativa). A composição de fase móvel mais comum foi acetonitrila/água (60:40) (v/v). As amostras foram injetadas em volumes de $10 \mu \mathrm{L}$ (analítica) e $1000 \mu \mathrm{L}$ (semipreparativa). A quantificação foi realizada a 200-800 nm e o tempo de execução cromatográfica variou de acordo com a amostra.

O método desenvolvido para caracterização ou purificação dos compostos do tipo imidazopiridina foi executado em um HPLC da Varian e coluna semi-preparativa (Varian PrepStar, modelo 218, coluna YMC ODS-A, 100x20 mm, $5 \mu \mathrm{m}$, fluxo: $10 \mathrm{~mL} / \mathrm{min}$, detector UV ajustado em: $218 \mathrm{~nm}$ e $254 \mathrm{~nm}$ ) com fase móvel: água:metanol, gradiente 10\%-100\% metanol durante 35 minutos.

Todos os compostos finais apresentam pureza $>95 \%$ de acordo com as análises de HPLC.

As rotações específicas $\left([\alpha] \mathrm{T}=100 \alpha / \mathrm{lc}\right.$, em deg $\mathrm{mL} \mathrm{g}^{-1} \mathrm{dm}^{-1}$, relatadas aqui em graus) foram observadas no comprimento de onda de $589 \mathrm{~nm}$, na linha D de uma lâmpada de sódio. A temperatura foi definida como $25^{\circ} \mathrm{C}$. As amostras foram pesadas de 1,0 a 10,6 mg utilizando uma balança de precisão (Sartorius, Modelo CPA26P) e foram completamente dissolvidas em metanol (grau HPLC, Panreac) ou dimetilsulfóxido (Sigma Aldrich) para aqueles que não eram completamente solúveis em metanol. As rotações foram medidas 
usando um Polarímetro Digital (P2000, Jasco): $\alpha=$ rotação observada em graus; $1=$ comprimento do caminho da célula de 0,1 decímetro de comprimento; c $=$ concentração em g $100 \mathrm{~mL}^{-1}$. Os valores foram calculados usando 5 medidas para cada composto.

Neste capítulo a representação utilizada para separação decimal foi o ponto, conforme exemplo: 1,0 foi representado por 1.0 .

\subsection{Procedimentos experimentais para síntese dos compostos do tipo dipeptidil}

\subsubsection{Sínteses dos intermediários dipeptidil}

7.2.1.1 N-Carbobenzoxy-L-fenilalanina (Cbz-Phe-OH) (A).

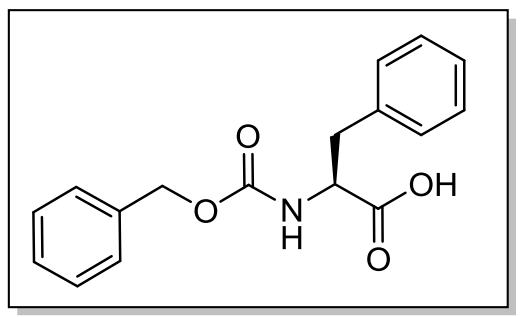

O aminoácido L-Fenilalanina (1.0 g, $6 \mathrm{mmol})$ foi dissolvido em água destilada $(30 \mathrm{ml})$ em um balão de $100 \mathrm{~mL}$ a temperatura ambiente sob agitação. Carbonato de Sódio $\left(\mathrm{Na}_{2} \mathrm{CO}_{3}, 0.504 \mathrm{mg}, 6 \mathrm{mmol}\right)$ e $\mathrm{NaHCO}_{3}(1.27 \mathrm{~g}, 12 \mathrm{mmol})$ foram adicionados, resultando em uma solução incolor.

Acetona $(4 \mathrm{~mL})$ foi adicionada na mistura reacional, tornando a solução turva, em seguida a temperatura foi ajustada entre $-15-20{ }^{\circ} \mathrm{C}$. Benzil Cloroformato $(\mathrm{Cbz}-\mathrm{Cl}, 1.07 \mathrm{~mL}, 7.5 \mathrm{mmol}$, $d=\sim 1.195 \mathrm{~g} / \mathrm{mL}$ ) foi adicionado lentamente e permitiu-se que a mistura reacional chegasse a temperatura ambiente. Após 3 horas adicionais a mistura foi extraída com $\mathrm{Et}_{2} \mathrm{O}(50 \mathrm{ml})$ e essa fase orgânica foi descartada. $\mathrm{Na}$ fase aquosa, $\mathrm{HCl}$ foi gotejado lentamente até atingir o $\mathrm{pH} 2$. O óleo resultante foi extraído com EtOAc $(150 \mathrm{ml})$, lavado com água destilada $(100 \mathrm{ml})$, secado em $\mathrm{MgSO}_{4}$ anidro e concentrado, obtendo-se um óleo incolor. ${ }^{89} \mathrm{RMN}$ de ${ }^{1} \mathrm{H}$ (400 $\left.\mathrm{MHz}, \mathrm{CDCL}_{3}\right) \delta 7.50-6.96(\mathrm{~m}, 14 \mathrm{H}), 5.24(\mathrm{~d}, J=8.1 \mathrm{~Hz}, 1 \mathrm{H}), 5.13-5.03(\mathrm{~m}, 2 \mathrm{H}), 4.69$ $(\mathrm{dd}, J=13.7,6.1 \mathrm{~Hz}, 1 \mathrm{H}), 3.20(\mathrm{dd}, J=14.0,5.4 \mathrm{~Hz}, 1 \mathrm{H}), 3.09$ (dd, $J=14.0,6.3 \mathrm{~Hz}, 1 \mathrm{H})$. Rendimento: $94 \%$.

\subsubsection{N-benzoil-L-fenilalanina (Bz-L-Phe-OH) (B)}

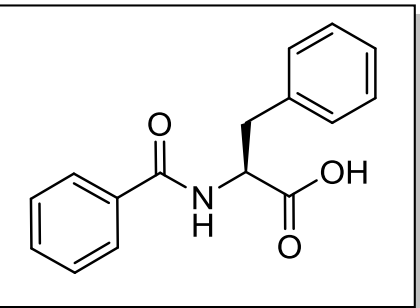

L-fenilalanina (1.65 g, $10 \mathrm{mmol}$ ) foi tratada com solução aquosa de hidróxido de sódio $(\mathrm{NaOH}, 1.62 \mathrm{~g}, 40 \mathrm{mmol})$ e cloreto de benzoíla (1.22 mL, $10.5 \mathrm{mmol})$. Após 3 horas a mistura foi extraída com éter etílico $\left(\mathrm{Et}_{2} \mathrm{O}, 3\right.$ x $\left.20 \mathrm{~mL}\right)$ e descartada. $\mathrm{Na}$ fase 
aquosa foi adicionado lentamente ácido clorídrico $(\mathrm{HCl})$ até o $\mathrm{pH}$ 2. A solução branca resultante foi extraída com acetato de etila (EtOAc, 3 x $20 \mathrm{~mL}$ ), lavada com água destilada $(50 \mathrm{~mL})$, secada em $\mathrm{MgSO}_{4}$ anidro e concentrada, resultando em um óleo incolor. Quando armazenado em baixas temperaturas resulta em um sólido branco. ${ }^{88} \mathrm{RMN}$ de ${ }^{1} \mathrm{H}(400 \mathrm{MHz}$, $\left.\mathrm{CDCl}_{3}\right) \delta 8.06(\mathrm{~s}, 1 \mathrm{H}), 8.05(\mathrm{~s}, 1 \mathrm{H}) . \delta 8.63(\mathrm{~d}, J=8.1 \mathrm{~Hz}, 1 \mathrm{H}), 7.81-7.76(\mathrm{~m}, 2 \mathrm{H}), 7.51(\mathrm{t}, J$ $=7.3 \mathrm{~Hz}, 1 \mathrm{H}), 7.44(\mathrm{t}, J=7.4 \mathrm{~Hz}, 2 \mathrm{H}), 7.31(\mathrm{~d}, J=7.0 \mathrm{~Hz}, 2 \mathrm{H}), 7.26(\mathrm{t}, J=7.5 \mathrm{~Hz}, 2 \mathrm{H}), 7.17$ (t, $J=7.2 \mathrm{~Hz}, 1 \mathrm{H}), 4.61$ (ddd, $J=10.4,8.2,4.4 \mathrm{~Hz}, 1 \mathrm{H}), 3.21$ (dd, $J=13.8,4.4 \mathrm{~Hz}, 1 \mathrm{H}), 3.07$ (dd, $J=13.7,10.5 \mathrm{~Hz}, 1 \mathrm{H})$. Rendimento: $83 \%$.

\subsubsection{Procedimento Geral 1 - reação de acoplamento}

O aminoácido protegido, N'-(3-dimetilaminopropil)-N-etilcarbodimida (EDC.HCl, 1.3 eq.) e 1-hidroxibenzotriazol ( $\mathrm{HOBt} \cdot \mathrm{xH}_{2} \mathrm{O}, 1.3$ eq.) em diclorometano (DCM) foram agitados em um balão de $25 \mathrm{~mL}$ a $0{ }^{\circ} \mathrm{C}$ durante uma hora. Após esse período, a amina que se deseja acoplar (1.3 eq.) e N,N-diisopropiletilamina (DIPEA, 1.3 eq.) foram adicionadas na mistura reacional a $0{ }^{\circ} \mathrm{C}$. A reação foi agitada na temperatura ambiente durante 15 horas, diluída em água destilada (30 mL) e extraída com diclorometano (DCM, 3 x $30 \mathrm{~mL})$. A fase orgânica foi lavada com água destilada, solução saturada de Cloreto de Sódio $(\mathrm{NaCl})$, Bicarbonato de Sódio $\left(\mathrm{NaHCO}_{3}\right)$ e solução $1 \mathrm{M}$ de Ácido Clorídrico $(\mathrm{HCl})$; secada em $\mathrm{MgSO}_{4}$ anidro e concentrada, resultando no produto desejado após purificação por coluna cromatográfica. ${ }^{12 f \text {, }}$ 117,129

\subsubsection{Procedimento Geral 2 - reação de proteção com BOC}

Em uma solução de 3,8 $\mathrm{N}$ de Hidróxido de Sódio $(\mathrm{NaOH}, 8 \mathrm{~mL})$ foi adicionado o aminoácido (1g, 1 eq.) dissolvido em $10 \mathrm{~mL}$ de tetrahidrofurano (THF). A mistura reacional foi resfriada entre $0-5{ }^{\circ} \mathrm{C}$. Dicarbonato de di-terc-butila ( $t$-BOC, 1 eq.) foi adicionado lentamente sob agitação. Terminada a adição a reação foi agitada em temperatura ambiente por um período de 30 horas. Após o termino da reação, o pH foi ajustado para 3 usando solução $2 \mathrm{~N}$ de $\mathrm{HCl}$. A extração do produto desejado foi feita com DCM (3 x $25 \mathrm{~mL}$ ), lavado com água destilada ( $3 \times 25 \mathrm{ml}$ ), secado em $\mathrm{MgSO}_{4}$ anidro e concentrado, resultando em um sólido branco e usado na próxima reação sem nenhuma purificação. ${ }^{118}$ 


\subsubsection{Procedimento Geral 3 - reação de desproteção com TFA}

Ácido Trifluoroacético (TFA, $25 \mathrm{~mL}$ ) foi adicionado na solução do aminoácido protegido com Boc $(1.0 \mathrm{~g})$ diluído em $\mathrm{CH}_{2} \mathrm{Cl}_{2}(25 \mathrm{~mL})$ ha $0{ }^{\circ} \mathrm{C}$, sob agitação por um período de 12 horas. A mistura reacional foi evaporada. O resíduo foi suspenso em $20 \mathrm{~mL}$ de THF e usado imediatamente, sem nenhuma purificação, na próxima reação. ${ }^{40 b, 119}$

\subsubsection{Benzil (S)-(1-((cianometil)amino)-1-oxo-3-fenilpropan-2-il)carbamato (1)}

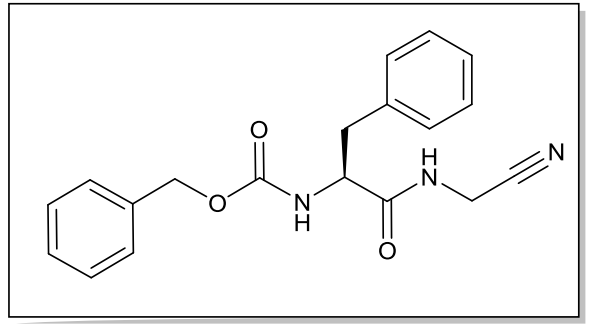

O reagente comercial aminoacetonitrila foi acoplado ao Cbz-L-Phe-OH (preparado de acordo com o procedimento A, 7.2.1.1), seguindo o procedimento geral 1 (7.2.2). O produto foi purificado por coluna cromatográfica [silica gel, usando acetato de etila

(EtOAc) $/ n$-hexano 70:30 v/v como fase móvel], resultando no produto desejado, um sólido branco $\left(0.50 \mathrm{~g}, 89 \%\right.$ de rendimento). ${ }^{117}$ A purificação final foi realizada por HPLC seguindo o protocolo mostrado nas considerações gerais: $t_{R}=10.6 \mathrm{~min} .[\alpha]_{\mathrm{D}}^{25}=-13.68(\mathrm{c}=0.285$, $\mathrm{MeOH}) \mathrm{RMN}$ de ${ }^{1} \mathrm{H}\left(500 \mathrm{MHz}, \mathrm{DMSO}-d_{6}\right) \delta 8.77(\mathrm{t}, J=5.5 \mathrm{~Hz}, 1 \mathrm{H}), 7.64(\mathrm{~d}, J=8.5 \mathrm{~Hz}$, 1H), $7.36-7.18(\mathrm{~m}, 10 \mathrm{H}), 4.95(\mathrm{q}, J=12.7 \mathrm{~Hz}, 2 \mathrm{H}), 4.23$ (ddd, $J=10.4,8.6,4.6 \mathrm{~Hz}, 1 \mathrm{H})$, $4.14(\mathrm{~d}, J=5.6 \mathrm{~Hz}, 2 \mathrm{H}), 2.99(\mathrm{dd}, J=13.7,4.5 \mathrm{~Hz}, 1 \mathrm{H}), 2.77(\mathrm{dd}, J=13.7,10.4 \mathrm{~Hz}, 1 \mathrm{H})$. $\mathrm{RMN} \mathrm{de}{ }^{13} \mathrm{C}\left(126 \mathrm{MHz}, \mathrm{CDCl}_{3}\right) \delta 171.73,156.37,135.95,135.91,129.36,128.97,128.74$, 128.47, 128.04, 127.40, 115.72, 67.47, 56.18, 38.43, 27.42. HRMS (ESI):m/z Calculado $\left[\mathrm{C}_{19} \mathrm{H}_{20} \mathrm{~N}_{3} \mathrm{O}_{3}\right]$ 338.1499, observado: $338.1494[\mathrm{M}+\mathrm{H}]^{+}$. Lit. ${ }^{66 b}$

\subsubsection{Benzil (S)-(1-((1-cianociclopropil)amino)-1-oxo-3-fenilpropan-2-il)carbamato (2)}

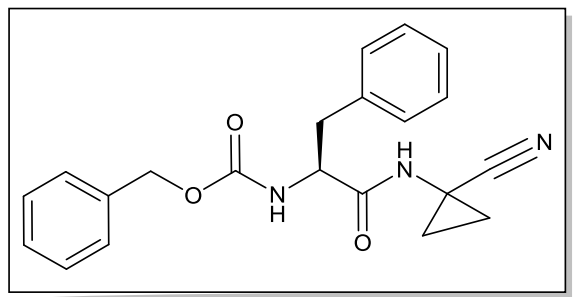

O reagente comercial 1-Amino-1ciclopropanocarbonitrila hidrocloreto foi acoplado ao Cbz-L-Phe-OH (preparado de acordo com o procedimento A, 7.2.1.1), seguindo o procedimento geral 1 (7.2.2). O produto foi purificado por coluna cromatográfica [silica gel, usando EtOAc/n-hexano 70:30 v/v como fase móvel], resultando 
no produto desejado, um sólido branco $(0.40 \mathrm{~g}, 89 \%$ rendimento). A purificação final foi realizada por HPLC seguindo o protocolo mostrado nas considerações gerais: $t_{R}=9.75$ min . $[\alpha]^{25}=-3.15(\mathrm{c}=0.285, \mathrm{MeOH}) . \mathrm{RMN}$ de ${ }^{1} \mathrm{H}\left(500 \mathrm{MHz}, \mathrm{CDCl}_{3}\right) \delta 7.40-7.10(\mathrm{~m}, 10 \mathrm{H})$, 6.90 (br s, 1H), 5.67 (d, $J=7.0 \mathrm{~Hz}, 1 \mathrm{H}), 5.10-4.98$ (m, 2H), 4.37 (4.37 (dd, $J=14.2,7.0 \mathrm{~Hz}$, 1H), $3.07(\mathrm{dd}, J=13.6,6.7 \mathrm{~Hz}, 1 \mathrm{H}), 2.99(\mathrm{dd}, J=13.5,7.8 \mathrm{~Hz}, 1 \mathrm{H}), 1.46-1.34(\mathrm{~m}, 2 \mathrm{H})$, 0.96 (m, 2H). RMN de ${ }^{13} \mathrm{C}\left(126 \mathrm{MHz}, \mathrm{CDCl}_{3}\right) \delta 172.07,156.12,135.88,135.86,129.30$, $128.82,128.61,128.33,127.95,127.25,119.57,67.26,60.42,55.96,38.61,20.13,16.61$.

HRMS (ESI): m/z calculado[ $\left.\mathrm{C}_{21} \mathrm{H}_{22} \mathrm{~N}_{3} \mathrm{O}_{3}\right] 364.1655$, observado: $364.1632[\mathrm{M}+\mathrm{H}]{ }^{+}{ }^{+}$Lit. $^{130}$

\subsubsection{Benzil (S)-(1-oxo-1-((2-oxoetil)amino)-3-fenilpropan-2-il)carbamato (3)}

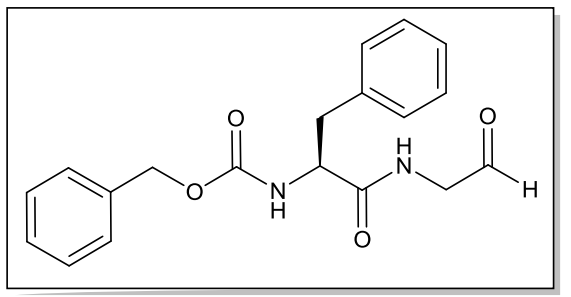

a) Benzil (S)-(1-((2-hidroxiethil)amino)-1-oxo-3fenilpropan-2-il)carbamato (Cbz-Phe-ETA). O reagente comercial etanolamina (ETA) foi acoplado ao Cbz-L-Phe$\mathrm{OH}$ (preparado de acordo com o procedimento $\mathbf{A}$, 7.2.1.1), seguindo o procedimento geral 1 (7.2.2), resultando no intermediário Cbz-Phe-ETA. O produto foi purificado por coluna cromatográfica [silica gel, usando EtOAc/n-hexano 70:30 v/v como fase móvel], resultando no produto desejado, um sólido branco (0.80 g, 79\% rendimento). b) Em uma solução de Cbz-Phe-ETA (500 mg, $1.46 \mathrm{mmol}$ ) em EtOAc (40 mL, grau HPLC) foi adicionado o Ácido 2-Iodobenzoíco (IBX, $8.76 \mathrm{mmol}$ ), previamente preparado de acordo com Frigerio et al. ${ }^{123 \mathrm{~b}}$ A mistura reacional permaneceu sob agitação por aproximadamente 6 horas em uma temperatura de $60{ }^{\circ} \mathrm{C}$ (ou até a TLC indicar a completa consumição do produto de partida). Após esse período, permitiu-se que a reação chegasse à temperatura ambiente. A mistura reacional foi diluída com EtOAc e a parte insolúvel foi filtrada em Celite. A fase orgânica foi lavada com $\mathrm{NaCl}$, secada em $\mathrm{MgSO}_{4}$, filtrada e concentrada, resultando no produto desejado, um sólido branco (495 mg, rendimento quantitativo). ${ }^{123} \mathrm{~A}$ purificação final foi realizada por HPLC seguindo o protocolo mostrado nas considerações gerais: $t_{R}=11.33$ min. RMN de ${ }^{1} \mathrm{H}$ $\left(400 \mathrm{MHz}, \mathrm{CDCl}_{3}\right) \delta 9.52(\mathrm{~s}, 1 \mathrm{H}), 7.40-7.11(\mathrm{~m}, 10 \mathrm{H}), 6.56(\mathrm{br}, 1 \mathrm{H}), 5.41$ (dd, $J=15.8,8.1$ $\mathrm{Hz}, 2 \mathrm{H}), 5.08$ (s, 2H), $4.16-4.05(\mathrm{~m}, 1 \mathrm{H}), 3.08$ (m, 2H). RMN de ${ }^{13} \mathrm{C}\left(101 \mathrm{MHz}, \mathrm{CDCl}_{3}\right) \delta$ $195.48,171.96,156.04,136.01,129.30,129.23$, 128.78, 128.56, 128.27, 128.05, 127.18, 67.22, 55.85, 50.03, 37.52. ${ }^{131}$ HRMS (ESI): $\mathrm{m} / \mathrm{z}$ calculado[ $\left.\mathrm{C}_{19} \mathrm{H}_{21} \mathrm{~N}_{2} \mathrm{O}_{4}\right]$ 341.1495, observado: $341.1485[\mathrm{M}+\mathrm{H}]^{+}$. .it. $^{91}$ 


\subsubsection{Benzil (S)-(1-((1-formilciclopropil)amino)-1-oxo-3-phenilpropan-2-il)carbamato} (4)

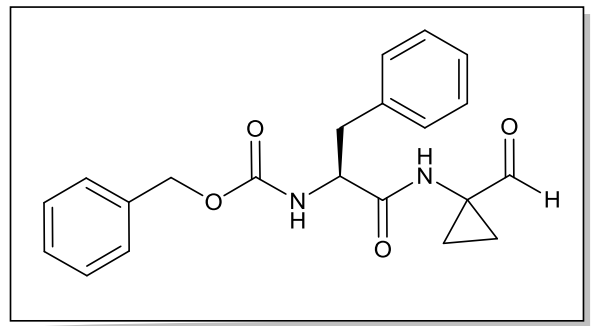

O Composto 4 foi preparado utilizando o Procedimento 7.2.7 e o aminoalcool apropriado. O produto foi purificado por coluna cromatográfica [silica gel, usando EtOAc/n-hexano 80:20 $v / v$ como fase móvel], resultando no produto desejado, um sólido branco $(0.38$

g, 96\% rendimento). ${ }^{123} \mathrm{~A}$ purificação final foi realizada por HPLC seguindo o protocolo mostrado nas considerações gerais: $t_{R}=11.33 \min .[\alpha]^{25}=-12.10(c=0.140, \mathrm{MeOH})$. RMN de ${ }^{1} \mathrm{H}\left(500 \mathrm{MHz}, \mathrm{CDCl}_{3}\right) \delta 9.02$ (s, 1H), $7.40-7.10$ (m, 10H), 6.90 (br, 1H), 5.67 (d, J= 7.0 $\mathrm{Hz}, 1 \mathrm{H}), 5.10-4.98(\mathrm{~m}, 2 \mathrm{H}), 4.37(\mathrm{dd}, J=14.2,7.0 \mathrm{~Hz}, 1 \mathrm{H}), 3.07$ (dd, $J=13.6,6.7 \mathrm{~Hz}, 1 \mathrm{H})$, 2.99 (dd, $J=13.5,7.8 \mathrm{~Hz}, 1 \mathrm{H}), 1.46-1.34(\mathrm{~m}, 2 \mathrm{H}), 0.96$ (dd, $J=29.4,12.3 \mathrm{~Hz}, 2 \mathrm{H}) . \mathrm{RMN}$ de ${ }^{13} \mathrm{C}\left(126 \mathrm{MHz}, \mathrm{CDCl}_{3}\right) \delta 198.51,172.31,156.03,136.28,136.00,129.34,128.78,128.57$, 128.30, 128.04, 127.19, 67.19, 56.15, 41.25, 38.62, 17.03, 16.88. MS (ESI): m/z calculado $\left[\mathrm{C}_{21} \mathrm{H}_{23} \mathrm{~N}_{2} \mathrm{O}_{4}\right]$ 367.1652, observado: $367.16[\mathrm{M}+\mathrm{H}]^{+}$e $389.15[\mathrm{M}+\mathrm{Na}]^{+}$.

\subsubsection{Benzil (S)-(1-((2-(hidroxiimino)etil)amino)-1-oxo-3-fenilpropan-2-il)carbamato(5)}

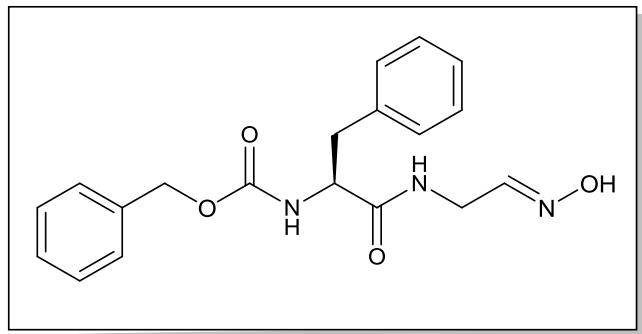

O composto aldeído $3(0.30 \mathrm{~g}, 0.88 \mathrm{mmol})$, cloridrato de hidroxilamina $(0.122 \mathrm{~g}, 1.76 \mathrm{mmol}) \mathrm{e}$ bicarbonate de sódio (0.148 g, $1.76 \mathrm{mmol})$ foram dissolvidos em etanol $(1.5 \mathrm{~mL})$ e a mistura reacional foi agitada durante $12 \mathrm{~h}$ à temperatura ambiente. $\mathrm{O}$ solvente foi removido sob pressão reduzida. O resíduo resultante foi diluído com acetato de etila $(1 \mathrm{~mL})$ e lavado com água $(2 \times 1 \mathrm{~mL})$. A fase orgânica foi secada em sulfato de sódio anidro e concentrada sob pressão reduzida. ${ }^{84 \mathrm{~b}} \mathrm{O}$ produto foi purificado por coluna cromatográfica [silica gel, usando EtOAc/n-hexano 60:40 $v / v$ como fase móvel], resultando no produto desejado, um sólido branco $(0.17 \mathrm{~g}, 56 \%$ de rendimento, mistura de isômeros E/Z). A purificação final foi realizada por HPLC seguindo o protocolo mostrado nas considerações gerais: $t_{R}=11.95$ minutos em acetonitrila/água $(50: 50)$. $[\alpha]_{D}^{25}=+30.05(\mathrm{c}=$ $0.470, \mathrm{MeOH}) \mathrm{RMN}$ de ${ }^{1} \mathrm{H}\left(500 \mathrm{MHz}, \mathrm{DMSO}-d_{6}\right) \delta 11.08(\mathrm{~N}-\mathrm{OH}$ anti), $10.76(\mathrm{~N}-\mathrm{OH}$ syn), $8.34(\mathrm{dt}, J=19.5,5.5 \mathrm{~Hz}, 1 \mathrm{H}), 7.54(\mathrm{dd}, J=19.8,8.5 \mathrm{~Hz}, 1 \mathrm{H}), 7.37-7.19(\mathrm{~m}, 10 \mathrm{H}), 7.18(\mathrm{t}$, 
$J=5.5 \mathrm{~Hz}, 0.5 \mathrm{H}$ marcado como isômero 'syn' de acordo com a literatura), ${ }^{15} 6.42$ (t, $J=4.0$ $\mathrm{Hz}, 0.5 \mathrm{H}$, marcado como isômero 'anti' de acordo com a literatura), ${ }^{15} 4.99-4.90$ (m, 2H), $4.24-4.18(\mathrm{~m}, 1 \mathrm{H}), 3.93-3.83(\mathrm{~m}, J=21.8,16.2,7.9 \mathrm{~Hz}, 1 \mathrm{H}), 3.83-3.73(\mathrm{~m}, 1 \mathrm{H}), 3.02-$ $2.94(\mathrm{~m}, 1 \mathrm{H}), 2.76(\mathrm{td}, J=14.2,10.3 \mathrm{~Hz}, 1 \mathrm{H}) . \mathrm{RMN} d e{ }^{13} \mathrm{C}\left(101 \mathrm{MHz}, \mathrm{DMSO}-d_{6}\right) \delta 171.79$, 155.82, 148.75 (C-anti), 146.25(C-syn), 138.05, 137.01, 129.19, 128.28, 128.04, 127.67, 127.46, 126.26, 65.26, 56.24, 37.98, 34.84. As configurações das oximas foram atribuídas com base na evidência de RMN relatada na literatura. ${ }^{15,128} \mathrm{MS}$ (ESI): m/z calculado $\left[\mathrm{C}_{19} \mathrm{H}_{21} \mathrm{~N}_{3} \mathrm{O}_{4}\right]$ 355.3877, observado: $356.23[\mathrm{M}+\mathrm{H}]^{+}$.

\subsubsection{Benzil N-[1-(\{[metoxi(metil)carbamoil $]$ metil $\}$ carbamoil $)-2-f e n i l e t i l]$ carbamato (6)}

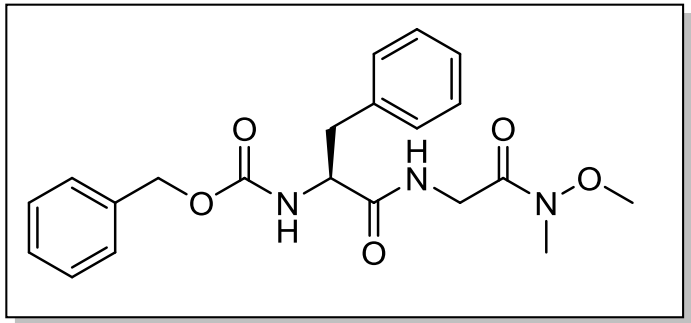

a) N-(terc-butoxicarbonil)glicina (Boc-Gly-OH). O aminoácido glicina (Gly, 1g, 0,013 mmol) foi protegido com BOC, utilizando o procedimento geral 2, 7.2.3 (rendimento quantitativo). ${ }^{118} \mathrm{RMN}$ de ${ }^{1} \mathrm{H}(500 \mathrm{MHz}, \mathrm{DMSO}) \delta 7.04(\mathrm{t}, \mathrm{J}=6.1 \mathrm{~Hz}$,

$1 \mathrm{H}), 3.57(\mathrm{~d}, \mathrm{~J}=6.2 \mathrm{~Hz}, 2 \mathrm{H}), 1.38(\mathrm{~s}, 9 \mathrm{H})$. Rendimento: 95\%. b) terc-Butil-2[methoxi(metil)amino]-2-oxaetil-carbamato (Boc-Gly-N,O-dimetilhidroxilamina). procedimento geral 1 (7.2.2), foi seguido com as modificações a seguir. Em uma solução de Boc-Gly-OH $(175,18 \mathrm{mg}, 0,86 \mathrm{mmol})$ em THF seco $(2.7 \mathrm{~mL})$ a $0{ }^{\circ} \mathrm{C}$ foi adicionado EDC (197,00 mg, 1,03 mmol) e HOBt (139,00 mg, 0,51 mmol). Após 30 minutos foi adicionado na mistura reacional $N, O$-dimetilhidroxilamina ([MeO $(\mathrm{Me}) \mathrm{NH} \cdot \mathrm{HCl}] 100,00 \mathrm{mg}, 1,03 \mathrm{mmol})$ e N,N-Diisopropiletilamina (DIPEA, 165,00 mg, 1,28 mmol, $d=\sim 0,742 \mathrm{~g} / \mathrm{mL}$ ). A reação foi agitada na temperatura ambiente "overnight", diluída em água destilada (30 mL) e extraída com EtOAc (3 x $25 \mathrm{~mL}$ ). A fase orgânica foi lavada com água destilada, solução saturada $\mathrm{NaCl}, \mathrm{NaHCO}_{3}$ e solução $1 \mathrm{M}$ de $\mathrm{HCl}$; secada em $\mathrm{MgSO} 4$ anidro e concentrada, resultando no produto desejado, um sólido branco. ${ }^{119} \mathrm{RMN}$ de ${ }^{1} \mathrm{H}$ (400 MHz, DMSO) $\delta 6.83$ (t, J = 6.0 Hz, 1H), $3.82(\mathrm{~d}, \mathrm{~J}=6.1 \mathrm{~Hz}, 2 \mathrm{H}), 3.67$ (s, 3H), 3.08 (s, 3H), 1.38 (s, 9H). Rendimento: 78\%. c) 2Amino- $\mathrm{N}$-metoxi-N-metil-acetamida (Gly-N,O-dimetilhidroxilamina). O procedimento geral 3 (7.2.4) foi usado para obter o intermediário desprotegido (rendimento quantitativo). RMN de ${ }^{1} \mathrm{H}(400 \mathrm{MHz}, \mathrm{DMSO}) \delta 8,23-8.04$ (m, 2H), 3,89 (s, 2H), 3,71 (s, 3H), 3,16 (s, 3H). d) Gly- $N, O$-dimetilhidroxilamina $(239,11 \mathrm{mg}, 1,03 \mathrm{mmol})$ foi acoplado ao Cbz-L-Phe-OH (preparado de acordo com o procedimento A (7.2.1.1); 256,21 mg, 0,86 mmol) em $7 \mathrm{~mL}$ de THF seco, seguindo o procedimento geral 1 (7.2.2). ${ }^{40 \mathrm{~b}, 119} \mathrm{O}$ produto foi purificado por coluna 
cromatográfica [silica gel, usando EtOAc/n-hexano 60:40 $v / v$ como fase móvel], resultando no produto desejado, um sólido branco (rendimento: 67\%). RMN de ${ }^{1} \mathrm{H}$ (500 MHz, DMSO) $\delta$ $8.18(\mathrm{t}, \mathrm{J}=5.4 \mathrm{~Hz}, 1 \mathrm{H}), 7.52(\mathrm{~d}, \mathrm{~J}=8.8 \mathrm{~Hz}, 1 \mathrm{H}), 7.33-7.18(\mathrm{~m}, 10 \mathrm{H}), 4.96-4.89(\mathrm{~m}, 3 \mathrm{H})$, $4.05(\mathrm{dd}, \mathrm{J}=10.9,4.6 \mathrm{~Hz}, 2 \mathrm{H}), 3.71$ (s, 3H), 3.11 (s, 3H), $3.05(\mathrm{dd}, \mathrm{J}=13.8,3.6 \mathrm{~Hz}, 1 \mathrm{H})$, $2.73(\mathrm{dd}, \mathrm{J}=13.8,11.1 \mathrm{~Hz}, 1 \mathrm{H})$.

\subsubsection{Benzil (S)-(1-(isoxazol-4-ilamino)-1-oxo-3-fenilpropan-2-il)carbamato (7)}

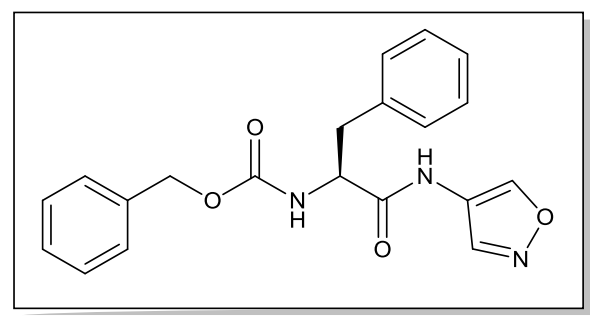

a) 4-nitroisoxazol. $\mathrm{O}$ isoxazol $(4.74 \mathrm{~mL}, 72.4 \mathrm{mmol}, d$ $=\sim 1,075 \mathrm{~g} / \mathrm{mL}$ ) foi dissolvido em ácido trifluoroacético anidrido (TFA, $30 \mathrm{~mL}, d=\sim 1,487 \mathrm{~g} / \mathrm{mL}$ ), e nitrato de amônio $\left(\mathrm{NH}_{4} \mathrm{NO}_{3}, 6.37 \mathrm{~g}, 80 \mathrm{mmol}\right)$ foi adicionado em pequenas porções $(0.5 \mathrm{~g})$, mantendo a temperatura entre 25 e $30{ }^{\circ} \mathrm{C}$. Após 30 minutos, outra porção de $\mathrm{NH}_{4} \mathrm{NO}_{3}(3,6 \mathrm{~g})$ foi adicionada. Depois de 24 horas, adicionou-se na mistura reacional água gelada e extraiu o produto com DCM (4 x 60 $\mathrm{mL})$. As porções extraídas foram combinadas e lavadas com água destilada (3 x 80mL). A fase orgânica foi secada com sulfato de magnésio anidro $\left(\mathrm{MgSO}_{4}\right)$, filtrada e concentrada, resultando em um óleo amarelo. ${ }^{120} \mathrm{RMN}$ de ${ }^{1} \mathrm{H}\left(500 \mathrm{MHz}, \mathrm{CDCl}_{3}\right) \delta 9.28(\mathrm{~s}, 1 \mathrm{H}), 8.83(\mathrm{~s}$, 1H). Rendimento: 63\%. b) 4-aminoisoxazol. 4-Nitroisoxazol (0,85g, 7,45 mmol) e cloreto de amônio $\left(\mathrm{NH}_{4} \mathrm{Cl}, 9,17 \mathrm{~g}, 171 \mathrm{mmol}\right.$ em $60 \mathrm{~mL}$ de água destilada) foram colocados em um balão. A suspensão resultante foi resfriada a $0{ }^{\circ} \mathrm{C}$ sob vigorosa agitação. Zinco $(\mathrm{Zn}, 4,14 \mathrm{~g}$, $63,3 \mathrm{mmol}$ ) foi adicionado em pequenas porções mantendo a temperatura a $0{ }^{\circ} \mathrm{C}$. Depois de 10 minutos, a reação foi deixada a temperatura ambiente. Após 4 horas, a mistura reacional foi filtrada em Celite e o filtrado foi extraído com acetato de etila (4 x100 mL). A fase orgânica foi lavada com água destilada (2 x $100 \mathrm{~mL}$ ), secada em $\mathrm{MgSO}_{4}$ anidro e concentrada, resultando em um óleo marrom. ${ }^{121} \mathrm{RMN}$ de ${ }^{1} \mathrm{H}\left(400 \mathrm{MHz}, \mathrm{CDCl}_{3}\right) \delta 8.06(\mathrm{~s}$, 1H), $8.05(\mathrm{~s}, 1 \mathrm{H})$. Rendimento: $57 \% .{ }^{117}$ c) $\mathrm{O} 4$-aminoisoxazol foi acoplado ao Cbz-L-Phe-OH (preparado de acordo com o procedimento A, 7.2.1.1), seguindo o procedimento geral 1 (7.2.2). O produto foi purificado por coluna cromatográfica [silica gel, usando EtOAc/nhexano 70:30 $v / v$ como fase móvel], resultando no produto desejado, um sólido branco (0.54 $\mathrm{g}$, 69\% rendimento). A purificação final foi realizada por HPLC seguindo o protocolo mostrado nas considerações gerais: $t_{R}=15.10 \min .[\alpha]_{D}^{25}=+5.98(c=0.183, \mathrm{MeOH})$. RMN de ${ }^{1} \mathrm{H}\left(500 \mathrm{MHz} \mathrm{CDCl}_{3}\right) \delta 8.80(\mathrm{~s}, 1 \mathrm{H}), 8.50(\mathrm{br}, 1 \mathrm{H}), 8.06(\mathrm{~s}, 1 \mathrm{H}), 7.37-7.09(\mathrm{~m}, 10 \mathrm{H})$, $5.62(\mathrm{br}, 1 \mathrm{H}), 5.07-4.99(\mathrm{~m}, 2 \mathrm{H}), 4.54(\mathrm{~m}, 1 \mathrm{H}), 3.12(\mathrm{dd}, J=13.8,7.0 \mathrm{~Hz}, 1 \mathrm{H}), 3.07$ (dd, $J=$ 
13.4, 7.4 Hz, 1H). RMN de ${ }^{13} \mathrm{C}\left(500 \mathrm{MHz}, \mathrm{CDCl}_{3}\right) \delta 169.01,156.52,147.70,143.50,135.78$, 135.61, 129.17, 128.89, 128.66, 128.51, 127.96, 127.38, 118.55, 67.56, 56.42, 38.11. HRMS (ESI): $\mathrm{m} / \mathrm{z}$ calculado $\left[\mathrm{C}_{20} \mathrm{H}_{20} \mathrm{~N}_{3} \mathrm{O}_{4}\right] 366.1448$, observado: $366.1441[\mathrm{M}+\mathrm{H}]^{+}$.

\subsubsection{N-(1,2-oxazol-4-il)-3-fenil-2-(fenilformamida)propanamida (8-10)}

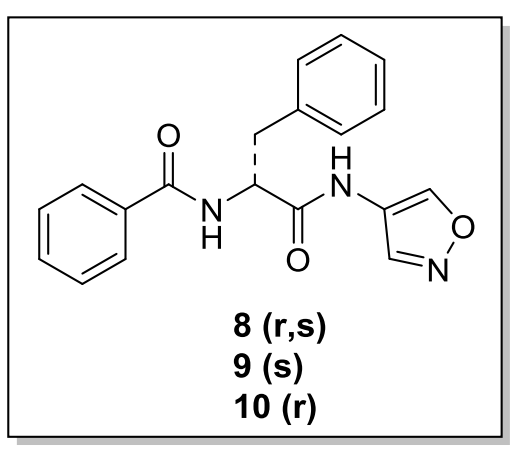

O 4-aminoisoxazol foi acoplado ao $\boldsymbol{B z}$ - $\mathbf{L}-\boldsymbol{P h} \boldsymbol{e}-\boldsymbol{O H}$ (preparado de acordo com o procedimento $\mathbf{B}$, 7.2.1.2), seguindo o procedimento geral 1 (7.2.2). O produto foi purificado por coluna cromatográfica [silica gel, usando EtOAc/n-hexano 70:30 $v / v$ como fase móvel], resultando no produto desejado, um sólido branco (0.90 g, 70\% rendimento). A purificação final foi realizada por HPLC seguindo o protocolo mostrado nas considerações gerais em coluna quiral: $t_{R}$ isômero $r=14.27$ min. e $t_{R}$ isômero $s=16.89$ min. RMN de ${ }^{1} \mathrm{H}\left(500 \mathrm{MHz}, \mathrm{CDCl}_{3}\right) \delta 8.89$ (s, 1H), 8.87 (s, 1H), $8.18(\mathrm{~s}, 1 \mathrm{H}), 7.70-7.22$ (m, $10 \mathrm{H}), 6.84(\mathrm{~d}, J=7.5 \mathrm{~Hz}, 1 \mathrm{H}), 5.08(\mathrm{q}, J=7.3 \mathrm{~Hz}, 1 \mathrm{H}), 3.29$ (d, $J=7.2 \mathrm{~Hz}, 2 \mathrm{H}) . \mathrm{RMN} \mathrm{de}$ ${ }^{13} \mathrm{C}\left(126 \mathrm{MHz}, \mathrm{CDCL}_{3}\right) \delta 168.80,168.28,147.70,143.64,135.99,133.06,132.42,129.25$, $128.93,128.88,127.42,127.00,118.72,55.03,37.89$. MS (ESI): $\mathrm{m} / \mathrm{z}$ calculado $\left[\mathrm{C}_{19} \mathrm{H}_{17} \mathrm{~N}_{3} \mathrm{O}_{3}\right]$ 335.1269, observado: $336.1337[\mathrm{M}+\mathrm{H}]^{+}$.

\subsubsection{3 (S)-N-(4-metiloxazol-2-il)-3-fenil-2-(3-fenilpropanamida) propanamida (11)}

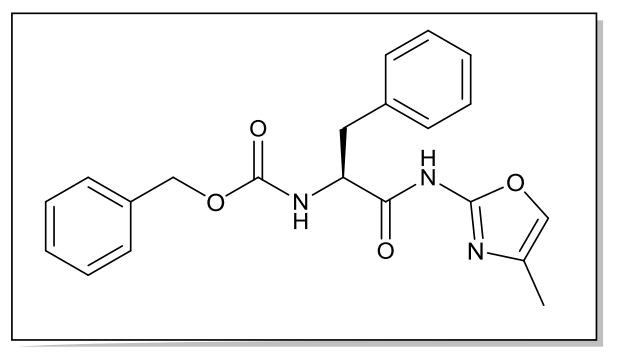

O reagente comercial 2-Amino-4-metiloxazol foi acoplado ao $\mathrm{Cbz}$ - $\mathrm{L}-\mathrm{Phe}$ - $\mathrm{OH}$ (preparado de acordo com o procedimento A, 7.2.1.1), seguindo o procedimento geral 1 (7.2.2). O produto foi purificado por coluna cromatográfica [silica gel, usando EtOAc/n-hexano 60:40 v/v como fase móvel], resultando no produto desejado, um sólido branco $(0.43 \mathrm{~g}, 91 \%$ de rendimento). A purificação final foi realizada por HPLC seguindo o protocolo mostrado nas considerações gerais: $t_{R}=12.65 \min .[\alpha]^{25}=+21.47(\mathrm{c}=0.232, \mathrm{MeOH}) \mathrm{RMN}$ de ${ }^{1} \mathrm{H}$ $\left(500 \mathrm{MHz}, \mathrm{CDCl}_{3}\right) \delta 7.36-7.10(\mathrm{~m}, 10 \mathrm{H}), 7.07(\mathrm{~s}, 1 \mathrm{H}), 5.95(\mathrm{br}, 1 \mathrm{H}), 5.05(\mathrm{~m}, 2 \mathrm{H}), 4.87$ 4.57 (m, 1H), 3.19 (dd, $J=13.9,5.9 \mathrm{~Hz}, 1 \mathrm{H}), 3.04$ (dd, $J=13.4,5.9 \mathrm{~Hz}, 1 \mathrm{H}), 2.04$ (s, 3H). $\mathrm{RMN} d{ }^{13} \mathrm{C}\left(126 \mathrm{MHz}, \mathrm{CDCl}_{3}\right) \delta 156.27,136.02,135.97,130.18,129.32,128.91,128.60$, 
128.49, 128.16, 127.96, 127.58, 127.29, 127.05, 67.21, 56.70, 38.22, 11.22. MS (ESI): m/z calculado $\left[\mathrm{C}_{21} \mathrm{H}_{22} \mathrm{~N}_{3} \mathrm{O}_{4}\right]$ 380.1604, observado: 380.1586 .

7.2.14 Etil (S,E)-4-(2-(((Benziloxi)carbonil)amino)-3-fenilpropanamida)but-2-enoato (12) e Etil (S,Z)-4-(2-(((Benziloxi)carbonil)amino)-3-fenilpropanamida)but-2enoato (12)

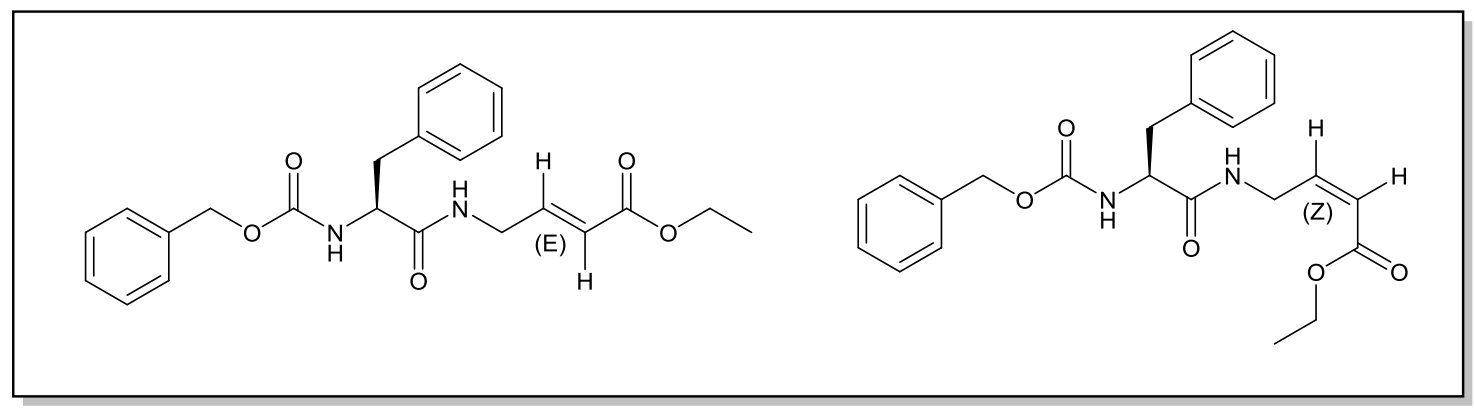

Trietilfosfonato $(0.29 \mathrm{~mL}, 1.46 \mathrm{mmol})$ foi dissolvido em THF (1 mL) e adicionado a uma suspensão de $\mathrm{NaH}(1.46 \mathrm{mmol})$ em THF $(1 \mathrm{~mL})$ sob agitação. Após 30 min à temperatura ambiente, adicionou-se uma solução do aldeído 3 (0,340 g, 1,0 mmol) em THF (2 mL) e continuou-se a agitação durante $4 \mathrm{~h}$. A reação foi interrompida com a adição de água $(1 \mathrm{~mL})$ gota a gota com agitação, concentrou-se a mistura e separou-se o resíduo entre DCM (10 mL) e água (2 mL). A suspenção de DCM foi extraída com solução de HC1 1 molar, solução de $\mathrm{NaHCO}_{3}$ e salmoura. Em seguida, a fase orgânica foi secada em $\mathrm{MgSO}_{4}$ e concentrado. O produto foi purificado por coluna cromatográfica [silica gel, usando EtOAc/n-hexano 50:50 $v / v$ como fase móvel], resultando predominantemente o isômero E $(0.35 \mathrm{~g}, 85 \%$ de rendimento) e isômero $\mathrm{Z}$ (0.02 g, 6\% de rendimento), ambos um sólido branco. ${ }^{132} \mathrm{~A}$ purificação final foi realizada por HPLC seguindo o protocolo mostrado nas considerações gerais: $t_{R}=46.21 \min (E)$ and $t_{R}=36.27 \min (Z)$. Composto $12(E): R M N$ de ${ }^{1} \mathrm{H}(500 \mathrm{MHz}$, $\left.\mathrm{CDCl}_{3}\right) \delta 7.38-7.15(\mathrm{~m}, 10 \mathrm{H}), 6.73(\mathrm{dt}, J=15.7,5.1 \mathrm{~Hz}, 1 \mathrm{H}), 6.15$ (br, 1H), 5.72 (dt, $J=$ 15.7, $1.8 \mathrm{~Hz}, 1 \mathrm{H}), 5.43$ (br, 1H), $5.10-5.04$ (m, 2H), 4.42 (dd, $J=13.8,6.6 \mathrm{~Hz}, 1 \mathrm{H}), 4.17$ (q, $J=7.1 \mathrm{~Hz}, 2 \mathrm{H}), 3.92(\mathrm{~m}, 2 \mathrm{H}), 3.12(\mathrm{dd}, J=13.6,6.4 \mathrm{~Hz}, 1 \mathrm{H}), 3.04(\mathrm{dd}, J=13.7,7.6 \mathrm{~Hz}, 1 \mathrm{H})$, $1.28(\mathrm{t}, J=7.1 \mathrm{~Hz}, 3 \mathrm{H}) . \mathrm{RMN} d{ }^{13} \mathrm{C}\left(126 \mathrm{MHz}, \mathrm{CDCl}_{3}\right) \delta 170.93,165.87,156.05,143.03$, 136.23, 135.98, 129.26, 128.83, 128.57, 128.29, 128.07, 127.22, 122.01, 67.24, 60.42, 56.41, 39.95, 29.70, 14.23. HRMS (ESI): $\mathrm{m} / \mathrm{z}$ calculado $\left[\mathrm{C}_{23} \mathrm{H}_{27} \mathrm{~N}_{2} \mathrm{O}_{5}\right]$ 411.1914, observado: $411.1907[\mathrm{M}+\mathrm{H}]^{+}$. Composto $13(\mathrm{Z})$ : RMN de ${ }^{1} \mathrm{H}\left(400 \mathrm{MHz}, \mathrm{CDCl}_{3}\right) \delta 8.22$ (br, $\left.1 \mathrm{H}\right), 7.38-$ $7.18(\mathrm{~m}, 10 \mathrm{H}), 6.76$ (ddt, $J=10.2,8.9,1.3 \mathrm{~Hz}, 1 \mathrm{H}), 5.37$ (br, 1H), $5.14-5.06$ (m, 2H), 4.87 $(\mathrm{dd}, J=16.0,7.7 \mathrm{~Hz}, 1 \mathrm{H}), 4.48(\mathrm{dd}, J=14.2,6.6 \mathrm{~Hz}, 1 \mathrm{H}), 4.09$ (q, $J=7.1 \mathrm{~Hz}, 2 \mathrm{H}), 3.16$ (dd, $J=14.4,6.6 \mathrm{~Hz}, 1 \mathrm{H}), 3.08(\mathrm{dd}, J=13.8,7.3 \mathrm{~Hz}, 1 \mathrm{H}), 2.84-2.66(\mathrm{~m}, 2 \mathrm{H}), 1.23(\mathrm{t}, J=7.1 \mathrm{~Hz}$, 
3H). RMN de ${ }^{13} \mathrm{C}\left(101 \mathrm{MHz}, \mathrm{CDCl}_{3}\right) \delta 171.17,168.58,155.94,136.03,129.26,128.79$, 128.49, 128.19, 128.02, 127.11, 124.28, 102.69, 67.05, 60.99, 56.82, 38.43, 31.60, 14.05. HRMS (ESI): m/z calculado $\left[\mathrm{C}_{23} \mathrm{H}_{27} \mathrm{~N}_{2} \mathrm{O}_{5}\right] 411.1914$, observado: $411.1904[\mathrm{M}+\mathrm{H}]^{+}$. Lit. $^{133}$

7.2.15 Etil (S,E)-3-(1-(2-(((Benziloxi)carbonil)amino)-3-fenilpropanamida) ciclopropil)acrilato (14)

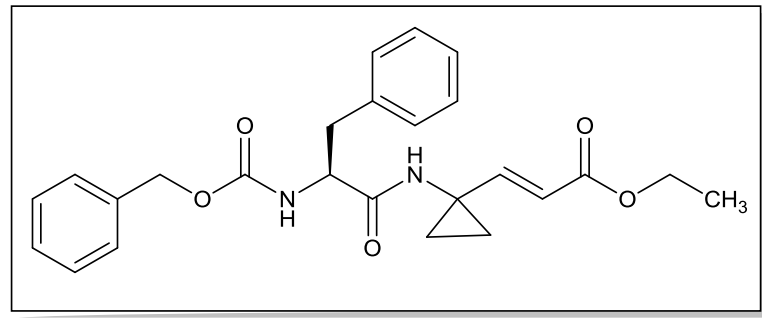

O composto $\mathbf{1 4}$ foi preparado usando o procedimento 7.2.14 e o aldeído 4. O produto foi purificado por coluna cromatográfica [silica gel, usando EtOAc/ $n$-hexano 80:20 v/v como fase móvel], resultando predominantemente o isômero $\mathrm{E}$ como um sólido branco $(0.35 \mathrm{~g}, 86 \%$ de rendimento). A purificação final foi realizada por HPLC seguindo o protocolo mostrado nas considerações gerais: $\mathrm{t}_{\mathrm{R}}=21.67 \mathrm{~min} .[\alpha]_{\mathrm{D}}^{25}=-4.41(\mathrm{c}=0.498, \mathrm{MeOH}) . \mathrm{RMN}$ de ${ }^{1} \mathrm{H}\left(500 \mathrm{MHz}, \mathrm{CDCl}_{3}\right) \delta$ $7.39-7.13(\mathrm{~m}, 10 \mathrm{H}), 6.38(\mathrm{~d}, J=15.4 \mathrm{~Hz}, 1 \mathrm{H}), 6.21(\mathrm{br}, 1 \mathrm{H}), 5.63$ (d, $J=15.4 \mathrm{~Hz}, 1 \mathrm{H}), 5.45$ (br s, 1H), 5.09 (s, 2H), 4.35 (dd, $J=14.0,7.2 \mathrm{~Hz}, 1 \mathrm{H}), 4.14$ (q, $J=7.1 \mathrm{~Hz}, 2 \mathrm{H}), 3.13$ (dd, $J=$ 13.6, 6.2 Hz, 1H), 2.99 (dd, $J=13.6,8.2 \mathrm{~Hz}, 1 \mathrm{H}), 1.25$ (t, $J=7.1 \mathrm{~Hz}, 3 \mathrm{H}), 1.17-1.02$ (m, $3 \mathrm{H}), 0.92-0.84(\mathrm{~m}, 1 \mathrm{H}) . \mathrm{RMN} d e{ }^{13} \mathrm{C}\left(126 \mathrm{MHz}, \mathrm{CDCl}_{3}\right) \delta 171.23,166.44,156.16,150.55$, 136.43, 136.13, 129.37, 129.02, 128.71, 128.43, 128.23, 127.35, 118.06, 67.37, 60.35, 56.56, 38.61, 33.87, 18.28, 18.12, 14.41. HRMS (ESI): $\mathrm{m} / \mathrm{z}$ calculado $\left[\mathrm{C}_{25} \mathrm{H}_{29} \mathrm{~N}_{2} \mathrm{O}_{5}\right]$ 437.2071, observado: $437.2039[\mathrm{M}+\mathrm{H}]^{+}$.

7.2.16 Benzil (S,E)-(1-((1-(3-(dietilamino)-3-oxoprop-1-en-1-il)ciclopropil) amino)-1oxo-3-fenilpropan-2-il)carbamato (15)

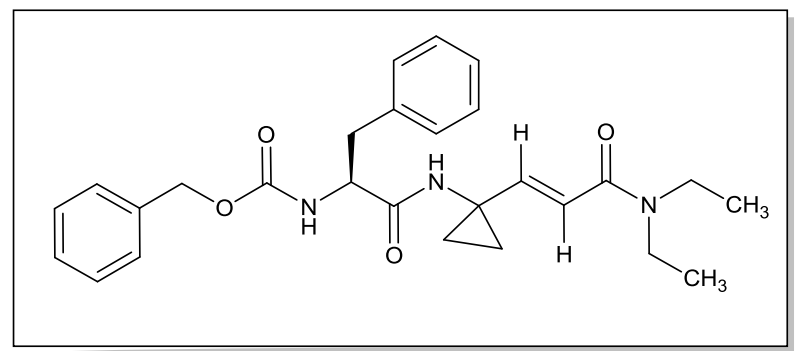

a) Bromo acetamida foi preparada de acordo com o procedimento descrito por Riches et al $\left(98 \%\right.$ rendimento). ${ }^{134}$ b) A reação de Michaelis-Arbuzov foi empregada para obter o dietil (2-(dietilamino)-2-oxoetil)

fosfonato, de acordo com o procedimento descrito por Gois et al (84\% rendimento). ${ }^{135}$ c) $\mathrm{Na}$ próxima etapa, esse intermediário e o aldeído 4 foram usados para obter o composto $\mathbf{1 5}$, por meio de uma reação de Horner-Wadsworth-Emmons reaction (HWE), previamente descrita 
no procedimento 7.2.14. O produto foi purificado por coluna cromatográfica [silica gel, usando EtOAc/n-hexano 60:40 v/v como fase móvel], resultando predominantemente o isômero E como um sólido branco $(0.32 \mathrm{~g}, 70 \%$ de rendimento). A purificação final foi realizada por HPLC seguindo o protocolo mostrado nas considerações gerais: $t_{R}=12.65$ min. $[\alpha]_{\mathrm{D}}^{25}=+10.93(\mathrm{c}=1.061, \mathrm{MeOH}) . \mathrm{RMN}$ de ${ }^{1} \mathrm{H}\left(400 \mathrm{MHz}, \mathrm{CDCl}_{3}\right) \delta 7.38-7.14(\mathrm{~m}, 10 \mathrm{H})$, $6.31(\mathrm{~d}, J=14.9 \mathrm{~Hz}, 1 \mathrm{H}), 6.24$ (br, 1H), 6.17 (d, $J=14.9 \mathrm{~Hz}, 1 \mathrm{H}), 5.35$ (br s, 1H), $5.14-5.01$ $(\mathrm{m}, 2 \mathrm{H}), 4.31(\mathrm{q}, J=7.3 \mathrm{~Hz}, 1 \mathrm{H}), 3.33(\mathrm{~m}, 4 \mathrm{H}), 3.08(\mathrm{dd}, J=13.6,6.7 \mathrm{~Hz}, 1 \mathrm{H}), 3.00(\mathrm{dd}, J=$ 13.6, 7.7 Hz, 1H), 1.10 (q, $J=8.0 \mathrm{~Hz}, 6 \mathrm{H}), 1.06-0.78$ (m, 4H). RMN de ${ }^{13} \mathrm{C}(101 \mathrm{MHz}$, $\left.\mathrm{CDCl}_{3}\right) \delta 171.24,165.61,156.14,147.06,136.38,136.10,129.29,128.96,128.74,128.48$, 128.13, 127.37, 117.75, 67.24, 56.80, 42.36, 40.96, 38.47, 34.07, 17.57, 17.52, 15.01, 13.27. HRMS (ESI): m/z calculado $\left[\mathrm{C}_{27} \mathrm{H}_{34} \mathrm{~N}_{3} \mathrm{O}_{4}\right]$ 464.2543, observado: $464.2562[\mathrm{M}+\mathrm{H}]^{+}$.

\subsubsection{Benzil (S,E)-(1-((1-(3-(metilamino)-3-oxoprop-1-en-1-il)ciclopropil) amino)-1- oxo-3-fenilpropan-2-il)carbamato (16)}

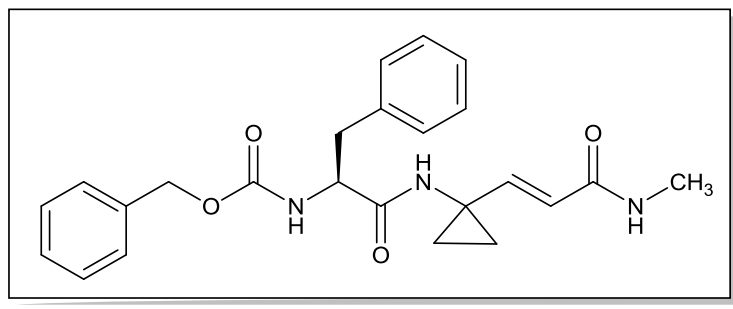

adicionados na sequência. Permitiu-se que a reação atingisse a temperatura ambiente vagarosamente. A reação foi agitada por 24 horas. A mistura foi concentrada. ${ }^{125} \mathrm{O}$ RMN de $\mathrm{H}^{1}$ indicou a conversão quantitativa do produto desejado (líquido incolor) e está de acordo com o reportado na literatura. ${ }^{136}{ }^{1} \mathrm{H} \mathrm{NMR}\left(500 \mathrm{MHz}, \mathrm{CDCl}_{3}\right) \delta 4.12$ (quintet, $J=8.2,7.1,1.3$ $\mathrm{Hz}, 4 \mathrm{H}), 2.85$ (br, 1H), 2.81(d, $J=20.0,2 \mathrm{H}), 2.80(\mathrm{~d}, J=4.5 \mathrm{~Hz}, 3 \mathrm{H}), 1.33(\mathrm{t}, J=7.1 \mathrm{~Hz}$, 6H). b) Na próxima etapa, esse intermediário e o aldeído 4 foram usados para obter o composto 16, por meio de uma reação de Horner-Wadsworth-Emmons reaction (HWE), previamente descrita no procedimento 7.2.14. O produto foi purificado por coluna cromatográfica [silica gel, usando EtOAc/ $n$-hexano 50:50 v/v como fase móvel], resultando predominantemente o isômero $\mathrm{E}$ como um sólido branco $(0.51 \mathrm{~g}, 80 \%$ rendimento). A purificação final foi realizada por HPLC seguindo o protocolo mostrado nas considerações gerais: $t_{\mathrm{R}}=9.48 \mathrm{~min} .[\alpha]_{\mathrm{D}}^{25}=+0.95(\mathrm{c}=0.00209, \mathrm{MeOH}) . \mathrm{RMN}$ de ${ }^{1} \mathrm{H}\left(500 \mathrm{MHz}, \mathrm{CDCl}_{3}\right) \delta$ $7.29-7.05$ (m, 10H), 6.98 (br, 1H), 6.12 (d, $J=15.1 \mathrm{~Hz}, 1 \mathrm{H}), 6.01$ (dd, $J=10.3,5.0 \mathrm{~Hz}, 1 \mathrm{H})$, $5.77(\mathrm{br}, 1 \mathrm{H}), 5.52$ (d, $J=15.0 \mathrm{~Hz}, 1 \mathrm{H}), 4.96$ (q, $J=12.4 \mathrm{~Hz}, 2 \mathrm{H}), 4.42(\mathrm{dd}, J=14.4,7.1 \mathrm{~Hz}$, 
1H), $2.95(\mathrm{~m}, 2 \mathrm{H}), 2.63(\mathrm{~d}, J=4.8 \mathrm{~Hz}, 3 \mathrm{H}), 0.88(\mathrm{~m}, 4 \mathrm{H}) . \mathrm{RMN} \mathrm{de}{ }^{13} \mathrm{C}\left(126 \mathrm{MHz}, \mathrm{CDCl}_{3}\right) \delta$ $171.74,166.35,156.31,145.98,136.52$, 136.15, 129.47, 128.73, 128.68, 128.34, 127.92, 127.08, 120.39, 67.09, 56.20, 38.86, 33.73, 26.31, 17.62, 17.38. MS ESI (+):m/z calculado $\left[\mathrm{C}_{24} \mathrm{H}_{28} \mathrm{~N}_{3} \mathrm{O}_{4}\right]$ 422.2074, observado: $420.19[\mathrm{M}+\mathrm{H}]^{+}$e $444.19[\mathrm{M}+\mathrm{Na}]^{+}$.

\subsubsection{Benzil (S)-(1-(2-ciano-1,2-dimetilhidrazinil)-1-oxo-3-fenilpropan-2-il)carbamato} (17)

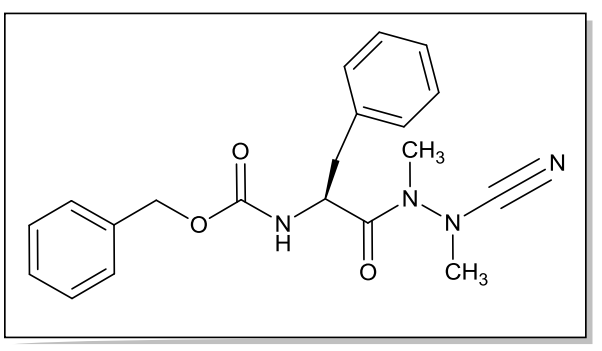

a) 1,2-Dimetilhidrazina dicloridrato (DMH) foi acoplado ao material de partida (Cbz-Phe-OH) usando o procedimento geral 1 (7.2.2), com as modificações descritas a seguir. Utilizou-se 2.6 eq. de DIPEA e mistura resultante foi agitada durante $28 \mathrm{~h}$ à temperatura ambiente. A extração do produto foi feita de acordo com o procedimento geral 1 (7.2.2). O produto foi purificado por coluna cromatográfica [silica gel, usando EtOAc/ $n$-hexano 60:40 v/v como fase móvel], resultando no intermediário desejado, um óleo viscoso (Cbz-Phe-DMH 0.53 g, 83\% rendimento). b) Cbz-Phe-DMH (0.50 g, 1.83 mmol) foi dissolvido em MeOH (10 mL, grau HPLC) e tratado com NaOAc (0.40 g, 4.94 mmol) e $\operatorname{BrCN}(0.39 \mathrm{~g}, 3.65 \mathrm{mmol})$. A mistura reacional resultante foi agitada durante $18 \mathrm{~h}$ à temperatura ambiente. $\mathrm{O}$ solvente foi evaporado sob pressão reduzida. $\mathrm{O}$ resíduo foi suspenso em $\mathrm{H}_{2} \mathrm{O}(10 \mathrm{~mL})$, a pH de 1-2 foi ajustado $\left(10 \% \mathrm{KHSO}_{4}\right)$, e foi extraído com acetato de etila $(3 \times 20 \mathrm{~mL})$. As fases orgânicas combinadas foram lavadas com $\mathrm{H}_{2} \mathrm{O}(10 \mathrm{~mL})$, sat. $\mathrm{NaHCO}_{3}$ $(2 \times 10 \mathrm{~mL}), \mathrm{H}_{2} \mathrm{O}(10 \mathrm{~mL})$, e solução salina $(10 \mathrm{~mL})$. A fase orgânica foi secada em $\mathrm{Na}_{2} \mathrm{SO}_{4} \mathrm{e}$ concentrada. ${ }^{72 \mathrm{~b}} \mathrm{O}$ óleo viscoso obtido foi purificado por coluna cromatográfica (silica gel, usando EtOAc/ $n$-hexano 20:80 v/v como fase móvel), resultando no produto desejado, um sólido branco (0.63 g, 87\% de rendimento). A purificação final foi realizada por HPLC seguindo o protocolo mostrado nas considerações gerais, usando $70 \%$ de hexano para $30 \%$ de etanol a $40{ }^{\circ} \mathrm{C}: \mathrm{t}_{\mathrm{R}}=7.43 \mathrm{~min} .[\alpha]_{\mathrm{D}}^{25}=+6.29(\mathrm{c}=0.540, \mathrm{MeOH})$. RMN de ${ }^{1} \mathrm{H}(500 \mathrm{MHz}$, DMSO- $\left.d_{6}\right) \delta 7.59-7.42(\mathrm{~m}, 1 \mathrm{H}), 7.36-7.20(\mathrm{~m}, 10 \mathrm{H}), 5.04-4.94(\mathrm{~m}, 2 \mathrm{H}), 4.81-4.72(\mathrm{~m}$, $J=12.3,7.1 \mathrm{~Hz}, 1 \mathrm{H}), 3.11(\mathrm{~s}, 3 \mathrm{H}), 3.04$ (s, 3H), 2.95 (dd, $J=13.9,5.3 \mathrm{~Hz}, 1 \mathrm{H}), 2.89$ (dd, $J=$ 13.8, 9.0 Hz, 1H). RMN de ${ }^{13} \mathrm{C}\left(126 \mathrm{MHz}, \mathrm{CDCl}_{3}\right) \delta 173.30,155.99,135.99,135.35,129.22$, $128.79,128.52$, 128.20, 127.96, 127.35, 113.38, 67.03, 51.99, 41.21, 38.39, 30.46. MS (ESI): $\mathrm{m} / \mathrm{z}$ calculado $\left[\mathrm{C}_{20} \mathrm{H}_{22} \mathrm{~N}_{4} \mathrm{O}_{3}\right]$ 366.4137, observado: $367.21[\mathrm{M}+\mathrm{H}]^{+}$. Lit. $^{137}$ 
il)carbamato (18)

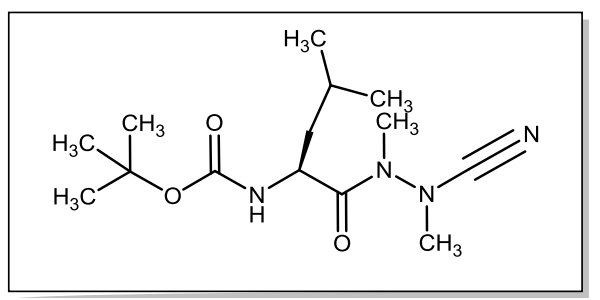

a) (tert-butoxycarbonil)-L-leucine (Boc-Leu-OH). O aminoácido Leucina foi protegido com BOC, utilizando o procedimento geral 2 (7.2.3), para obter o intermediário Boc-Leu-OH $\quad(1.84 \mathrm{~g}, \quad 90 \%$ de rendimento). ${ }^{138}$ b) Em seguida, o produto final foi obtido usando o 7.3.18 (partes a e b), e o intermediário Boc-Leu-OH como material de partida. A purificação final foi realizada por HPLC seguindo o protocolo mostrado nas considerações gerais, usando $70 \%$ de hexano para $30 \%$ de etanol a $60{ }^{\circ} \mathrm{C}: \mathrm{t}_{\mathrm{R}}=6.24 \mathrm{~min}$. $[\alpha]^{25}=+4.15(\mathrm{c}=0.241, \mathrm{MeOH}) . \mathrm{RMN} d e{ }^{1} \mathrm{H}\left(500 \mathrm{MHz}, \mathrm{CDCl}_{3}\right) \delta 4.96(\mathrm{~d}, J=8.9 \mathrm{~Hz}, 1 \mathrm{H})$, $4.77(\mathrm{dd}, J=14.8,8.1 \mathrm{~Hz}, 1 \mathrm{H}), 3.25$ (s, 3H), 3.20 (s, 3H), $1.81-1.72$ (m, 2H), $1.52-1.47$ $(\mathrm{m}, 2 \mathrm{H}), 1.42(\mathrm{~s}, 9 \mathrm{H}), 1.02(\mathrm{~d}, J=6.5 \mathrm{~Hz}, 3 \mathrm{H}), 0.97(\mathrm{~d}, J=6.7 \mathrm{~Hz}, 3 \mathrm{H}) . \mathrm{RMN}$ de ${ }^{13} \mathrm{C}(500$ $\left.\mathrm{MHz}, \mathrm{CDCl}_{3}\right) \delta 175.01,155.75,113.54,79.87,49.07,41.60,41.03,30.43,28.30,24.82$, 23.23, 21.35. MS (ESI):m/z calculado[ $\left[\mathrm{C}_{14} \mathrm{H}_{26} \mathrm{~N}_{4} \mathrm{O}_{3}\right]$ 298.3812, observado: $299.22[\mathrm{M}+\mathrm{H}]^{+}$.

\subsubsection{3-tert-butil-N-[(1S)-1-(N'-ciano-N,N'-dimetilhidrazinacarbonil)-2-feniletil]-1- metil-1H-pirazol-5-carboxamida (19)}

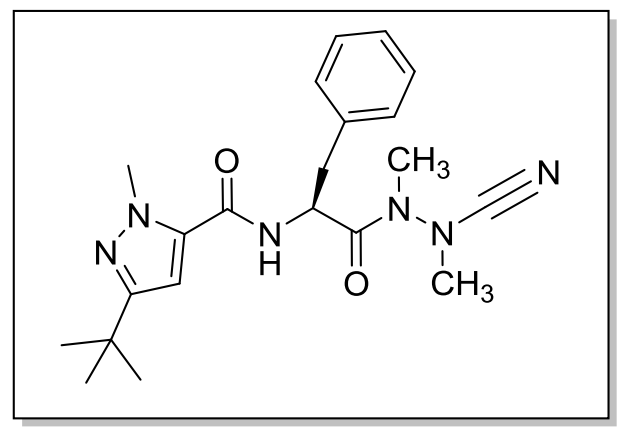

a) (tert-butoxycarbonil)-L-Fenilalanina (Boc-Phe$\boldsymbol{O H}$ ). O aminoácido Fenilalanina foi protegido com BOC, utilizando o procedimento geral 2 (7.2.3), para obter o intermediário Boc-Phe-OH (1.56 g, 97\% rendimento). ${ }^{138}$ b) tert-butil $\quad N-\left[(1 S)-1-\left(N, N^{\prime}-\right.\right.$ dimetilhidrazinacarbonil)-2-feniletil]carbamato (BocPhe-DMH). Em seguida, utilizando Boc-Phe-OH, o intermediário de interesse foi obtido usando o procedimento 7.3.18 (parte a). O óleo viscoso obtido foi purificado por coluna cromatográfica de alumina (usando EtOAc/n-hexano 40:60 $v / v$ como fase móvel), resultando no produto desejado, um sólido branco (0.435 g, $75 \%$ de rendimento). RMN de ${ }^{1} \mathrm{H}\left(500 \mathrm{MHz}, \mathrm{DMSO}-d_{6}\right): \delta$ 7.27-7.16 (m, 5H), $6.70(\mathrm{~d}, \mathrm{~J}=9.0 \mathrm{~Hz}$, 2H), $4.96(\mathrm{dt}, \mathrm{J}=9.5 \mathrm{~Hz}, \mathrm{~J}=3.0 \mathrm{~Hz}, 1 \mathrm{H}), 4.90(\mathrm{q}, \mathrm{J}=5.5 \mathrm{~Hz}, 1 \mathrm{H}), 2.95$ (s, 3H), 2.87 (dd, J = $13.0 \mathrm{~Hz}, \mathrm{~J}=4.0 \mathrm{~Hz}, 1 \mathrm{H}), 2.64(\mathrm{dd}, \mathrm{J}=13.5 \mathrm{~Hz}, \mathrm{~J}=10.0 \mathrm{~Hz}, 1 \mathrm{H}), 2.47$ (m, 3H, parcialmente sobreposto com DMSO); 1.29 (s, 9H). c) O intermediário obtido Boc-Phe-DMH foi 
desprotegido utilizando o procedimento geral 3 (7.2.4). d) 3-tert-butil-N-[(1S)-1-(N,N'dimetilhidrazinacarbonil)-2-feniletil]-1-methyl-1H-pirazol-5-carboxamida

(PyrA-PheDMH). O Boc-Phe-DMH foi acoplado ao acido 3-tert-butil-1-metil-1H-pirazol-5-carboxilico $(0.090 \mathrm{~g}, 0.49 \mathrm{mmol})$ de acordo com o procedimento geral 1 (7.2.2), com as modificações a seguir. $\mathrm{O}$ sal de TFA foi suspenso em $\mathrm{CH}_{2} \mathrm{Cl}_{2}(3 \mathrm{~mL})$ e tratado com trietilamina (136 $\mu \mathrm{L}, 0,98$ mmol) a $0^{\circ} \mathrm{C}$. A mistura resultante foi combinada com o ácido ativado e agitada durante $18 \mathrm{~h}$ à temperatura ambiente. $\mathrm{O}$ óleo viscoso obtido foi purificado por coluna cromatográfica (silica gel, usando EtOAc como fase móvel), resultando no produto desejado (33\% de rendimento). RMN de ${ }^{1} \mathrm{H}\left(500 \mathrm{MHz}, \mathrm{DMSO}_{-} d_{6}\right): \delta 8.37\left(\mathrm{~d}, \mathrm{~J}=8.5 \mathrm{~Hz}, 1 \mathrm{H}, \mathrm{D}_{2} \mathrm{O}\right.$ trocado), 7.30-7.15 (m, 5H), $6.83(\mathrm{~s}, 1 \mathrm{H}), 5.46(\mathrm{~m}, 1 \mathrm{H}), 4.98\left(\mathrm{q}, \mathrm{J}=5.5 \mathrm{~Hz}, 1 \mathrm{H}, \mathrm{D}_{2} \mathrm{O}\right.$ trocado), 3.85 (s, $3 \mathrm{H}), 3.02-2.96(\mathrm{~m}, 4 \mathrm{H}), 2.86(\mathrm{dd}, \mathrm{J}=10.5 \mathrm{~Hz}, \mathrm{~J}=8.5 \mathrm{~Hz}, 1 \mathrm{H}), 2.53(\mathrm{~d}, \mathrm{~J}=5.5 \mathrm{~Hz}, 3 \mathrm{H}), 1.23$ $(\mathrm{s}, 9 \mathrm{H})$. e) $\mathrm{O}$ composto de interesse foi obtido utilizando o intermediário PyrA-Phe-DMH e o procedimento 7.3.18 (parte b). O produto foi purificado por coluna cromatográfica [silica gel, usando EtOAc/ $n$-hexano 70:30 v/v como fase móvel], resultando no produto desejado, um sólido pálido (0.40g, 40\% rendimento). A purificação final foi realizada por HPLC seguindo o protocolo mostrado nas considerações gerais (Acetonitrila/Água: 50:50): $\mathrm{t}_{\mathrm{R}}: 13.21 .[\alpha]_{\mathrm{D}}{ }^{24}$ : 9, $1^{\circ}$. RMN de ${ }^{1} \mathrm{H}\left(500 \mathrm{MHz}, 85^{\circ} \mathrm{C}\right.$, DMSO- $\left.d_{6}\right): \delta 8.51(\mathrm{~d}, \mathrm{~J}=8.0 \mathrm{~Hz}, 1 \mathrm{H}), 7.31-7.19(\mathrm{~m}, 5 \mathrm{H})$, $6.76(\mathrm{~s}, 1 \mathrm{H}), 5.14(\mathrm{~m}, 1 \mathrm{H}), 3.87(\mathrm{~s}, 3 \mathrm{H}), 3.14-3.00(\mathrm{~m}$, parcialmente sobreposto com o sinal da $\left.\mathrm{H}_{2} \mathrm{O}\right), 1.25$ (s, 9H). RMN de ${ }^{13} \mathrm{C}\left(125 \mathrm{MHz}, 85^{\circ} \mathrm{C}\right.$, DMSO- $\left.d_{6}\right): \delta 160.14,159.46,159.45$, $137,77,135.50,129.54,128.70,127.01,114.26$, 104.30, 51.30, 38.74, 37.11, 37.10, 37.09, 32.03, 30.82. MS (ESI):m/z calculado $\left[\mathrm{C}_{21} \mathrm{H}_{29} \mathrm{~N}_{6} \mathrm{O}_{2}\right]$ 298.2356, observado: $397.2348[\mathrm{M}+$ $\mathrm{H}]^{+}$.

\subsubsection{3-tert-butil-N-[(1S)-1-(N'-ciano-N,N'-dimetilhidrazinacarbonil)-3-metilbutil]-1- metil-1H-pirazol-5-carboxamida (20)}

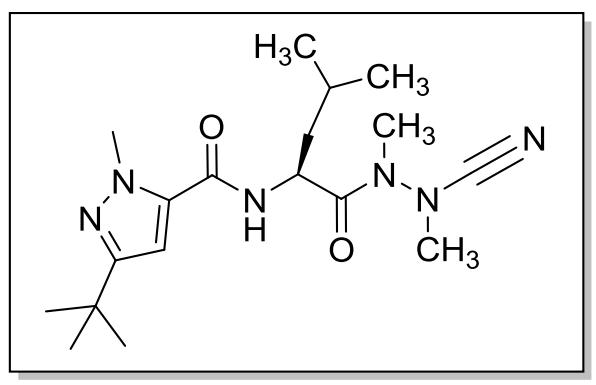

realizada por HPLC seguindo o protocolo mostrado nas considerações gerais

(Acetonitrila/Água: 50:50, $\left.\mathrm{T}=32^{\circ} \mathrm{C}\right): \mathrm{t}_{\mathrm{R}}: 12.02 .[\alpha] \mathrm{D}^{22}:+8.98^{\circ}(\mathrm{c}=0.245, \mathrm{MeOH}) . \mathrm{RMN}$ de

Os procedimentos 7.3.18 (a-e) foram seguidos para obter o produto final, partindo do amoniácido leucina. $\mathrm{O}$ produto foi purificado por coluna cromatográfica [silica gel, usando EtOAc/n-hexano 60:40 $v / v$ como fase móvel], resultando no produto desejado, um sólido ceroso (71\% de rendimento). A purificação final foi 
${ }^{1} \mathrm{H}\left(500 \mathrm{MHz}, 85^{\circ} \mathrm{C}, \mathrm{DMSO}-d_{6}\right): \delta 8.34(\mathrm{~d}, \mathrm{~J}=7.5 \mathrm{~Hz}, 1 \mathrm{H}), 6.83(\mathrm{~s}, 1 \mathrm{H}), 4.98(\mathrm{~m}, 1 \mathrm{H}), 3.96$ (s, 3H), 3.22 (s, 3H), 3.16 (s, 3H), 1.79-1.69 (m, 2H), 1.50-1.45 (m, 1H), 1.27 (s, 9H), 0.96 (d, $\mathrm{J}=6.5 \mathrm{~Hz}, 6 \mathrm{H}) . \mathrm{RMN}$ de ${ }^{13} \mathrm{C}\left(125 \mathrm{MHz}, 85^{\circ} \mathrm{C}, \mathrm{DMSO}-d_{6}\right): \delta 160.37,159.48,135.51,114.43$, 104.33, 48.42, 38.86, 32.04, 30.83, 25.01, 23.30, 21.69. MS (ESI): m/z calculado $\left[\mathrm{C}_{18} \mathrm{H}_{31} \mathrm{~N}_{6} \mathrm{O}_{2}\right]$ 363.2503, observado: $=363.2509\left([\mathrm{M}+\mathrm{H}]^{+}\right)$.

\subsection{Procedimentos experimentais para síntese dos compostos do tipo imidazopiridina}

\subsubsection{Procedimento geral 4 - sínteses dos intermediários imidazopiridina}

Em balão de fundo redondo seco foi adicionado diaminopiridina/pirimidina apropriada (1 eq.), bicarbonato de sódio (1.05 eq.) e metanol sob uma atmosfera de argônio. O reagente bromoacetofenona apropriado (1.05 eq.) foi adicionado lentamente à temperatura ambiente. Em seguida, a mistura reacional foi agitada a refluxo durante $12 \mathrm{~h}$. A mistura reacional foi colocada à temperatura ambiente, diluída com água, evaporado o solvente orgânico e extraída a água com EtOAc. Após secagem sobre sulfato de sódio e evaporação do solvente, o produto foi purificado em coluna cromatográfica Combiflash de sílica gel com eluente $0-100 \%$ de EtOAc em hexano. ${ }^{139}$

7.3.1.1 2-fenilimidazo[1,2-a]piridin-7-amina (a) foi preparado partindo de piridina-2,4-

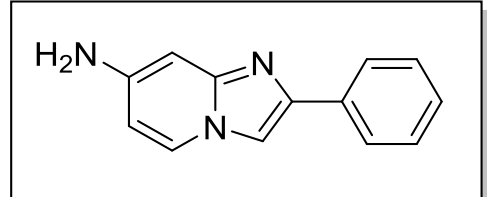
diamina e 2-bromo-1-feniletan-1-ona, de acordo com o procedimento geral 4, 7.3.1. (250 mg, 52\%); RMN de ${ }^{1} \mathrm{H}(300$ $\mathrm{MHz}, \mathrm{MeOD}) \delta 7.94(\mathrm{~d}, J=7.2 \mathrm{~Hz}, 1 \mathrm{H}), 7.77(\mathrm{~d}, J=7.7 \mathrm{~Hz}$, 2H), $7.70(\mathrm{~s}, 1 \mathrm{H}), 7.33(\mathrm{t}, J=7.6 \mathrm{~Hz}, 2 \mathrm{H}), 7.27-7.17(\mathrm{~m}$,

$1 \mathrm{H}), 6.49(\mathrm{~s}, 1 \mathrm{H}), 6.38(\mathrm{dd}, J=7.2,1.6 \mathrm{~Hz}, 1 \mathrm{H})$. ESI-MS calculado para $\mathrm{C}_{13} \mathrm{H}_{12} \mathrm{~N}_{3}(\mathrm{M}+\mathrm{H})^{+}$ 210.10, observado 209.9 .

7.3.1.2 2-(3-fluorofenil)imidazo[1,2-a]piridin-7-amina (b) foi preparado partindo de

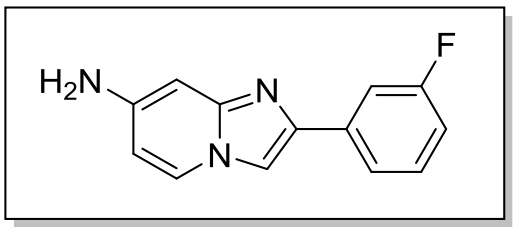
piridina-2,4-diamina e 2-bromo-1-(3-fluorofenil)etan-1-ona, de acordo com o procedimento geral 4, 7.3.1. (469 mg, 47\%); RMN de ${ }^{1} \mathrm{H}(500 \mathrm{MHz}, \mathrm{MeOD}) \delta 7.72(\mathrm{~d}, J=7.0 \mathrm{~Hz}, 1 \mathrm{H})$, $7.51(\mathrm{~s}, 1 \mathrm{H}), 7.43-7.31(\mathrm{~m}, 2 \mathrm{H}), 7.15(\mathrm{dd}, J=13.8,6.8 \mathrm{~Hz}$,

$1 \mathrm{H}), 6.79(\mathrm{t}, J=8.2 \mathrm{~Hz}, 1 \mathrm{H}), 6.34(\mathrm{~s}, 1 \mathrm{H}), 6.22$ (d, $J=7.0 \mathrm{~Hz}, 1 \mathrm{H})$. ESI-MS calculado para $\mathrm{C}_{13} \mathrm{H}_{11} \mathrm{FN}_{3}(\mathrm{M}+\mathrm{H})^{+}$228.09, observado 227.9. 
7.3.1.3 2-(2,3-difluorofenil)imidazo[1,2-a]piridin-7-amina (c) foi preparado partindo de

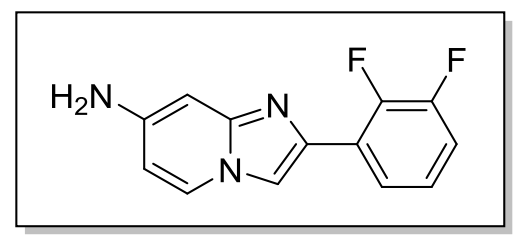
piridina-2,4-diamina e 2-bromo-1-(2,3-difluorofenil)etan-1ona, de acordo com o procedimento geral 4, 7.3.1. (168 mg, $40 \%)$; RMN de ${ }^{1} \mathrm{H}(300 \mathrm{MHz}, \mathrm{MeOD}) \delta 8.07$ (d, $J=7.3 \mathrm{~Hz}$, 1H), $7.89(\mathrm{~d}, J=3.9 \mathrm{~Hz}, 1 \mathrm{H}), 7.87-7.80(\mathrm{~m}, 1 \mathrm{H}), 7.24-$ $7.10(\mathrm{~m}, 2 \mathrm{H}), 6.52(\mathrm{~s}, 1 \mathrm{H}), 6.47(\mathrm{dd}, J=7.3,2.1 \mathrm{~Hz}, 1 \mathrm{H})$. ESI-MS calculado para $\mathrm{C}_{13} \mathrm{H}_{10} \mathrm{~F}_{2} \mathrm{~N}_{3}$ $(\mathrm{M}+\mathrm{H})^{+}$246.08, observado 245.9 .

7.3.1.4 2-(3,4-difluorofenil)imidazo[1,2-a]piridin-7-amina (d) foi preparado partindo de

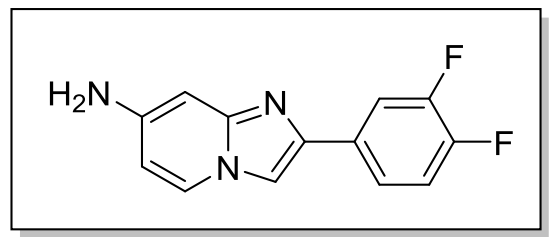
piridina-2,4-diamina e 2-bromo-1-(3,4-difluorofenil)etan1-ona, de acordo com o procedimento geral 4, 7.3.1. (250 $\mathrm{mg}, 65 \%)$; RMN de ${ }^{1} \mathrm{H}(300 \mathrm{MHz}, \mathrm{MeOD}) \delta 8.01(\mathrm{~d}, J=$ $7.0 \mathrm{~Hz}, 1 \mathrm{H}), 7.78(\mathrm{~s}, 1 \mathrm{H}), 7.68$ (ddd, $J=11.8,8.6,1.6 \mathrm{~Hz}$, 1H), $7.61-7.52(\mathrm{~m}, 1 \mathrm{H}), 7.24(\mathrm{dd}, J=18.0,11.2 \mathrm{~Hz}, 1 \mathrm{H}), 6.50(\mathrm{~s}, 1 \mathrm{H}), 6.46(\mathrm{~d}, J=7.2 \mathrm{~Hz}$, 1H). ESI-MS calculado para $\mathrm{C}_{13} \mathrm{H}_{10} \mathrm{~F}_{2} \mathrm{~N}_{3}(\mathrm{M}+\mathrm{H})^{+}$246.08, observado 245.9.

7.3.1.5 2-(1,3-tiazol-2-il)imidazo[1,2-a]piridin-7-amina (e) foi preparado partindo de

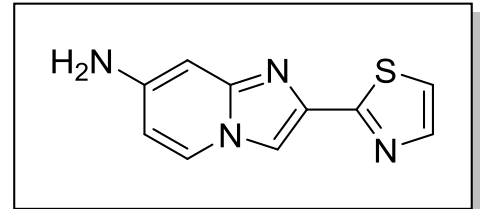
piridina-2,4-diamina e 2-bromo-1-(1,3-tiazol-2-il)etan-1-ona, de acordo com o procedimento geral 4, 7.3.1 (235 mg, 60\%); RMN de ${ }^{1} \mathrm{H}(500 \mathrm{MHz}, \mathrm{MeOD}) \delta 8.12(\mathrm{~d}, J=8.1 \mathrm{~Hz}, 1 \mathrm{H})$, $8.01(\mathrm{~s}, 1 \mathrm{H}), 7.84(\mathrm{~d}, J=3.3 \mathrm{~Hz}, 1 \mathrm{H}), 7.57(\mathrm{~d}, J=3.3 \mathrm{~Hz}, 1 \mathrm{H})$, $6.52(\mathrm{dd}, J=8.1,3.5 \mathrm{~Hz}, 1 \mathrm{H}), 6.51(\mathrm{~d}, J=3.5 \mathrm{~Hz}, 1 \mathrm{H})$. ESI-MS calculado para $\mathrm{C}_{10} \mathrm{H}_{9} \mathrm{~N}_{4} \mathrm{~S}$ $(\mathrm{M}+\mathrm{H})^{+}$217.05, observado 216.9 .

7.3.1.6 2-(tiofen-2-il)imidazo[1,2-a]piridin-7-amina (f) foi preparado partindo de piridina-

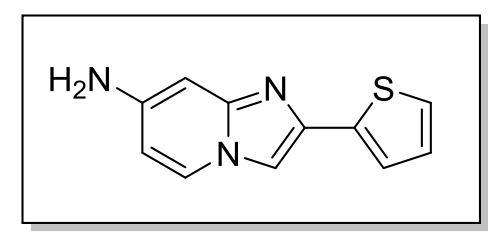

2,4-diamina e 2-bromo-1-(tiofen-2-il)etan-1-ona, de acordo com o procedimento geral 4, 7.3.1 (290 mg, 69\%); RMN de ${ }^{1} \mathrm{H}(500$ $\mathrm{MHz}, \mathrm{MeOD}) \delta 7.80(\mathrm{~d}, J=7.5 \mathrm{~Hz}, 1 \mathrm{H}), 7.48$ (s, 1H), 7.24 (dd, $J=3.6,1.0 \mathrm{~Hz}, 1 \mathrm{H}), 7.18(\mathrm{dd}, J=5.0,1.0 \mathrm{~Hz}, 1 \mathrm{H}), 6.91(\mathrm{dd}, J$ $=5.0,3.6 \mathrm{~Hz}, 1 \mathrm{H}), 6.36(\mathrm{~d}, J=2.1 \mathrm{~Hz}, 1 \mathrm{H}), 6.27(\mathrm{dd}, J=7.5,2.1 \mathrm{~Hz}, 1 \mathrm{H})$. ESI-MS calculado para $\mathrm{C}_{11} \mathrm{H}_{10} \mathrm{~N}_{3} \mathrm{~S}(\mathrm{M}+\mathrm{H})^{+} 216.05$, observado 215.9 . 
7.3.1.7 2-(3,4-difluorofenil)imidazo[1,2-a]pirimidin-7-amina (g) foi preparado partindo de

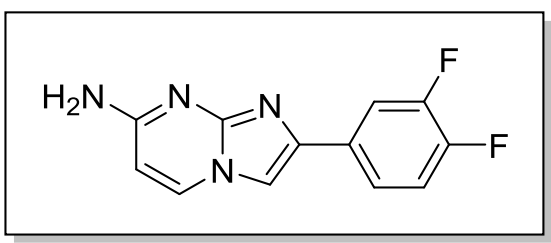

pirimidina-2,4-diamina

$\mathrm{e}$

2-bromo-1-(3,4-

difluorofenil)etan-1-ona, de acordo com o procedimento geral 4, 7.3.1. (287 mg, 45\%); RMN de ${ }^{1} \mathrm{H}(500 \mathrm{MHz}$, MeOD) $\delta 8.23(\mathrm{~d}, J=7.3 \mathrm{~Hz}, 1 \mathrm{H}), 7.69$ (ddd, $J=11.8$,

8.6, 1.6 Hz, 1H), 7.65 (s, 1H), $7.61-7.54(\mathrm{~m}, 1 \mathrm{H}), 7.31-7.19(\mathrm{~m}, 1 \mathrm{H}), 6.34$ (d, J = 7.3 Hz, 1H). ESI-MS calculado para $\mathrm{C}_{12} \mathrm{H}_{9} \mathrm{~F}_{2} \mathrm{~N}_{4}(\mathrm{M}+\mathrm{H})^{+}$247.07, observado 246.9 .

7.3.1.8 2-(3,4-difluorofenil)imidazo[1,2-c]pirimidin-7-amina (h) foi preparado partindo de

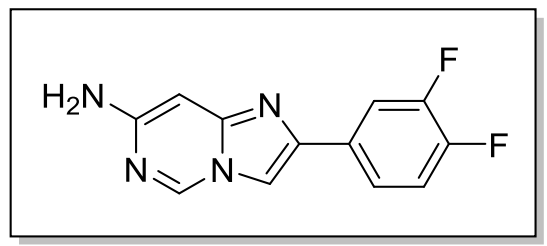

pirimidina-4,6-diamina

$\mathrm{e}$

2-bromo-1-(3,4difluorofenil)etan-1-ona, de acordo com o procedimento geral 4, 7.3.1. (426 mg, 58\%); RMN de ${ }^{1} \mathrm{H}(500 \mathrm{MHz}$, MeOD) $\delta 8.85(\mathrm{~s}, 1 \mathrm{H}), 7.93(\mathrm{~s}, 1 \mathrm{H}), 7.75$ (ddd, $J=11.8$, 8.6, 1.6 Hz, 1H), $7.68-7.63(\mathrm{~m}, 1 \mathrm{H}), 7.31$ (dd, $J=17.9,9.3 \mathrm{~Hz}, 1 \mathrm{H}), 6.34$ (s, 1H). ESI-MS calculado para $\mathrm{C}_{12} \mathrm{H}_{9} \mathrm{~F}_{2} \mathrm{~N}_{4}(\mathrm{M}+\mathrm{H})^{+} 247.07$, observado 246.9 .

7.3.1.9 2-(3,4-difluorofenil)imidazo[1,2-a]piridin-6-amina (i) foi preparado partindo de

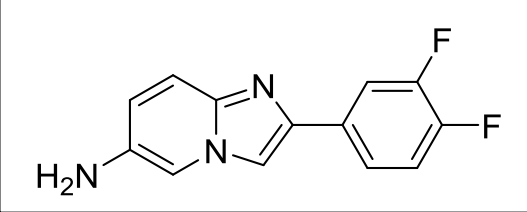

piridina-2,5-diamina e 2-bromo-1-(3,4-difluorofenil)etan-1ona, de acordo com o procedimento geral 4, 7.3.1. (245 mg, $65 \%)$; RMN de ${ }^{1} \mathrm{H}(500 \mathrm{MHz}, \mathrm{MeOD}) \delta 8.01$ (s, 1H), 7.84 (dd, $J=21.6,13.7 \mathrm{~Hz}, 1 \mathrm{H}), 7.78(\mathrm{~s}, 1 \mathrm{H}), 7.69-7.63(\mathrm{~m}$,

1H), $7.37(\mathrm{~d}, J=9.6 \mathrm{~Hz}, 1 \mathrm{H}), 7.31(\mathrm{dd}, J=18.1,9.1 \mathrm{~Hz}, 1 \mathrm{H}), 7.03$ (d, $J=9.5 \mathrm{~Hz}, 1 \mathrm{H})$. ESIMS calculado para $\mathrm{C}_{13} \mathrm{H}_{10} \mathrm{~F}_{2} \mathrm{~N}_{3}(\mathrm{M}+\mathrm{H})^{+} 246.08$, observado 245.9.

\subsubsection{Procedimento geral 5 - sínteses dos compostos derivados de ureia}

Uma solução com material de partida (a-i, 1 eq, tipicamente $250 \mathrm{mg}$ ) em $\mathrm{CH}_{2} \mathrm{Cl}_{2}$ anidro $(30 \mathrm{~mL})$ foi colocada sob argônio e resfriada a $5{ }^{\circ} \mathrm{C}$. Nesta solução, adicionoucuidadosamente trifosgênio (1 eq.), depois trietilamina (2 eq.). Após $30 \mathrm{~min}$, a reação foi deixada até à temperatura ambiente e agitada durante $1 \mathrm{~h}$. Em seguida, foi adicionada a amina secundária apropriada (2 eq.) gota a gota [se necessário, adicionou-se mais trietilamina ( 2 eq.) para neutralizar o sal de amina secundária] e a reação foi agitada durante a noite (15h). A mistura reacional foi então diluída com $\mathrm{H}_{2} \mathrm{O}$ e a fase aquosa foi separada e extraída com $\mathrm{CH}_{2} \mathrm{Cl}_{2}$. Após a secagem sobre sulfato de sódio e evaporação do solvente, o produto foi 
purificado em coluna cromatográfica CombiFlash de sílica gel, com 0-5\% de $\mathrm{MeOH}$ em DCM, como eluente; seguido de recristalização a partir de $\mathrm{MeOH}$, resultando em um sólido. 127

\subsubsection{Procedimento geral 6 - sínteses dos compostos derivados de amida}

Uma solução com o material de partida (d ou h, 1 eq., tipicamente $250 \mathrm{mg}$ ) em $\mathrm{CH}_{2} \mathrm{Cl}_{2}$ anidro $\left(30 \mathrm{~mL}\right.$ ) foi colocado sob argônio e resfriado a $0{ }^{\circ} \mathrm{C}$. A esta solução foi adicionada cuidadosamente uma solução do cloreto de carbonil apropriada (1,5 eq.), em trietilamina (2 eq.). A reação foi gradualmente deixada até à temperatura ambiente e agitada durante 16 horas, depois interrompida com água e extraída em $\mathrm{CH}_{2} \mathrm{Cl}_{2}$. Após a secagem sobre sulfato de sódio e evaporação do solvente, o produto foi purificado em coluna cromatográfica CombiFlash de sílica gel com 0-5\% de $\mathrm{MeOH}$ em DCM como eluente; seguido de recristalização a partir de $\mathrm{MeOH}$ para dar um sólido.

\subsubsection{N-\{2-fenilimidazo[1,2-a]piridin-7-il\}piperidina-1-carboxamida (21)}

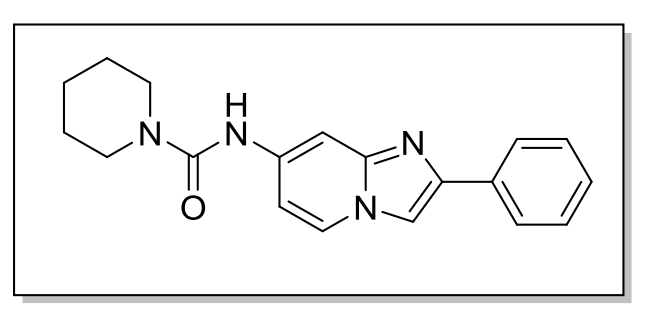

O composto 21 foi preparado partindo de 2fenilimidazo[1,2-a]piridin-7-amina (a) previamente sintetizado e piperidina, de acordo com o procedimento geral 5, 7.3.2. Um sólido marrom foi obtido (72 mg, 75\%); RMN de ${ }^{1} \mathrm{H}(500 \mathrm{MHz}$, MeOD) $\delta 8.16(\mathrm{~d}, J=7.3 \mathrm{~Hz}, 1 \mathrm{H}), 7.91(\mathrm{~s}, 1 \mathrm{H}), 7.73(\mathrm{~d}, J=7.6 \mathrm{~Hz}, 2 \mathrm{H}), 7.69$ (s, 1H), 7.33 (t, $J=7.5 \mathrm{~Hz}, 2 \mathrm{H}), 7.29-7.23(\mathrm{~m}, 1 \mathrm{H}), 7.06(\mathrm{dd}, J=7.2,1.7 \mathrm{~Hz}, 1 \mathrm{H}), 3.58-3.27(\mathrm{~m}, 6 \mathrm{H}), 1.64$ - $1.57(\mathrm{~m}, 2 \mathrm{H}), 1.57-1.50(\mathrm{~m}, J=3.5 \mathrm{~Hz}, 4 \mathrm{H})$. RMN de ${ }^{13} \mathrm{C}(126 \mathrm{MHz}, \mathrm{MeOD}) \delta$ 156.50, $146.68,143.59,142.07,132.99,129.87,129.42,127.78,126.81,110.51,109.48,101.36$, 49.00, 46.36, 26.98, 25.42, 23.70, 9.19. ESI-MS calculado para $\mathrm{C}_{19} \mathrm{H}_{21} \mathrm{~N}_{4} \mathrm{O}(\mathrm{M}+\mathrm{H})^{+} 321.17$, observado 321.1 . 


\subsubsection{N-\{2-fenilimidazo[1,2-a]piridin-7-il\}pirrolidina-1-carboxamida (22)}

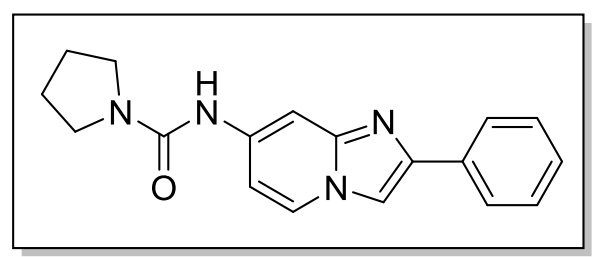

O composto 22 foi preparado partindo de 2fenilimidazo[1,2-a]piridin-7-amina (a) previamente sintetizado e pirrolidina, de acordo com o procedimento geral 5, 7.3.2. Um sólido branco foi obtido $(90 \mathrm{mg}$, 78\%); RMN de ${ }^{1} \mathrm{H}(500 \mathrm{MHz}, \mathrm{MeOD}) \delta 8.49$ (d, $\left.J=7.40 \mathrm{~Hz}, 1 \mathrm{H}\right), 8.25$ (s, 2H), 7.74 (d, $J=$ $7.70 \mathrm{~Hz}, 2 \mathrm{H}), 7.51-7.46(\mathrm{~m}, 3 \mathrm{H}), 7.44(\mathrm{dd}, 7.40,2.0 \mathrm{~Hz}, 1 \mathrm{H}), 3.50-3.40(\mathrm{~m}, 4 \mathrm{H}), 1.99$ $1.88(\mathrm{~m}, 4 \mathrm{H}) . \mathrm{RMN}$ de ${ }^{13} \mathrm{C}(126 \mathrm{MHz}, \mathrm{MeOD}) \delta 153.70,145.76,142.13,135.34,130.06$, 129.23, 128.56, 126.44, 125.60, 111.03, 109.50, 95.12, 46.00, 23.64. ESI-MS calculado para $\mathrm{C}_{18} \mathrm{H}_{19} \mathrm{~N}_{4} \mathrm{O}(\mathrm{M}+\mathrm{H})^{+}$307.15, observado 307.3.

\subsection{6 (3S)-3-fluoro-N-\{2-fenilimidazo[1,2-a]piridin-7-il\}pirrolidina-1-carboxamida (23)}

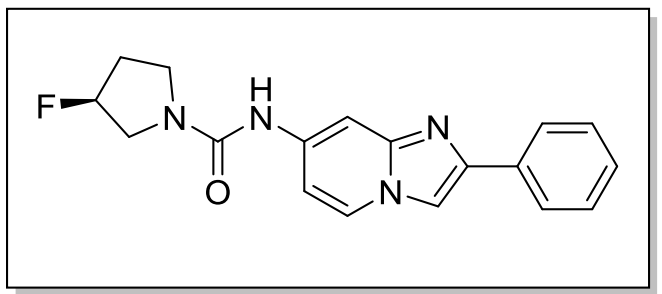

O composto $\mathbf{2 3}$ foi preparado partindo de 2fenilimidazo[1,2-a]piridin-7-amina (a) previamente sintetizado e (S)-(+)-3-Fluoropirrolidina/ $\mathrm{HCl}$, de acordo com o procedimento geral 5, 7.3.2. Um sólido amarelo pálido foi obtido (78 $\mathrm{mg}, 76 \%)$;

RMN de ${ }^{1} \mathrm{H}(300 \mathrm{MHz}, \mathrm{MeOD}) \delta 8.23(\mathrm{~d}, J=7.40 \mathrm{~Hz}, 1 \mathrm{H}), 7.98(\mathrm{~s}, 1 \mathrm{H}), 7.83$ (dd, $J=7.40$, 2H), $7.80(\mathrm{~d}, J=1.90 \mathrm{~Hz}, 1 \mathrm{H}), 7.40(\mathrm{t}, J=7.4 \mathrm{~Hz}, 2 \mathrm{H}), 7.35-7.27(\mathrm{~m}, 1 \mathrm{H}), 7.15$ (dd, $J=$ 7.40, $2.0 \mathrm{~Hz}, 1 \mathrm{H}), 5.30(\mathrm{dm}, J=52.7 \mathrm{~Hz}, 1 \mathrm{H}), 3.86-3.49(\mathrm{~m}, 4 \mathrm{H}), 2.37-1.98(\mathrm{~m}, 2 \mathrm{H})$. $\mathrm{RMN}$ de ${ }^{13} \mathrm{C}$ (75 MHz, MeOD) $\delta 156.12,147.44,145.31,140.62,134.13,129.79,129.15$, 127.50, 126.95, 110.14, $109.20(\mathrm{~d}, J=19.3 \mathrm{~Hz}), 102.79,93.69\left(\mathrm{~d},{ }^{1} J_{\mathrm{CF}}=174.9 \mathrm{~Hz}, 3-\right.$ $\left.\mathrm{C}_{\text {pirrolidinil }}\right), 53.83\left(\mathrm{~d},{ }^{2} J_{\mathrm{CCF}}=23.2 \mathrm{~Hz}, 2-\mathrm{C}_{\text {pirrolidinil }}\right), 44.94,33.02\left(\mathrm{~d}, J=22.3 \mathrm{~Hz}, 4-\mathrm{C}_{\text {pirrolidinil }}\right)$. ESI-MS calculado para $\mathrm{C}_{18} \mathrm{H}_{18} \mathrm{FN}_{4} \mathrm{O}(\mathrm{M}+\mathrm{H})^{+} 325.14$, observado 325.1 .

\subsubsection{N-[2-(3-fluorofenil)imidazo[1,2-a]piridin-7-il]piperidina-1-carboxamida(24)}

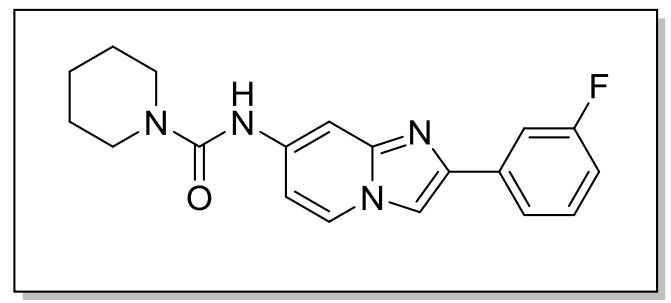

O composto 24 foi preparado partindo de 2-(3fluorofenil)imidazo[1,2-a]piridin-7-amina previamente sintetizado e piperidina, de acordo com o procedimento geral 5 , 7.3.2. Um sólido amarelo 
pálido foi obtido (65 mg, 55\%); RMN de ${ }^{1} \mathrm{H}(500 \mathrm{MHz}, \mathrm{MeOD}) \delta 8.20(\mathrm{~d}, J=7.4 \mathrm{~Hz}, 1 \mathrm{H})$, $8.01(\mathrm{~s}, 1 \mathrm{H}), 7.71(\mathrm{~d}, J=1.40 \mathrm{~Hz}, 1 \mathrm{H}), 7.57(\mathrm{~d}, J=7.8 \mathrm{~Hz}, 1 \mathrm{H}), 7.51(\mathrm{~d}, J=10.20 \mathrm{~Hz}, 1 \mathrm{H})$, $7.36(\mathrm{td}, J=7.80,6.0 \mathrm{~Hz}, 1 \mathrm{H}), 7.09(\mathrm{dd}, J=7.40,1.90 \mathrm{~Hz}, 1 \mathrm{H}), 7.00(\mathrm{td}, J=10.20,7.80,2.4$ $\mathrm{Hz}, 1 \mathrm{H}), 3.50-3.46(\mathrm{~m}, 4 \mathrm{H}), 1.67-1.61(\mathrm{~m}, 2 \mathrm{H}), 1.60-1.54(\mathrm{~m}, J=4 \mathrm{H})$. ESI-MS calculado para $\mathrm{C}_{19} \mathrm{H}_{20} \mathrm{FN}_{4} \mathrm{O}(\mathrm{M}+\mathrm{H})^{+} 339.16$, observado 339.1 .

\subsubsection{N-[2-(3-fluorofenil)imidazo[1,2-a]piridin-7-il]pirrolidina-1-carboxamida(25)}

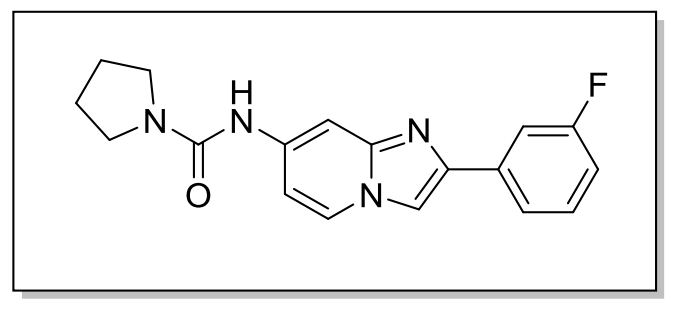

O composto 25 foi preparado partindo de 2-(3fluorofenil)imidazo[1,2-a]piridin-7-amina previamente sintetizado e pirrolidina, de acordo com o procedimento geral 5, 7.3.2. Um sólido laranja foi obtido $(71 \mathrm{mg}, 48 \%)$; RMN de ${ }^{1} \mathrm{H}(500$ $\mathrm{MHz}, \mathrm{MeOD}) \delta 8.02(\mathrm{~d}, J=7.25 \mathrm{~Hz}, 1 \mathrm{H}), 7.84(\mathrm{~s}, 1 \mathrm{H}), 7.63(\mathrm{~s}, 1 \mathrm{H}), 7.53$ (d, $J=7.70 \mathrm{~Hz}$, $1 \mathrm{H}), 7.47(\mathrm{~d}, J=10.4 \mathrm{~Hz}, 1 \mathrm{H}), 7.28(\mathrm{td}, J=7.70,6.00 \mathrm{~Hz}, 1 \mathrm{H}), 6.96(\mathrm{dd}, J=7.25,3.25 \mathrm{~Hz}$, $1 \mathrm{H}), 6.91(\mathrm{dd}, J=10.40,7.70 \mathrm{~Hz}, 1 \mathrm{H}), 3.32(\mathrm{~s}, 4 \mathrm{H}), 1.82(\mathrm{~s}, 4 \mathrm{H}) . \mathrm{RMN}$ de ${ }^{13} \mathrm{C}(126 \mathrm{MHz}$, MeOD) $\delta 164.64\left(\mathrm{~d},{ }^{1} J_{\mathrm{CF}}=243.60 \mathrm{~Hz}, 3-\mathrm{C}_{\text {benzeno }}\right), 156.03,147.96,144.74(\mathrm{~s}), 140.28(\mathrm{~s})$, $137.37\left(\mathrm{~d},{ }^{3} J_{\mathrm{CCCF}}=8.20 \mathrm{~Hz}, 1-\mathrm{C}_{\text {benzeno }}\right), 131.45\left(\mathrm{~d},{ }^{3} J_{\mathrm{CCCF}}=8.40 \mathrm{~Hz}, 5-\mathrm{C}_{\text {benzeno }}\right), 127.19(\mathrm{~s})$, $122.60\left(\mathrm{~d},{ }^{4} J_{\mathrm{CCCCF}}=2.4 \mathrm{~Hz}, 6-\mathrm{C}_{\text {benzeno }}\right), 115.28\left(\mathrm{~d},{ }^{2} J_{\mathrm{CCF}}=21.4 \mathrm{~Hz}, 4-\mathrm{C}_{\text {benzeno }}\right), 113.35(\mathrm{~d}$, ${ }^{2} J_{\mathrm{CCF}}=23.0 \mathrm{~Hz}, 2-\mathrm{C}_{\text {benzeno}}$ ), 109.88 (s), 109.76 (s), 102.81 (s), 47.08 (s), 26.37 (s). ESI-MS calculado para $\mathrm{C}_{18} \mathrm{H}_{18} \mathrm{FN}_{4} \mathrm{O}(\mathrm{M}+\mathrm{H})^{+} 325.14$, observado 325.1 .

\subsection{9 (3S)-3-fluoro-N-[2-(3-fluorofenil)imidazo[1,2-a]piridin-7-il]pirrolidina-1- carboxamida (26)}

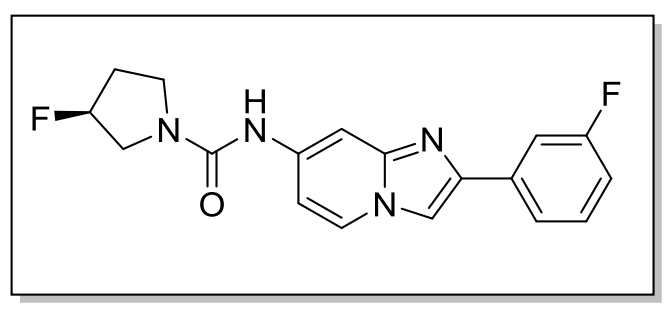

O composto 26 foi preparado partindo de 2-(3fluorofenil)imidazo[1,2-a]piridin-7-amina previamente sintetizado e $(\mathrm{S})-(+)-3-$ Fluoropirrolidina/ $\mathrm{HCl}$, de acordo com o procedimento geral 5, 7.3.2. Um sólido laranja foi obtido (75 mg, 49\%); RMN de ${ }^{1} \mathrm{H}(500 \mathrm{MHz}, \mathrm{MeOD}) \delta 8.18$ (d, $\left.J=7.25 \mathrm{~Hz}, 1 \mathrm{H}\right), 7.99$ (s, 1H), $7.71(\mathrm{~s}, 1 \mathrm{H}), 7.61(\mathrm{~d}, J=7.65 \mathrm{~Hz}, 1 \mathrm{H}), 7.55(\mathrm{~d}, J=10.25 \mathrm{~Hz}, 1 \mathrm{H}), 7.35(\mathrm{td}, J=7.65,6.0$ $\mathrm{Hz}, 1 \mathrm{H}), 7.09$ (dd, $J=7.25,3.5 \mathrm{~Hz}, 1 \mathrm{H}), 6.97(\mathrm{dd}, J=10.25,7.65 \mathrm{~Hz}, 1 \mathrm{H}), 5.26(\mathrm{dm}, J=52.7$ $\mathrm{Hz}, 1 \mathrm{H}), 3.78-3.47(\mathrm{~m}, 4 \mathrm{H}), 2.30-2.04(\mathrm{~m}, 2 \mathrm{H}) . \mathrm{RMN}$ de ${ }^{13} \mathrm{C}(126 \mathrm{MHz}, \mathrm{MeOD}) \delta 164.71$ 
$\left(\mathrm{q},{ }^{1} J_{\mathrm{CF}}=243.4,3-\mathrm{C}_{\text {benzeno }}\right), 156.21,148.02,144.98,140.20,137.38\left(\mathrm{~d},{ }^{3} J_{\mathrm{CCCF}}=8.1 \mathrm{~Hz}, 1-\right.$

$\left.\mathrm{C}_{\text {benzeno }}\right), 131.53\left(\mathrm{~d},{ }^{3} J_{\mathrm{CCCF}}=8.4 \mathrm{~Hz}, 5-\mathrm{C}_{\text {benzeno }}\right), 127.41,122.67\left(\mathrm{~d},{ }^{4} J_{\mathrm{CCCCF}}=2.6 \mathrm{~Hz}, 6-\right.$ $\left.\mathrm{C}_{\text {benzeno }}\right), 115.39\left(\mathrm{~d},{ }^{2} J_{\mathrm{CCF}}=21.4 \mathrm{~Hz}, 4-\mathrm{C}_{\text {benzeno }}\right), 113.42\left(\mathrm{~d},{ }^{2} J_{\mathrm{CCF}}=23.1 \mathrm{~Hz}, 2-\mathrm{C}_{\text {benzeno }}\right)$, 110.03, 109.88, 103.26, $93.79\left(\mathrm{~d},{ }^{1} J_{\mathrm{CF}}=195.3 \mathrm{~Hz}, 3-\mathrm{C}_{\text {pirrolidinil }}\right), 53.85\left(\mathrm{~d},{ }^{2} J_{\mathrm{CCF}}=23.1 \mathrm{~Hz}, 2-\right.$ $\left.\mathrm{C}_{\text {pirrolidinil }}\right)$, 44.95, 33.10. ESI-MS calculado para $\mathrm{C}_{18} \mathrm{H}_{17} \mathrm{~F}_{2} \mathrm{~N}_{4} \mathrm{O}(\mathrm{M}+\mathrm{H})^{+}$343.13, observado 343.1.

\subsubsection{N-[2-(2,3-difluorofenil)imidazo[1,2-a]piridin-7-il]piperidina-1-carboxamida (27)}

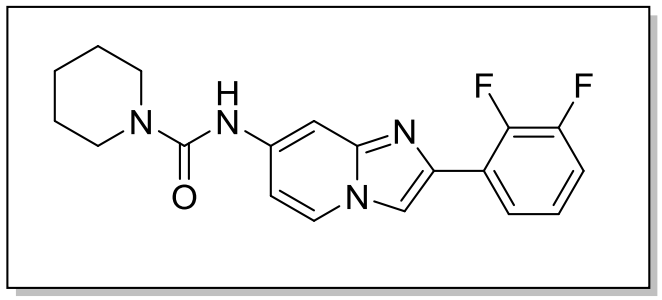

O composto 27 foi preparado partindo de 2-(2,3difluorofenil)imidazo[1,2-a]piridin-7-amina previamente sintetizado e piperidina, de acordo com o procedimento geral 5, 7.3.2. Um sólido amarelo foi obtido (83 mg, 58\%); RMN de ${ }^{1} \mathrm{H}(500 \mathrm{MHz}$, MeOD) $\delta 8.24(\mathrm{~s}, J=7.4,1 \mathrm{H}), 8.05(\mathrm{~d}, J=3.8 \mathrm{~Hz}, 1 \mathrm{H}), 7.89(\mathrm{t}, J=6.25 \mathrm{~Hz}, 1 \mathrm{H}), 7.68$ (s, 1H), $7.27-7.16(\mathrm{~m}, 2 \mathrm{H}), 7.08(\mathrm{dd}, J=7.4,2.1 \mathrm{~Hz}, 1 \mathrm{H}), 3.56-3.51(\mathrm{~m}, 4 \mathrm{H}), 1.74-1.67$ (m, $2 \mathrm{H}), 1.67-1.60(\mathrm{~m}, 4 \mathrm{H}) . \mathrm{RMN} d e{ }^{13} \mathrm{C}(126 \mathrm{MHz}, \mathrm{MeOD}) \delta 156.91,152.26$ (q, ${ }^{1} J_{\mathrm{CF}}=244.1$, $\left.{ }^{2} J_{\mathrm{CCF}}=11.8 \mathrm{~Hz}, 2-\mathrm{C}_{\text {benzeno }}\right), 149.42\left(\mathrm{q},{ }^{1} J_{\mathrm{CF}}=249.8,{ }^{2} J_{\mathrm{CCF}}=13.1 \mathrm{~Hz}, 3-\mathrm{C}_{\text {benzeno }}\right), 147.47$, $140.91,138.35\left(\mathrm{q},{ }^{3} J_{\mathrm{CCCF}}=6.30,{ }^{4} J_{\mathrm{CCCCF}}=3.60 \mathrm{~Hz}, 6-\mathrm{C}_{\mathrm{benzeno}}\right), 127.35,126.28\left(\mathrm{q},{ }^{3} J_{\mathrm{CCCF}}=\right.$ $\left.7.5,{ }^{4} J_{\mathrm{CCCCF}}=4.6 \mathrm{~Hz}, 5-\mathrm{C}_{\text {benzeno }}\right), 125.58,124.34,116.87\left(\mathrm{~d},{ }^{2} J_{\mathrm{CCF}}=17.3 \mathrm{~Hz}, 1-\mathrm{C}_{\text {benzeno }}\right)$, $113.06\left(\mathrm{~d},{ }^{2} J_{\mathrm{CCF}}=14.4 \mathrm{~Hz}, 4-\mathrm{C}_{\text {benzeno }}\right), 110.30,102.98,46.39,26.99,25.47$. ESI-MS calculado para $\mathrm{C}_{19} \mathrm{H}_{19} \mathrm{~F}_{2} \mathrm{~N}_{4} \mathrm{O}(\mathrm{M}+\mathrm{H})^{+} 357.15$, observado 357.1.

7.3.11 N-[2-(2,3-difluorofenil)imidazo[1,2-a]piridin-7-il]pirrolidina-1-carboxamida (28)

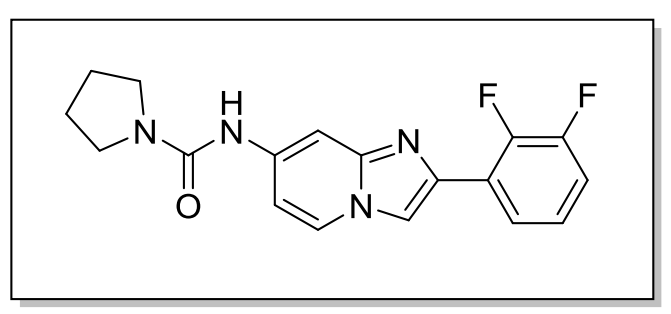

O composto 28 foi preparado partindo de 2-(2,3difluorofenil)imidazo[1,2-a]piridin-7-amina previamente sintetizado e pirrolidina, de acordo com o procedimento geral 5, 7.3.2. Um sólido amarelo foi obtido (81 mg, 58\%); RMN de ${ }^{1} \mathrm{H}(500 \mathrm{MHz}$, MeOD) $\delta 8.21(\mathrm{~d}, J=7.4 \mathrm{~Hz}, 1 \mathrm{H}), 8.02(\mathrm{~s}, 1 \mathrm{H}), 7.83(\mathrm{t}, J=6.8 \mathrm{~Hz}, 1 \mathrm{H}), 7.74(\mathrm{~s}, 1 \mathrm{H}), 7.19-$ $7.10(\mathrm{~m}, 2 \mathrm{H}), 7.09$ (d, $J=5.7 \mathrm{~Hz}, 1 \mathrm{H}), 3.41(\mathrm{~s}, 4 \mathrm{H}), 1.91(\mathrm{~s}, 4 \mathrm{H}) . \mathrm{RMN}$ de ${ }^{13} \mathrm{C}(126 \mathrm{MHz}$, $\mathrm{MeOD}) \delta 156.18,152.28\left(\mathrm{q},{ }^{1} J_{\mathrm{CF}}=244.2,{ }^{2} J_{\mathrm{CCF}}=12.0 \mathrm{~Hz}, 2-\mathrm{C}_{\mathrm{benzeno}}\right), 149.45\left(\mathrm{q},{ }^{1} J_{\mathrm{CF}}=\right.$ $\left.249.5,{ }^{2} J_{\mathrm{CCF}}=13.5 \mathrm{~Hz}, 3-\mathrm{C}_{\mathrm{benzeno}}\right), 147.51,140.67,138.44\left(\mathrm{q},{ }^{3} J_{\mathrm{CCCF}}=6.30,{ }^{4} J_{\mathrm{CCCCF}}=3.60 \mathrm{~Hz}\right.$, 
6- $\mathrm{C}_{\text {benzeno }}$ ), 127.48, 125.70 (q, ${ }^{3} J_{\mathrm{CCCF}}=7.5,{ }^{4} J_{\mathrm{CCCCF}}=4.6 \mathrm{~Hz}, 5-\mathrm{C}_{\text {benzeno }}$ ), 124.92, 124.34, $116.96\left(\mathrm{~d},{ }^{2} J_{\mathrm{CCF}}=17.5 \mathrm{~Hz}, 1-\mathrm{C}_{\text {benzeno }}\right), 113.14\left(\mathrm{~d},{ }^{2} J_{\mathrm{CCF}}=14.5 \mathrm{~Hz}, 4-\mathrm{C}_{\text {benzeno }}\right), 110.16,102.80$, 47.16, 26.38. ESI-MS calculado para $\mathrm{C}_{18} \mathrm{H}_{17} \mathrm{~F}_{2} \mathrm{~N}_{4} \mathrm{O}(\mathrm{M}+\mathrm{H})^{+} 343.13$, observado 343.0.

\subsubsection{2 (3S)-N-[2-(2,3-difluorofenil)imidazo[1,2-a]piridin-7-il]-3-fluoropirrolidina-1- carboxamida (29)}

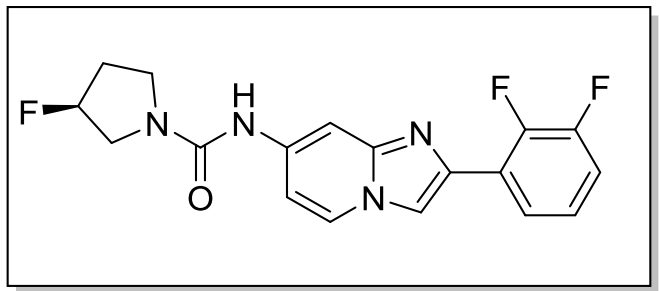

O composto 29 foi preparado partindo de 2-(2,3difluorofenil)imidazo[1,2-a]piridin-7-amina previamente sintetizado e (S)-(+)-3Fluoropirrolidina/HCl, de acordo com o procedimento geral 5, 7.3.2. Um sólido amarelo pálido foi obtido (67 mg, 55\%); RMN de ${ }^{1} \mathrm{H}(500 \mathrm{MHz}, \mathrm{MeOD}) \delta 8.23(\mathrm{~d}, J=7.2 \mathrm{~Hz}, 1 \mathrm{H})$, $8.04(\mathrm{~s}, 1 \mathrm{H}), 7.84(\mathrm{t}, J=7.2 \mathrm{~Hz}, 1 \mathrm{H}), 7.76(\mathrm{~s}, 1 \mathrm{H}), 7.20-7.12(\mathrm{~m}, 2 \mathrm{H}), 7.10(\mathrm{~d}, J=7.4,3.5$ $\mathrm{Hz}, 1 \mathrm{H}), 5.27(\mathrm{~d}, J=52.6 \mathrm{~Hz}, 1 \mathrm{H}), 3.79-3.47(\mathrm{~m}, 4 \mathrm{H}), 2.31-2.01(\mathrm{~m}, 2 \mathrm{H}) . \mathrm{RMN}$ de ${ }^{13} \mathrm{C}$ $(126 \mathrm{MHz}, \mathrm{MeOD}) \delta 156.18,152.28\left(\mathrm{q},{ }^{1} J_{\mathrm{CF}}=244.2,{ }^{2} J_{\mathrm{CCF}}=12.0 \mathrm{~Hz}, 2-\mathrm{C}_{\text {benzeno }}\right), 149.45(\mathrm{q}, J$ $\left.=249.5,{ }^{2} J_{\mathrm{CCF}}=13.5 \mathrm{~Hz}, 3-\mathrm{C}_{\text {benzeno }}\right), 147.44,140.47,138.51\left(\mathrm{q},{ }^{3} J_{\mathrm{CCCF}}=6.30,{ }^{4} J_{\mathrm{CCCCF}}=3.60\right.$ $\left.\mathrm{Hz}, 6-\mathrm{C}_{\text {benzeno }}\right), 127.54,125.69\left(\mathrm{q},{ }^{3} J_{\mathrm{CCCF}}=7.5,{ }^{4} J_{\mathrm{CCCCF}}=4.6 \mathrm{~Hz}, 5-\mathrm{C}_{\text {benzeno }}\right) \quad 124.86,124.34$, $116.98\left(\mathrm{~d},{ }^{2} J_{\mathrm{CCF}}=17.6 \mathrm{~Hz}, 1-\mathrm{C}_{\text {benzeno }}\right), 113.18\left(\mathrm{~d},{ }^{2} J_{\mathrm{CCF}}=14.6 \mathrm{~Hz}, 4-\mathrm{C}_{\text {benzeno }}\right), 110.13,103.06$, $93.72\left(\mathrm{~d},{ }^{1} J_{\mathrm{CF}}=172.6 \mathrm{~Hz}, 3-\mathrm{C}_{\text {pirrolidinil }}\right), 53.86\left(\mathrm{~d},{ }^{2} J_{\mathrm{CCF}}=23.3 \mathrm{~Hz}, 2-\mathrm{C}_{\text {pirrolidinil }}\right), 44.96,33.03$ $\left(\mathrm{d},{ }^{2} J_{\mathrm{CCF}}=19.9 \mathrm{~Hz}, 4-\mathrm{C}_{\text {pirrolidinil }}\right)$. ESI-MS calculado para $\mathrm{C}_{18} \mathrm{H}_{16} \mathrm{~F}_{3} \mathrm{~N}_{4} \mathrm{O}(\mathrm{M}+\mathrm{H})^{+}$361.12, observado 361.3 .

\subsubsection{N-[2-(3,4-difluorofenil)imidazo[1,2-a]piridin-7-il]piperidina-1-carboxamida (30)}

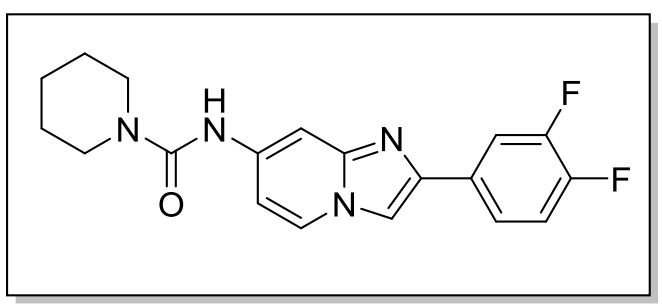

O composto 30 foi preparado partindo de 2-(3,4difluorofenil)imidazo[1,2-a]piridin-7-amina previamente sintetizado e piperidina, de acordo com o procedimento geral 5, 7.3.2. Um sólido amarelo foi obtido (98 mg, 57\%); RMN de ${ }^{1} \mathrm{H}(500 \mathrm{MHz}$,

MeOD) $\delta 8.13(\mathrm{~d}, J=7.3 \mathrm{~Hz}, 1 \mathrm{H}), 7.92(\mathrm{~s}, 1 \mathrm{H}), 7.67$ (ddd, $J=11.8,8.6,1.6,1 \mathrm{H}), 7.60-7.54$ (m, 2H), $7.22(\mathrm{dd}, J=18.0,11.2 \mathrm{~Hz}, 1 \mathrm{H}), 7.00(\mathrm{dd}, J=7.4,3.5 \mathrm{~Hz}, 1 \mathrm{H}), 3.47-3.42(\mathrm{~m}, 4 \mathrm{H})$, $1.66-1.58(\mathrm{~m}, 2 \mathrm{H}), 1.59-1.51(\mathrm{~m}, 4 \mathrm{H}) . \mathrm{RMN}$ de ${ }^{13} \mathrm{C}(126 \mathrm{MHz}, \mathrm{MeOD}) \delta 156.92,152.49$ $\left(\mathrm{q},{ }^{1} J_{\mathrm{CF}}=82.3,{ }^{2} J_{\mathrm{CCF}}=12.7 \mathrm{~Hz}, 4-\mathrm{C}_{\text {benzeno }}\right), 150.53\left(\mathrm{q},{ }^{1} J_{\mathrm{CF}}=84.0,{ }^{2} J_{\mathrm{CCF}}=12.9 \mathrm{~Hz}, 3-\mathrm{C}_{\text {benzeno }}\right.$ ), 
148.11, 144.06, 140.79, 132.57 (q, ${ }^{3} J_{\mathrm{CCCF}}=6.3,{ }^{4} J_{\mathrm{CCCCF}} 3.7 \mathrm{~Hz}, 1-\mathrm{C}_{\text {benzeno }}$ ), 127.33, 123.24 $\left(\mathrm{dd},{ }^{3} J_{\mathrm{CCCF}}=6.2,{ }^{4} J_{\mathrm{CCCCF}}=3.4 \mathrm{~Hz}, 6-\mathrm{C}_{\text {benzeno }}\right), 118.62\left(\mathrm{~d},{ }^{2} J_{\mathrm{CCF}}=17.6 \mathrm{~Hz}, 2-\mathrm{C}_{\text {benzeno }}\right), 115.61$ $\left(\mathrm{d},{ }^{2} J_{\mathrm{CCF}}=18.8 \mathrm{~Hz}, 5-\mathrm{C}_{\text {benzeno }}\right), 110.20,109.60,103.00,46.38,27.02,25.49$. ESI-MS calculado para $\mathrm{C}_{19} \mathrm{H}_{19} \mathrm{~F}_{2} \mathrm{~N}_{4} \mathrm{O}(\mathrm{M}+\mathrm{H})^{+} 357.15$, observado 357.1 .

\subsubsection{N-[2-(3,4-difluorofenil)imidazo[1,2-a]piridin-7-il]pirrolidina-1-carboxamida (31)}

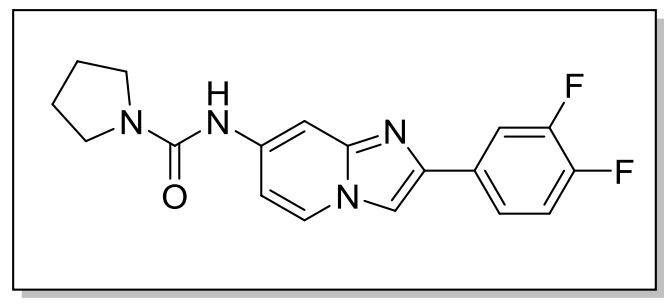

O composto 31 foi preparado partindo de 2-(3,4difluorofenil)imidazo[1,2-a]piridin-7-amina previamente sintetizado e pirrolidina, de acordo com o procedimento geral 5, 7.3.2. Um sólido amarelo foi obtido (56 mg, 69\%); RMN de ${ }^{1} \mathrm{H}(500$ MHz, MeOD) $\delta 8.20(\mathrm{~d}, J=7.4 \mathrm{~Hz}, 1 \mathrm{H}), 7.97(\mathrm{~s}, 1 \mathrm{H}), 7.80-7.71(\mathrm{~m}, 2 \mathrm{H}), 7.68-7.61(\mathrm{~m}$, 1H), 7.29 (dd, 18.0, 11.2, 1H), $7.14(\mathrm{dd}, 7.4,2.1,1 \mathrm{H}), 3.56-3.42(\mathrm{~m}, 4 \mathrm{H}), 2.05-1.91$ (m, $4 \mathrm{H}) . \mathrm{RMN} d e{ }^{13} \mathrm{C}(126 \mathrm{MHz}, \mathrm{MeOD}) \delta 156.13,152.47\left(\mathrm{q},{ }^{1} J_{\mathrm{CF}}=82.6,{ }^{2} J_{\mathrm{CCF}}=13.0 \mathrm{~Hz}, 4-\right.$ $\left.\mathrm{C}_{\text {benzeno }}\right), 150.51\left(\mathrm{q},{ }^{1} J_{\mathrm{CF}}=84.2,{ }^{2} J_{\mathrm{CCF}}=12.9 \mathrm{~Hz}, 3-\mathrm{C}_{\text {benzeno }}\right), 148.07,143.94,140.41,132.58$ $\left(\mathrm{q},{ }^{3} J_{\mathrm{CCCF}}=6.47,{ }^{4} J_{\mathrm{CCCCF}}=3.61 \mathrm{~Hz}, 1-\mathrm{C}_{\mathrm{benzeno}}\right), 127.27,123.23\left(\mathrm{q},{ }^{3} J_{\mathrm{CCCF}}=6.09,{ }^{4} J_{\mathrm{CCCCF}}=\right.$ $\left.3.35 \mathrm{~Hz}, 6-\mathrm{C}_{\text {benzeno }}\right), 118.58\left(\mathrm{~d},{ }^{2} J_{\mathrm{CCF}}=17.6 \mathrm{~Hz}, 2-\mathrm{C}_{\text {benzeno }}\right), 115.60\left(\mathrm{~d},{ }^{2} J_{\mathrm{CCF}}=18.7 \mathrm{~Hz}, 5-\right.$ $\left.\mathrm{C}_{\text {benzeno }}\right), 109.98,109.55,102.91,47.13,26.42$. ESI-MS calculado para $\mathrm{C}_{18} \mathrm{H}_{17} \mathrm{~F}_{2} \mathrm{~N}_{4} \mathrm{O}(\mathrm{M}+\mathrm{H})^{+}$ 343.13, observado 343.1 .

\subsubsection{5 (3S)-N-[2-(3,4-difluorofenil)imidazo[1,2-a]piridin-7-il]-3-fluoropirrolidina-1- carboxamida (32)}

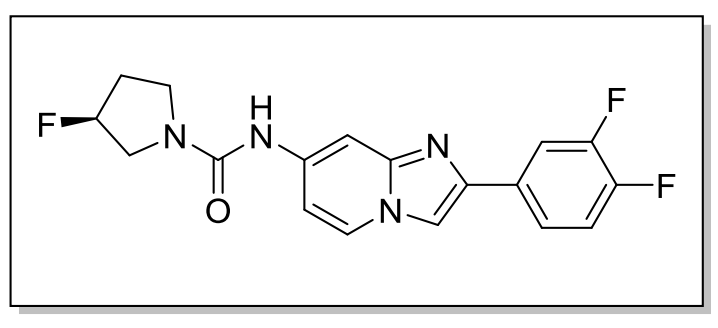

O composto 32 foi preparado partindo de 2-(3,4difluorofenil)imidazo[1,2-a]piridin-7-amina (d) previamente sintetizado e (S)-(+)-3Fluoropirrolidina/ $\mathrm{HCl}$, de acordo com o procedimento geral 5, 7.3.2. Um sólido laranja foi obtido (45 mg, 73\%); RMN de ${ }^{1} \mathrm{H}(500 \mathrm{MHz}, \mathrm{MeOD}) \delta 8.16$ (d, $J=7.3 \mathrm{~Hz}, 1 \mathrm{H}$ ), 7.94 (s, $1 \mathrm{H}), 7.70(\mathrm{~s}, 1 \mathrm{H}), 7.68(\mathrm{ddd}, J=11.8,8.6,1.6,1 \mathrm{H}), 7.58(\mathrm{~m}, 1 \mathrm{H}), 7.22$ (dd, $J=18.0,11.2$, $1 \mathrm{H}), 7.07(\mathrm{dd}, J=7.3,3.5,1 \mathrm{H}), 5.42(\mathrm{~s}, 1 \mathrm{H}), 5.26(\mathrm{dm}, J=52.7 \mathrm{~Hz}, 1 \mathrm{H}), 3.77-3.46(\mathrm{~m}, 4 \mathrm{H})$, $2.30-1.99(\mathrm{~m}, 2 \mathrm{H}) . \mathrm{RMN} d{ }^{13} \mathrm{C}(126 \mathrm{MHz}, \mathrm{MeOD}) \delta 156.18,152.50\left(\mathrm{q},{ }^{1} J_{\mathrm{CF}}=80.7,{ }^{2} J_{\mathrm{CCF}}=\right.$ $13.0 \mathrm{~Hz}, 4-\mathrm{C}_{\text {benzeno }}$ ), $150.54\left(\mathrm{q},{ }^{1} J_{\mathrm{CF}}=82.6,{ }^{2} J_{\mathrm{CCF}}=12.9 \mathrm{~Hz}, 3-\mathrm{C}_{\text {benzeno }}\right.$ ), 148.04, 144.16, 
$140.25,132.55\left(\mathrm{q},{ }^{3} J_{\mathrm{CCCF}}=6.47,{ }^{4} J_{\mathrm{CCCF}}=3.61 \mathrm{~Hz}, 1-\mathrm{C}_{\mathrm{benzeno}}\right), 127.40,123.27\left(\mathrm{q},{ }^{3} J_{\mathrm{CCCF}}=\right.$ $\left.6.09,{ }^{4} J_{\mathrm{CCCCF}}=3.35 \mathrm{~Hz}, 6-\mathrm{C}_{\text {benzeno }}\right), 118.62\left(\mathrm{~d},{ }^{2} J_{\mathrm{CCF}}=17.7 \mathrm{~Hz}, 2-\mathrm{C}_{\text {benzeno }}\right), 115.63\left(\mathrm{~d},{ }^{2} J_{\mathrm{CCF}}=\right.$ $18.8 \mathrm{~Hz}, 5-\mathrm{C}_{\text {benzeno }}$ ), 110.00, 109.65, $103.18,93.71$ (d, ${ }^{1} J_{\mathrm{CF}}=174.6 \mathrm{~Hz}, 3-\mathrm{C}_{\text {pirrolidinil }}$ ), 54.80, $53.85\left(\mathrm{~d},{ }^{2} J_{\mathrm{CCF}}=23.2 \mathrm{~Hz}, 2-\mathrm{C}_{\text {pirrolidinil }}\right)$, 44.95. ESI-MS calculado para $\mathrm{C}_{18} \mathrm{H}_{16} \mathrm{~F}_{3} \mathrm{~N}_{4} \mathrm{O}(\mathrm{M}+\mathrm{H})^{+}$ 361.12, observado 361.1 .

\subsubsection{6 (3S)-3-fluoro-N-[2-(1,3-tiazol-2-il)imidazo[1,2-a]piridin-7-il]pirrolidina-1- carboxamida (33)}

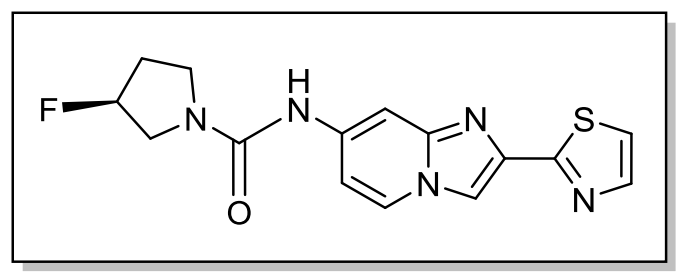

O composto 33 foi preparado partindo de 2-(1,3tiazol-2-il)imidazo[1,2-a]piridin-7-amina previamente sintetizado e $(\mathrm{S})-(+)-3-$ Fluoropirrolidina/ $\mathrm{HCl}$, de acordo com o procedimento geral 5, 7.3.2. Um sólido branco foi obtido (40 mg, 64\%). RMN de ${ }^{1} \mathrm{H}(500$ MHz, MeOD) $\delta 8.39$ (d, $J=7.4 \mathrm{~Hz}, 1 \mathrm{H}), 8.25(\mathrm{~s}, 1 \mathrm{H}), 7.91(\mathrm{~d}, J=3.3 \mathrm{~Hz}, 1 \mathrm{H}), 7.85$ (d, $J=$ $2.1 \mathrm{~Hz}, 1 \mathrm{H}), 7.65$ (d, $J=3.3 \mathrm{~Hz}, 1 \mathrm{H}), 7.27(\mathrm{dd}, J=7.4,2.1 \mathrm{~Hz}, 1 \mathrm{H}), 5.53$ (s, 1H), 5.38 (dm, $J$ $=52.7 \mathrm{~Hz}, 1 \mathrm{H}), 3.89-3.60(\mathrm{~m}, 4 \mathrm{H}), 2.42-2.12(\mathrm{~m}, 2 \mathrm{H})$. ESI-MS calculado para $\mathrm{C}_{15} \mathrm{H}_{15} \mathrm{FN}_{5} \mathrm{OS}(\mathrm{M}+\mathrm{H})^{+}$332.09, observado 332.1.

\subsubsection{7 (3S)-3-fluoro-N-[2-(tiofen-2-il)imidazo[1,2-a]piridin-7-il]pirrolidina-1- carboxamida (34)}

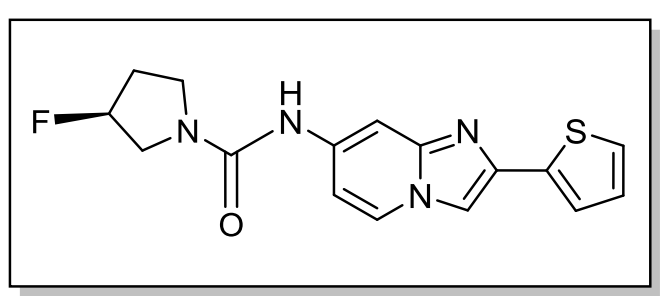

O composto 34 foi preparado partindo de 2-(tiofen2-il)imidazo[1,2-a]piridin-7-amina (f) previamente sintetizado e (S)-(+)-3-Fluoropirrolidina/HCl, de acordo com o procedimento geral 5, 7.3.2. Um sólido amarelo pálido foi obtido (49 $\mathrm{mg}, 56 \%$ ). RMN de ${ }^{1} \mathrm{H}(500 \mathrm{MHz}, \mathrm{MeOD}) \delta 8.24(\mathrm{~d}, J=7.4 \mathrm{~Hz}, 1 \mathrm{H}), 7.92(\mathrm{~s}, 1 \mathrm{H}), 7.74(\mathrm{~d}, J=1.9 \mathrm{~Hz}$, 1H), 7.49 (dd, $J=3.5,0.9 \mathrm{~Hz}, 1 \mathrm{H}), 7.39$ (dd, $J=5.0,0.9 \mathrm{~Hz}, 1 \mathrm{H}), 7.18$ (dd, $J=7.4,1.9 \mathrm{~Hz}$, $1 \mathrm{H}), 7.10(\mathrm{dd}, J=5.0,3.6 \mathrm{~Hz}, 1 \mathrm{H}), 5.34(\mathrm{~d}, J=52.8 \mathrm{~Hz}, 1 \mathrm{H}), 3.87-3.56(\mathrm{~m}, 4 \mathrm{H}), 2.39-$ 2.09 (m, 2H). RMN de ${ }^{13} \mathrm{C}(126 \mathrm{MHz}, \mathrm{MeOD}) \delta 156.20,147.69,141.17,140.21,137.96$, $128.72,127.24,125.95,125.09,109.93,108.48,103.07,93.71\left(\mathrm{~d},{ }^{1} J_{\mathrm{CF}}=173.9 \mathrm{~Hz}, 3-\right.$ $\left.\mathrm{C}_{\text {pirrolidinil }}\right), 53.84\left(\mathrm{~d},{ }^{2} J_{\mathrm{CCF}}=23.1 \mathrm{~Hz}, 2-\mathrm{C}_{\text {pirrolidinil }}\right), 44.94,33.02\left(\mathrm{~d},{ }^{2} J_{\mathrm{CCF}}=19.0 \mathrm{~Hz}, 4-\right.$ $\mathrm{C}_{\text {pirrolidinil }}$ ). ESI-MS calculado para $\mathrm{C}_{16} \mathrm{H}_{16} \mathrm{FN}_{4} \mathrm{OS}(\mathrm{M}+\mathrm{H})^{+} 331.10$, observado 331.1 . 


\subsubsection{2-cloro-N-[2-(3,4-difluorofenil)imidazo[1,2-a]piridin-7-il]piridina-3-carboxamida} (35)

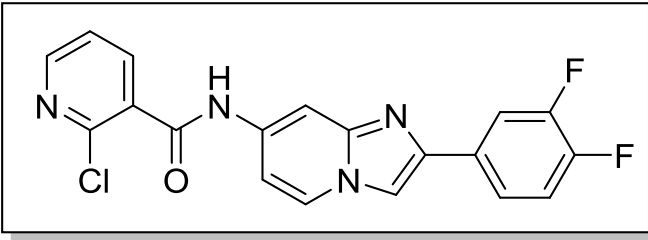

O composto 35 foi preparado partindo de 2-(3,4difluorofenil)imidazo[1,2-a]piridin-7-amina previamente sintetizado e 2-cloropiridina-3-carbonil cloreto, de acordo com o procedimento geral 6,

7.3.3. Um sólido laranja foi obtido (42 mg, 80\%). RMN de ${ }^{1} \mathrm{H}(500 \mathrm{MHz}, \mathrm{MeOD}) \delta 8.46$ (dd, $J=4.9,1.9 \mathrm{~Hz}, 1 \mathrm{H}), 8.32(\mathrm{~d}, J=7.3 \mathrm{~Hz}, 1 \mathrm{H}), 8.12(\mathrm{~d}, J=1.7 \mathrm{~Hz}, 1 \mathrm{H}), 8.08$ (s, 1H), 8.00 (dd, $J=7.5,1.9 \mathrm{~Hz}, 1 \mathrm{H}), 7.73(\mathrm{ddd}, J=11.8,7.7,2.0 \mathrm{~Hz}, 1 \mathrm{H}), 7.66-7.61(\mathrm{~m}, 1 \mathrm{H}), 7.47$ (dd, $J=$ 7.5, 4.9 Hz, 1H), 7.26 (ddd, $J=21.5,11.8,8.45 \mathrm{~Hz}, 1 \mathrm{H}), 7.08$ (dd, $J=7.3,2.1 \mathrm{~Hz}, 1 \mathrm{H})$. RMN de ${ }^{13} \mathrm{C}(126 \mathrm{MHz}, \mathrm{MeOD}) \delta 166.48,152.62$ (q, ${ }^{1} J_{\mathrm{CF}}=65.3,{ }^{2} J_{\mathrm{CCF}}=12.8 \mathrm{~Hz}, 4-\mathrm{C}_{\text {benzeno }}$ ), $151.95,150.66\left(\mathrm{q},{ }^{1} J_{\mathrm{CF}}=67.1,{ }^{2} J_{\mathrm{CCF}}=12.9 \mathrm{~Hz}, 3-\mathrm{C}_{\text {benzeno }}\right), 148.52,147.45,144.87,139.46$, $138.20,134.18,132.37\left(\mathrm{q},{ }^{3} J_{\mathrm{CCCF}}=6.47,{ }^{4} J_{\mathrm{CCCCF}}=3.61 \mathrm{~Hz}, 1-\mathrm{C}_{\text {benzeno }}\right), 128.19,124.20$, $123.46\left(\mathrm{q},{ }^{3} J_{\mathrm{CCCF}}=6.09,{ }^{4} J_{\mathrm{CCCCF}}=3.35 \mathrm{~Hz}, 6-\mathrm{C}_{\mathrm{benzeno}}\right), 118.71\left(\mathrm{~d},{ }^{2} J_{\mathrm{CCF}}=17.8 \mathrm{~Hz}, 2-\mathrm{C}_{\mathrm{benzeno}}\right)$, $115.79\left(\mathrm{~d},{ }^{2} J_{\mathrm{CCF}}=18.9 \mathrm{~Hz}, 5-\mathrm{C}_{\text {benzeno }}\right), 110.39$, 109.06, 104.82. ESI-MS calculado para $\mathrm{C}_{19} \mathrm{H}_{12} \mathrm{ClF}_{2} \mathrm{~N}_{4} \mathrm{O}(\mathrm{M}+\mathrm{H})^{+}$385.06, observado 385.3.

\subsubsection{N-[2-(3,4-difluorofenil)imidazo[1,2-a]piridin-7-il]-3,5-dimetil-1,2-oxazol-4- carboxamida (36)}

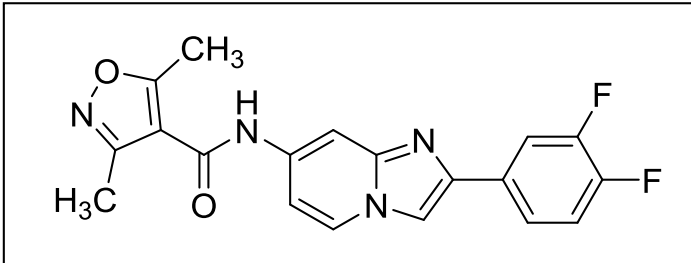

O composto 36 foi preparado partindo de 2-(3,4difluorofenil)imidazo[1,2-a]piridin-7-amina (d) previamente sintetizado e dimetil-1,2-oxazol-4carbonil cloreto, de acordo com o procedimento geral 6 , 7.3.3. Um sólido laranja foi obtido ( 35 mg, 79\%). RMN de ${ }^{1} \mathrm{H}(500 \mathrm{MHz}, \mathrm{MeOD}) \delta 8.68$ (d, $\left.J=7.3 \mathrm{~Hz}, 1 \mathrm{H}\right), 8.55$ (s, 1H), 8.42 (s, 1H), 7.88 (ddd, $J=12.0,7.4,2.1 \mathrm{~Hz}, 1 \mathrm{H}), 7.77-7.72(\mathrm{~m}, 1 \mathrm{H}), 7.53(\mathrm{dd}, J=20.0,8.5 \mathrm{~Hz}$, 1H), $7.46(\mathrm{dd}, J=7.3,1.9 \mathrm{~Hz}, 1 \mathrm{H}), 2.67(\mathrm{~s}, 3 \mathrm{H}), 2.46$ (s, 3H). ESI-MS calculado para $\mathrm{C}_{19} \mathrm{H}_{15} \mathrm{~F}_{2} \mathrm{~N}_{4} \mathrm{O}_{2}(\mathrm{M}+\mathrm{H})^{+}$369.11, observado 369.1 . 


\subsubsection{N-[2-(3,4-difluorofenil)imidazo[1,2-a]piridin-7-il]piridina-3-carboxamida (37)}

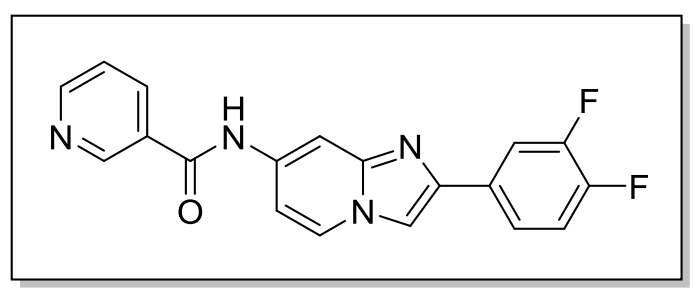

O composto 37 foi preparado partindo de 2-(3,4difluorofenil)imidazo[1,2-a]piridin-7-amina previamente sintetizado e piridina-3-carbonil cloreto, de acordo com o procedimento geral 6 , 7.3.3. Um sólido branco foi obtido (47 mg, 85\%). RMN de ${ }^{1} \mathrm{H}(500 \mathrm{MHz}, \mathrm{MeOD}) \delta 9.11(\mathrm{~s}, 1 \mathrm{H}), 8.75(\mathrm{~d}, J=5.9 \mathrm{~Hz}, 1 \mathrm{H}), 8.38(\mathrm{~d}, J=7.5 \mathrm{~Hz}$, 2H), $8.21(\mathrm{~s}, 1 \mathrm{H}), 8.14(\mathrm{~s}, 1 \mathrm{H}), 7.80(\mathrm{ddd}, J=10.4,9.0,1.6 \mathrm{~Hz}, 1 \mathrm{H}), 7.73-7.68(\mathrm{~m}, 1 \mathrm{H})$, $7.61(\mathrm{dd}, J=7.5,5.9, \mathrm{~Hz}, 1 \mathrm{H}), 7.33(\mathrm{dd}, J=18.0,11.2,1 \mathrm{H}), 7.30(\mathrm{dd}, J=7.5,3.5,1 \mathrm{H})$. ESIMS calculado para $\mathrm{C}_{19} \mathrm{H}_{13} \mathrm{~F}_{2} \mathrm{~N}_{4} \mathrm{O}(\mathrm{M}+\mathrm{H})^{+} 351.10$, observado 351.1 .

\subsubsection{N-[2-(3,4-difluorofenil)imidazo[1,2-a]piridin-7-il]-1,3-tiazol-2-carboxamida (38)}

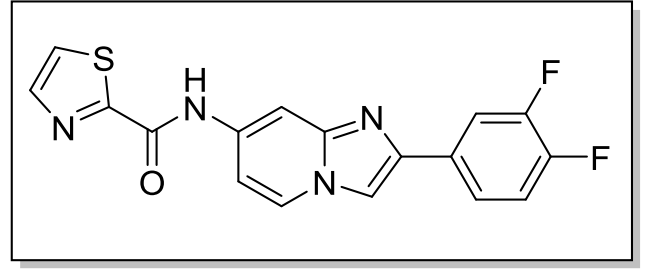

O composto 38 foi preparado partindo de 2-(3,4difluorofenil)imidazo[1,2-a]piridin-7-amina previamente sintetizado e 1,3-tiazol-2-carbonil cloreto, de acordo com o procedimento geral 6, 7.3.3. Um sólido branco foi obtido $(47 \mathrm{mg}, 85 \%) .{ }^{1} \mathrm{H} \mathrm{NMR}\left(500 \mathrm{MHz}, \mathrm{CD}_{3} \mathrm{CO}_{2} \mathrm{D}\right) \delta 8.72(\mathrm{~d}, J=$ $7.4 \mathrm{~Hz}, 1 \mathrm{H}), 8.65(\mathrm{~s}, 1 \mathrm{H}), 8.38(\mathrm{~s}, 1 \mathrm{H}), 8.12(\mathrm{~d}, J=3.0 \mathrm{~Hz}, 1 \mathrm{H}), 8.06(\mathrm{~d}, J=1.3 \mathrm{~Hz}, 1 \mathrm{H}), 8.05$ $(\mathrm{d}, J=3.0 \mathrm{~Hz}, 1 \mathrm{H}), 7.89$ (ddd, 1H), $7.84-7.79$ (m, $J=8.4 \mathrm{~Hz}, 1 \mathrm{H}), 7.48$ (dd, $J=18.4,8.5$ $\mathrm{Hz}, 1 \mathrm{H})$. ESI-MS calculado para $\mathrm{C}_{17} \mathrm{H}_{10} \mathrm{~F}_{2} \mathrm{~N}_{4} \mathrm{OS}(\mathrm{M}+\mathrm{H})^{+}$357.06, observado 357.1.

\subsubsection{3-tert-butil-N-[2-(3,4-difluorofenil)imidazo[1,2-a]piridin-7-il]-1-metil-1H-pirazol- 5-carboxamida (39)}

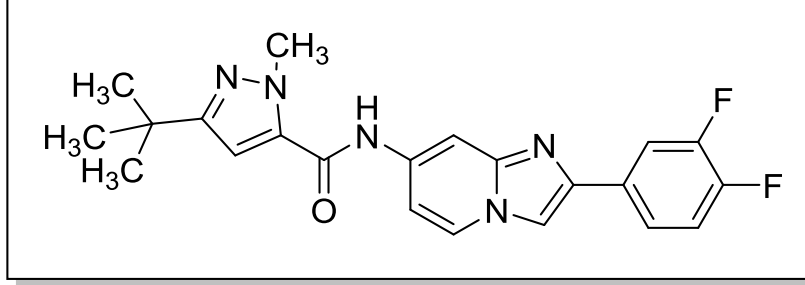

O composto 39 foi preparado partindo de 2-(3,4-difluorofenil)imidazo[1,2-a]piridin7-amina (d) previamente sintetizado e 3tert-butil-1-metil-1H-pirazol-5-carbonil cloreto, de acordo com o procedimento geral 6, 7.3.3. Um sólido amarelo pálido foi obtido (55 mg, 81\%). RMN de ${ }^{1} \mathrm{H}(500 \mathrm{MHz}$, MeOD) $\delta 8.19(\mathrm{~d}, J=7.3 \mathrm{~Hz}, 1 \mathrm{H}), 8.03(\mathrm{~d}, J=1.9 \mathrm{~Hz}, 1 \mathrm{H}), 7.94(\mathrm{~s}, 1 \mathrm{H}), 7.67$ (ddd, $J=11.7$, 7.7, $2.0 \mathrm{~Hz}, 1 \mathrm{H}), 7.59-7.54(\mathrm{~m}, 1 \mathrm{H}), 7.22(\mathrm{dd}, 18.0,11.2,1 \mathrm{H}), 7.18(\mathrm{dd}, J=7.3,2.0 \mathrm{~Hz}$, 
1H), $6.87(\mathrm{~s}, 1 \mathrm{H}), 4.09$ (s, 3H), 1.32 (s, 9H). RMN de ${ }^{13} \mathrm{C}(126 \mathrm{MHz}, \mathrm{MeOD}) \delta$ 161.59, $160.35,152.51\left(\mathrm{q},{ }^{1} J_{\mathrm{CF}}=64.9,{ }^{2} J_{\mathrm{CCF}}=13.1 \mathrm{~Hz}, 4-\mathrm{C}_{\mathrm{benzeno}}\right), 150.55\left(\mathrm{q},{ }^{1} J_{\mathrm{CF}}=66.9,{ }^{2} J_{\mathrm{CCF}}=13.0\right.$ $\left.\mathrm{Hz}, 3-\mathrm{C}_{\text {benzeno }}\right), 147.19,144.10,138.67,136.57,131.99\left(\mathrm{q},{ }^{3} J_{\mathrm{CCCF}}=6.47,{ }^{4} J_{\mathrm{CCCCF}}=3.61 \mathrm{~Hz}, 1-\right.$ $\left.\mathrm{C}_{\text {benzeno }}\right), 127.66,123.31\left(\mathrm{q},{ }^{3} J_{\mathrm{CCCF}}=6.09,{ }^{4} J_{\mathrm{CCCCF}}=3.35 \mathrm{~Hz}, 6-\mathrm{C}_{\text {benzeno }}\right), 118.60\left(\mathrm{~d},{ }^{2} J_{\mathrm{CCF}}=\right.$ $\left.17.9 \mathrm{~Hz}, 2-\mathrm{C}_{\text {benzeno }}\right), 115.67$ (d, ${ }^{2} J_{\mathrm{CCF}}=19.1 \mathrm{~Hz}, 5-\mathrm{C}_{\text {benzeno }}$ ), 110.11, 109.48, 105.27, 104.35, 39.19, 32.96, 30.90. ESI-MS calculado para $\mathrm{C}_{22} \mathrm{H}_{22} \mathrm{~F}_{2} \mathrm{~N}_{5} \mathrm{O}(\mathrm{M}+\mathrm{H})^{+} 410.17$, observado 410.3.

\subsubsection{3 (3S)-N-[2-(3,4-difluorofenil)imidazo[1,2-a]pirimidin-7-il]-3-fluoropirrolidina-1- carboxamida (40)}

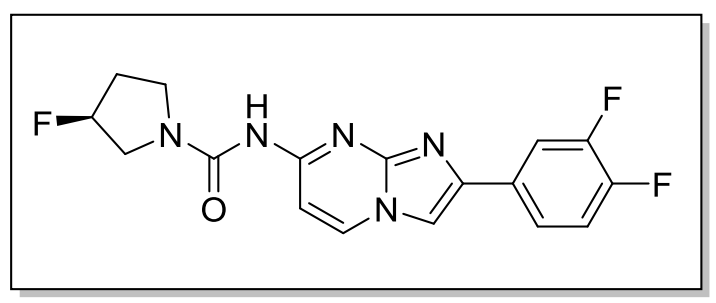

O composto 40 foi preparado partindo de 2-(3,4difluorofenil)imidazo[1,2-a]pirimidin-7-amina (g) previamente sintetizado e (S)-(+)-3Fluoropirrolidina/HCl, de acordo com o procedimento geral 5, 7.3.2. Um sólido amarelo pálido foi obtido (50 mg, 55\%); RMN de ${ }^{1} \mathrm{H}(500 \mathrm{MHz}, \mathrm{MeOD}) \delta 8.58(\mathrm{~d}, J=7.5 \mathrm{~Hz}, 1 \mathrm{H})$, 7.94 (s, 1H), 7.78 (d, $J=7.5 \mathrm{~Hz}, 1 \mathrm{H}), 7.75$ (ddd, $J=11.8,8.6,1.6,1 \mathrm{H}), 7.69-7.64(\mathrm{~m}, 1 \mathrm{H})$, $7.30(\mathrm{dd}, J=18.8,8.5 \mathrm{~Hz}, 1 \mathrm{H}), 5.33(\mathrm{dm}, J=52.7,1 \mathrm{H}), 3.86-3.56(\mathrm{~m}, 4 \mathrm{H}), 2.37-2.07$ (m, $2 \mathrm{H})$. ESI-MS calculado para $\mathrm{C}_{17} \mathrm{H}_{15} \mathrm{~F}_{3} \mathrm{~N}_{5} \mathrm{O}(\mathrm{M}+\mathrm{H})^{+}$362.12, observado 362.1 .

\subsubsection{4 (3S)-N-[2-(3,4-difluorofenil)imidazo[1,2-c]pirimidin-7-il]-3-fluoropirrolidina-1- carboxamida (41)}

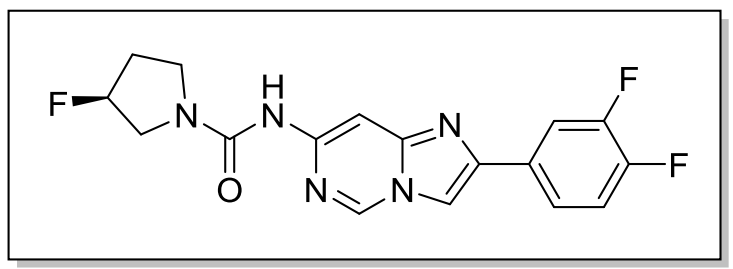

O composto 41 foi preparado partindo de 2-(3,4difluorofenil)imidazo[1,2-c]pirimidin-7-amina (h) previamente sintetizado e (S)-(+)-3Fluoropirrolidina/ $\mathrm{HCl}$, de acordo com o procedimento geral 5, 7.3.2. Um sólido amarelo foi obtido ( $300 \mathrm{mg}, 56 \%)$. RMN de ${ }^{1} \mathrm{H}(500$ MHz, DMSO) $\delta 9.25$ (s, 1H), 8.98 (s, 1H), 8.34 (s, 1H), 8.00 (ddd, $J=11.8,8.6,1.6,1 \mathrm{H})$, $7.87(\mathrm{~s}, 1 \mathrm{H}), 7.87-7.80(\mathrm{~m}, 1 \mathrm{H}), 7.51$ (dd, $J=18.00,11.20 \mathrm{~Hz}, 1 \mathrm{H}), 5.36(\mathrm{~d}, \mathrm{~m} J=53.1 \mathrm{~Hz}$, $1 \mathrm{H}), 3.82-3.45(\mathrm{~m}, 4 \mathrm{H}), 2.23-1.98(\mathrm{~m}, 2 \mathrm{H})$. RMN de ${ }^{13} \mathrm{C}$ (126 MHz, DMSO) $\delta 153.18$, $150.46\left(\mathrm{q},{ }^{1} J_{\mathrm{CF}}=67.0,{ }^{2} J_{\mathrm{CCF}}=12.3 \mathrm{~Hz}\right), 148.51\left(\mathrm{q},{ }^{1} J_{\mathrm{CF}}=68.8,{ }^{2} J_{\mathrm{CCF}}=12.6 \mathrm{~Hz}\right), 146.55$, $146.39,143.86,139.63,131.08\left(\mathrm{q} \mathrm{q},{ }^{3} J_{\mathrm{CCCF}}=6.47,{ }^{4} J_{\mathrm{CCCCF}}=3.61 \mathrm{~Hz}, 1-\mathrm{C}_{\text {benzeno }}\right), 122.57$ (q, $\left.{ }^{3} J_{\mathrm{CCCF}}=6.09,{ }^{4} J_{\mathrm{CCCCF}}=3.35 \mathrm{~Hz}, 6-\mathrm{C}_{\text {benzeno }}\right), 117.90\left(\mathrm{~d},{ }^{2} J_{\mathrm{CCF}}=17.1 \mathrm{~Hz}, 2-\mathrm{C}_{\text {benzeno }}\right), 114.61(\mathrm{~d}$, 
$\left.{ }^{2} J_{\mathrm{CCF}}=18.4 \mathrm{~Hz}, 5-\mathrm{C}_{\text {benzeno }}\right), 106.37,93.78\left(\mathrm{~d},{ }^{1} J_{\mathrm{CF}}=174.6 \mathrm{~Hz}, 3-\mathrm{C}_{\text {pirrolidinil }}\right), 52.52\left(\mathrm{~d},{ }^{2} J_{\mathrm{CCF}}=\right.$ $21.9 \mathrm{~Hz}, 2-\mathrm{C}_{\text {pirrolidinil }}$ ), 43.61, 31.30. ESI-MS calculado para $\mathrm{C}_{17} \mathrm{H}_{15} \mathrm{~F}_{3} \mathrm{~N}_{5} \mathrm{O}(\mathrm{M}+\mathrm{H})^{+} 362.12$, observado 362.1 .

\subsubsection{3-tert-butil-N-[2-(3,4-difluorofenil)imidazo[1,2-c]pirimidin-7-il]-1-metil-1H- pirazol-5-carboxamida (42)}

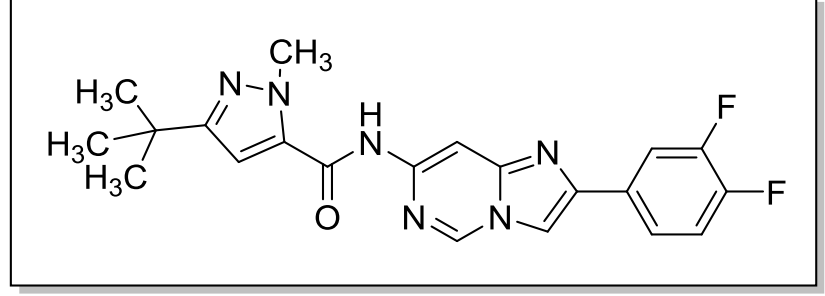

O composto 42 foi preparado partindo de 2-(3,4-difluorofenil)imidazo[1,2c]pirimidin-7-amina

(d) previamente sintetizado e (3-tert-butil-1-metil-1Hpirazol-5-carbonil cloreto, de acordo com o procedimento geral 6, 7.3.3. Um sólido branco foi obtido (46 $\mathrm{mg}, 83 \%)$. RMN de ${ }^{1} \mathrm{H}(500$ $\mathrm{MHz}, \mathrm{MeOD}) \delta 9.13(\mathrm{~s}, 1 \mathrm{H}), 8.34$ (s, 1H), 8.22 (s, 1H), 7.85 (ddd, $J=11.4,7.7,1.8 \mathrm{~Hz}, 1 \mathrm{H})$, $7.79-7.72(\mathrm{~m}, 1 \mathrm{H}), 7.36(\mathrm{dd}, J=18.7,8.5 \mathrm{~Hz}, 1 \mathrm{H}), 6.97$ (s, 1H), 4.17 (s, 3H), 1.37 (s, 9H). ESI-MS calculado para $\mathrm{C}_{21} \mathrm{H}_{21} \mathrm{~F}_{2} \mathrm{~N}_{6} \mathrm{O}(\mathrm{M}+\mathrm{H})^{+} 411.17$, observado 411.3.

\subsubsection{6 (3S)-N-[2-(3,4-difluorofenil)imidazo[1,2-a]piridin-6-il]-3-fluoropirrolidina-1- carboxamida (43)}

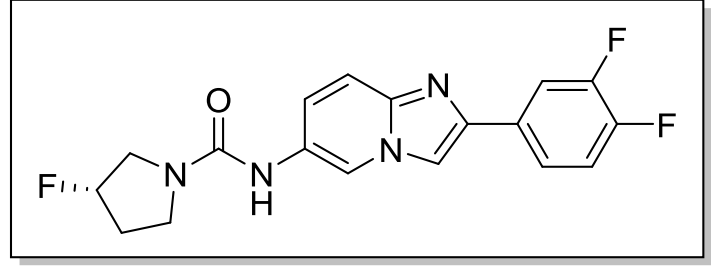

O composto 43 foi preparado partindo de 2-(3,4difluorofenil)imidazo[1,2-a]piridin-6-amina (i) previamente sintetizado e (S)-(+)-3Fluoropirrolidina/ $\mathrm{HCl}$, de acordo com o procedimento geral 5, 7.3.2. Um sólido marrom foi obtido (45 mg, $51 \%$ ). $\mathrm{RMN}$ de ${ }^{1} \mathrm{H}(500$ MHz, MeOD) $\delta 8.76(\mathrm{~s}, 1 \mathrm{H}), 8.17(\mathrm{~s}, 1 \mathrm{H}), 7.80(\mathrm{ddd}, J=11.8,8.6,1.6,1 \mathrm{H}), 7.73-7.67(\mathrm{~m}, J$ $=6.5 \mathrm{~Hz}, 1 \mathrm{H}), 7.47(\mathrm{~d}, J=9.6 \mathrm{~Hz}, 1 \mathrm{H}), 7.34(\mathrm{~d}, J=9.6 \mathrm{~Hz}, 1 \mathrm{H}), 7.32(\mathrm{dd}, J=16.3,6.9$ $\mathrm{Hz}, 1 \mathrm{H}), 5.33(\mathrm{dm}, J=52.8 \mathrm{~Hz}, 1 \mathrm{H}), 3.84-3.54(\mathrm{~m}, 4 \mathrm{H}), 2.38-2.08$ (m, 2H). ESI-MS calculado para $\mathrm{C}_{18} \mathrm{H}_{16} \mathrm{~F}_{3} \mathrm{~N}_{4} \mathrm{O}(\mathrm{M}+\mathrm{H})^{+}$361.12, observado 361.1 . 


\section{Conclusão geral}

A modelagem molecular HQSAR provou ser eficaz na predição de bioatividades de compostos não sintetizados. A docagem em conjunto com os estudos de ROCS validam as interpretações obtidas nos mapas de contribuições fornecidos pelo HQSAR, e ainda corroboram na identificação de grupos substituintes promissores no processo de inibição da enzima cruzaína. A combinação dos métodos deposta como uma ferramenta útil no processo de planejamento de novas estruturas químicas.

O planejamento e a síntese de novos grupos warheads introduzidos no esqueleto básico dipeptidil resultou em incrementos da potência contra a enzima cruzaína, quais sejam: azanitrila, aldeído e oxima. A função orgânica oxima foi introduzida como uma nova potente classe de warhead. Em contrapartida, grupos eletrofílicos alpha-beta insaturados demonstraram baixo potencial como warheads. Ainda, a substituição do grupo $\mathrm{CH}_{2}$ pelo grupo ciclopropil na porção P1, diminuiu a potência dos grupos warheads. Contudo, os estudos de SAR demonstraram que a substituições com novos grupos warheads, no esqueleto do tipo dipeptidil, resultaram em significativos aumentos na potência dos inibidores de cruzaína sintetizados e comprovam a hipótese estabelecida no ciclo planeja-sintetiza-testa.

A nova série de derivados de imidazopiridina demostraram alto potencial como agentes tripanossomicidas em culturas de parasitas (T. cruzi e T. brucei), baixa citotoxicidade e alta estabilidade metabólica. Nos estudos de eficácia in vivo, em um modelo agudo com infecção de T. cruzi o composto $\mathbf{4 1}$ demonstrou taxas de cura da infecção comparáveis com o fármaco benzonidazol.

Os compostos foram planejados utilizando técnicas e estratégias diversificadas de Química Medicinal. Sempre que possível os estudos computacionais guiaram o planejamento. Duas séries de compostos foram sintetizadas, uma série contendo o esqueleto básico dipeptil e outra série contendo o anel fundido imidazopiridina; totalizando 43 compostos sintetizados (em apêndice encontra-se uma tabela com todos os compostos sintetizados, os resultados biológicos e os respectivos "smiles"). Os compostos foram sintetizados utilizando diversas rotas sintéticas; modificadas de acordo com a necessidade. Todos os compostos foram devidamente caracterizados por técnicas espectroscópicas.

Nesse sentido o trabalho possui grande potencial para futuros estudos na busca por novos agentes tripanossomicidas. 


\section{Referências}

1. WHO. World Health Organization. http://www.who.int/trypanosomiasis_african/disease/parasite/en/ (accessed March 12).

2. (a) Olmo, F.; Rotger, C.; Ramírez-Macías, I.; Martínez, L.; Marín, C.; Carreras, L.; Urbanová, K.; Vega, M.; Chaves-Lemaur, G.; Sampedro, A.; Rosales, M. J.; Sánchez-Moreno, M.; Costa, A. Synthesis and Biological Evaluation of N,N'-Squaramides with High in Vivo Efficacy and Low Toxicity: Toward a Low-Cost Drug against Chagas Disease. Journal of Medicinal Chemistry 2014, 57 (3), 987-999; (b) Nogueira Silva, J. J.; Pavanelli, W. R.; Salazar Gutierrez, F. R.; Alves Lima, F. C.; Ferreira da Silva, A. B.; Santana Silva, J.; Wagner Franco, D. Complexation of the anti-Trypanosoma cruzi Drug Benznidazole Improves Solubility and Efficacy. Journal of Medicinal Chemistry 2008, 51 (14), 4104-4114; (c) Garcia, S.; Ramos, C. O.; Senra, J. F. V.; Vilas-Boas, F.; Rodrigues, M. M.; Campos-de-Carvalho, A. C.; Ribeirodos-Santos, R.; Soares, M. B. P. Treatment with Benznidazole during the Chronic Phase of Experimental Chagas' Disease Decreases Cardiac Alterations. Antimicrobial Agents and Chemotherapy 2005, 49 (4), 1521-1528; (d) Russell, S.; Rahmani, R.; Jones, A. J.; Newson, H. L.; Neilde, K.; Cotillo, I.; Rahmani Khajouei, M.; Ferrins, L.; Qureishi, S.; Nguyen, N.; Martinez-Martinez, M. S.; Weaver, D. F.; Kaiser, M.; Riley, J.; Thomas, J.; De Rycker, M.; Read, K. D.; Flematti, G. R.; Ryan, E.; Tanghe, S.; Rodriguez, A.; Charman, S. A.; Kessler, A.; Avery, V. M.; Baell, J. B.; Piggott, M. J. Hit-to-Lead Optimization of a Novel Class of Potent, Broad-Spectrum Trypanosomacides. Journal of Medicinal Chemistry 2016, 59 (21), 9686-9720; (e) Urbina, J. A.; Docampo, R. Specific chemotherapy of Chagas disease: controversies and advances. Trends in Parasitology 2003, 19 (11), 495-501; (f) Castro, J. A.; de Mecca, M. M.; Bartel, L. C. Toxic side effects of drugs used to treat Chagas' disease (American trypanosomiasis). Hum Exp Toxicol 2006, 25 (8), 471-9.

3. (a) Zhao, H. Y.; Guo, Z. Medicinal chemistry strategies in follow-on drug discovery. Drug Discovery Today 2009, 14 (9-10), 516-522; (b) Colombo, M.; Peretto, I. Chemistry strategies in early drug discovery: an overview of recent trends. Drug Discovery Today 2008, 13 (1516), 677-684.

4. Zhao, H. Scaffold selection and scaffold hopping in lead generation: a medicinal chemistry perspective. Drug Discovery Today 2007, 12 (3-4), 149-155.

5. Kubinyi, H. Similarity and dissimilarity: A medicinal chemist's view. Perspectives in Drug Discovery and Design 1998, 9-11, 225-252.

6. (a) Wassermann, A. M.; Dimova, D.; Iyer, P.; Bajorath, J. Advances in Computational Medicinal Chemistry: Matched Molecular Pair Analysis. Drug Development Research 2012, 73 (8), 518-527; (b) Hussain, J.; Rea, C. Computationally Efficient Algorithm to Identify Matched Molecular Pairs (MMPs) in Large Data Sets. Journal of Chemical Information and Modeling 2010, 50 (3), 339-348; (c) Golbraikh, A.; Shen, M.; Xiao, Z.; Xiao, Y.-D.; Lee, K.H.; Tropsha, A. Rational selection of training and test sets for the development of validated QSAR models. Journal of Computer-Aided Molecular Design 2003, 17 (2-4), 241-253; (d) Golbraikh, A.; Tropsha, A. Beware of q(2)! Journal of Molecular Graphics \& Modelling 2002, 20 (4), 269-276; (e) Tropsha, A. Best Practices for QSAR Model Development, Validation, and Exploitation. Molecular Informatics 2010, 29 (6-7), 476-488; (f) Tropsha, A.; Golbraikh, A. Predictive QSAR Modeling workflow, model applicability domains, and virtual screening. Current Pharmaceutical Design 2007, 13 (34), 3494-3504; (g) Fujita, T.; Hansch, C.; Iwasa, J. NEW SUBSTITUENT CONSTANT PI DERIVED FROM PARTITION COEFFICIENTS. Journal of the American Chemical Society 1964, 86 (23), 5175-\&; (h) Verma, R. P.; Hansch, C. An approach toward the problem of outliers in QSAR. Bioorganic \& medicinal chemistry 2005, 13 (15), 4597-4621; (i) Cramer, R. D.; Patterson, D. E.; Bunce, J. D. COMPARATIVE MOLECULAR-FIELD ANALYSIS (COMFA) .1. EFFECT OF SHAPE ON BINDING OF STEROIDS TO CARRIER PROTEINS. Journal of the American Chemical Society 1988, 110 (18), 5959-5967; (j) Hopfinger, A. J.; Wang, S.; Tokarski, J. S.; Jin, B. Q.; Albuquerque, M.; Madhav, P. J.; Duraiswami, C. Construction of 3D-QSAR models using the 4D-QSAR analysis formalism. Journal of the American Chemical Society 1997, 119 (43), 
10509-10524; (k) Vedani, A.; Dobler, M. 5D-QSAR: The key for simulating induced fit? Journal of Medicinal Chemistry 2002, 45 (11), 2139-2149; (1) Lowis, D. R. HQSAR: A New, Highly Predictive QSAR Technique. Tripos Technical Notes 1997, 1 (5), 1-17; (m) Silva, D. G.; Freitas, M. P.; da Cunha, E. F. F.; Ramalho, T. C.; Nunes, C. A. Rational design of small modified peptides as ACE inhibitors. MedChemComm 2012, 3 (10), 1290-1293.

7. Silva, D. G.; Rocha, J. R.; Sartori, G. R.; Montanari, C. A. Highly Predictive Hologram QSAR Models of Nitrile-containing Cruzain Inhibitors. Journal of Biomolecular Structure and Dynamics 2016, 1-87.

8. Silva, D. G.; Ribeiro, J. F. R.; De Vita, D.; Cianni, L.; Franco, C. H.; Freitas-Junior, L. H.; Moraes, C. B.; Rocha, J. R.; Burtoloso, A. C. B.; Kenny, P. W.; Leitão, A.; Montanari, C. A. A comparative study of warheads for design of cysteine protease inhibitors. Bioorganic \& Medicinal Chemistry Letters 2017, 27 (22), 5031-5035.

9. $\quad$ Silva, D. G.; Gillespie, J. R.; Ranade, R. M.; Herbst, Z. M.; Nguyen, U. T. T.; Buckner, F. S.; Montanari, C. A.; Gelb, M. H. New Class of Antitrypanosomal Agents Based on Imidazopyridines. ACS Medicinal Chemistry Letters 2017.

10. Tidwell, R. R.; PATRICK, D. A.; Buckner, F. S.; Gelb, M. H.; Gillespie, J. R.; SILVA, D. G. Compounds for treatment of trypanosomes and neurological pathogens and uses thereof. Google Patents: 2017.

11. Gillmor, S. A.; Craik, C. S.; Fletterick, R. J. Structural determinants of specificity in the cysteine protease cruzain. Protein Science 1997, 6 (8), 1603-1611.

12. (a) Powers, J. C.; Asgian, J. L.; Ekici, Ö. D.; James, K. E. Irreversible Inhibitors of Serine, Cysteine, and Threonine Proteases. Chemical Reviews 2002, 102 (12), 4639-4750; (b) Otto, H. H.; Schirmeister, T. Cysteine Proteases and Their Inhibitors. Chem Rev 1997, 97 (1), 133-172; (c) Demuth, H. U. Recent developments in inhibiting cysteine and serine proteases. J Enzyme Inhib 1990, 3 (4), 249-78; (d) Scheidt, K. A.; Roush, W. R.; McKerrow, J. H.; Selzer, P. M.; Hansell, E.; Rosenthal, P. J. Structure-based design, synthesis and evaluation of conformationally constrained cysteine protease inhibitors. Bioorganic \& medicinal chemistry 1998, 6 (12), 2477-94; (e) Chen, Y. T.; Brinen, L. S.; Kerr, I. D.; Hansell, E.; Doyle, P. S.; McKerrow, J. H.; Roush, W. R. In vitro and in vivo studies of the trypanocidal properties of WRR-483 against Trypanosoma cruzi. PLoS Negl Trop Dis 2010, 4 (9), 0000825; (f) Yang, P. Y.; Wang, M.; He, C. Y.; Yao, S. Q. Proteomic profiling and potential cellular target identification of K11777, a clinical cysteine protease inhibitor, in Trypanosoma brucei. Chem Commun 2012, 48 (6), 835-7.

13. (a) Gotz, M. G.; Caffrey, C. R.; Hansell, E.; McKerrow, J. H.; Powers, J. C. Peptidyl allyl sulfones: a new class of inhibitors for clan CA cysteine proteases. Bioorganic \& medicinal chemistry 2004, 12 (19), 5203-11; (b) Shirasaki, Y.; Miyashita, H.; Yamaguchi, M.; Inoue, J.; Nakamura, M. Exploration of orally available calpain inhibitors: peptidyl alpha-ketoamides containing an amphiphile at $\mathrm{P} 3$ site. Bioorganic \& medicinal chemistry 2005, 13 (14), 4473 84; (c) Angelastro, M. R.; Peet, N. P.; Bey, P. An efficient synthesis of novel .alpha.-diketone and .alpha.-keto ester derivatives of N-protected amino acids and peptides. The Journal of Organic Chemistry 1989, 54 (16), 3913-3916; (d) Johansson, A.; Poliakov, A.; Akerblom, E.; Wiklund, K.; Lindeberg, G.; Winiwarter, S.; Danielson, U. H.; Samuelsson, B.; Hallberg, A. Acyl sulfonamides as potent protease inhibitors of the hepatitis C virus full-Length NS3 (protease-helicase/NTPase): a comparative study of different C-terminals. Bioorganic \& medicinal chemistry 2003, 11 (12), 2551-68; (e) Demko, Z. P.; Sharpless, K. B. Preparation of 5-substituted 1H-tetrazoles from nitriles in water. J Org Chem 2001, 66 (24), 7945-50.

14. Farady, C. J.; Craik, C. S. Mechanisms of macromolecular protease inhibitors. Chembiochem 2010, 11 (17), 2341-6.

15. Hodge, C. N.; Aldrich, P. E.; Fernandez, C. H.; Otto, M. J.; Rayner, M. M.; Wong, Y. N.; Erickson-Viitanen, S. Studies on Orally Available Inhibitors of HIV Protease. Peptidyl Aldehydes and Trifluoromethyl Ketones. Antiviral Chemistry and Chemotherapy 1994, 5 (4), 257-262.

16. (a) Grant, J. A.; Gallardo, M. A.; Pickup, B. T. A fast method of molecular shape comparison: A simple application of a Gaussian description of molecular shape. Journal of Computational Chemistry 1996, 17 (14), 1653-1666; (b) Rush, T. S., 3rd; Grant, J. A.; Mosyak, L.; Nicholls, 
A. A shape-based 3-D scaffold hopping method and its application to a bacterial proteinprotein interaction. J Med Chem 2005, 48 (5), 1489-95; (c) vROCS. OpenEye Scientific Software, Santa Fe, NM., 3.2.0.4; 2007.

17. (a) Lowe, G.; Yuthavong, Y. Kinetic specificity in papain-catalysed hydrolyses. Biochemical Journal 1971, 124 (1), 107-115; (b) Jaishankar, P.; Hansell, E.; Zhao, D.-M.; Doyle, P. S.; McKerrow, J. H.; Renslo, A. R. Potency and selectivity of P2/P3-modified inhibitors of cysteine proteases from trypanosomes. Bioorganic \& Medicinal Chemistry Letters 2008, 18 (2), 624-628.

18. Hann, M. M.; Leach, A. R.; Harper, G. Molecular complexity and its impact on the probability of finding leads for drug discovery. J. Chem. Inf. Comput. Sci. 2001, 41 (3), 856-864.

19. Tatipaka, H. B.; Gillespie, J. R.; Chatterjee, A. K.; Norcross, N. R.; Hulverson, M. A.; Ranade, R. M.; Nagendar, P.; Creason, S. A.; McQueen, J.; Duster, N. A.; Nagle, A.; Supek, F.; Molteni, V.; Wenzler, T.; Brun, R.; Glynne, R.; Buckner, F. S.; Gelb, M. H. Substituted 2phenylimidazopyridines: a new class of drug leads for human African trypanosomiasis. J Med Chem 2014, 57 (3), 828-35.

20. Tatipaka, H. B.; Gillespie, J. R.; Chatterjee, A. K.; Norcross, N. R.; Hulverson, M. A.; Ranade, R. M.; Nagendar, P.; Creason, S. A.; McQueen, J.; Duster, N. A. Substituted 2phenylimidazopyridines: a new class of drug leads for human African trypanosomiasis. Journal of Medicinal Chemistry 2014, 57 (3), 828-835.

21. Gobbi, L.; Knust, H.; Koerner, M.; Muri, D. Imidazo [1, 2-a] pyridin-7-amines as imaging tools. International Patent 2015.

22. Freitas, M. P.; Brown, S. D.; Martins, J. A. MIA-QSAR: a simple 2D image-based approach for quantitative structure-activity relationship analysis. Journal of Molecular Structure 2005, 738 (1-3), 149-154.

23. Du, Q. S.; Huang, R. B.; Wei, Y. T.; Pang, Z. W.; Du, L. Q.; Chou, K. C. Fragment-Based Quantitative Structure-Activity Relationship (FB-QSAR) for Fragment-Based Drug Design. Journal of Computational Chemistry 2009, 30 (2), 295-304.

24. Myint, K. Z.; Xie, X. Q. Recent Advances in Fragment-Based QSAR and Multi-Dimensional QSAR Methods. International Journal of Molecular Sciences 2010, 11 (10), 3846-3866.

25. Ferreira, M. M. C.; Montanari, C. A.; Gaudio, A. C. Variable selection in QSAR. Quimica Nova 2002, 25 (3), 439-448.

26. Rodrigues, C. R.; Flaherty, T. M.; Springer, C.; McKerrow, J. H.; Cohen, F. E. CoMFA and HQSAR of acylhydrazide cruzain inhibitors. Bioorganic \& Medicinal Chemistry Letters 2002, 12 (11), 1537-1541.

27. (a) Freitas, R. F.; Oprea, T. I.; Montanari, C. A. 2D QSAR and similarity studies on cruzain inhibitors aimed at improving selectivity over cathepsin L. Bioorganic \& medicinal chemistry 2008, 16 (2), 838-853; (b) Matter, H.; Potter, T. Comparing 3D pharmacophore triplets and 2D fingerprints for selecting diverse compound subsets. J. Chem. Inf. Comput. Sci. 1999, 39 (6), 1211-1225.

28. Silva, D. G.; Gillespie, J. R.; Ranade, R. M.; Herbst, Z. M.; Nguyen, U. T. T.; Buckner, F. S.; Montanari, C. A.; Gelb, M. H. New Class of Antitrypanosomal Agents Based on Imidazopyridines. ACS Medicinal Chemistry Letters 2017, 8 (7), 766-770.

29. (a) DiMasi, J. A.; Hansen, R. W.; Grabowski, H. G. The price of innovation: new estimates of drug development costs. J Health Econ 2003, 22 (2), 151-85; (b) Freitas, R. F.; Oprea, T. I.; Montanari, C. A. 2D QSAR and similarity studies on cruzain inhibitors aimed at improving selectivity over cathepsin L. Bioorganic \& medicinal chemistry 2008, 16 (2), 838-53; (c) Wiggers, H. J.; Rocha, J. R.; Cheleski, J.; Montanari, C. A. Integration of Ligand- and TargetBased Virtual Screening for the Discovery of Cruzain Inhibitors. Molecular Informatics 2011, 30 (6-7), 565-578; (d) Wiggers, H. J.; Rocha, J. R.; Fernandes, W. B.; Sesti-Costa, R.; Carneiro, Z. A.; Cheleski, J.; da Silva, A. B.; Juliano, L.; Cezari, M. H.; Silva, J. S.; McKerrow, J. H.; Montanari, C. A. Non-peptidic cruzain inhibitors with trypanocidal activity discovered by virtual screening and in vitro assay. PLoS Negl Trop Dis 2013, 7 (8).

30. Mizutani, M. Y.; Tomioka, N.; Itai, A. Rational automatic search method for stable docking models of protein and ligand. J Mol Biol 1994, 243 (2), 310-26. 
31. Montanari, C. Química medicinal: métodos e fundamentos em planejamento de fármacos. São Paulo: Edusp 2011.

32. (a) Kuntz, I. D.; Meng, E. C.; Shoichet, B. K. Structure-based molecular design. Accounts of Chemical research 1994, 27 (5), 117-123; (b) Goodsell, D. S.; Morris, G. M.; Olson, A. J. Automated docking of flexible ligands: applications of AutoDock. Journal of Molecular Recognition 1996, 9 (1), 1-5; (c) Rarey, M.; Wefing, S.; Lengauer, T. Placement of mediumsized molecular fragments into active sites of proteins. Journal of Computer-Aided Molecular Design 1996, 10 (1), 41-54; (d) McMartin, C.; Bohacek, R. S. QXP: powerful, rapid computer algorithms for structure-based drug design. Journal of Computer-Aided Molecular Design 1997, 11 (4), 333-344; (e) Welch, W.; Ruppert, J.; Jain, A. N. Hammerhead: fast, fully automated docking of flexible ligands to protein binding sites. Chemistry \& biology 1996, 3 (6), 449-462.

33. Hillebrecht, A.; Klebe, G. Use of 3D QSAR models for database screening: A feasibility study. Journal of Chemical Information and Modeling 2008, 48 (2), 384-396.

34. $\quad$ ROCS. version 2.4.1, Openeye Scientific Software Inc: Santa Fe, 2007.

35. Heritage Trevor, W.; Lowis David, R. Molecular Hologram QSAR. In Rational Drug Design, American Chemical Society: 1999; Vol. 719, pp 212-225.

36. (a) Mah, R.; Thomas, J. R.; Shafer, C. M. Drug discovery considerations in the development of covalent inhibitors. Bioorganic \& Medicinal Chemistry Letters 2014, 24 (1), 33-39; (b) Pinheiro, J. R.; Bitencourt, M.; da Cunha, E. F.; Ramalho, T. C.; Freitas, M. P. Novel anti-HIV cyclotriazadisulfonamide derivatives as modeled by ligand-and receptor-based approaches. Bioorganic \& medicinal chemistry 2008, 16 (4), 1683-1690; (c) Santos-Garcia, L.; Assis, L. C.; Silva, D. R.; Ramalho, T. C.; da Cunha, E. F. QSAR Analysis of Nicotinamidic Compouds and Design of Potential Bruton's Tyrosine Kinase (Btk) Inhibitors. J Biomol Struct Dyn 2015, 25, 1-50; (d) de Paula da Silva, C. H. T.; Bernardes, L. S. C.; da Silva, V. B.; Zani, C. L.; Carvalho, I. Novel aryl $\beta$-aminocarbonyl derivatives as inhibitors of Trypanosoma cruzi trypanothione reductase: binding mode revised by docking and GRIND2-based 3D-QSAR procedures. Journal of Biomolecular Structure and Dynamics 2012, 29 (6), 1206-1220.

37. Kerr, I. D.; Lee, J. H.; Farady, C. J.; Marion, R.; Rickert, M.; Sajid, M.; Pandey, K. C.; Caffrey, C. R.; Legac, J.; Hansell, E.; McKerrow, J. H.; Craik, C. S.; Rosenthal, P. J.; Brinen, L. S. Vinyl Sulfones as Antiparasitic Agents and a Structural Basis for Drug Design. Journal of Biological Chemistry 2009, 284 (38), 25697-25703.

38. Bento, A. P.; Gaulton, A.; Hersey, A.; Bellis, L. J.; Chambers, J.; Davies, M.; Kruger, F. A.; Light, Y.; Mak, L.; McGlinchey, S.; Nowotka, M.; Papadatos, G.; Santos, R.; Overington, J. P. The ChEMBL bioactivity database: an update. Nucleic Acids Research 2014, 42 (D1), D1083D1090.

39. Hohman, M.; Gregory, K.; Chibale, K.; Smith, P. J.; Ekins, S.; Bunin, B. Novel web-based tools combining chemistry informatics, biology and social networks for drug discovery. Drug Discovery Today 2009, 14 (5-6), 261-270.

40. (a) Beaulieu, C.; Isabel, E.; Fortier, A.; Masse, F.; Mellon, C.; Methot, N.; Ndao, M.; NicollGriffith, D.; Lee, D.; Park, H.; Black, W. C. Identification of potent and reversible cruzipain inhibitors for the treatment of Chagas disease. Bioorganic \& Medicinal Chemistry Letters 2010, 20 (24), 7444-7449; (b) Yang, P. Y.; Wang, M.; Li, L.; Wu, H.; He, C. Y.; Yao, S. Q. Design, Synthesis and Biological Evaluation of Potent Azadipeptide Nitrile Inhibitors and Activity-Based Probes as Promising Anti-Trypanosoma brucei Agents. Chemistry-a European Journal 2012, 18 (21), 6528-6541.

41. (a) Reyes, C. D. C. Síntese de dipeptidil-nitrilas como inibidores da enzíma cruzaína. Master. Thesis [Online] Universidade de São Paulo, São Carlos, SP, October 2014.

http://www.teses.usp.br/teses/disponiveis/75/75133/tde-29072014-153915/pt-br.php (accessed Apr 31, 2015); (b) Orozco, E. V. M. Síntese e Relações Estrutura-Atividade de Dipeptidilnitrilas Inibidoras da Cruzaína. Master. Thesis [Online] Universidade de São Paulo, São Carlos, SP, November 2014.

http://www.teses.usp.br/index.php?option=com_jumi\&fileid=14\&Itemid=161\&id=C7A0EEC 18E8C\&lang=pt-br\&pagina=1 (accessed Apr 31, 2015); (c) Avelar, L. A. A. Síntese de inibidores das enzimas cruzaína e diidroorotato desidrogenase de Trypanosoma cruzi. Master. 
Thesis [Online] Universidade de São Paulo, São Carlos, SP, April 2014. http://www.teses.usp.br/teses/disponiveis/75/75133/tde-21112014-155848/fr.php (accessed Apr 31, 2015); (d) Avelar, L. A.; Camilo, C. D.; de Albuquerque, S.; Fernandes, W. B.; Goncalez, C.; Kenny, P. W.; Leitao, A.; McKerrow, J. H.; Montanari, C. A.; Orozco, E. V.; Ribeiro, J. F.; Rocha, J. R.; Rosini, F.; Saidel, M. E. Molecular Design, Synthesis and Trypanocidal Activity of Dipeptidyl Nitriles as Cruzain Inhibitors. PLoS Negl Trop Dis 2015, 9 (7).

42. SYBYL-X. Tripos International, South Hanley Rd., St. Louis, Missouri, 63144, USA, 1.2; 2010.

43. (a) Geladi, P.; Kowalski, B. R. Partial Least-Squares Regression - A Tutorial. Analytica Chimica Acta 1986, 185, 1-17; (b) Gonzalez, M. P.; Teran, C.; Saiz-Urra, L.; Teijeira, M. Variable Selection Methods in QSAR: An Overview. Current Topics in Medicinal Chemistry 2008, 8 (18), 1606-1627; (c) Wold, S.; Sjostrom, M.; Eriksson, L. PLS-regression: a basic tool of chemometrics. Chemometrics and Intelligent Laboratory Systems 2001, 58 (2), 109-130.

44. Triballeau, N.; Acher, F.; Brabet, I.; Pin, J. P.; Bertrand, H. O. Virtual screening workflow development guided by the "receiver operating characteristic" curve approach. Application to high-throughput docking on metabotropic glutamate receptor subtype 4. J Med Chem 2005, 48 (7), 2534-47.

45. (a) Hawkins, P. C. D.; Skillman, A. G.; Warren, G. L.; Ellingson, B. A.; Stahl, M. T. Conformer Generation with OMEGA: Algorithm and Validation Using High Quality Structures from the Protein Databank and Cambridge Structural Database. Journal of Chemical Information and Modeling 2010, 50 (4), 572-584; (b) OMEGA. OpenEye Scientific Software, Santa Fe, NM., 2.5.1.4; 2010; (c) Hawkins, P. C. D.; Skillman, A. G.; Nicholls, A. Comparison of Shape-Matching and Docking as Virtual Screening Tools. Journal of Medicinal Chemistry 2007, 50 (1), 74-82.

46. Boström, J.; Greenwood, J. R.; Gottfries, J. Assessing the performance of OMEGA with respect to retrieving bioactive conformations. Journal of Molecular Graphics and Modelling 2003, 21 (5), 449-462.

47. Marvin. ChemAxon, Záhony u. 7, Building HX, 1031, Budapest, Hungary, 6.0.4; 2013.

48. Maestro. Schrödinger, LLC, New York, NY., 9.3; 2013.

49. Bernstein, F. C.; Koetzle, T. F.; Williams, G. J. B.; Meyer, E. F.; Brice, M. D.; Rodgers, J. R.; Kennard, O.; Shimanouchi, T.; Tasumi, M. The Protein Data Bank: a computer-based archival file for macromolecular structures. European Journal of Biochemistry 1977, 80 (2), 319-324.

50. Wiggers, H. J.; Rocha, J. R.; Fernandes, W. B.; Sesti-Costa, R.; Carneiro, Z. A.; Cheleski, J.; da Silva, A. B. F.; Juliano, L.; Cezari, M. H. S.; Silva, J. S.; McKerrow, J. H.; Montanari, C. A. Non-peptidic Cruzain Inhibitors with Trypanocidal Activity Discovered by Virtual Screening and In Vitro Assay. Plos Neglected Tropical Diseases 2013, 7 (8).

51. Kellenberger, E.; Rodrigo, J.; Muller, P.; Rognan, D. Comparative evaluation of eight docking tools for docking and virtual screening accuracy. Proteins-Structure Function and Bioinformatics 2004, 57 (2), 225-242.

52. (a) Friesner, R. A.; Banks, J. L.; Murphy, R. B.; Halgren, T. A.; Klicic, J. J.; Mainz, D. T.; Repasky, M. P.; Knoll, E. H.; Shelley, M.; Perry, J. K.; Shaw, D. E.; Francis, P.; Shenkin, P. S. Glide: A New Approach for Rapid, Accurate Docking and Scoring. 1. Method and Assessment of Docking Accuracy. Journal of Medicinal Chemistry 2004, 47 (7), 1739-1749; (b) Halgren, T. A.; Murphy, R. B.; Friesner, R. A.; Beard, H. S.; Frye, L. L.; Pollard, W. T.; Banks, J. L. Glide: A New Approach for Rapid, Accurate Docking and Scoring. 2. Enrichment Factors in Database Screening. Journal of Medicinal Chemistry 2004, 47 (7), 1750-1759.

53. Gillmor, S. A.; Craik, C. S.; Fletterick, R. J. Structural determinants of specificity in the cysteine protease cruzain. Protein Sci 1997, 6 (8), 1603-11.

54. Polticelli, F.; Zaini, G.; Bolli, A.; Antonini, G.; Gradoni, L.; Ascenzi, P. Probing the cruzain S2 recognition subsite: a kinetic and binding energy calculation study. Biochemistry 2005, 44 (8), 2781-9.

55. Senger, S. Using Tversky Similarity Searches for Core Hopping: Finding the Needles in the Haystack. Journal of Chemical Information and Modeling 2009, 49 (6), 1514-1524. 
56. Gauthier, J. Y.; Chauret, N.; Cromlish, W.; Desmarais, S.; Duong le, T.; Falgueyret, J. P.; Kimmel, D. B.; Lamontagne, S.; Leger, S.; LeRiche, T.; Li, C. S.; Masse, F.; McKay, D. J.; Nicoll-Griffith, D. A.; Oballa, R. M.; Palmer, J. T.; Percival, M. D.; Riendeau, D.; Robichaud, J.; Rodan, G. A.; Rodan, S. B.; Seto, C.; Therien, M.; Truong, V. L.; Venuti, M. C.; Wesolowski, G.; Young, R. N.; Zamboni, R.; Black, W. C. The discovery of odanacatib (MK0822), a selective inhibitor of cathepsin K. Bioorg Med Chem Lett 2008, 18 (3), 923-8.

57. Antunes, J. E.; Freitas, M. P.; Rittner, R. Bioactivities of a series of phosphodiesterase type 5 (PDE-5) inhibitors as modelled by MIA-QSAR. European Journal of Medicinal Chemistry 2008, 43 (8), 1632-1638.

58. (a) Dufour, E.; Storer, A. C.; Menard, R. Peptide aldehydes and nitriles as transition state analog inhibitors of cysteine proteases. Biochemistry 1995, 34 (28), 9136-43; (b) Greenspan, P. D.; Clark, K. L.; Cowen, S. D.; McQuire, L. W.; Tommasi, R. A.; Farley, D. L.; Quadros, E.; Coppa, D. E.; Du, Z.; Fang, Z.; Zhou, H.; Doughty, J.; Toscano, K. T.; Wigg, A. M.; Zhou, $\mathrm{S}$. N-arylaminonitriles as bioavailable peptidomimetic inhibitors of cathepsin B. Bioorg Med Chem Lett 2003, 13 (22), 4121-4.

59. (a) Lecaille, F.; Kaleta, J.; Bromme, D. Human and parasitic papain-like cysteine proteases: Their role in physiology and pathology and recent developments in inhibitor design. Chemical Reviews 2002, 102 (12), 4459-4488; (b) Powers, J. C.; Asgian, J. L.; Ekici, O. D.; James, K. E. Irreversible inhibitors of serine, cysteine, and threonine proteases. Chemical Reviews 2002, 102 (12), 4639-4750; (c) Leung, D.; Abbenante, G.; Fairlie, D. P. Protease inhibitors: Current status and future prospects. J. Med. Chem. 2000, 43 (3), 305-341.

60. (a) McKerrow, J. H. Development of cysteine protease inhibitors as chemotherapy for parasitic diseases: insights on safety, target validation, and mechanism of action. Int $J$ Parasitol 1999, 29 (6), 833-7; (b) Siles, R.; Chen, S. E.; Zhou, M.; Pinney, K. G.; Trawick, M. L. Design, synthesis, and biochemical evaluation of novel cruzain inhibitors with potential application in the treatment of Chagas' disease. Bioorg Med Chem Lett 2006, 16 (16), 4405-9.

61. DNDi. Disponível em:. http://www.dndi.org/diseasesprojects/portfolio/k777.html?highlight $=W y J r N z c 3 I l 0=\mathbf{2 0 1 3}$, acessado em: $22 / 03 / 2015$.

62. Donkor, I. O. A survey of calpain inhibitors. Curr Med Chem 2000, 7 (12), 1171-88.

63. (a) Hanzlik, R. P.; Jacober, S. P.; Zygmunt, J. Reversible binding of peptide aldehydes to papain. Structure-activity relationships. Biochimica et Biophysica Acta (BBA) - General Subjects 1991, 1073 (1), 33-42; (b) Aoyagi, T.; Takeuchi, T.; Matsuzaki, A.; Kawamura, K.; Kondo, S. Leupeptins, new protease inhibitors from Actinomycetes. J Antibiot 1969, 22 (6), 283-6; (c) Leung-Toung, R.; Li, W.; Tam, T. F.; Karimian, K. Thiol-dependent enzymes and their inhibitors: a review. Curr Med Chem 2002, 9 (9), 979-1002; (d) Iqbal, M.; Messina, P. A.; Freed, B.; Das, M.; Chatterjee, S.; Tripathy, R.; Ming, T.; Josef, K. A.; Dembofsky, B.; Dunn, D.; Griffith, E.; Siman, R.; Senadhi, S. E.; Biazzo, W.; Bozyczko-Coyne, D.; Meyer, S. L.; Ator, M. A.; Bihovsky, R. Subsite requirements for peptide aldehyde inhibitors of human calpain I. Bioorganic \& Medicinal Chemistry Letters 1997, 7 (5), 539-544; (e) Harris, A. L.; Gregory, J. S.; Maycock, A. L.; Graybill, T. L.; Osifo, I. K.; Schmidt, S. J.; Dolle, R. E. Characterization of a continuous fluorogenic assay for calpain I. Kinetic evaluation of peptide aldehydes, halomethyl ketones and (acyloxy)methyl ketones as inhibitors of the enzyme. Bioorganic \& Medicinal Chemistry Letters 1995, 5 (4), 393-398; (f) Mehdi, S. Cellpenetrating inhibitors of calpain. Trends Biochem Sci 1991, 16 (4), 150-3; (g) Inoue, J.; Nakamura, M.; Cui, Y. S.; Sakai, Y.; Sakai, O.; Hill, J. R.; Wang, K. K.; Yuen, P. W. Structure-activity relationship study and drug profile of N-(4-fluorophenylsulfonyl)-L-valyl-Lleucinal (SJA6017) as a potent calpain inhibitor. J Med Chem 2003, 46 (5), 868-71; (h) Sasaki, T.; Kishi, M.; Saito, M.; Tanaka, T.; Higuchi, N.; Kominami, E.; Katunuma, N.; Murachi, T. Inhibitory effect of di- and tripeptidyl aldehydes on calpains and cathepsins. J Enzyme Inhib 1990, 3 (3), 195-201.

64. Fukiage, C.; Azuma, M.; Nakamura, Y.; Tamada, Y.; Nakamura, M.; Shearer, T. R. SJA6017, a newly synthesized peptide aldehyde inhibitor of calpain: amelioration of cataract in cultured rat lenses. Biochim Biophys Acta 1997, 24 (3), 304-12.

65. (a) Adkison, K. K.; Barrett, D. G.; Deaton, D. N.; Gampe, R. T.; Hassell, A. M.; Long, S. T.; McFadyen, R. B.; Miller, A. B.; Miller, L. R.; Payne, J. A.; Shewchuk, L. M.; Wells-Knecht, 
K. J.; Willard Jr, D. H.; Wright, L. L. Semicarbazone-based inhibitors of cathepsin K, are they prodrugs for aldehyde inhibitors? Bioorganic \& Medicinal Chemistry Letters 2006, 16 (4), 978-983; (b) Nakamura, M.; Inoue, J. Exploration of peptidyl hydrazones as water-soluble calpain inhibitors. Bioorg Med Chem Lett 2002, 12 (12), 1603-6; (c) Du, X.; Guo, C.; Hansell, E.; Doyle, P. S.; Caffrey, C. R.; Holler, T. P.; McKerrow, J. H.; Cohen, F. E. Synthesis and structure-activity relationship study of potent trypanocidal thio semicarbazone inhibitors of the trypanosomal cysteine protease cruzain. J Med Chem 2002, 45 (13), 2695-707.

66. (a) Hanzlik, R. P.; Zygmunt, J.; Moon, J. B. Reversible covalent binding of peptide nitriles to papain. Biochim Biophys Acta 1990, 20 (1), 62-70; (b) Loser, R.; Schilling, K.; Dimmig, E.; Gutschow, M. Interaction of papain-like cysteine proteases with dipeptide-derived nitriles. $J$ Med Chem 2005, 48 (24), 7688-707.

67. (a) Brak, K.; Doyle, P. S.; McKerrow, J. H.; Ellman, J. A. Identification of a New Class of Nonpeptidic Inhibitors of Cruzain. Journal of the American Chemical Society 2008, 130 (20), 6404-6410; (b) Pinner, A.; Klein, F. Umwandlung der Nitrile in Imide. Berichte der deutschen chemischen Gesellschaft 1877, 10 (2), 1889-1897; (c) Frizler, M.; Stirnberg, M.; Sisay, M. T.; Gutschow, M. Development of nitrile-based peptidic inhibitors of cysteine cathepsins. Curr Top Med Chem 2010, 10 (3), 294-322.

68. Le Gall, C.; Bonnelye, E.; Clezardin, P. Cathepsin K inhibitors as treatment of bone metastasis. Curr Opin Support Palliat Care 2008, 2 (3), 218-22.

69. Zega, A. Azapeptides as pharmacological agents. Curr Med Chem 2005, 12 (5), 589-97.

70. (a) Löser, R.; Frizler, M.; Schilling, K.; Gütschow, M. Azadipeptide Nitriles: Highly Potent and Proteolytically Stable Inhibitors of Papain-Like Cysteine Proteases. Angewandte Chemie International Edition 2008, 47 (23), 4331-4334; (b) Löser, R.; Frizler, M.; Schilling, K.; Gütschow, M. Azadipeptidnitrile - hochpotente und proteolysestabile Inhibitoren Papainähnlicher Cysteinproteasen. Angewandte Chemie 2008, 120 (23), 4403-4406.

71. Golicnik, M.; Stojan, J. Slow-binding inhibition: A theoretical and practical course for students. Biochem Mol Biol Educ 2004, 32 (4), 228-35.

72. (a) Frizler, M.; Lohr, F.; Furtmann, N.; Kläs, J.; Gütschow, M. Structural Optimization of Azadipeptide Nitriles Strongly Increases Association Rates and Allows the Development of Selective Cathepsin Inhibitors. Journal of Medicinal Chemistry 2011, 54 (1), 396-400; (b) Frizler, M.; Lohr, F.; Lülsdorff, M.; Gütschow, M. Facing the gem-Dialkyl Effect in Enzyme Inhibitor Design: Preparation of Homocycloleucine-Based Azadipeptide Nitriles. Chemistry A European Journal 2011, 17 (41), 11419-11423; (c) Löser, R.; Gut, J.; Rosenthal, P. J.; Frizler, M.; Gütschow, M.; Andrews, K. T. Antimalarial activity of azadipeptide nitriles. Bioorganic \& Medicinal Chemistry Letters 2010, 20 (1), 252-255.

73. (a) Kumar, S.; Pearson, A. L.; Pratt, R. F. Design, synthesis, and evaluation of alphaketoheterocycles as class $\mathrm{C}$ beta-lactamase inhibitors. Bioorganic \& medicinal chemistry 2001, 9 (8), 2035-44; (b) Hamze, A.; Hernandez, J. F.; Fulcrand, P.; Martinez, J. Synthesis of various 3-substituted 1,2,4-oxadiazole-containing chiral beta 3 - and alpha-amino acids from Fmoc-protected aspartic acid. J Org Chem 2003, 68 (19), 7316-21; (c) Edwards, P. D.; Wolanin, D. J.; Andisik, D. W.; Davis, M. W. Peptidyl alpha-ketoheterocyclic inhibitors of human neutrophil elastase. 2. Effect of varying the heterocyclic ring on in vitro potency. $J$ Med Chem 1995, 38 (1), 76-85; (d) Tsutsumi, S.; Okonogi, T.; Shibahara, S.; Ohuchi, S.; Hatsushiba, E.; Patchett, A. A.; Christensen, B. G. Synthesis and structure-activity relationships of peptidyl alpha-keto heterocycles as novel inhibitors of prolyl endopeptidase. $J$ Med Chem 1994, 37 (21), 3492-502.

74. (a) Loner, C. M.; Luzzio, F. A.; Demuth, D. R. Preparation of azidoaryl- and azidoalkyloxazoles for click chemistry. Tetrahedron Letters 2012, 53 (42), 5641-5644; (b) Abbenante, G.; Fairlie, D. P.; Gahan, L. R.; Hanson, G. R.; Pierens, G. K.; van den Brenk, A. L. Conformational Control by Thiazole and Oxazoline Rings in Cyclic Octapeptides of Marine Origin. Novel Macrocyclic Chair and Boat Conformations. Journal of the American Chemical Society 1996, 118 (43), 10384-10388.

75. (a) Edwards, P. D.; Meyer, E. F.; Vijayalakshmi, J.; Tuthill, P. A.; Andisik, D. A.; Gomes, B.; Strimpler, A. Design, synthesis, and kinetic evaluation of a unique class of elastase inhibitors, the peptidyl .alpha.-ketobenzoxazoles, and the x-ray crystal structure of the covalent complex 
between porcine pancreatic elastase and Ac-Ala-Pro-Val-2-benzoxazole. Journal of the American Chemical Society 1992, 114 (5), 1854-1863; (b) Chan, A. W.; Golec, J. M. Prediction of relative potency of ketone protease inhibitors using molecular orbital theory. Bioorganic \& medicinal chemistry 1996, 4 (10), 1673-7; (c) Taylor, P. J.; Wait, A. R. [sigma]I Values for heterocycles. Journal of the Chemical Society, Perkin Transactions 2 1986, (11), 1765-1770.

76. (a) Kenny, P. W.; Sadowski, J. Structure Modification in Chemical Databases. In Chemoinformatics in Drug Discovery, Wiley-VCH Verlag GmbH \& Co. KGaA: 2005; pp 271-285; (b) Griffen, E.; Leach, A. G.; Robb, G. R.; Warner, D. J. Matched molecular pairs as a medicinal chemistry tool. J Med Chem 2011, 54 (22), 7739-50; (c) Wassermann, A. M.; Wawer, M.; Bajorath, J. Activity landscape representations for structure-activity relationship analysis. J Med Chem 2010, 53 (23), 8209-23; (d) Leach, A. G.; Jones, H. D.; Cosgrove, D. A.; Kenny, P. W.; Ruston, L.; MacFaul, P.; Wood, J. M.; Colclough, N.; Law, B. Matched molecular pairs as a guide in the optimization of pharmaceutical properties; a study of aqueous solubility, plasma protein binding and oral exposure. J Med Chem 2006, 49 (23), 6672-82.

77. (a) Raymond, J. W.; Watson, I. A.; Mahoui, A. Rationalizing lead optimization by associating quantitative relevance with molecular structure modification. J Chem Inf Model 2009, 49 (8), 1952-62; (b) Sheridan, R. P. The most common chemical replacements in drug-like compounds. J Chem Inf Comput Sci 2002, 42 (1), 103-8; (c) Southall, N. T.; Ajay. Kinase patent space visualization using chemical replacements. J Med Chem 2006, 49 (6), 2103-9.

78. (a) Haubertin, D. Y.; Bruneau, P. A database of historically-observed chemical replacements. J Chem Inf Model 2007, 47 (4), 1294-302; (b) Gleeson, P.; Bravi, G.; Modi, S.; Lowe, D. ADMET rules of thumb II: A comparison of the effects of common substituents on a range of ADMET parameters. Bioorganic \& medicinal chemistry 2009, 17 (16), 5906-19.

79. Sheridan, R. P.; Hunt, P.; Culberson, J. C. Molecular transformations as a way of finding and exploiting consistent local QSAR. J Chem Inf Model 2006, 46 (1), 180-92.

80. Lewis, M. L.; Cucurull-Sanchez, L. Structural pairwise comparisons of HLM stability of phenyl derivatives: Introduction of the Pfizer metabolism index (PMI) and metabolismlipophilicity efficiency (MLE). J Comput Aided Mol Des 2009, 23 (2), 97-103.

81. (a) Hajduk, P. J.; Sauer, D. R. Statistical analysis of the effects of common chemical substituents on ligand potency. J Med Chem 2008, 51 (3), 553-64; (b) Birch, A. M.; Kenny, P. W.; Simpson, I.; Whittamore, P. R. Matched molecular pair analysis of activity and properties of glycogen phosphorylase inhibitors. Bioorg Med Chem Lett 2009, 19 (3), 850-3.

82. Khedkar, V. M.; Joseph, J.; Pissurlenkar, R.; Saran, A.; Coutinho, E. C. How good are ensembles in improving QSAR models? The case with eCoRIA. J Biomol Struct Dyn 2015, 33 (4), 749-69.

83. Hoelz, L. V.; Leal, V. F.; Rodrigues, C. R.; Pascutti, P. G.; Albuquerque, M. G.; Muri, E. M.; Dias, L. R. Molecular dynamics simulations of the free and inhibitor-bound cruzain systems in aqueous solvent: insights on the inhibition mechanism in acidic pH. J Biomol Struct Dyn 2016, 34 (9), 1969-78.

84. (a) Santos-Garcia, L.; Assis, L. C.; Silva, D. R.; Ramalho, T. C.; da Cunha, E. F. QSAR analysis of nicotinamidic compounds and design of potential Bruton's tyrosine kinase (Btk) inhibitors. J Biomol Struct Dyn 2016, 34 (7), 1421-40; (b) Chikkanna, D.; Khairnar, V. 4,5dihydroisoxazole derivatives as nampt inhibitors. Google Patents: 2016.

85. Yamamoto, M.; Ikeda, S.; Kondo, H.; Inoue, S. Design and synthesis of dual inhibitors for matrix metalloproteinase and cathepsin. Bioorganic \& Medicinal Chemistry Letters 2002, 12 (3), 375-378.

86. Plowright, A. T.; Johnstone, C.; Kihlberg, J.; Pettersson, J.; Robb, G.; Thompson, R. A. Hypothesis driven drug design: improving quality and effectiveness of the design-make-testanalyse cycle. Drug Discovery Today 2012, 17 (1-2), 56-62.

87. Kenny, P. W. Hydrogen Bonding, Electrostatic Potential, and Molecular Design. Journal of Chemical Information and Modeling 2009, 49 (5), 1234-1244.

88. Frizler, M.; Stirnberg, M.; Sisay, M. T.; Gütschow, M. Development of nitrile-based peptidic inhibitors of cysteine cathepsins. Current Topics In Medicinal Chemistry 2010, 10 (3), 294322. 
89. Pehere, A. D.; Abell, A. D. An improved large scale procedure for the preparation of N-Cbz amino acids. Tetrahedron Letters 2011, 52 (13), 1493-1494.

90. Gaulton, A.; Bellis, L. J.; Bento, A. P.; Chambers, J.; Davies, M.; Hersey, A.; Light, Y.; McGlinchey, S.; Michalovich, D.; Al-Lazikani, B.; Overington, J. P. ChEMBL: a large-scale bioactivity database for drug discovery. Nucleic Acids Research 2012, 40 (D1), D1100D1107.

91. Choe, Y.; Brinen, L. S.; Price, M. S.; Engel, J. C.; Lange, M.; Grisostomi, C.; Weston, S. G.; Pallai, P. V.; Cheng, H.; Hardy, L. W.; Hartsough, D. S.; McMakin, M.; Tilton, R. F.; Baldino, C. M.; Craik, C. S. Development of alpha-keto-based inhibitors of cruzain, a cysteine protease implicated in Chagas disease. Bioorganic \& medicinal chemistry 2005, 13 (6), 2141-56.

92. (a) Yu, J.; Folmer, J. J.; Hoesch, V.; Doherty, J.; Campbell, J. B.; Burdette, D. Elucidation of a novel bioactivation pathway of a 3,4-unsubstituted isoxazole in human liver microsomes: formation of a glutathione adduct of a cyanoacrolein derivative after isoxazole ring opening. Drug Metab Dispos 2011, 39 (2), 302-11; (b) Kalgutkar, A. S.; Nguyen, H. T.; Vaz, A. D.; Doan, A.; Dalvie, D. K.; McLeod, D. G.; Murray, J. C. In vitro metabolism studies on the isoxazole ring scission in the anti-inflammatory agent lefluonomide to its active alphacyanoenol metabolite A771726: mechanistic similarities with the cytochrome P450-catalyzed dehydration of aldoximes. Drug Metab Dispos 2003, 31 (10), 1240-50.

93. Dalvie, D. K.; Kalgutkar, A. S.; Khojasteh-Bakht, S. C.; Obach, R. S.; O'Donnell, J. P. Biotransformation reactions of five-membered aromatic heterocyclic rings. Chem Res Toxicol 2002, 15 (3), 269-99.

94. Cywin, C. L.; Firestone, R. A.; McNeil, D. W.; Grygon, C. A.; Crane, K. M.; White, D. M.; Kinkade, P. R.; Hopkins, J. L.; Davidson, W.; Labadia, M. E. The design of potent hydrazones and disulfides as cathepsin S inhibitors. Bioorganic \& medicinal chemistry 2003, 11 (5), 733 740 .

95. (a) Liu, S.; Hanzlik, R. P. Structure-activity relationships for inhibition of papain by peptide Michael acceptors. J Med Chem 1992, 35 (6), 1067-75; (b) Niestroj, A. J.; Feussner, K.;

Heiser, U.; Dando, P. M.; Barrett, A.; Gerhartz, B.; Demuth, H. U. Inhibition of mammalian legumain by Michael acceptors and AzaAsn-halomethylketones. Biol Chem 2002, 383 (7-8), 1205-14.

96. Roy, K.; Kar, S.; Ambure, P. On a simple approach for determining applicability domain of QSAR models. Chemometrics and Intelligent Laboratory Systems 2015, 145, $22-29$.

97. (a) Roy, K.; Chakraborty, P.; Mitra, I.; Ojha, P. K.; Kar, S.; Das, R. N. Some case studies on application of "rm2" metrics for judging quality of quantitative structure-activity relationship predictions: Emphasis on scaling of response data. Journal of Computational Chemistry 2013, 34 (12), 1071-1082; (b) Mitra, I.; Saha, A.; Roy, K. Exploring quantitative structure-activity relationship studies of antioxidant phenolic compounds obtained from traditional Chinese medicinal plants. Molecular Simulation 2010, 36 (13), 1067-1079.

98. Jaffe, H. H. A REEXAMINATION OF THE HAMMETT EQUATION. Chemical Reviews 1953, 53 (2), 191-261.

99. (a) Moraes, C. B.; Giardini, M. A.; Kim, H.; Franco, C. H.; Araujo-Junior, A. M.; Schenkman, S.; Chatelain, E.; Freitas-Junior, L. H. Nitroheterocyclic compounds are more efficacious than CYP51 inhibitors against Trypanosoma cruzi: implications for Chagas disease drug discovery and development. Scientific Reports 2014, 4, 4703; (b) Silva, F. T.; Franco, C. H.; Favaro, D. C.; Freitas-Junior, L. H.; Moraes, C. B.; Ferreira, E. I. Design, synthesis and antitrypanosomal activity of some nitrofurazone 1,2,4-triazolic bioisosteric analogues. European Journal of Medicinal Chemistry 2016, 121, 553-560.

100. van de Waterbeemd, H.; Gifford, E. ADMET in silico modelling: Towards prediction paradise? Nature Reviews Drug Discovery 2003, 2 (3), 192-204.

101. (a) Anbazhagan, M.; Boykin, D. W. A facile synthesis of the prodrug 2,5-bis(4-Omethoxyamidinophenyl)furan and analogs. Heterocycl. Commun. 2003, 9 (2), 117-118; (b) Ansede, J. H.; Anbazhagan, M.; Brun, R.; Easterbrook, J. D.; Hall, J. E.; Boykin, D. W. OAlkoxyamidine Prodrugs of Furamidine: In Vitro Transport and Microsomal Metabolism as Indicators of in Vivo Efficacy in a Mouse Model of Trypanosoma brucei rhodesiense Infection. J. Med. Chem. 2004, 47 (17), 4335-4338. 
102. (a) Dann, O.; Fick, H.; Pietzner, B.; Walkenhorst, E.; Fernbach, R.; Zeh, D. Trypanocidal diamidines with three isolated ring systems. Justus Liebigs Ann. Chem. 1975, (1), 160-94; (b) Das, B. P.; Boykin, D. W. Synthesis and antiprotozoal activity of 2,5-bis(4guanylphenyl)furans. J. Med. Chem. 1977, 20 (4), 531-6.

103. Harrill, A. H.; DeSmet, K. D.; Wolf, K. K.; Bridges, A. S.; Eaddy, J. S.; Kurtz, C. L.; Hall, J. E.; Paine, M. F.; Tidwell, R. R.; Watkins, P. B. A Mouse Diversity Panel Approach Reveals the Potential for Clinical Kidney Injury Due to DB289 Not Predicted by Classical Rodent Models. Toxicol. Sci. 2012, 130 (2), 416-426.

104. Torreele, E.; Trunz, B. B.; Tweats, D.; Kaiser, M.; Brun, R.; Mazue, G.; Bray, M. A.; Pecoul, B. Fexinidazole - a new oral nitroimidazole drug candidate entering clinical development for the treatment of sleeping sickness. PLoS Neglected Trop. Dis. 2010, 4 (12), e923.

105. Jacobs, R. T.; Nare, B.; Wring, S. A.; Orr, M. D.; Chen, D.; Sligar, J. M.; Jenks, M. X.; Noe, R. A.; Bowling, T. S.; Mercer, L. T.; Rewerts, C.; Gaukel, E.; Owens, J.; Parham, R.; Randolph, R.; Beaudet, B.; Bacchi, C. J.; Yarlett, N.; Plattner, J. J.; Freund, Y.; Ding, C.; Akama, T.; Zhang, Y. K.; Brun, R.; Kaiser, M.; Scandale, I.; Don, R. SCYX-7158, an orallyactive benzoxaborole for the treatment of stage 2 Human African trypanosomiasis. PLoS Neglected Trop. Dis. 2011, 5 (6), e1151.

106. Pammolli, F.; Magazzini, L.; Riccaboni, M. The productivity crisis in pharmaceutical R\&D. Nat. Rev. Drug Discovery 2011, 10 (6), 428-438.

107. (a) Lipinski, C. A. Drug-like properties and the causes of poor solubility and poor permeability. J Pharmacol Toxicol Methods 2000, 44 (1), 235-49; (b) Lipinski, C. A.; Lombardo, F.; Dominy, B. W.; Feeney, P. J. Experimental and computational approaches to estimate solubility and permeability in drug discovery and development settings. Adv Drug Deliv Rev 2001, 46 (1-3), 3-26.

108. Tatipaka, H. B.; Gillespie, J. R.; Chatterjee, A. K.; Norcross, N. R.; Hulverson, M. A.; Ranade, R. M.; Nagendar, P.; Creason, S. A.; McQueen, J.; Duster, N. A.; Nagle, A.; Supek, F.; Molteni, V.; Wenzler, T.; Brun, R.; Glynne, R.; Buckner, F. S.; Gelb, M. H. Substituted 2Phenylimidazopyridines: A New Class of Drug Leads for Human African Trypanosomiasis. $J$. Med. Chem. 2014, 57 (3), 828-835.

109. Patrick, D. A.; Wenzler, T.; Yang, S.; Weiser, P. T.; Wang, M. Z.; Brun, R.; Tidwell, R. R. Synthesis of novel amide and urea derivatives of thiazol-2-ethylamines and their activity against Trypanosoma brucei rhodesiense. Bioorg. Med. Chem. 2016, 24 (11), 2451-2465.

110. Patrick, D. A.; Gillespie, J. R.; McQueen, J.; Hulverson, M. A.; Ranade, R. M.; Creason, S. A.; Herbst, Z. M.; Gelb, M. H.; Buckner, F. S.; Tidwell, R. R. Urea Derivatives of 2-Arylbenzothiazol-5-amines: A New Class of Potential Drugs for Human African Trypanosomiasis. Journal of Medicinal Chemistry 2017, 60 (3), 957-971.

111. Patrick, D. A.; Wenzler, T.; Yang, S.; Weiser, P. T.; Wang, M. Z.; Brun, R.; Tidwell, R. R. Synthesis of novel amide and urea derivatives of thiazol-2-ethylamines and their activity against Trypanosoma brucei rhodesiense. Bioorganic \& medicinal chemistry 2016, 24 (11), 2451-2465.

112. Salva, P.; Costa, J. Clinical pharmacokinetics and pharmacodynamics of zolpidem. Therapeutic implications. Clin Pharmacokinet 1995, 29 (3), 142-53.

113. Kerns, E. H.; Di, L.; Carter, G. T. In Vitro Solubility Assays in Drug Discovery. Curr. Drug Metab. 2008, 9 (9), 879-885.

114. Francisco, A. F.; Jayawardhana, S.; Lewis, M. D.; White, K. L.; Shackleford, D. M.; Chen, G.; Saunders, J.; Osuna-Cabello, M.; Read, K. D.; Charman, S. A.; Chatelain, E.; Kelly, J. M. Nitroheterocyclic drugs cure experimental Trypanosoma cruzi infections more effectively in the chronic stage than in the acute stage. Sci Rep 2016, 6 (35351).

115. Lewis, M. D.; Francisco, A. F.; Taylor, M. C.; Kelly, J. M. A new experimental model for assessing drug efficacy against Trypanosoma cruzi infection based on highly sensitive in vivo imaging. J Biomol Screen 2015, 20 (1), 36-43.

116. Oprea, T. I.; Davis, A. M.; Teague, S. J.; Leeson, P. D. Is there a difference between leads and drugs? A historical perspective. J. Chem. Inf. Comput. Sci. 2001, 41 (5), 1308-1315.

117. Nichols, P. L.; Eatherton, A. J.; Bamborough, P.; Jandu, K. S.; Philps, O. J.; Andreotti, D. Novel compounds. Google Patents: 2012. 
118. Reddy, L. A.; Chakraborty, S.; Swapna, R.; Bhalerao, D.; Malakondaiah, G. C.; Ravikumar, M.; Kumar, A.; Reddy, G. S.; Naram, J.; Dwivedi, N.; Roy, A.; Himabindu, V.; Babu, B.; Bhattacharya, A.; Bandichhor, R. Synthesis and Process Optimization of Amtolmetin: An Antiinflammatory Agent†. Organic Process Research \& Development 2010, 14 (2), 362-368.

119. Yang, P.-Y.; Wang, M.; He, C. Y.; Yao, S. Q. Proteomic profiling and potential cellular target identification of K11777, a clinical cysteine protease inhibitor, in Trypanosoma brucei. Chemical Communications 2012, 48 (6), 835-837.

120. Reiter, L. A. Synthesis of 4(5)-acyl-, 1-substituted 5-acyl- and 1-substituted 4-acyl-1Himidazoles from 4-aminoisoxazoles. The Journal of Organic Chemistry 1987, 52 (13), 27142726.

121. Pascual, A. Herstellung von substituierten 2-Aminooxazol-4-carbonitrilen. Helvetica Chimica Acta 1989, 72 (3), 556-569.

122. (a) Parikh, J. R.; Doering, W. v. E. Sulfur trioxide in the oxidation of alcohols by dimethyl sulfoxide. Journal of the American Chemical Society 1967, 89 (21), 5505-5507; (b) Hamada, Y.; Shioiri, T. NEW METHODS AND REAGENTS IN ORGANIC SYNTHESIS. 29. A PRACTICAL METHOD FOR THE PREPARATION OF OPTICALLY ACTIVE nPROTECTED \&alpha;-AMINO ALDEHYDES AND PEPTIDE ALDEHYDES. CHEMICAL \& PHARMACEUTICAL BULLETIN 1982, 30 (5), 1921-1924.

123. (a) Tanaka, M.; Oishi, S.; Ohno, H.; Fujii, N. A Novel Oxazolidine Linker for the Synthesis of Peptide Aldehydes. Int J Pept Res Ther 2007, 13 (1-2), 271-279; (b) Frigerio, M.; Santagostino, M.; Sputore, S. A User-Friendly Entry to 2-Iodoxybenzoic Acid (IBX). The Journal of Organic Chemistry 1999, 64 (12), 4537-4538.

124. (a) Krehan, D.; Storustovu, S. I.; Liljefors, T.; Ebert, B.; Nielsen, B.; Krogsgaard-Larsen, P.; Frolund, B. Potent 4-arylalkyl-substituted 3-isothiazolol GABA(A) competitive/noncompetitive antagonists: synthesis and pharmacology. J Med Chem 2006, 49 (4), 1388-96; (b) Blanchette, M. A.; Choy, W.; Davis, J. T.; Essenfeld, A. P.; Masamune, S.; Roush, W. R.; Sakai, T. HORNER-WADSWORTH-EMMONS REACTION - USE OF LITHIUM-CHLORIDE AND AN AMINE FOR BASE SENSITIVE COMPOUNDS. Tetrahedron Letters 1984, 25 (21), 2183-2186; (c) Nicolaou, K. C.; Harter, M. W.; Gunzner, J. L.; Nadin, A. The Wittig and related reactions in natural product synthesis. Liebigs AnnalenRecueil 1997, (7), 1283-1301.

125. Trost, B. M.; Malhotra, S.; Chan, W. H. Exercising Regiocontrol in Palladium-Catalyzed Asymmetric Prenylations and Geranylation: Unifying Strategy toward Flustramines A and B. Journal of the American Chemical Society 2011, 133 (19), 7328-7331.

126. Palermo, C.; Joyce, J. A. Cysteine cathepsin proteases as pharmacological targets in cancer. Trends Pharmacol Sci 2008, 29 (1), 22-8.

127. O’Brien, N. J.; Brzozowski, M.; Buskes, M. J.; Deady, L. W.; Abbott, B. M. Synthesis and biological evaluation of 2-anilino-4-substituted-7H-pyrrolopyrimidines as PDK1 inhibitors. Bioorganic \& medicinal chemistry 2014, 22 (15), 3879-3886.

128. Forman, S. E. Synthesis of Oximes1. The Journal of Organic Chemistry 1964, 29 (11), 33233327.

129. Nelissen, J.; Nuyts, K.; Dehaen, W.; De Borggraeve, W. M. Synthesis of the orthogonally protected amino alcohol Phaol and analogs. J Pept Sci 2011, 17 (7), 527-32.

130. McMath, A. R.; Guillaume, D.; Aitken, D. J.; Husson, H.-P. Direct dialkylation of peptide nitriles. Application to the synthesis of 1-aminocyclopropane-1-carboxylic acid (Acc)containing dipeptides. Bull. Soc. Chim. Fr. 1997, 134 (Copyright (C) 2016 American Chemical Society (ACS). All Rights Reserved.), 105-110.

131. Choe, Y.; Brinen, L. S.; Price, M. S.; Engel, J. C.; Lange, M.; Grisostomi, C.; Weston, S. G.; Pallai, P. V.; Cheng, H.; Hardy, L. W.; Hartsough, D. S.; McMakin, M.; Tilton, R. F.; Baldino, C. M.; Craik, C. S. Development of $\alpha$-keto-based inhibitors of cruzain, a cysteine protease implicated in Chagas disease. Bioorganic \& medicinal chemistry 2005, 13 (6), 2141-2156.

132. Kong, J. S.; Venkatraman, S.; Furness, K.; Nimkar, S.; Shepherd, T. A.; Wang, Q. M.; Aube, J.; Hanzlik, R. P. Synthesis and evaluation of peptidyl Michael acceptors that inactivate human rhinovirus 3C protease and inhibit virus replication. J Med Chem 1998, 41 (14), 257987. 
133. Dussault, P. H.; George, A. D.; Trullinger, T. K. Peroxides as oxidative enzyme inhibitors: mechanism-based inhibition of a cysteine protease by an amino acid ozonide. Bioorg. Med. Chem. Lett. 1999, 9 (Copyright (C) 2016 American Chemical Society (ACS). All Rights Reserved.), 3255-3258.

134. Riches, S. L.; Saha, C.; Filgueira, N. F.; Grange, E.; McGarrigle, E. M.; Aggarwal, V. K. On the Mechanism of Ylide-Mediated Cyclopropanations: Evidence for a Proton-Transfer Step and Its Effect on Stereoselectivity. Journal of the American Chemical Society 2010, 132 (22), 7626-7630.

135. Ettari, R.; Tamborini, L.; Angelo, I. C.; Micale, N.; Pinto, A.; De Micheli, C.; Conti, P. Inhibition of rhodesain as a novel therapeutic modality for human African trypanosomiasis. $J$ Med Chem 2013, 56 (14), 5637-58.

136. Osman, F. H.; El-Samahy, F. A. On the Reaction of Isatin with Cyanomethylene (triphenyl)phosphorane. A Nucleophilic Attack of Alkyl Phosphites on the Carbon-Carbon Double Bond of (E)-Oxindolylideneacetonitrile. Tetrahedron 2000, 56 (13), 1863-1871.

137. Loeser, R.; Frizler, M.; Schilling, K.; Guetschow, M. Azadipeptide nitriles: highly potent and proteolytically stable inhibitors of papain-like cysteine proteases. Angew. Chem., Int. Ed. 2008, 47 (Copyright (C) 2016 American Chemical Society (ACS). All Rights Reserved.), 4331-4334.

138. Xu, Y.; Chen, L.; Duan, X.; Meng, Y.; Jiang, L.; Li, M.; Zhao, G.; Li, Y. Total synthesis of hirsutellide A. Tetrahedron Letters 2005, 46 (25), 4377-4379.

139. Gobbi, L.; Knust, H.; Koerner, M.; MURI, D. Imidazo[1,2-a]pyridin-7-amines as imaging tools. Google Patents: 2015. 
10 Apêndice

APÊNDICE A - Tabela com a série de compostos usada para construir os modelos HQSAR, ROCS e os estudos de docagem. Os valores experimentais, preditos e ajustados de $\mathrm{pIC}_{50}$ obtidos pelo modelo HQSAR 3.4

\begin{tabular}{|c|c|c|c|c|c|c|}
\hline \multirow{2}{*}{ Comp. } & \multirow{2}{*}{ Estrutura Química } & \multicolumn{4}{|c|}{$\mathrm{pIC}_{50}$} & \multirow{2}{*}{ Ref. Numb. } \\
\hline & & Exp. & Pred. & Ajust. & Teste & \\
\hline
\end{tabular}

$1^{*}$<smiles>CN(C#N)N(C)C(=O)[C@H](Cc1ccccc1)NC(=O)c1ccc2c(c1)OCCO2</smiles>

2<smiles>CN(C(=O)[C@H](Cc1ccccc1)NC(=O)c1ccc2c(c1)OCCO2)N(C#N)Cc1ccccc1</smiles>

7.71

7.90

8.20

6.99

$3^{*}$<smiles>CN(C(=O)[C@H](Cc1ccccc1)NC(=O)c1ccc2c(c1)OCCO2)N(C#N)Cc1ccccc1</smiles>

4<smiles>CN(C(=O)[C@H](Cc1ccccc1)NC(=O)c1ccc2c(c1)OCCO2)N(C#N)CCCc1ccccc1</smiles>

8.09

7.66

7.30

7.55

$-0.56$

1c

5<smiles>CCCN(C#N)N(C)C(=O)[C@H](Cc1ccccc1)NC(=O)c1ccc2c(c1)OCCO2</smiles>

$6^{*}$<smiles>CC(C)[C@H](NC(=O)c1ccc2c(c1)OCCO2)C(=O)N(C)N(C)C#N</smiles> 


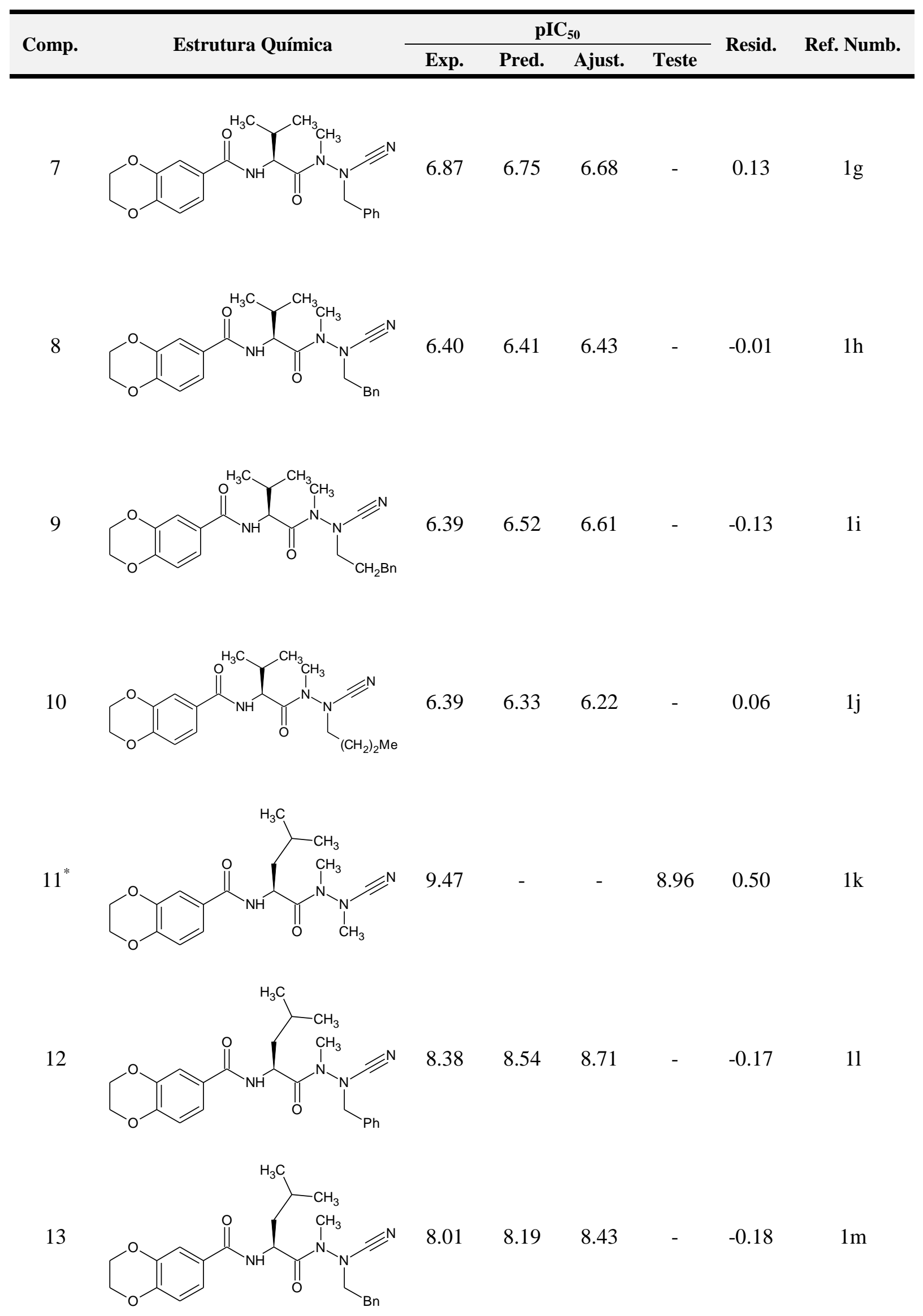




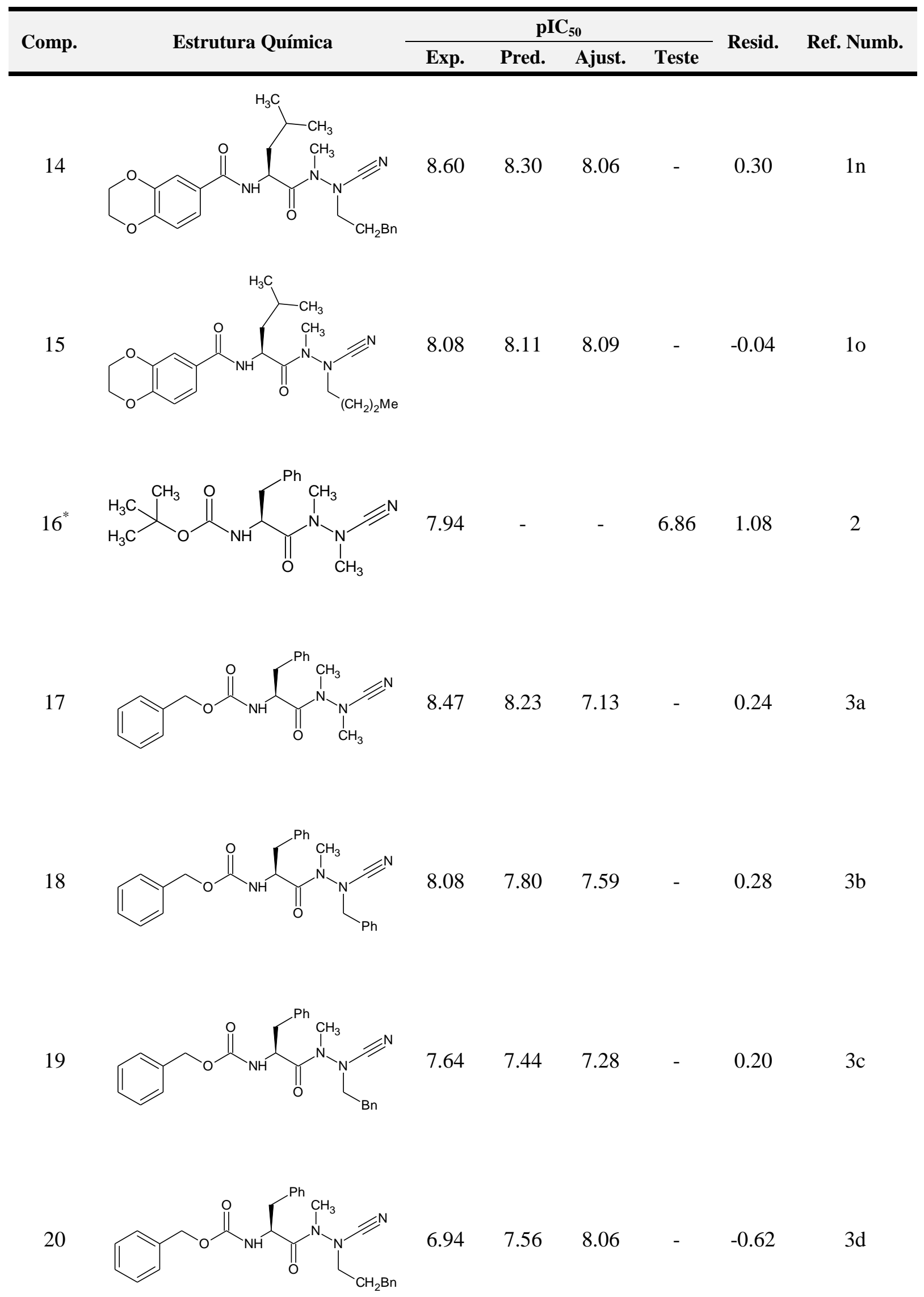




\begin{tabular}{lllll}
\hline \multirow{2}{*}{ Comp. } & \multicolumn{3}{c}{ pIC $_{50}$} & \\
\cline { 3 - 4 } & Extrutura Química & Pred. $\quad$ Ajust. $\quad$ Teste & Ref. Numb. \\
\hline
\end{tabular}

$21^{*}$<smiles>CC(C)CCN(C#N)N(C)C(=O)[C@H](Cc1ccccc1)NC(=O)OCc1ccccc1</smiles>

$\begin{array}{llllll}8.51 & - & - & 7.81 & 0.70 & 3 \mathrm{e}\end{array}$

$22^{*}$<smiles>CC(C)CC(NC(c1ccc(-c2ccc(N3CCNCC3)cc2)cc1)C(F)(F)F)C(=O)NCC#N</smiles>

8.75

$\begin{array}{lll}6.88 & 1.87 & 3\end{array}$

23<smiles>CC(C)(F)CC(NC(c1ccc(-c2ccc(S(C)(=O)=O)cc2)cc1)C(F)(F)F)C(=O)N[C@@H](C#N)c1ccccc1</smiles>

8.09 8.03 8.01

0.07 4

24<smiles>CC(C)(F)C[C@H](NC(=O)[C@@H](c1ccc(-c2ccc(S(C)(=O)=O)cc2)cc1)C(F)(F)F)C(=O)NCC#N</smiles>

6.74

25<smiles>CC(C)(F)CC(NC(=O)C(CC(F)(F)F)NC(C#N)CC(F)(F)F)c1ccc(-c2ccc(S(C)(=O)=O)cc2)cc1</smiles>

6.89

6.68

6.81

0.21

$26^{*}$<smiles>[B]C[C@H](C#N)C(=O)N[C@@H](CC(C)(C)F)C(F)(F)F</smiles>
6.29

$27^{*}$<smiles>CC(C)(F)CC(NC(C)(C)C)C(=O)N[C@H](C#N)Cc1ccncc1</smiles> 


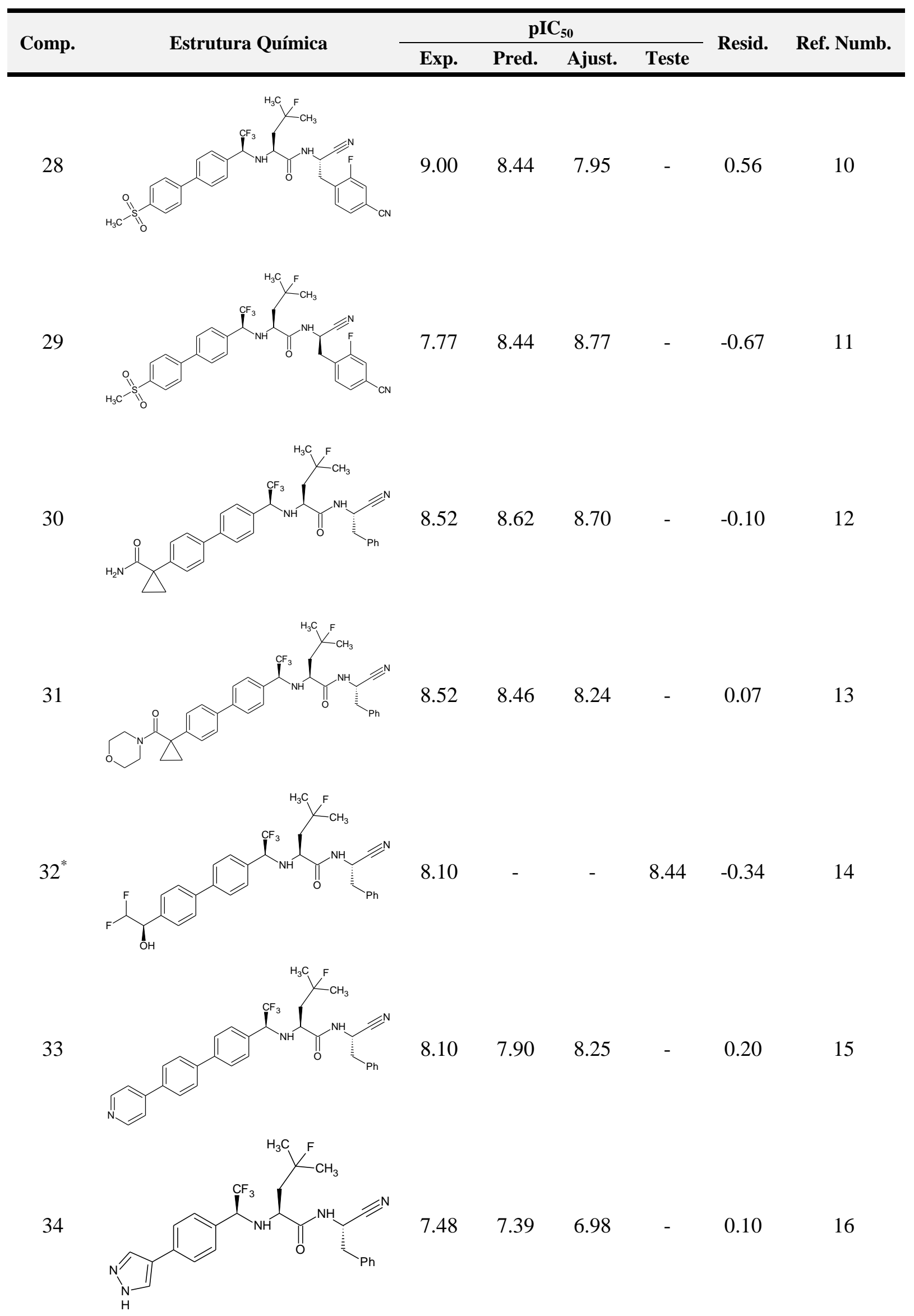




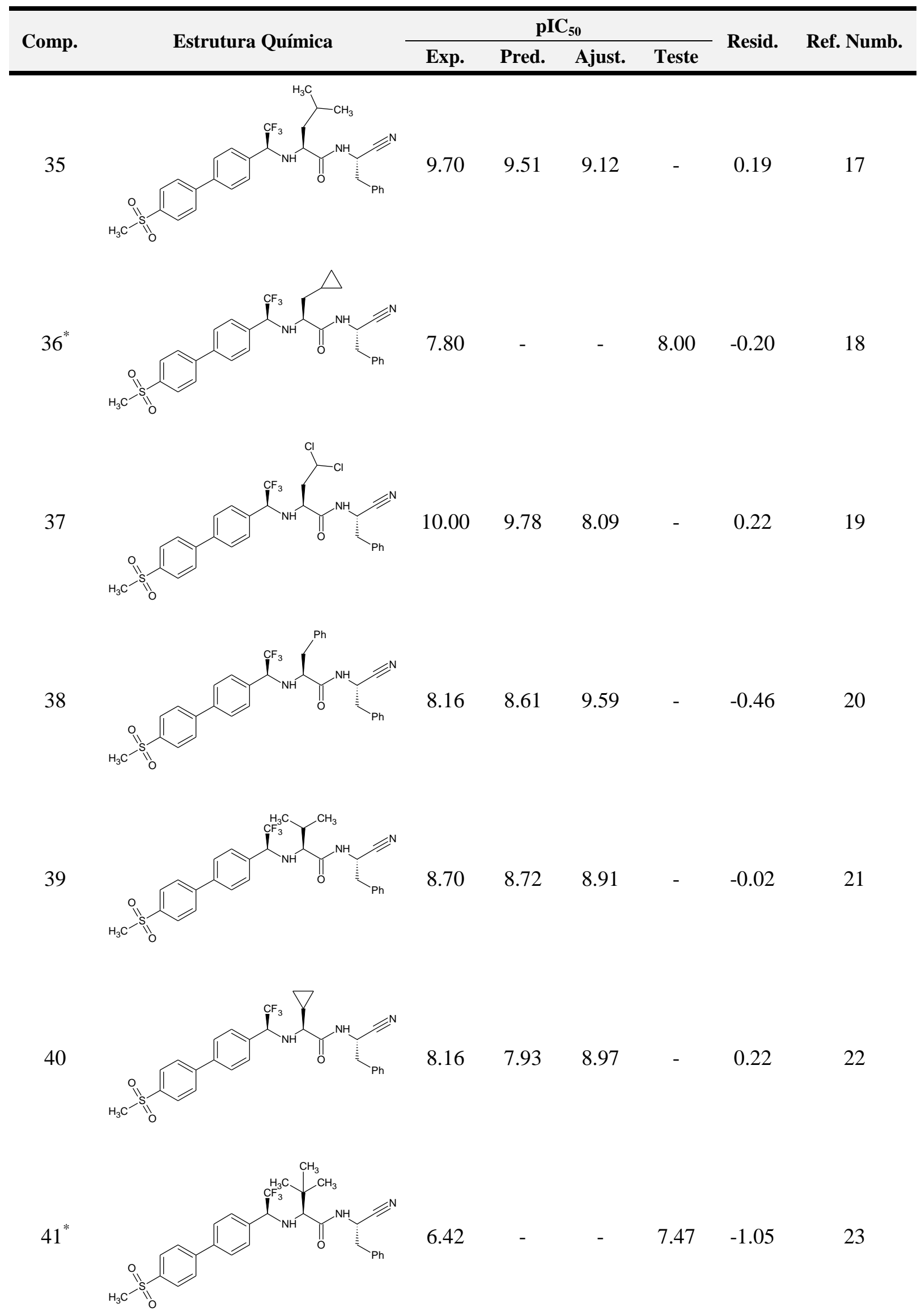




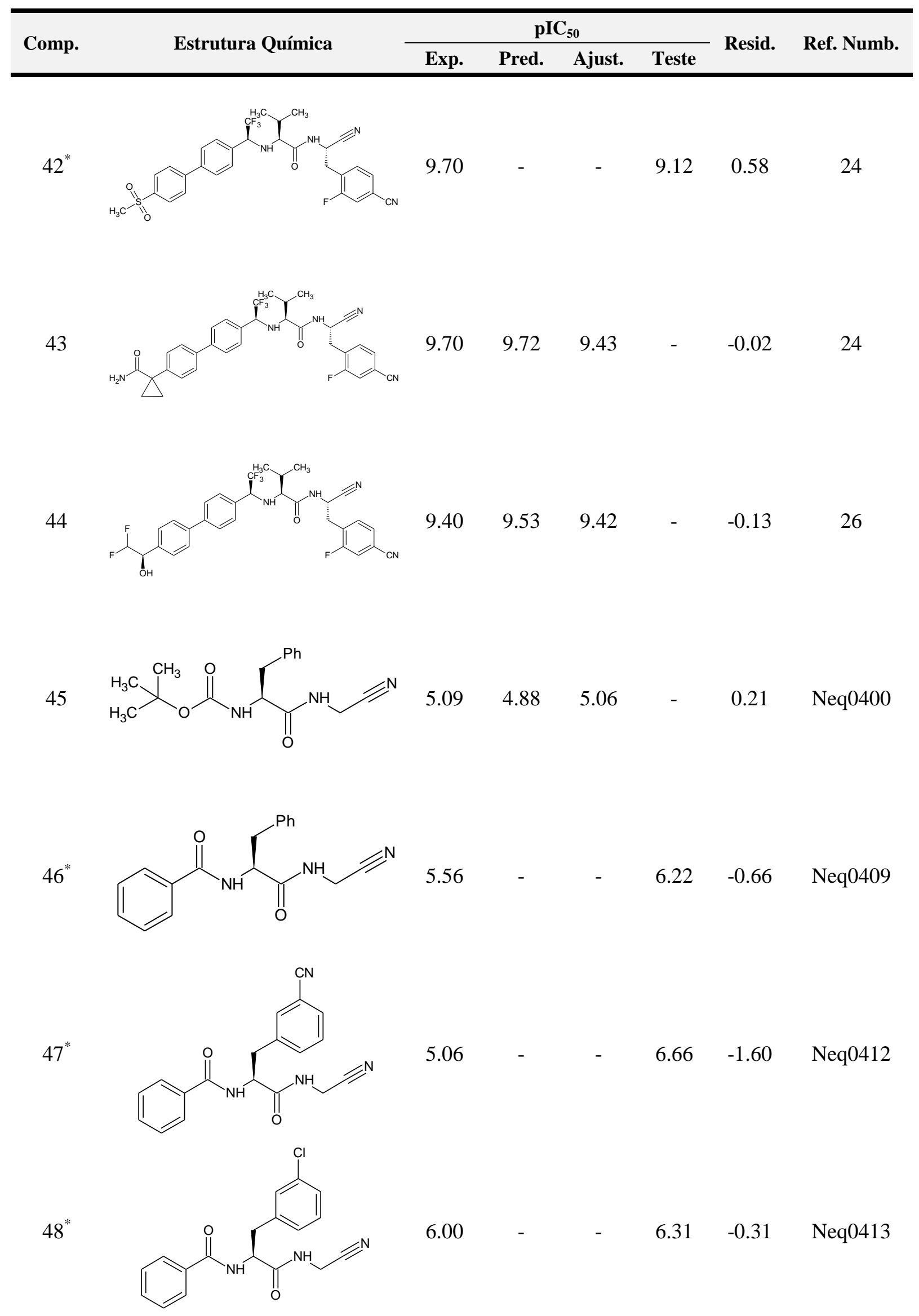




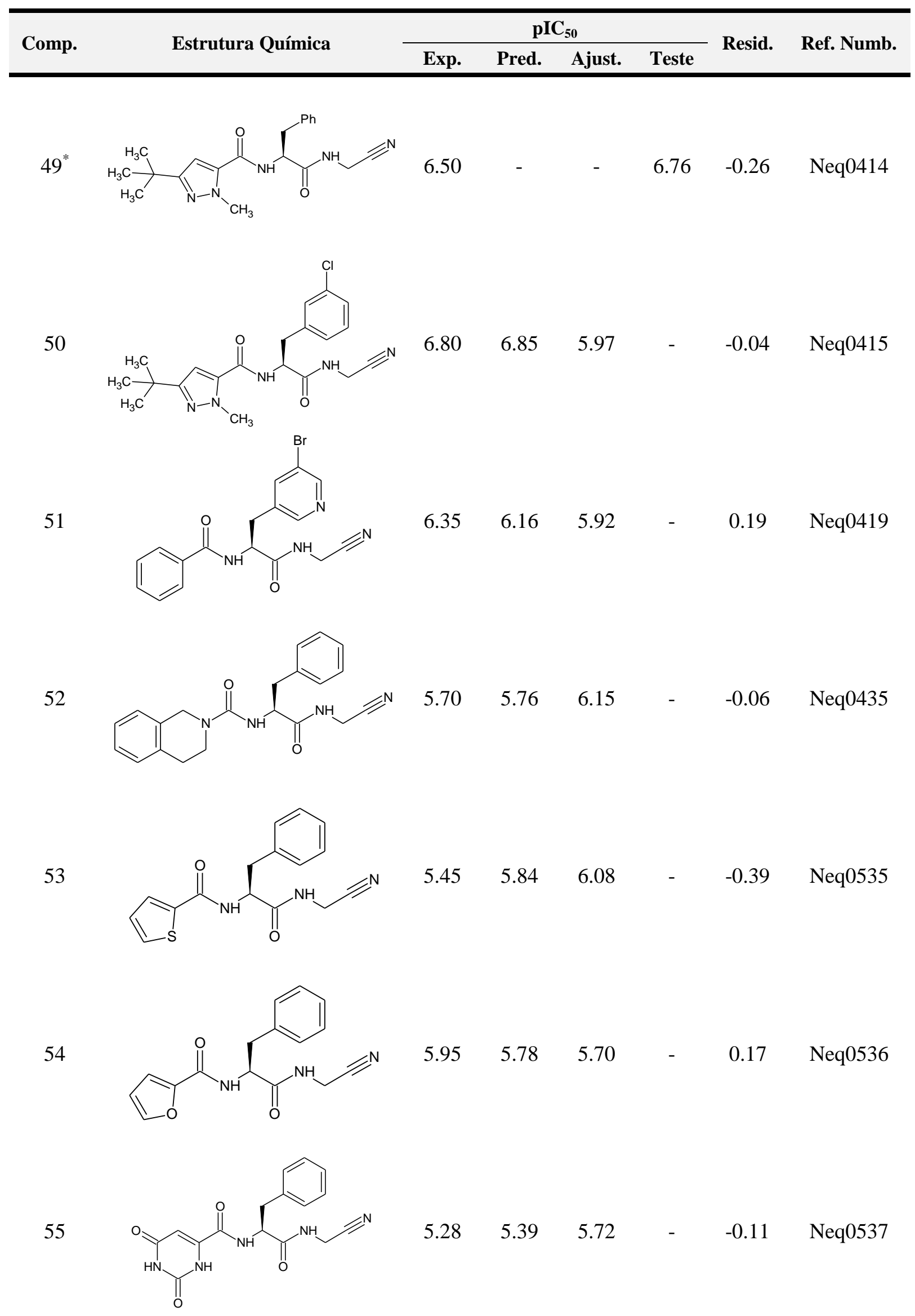




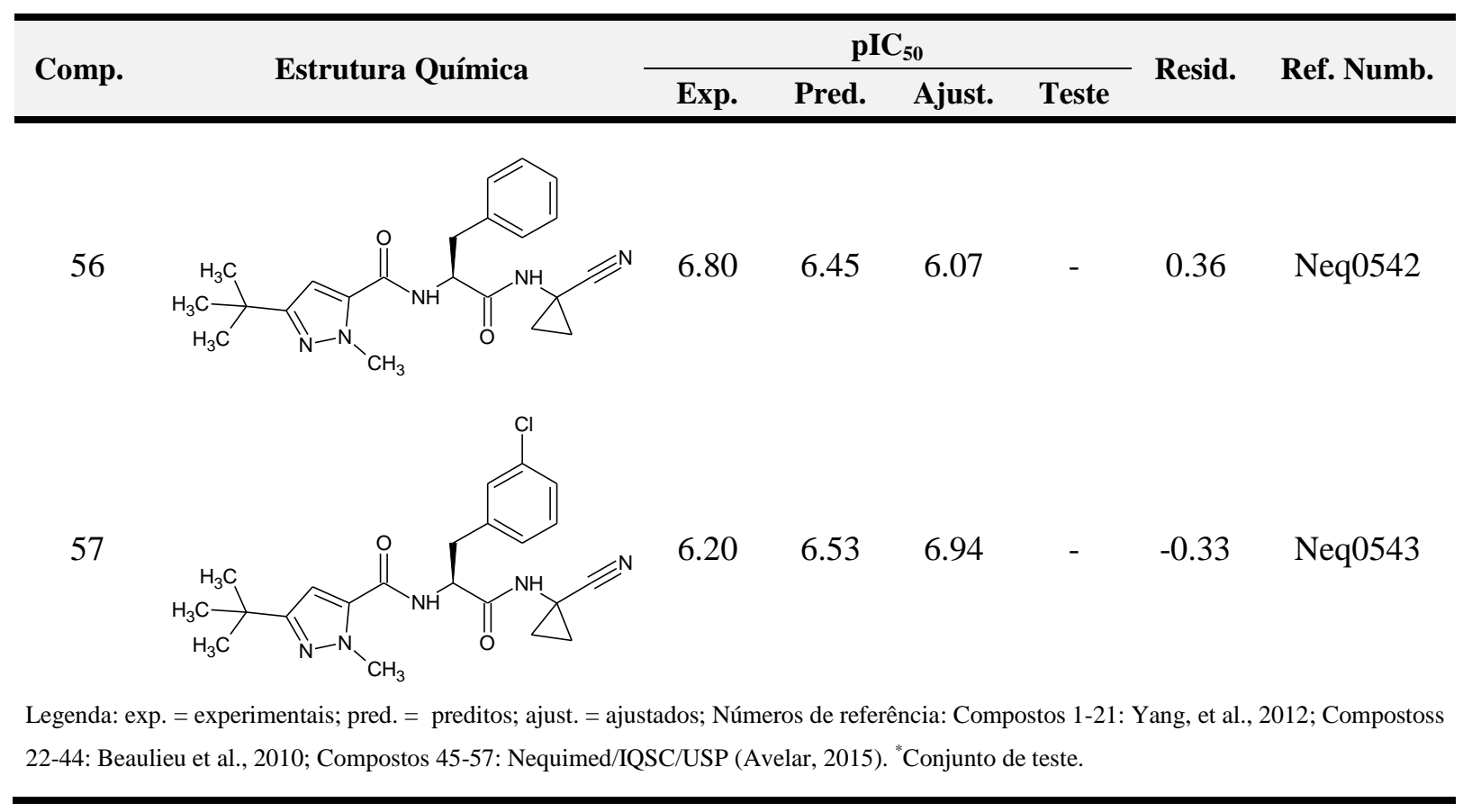

APÊNDICE B - $\quad$ Tabela com os resultados das análises HQSAR com o bloco Y usando diferentes distinções de fragmento e tamanho do fragmento fixado de 4-7 átomos

\begin{tabular}{cccccc}
\hline Modelo (4-7) & Distinção do fragmento & $\boldsymbol{q}^{2}$-Y-rand & $\boldsymbol{r}^{2}$-Y-rand & SEP-Y-rand* & SEE-Y-rand* \\
\hline 1 & $\mathrm{~A} / \mathrm{B}$ & 0.102 & 0.328 & 1.216 & 1.037 \\
2 & $\mathrm{~A} / \mathrm{B} / \mathrm{C}$ & 0.088 & 0.281 & 1.219 & 1.075 \\
3 & $\mathrm{~A} / \mathrm{B} / \mathrm{H}$ & 0.115 & 0.280 & 1.201 & 1.069 \\
4 & $\mathrm{~A} / \mathrm{B} / \mathrm{Ch}$ & 0.106 & 0.333 & 1.210 & 1.032 \\
5 & $\mathrm{~A} / \mathrm{B} / \mathrm{D}$ & 0.092 & 0.436 & 1.235 & 0.948 \\
6 & $\mathrm{~A} / \mathrm{B} / \mathrm{C} / \mathrm{H}$ & 0.130 & 0.353 & 1.192 & 1.015 \\
7 & $\mathrm{~A} / \mathrm{B} / \mathrm{C} / \mathrm{Ch}$ & 0.163 & 0.444 & 1.179 & 0.951 \\
8 & $\mathrm{~A} / \mathrm{B} / \mathrm{C} / \mathrm{D}$ & 0.082 & 0.326 & 1.231 & 1.045 \\
9 & $\mathrm{~A} / \mathrm{B} / \mathrm{H} / \mathrm{Ch}$ & 0.122 & 0.310 & 1.197 & 1.045 \\
10 & $\mathrm{~A} / \mathrm{B} / \mathrm{H} / \mathrm{D}$ & 0.099 & 0.376 & 1.224 & 1.012 \\
11 & $\mathrm{~A} / \mathrm{B} / \mathrm{Ch} / \mathrm{D}$ & 0.087 & 0.396 & 1.238 & 0.977 \\
12 & $\mathrm{~A} / \mathrm{B} / \mathrm{C} / \mathrm{H} / \mathrm{Ch} / \mathrm{D}$ & 0.102 & 0.342 & 1.218 & 1.043 \\
$*$ Valores correspondentes a média de 5 repetições. & & & & \\
\hline
\end{tabular}


APÊNDICE C - Influência do tamanho do fragmento nos parâmetros estatísticos do modelo 11 usando $\mathrm{A} / \mathrm{B} / \mathrm{Ch} / \mathrm{D}$ como distinção do fragmento

\begin{tabular}{ccccccccc}
\hline Modelo (11) & $\begin{array}{c}\text { Tamanho do } \\
\text { fragmento }\end{array}$ & $\boldsymbol{q}^{\mathbf{2}}(\mathrm{LOOCV})$ & $\boldsymbol{r}^{2}$ & SEP & SEE & $\mathbf{N}$ & $\mathbf{H L}$ & $\boldsymbol{r}_{\text {test }}^{2}$ \\
\hline 11.1 & $(2-5)$ & 0.595 & 0.950 & 0.924 & 0.325 & 10 & 151 & 0.390 \\
11.2 & $(3-6)$ & 0.621 & 0.970 & 0.894 & 0.252 & 10 & 257 & 0.450 \\
11.0 & $(4-7)$ & 0.703 & 0.959 & 0.765 & 0.284 & 8 & 199 & 0.552 \\
11.3 & $(5-8)$ & 0.793 & 0.946 & 0.618 & 0.316 & 6 & 61 & 0.534 \\
11.4 & $(6-9)$ & 0.738 & 0.889 & 0.676 & 0.440 & 4 & 257 & 0.317 \\
11.5 & $(7-10)$ & 0.708 & 0.908 & 0.714 & 0.401 & 4 & 257 & 0.456 \\
\hline
\end{tabular}

APÊNDICE D - Resultados das análises HQSAR com diferentes tamanhos de fragmentos e aleatorização do bloco Y (Y-rand) para o modelo 11 (A/B/Ch/D)

\begin{tabular}{cccccc}
\hline Modelo (11) & $\begin{array}{c}\text { Tamanho do } \\
\text { fragmento }\end{array}$ & $\boldsymbol{q}^{2}$-Y-rand* & $\boldsymbol{r}^{2}$-Y-rand* & SEP-Y-rand* & SEE-Y-rand* \\
\hline 11.1 & $(2-5)$ & 0.056 & 0.299 & 1.248 & 1.107 \\
11.2 & $(3-6)$ & 0.120 & 0.418 & 1.222 & 0.963 \\
11.0 & $(4-7)$ & 0.087 & 0.396 & 1.238 & 0.977 \\
11.3 & $(5-8)$ & 0.102 & 0.376 & 1.223 & 1.010 \\
11.4 & $(6-9)$ & 0.107 & 0.382 & 1.224 & 1.006 \\
11.5 & $(7-10)$ & 0.109 & 0.372 & 1.144 & 1.086 \\
*Valores correspondentes a média de 5 repetições. & & & & \\
\hline
\end{tabular}


APÊNDICE E - Números ChEMBL de referência para os compostos extraídos da base de dados e utilizados nas análises de MMPs e os números dos respectivos ensaios biológicos.

\begin{tabular}{cccc}
\hline MMP & ChEMBL & ChEMBL & Ensaio \\
\hline $\mathbf{1}$ & 1651360 & 1651362 & 702782 \\
& 1651358 & 1651350 & 702783 \\
& & 1651361 & 702784 \\
$\mathbf{2}$ & 200374 & 200521 & 325777 \\
& & & 325778 \\
& & & 325780 \\
$\mathbf{3}$ & 200374 & 200181 & 325777 \\
& & & 325780 \\
\hline $\mathbf{4}$ & 200374 & 200150 & 325778 \\
\hline $\mathbf{5}$ & 200374 & 197975 & 325777 \\
\hline $\mathbf{6}$ & 200521 & 200150 & 325777 \\
\hline $\mathbf{7}$ & 200521 & 197975 & 325777 \\
\hline & & & 325777 \\
$\mathbf{8}$ & 200521 & 200181 & 325779 \\
& & & 325780 \\
\hline $\mathbf{9}$ & 200181 & 200150 & 325777 \\
\hline $\mathbf{1 0}$ & 200181 & 197975 & 325777 \\
\hline & & & \\
\hline & & & \\
\hline & & & \\
\hline
\end{tabular}


APÊNDICE F - Série de compostos do tipo dipeptidil sintetizada

\begin{tabular}{|c|c|c|c|}
\hline Comp. & $\begin{array}{l}\text { Código } \\
\text { Nequimed }\end{array}$ & $\mathbf{p K i}$ & SMILES \\
\hline 1 & Neq0500 & 6.3 & $\mathrm{O}=\mathrm{C}(\mathrm{N}[\mathrm{C} @ @ \mathrm{H}](\mathrm{Cc} 2 \mathrm{ccccc} 2) \mathrm{C}(=\mathrm{O}) \mathrm{NCC} \# \mathrm{~N}) \mathrm{OCc} 1 \mathrm{ccccc} 1$ \\
\hline 2 & Neq0655 & 5.2 & $\mathrm{O}=\mathrm{C}(\mathrm{N}[\mathrm{C} @ @ \mathrm{H}](\mathrm{Cc} 1 \mathrm{ccccc} 1) \mathrm{C}(=\mathrm{O}) \mathrm{NC} 1(\mathrm{CC} 1) \mathrm{C \# N}) \mathrm{OCc} 2 \mathrm{ccccc} 2$ \\
\hline 3 & Neq0640 & 8.1 & $\mathrm{C}(=\mathrm{O}) \mathrm{CNC}(=\mathrm{O})[\mathrm{C} @ \mathrm{H}](\mathrm{Cc} 1 \mathrm{ccccc} 1) \mathrm{NC}(=\mathrm{O}) \mathrm{OCc} 2 \operatorname{ccccc} 2$ \\
\hline 4 & Neq0656 & 5.4 & $\mathrm{C}(=\mathrm{O}) \mathrm{C} 1(\mathrm{CC} 1) \mathrm{NC}(=\mathrm{O})[\mathrm{C} @ \mathrm{H}](\mathrm{Cc} 1 \mathrm{ccccc} 1) \mathrm{NC}(=\mathrm{O}) \mathrm{OCc} 2 \operatorname{ccccc} 2$ \\
\hline 5 & Neq0675 & 7 & $\mathrm{ON}=\mathrm{CCNC}(=\mathrm{O})[\mathrm{C} @ \mathrm{H}](\mathrm{Cc} 1 \mathrm{ccccc} 1) \mathrm{NC}(=\mathrm{O}) \mathrm{OCc} 2 \operatorname{ccccc} 2$ \\
\hline 6 & Neq0615 & 4.4 & $\operatorname{CON}(\mathrm{C}) \mathrm{C}(=\mathrm{O}) \mathrm{CNC}(=\mathrm{O})[\mathrm{C} @ \mathrm{H}](\mathrm{CC} 1=\mathrm{CC}=\mathrm{CC}=\mathrm{C} 1) \mathrm{NC}(=\mathrm{O}) \mathrm{OCC} 1=\mathrm{CC}=\mathrm{CC}=\mathrm{C} 1$ \\
\hline 7 & Neq0539 & 5 & $\mathrm{O}=\mathrm{C}(\mathrm{N}[\mathrm{C} @ @ \mathrm{H}](\mathrm{Cc} 1 \mathrm{ccccc} 1) \mathrm{C}(=\mathrm{O}) \mathrm{Nc} 2 \mathrm{cnoc} 2) \mathrm{OCc} 3 \mathrm{ccccc} 3$ \\
\hline 8 & Neq0646 & 4.7 & $\mathrm{O}=\mathrm{C}(\mathrm{NC} 1=\mathrm{CON}=\mathrm{C} 1) \mathrm{C}(\mathrm{CC} 1=\mathrm{CC}=\mathrm{CC}=\mathrm{C} 1) \mathrm{NC}(=\mathrm{O}) \mathrm{C} 1=\mathrm{CC}=\mathrm{CC}=\mathrm{C} 1$ \\
\hline 9 & Neq0650 & 5 & $\mathrm{O}=\mathrm{C}(\mathrm{NC} 1=\mathrm{CON}=\mathrm{C} 1)[\mathrm{C} @ \mathrm{H}](\mathrm{CC} 1=\mathrm{CC}=\mathrm{CC}=\mathrm{C} 1) \mathrm{NC}(=\mathrm{O}) \mathrm{C} 1=\mathrm{CC}=\mathrm{CC}=\mathrm{C} 1$ \\
\hline 10 & Neq0651 & 4 & $\mathrm{O}=\mathrm{C}(\mathrm{NC} 1=\mathrm{CON}=\mathrm{C} 1)[\mathrm{C} @ @ \mathrm{H}](\mathrm{CC} 1=\mathrm{CC}=\mathrm{CC}=\mathrm{C} 1) \mathrm{NC}(=\mathrm{O}) \mathrm{C} 1=\mathrm{CC}=\mathrm{CC}=\mathrm{C} 1$ \\
\hline 11 & Neq0653 & 4.6 & $\mathrm{Cc} 1 \operatorname{coc}(\mathrm{NC}(=\mathrm{O})[\mathrm{C} @ \mathrm{H}](\mathrm{Cc} 2 \operatorname{ccccc} 2) \mathrm{NC}(=\mathrm{O}) \mathrm{OCc} 3 \operatorname{ccccc} 3) \mathrm{n} 1$ \\
\hline 12 & Neq0638 & 5.8 & {$[\mathrm{H}] \backslash \mathrm{C}(\mathrm{CNC}(=\mathrm{O})[\mathrm{C} @ \mathrm{H}](\mathrm{Cc} 1 \mathrm{ccccc} 1) \mathrm{NC}(=\mathrm{O}) \mathrm{OCc} 2 \operatorname{ccccc} 2)=\mathrm{C}(\backslash[\mathrm{H}]) \mathrm{C}(=\mathrm{O}) \mathrm{OCC}$} \\
\hline 13 & Neq0637 & 5.2 & $\mathrm{CCOC}(=\mathrm{O}) \backslash \mathrm{C}=\mathrm{C} / \mathrm{CNC}(=\mathrm{O})[\mathrm{C} @ \mathrm{H}](\mathrm{Cc} 1 \operatorname{ccccc} 1) \mathrm{NC}(=\mathrm{O}) \mathrm{OCc} 2 \operatorname{ccccc} 2$ \\
\hline 14 & Neq0654 & 3.9 & $\operatorname{CCOC}(=\mathrm{O}) \backslash \mathrm{C}=\mathrm{ClC} 1(\mathrm{CC} 1) \mathrm{NC}(=\mathrm{O})[\mathrm{C} @ \mathrm{H}](\mathrm{Cc} 1 \mathrm{ccccc} 1) \mathrm{NC}(=\mathrm{O}) \mathrm{OCc} 2 \operatorname{ccccc} 2$ \\
\hline 15 & Neq0652 & 3.7 & $\begin{array}{c}{[\mathrm{H}] \backslash \mathrm{C}(=\mathrm{C}(\backslash[\mathrm{H}]) \mathrm{C} 1(\mathrm{CC} 1) \mathrm{NC}(=\mathrm{O})[\mathrm{C} @ \mathrm{H}](\mathrm{Cc} 2 \operatorname{ccccc} 2) \mathrm{NC}(=\mathrm{O}) \mathrm{OCc} 3 \operatorname{ccccc} 3) \mathrm{C}(=\mathrm{O}) \mathrm{N}} \\
(\mathrm{CC}) \mathrm{CC}\end{array}$ \\
\hline 16 & Neq0657 & 3.4 & $\mathrm{CNC}(=\mathrm{O}) \backslash \mathrm{C}=\mathrm{ClC} 1(\mathrm{CC} 1) \mathrm{NC}(=\mathrm{O})[\mathrm{C} @ \mathrm{H}](\mathrm{Cc} 2 \operatorname{ccccc} 2) \mathrm{NC}(=\mathrm{O}) \mathrm{OCc} 3 \operatorname{ccccc} 3$ \\
\hline 17 & Neq0677 & 8.7 & $\mathrm{CN}(\mathrm{CHN}) \mathrm{N}(\mathrm{C}) \mathrm{C}(=\mathrm{O})[\mathrm{C} @ \mathrm{H}](\mathrm{Cc} 1 \mathrm{ccccc} 1) \mathrm{NC}(=\mathrm{O}) \mathrm{OCc} 2 \operatorname{ccccc} 2$ \\
\hline 18 & Neq0676 & 8 & $\mathrm{CC}(\mathrm{C}) \mathrm{C}[\mathrm{C} @ \mathrm{H}](\mathrm{NC}(=\mathrm{O}) \mathrm{OC}(\mathrm{C})(\mathrm{C}) \mathrm{C}) \mathrm{C}(=\mathrm{O}) \mathrm{N}(\mathrm{C}) \mathrm{N}(\mathrm{C}) \mathrm{C \# N}$ \\
\hline 19 & Neq0689 & 8.8 & $\mathrm{CN}(\mathrm{C \# N}) \mathrm{N}(\mathrm{C}) \mathrm{C}(=\mathrm{O})[\mathrm{C} @ \mathrm{H}](\mathrm{Cc} 1 \mathrm{ccccc} 1) \mathrm{NC}(=\mathrm{O}) \mathrm{c} 2 \mathrm{cc}(\mathrm{nn} 2 \mathrm{C}) \mathrm{C}(\mathrm{C})(\mathrm{C}) \mathrm{C}$ \\
\hline 20 & Neq0690 & 8.8 & $\mathrm{CC}(\mathrm{C}) \mathrm{C}[\mathrm{C} @ \mathrm{H}](\mathrm{NC}(=\mathrm{O}) \mathrm{c} 1 \mathrm{cc}(\mathrm{nn} 1 \mathrm{C}) \mathrm{C}(\mathrm{C})(\mathrm{C}) \mathrm{C}) \mathrm{C}(=\mathrm{O}) \mathrm{N}(\mathrm{C}) \mathrm{N}(\mathrm{C}) \mathrm{C \# N}$ \\
\hline
\end{tabular}


APÊNDICE G - Série de análogos derivados de imidazopiridina sintetizada

\begin{tabular}{|c|c|c|c|c|c|c|}
\hline \multirow{2}{*}{$\dot{\tilde{g}}$} & \multirow{2}{*}{$\begin{array}{l}\text { Cód. } \\
\text { Neq. }\end{array}$} & \multicolumn{2}{|c|}{ T. cruzi } & \multicolumn{2}{|c|}{ T. brucei } & \multirow[b]{2}{*}{ SMILES } \\
\hline & & $\begin{array}{r}\mathbf{E C}_{50} \\
(\mu \mathbf{M})^{*} \\
\end{array}$ & $\begin{array}{r}\mathbf{E C}_{90} \\
(\mu \mathbf{M})^{*} \\
\end{array}$ & $\begin{array}{r}\mathbf{E C}_{50} \\
(\mu \mathbf{M})^{* * *} \\
\end{array}$ & $\begin{array}{r}\mathbf{E C}_{90} \\
(\boldsymbol{\mu M})^{* * *} \\
\end{array}$ & \\
\hline 21 & - & 2,75 & 12,28 & 2,51 & 4,20 & $\begin{array}{c}\mathrm{O}=\mathrm{C}(\mathrm{NC} 1=\mathrm{CC} 2=\mathrm{NC}(=\mathrm{CN} 2 \mathrm{C}=\mathrm{C} 1) \mathrm{C} 1=\mathrm{CC}=\mathrm{CC}=\mathrm{C} \\
\text { 1) } \mathrm{N} 1 \mathrm{CCCCC} 1\end{array}$ \\
\hline 22 & - & 4,46 & 6,44 & 2,23 & 3,27 & $\begin{array}{c}\mathrm{O}=\mathrm{C}(\mathrm{NC} 1=\mathrm{CC} 2=\mathrm{NC}(=\mathrm{CN} 2 \mathrm{C}=\mathrm{C} 1) \mathrm{C} 1=\mathrm{CC}=\mathrm{CC}=\mathrm{C} \\
1) \mathrm{N} 1 \mathrm{CCCC} 1\end{array}$ \\
\hline 23 & Neq0727 & 1,08 & 1,73 & 0,62 & 0,77 & $\begin{array}{c}\mathrm{F}[\mathrm{C} @ \mathrm{H}] 1 \mathrm{CCN}(\mathrm{C} 1) \mathrm{C}(=\mathrm{O}) \mathrm{NC} 1=\mathrm{CC} 2=\mathrm{NC}(=\mathrm{CN} 2 \mathrm{C} \\
=\mathrm{C} 1) \mathrm{C} 1=\mathrm{CC}=\mathrm{CC}=\mathrm{C} 1\end{array}$ \\
\hline 24 & - & 3,10 & 4,53 & 0,97 & 1,48 & $\begin{array}{c}\mathrm{FC} 1=\mathrm{CC}=\mathrm{CC}(=\mathrm{C} 1) \mathrm{C} 1=\mathrm{CN} 2 \mathrm{C}=\mathrm{CC}(\mathrm{NC}(=\mathrm{O}) \mathrm{N} 3 \mathrm{CC} \\
\mathrm{CCC} 3)=\mathrm{CC} 2=\mathrm{N} 1\end{array}$ \\
\hline 25 & - & 2,95 & 6,01 & 0,73 & 0,88 & $\begin{aligned} \mathrm{FC} 1=\mathrm{CC}=\mathrm{CC}(=\mathrm{C} 1) \mathrm{C} 1 & =\mathrm{CN} 2 \mathrm{C}=\mathrm{CC}(\mathrm{NC}(=\mathrm{O}) \mathrm{N} 3 \mathrm{CC} \\
\mathrm{CC} 3) & =\mathrm{CC} 2=\mathrm{N} 1\end{aligned}$ \\
\hline 26 & Neq0723 & 0,71 & 0,88 & 0,16 & 0,82 & $\begin{array}{c}\mathrm{F}[\mathrm{C} @ \mathrm{H}] 1 \mathrm{CCN}(\mathrm{C} 1) \mathrm{C}(=\mathrm{O}) \mathrm{NC} 1=\mathrm{CC} 2=\mathrm{NC}(=\mathrm{CN} 2 \mathrm{C} \\
=\mathrm{C} 1) \mathrm{C} 1=\mathrm{CC}=\mathrm{CC}(\mathrm{F})=\mathrm{C} 1\end{array}$ \\
\hline 27 & - & 1,00 & 1,58 & 0,72 & 0,87 & $\begin{array}{c}\mathrm{FC} 1=\mathrm{CC}=\mathrm{CC}(\mathrm{C} 2=\mathrm{CN} 3 \mathrm{C}=\mathrm{CC}(\mathrm{NC}(=\mathrm{O}) \mathrm{N} 4 \mathrm{CCCCC} \\
4)=\mathrm{CC} 3=\mathrm{N} 2)=\mathrm{C} 1 \mathrm{~F}\end{array}$ \\
\hline 28 & Neq0720 & 1,02 & 1,61 & 0,58 & 2,76 & $\begin{aligned} \mathrm{FC} 1=\mathrm{CC}=\mathrm{CC}(\mathrm{C} 2 & =\mathrm{CN} 3 \mathrm{C}=\mathrm{CC}(\mathrm{NC}(=\mathrm{O}) \mathrm{N} 4 \mathrm{CCCC} 4) \\
& =\mathrm{CC} 3=\mathrm{N} 2)=\mathrm{C} 1 \mathrm{~F}\end{aligned}$ \\
\hline 29 & Neq0722 & 0,94 & 1,36 & 0,18 & 0,92 & $\begin{array}{c}\mathrm{F}[\mathrm{C} @ \mathrm{H}] 1 \mathrm{CCN}(\mathrm{C} 1) \mathrm{C}(=\mathrm{O}) \mathrm{NC} 1=\mathrm{CC} 2=\mathrm{NC}(=\mathrm{CN} 2 \mathrm{C} \\
=\mathrm{C} 1) \mathrm{C} 1=\mathrm{CC}=\mathrm{CC}(\mathrm{F})=\mathrm{C} 1 \mathrm{~F}\end{array}$ \\
\hline 30 & - & 2,84 & 4,40 & 1,20 & 1,75 & $\begin{array}{c}\mathrm{FC} 1=\mathrm{CC}=\mathrm{C}(\mathrm{C}=\mathrm{C} 1 \mathrm{~F}) \mathrm{C} 1=\mathrm{CN} 2 \mathrm{C}=\mathrm{CC}(\mathrm{NC}(=\mathrm{O}) \mathrm{N} 3 \mathrm{C} \\
\mathrm{CCCC} 3)=\mathrm{CC} 2=\mathrm{N} 1\end{array}$ \\
\hline 31 & Neq0728 & 2,24 & 2,57 & 0,32 & 0,73 & $\begin{aligned} \mathrm{FC} 1=\mathrm{CC}=\mathrm{C}(\mathrm{C}=\mathrm{C} 1 \mathrm{~F}) \mathrm{C} 1=\mathrm{CN} 2 \mathrm{C}=\mathrm{CC}(\mathrm{NC}(=\mathrm{O}) \mathrm{N} 3 \mathrm{C} \\
\mathrm{CCC} 3)=\mathrm{CC} 2=\mathrm{N} 1\end{aligned}$ \\
\hline 32 & Neq0721 & 0,39 & 0,60 & 0,16 & 0,31 & $\begin{array}{c}\mathrm{F}[\mathrm{C} @ \mathrm{H}] 1 \mathrm{CCN}(\mathrm{C} 1) \mathrm{C}(=\mathrm{O}) \mathrm{NC} 1=\mathrm{CC} 2=\mathrm{NC}(=\mathrm{CN} 2 \mathrm{C} \\
=\mathrm{C} 1) \mathrm{C} 1=\mathrm{CC}=\mathrm{C}(\mathrm{F}) \mathrm{C}(\mathrm{F})=\mathrm{C} 1\end{array}$ \\
\hline 33 & - & $>20,0$ & $>20,0$ & $>20,0$ & $>20,0$ & $\begin{array}{c}\mathrm{F}[\mathrm{C} @ \mathrm{H}] 1 \mathrm{CCN}(\mathrm{C} 1) \mathrm{C}(=\mathrm{O}) \mathrm{NC} 1=\mathrm{CC} 2=\mathrm{NC}(=\mathrm{CN} 2 \mathrm{C} \\
=\mathrm{C} 1) \mathrm{C} 1=\mathrm{NC}=\mathrm{CS} 1\end{array}$ \\
\hline 34 & - & 2,68 & 3,92 & 1,00 & 2,67 & $\begin{array}{c}\mathrm{F}[\mathrm{C} @ \mathrm{H}] 1 \mathrm{CCN}(\mathrm{C} 1) \mathrm{C}(=\mathrm{O}) \mathrm{NC} 1=\mathrm{CC} 2=\mathrm{NC}(=\mathrm{CN} 2 \mathrm{C} \\
=\mathrm{C} 1) \mathrm{C} 1=\mathrm{CC}=\mathrm{CS} 1\end{array}$ \\
\hline 35 & - & 7,34 & $>20,0$ & $>20,0$ & $>20,0$ & $\begin{array}{c}\mathrm{FC} 1=\mathrm{CC}=\mathrm{C}(\mathrm{C}=\mathrm{C} 1 \mathrm{~F}) \mathrm{C} 1=\mathrm{CN} 2 \mathrm{C}=\mathrm{CC}(\mathrm{NC}(=\mathrm{O}) \mathrm{C} 3= \\
\mathrm{CC}=\mathrm{CN}=\mathrm{C} 3 \mathrm{Cl})=\mathrm{CC} 2=\mathrm{N} 1\end{array}$ \\
\hline 36 & - & 9,06 & $>20,0$ & $>20,0$ & $>20,0$ & $\begin{array}{c}\mathrm{CC} 1=\mathrm{C}(\mathrm{C}(=\mathrm{O}) \mathrm{NC} 2=\mathrm{CC} 3=\mathrm{NC}(=\mathrm{CN} 3 \mathrm{C}=\mathrm{C} 2) \mathrm{C} 2=\mathrm{C} \\
\mathrm{C}=\mathrm{C}(\mathrm{F}) \mathrm{C}(\mathrm{F})=\mathrm{C} 2) \mathrm{C}(\mathrm{C})=\mathrm{NO} 1\end{array}$ \\
\hline 37 & - & 6,27 & $>20,0$ & 6,30 & $>20,0$ & $\begin{array}{c}\mathrm{FC} 1=\mathrm{CC}=\mathrm{C}(\mathrm{C}=\mathrm{C} 1 \mathrm{~F}) \mathrm{C} 1=\mathrm{CN} 2 \mathrm{C}=\mathrm{CC}(\mathrm{NC}(=\mathrm{O}) \mathrm{C} 3= \\
\mathrm{CC}=\mathrm{CN}=\mathrm{C} 3)=\mathrm{CC} 2=\mathrm{N} 1\end{array}$ \\
\hline 38 & - & 7,85 & $>20,0$ & $>1,00$ & $>1,00$ & $\begin{aligned} \mathrm{FC} 1=\mathrm{CC}=\mathrm{C}(\mathrm{C}=\mathrm{C} 1 \mathrm{~F}) \mathrm{C} 1=\mathrm{CN} 2 \mathrm{C}=\mathrm{CC}(\mathrm{NC}(=\mathrm{O}) \mathrm{C} 3= \\
\mathrm{NC}=\mathrm{CS} 3)=\mathrm{CC} 2=\mathrm{N} 1\end{aligned}$ \\
\hline
\end{tabular}




\begin{tabular}{|c|c|c|c|c|c|c|}
\hline \multirow{2}{*}{$\dot{\tilde{g}}$} & \multirow{2}{*}{$\begin{array}{l}\text { Cód. } \\
\text { Neq. }\end{array}$} & \multicolumn{2}{|c|}{ T. cruzi } & \multicolumn{2}{|c|}{ T. brucei } & \multirow[b]{2}{*}{ SMILES } \\
\hline & & $\begin{array}{r}\mathbf{E C}_{50} \\
(\mu \mathrm{M})\end{array}$ & $\begin{array}{r}\mathbf{E C}_{90} \\
(\mu \mathbf{M})^{*} \\
\end{array}$ & $\begin{array}{r}\mathbf{E C}_{50} \\
(\mu \mathbf{M})^{* * *}\end{array}$ & $\begin{array}{r}\mathbf{E C}_{90} \\
(\boldsymbol{\mu M})^{* * *}\end{array}$ & \\
\hline 39 & Neq0756 & 0,57 & 1,52 & 0,71 & $>20,0$ & $\begin{array}{c}\mathrm{CN} 1 \mathrm{~N}=\mathrm{C}(\mathrm{C}=\mathrm{C} 1 \mathrm{C}(=\mathrm{O}) \mathrm{NC} 1=\mathrm{CC} 2=\mathrm{NC}(=\mathrm{CN} 2 \mathrm{C}=\mathrm{C} 1 \\
) \mathrm{C} 1=\mathrm{CC}=\mathrm{C}(\mathrm{F}) \mathrm{C}(\mathrm{F})=\mathrm{C} 1) \mathrm{C}(\mathrm{C})(\mathrm{C}) \mathrm{C}\end{array}$ \\
\hline 40 & - & 2,53 & $>20,0$ & $>20,0$ & $>20,0$ & $\begin{array}{c}\mathrm{F}[\mathrm{C} @ \mathrm{H}] 1 \mathrm{CCN}(\mathrm{C} 1) \mathrm{C}(=\mathrm{O}) \mathrm{NC} 1=\mathrm{NC} 2=\mathrm{NC}(=\mathrm{CN} 2 \mathrm{C} \\
=\mathrm{C} 1) \mathrm{C} 1=\mathrm{CC}=\mathrm{C}(\mathrm{F}) \mathrm{C}(\mathrm{F})=\mathrm{C} 1\end{array}$ \\
\hline 41 & Neq0720 & $0,09^{a}$ & $0,15^{a}$ & 0,02 & 0,05 & $\begin{array}{c}\mathrm{F}[\mathrm{C} @ \mathrm{H}] 1 \mathrm{CCN}(\mathrm{C} 1) \mathrm{C}(=\mathrm{O}) \mathrm{NC} 1=\mathrm{CC} 2=\mathrm{NC}(=\mathrm{CN} 2 \mathrm{C} \\
=\mathrm{N} 1) \mathrm{C} 1=\mathrm{CC}=\mathrm{C}(\mathrm{F}) \mathrm{C}(\mathrm{F})=\mathrm{C} 1\end{array}$ \\
\hline 42 & Neq0757 & $0,17^{a}$ & $0,64^{a}$ & $6,99^{a}$ & $>20,0$ & $\begin{array}{c}\mathrm{CN} 1 \mathrm{~N}=\mathrm{C}(\mathrm{C}=\mathrm{C} 1 \mathrm{C}(=\mathrm{O}) \mathrm{NC} 1=\mathrm{CC} 2=\mathrm{NC}(=\mathrm{CN} 2 \mathrm{C}=\mathrm{N} \\
1) \mathrm{C} 1=\mathrm{CC}=\mathrm{C}(\mathrm{F}) \mathrm{C}(\mathrm{F})=\mathrm{C} 1) \mathrm{C}(\mathrm{C})(\mathrm{C}) \mathrm{C}\end{array}$ \\
\hline 43 & - & 9,94 & $>20,0$ & $>20,0$ & $>20,0$ & $\begin{array}{c}\mathrm{F}[\mathrm{C} @ \mathrm{H}] 1 \mathrm{CCN}(\mathrm{C} 1) \mathrm{C}(=\mathrm{O}) \mathrm{NC} 1=\mathrm{CN} 2 \mathrm{C}=\mathrm{C}(\mathrm{N}=\mathrm{C} 2 \mathrm{C} \\
=\mathrm{C} 1) \mathrm{C} 1=\mathrm{CC}=\mathrm{C}(\mathrm{F}) \mathrm{C}(\mathrm{F})=\mathrm{C} 1\end{array}$ \\
\hline
\end{tabular}


APÊNDICE H - Espectros de RMN de ${ }^{1} \mathrm{H}$ e ${ }^{13} \mathrm{C}$ para os compostos sintetizados mais representativos

\subsection{Benzil (S)-(1-((cianometil)amino)-1-oxo-3-fenilpropan-2-il)carbamato (1)}
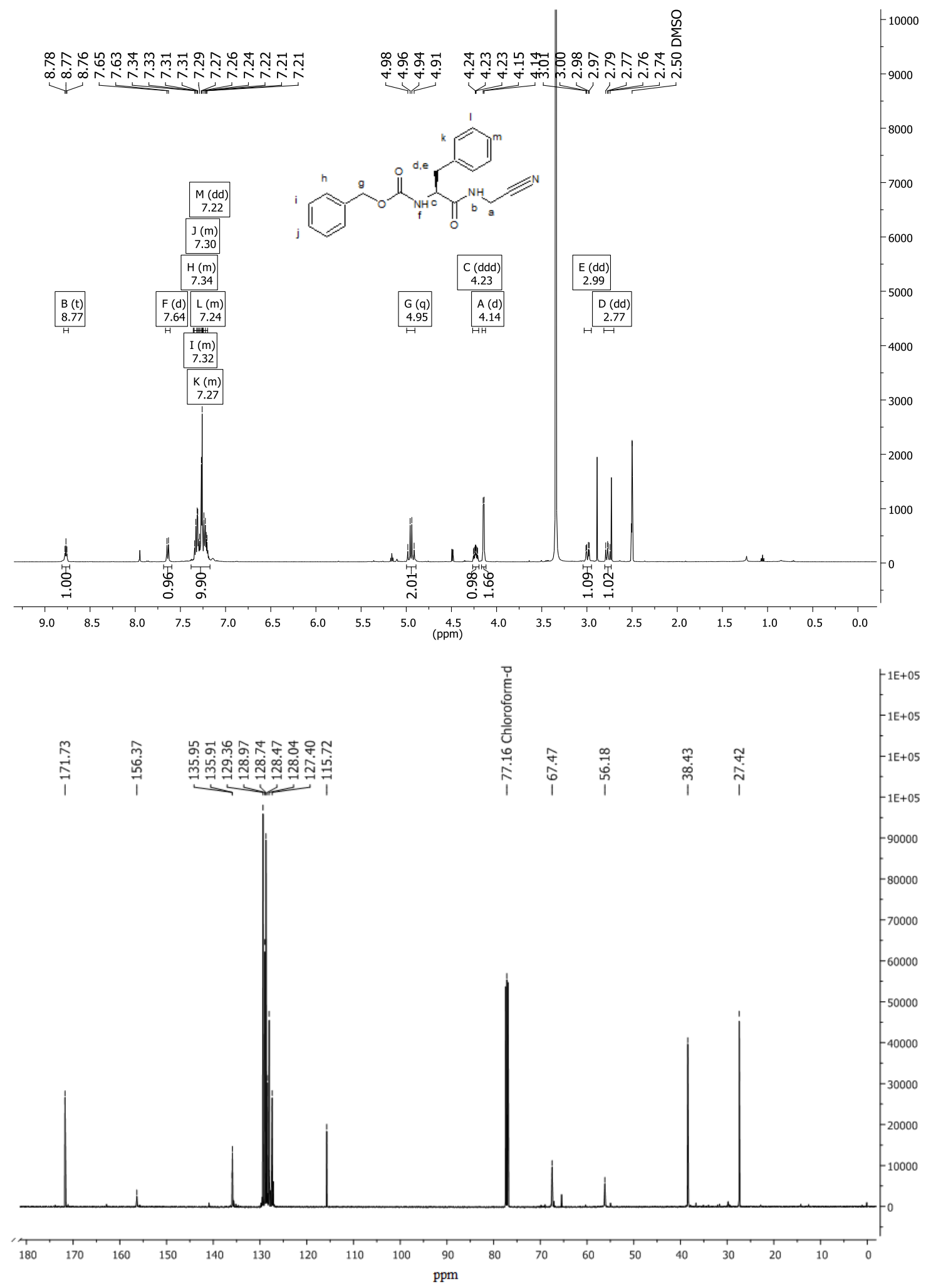
10.2 Benzil (S)-(1-((1-cianociclopropil)amino)-1-oxo-3-fenilpropan-2-il)carbamato (2)

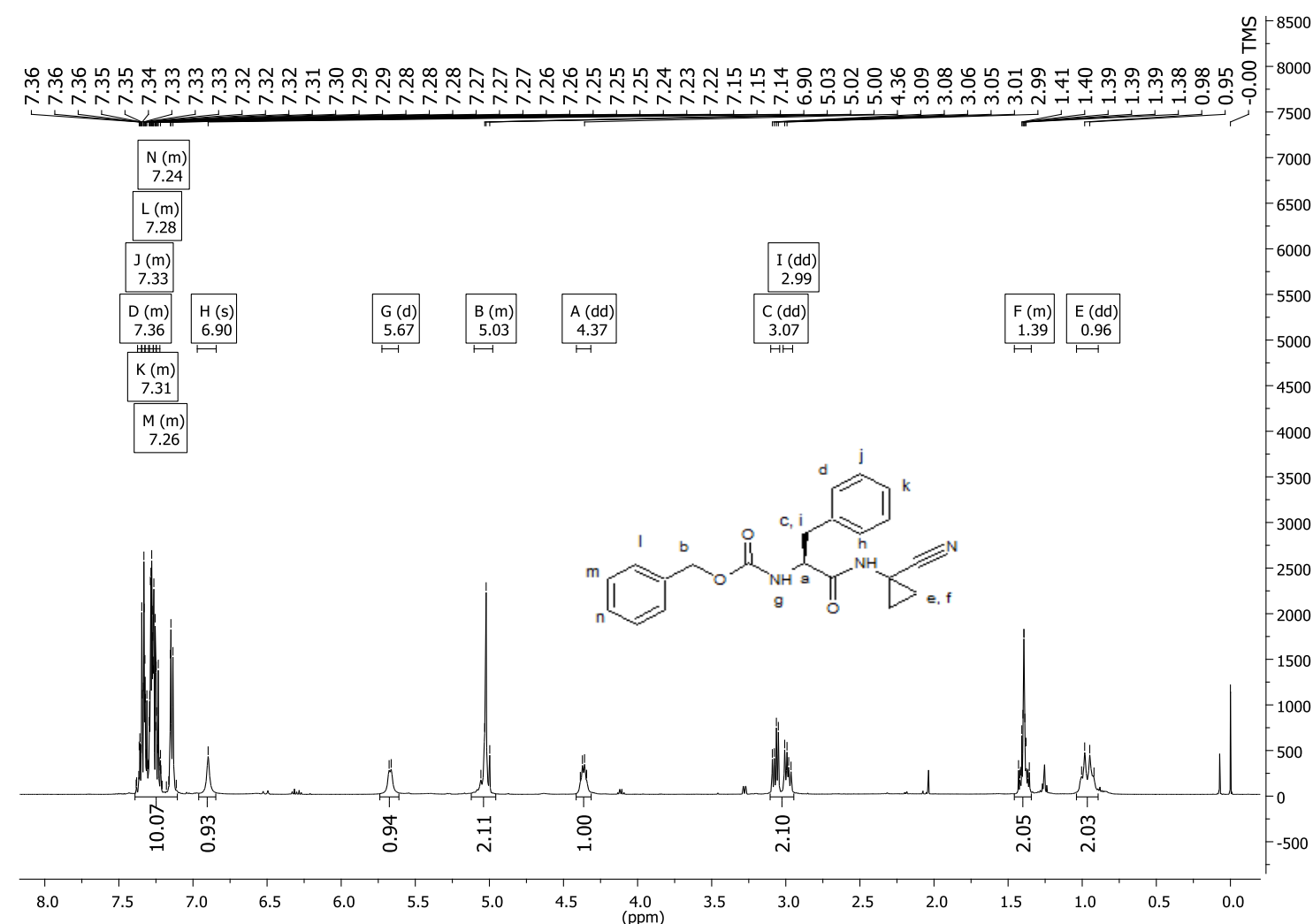

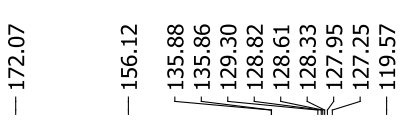

ำㅇำ

ํํำ

$\overrightarrow{0}$
$\infty$
0
1

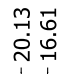

$n$
$\sum$
$\vdots$
0
0
$i$

$2 \mathrm{E}+05$

$1 \mathrm{E}+05$

$1 \mathrm{E}+05$

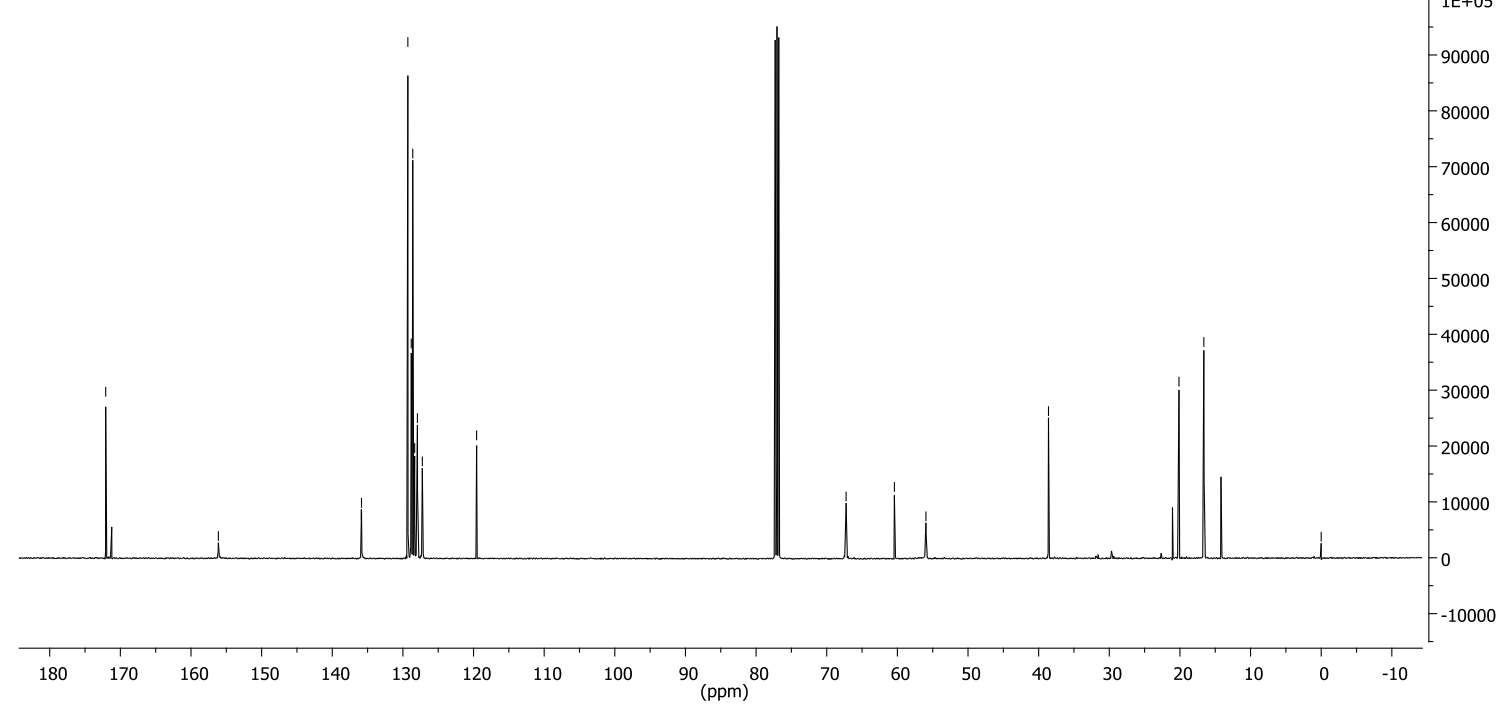


10.3 Benzil (S)-(1-((1-formilciclopropil)amino)-1-oxo-3-fenilpropan-2-il)carbamato(4)

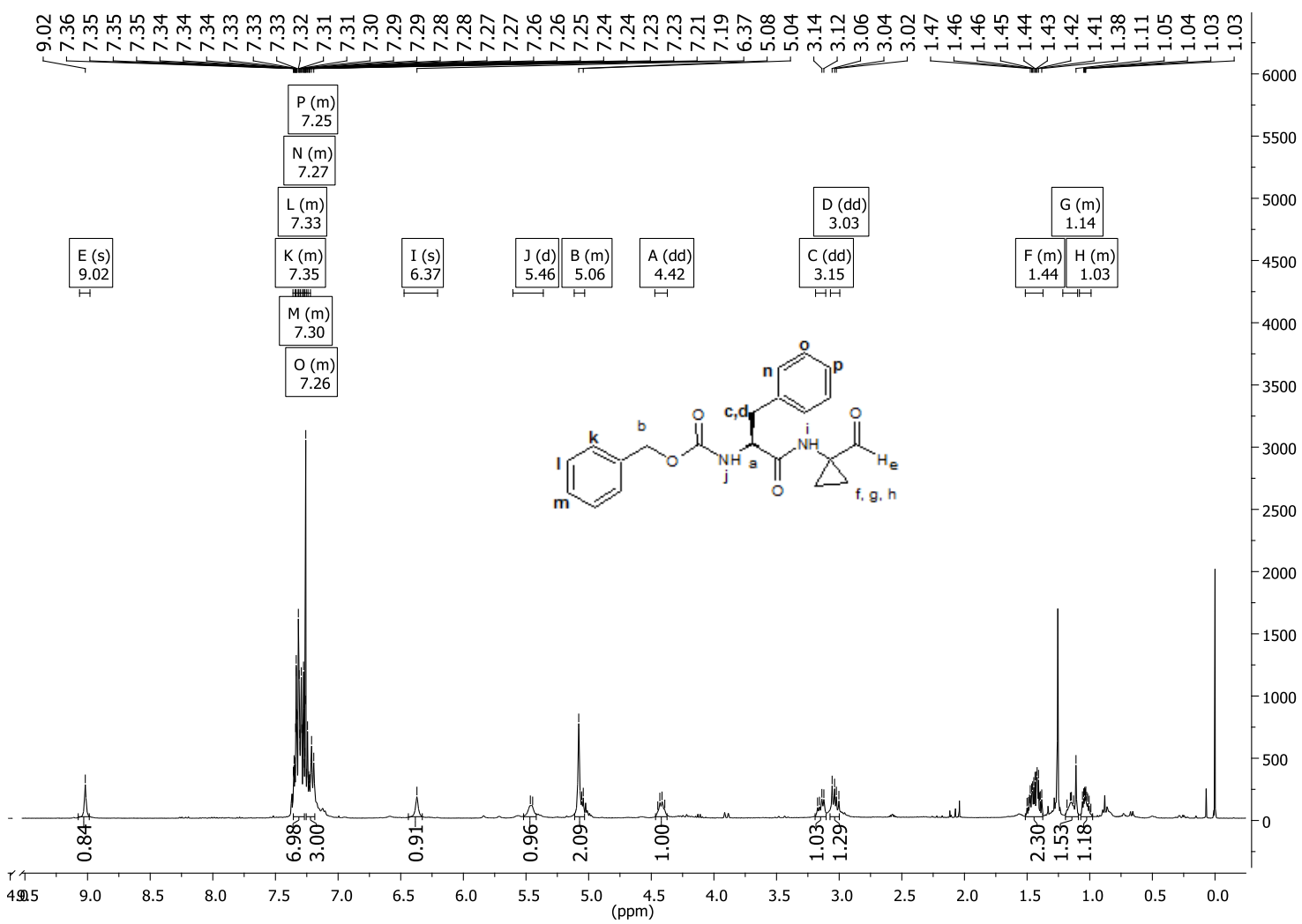

10.4 Benzil (S,E)-(1-((2-(hidroxiimino)etil)amino)-1-oxo-3-fenilpropan-2-il)carbamato (5)

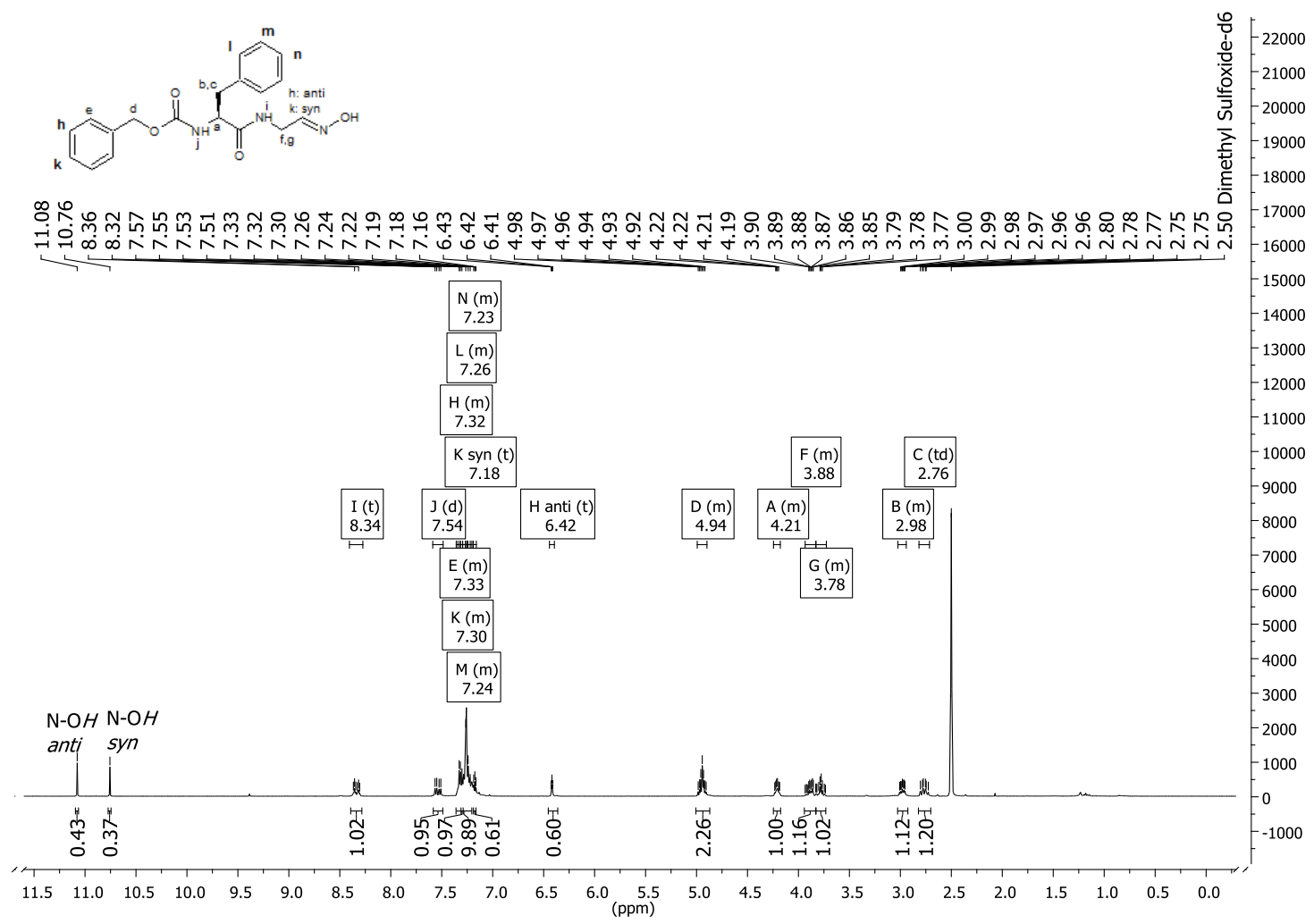




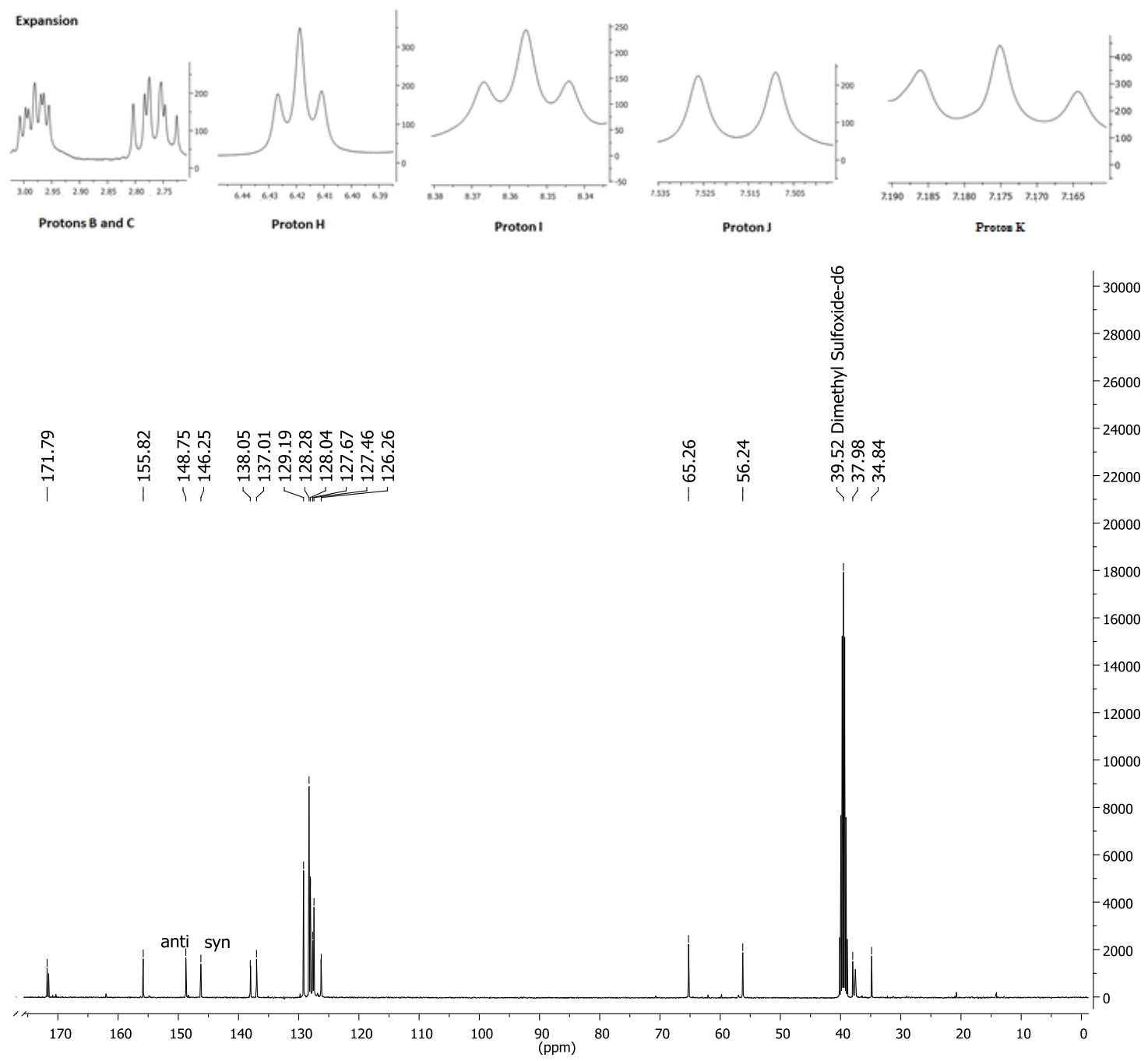


10.5 Benzil (S)-(1-(isoxazol-4-ilamino)-1-oxo-3-fenilpropan-2-il)carbamato (7)

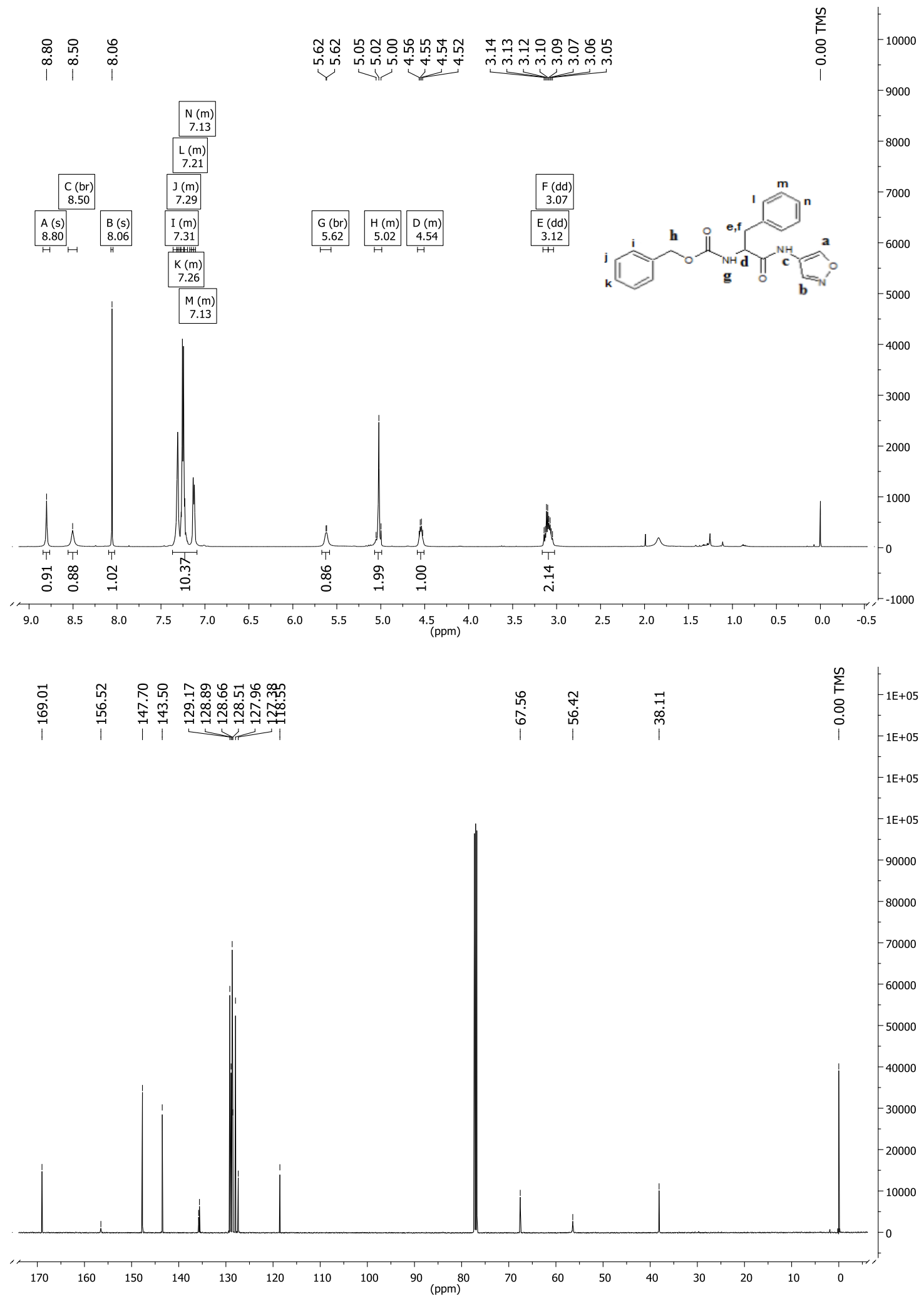


10.6 N-(1,2-oxazol-4-il)-3-fenil-2-(fenilformamido)propanamida (8-10)
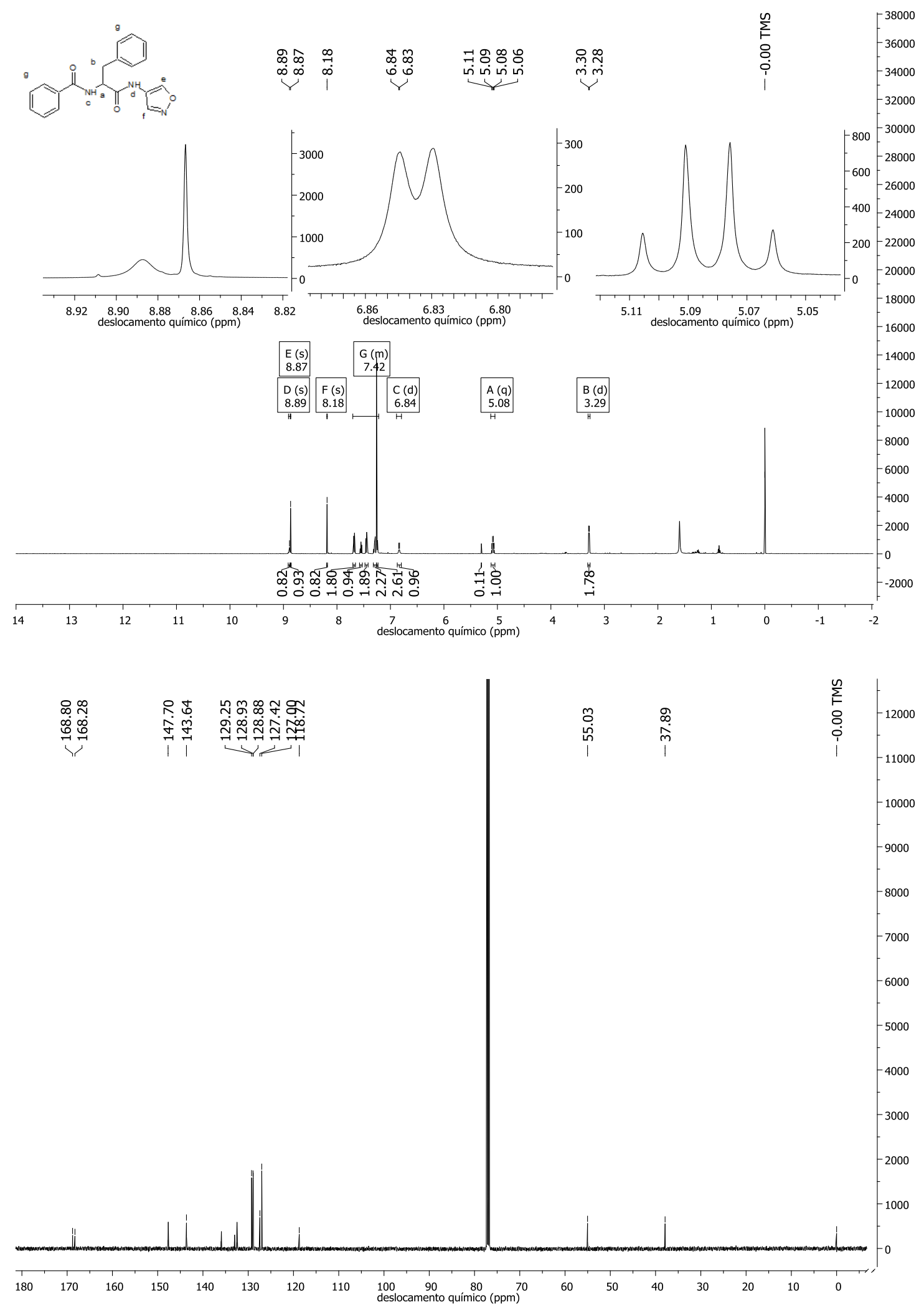
Espectros de HPLC para os compostos 8-10
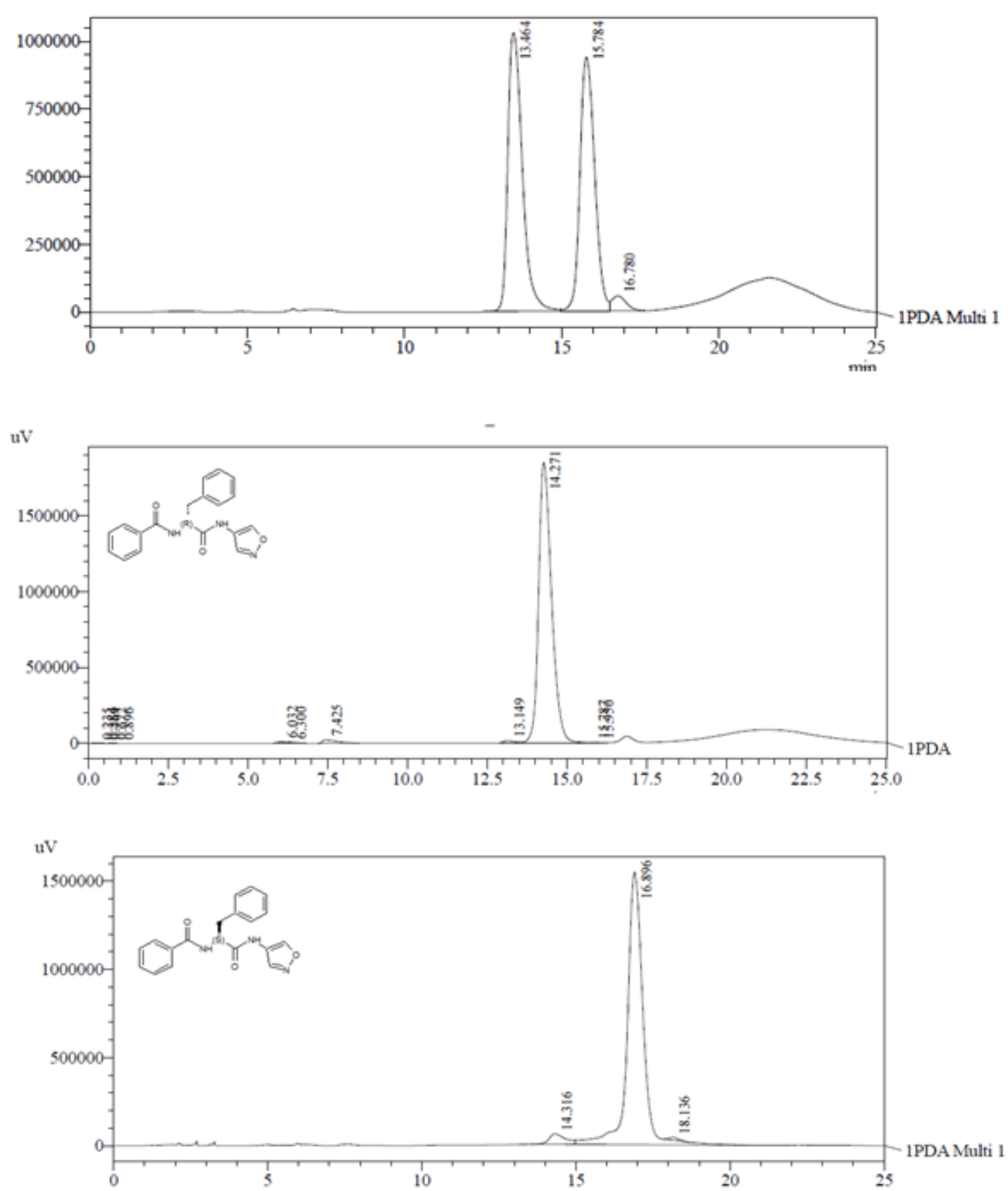

Os isômeros (9 e 10) foram separados por cromatografia de alta eficiência (HPLC, do inglês "High Performance Liquide Chromatography"), usando uma coluna quiral de celulose (2-phase da Phenomenex, tamanho da partícula de $5 \mu \mathrm{M}$, tamanho do poro $1000 \AA$ e fase móvel de $60 \%$ de acetonitrila em água) 
10.7 (S)-N-(4-metiloxazol-2-il)-3-fenil-2-(3-fenilpropanamida) propanamida (11)

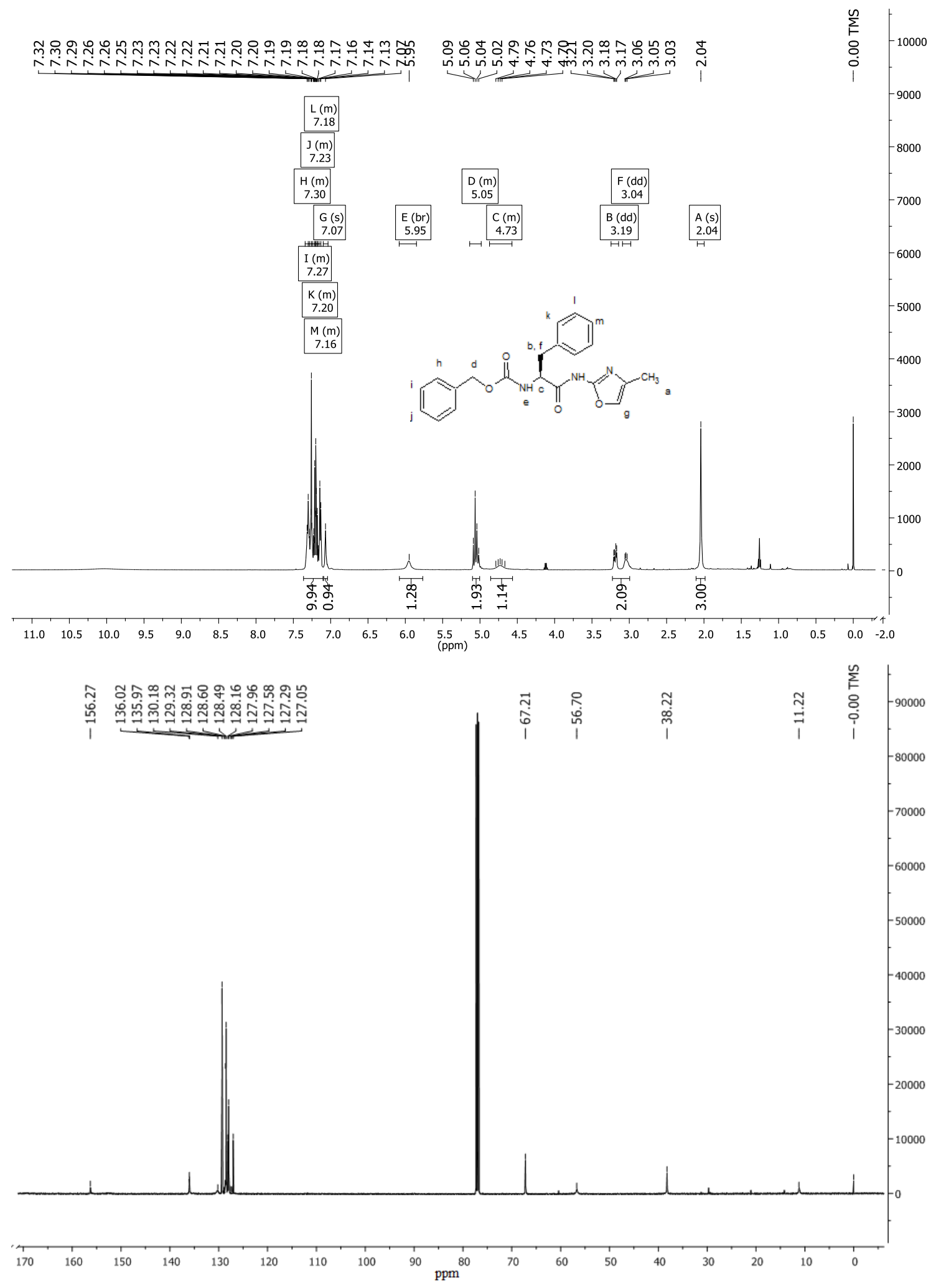


10.8 Etil (S,E)-4-(2-(((Benziloxi)carbonil)amino)-3-fenilpropanamida)but-2-enoato (12)

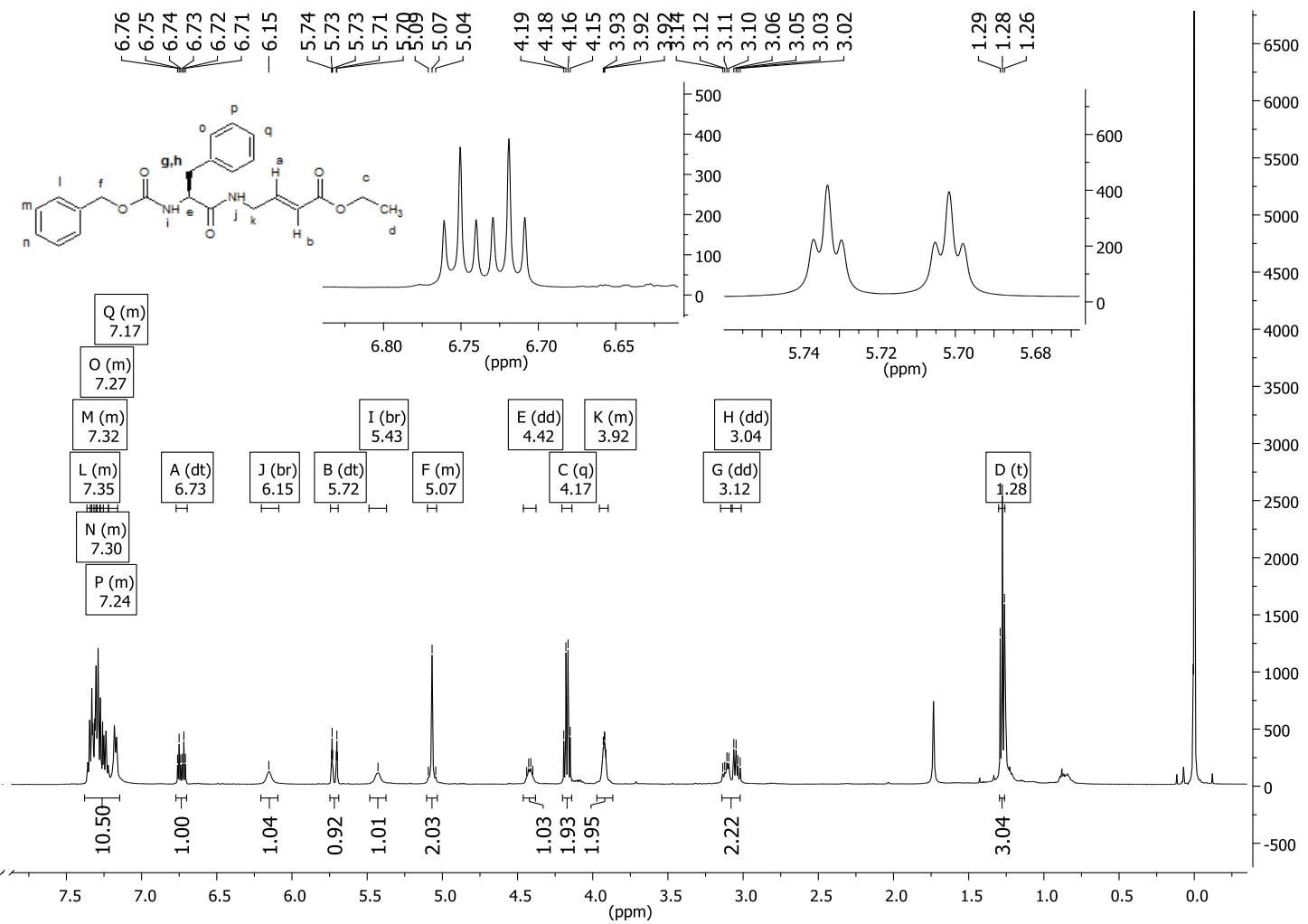

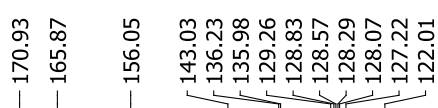

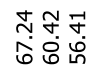

นัฒ

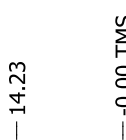

\begin{tabular}{l|l}
$\sum_{k}^{n}$ & -50000 \\
8 & \\
0 & \\
1 & -45000
\end{tabular}

40000

35000

30000

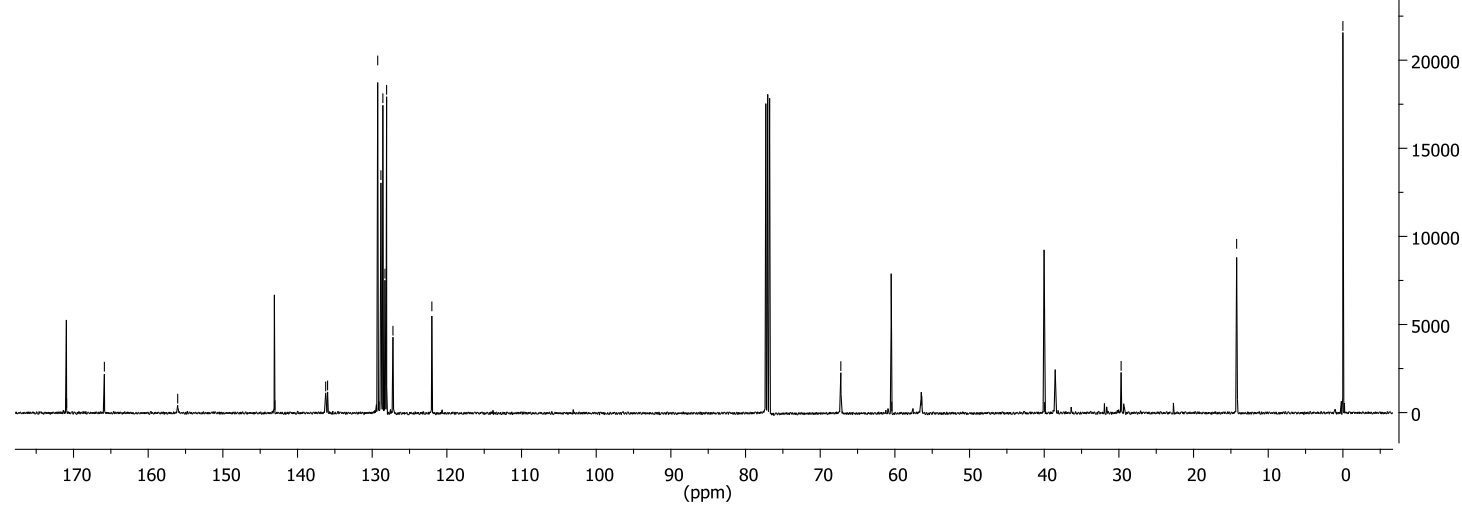


10.9 Etil (S,Z)-4-(2-(((Benziloxi)carbonil)amino)-3-fenilpropanamida)but-2-enoato (13)

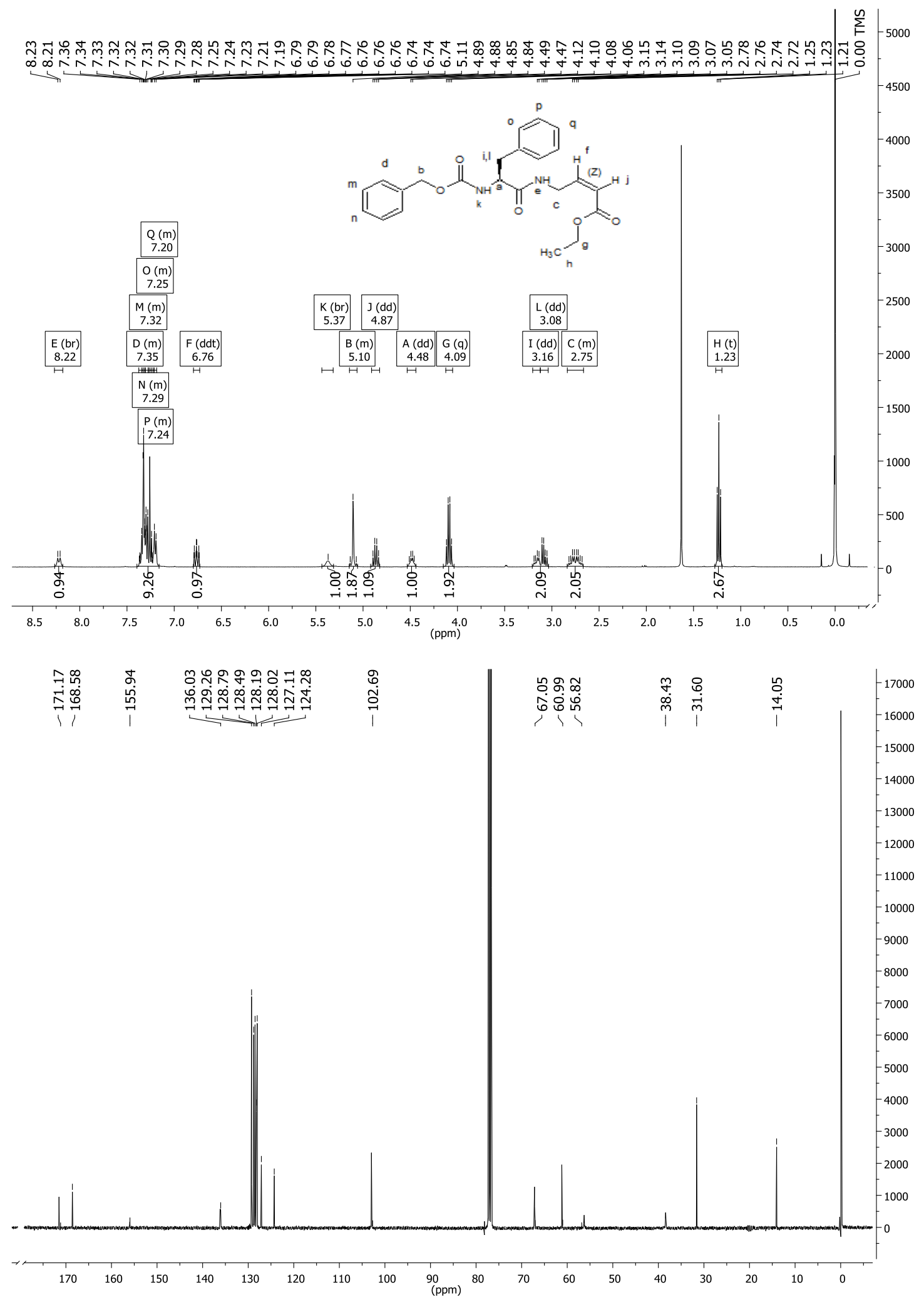


10.10 Etil (S,E)-3-(1-(2-(((Benziloxi)carbonil)amino)-3-fenilpropanamida) ciclopropil)acrilato (14)

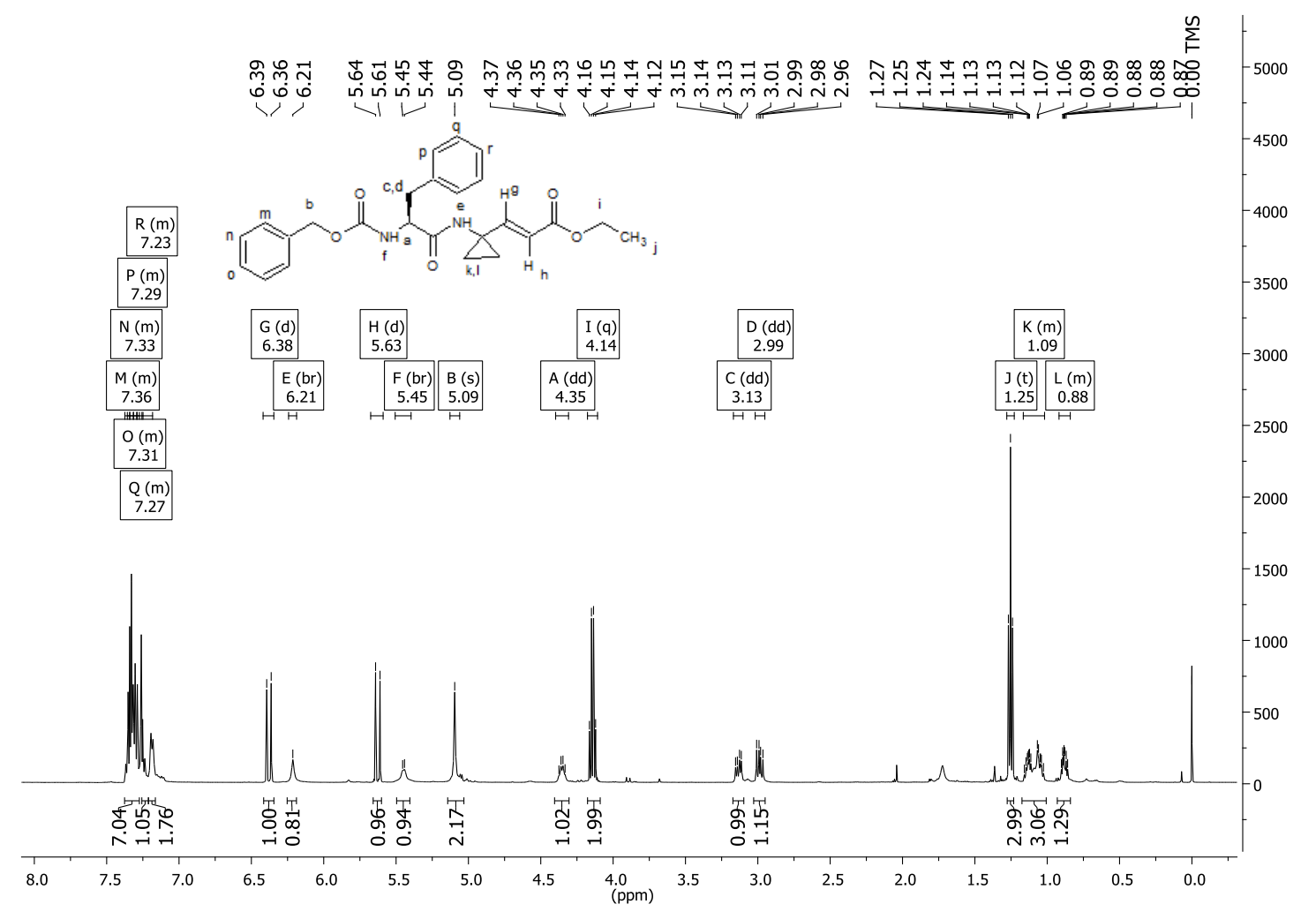

ขุ $\quad$ 눔

नิ

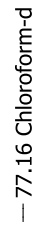

ஸิ宀

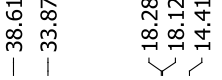

0000

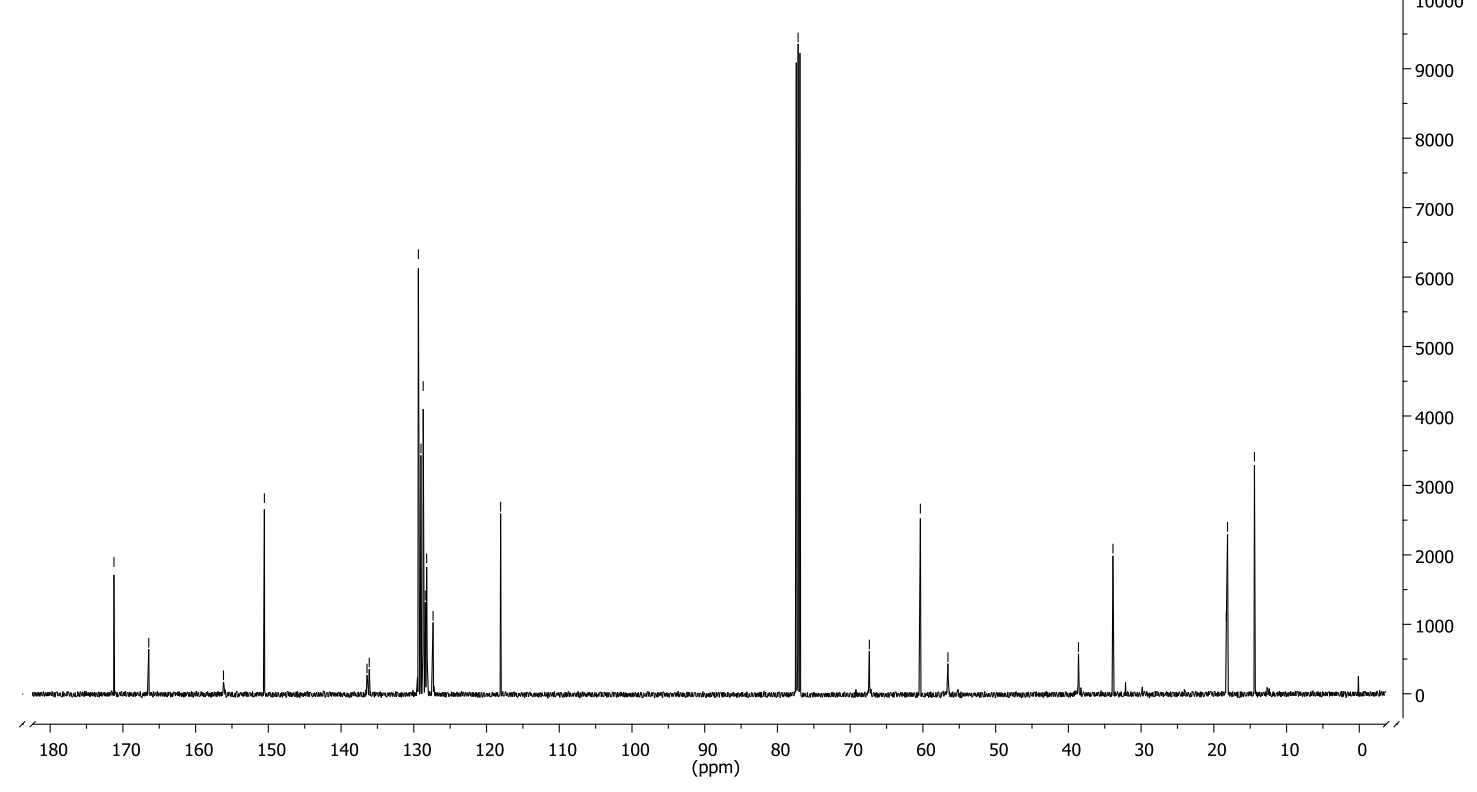


10.11 Benzil (S,E)-(1-((1-(3-(dietilamino)-3-oxoprop-1-en-1-il)ciclopropil) amino)-1-oxo-3fenilpropan-2-il)carbamato (15)

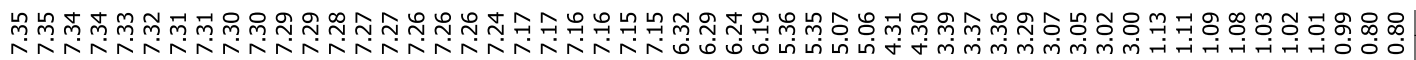

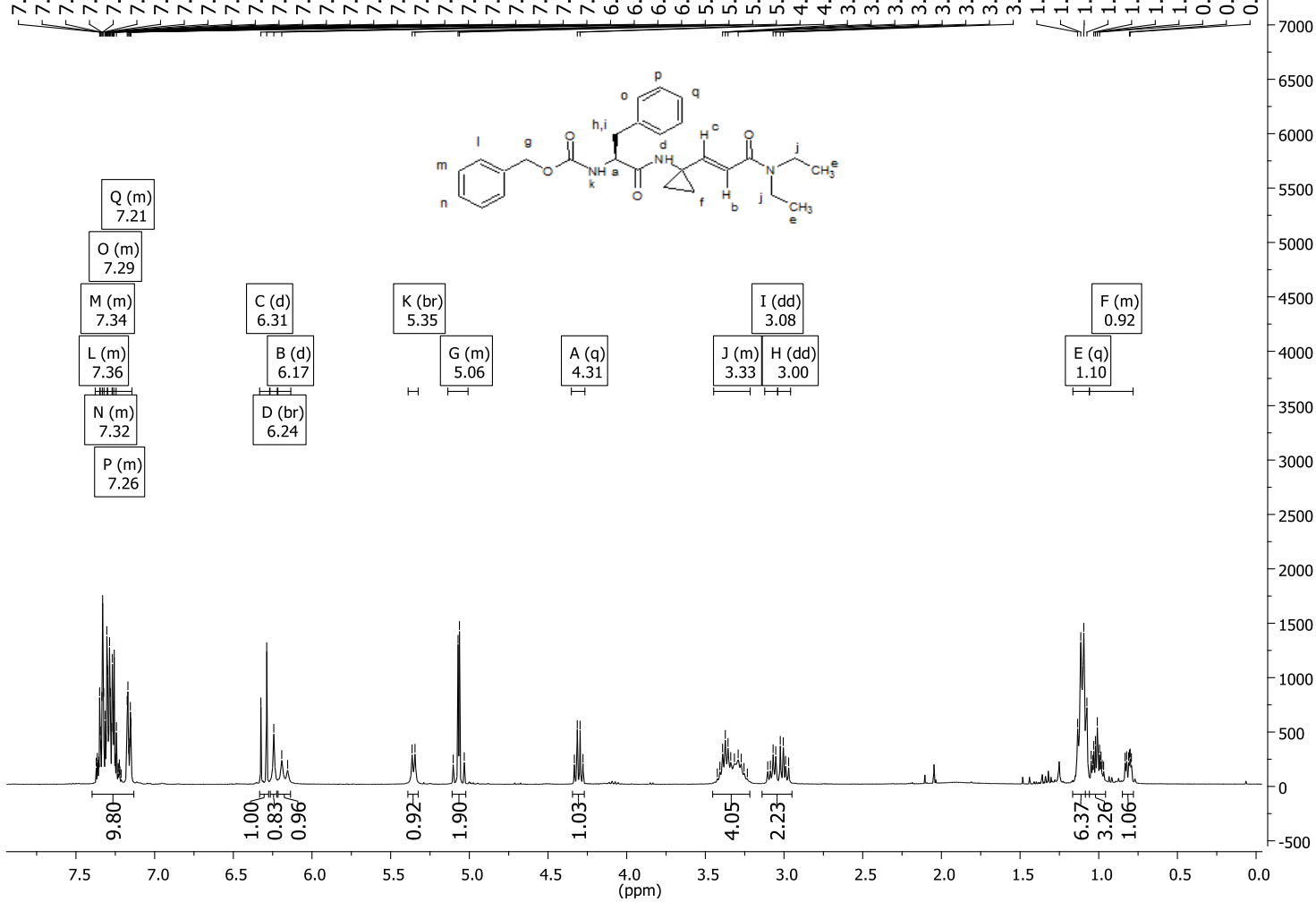

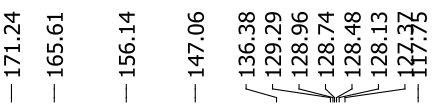

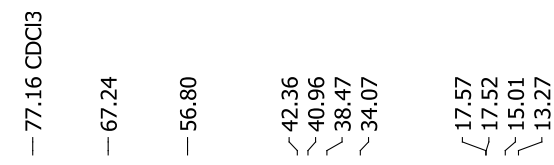

60000

55000

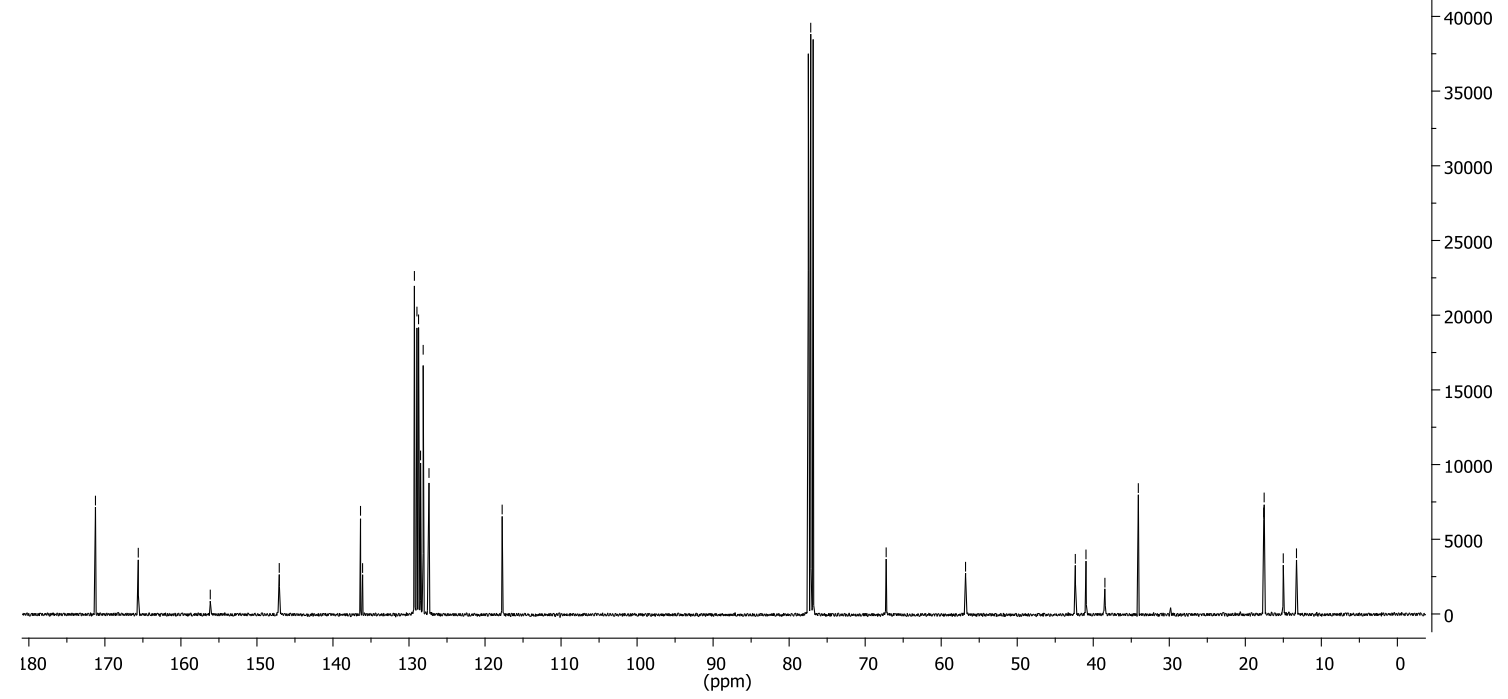


10.12 Benzil (S,E)-(1-((1-(3-(metilamino)-3-oxoprop-1-en-1-il)ciclopropil) amino)-1-oxo-3fenilpropan-2-il)carbamato (16)

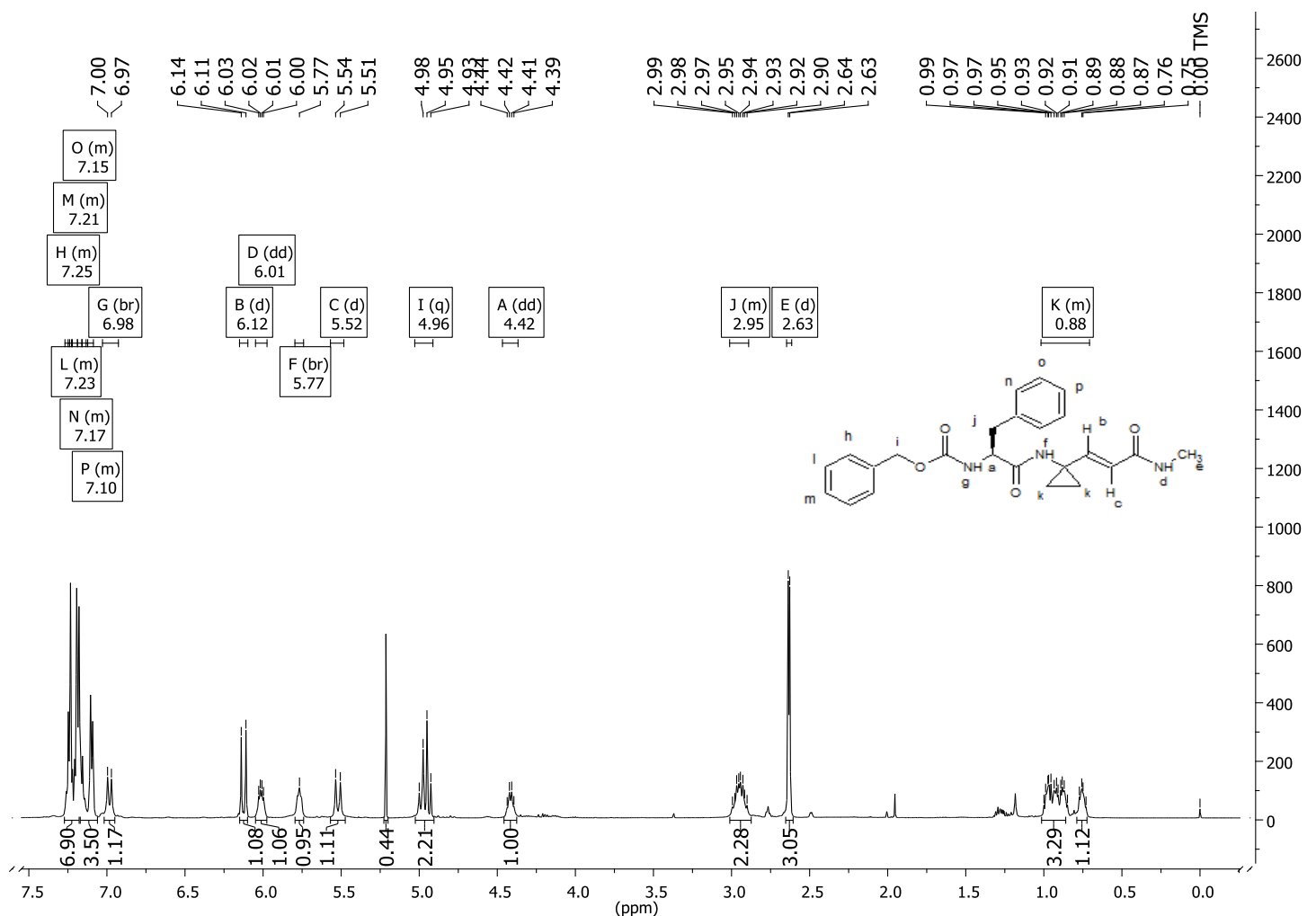

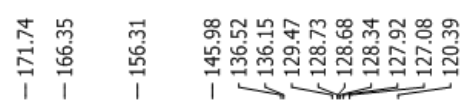
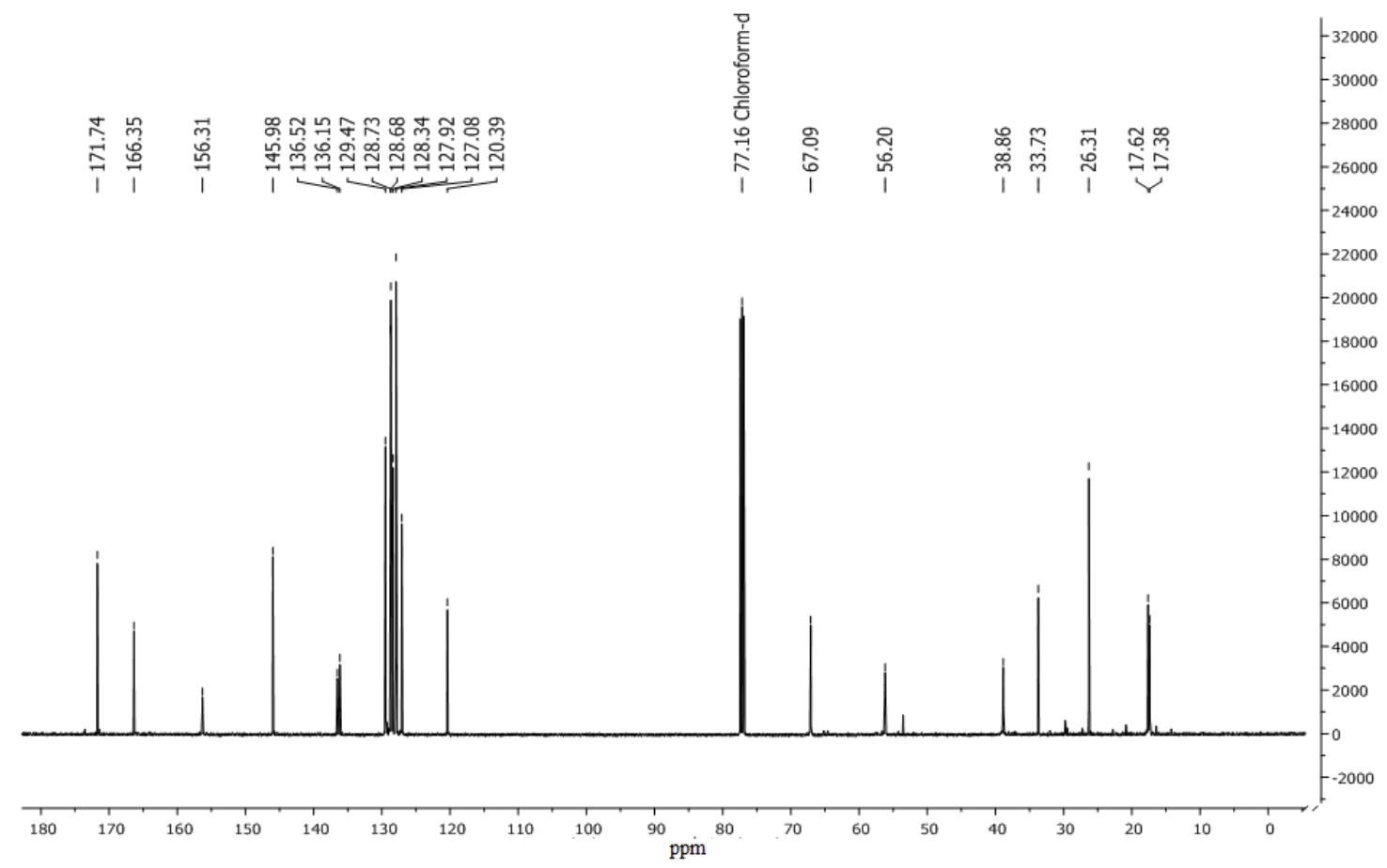
10.13 Benzil (S)-(1-(2-ciano-1,2-dimetilhidrazinil)-1-oxo-3-fenilpropan-2-il)carbamato (17)

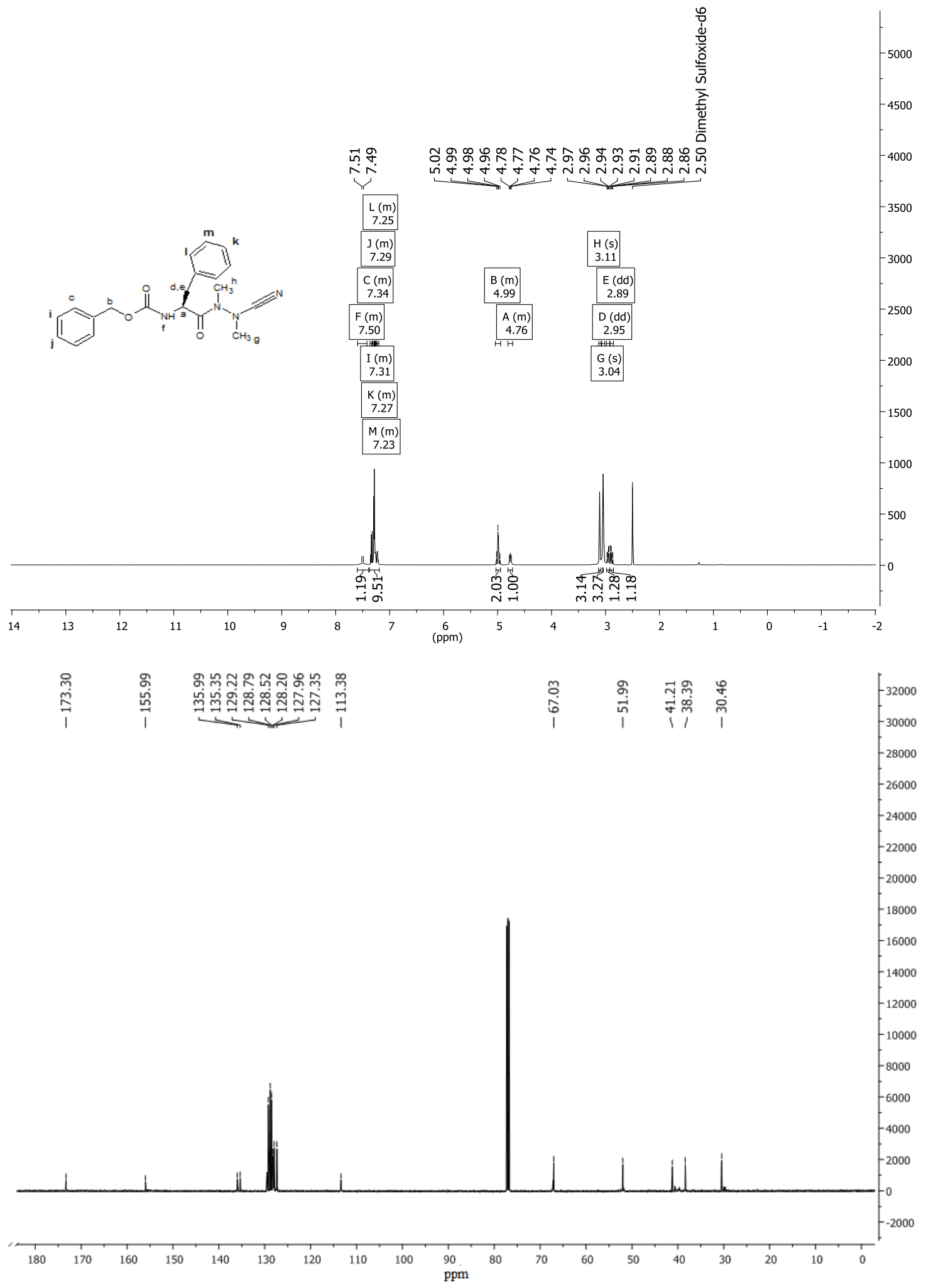


10.14 tert-butil (S)-(1-(2-ciano-1,2-dimetilhidrazinil)-4-metil-1-oxopentan-2-il)carbamato (18)

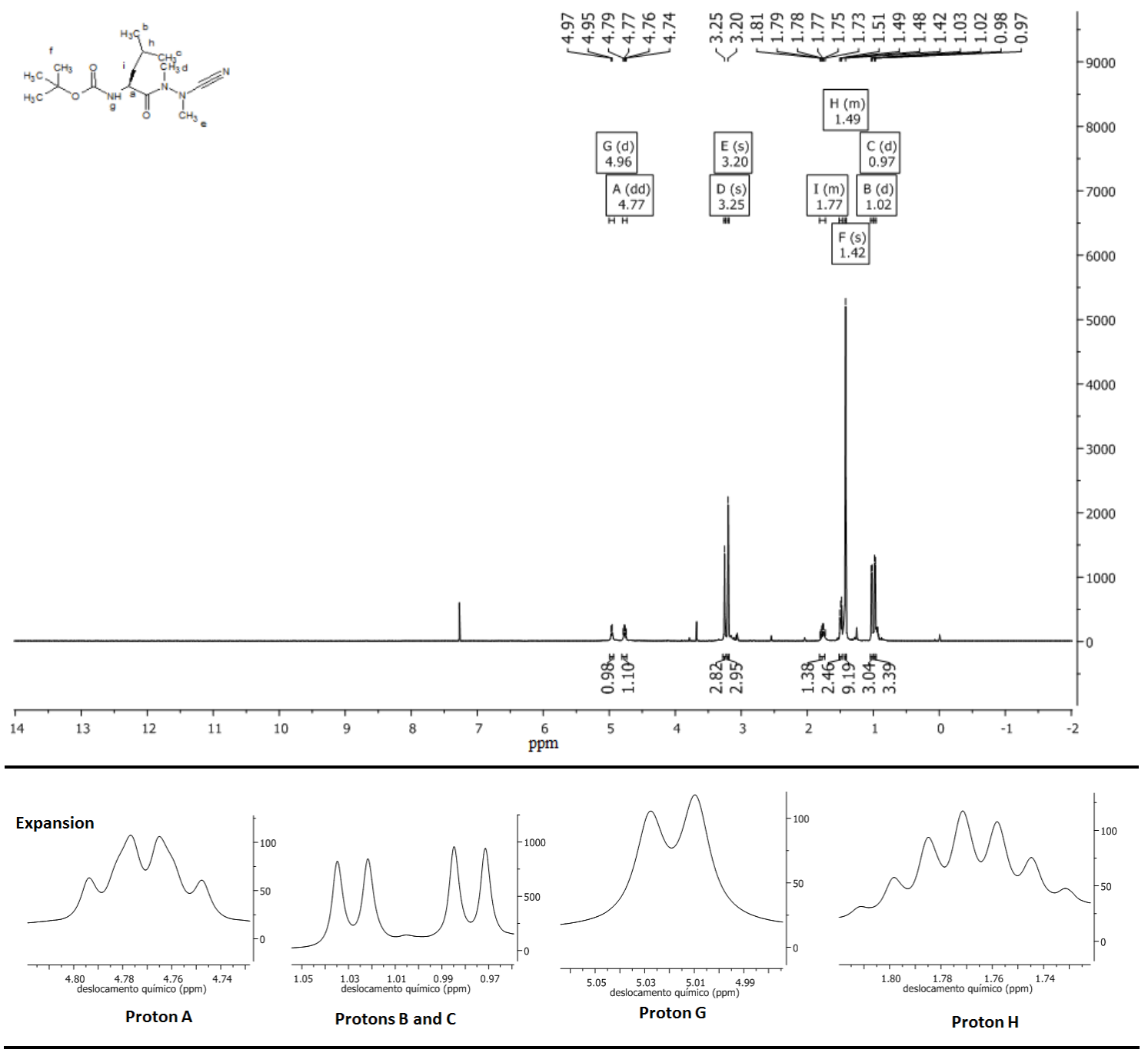




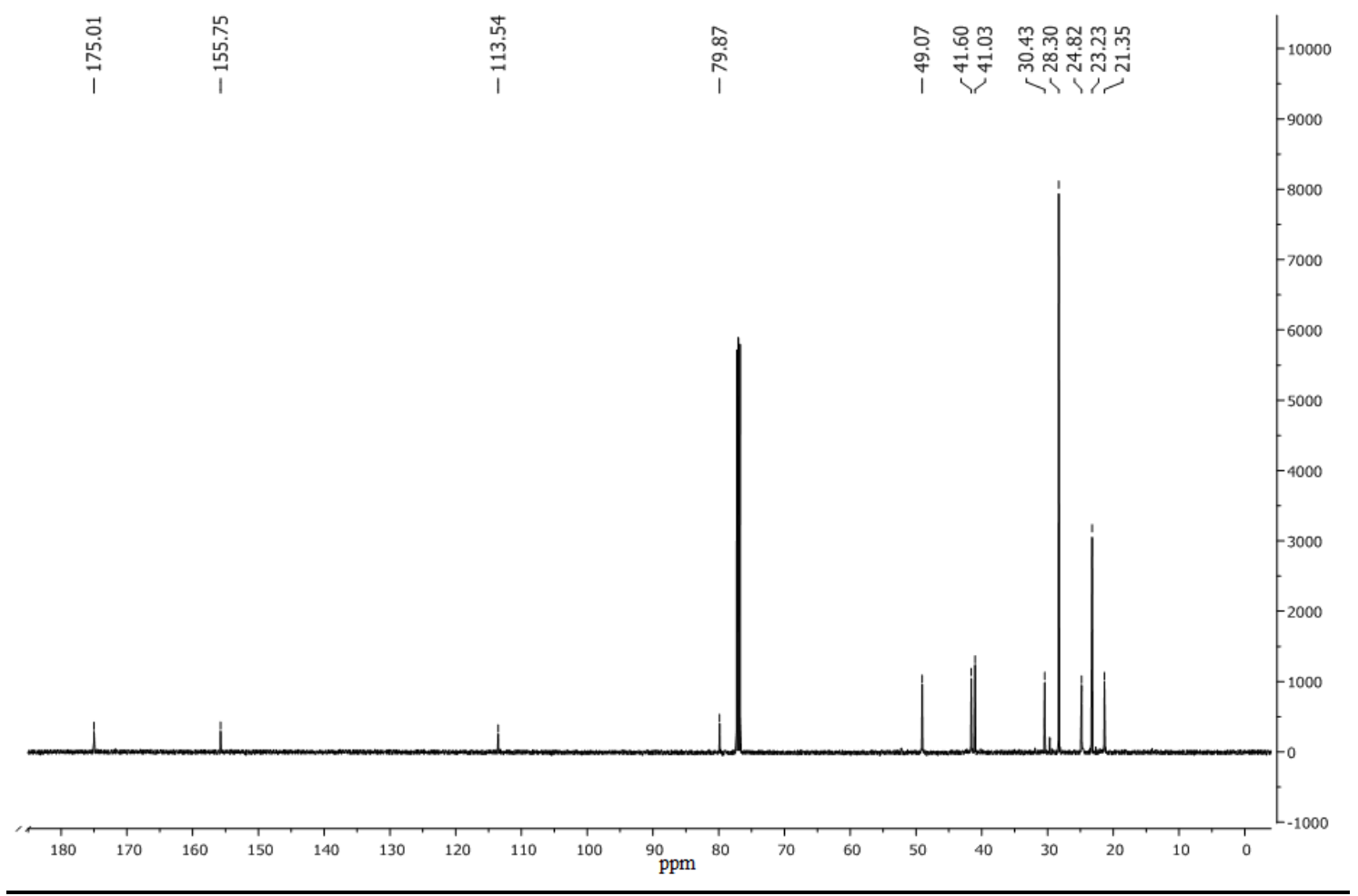


10.15 3-tert-butil-N-[(1S)-1-(N'-ciano-N,N'-dimetilhidrazinecarbonil)-2-feniletil]-1-metil-1Hpirazol-5-carboxamida (19)

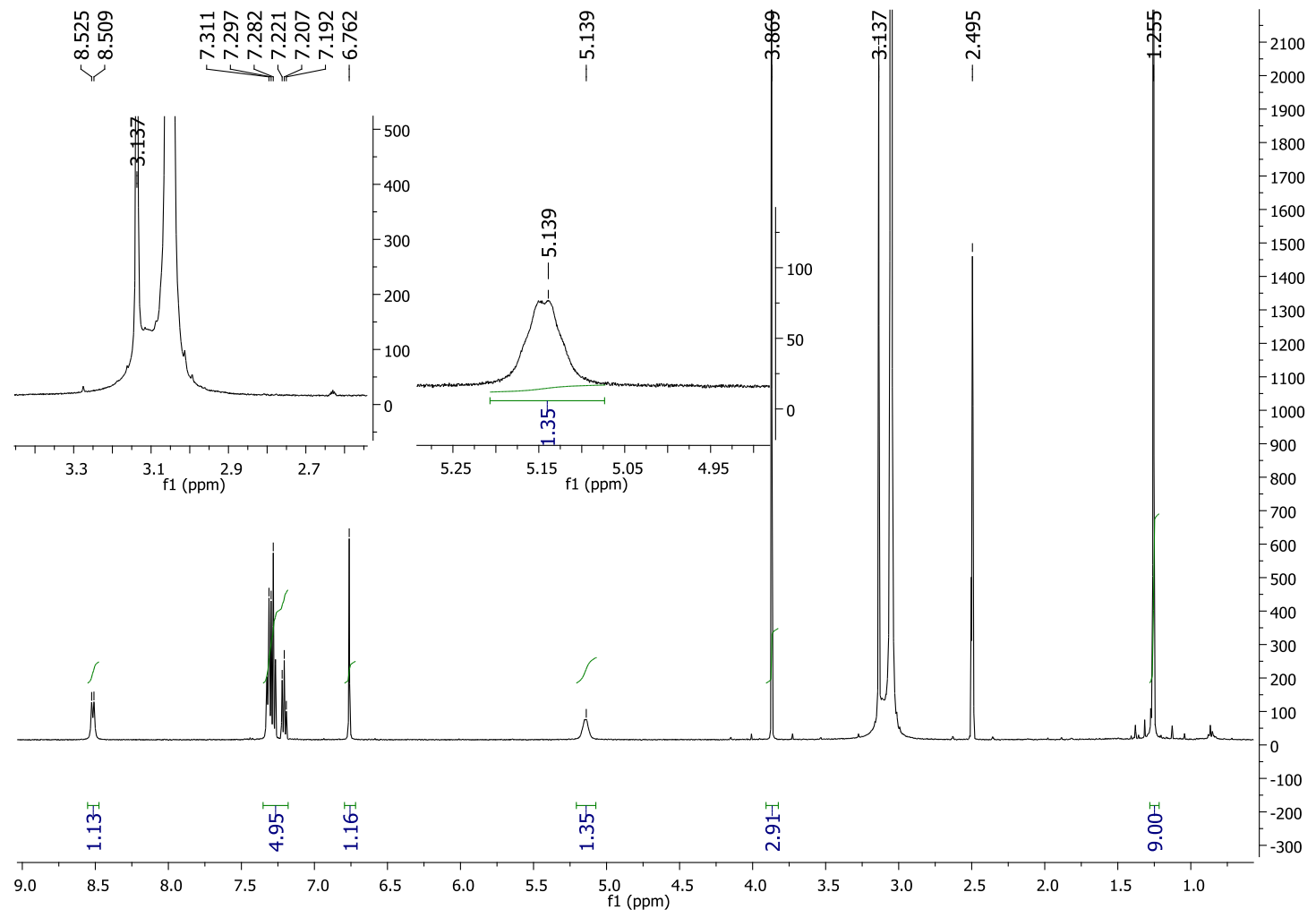

㠻字号

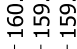

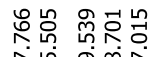

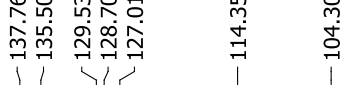

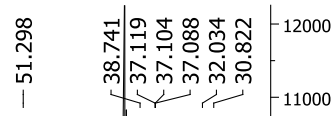

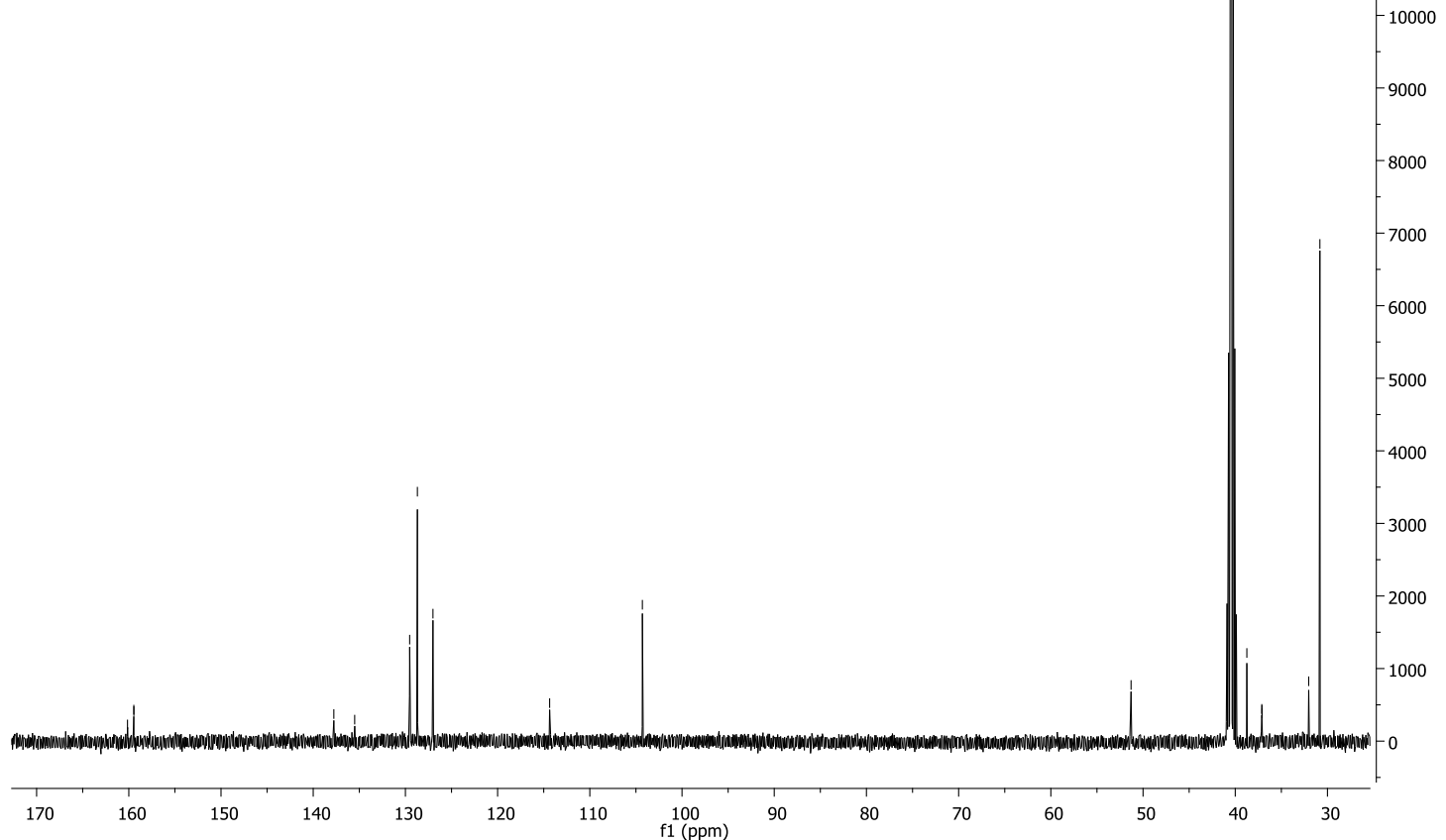


10.16 3-tert-butil-N-[(1S)-1-(N'-ciano-N,N'-dimetilhidrazinecarbonil)-3-metilbutil]-1-metil-1Hpirazol-5-carboxamida (20)
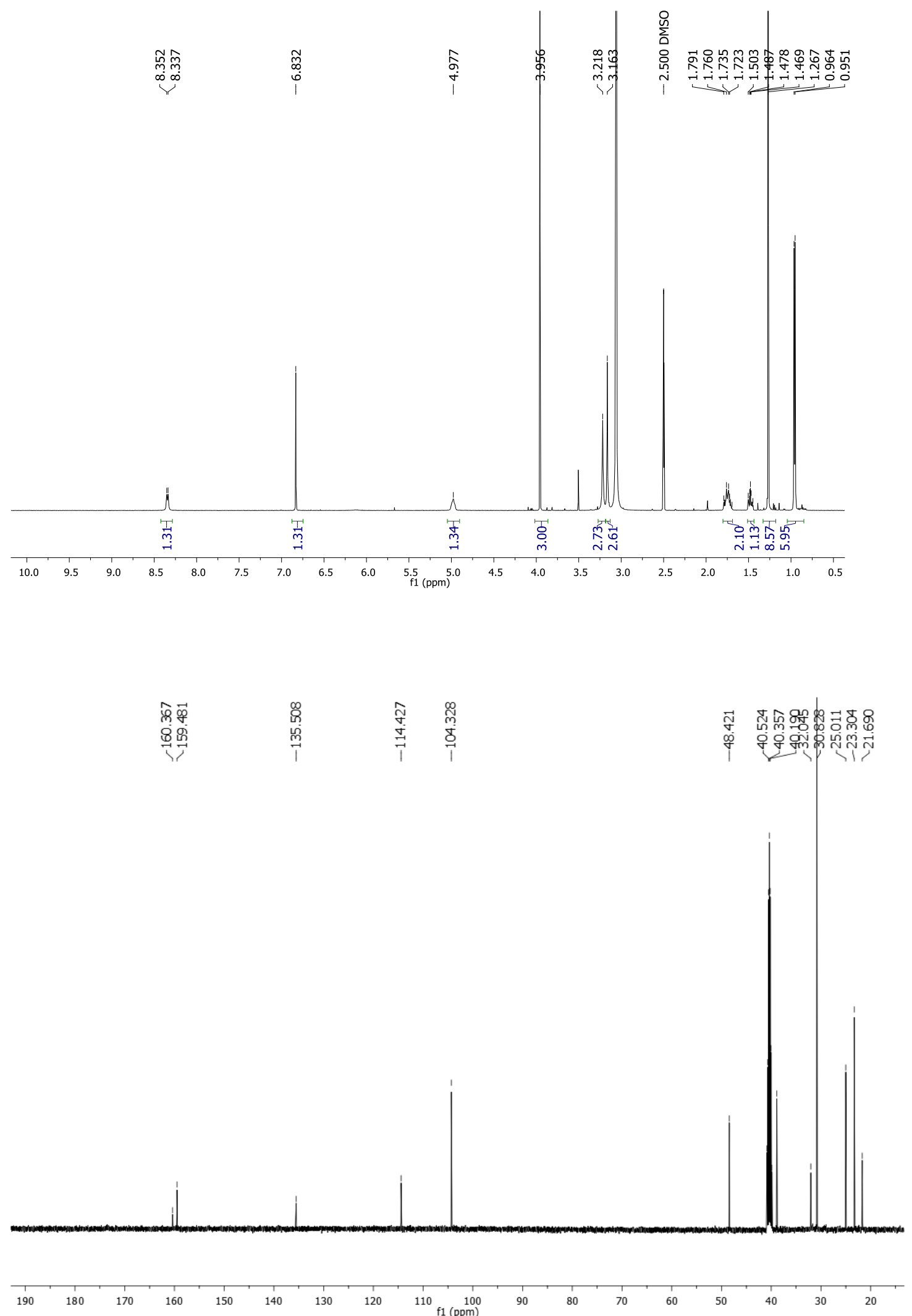
10.17 N-\{2-fenilimidazo[1,2-a]piridin-7-il\}pirrolidina-1-carboxamida (22)
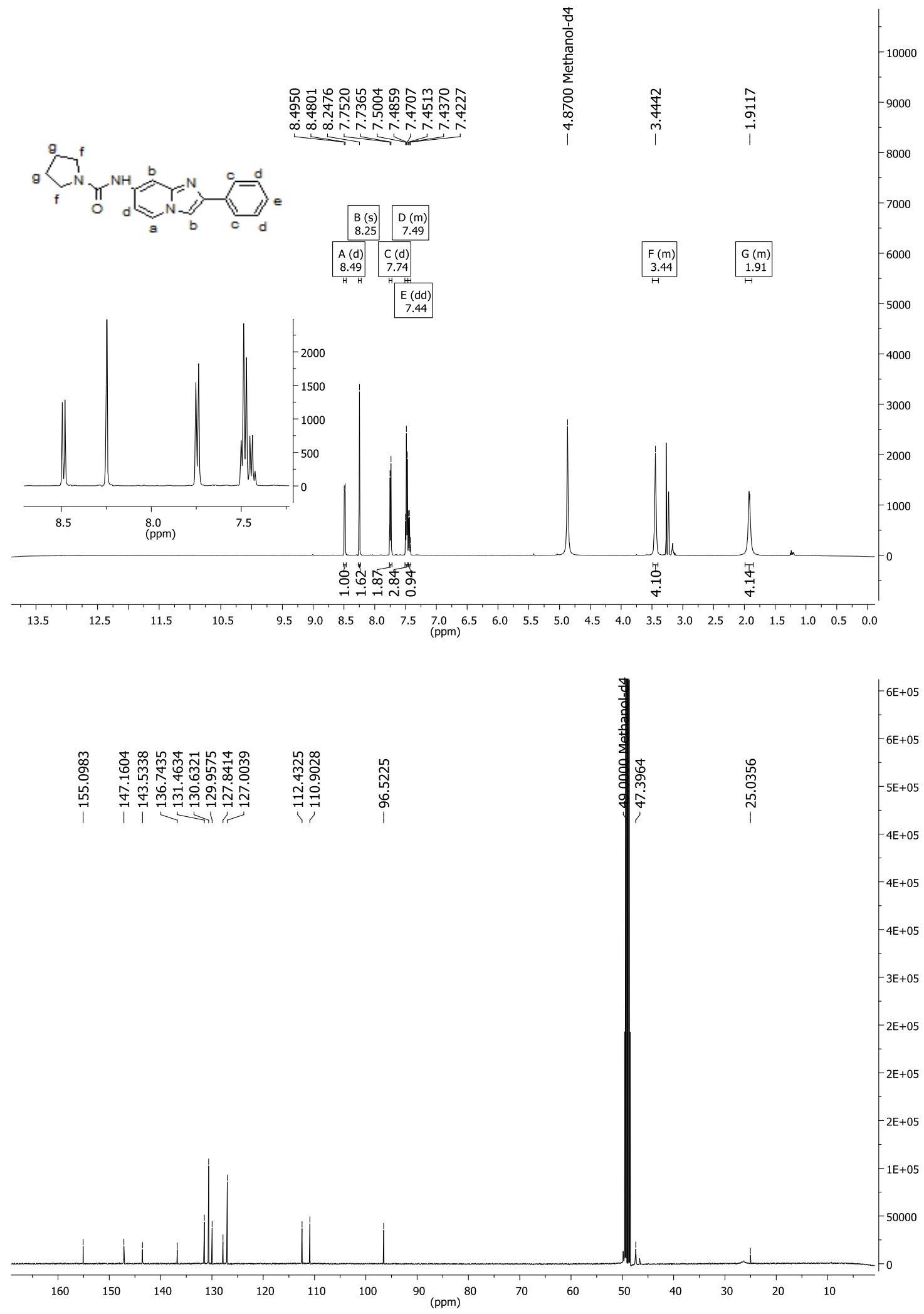
$\mathrm{N}$-[2-(3-fluorofenil)imidazo[1,2-a]piridin-7-il]pirrolidina-1-carboxamida (25)
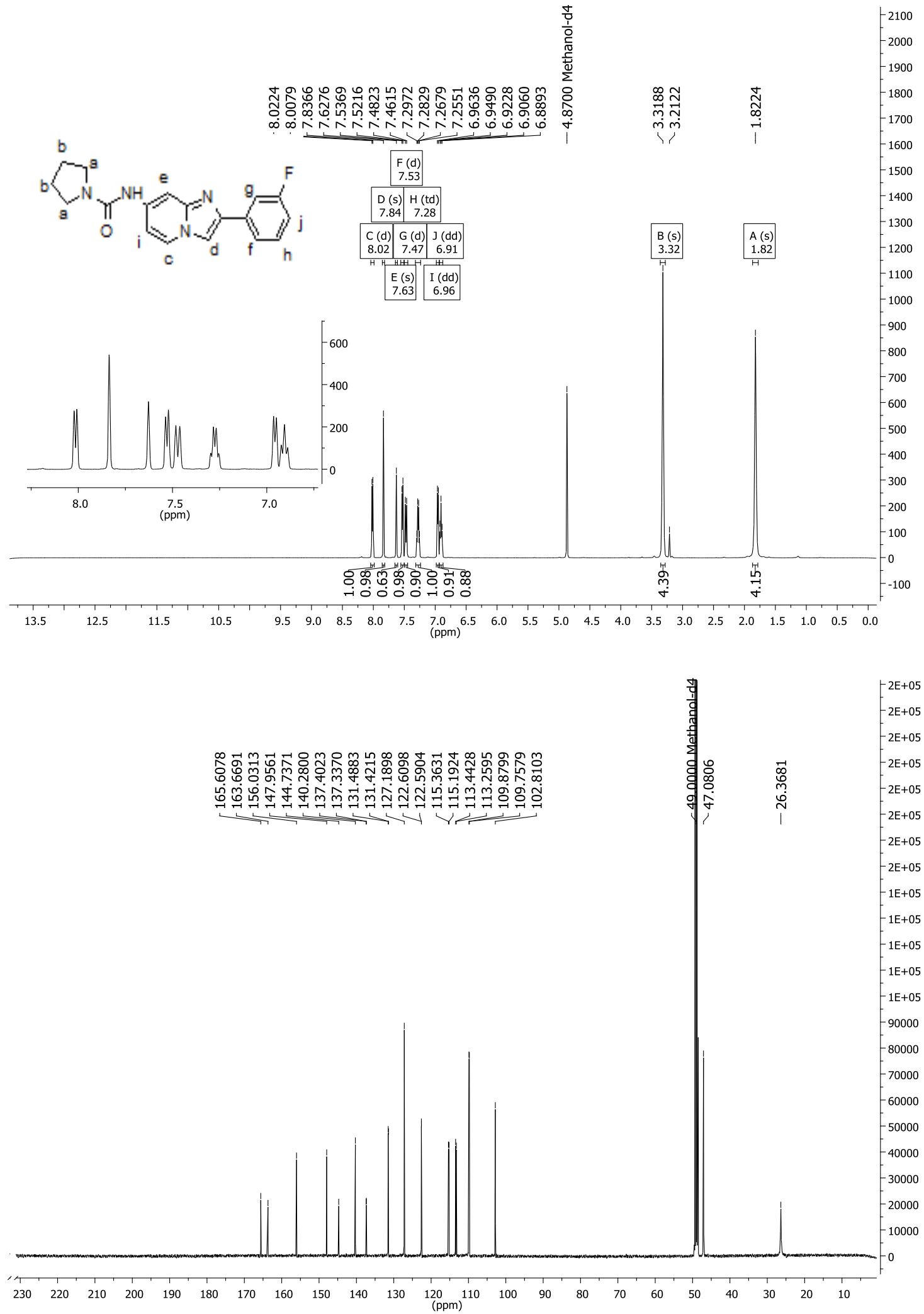
10.18 (3S)-3-fluoro-N-[2-(3-fluorofenil)imidazo[1,2-a]piridin-7-il]pirrolidina-1-carboxamida (26)

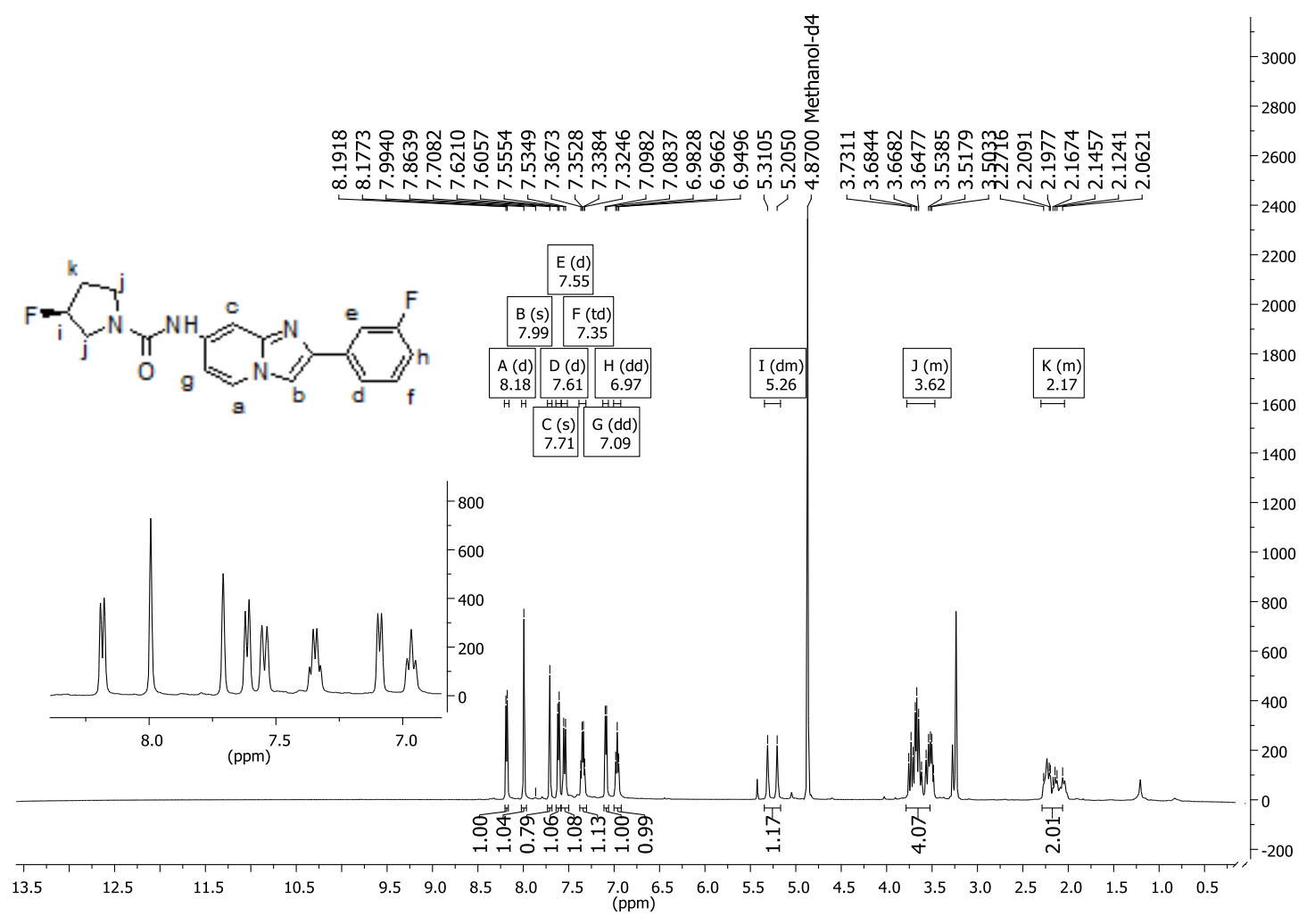

$10.19 \mathrm{~N}$-[2-(2,3-difluorofenil)imidazo[1,2-a]piridin-7-il]piperidina-1-carboxamida (27)

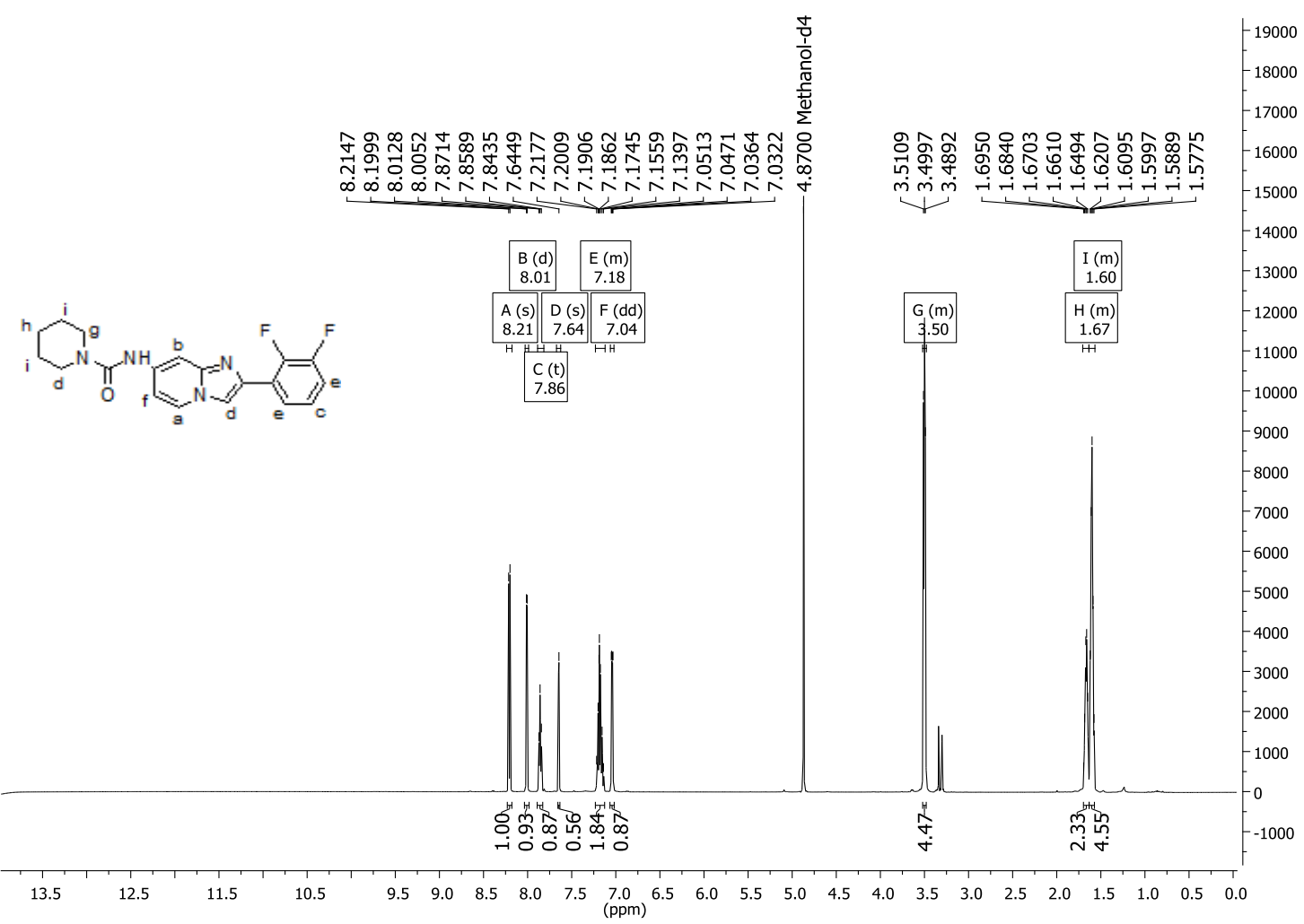


10.20 N-[2-(2,3-difluorofenil)imidazo[1,2-a]piridin-7-il]pirrolidina-1-carboxamida (28)
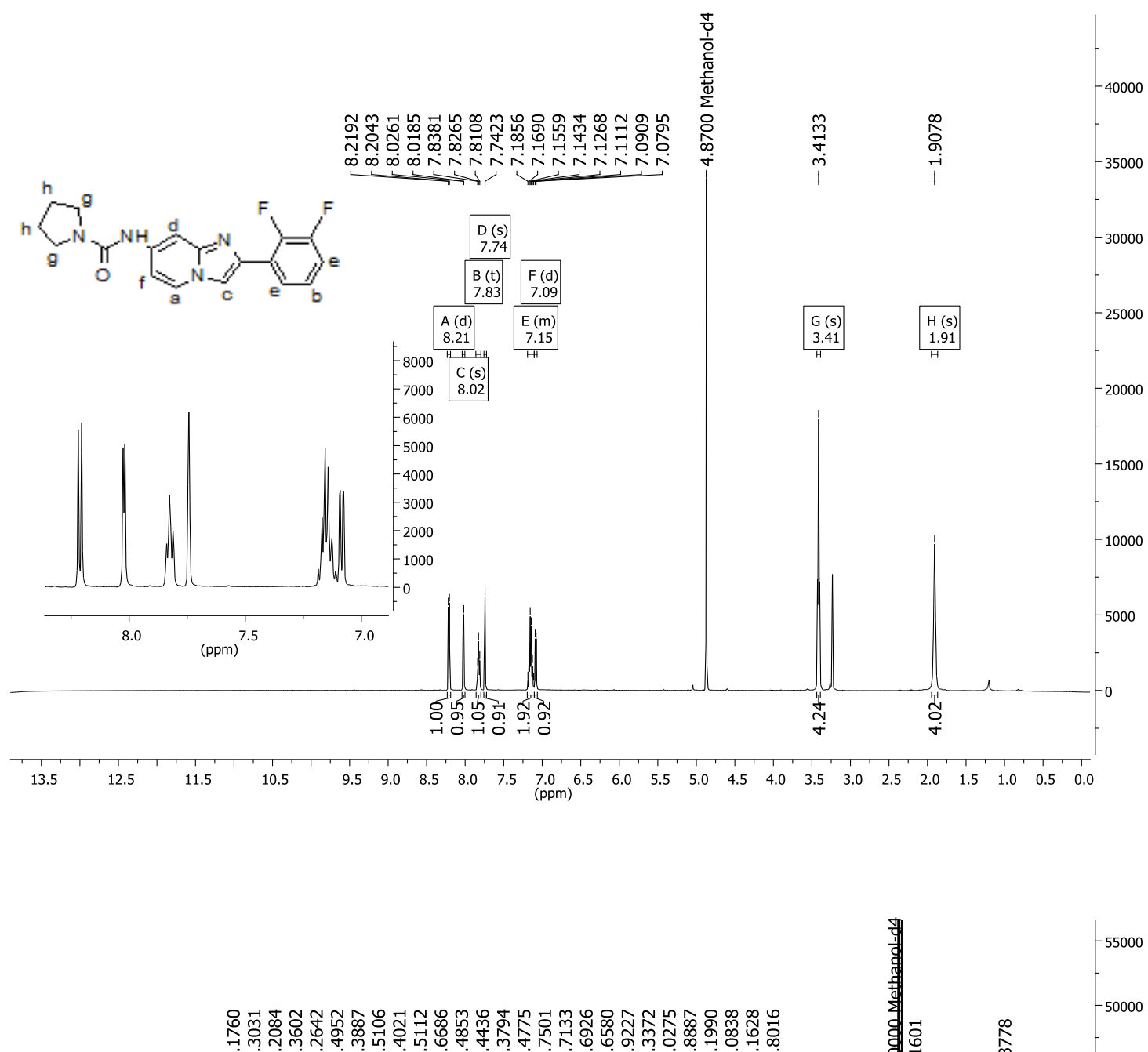

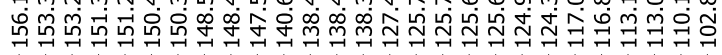
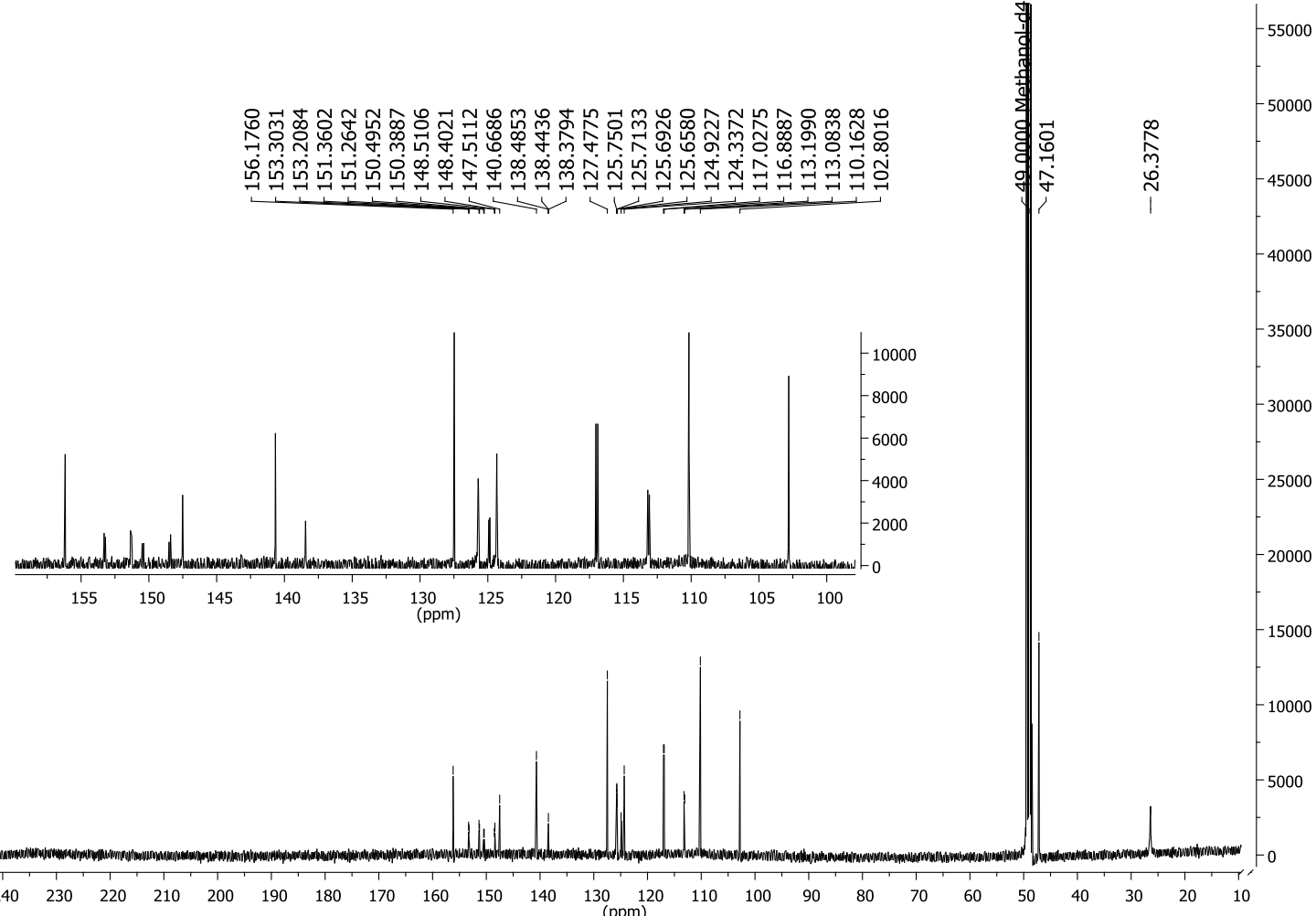

240

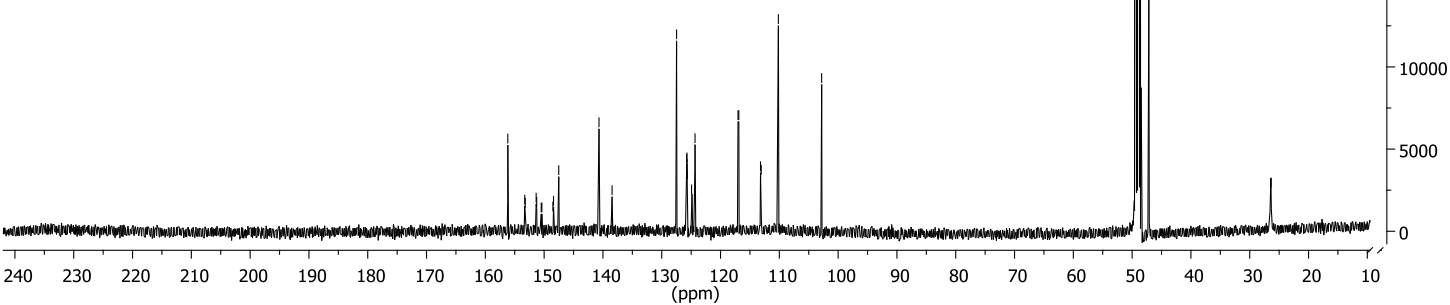


10.21 (3S)-N-[2-(2,3-difluorofenil)imidazo[1,2-a]piridin-7-il]-3-fluoropirrolidina-1carboxamida (29)
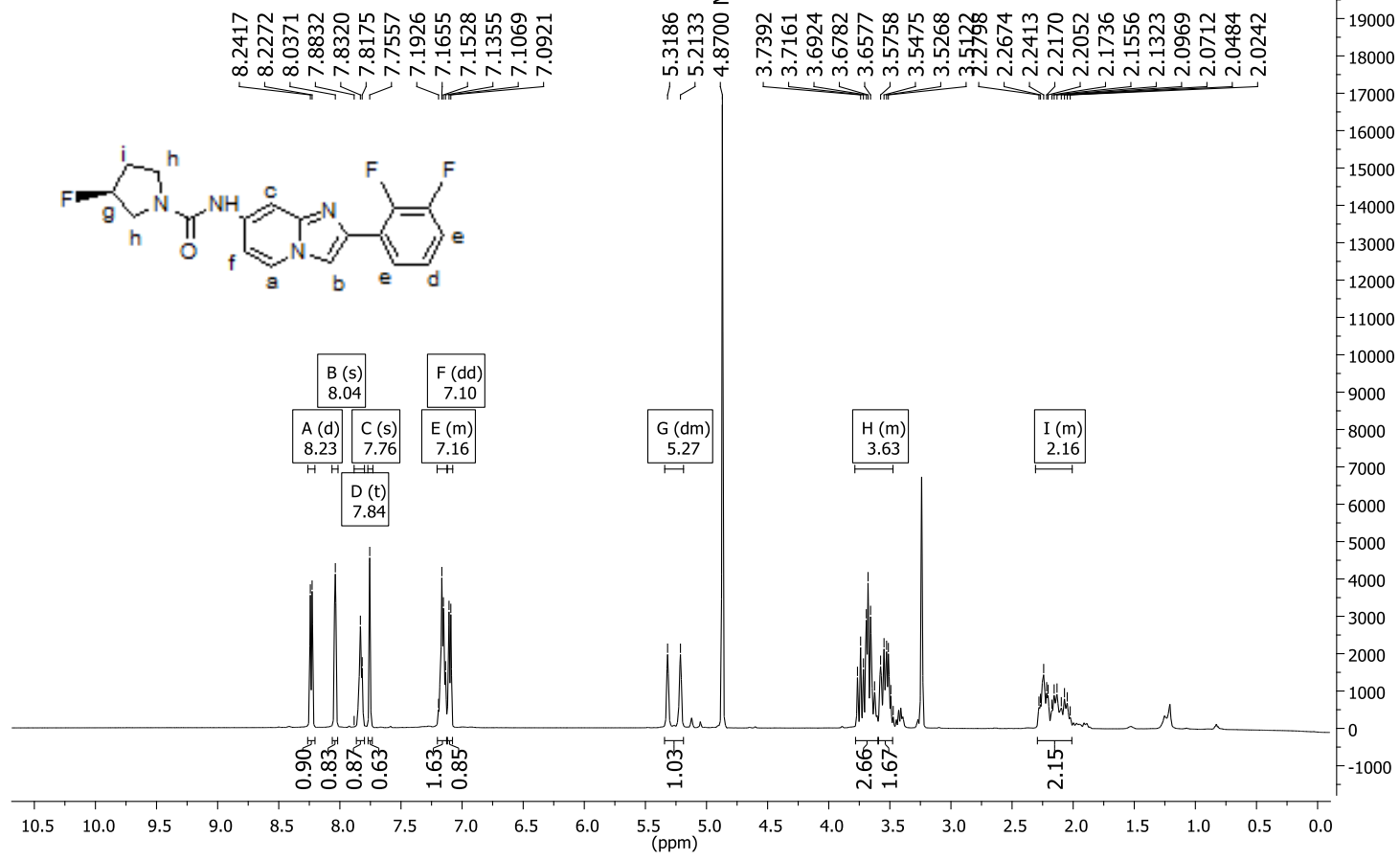
10.22 N-[2-(3,4-difluorofenil)imidazo[1,2-a]piridin-7-il]piperidina-1-carboxamida (30)
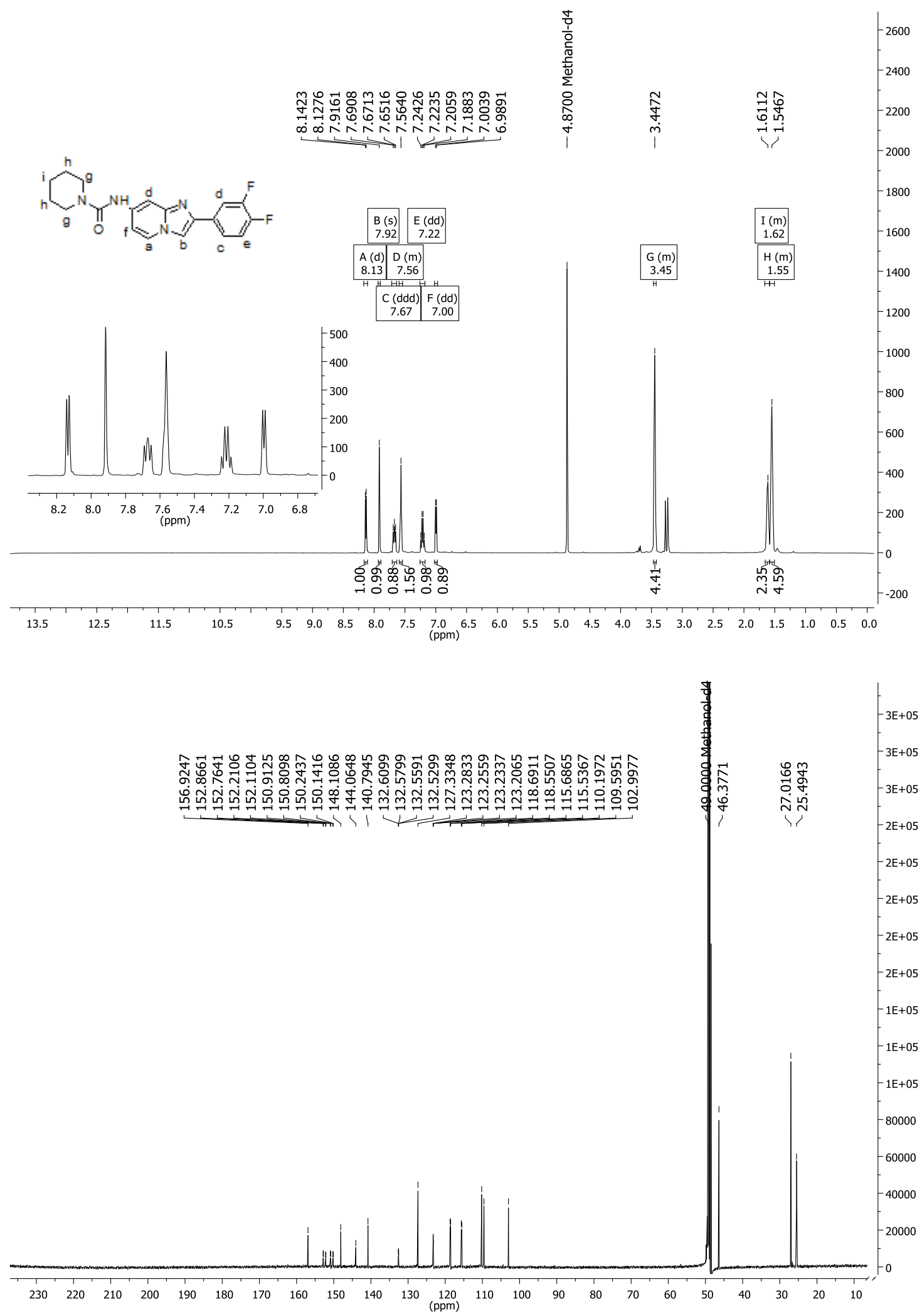
10.23 N-[2-(3,4-difluorofenil)imidazo[1,2-a]piridin-7-il]pirrolidina-1-carboxamida (31)
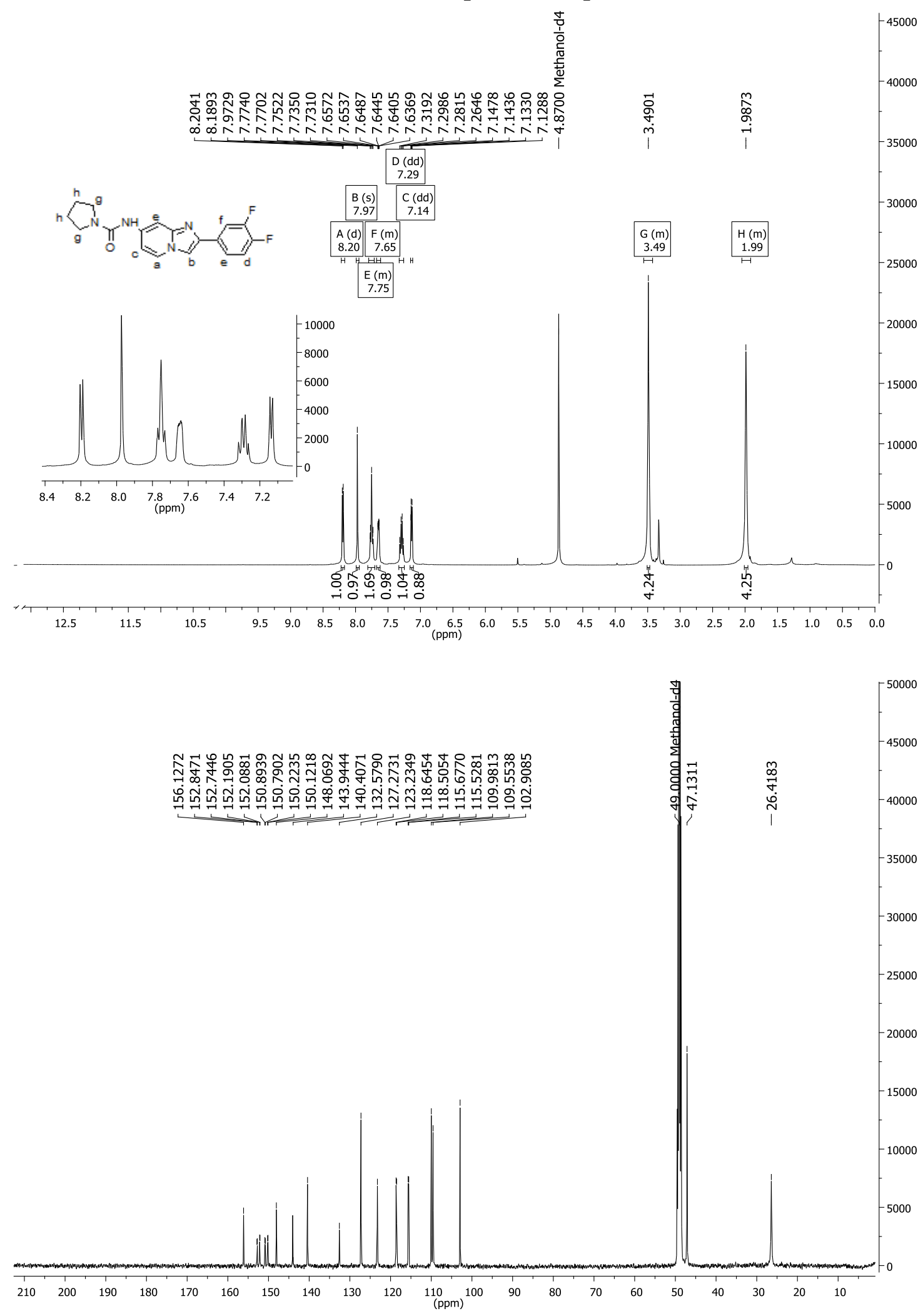
10.24 (3S)-N-[2-(3,4-difluorofenil)imidazo[1,2-a]piridin-7-il]-3-fluoropirrolidina-1carboxamida (32)

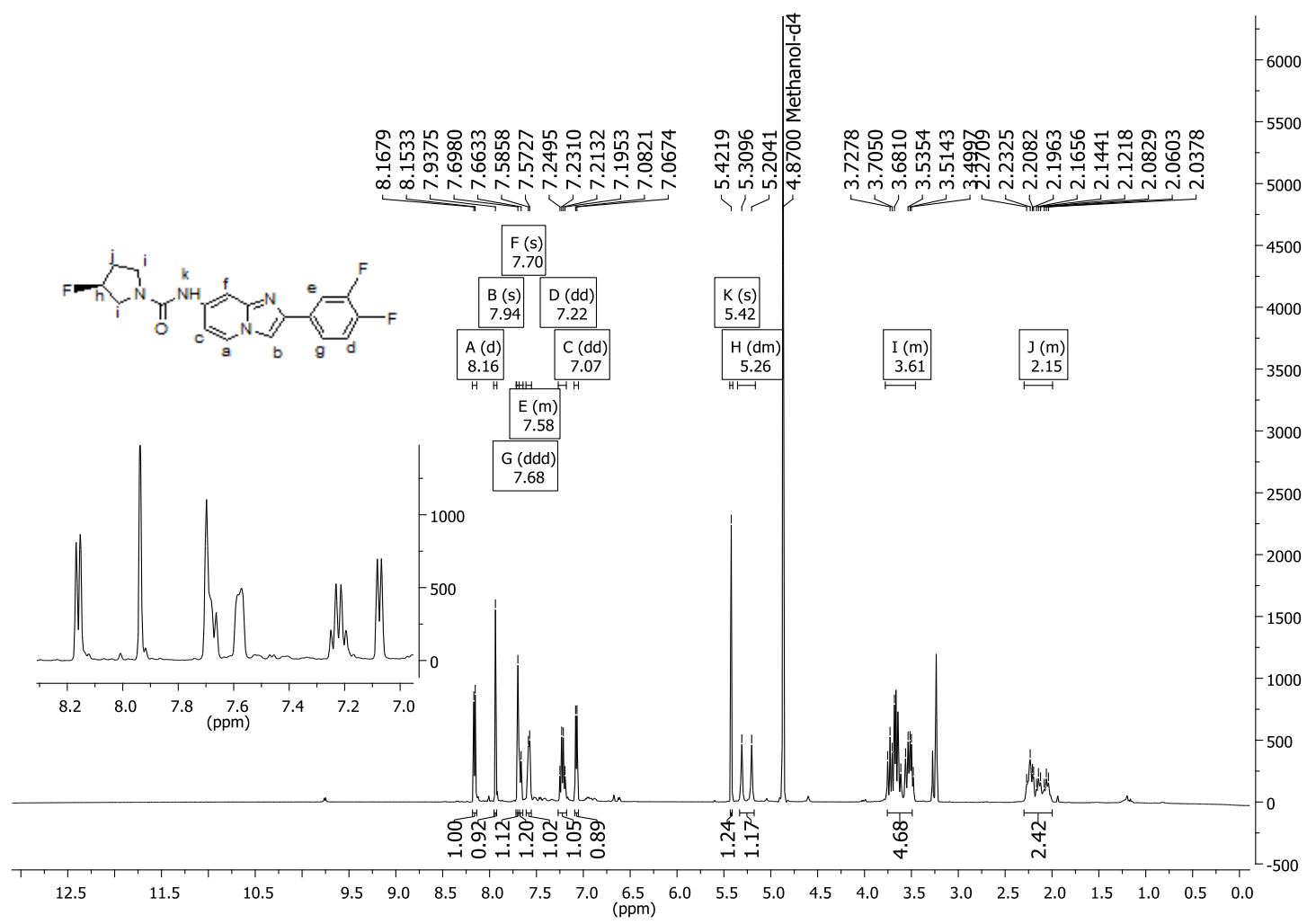

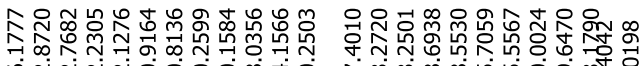

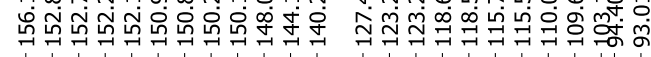

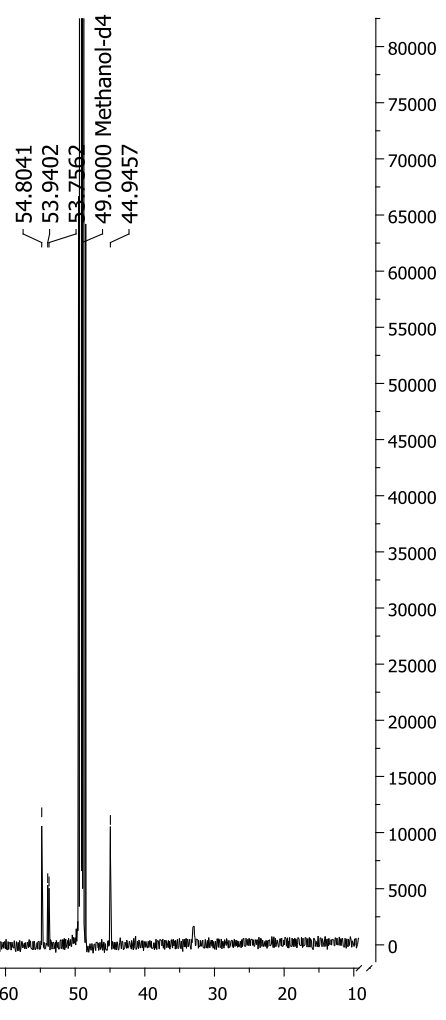

$\begin{array}{llllllllll}200 & 190 & 180 & 170 & 160 & 150 & 140 & 130 & \begin{array}{l}120 \\ \text { deslocamento químico (ppm) }\end{array}\end{array}$ 
10.25 (3S)-3-fluoro-N-[2-(1,3-tiazol-2-il)imidazo[1,2-a]piridin-7-il]pirrolidina-1-carboxamida (33)

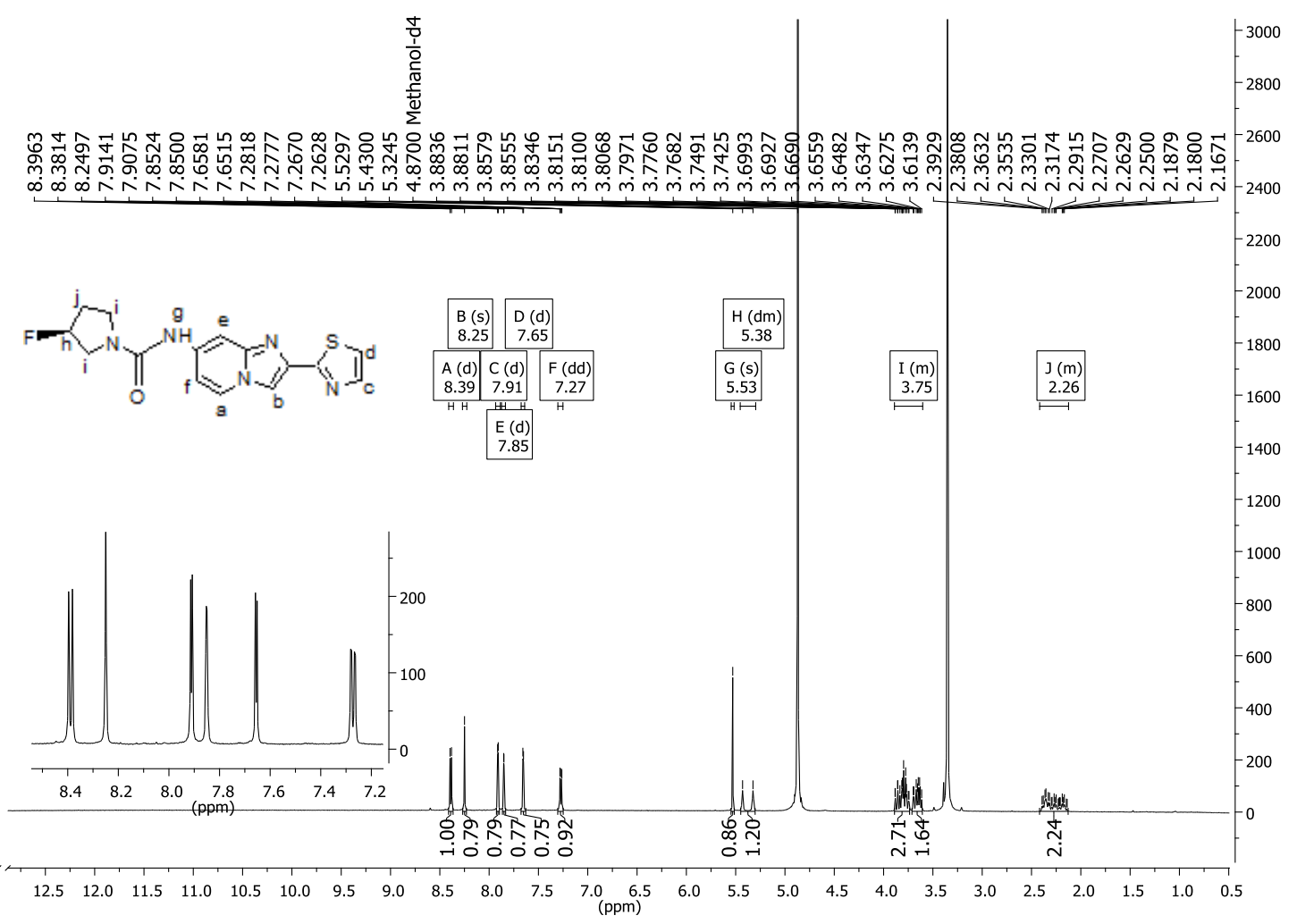

10.26 2-cloro-N-[2-(3,4-difluorofenil)imidazo[1,2-a]piridin-7-il]piridina-3-carboxamida (35)

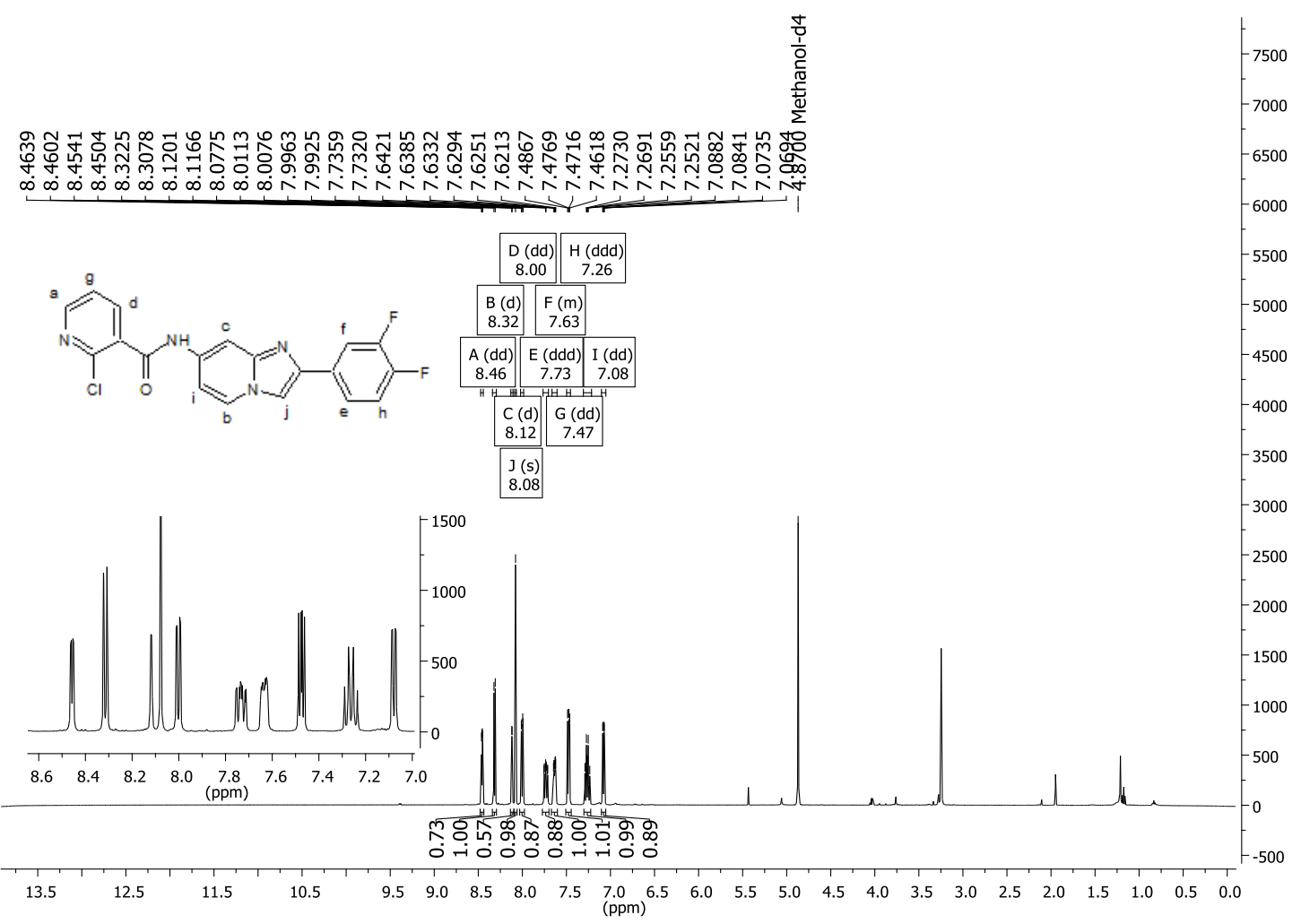


10.27 N-[2-(3,4-difluorofenil)imidazo[1,2-a]piridin-7-il]-3,5-dimetil-1,2-oxazol-4-carboxamida (36)

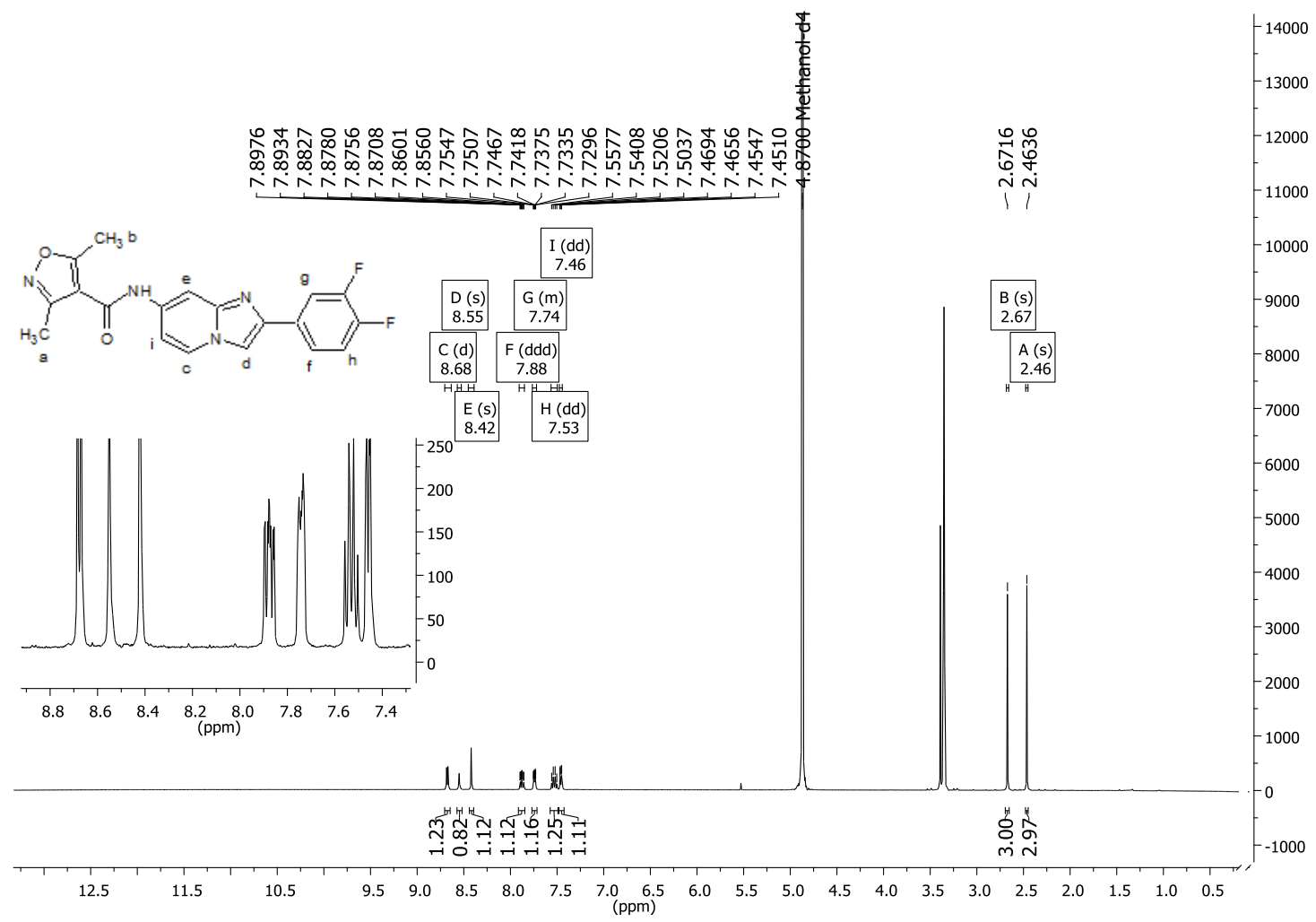

10.28 N-[2-(3,4-difluorofenil)imidazo[1,2-a]piridin-7-il]piridina-3-carboxamida (37)

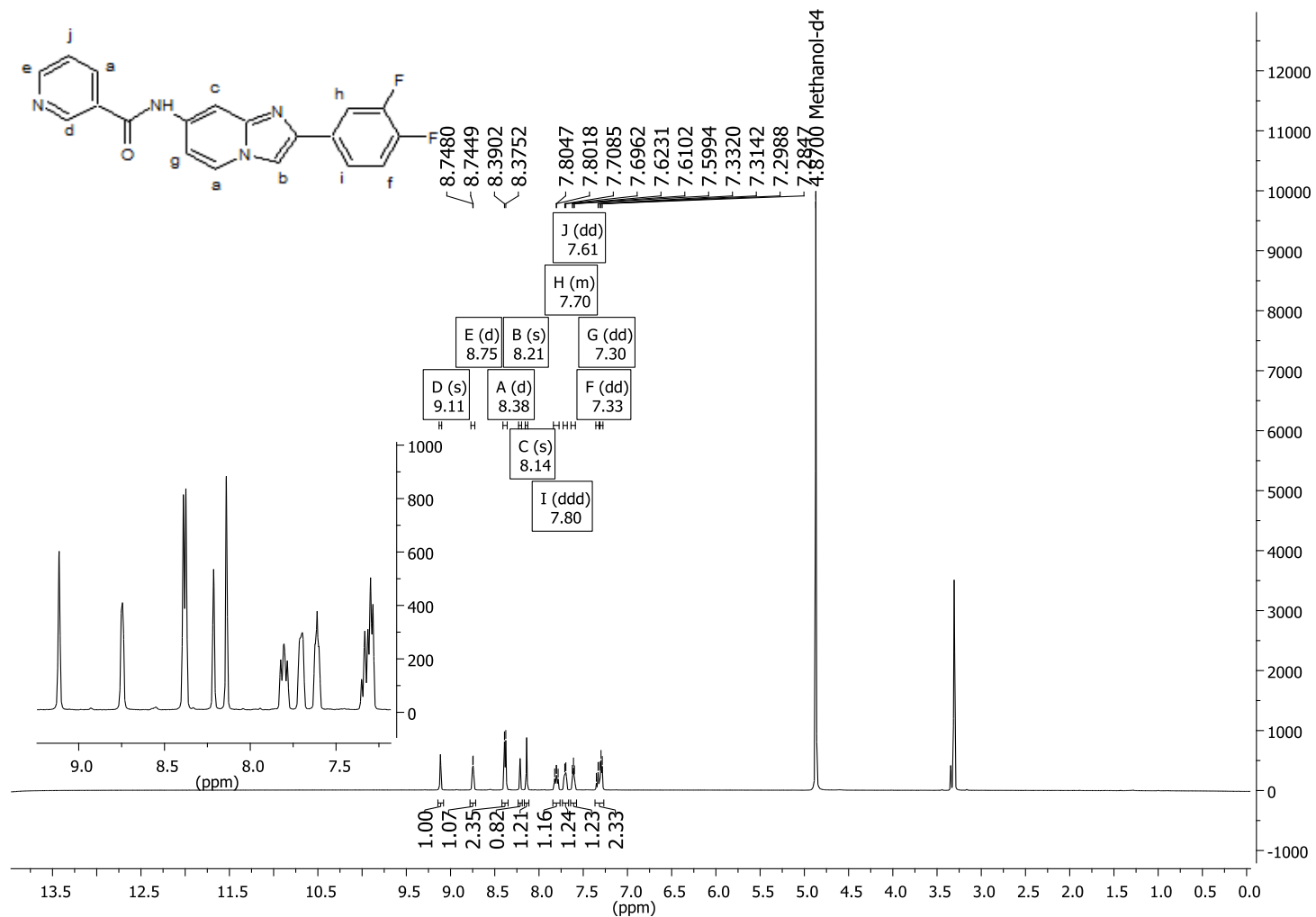


$10.29 \mathrm{~N}$-[2-(3,4-difluorofenil)imidazo[1,2-a]piridin-7-il]-1,3-tiazol-2-carboxamida (38)
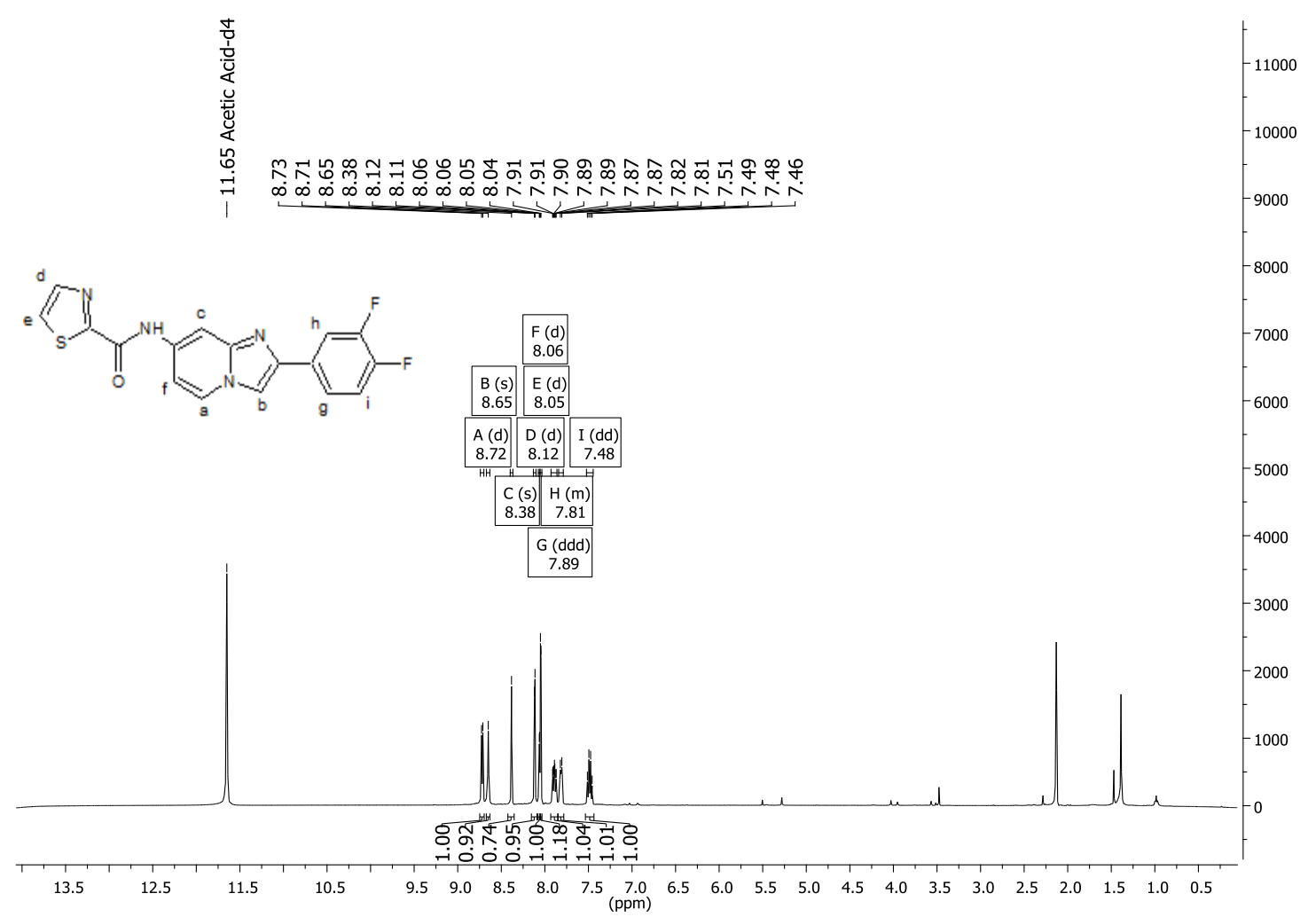

10.30 3-tert-butil-N-[2-(3,4-difluorofenil)imidazo[1,2-a]piridin-7-il]-1-metil-1H-pirazol-5carboxamida (39)

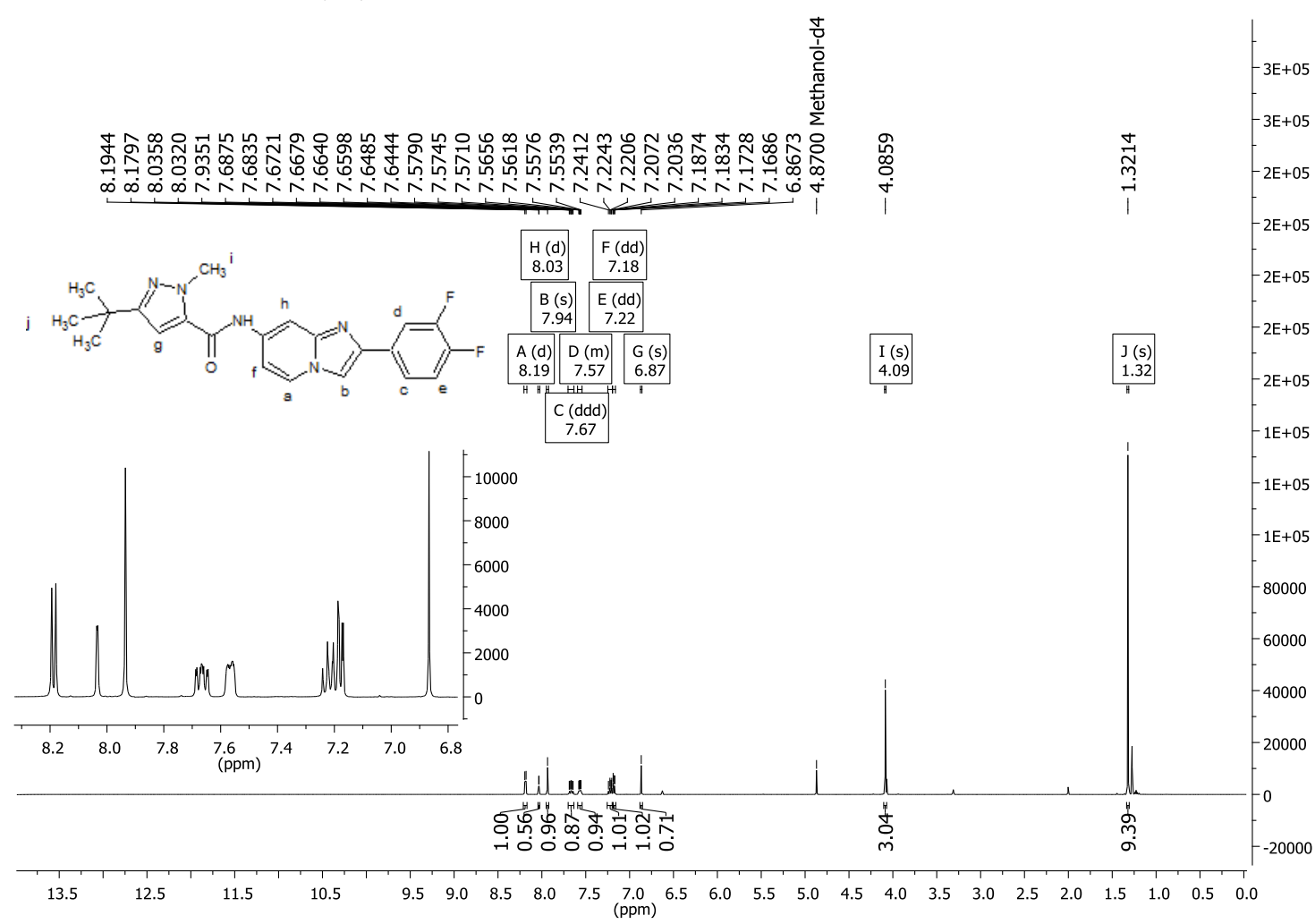


10.31 (3S)-N-[2-(3,4-difluorofenil)imidazo[1,2-a]pirimidin-7-il]-3-fluoropirrolidina-1carboxamida (40)

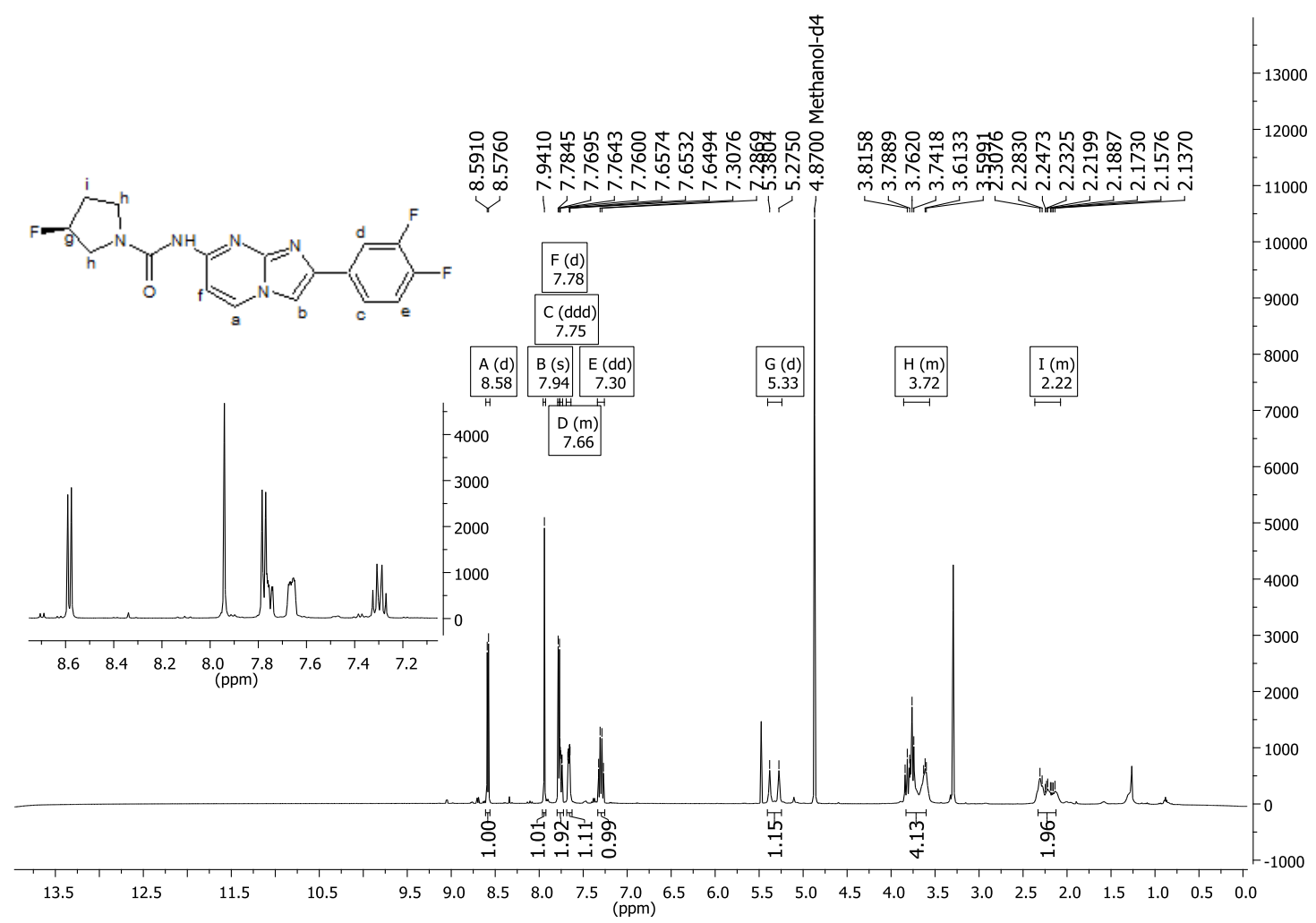


10.32 (3S)-N-[2-(3,4-difluorofenil)imidazo[1,2-c]pirimidin-7-il]-3-fluoropirrolidina-1carboxamida (41)<smiles>CC1[C@H](F)CCN1C(=O)Nc1cc2nc(-c3ccc(F)c(F)c3)cn2cn1</smiles>

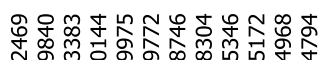

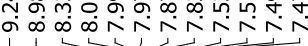

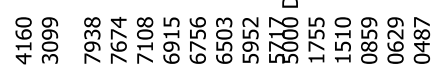

i.
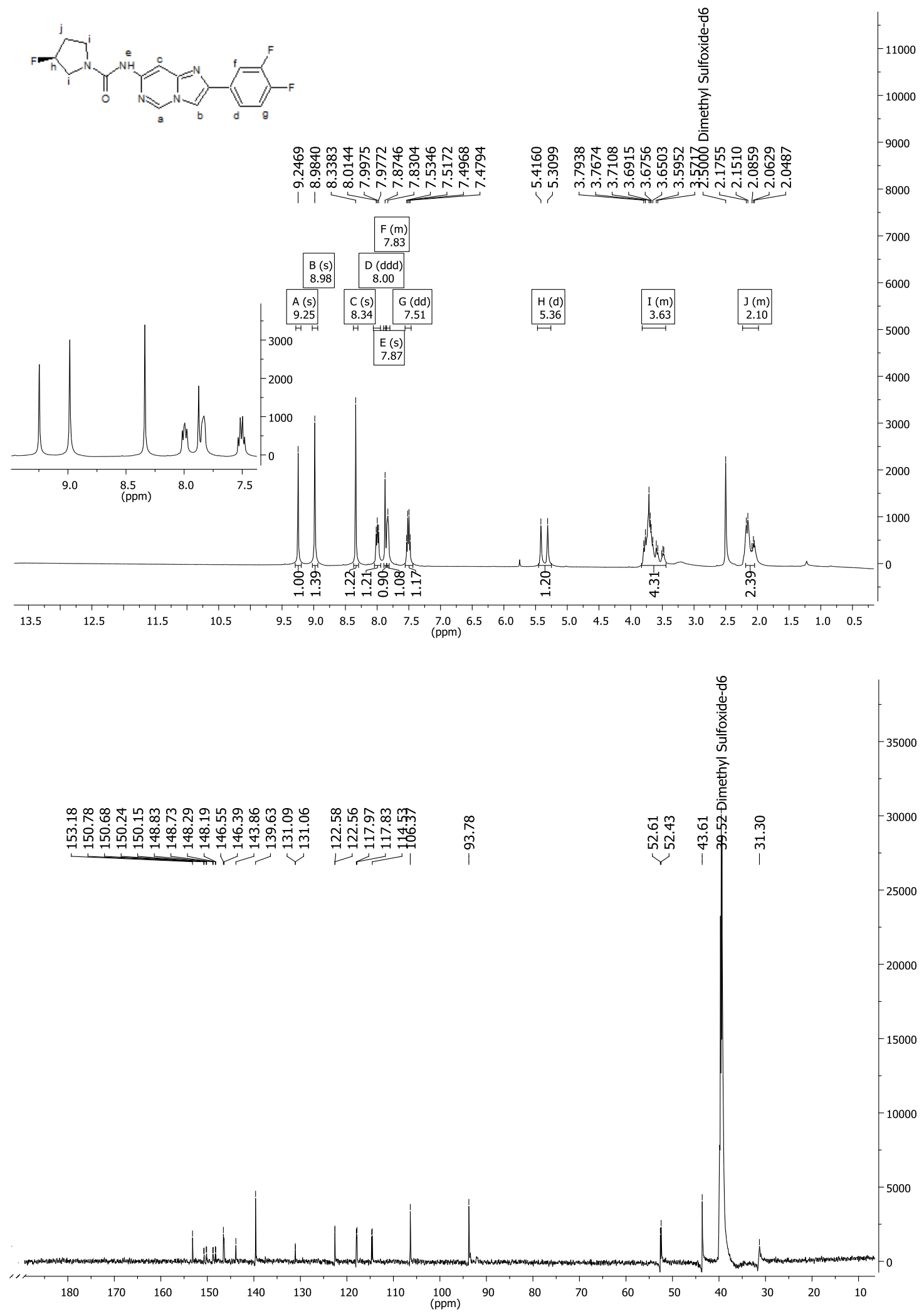
10.33 3-tert-butil-N-[2-(3,4-difluorofenil)imidazo[1,2-c]pirimidin-7-il]-1-metil-1H-pirazol-5carboxamida (42)

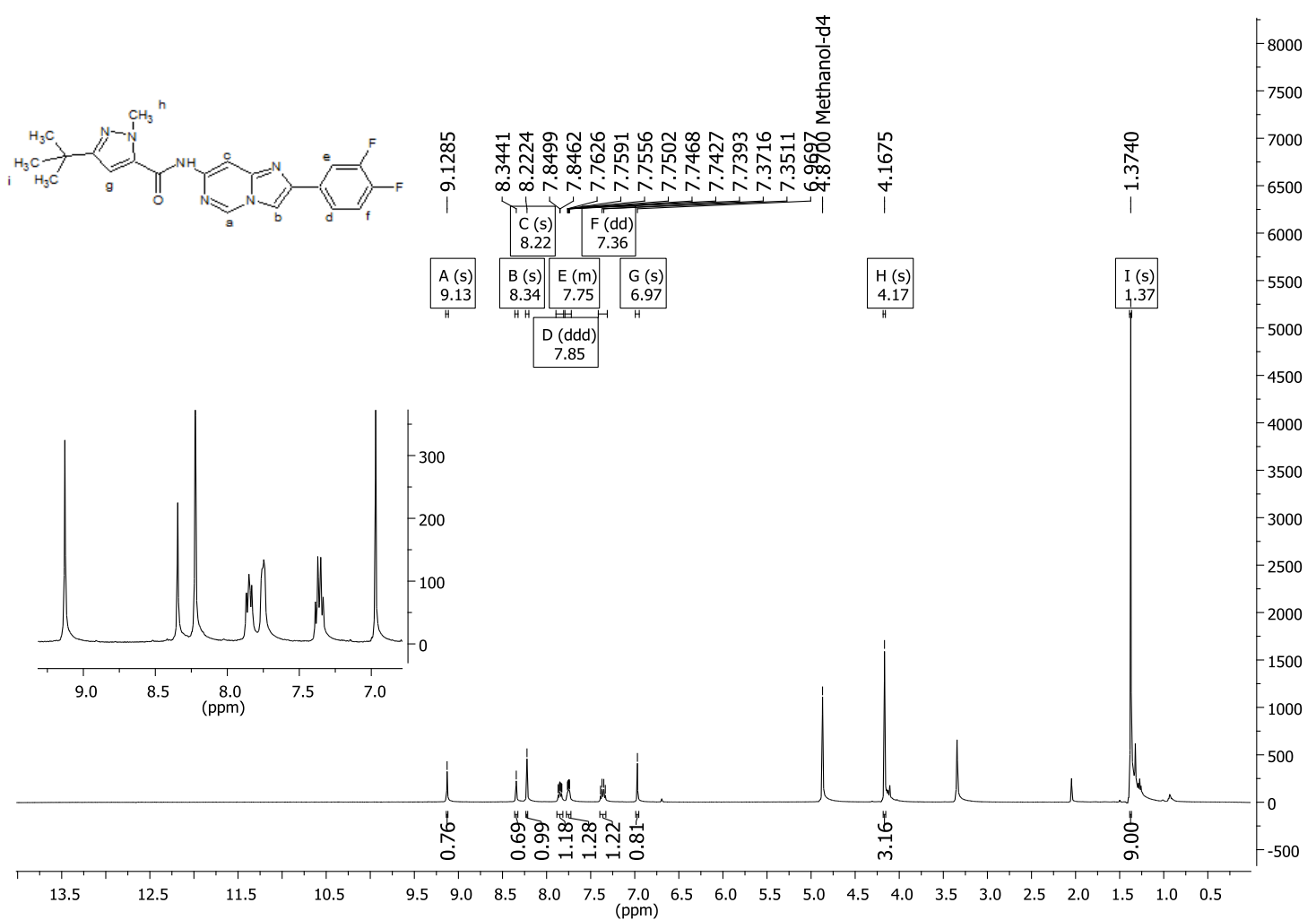

10.34 (3S)-N-[2-(3,4-difluorofenil)imidazo[1,2-a]piridin-6-il]-3-fluoropirrolidina-1-carboxamida (43)

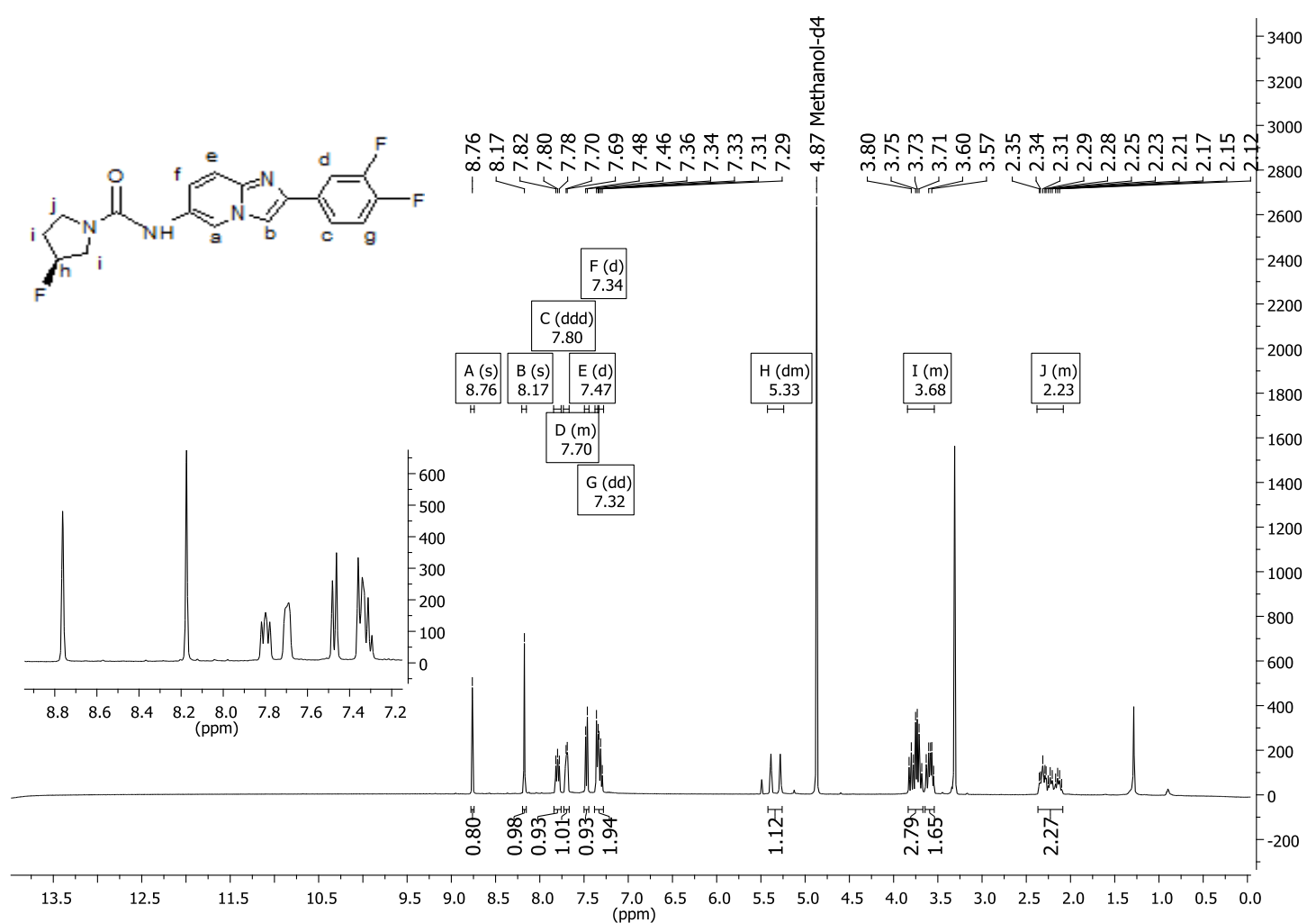


